\title{
A Phytosodiological Study of Glacier National Park, Montana, U.S.A., with Notes on the Syntaxonomy of Alpine Vegetation in Western North America
}

\author{
Dissertation zur Erlangung des Doktorgrades \\ der Mathematisch-N aturwissenschaftlichen Fakultäten \\ der G eorg-August-Universität zu G öttingen
}

Vorgelegt von

Christian Damm

aus Braunau/Inn

Göttingen, den 21.03.2001 


\section{7}

Referent: $\quad$ Prof. Dr. F.-G. Schroeder

Korreferent: Prof. Dr. H. Dierschke

Tag der mündlichen Prüfung: $\quad$ 03.05.2001 


\section{Table of contents}

\section{Index of Tables}

SUMMARY 1

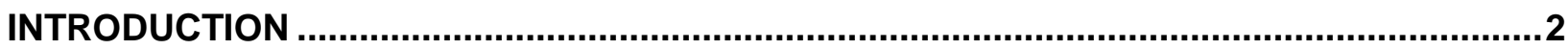

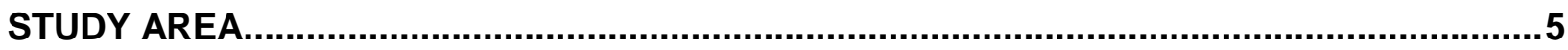

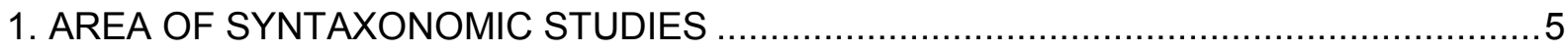

2. AREA OF PHYTOSOCIOLOGICAL FIELD STUDIES: GLACIER NATIONAL PARK ........5

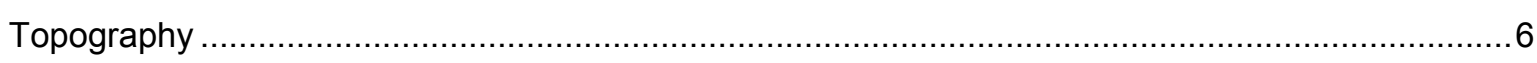

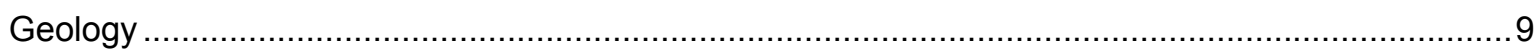

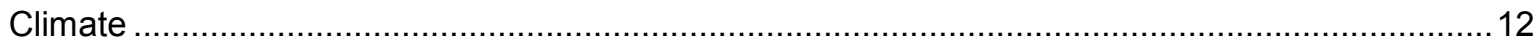

METHODS.................................................................................................................... 16

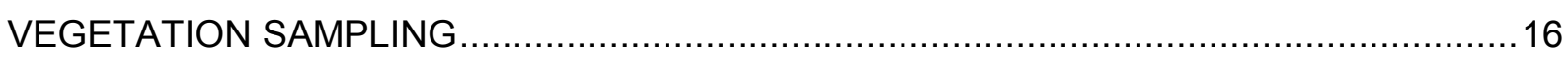

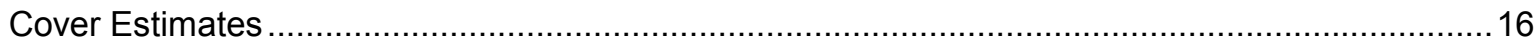

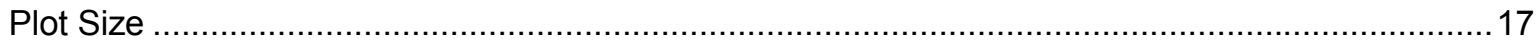

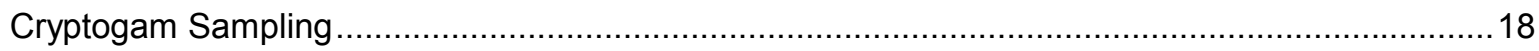

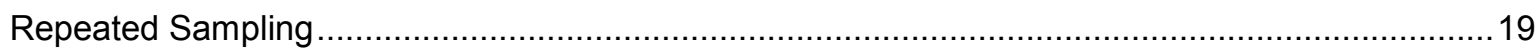

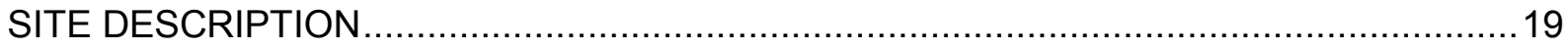

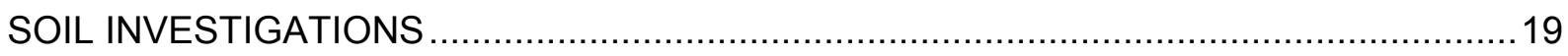

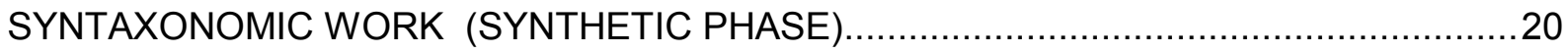

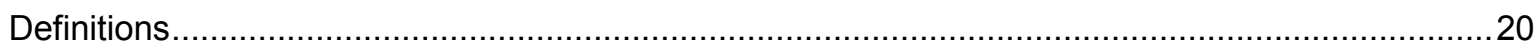

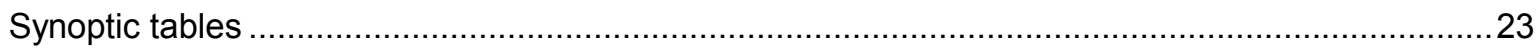

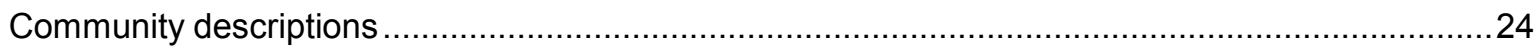

PLANT IDENTIFICATION, TAXONOMY AND NOMENCLATURE ................................... 25

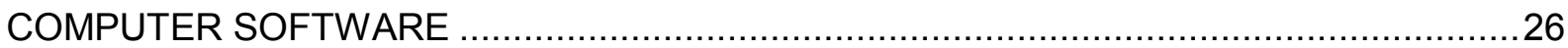


CLASSIFICATION SUMMARY:

1. CLASS: CARICI RUPESTRIS-KOBRESIETEA BELLARDII OHBA 1974.

1.1. ORDER: ARENARIO OBTUSILOBAE-FESTUCETALIA BRACHYPHYLLAE ORD. NOV. - WESTERN NORTH AMERICAN DRY ALPINE FELLFIELD COMMUNITIES

SUBORDER: GEO ROSSII-SILENENALIA ACAULIS SUBORD. NOV.

- SOUTHERN ROCKY MOUNTAIN FELLFIELD COMMUNITIES.

1.1.1. ALLIANCE: Arenario fendleri-Paronychion pulvinatae all. nov.

"ORDER: TRIFOLIO-DESCHAMPSIETALIA KOMÁRKOVÁ 1976"

1.1.2. Alliance: Deschampsio-Trifolion parryi Komárková ex Damm

1.1.3. ALLIANCE: Vaccinio-Danthonion Komárková.

SUBORDER: MYOSOTIDO ALPESTRIS-SILENENALIA ACAULIS SUBORD. PROV.

- NORTHERN ROCKY MOUNTAIN FELLFIELD COMMUNITIES.

1.1.4. Alliance: Besseyo wyomingensis-Arenarion obtusilobae all. nov.

- Besseya-Arctic Sandwort fellfield alliance.

1.1.5. Alliance: Antennario umbrinellae-Festucion idahoensis all. nov.

- Umber Pussy-toes - Idaho Fescue high elevation prairie community.....

1.1.6. Alliance: Salici nivalis-Dryadion octopetalae all. nov.

- Snow Willow-Mountain Avens alliance. .73

Arenario-Festucetalia brachyphyllae: Unclassified Associations of the Order .83

\section{CLASS: THLASPIETEA ROTUNDIFOLII BRAUN-BLANQUET 1947: TALUS AND} SCREE COMMUNITIES

2.1. ORDER: PHACELIETALIA HASTATAE ORD. PROV.

- SILVERLEAF-PHACELIA - SHRUBBY BEARDTONGUE-TALUS COMMUNITY ...113

2.1.1. Alliance: Epilobio alpini-Penstemonion elliptici all. nov.

- Alpine Willow-Herb - Shrubby Beardtongue talus slopes

2.1.2. Alliance: Phacelio hastatae-Arenarion nuttallii all. nov.

- Phacelia hastata-Arenaria nuttallii talus slope community

THLASPIETEA ROTUNDIFOLII: UNCLASSIFIED ASSOCIATIONS. 121 


\section{SUBCLASS: JUNCO DRUMMONDII-SIBBALDIENEA PROCUMBENTIS SUBCLASS. NOV.}

3.1. ORDER: CARICETALIA NIGRICANTIS BRETT ET AL. EX DAMM ORD. NOV. 133

3.1.1. Alliance: Caricion nigricantis Brooke et al.

- Western Cordilleran Black Sedge snowbeds

3.1.2. AllIANCE: Sibbaldio procumbentis-Caricion nigricantis all. nov.

- Sibbaldia-Black Sedge snowbed alliance

3.1.3. ALLIANCE: Luzulo piperi-Caricion spectabilis all. nov. 144

3.2. ORDER: SIBBALDIO-CARICETALIA PYRENAICAE KOMÁRKOVÁ 1979. 150

3.2.1. Alliance: Polytricho piliferi-Arenarion capillaris all. nov. 151

3.3. ORDER: PHYLLODOCO-CASSIOPETALIA BROOKE ET AL. EM. DAMM 164

SUBORDER: DRYADO OCTOPETALAE-CASSIOPENALIA TETRAGONAE SUBORD. PROV

3.3.1. ALLIANCE: Dryado octopetalae-Cassiopion tetragonae all. nov. 166

SUBORDER: PHYLLODOCO EMPETRIFORMIS-CASSIOPENALIA MERTENSIANAE SUBORD. PROV.

- MOUNTAIN HEATHER CASSIOPE SNOWBED COMMUNITIES

3.3.2. alliance: Phyllodoco-Cassiopion mertensianae Brooke et al. 1970

- Coastal Mountain heather communities

3.3.3. Alliance: Sibbaldio procumbentis-Phyllodocion glanduliflorae all. nov.

- Interior cordilleran Yellow Mountain Heather communities

3.4. ORDER: VALERIANETALIA SITCHENSIS BRETT ET AL. EX DAMM ORD. NOV.

- SITKA VALERIAN ORDER

3.4.1. Alliance: Lupino latifolii -Valerianion sitchensis all. nov.

- Broadleaf lupine - Sitka Valerian alliance

3.4.2. Alliance: Sibbaldio procumbentis-Trollion laxi all. nov.

- Rocky Mountain Sibbaldia-Globeflower alliance 182

3.4.3. ALLIANCE: Philonotido fontanae-Mimulion lewisii all. nov.

- Philonotis-Monkey Flower streambank alliance 186

3.4.4. ALLIANCE: Parnassio fimbriatae-Trollion laxi all.nov

VALERIANETALIA: UNCLASSIFIED COMMUNITY IN THE ORDER: 202

Fragaria virginiana-Carex haydeniana lush subalpine meadow community 202 
REFERENCES

APPENDIX .242

\section{Index of Tables}

Table 1: Synopsis: Dry Western North American Fellfield Communities

Table 2: Synopsis: Alliance Salici nivalis-Dryadion and related units

Table 3: Synopsis: Caricetalia nigricantis ord.nov.

Table 4: Synopsis: Phyllodoco-Cassiopetalia

Table 5: Western North American Valerianetalia Tall Herb Communities

Table 6: Myosotido alpestris-Caricetum albonigrae ass. nov.

Table 7: Oxytropido campestris-Bupleuretum americani ass. nov.

Table 8: Arenario capillaris-Festucetum idahoensis ass. nov.

Table 9: Salici nivalis-Dryadetum octopetalae ass. nov.

Table 10: Salici-Dryadion p.p. and Zigadeno elegantis-Caricetum scirpoideae ass. nov.

Table 11: Solidagini multiradiatae-Arctostaphyletum uva-ursi ass. nov.

Table 12: Astragalo bourgovii-Salicetum arcticae ass. nov.

Table 13: Artemisio michauxianae-Potentilletum fruticosae ass. nov.

Table 14: Saxifraga bronchialis colluvial slope community

Table 15: Phacelietalia hastatae ord. prov.

Table 16: Cryptogrammo crispae-Athyrietum distentifolii ass. nov.

Table 17: Saxifragetum mertensianae ass. nov.

Table 18: "Caricetum nigricantis Archer 1963"

Table 19: Sibbaldio procumbentis-Caricetum nigricantis ass. nov.

Table 20: Arnico diversifoliae-Caricetum spectabilis ass. nov.

Table 21: Polytricho piliferi-Arenarion capillaris all. nov.

Table 22: Sibbaldio procumbentis-Phyllodocetum glanduliflorae ass.nov.

Table 23: Valerianetum sitchensis Archer ex Damm

Table 24: Luzulo hitchcockii-Erythronietum grandiflorae ass. nov. separate folder

separate folder separate folder separate folder separate folder separate folder separate folder separate folder separate folder separate folder separate folder 98 separate folder 108 separate folder 124 128 136 separate folder 148 separate folder 172 181 separate folder 
Table 25: Senecio triangularis-Mimuletum lewisii ass. nov. and Saxifragetum Iyallii ass. nov.

separate folder 193

Table 26: Epilobio-Mimuletum lewisii Archer ex Damm

Table 27: Aulacomnio-Kalmietum ass. nov. and

Trollio-Parnassietum ass. nov.

Table 28: Fragaria virginiana-Carex haydeniana community

separate folder

Table 29: Hieracio albertini-Caricetum geyeri ass. nov.

204

Table 30: Xerophylletum tenaci ass. nov.

208

Table 31: Dodecatheo-Suksdorfietum ranunculifoliae ass. nov. 213

Table 32: Tofieldio glutinosae-Caricetum lenticularis ass. nov.
217

221 


\section{Table of contents (Appendix)}

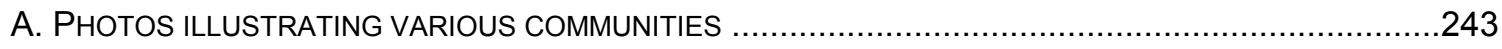

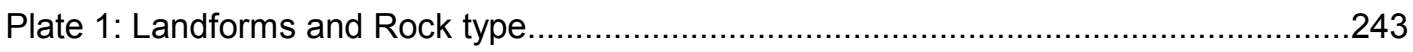

Plate 2: Examples of common Vegetation patterns............................................244

Plate 3: Important Talus Slope Communties ..........................................................245

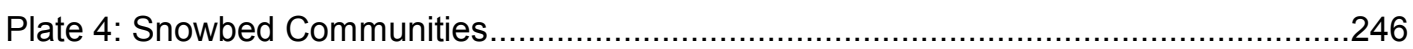

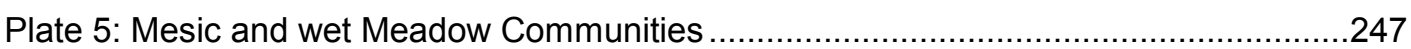

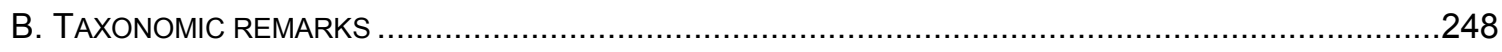

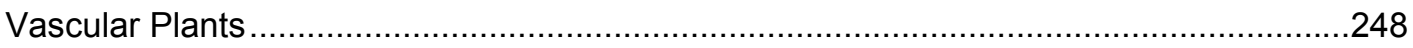

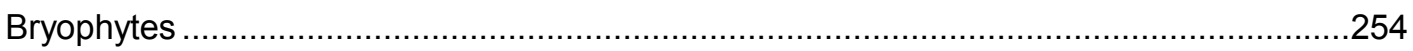

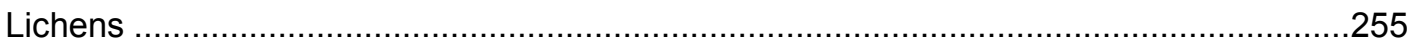

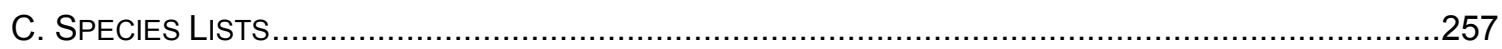

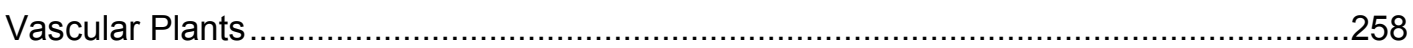

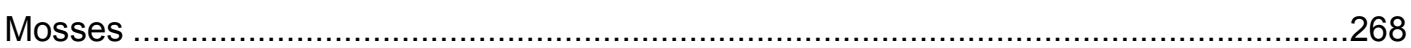

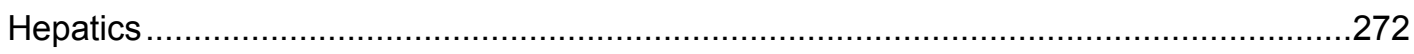

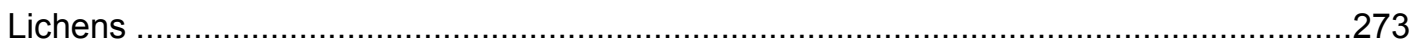

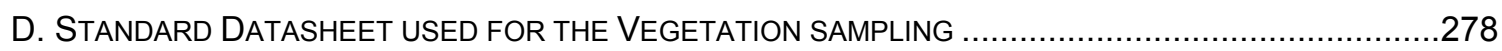

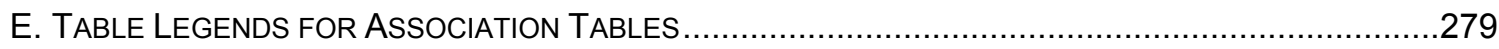

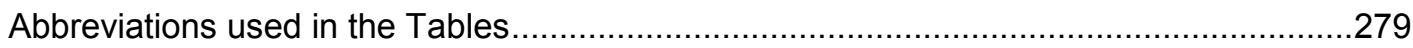

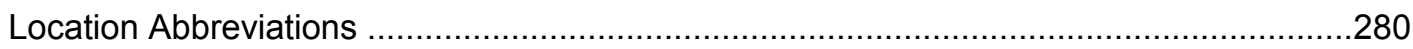

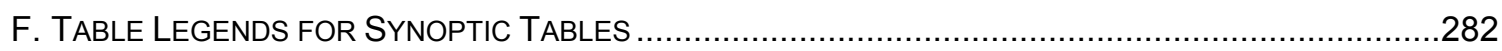

Legend Table 1: Synopsis of Western North American Fellfield units ............................282

Legend Table 2: Synopsis of Western North American Salix nivalis, Dryas octopetala and

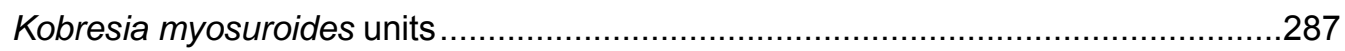

Legend Table 3: Synopsis of Western North American Carex nigricans units ..................290

Legend Table 4: Synopsis of Western North American Phyllodoce-Cassiope units ..........292

Legend Table 5: Synopsis of Western North American Valeriana sitchensis units ............295

G. Vegetation TABles: SEE SEPARATE FOLDER 


\section{Summary}

The alpine and parts of the subalpine vegetation of Glacier National Park, Montana, USA, are investigated using the European phytosociological method of Braun-Blanquet.

Based on data of about 700 detailed plot samples, a syntaxonomical classification is presented. The holarctic classes Carici rupestris-Kobresietea bellardii Ohba 1974, Thlaspietea rotundifolii Br.-Bl. 1947, and Salicetea herbaceae Br.-Bl. 1947 reasonably accommodate the Glacier NP alpine vegetation. Local units have been organised in 3 classes, 6 orders, 12 alliances, 32 associations, 26 subassociations, 10 variants, and 7 other communities. For each of these, detailed descriptions are provided. Syntaxonomical rank and circumscription, chorology, ecology, and succession dynamics are discussed.

In order to accommodate the alpine vegetation of Glacier NP, an area much wider than the study area had to be reviewed, covering the Rocky Mountains south of $53^{\circ} \mathrm{N}$, and including the interior ranges to the west and the western coastal mountains north of central Oregon.

An overview of western North American alpine vegetation units is presented by means of synoptic tables. Drawn from these tables are conclusions for the syntaxonomic system of the western North American alpine.

In the Carici-Kobresietea, a new order of alpine fellfield communities, Arenario obtusilobaeFestucetalia brachyphyllae ord. nov., is created, comprising a southern and a north-central suborder. In the snowbed class Salicetea herbaceae, a western North American subclass, Junco drummondiiSibbaldienea procumbentis subclass. nov. is created, which holds four orders. These are Caricetalia nigricantis ord. nov., Sibbaldio-Caricetalia pyrenaicae Komárková 1979, Phyllodoco-Cassiopetalia Brooke et al. ex Damm, and Valerianetalia sitchensis Brett et al. ex Damm. The Caricetalia nigricantis and the Valerianetalia sitchensis are divided into a western-coastal and interior cordilleran alliance each.

A number of previously described units are validated according to the Code of Phytosociological Nomenclature (CPN) or newly combined into the present system. 


\section{Introduction}

It has been mentioned many times that phytosociological studies on western North American subalpine and alpine vegetation are quite rare (Archer 1963, Ives et al. 1974, Ohba 1974, Komárková 1976, 1979, Willard 1963, 1979 and others). Thorough floristical investigations in the western mountains have begun early, starting with the collections of numerous famous botanists like Parry, Vasey, Coulter, A.Nelson, Lettermann, Holm, A.Gray, Nuttall, Rydberg and others (see Ewan 1950). Floristic research continues on in many Rocky Mountain areas with particular emphasis e.g. on Colorado. Much ecological research has also been carried out in the Rocky Mountains and other western mountain ranges (Daubenmire 1943, Griggs 1956, Billings \& Bliss 1959, 1954, Bliss 1956; Bliss 1958; Mooney \& Billings 1960; 1961; Bliss 1962; Johnson \& Billings 1962; Scott \& Billings 1964; Billings et al. 1966; Billings \& Mooney 1968, 1969; Billings 1969, 1973, 1974; Bliss 1969; Kuramoto \& Bliss 1970; Willard \& Marr 1970; Bell \& Bliss 1973; Ives 1977; Bell \& Bliss 1979, Oberbauer \& Billings 1981, Peterson \& Billings 1982, Komárková 1993 and numerous others).

Given the large amount of literature on floristics and ecology of the western North American alpine and subalpine, it is surprising to see that detailed studies of the vegetation and its distribution are still very scanty. Even fewer of those studies have been published, many of those being unpublished masters' and doctoral theses.

So far, no attempt has been made to organize the available information on high elevation vegetation into a comprehensive and standardized vegetation classification system as it has been done in other mountain regions of the world (Central Europe, Scandinavia, Japan).

First attempts of a syntaxonomical system using the European Braun-Blanquet method have been initiated by Willard (1979) and Komárková (1979). Unfortunately their pioneer work has so far not been continued.

For British Columbia, Krajina and his school have established a syntaxonomical system using a slightly modified approach which in some respects lacks the desired compatibility with the BraunBlanquet system (Krajina 1965, Hoefs et al. 1975, Klinka et al. 1997).

The current North American Vegetation Classification (Grossman et al.1998, Anderson et al. 1998) is another beginning of a comprehensive approach but it is not nearly as detailed and differs in its basic definitions of vegetation units being to a much greater extent a physiognomic classification system. At present the alpine has not been treated sufficiently in that system.

The present study is a first attempt to combine all available information in literature on the most important western North American alpine vegetation units into a floristic classification system. The Braun-Blanquet system as one of the most successfully applied vegetation classification systems was chosen for a number of reasons. Apart from its wide application it has been developed originally on alpine vegetation proving to be well suited for this kind of vegetation. Another reason was the lack of comprehensive and comparable vegetation data on other western North American mountain ranges, creating a gap for this region in comparative studies of world wide mountain systems. It has to be stressed that all data on areas beyond Glacier National Park has been taken from literature and does not originate from the authors own research.

A geographical overview of the literature studies used is presented with the following map. 


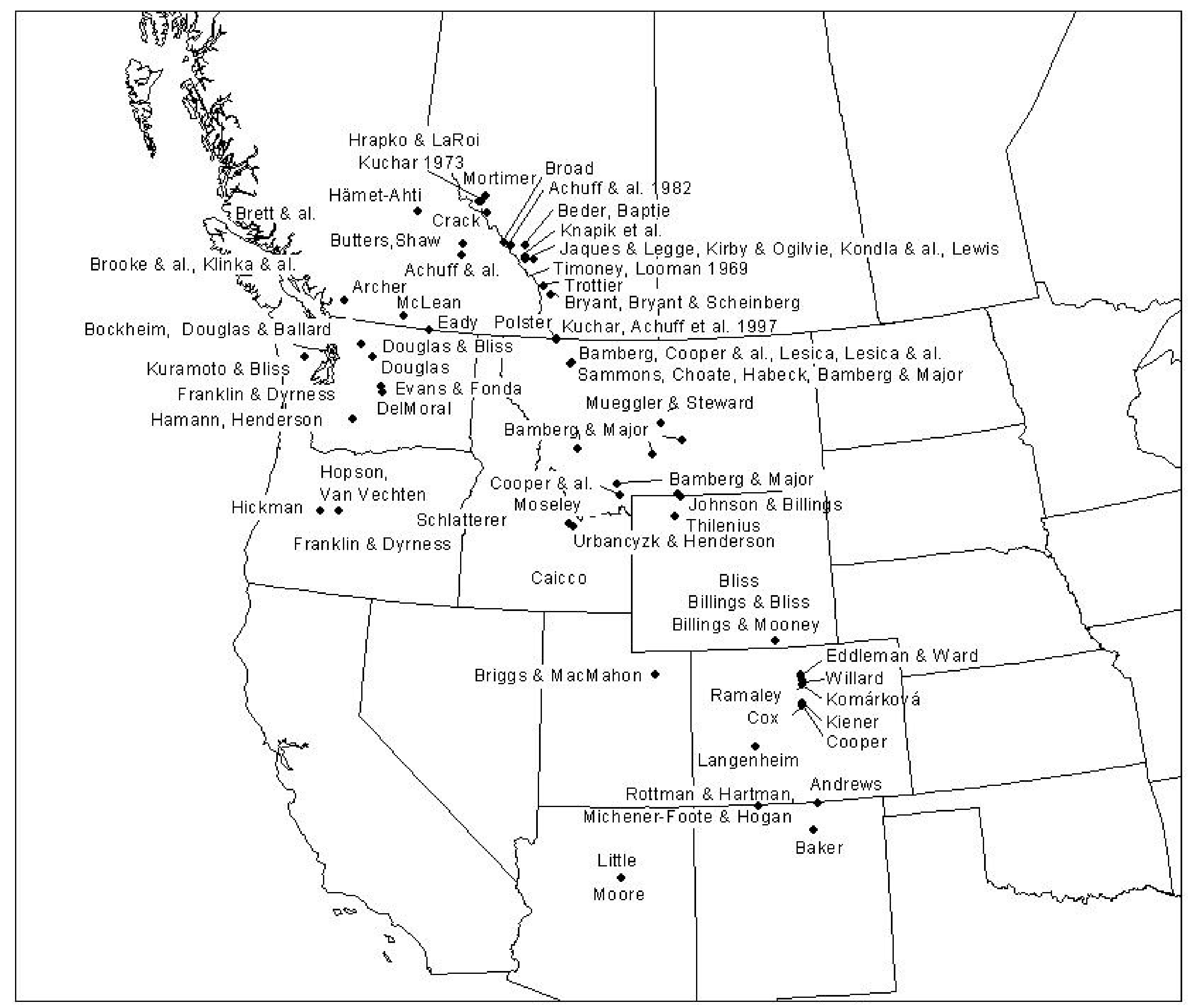

- Local Vegetation Study

- Vegetation Study treating a larger area

Locations and authors of vegetation descriptions from literature. Other studies used, which do not provide detailed vegetation descriptions, have been omitted. 
Historically the lack of interest in alpine vegetation studies is certainly a consequence of the interest being focussed on the lower elevation "lands of many uses", i.e. rangeland and forested areas used for agricultural, silvicultural and recreational purposes. As opposed to these economically relevant areas, high elevation areas have raised much less attention from the public, administration and researchers for a long time. It is the increase of human impact even in the so far mostly untouched high elevation areas that fosters a growing need for scientific information on these remote uplands.

The effects of increasing touristic use, whether it be mass tourism in the so-called "front country" areas or individual tourism in less accessible regions, have become an issue since an increasingly mobile society has gained much easier access into these formerly untravelled areas.

In combination with the growing awareness for ecological questions and the impacts of human society on the environment, also the more mediate effects of medium and large scale environmental changes on ecosystems have drawn some attention towards high elevation ecosystems.

The resulting need for detailed ecological information on high altitude environments should be addressed in this study. Next to the above mentioned large scale classification developed in this study, a second, regional level is addressed. Its purpose is to provide baseline data on alpine and subalpine vegetation for the area of Glacier National Park, Montana.

Even though this area has been designated National Park since 1910, descriptive vegetation research in the alpine has been scanty. Hansen (1948), Baden (1952), Sammons (1959), Bamberg (1961), Choate (1963), Habeck (1963, 1963a, 1968, 1969, 1970), Habeck and Choate (1963, 1967), Bamberg \& Major (1968), McClelland (1970), Koterba \& Habeck (1971), Hartley (1976), Lesica (1988, 1990), Butler (1985, 1979), Lesica \& McCune (1992), Butler \& Malanson (1994), Tardiff \& Stanford (1998) all presented vegetation related studies but detailed descriptions of alpine or subalpine vegetation have been provided only by the studies of Sammons, Bamberg, Bamberg \& Major, Habeck, Hartley and Lesica, all of which focussed on the limited area of Logan Pass and its vicinity.

None of those studies was meant to give detailed descriptions of the most widespread alpine vegetation types in the area and no other typification of the vegetation was so far attempted. Whereas Habeck's studies mention the alpine vegetation only marginally, Sammons used an ordination approach to describe local vegetation patterns in the Logan Pass meadow area. Bamberg and Bamberg \& Major were the first to describe alpine tundra vegetation in detail in comparison with other alpine areas in Montana. Lesica, apart from giving the most extensive floristic accounts of the Park, collected detailed information on some permanent plots in the floristic "hot spots" of the Park without any reference to widespread vegetation types. The studies of Tardiff et al. on subalpine meadows are focussing on ecophysiological questions trying to elucidate changing soil nutrient cycles after disturbance by grizzly digging activity. Butler and Malanson give some accounts on vegetation of avalanche chutes concentrating mostly on the subalpine.

The main objectives of the regional part of the current study are

- a detailed description of Glacier National Park's alpine (and partly subalpine) vegetation using the method of the European Braun-Blanquet approach

- the typification of vegetation units based on common floristic composition, common ecology and common functions of the vegetation units in the landscape 
- a hierarchical classification of the vegetation units based on floristic similarity and common ecology. The classification is according to the widely used Braun-Blanquet school and largely embedded in the proposed classification including other western North American alpine studies.

- to provide baseline data for long term vegetation studies on alpine vegetation providing a representative system of geo-referenced permanent plots through the study area representing all major alpine vegetation units.

\section{Study Area}

The area of this study has to be divided according to the two levels of study involved:

\section{Area of syntaxonomic studies}

The syntaxonomic study area, i.e. the area included in the literature research revealing suitable vegetation data, is generally called here the western North American mountains. It includes the Rocky Mountains from Jasper National Park in Alberta to southern Colorado. Treatments of alpine areas not continuous with the main range of the Rocky Mountains also have been used (e.g. Flint Creek Range, Big Belt Mtns., Pioneer Mtns. in Montana, Big White Mtns., and others including the mountains of Idaho). Studies included originate from the coastal Cascade Mountains of British Columbia to northern Oregon including Vancouver Island and the Olympic Mountains. The Sierra Nevada, the Great Basin and other southwestern mountains have been excluded since their plant communities are less related to the ones treated here. The differences of the alpine floras of these regions in relation to the Rocky Mountains and the Cascades have been described in detail by Loope (1969).

Throughout this work, the terms northern and southern Rocky Mountains have been used including Glacier National Park in the northern part. The southern Rocky Mountains are in accordance with phytogeographical evidence defined to begin in the southern Montanan mountain ranges (Beartooth Plateau), south of the edge of the Wisconsinian glaciation.

\section{Area of phytosociological field studies: Glacier National Park}

Glacier National Park is located in the Rocky Mountains of northwestern Montana, encompassing more than $130 \mathrm{~km}$ of the Continental Divide immediately south of the Canadian border at $49^{\circ} \mathrm{N}$. The main axis of the Park stretches from the Northwest at $114^{\circ} \mathrm{W} 49^{\circ} \mathrm{N}$ to $113^{\circ} \mathrm{W} 47^{\circ} \mathrm{N}$ in the park's southeastern corner. It continues north of the border by the Canadian Waterton National Park which together with Glacier National Park forms the "Glacier-Waterton International Peace Park".

The study area belongs to the eastern part of the Northern Rocky Mountain Physiographic Province (Mudge 1977). 


\section{Topography}

The park covers about $4100 \mathrm{~km}^{2}$ with elevations ranging from $950 \mathrm{~m}(3110 \mathrm{ft})$ at the confluence of the North and Middle Fork of the Flathead River to $3191 \mathrm{~m}$ (10466 ft) at the summit of Mt. Cleveland (Finklin 1986).

The topography of the park is dominated by two major mountain ranges which parallel each other stretching from northwest to southeast: firstly the Lewis Range to the east extending from the international boundary about $100 \mathrm{~km}$ SSE towards Maria's Pass and secondly the Livingston Range adjacent to the west, reaching only about $35 \mathrm{~km}$ from the Canadian border south to the Lake MacDonald area. Both ranges form parts of the Continental Divide, the latter in the northern, the first in the central and southern portions of the park.

Due to the inaccessibility of most of the Livingston Range and the lesser occurrence of well developed alpine vegetation in that area, most of this study is concerned with the vegetation of the Lewis Range. Exceptions to this are the vegetation of the Boulder Pass area, the Gyrfalcon Lake/Trapper Peak area and the Dutch Lakes region. The latter two have been covered in some reconnaissance trips only. The even less accessible southwestern portion of the park west of the Continental Divide and south of Lake Ellen Wilson has not been visited in this study.

Most of the alpine and subalpine areas in the park are confined to these parallel running ranges and perpendicular running, adjacent ridges. The eastern Lewis Range is connected by some eastward trending ridges and alternating valleys to the open plains just outside the park. These flat-topped ridges hold some of the largest expanses of alpine vegetation in the park. The western Livingston Range is connected similarily by perpendicular but shorter and steeper ridges to the broad, alluvial North Fork Valley which contains the western boundary of the Park. West of the North Fork borders the montane to barely subalpine Whitefish Range.

Alternating with the east and westward stretching ridges are a number of parallel, classically Ushaped glacial valleys. These extend to both sides of the Divide like ribs from a spine which suitably adds to the native Americans' description of the Continental Divide as "the backbone".

A number of those long and narrow side valleys hold deep glacial lakes. To the west these sidevalleys end in the alluvial valleys of the North- and Middle Fork of the Flathead River. To the east these valleys after less than 10 miles open with a narrow band of foothills into the Great Plains. Like in the Canadian Rockies the valleys on the west side of the Continental Divide are about $400 \mathrm{~m}$ deeper carved in than those on the east slope. Heavier glaciation as a consequence of higher precipitation and steeper descending and therefore faster rivers (shorter distance to the ocean plus sinking valley-bottoms due to graben-tectonics) account for this feature (Gadd 1995).

At least ten periods of glaciation (Richmond acc. to Mudge 1977) carved the present shape into the layers of sedimentary rock leaving deep glacial, often canyon-like valleys, rugged peaks and narrow ridges. The almost horizontally laying strata of the relatively crumbly sedimentary rocks in this area are more resistant to erosion than tilted layers of the same rock-types as found in the nearby Canadian Rockies. Thus the peaks in Glacier remained higher, intercepting more precipitation which led to more intense glacial activity resulting in even deeper valleys.

Compared to the non-sedimentary Central and Southern Rocky Mountains which experienced more uplift through rising masses of magma, the mountains in Glacier are generally of lesser elevation, but the valleys in the Northern Rockies are carved in much deeper making the "Matterhorn-shaped" mountains appear even higher than those further south. Even though both areas receive and most 
likely received similar amounts of precipitation far more intense glaciation occurred in these higher latitudes due to lesser evaporation.

Remnants of the formerly intense glaciation which Glacier aptly received its name for, can still be found in a number of small receding glaciers and snowfields along the Continental Divide. According to Carrara and McGimsey (1981) these small glaciers and snowfields are not genetically related to the former pleistocene glaciation but have originated about $4000 \mathrm{yr}$. BP after an intervening warm period.

A triple continental watershed originates at Triple Divide Mountain in the southern center of the park. The North and Middle Forks of the Flathead River on the western slope are tributaries of the Columbia River draining into the Pacific Ocean. The northeastern part of the park drains through Waterton River, St. Mary River and Belly River into the Saskatchwan River which finally leads its way to the Hudson Bay. The remaining southeastern section through Cutbank Creek, Two Medicine River and Summit Creek feeds the Missouri, leading into the Mississippi finally reaching the Gulf of Mexico. 
Study Area: Glacier National Park, Montana, USA
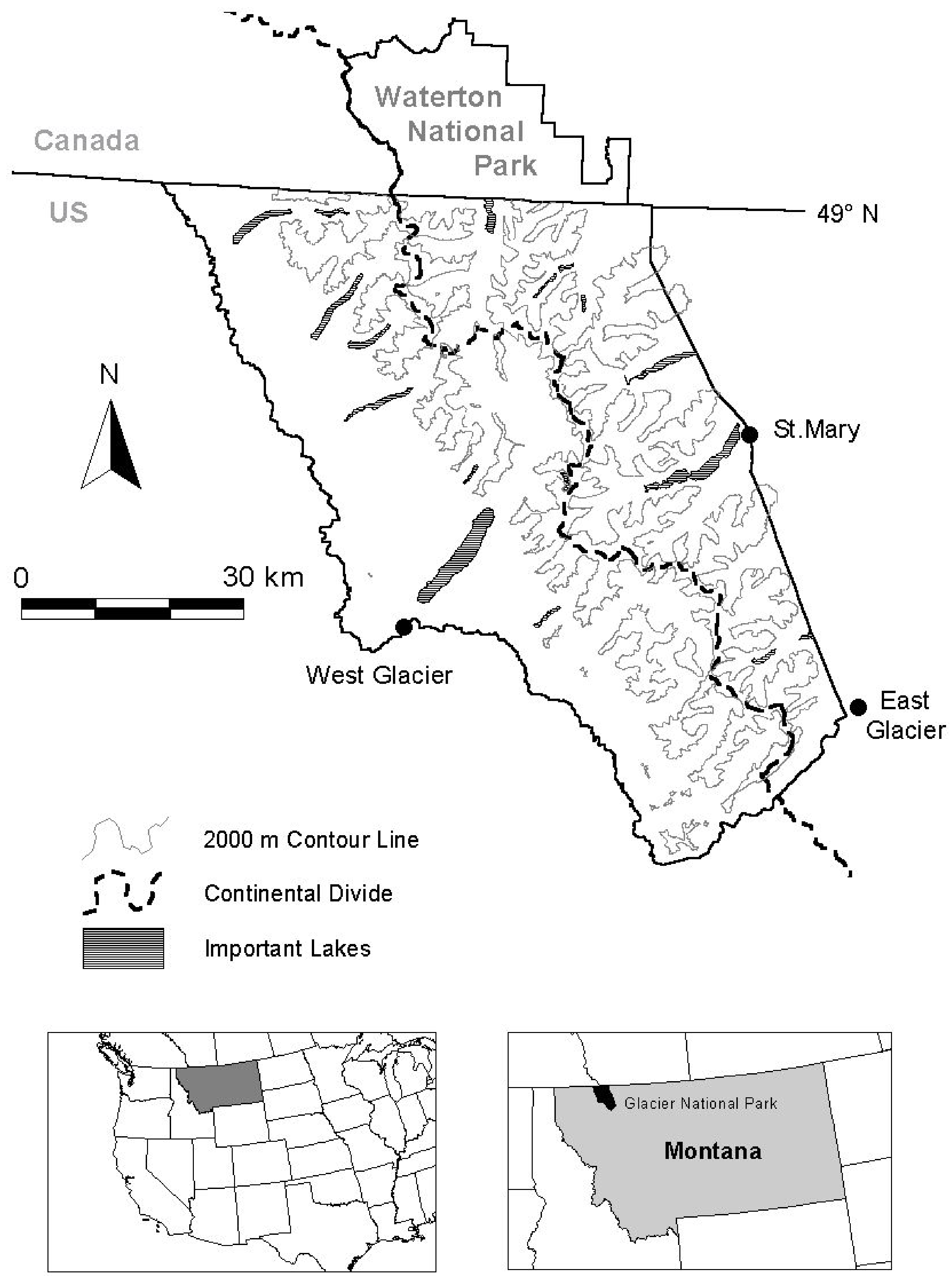


\section{Geology}

\section{Geological history}

A brief overview is given here of the three most important periods in geological history that led to the present-day geological situation. 1. the formation of the proterozoic rocks that make up for most of the present geology in the park, 2. the tectonic events that placed the rocks the way we find them arranged today, 3. the period of intense pleistocene glaciation that carved the recent topography out of the tertiary land surface.

The Proterozoic: The rocks encountered in the area are mainly of Proterozoic age. At that time (1600-750 mio yr. BP) a major syncline called the Belt Sea covered most of what is now Western North America (Mudge 1977). This trough was over millions of years filled in by deposits washed in from the adjacent landmasses. The sedimentary layers were originally reaching more than 10 kilometers in thickness. They are now known as the Belt Supergroup which is bedded on top of the basal granitic continental crust (Ross 1959).

Being deposited under changing conditions of waterdepth, salinity, oxygen availability, size and origin of the deposits, a variety of partly very colorful rocks resulted. Sand, silt, and carbonaceous muds as well as biogene deposits underwent the transformations typical for formations of sedimentary rocks which are compressed and cemented into sandstones, siltstones, shale, limestone and dolomite. Heat and pressure low-grade-metamorphosed much of them into quartzites, siltites, argillites and recrystallized/marbelized limestones and dolomites.

The most predominant geological parent materials for soil development in the area are argillites (plate 1, fig.4. These are weakly metamorphosed shales not altered enough to be called "slate". Slates are altered by metamorphosis so that they are not cracking along their original layered structure anymore (Gadd 1995) as the present argillites mostly do. Important in many locations are also limestone and dolomite which occur mostly as biogene sediments. They often still reveal structural features of their origin (e.g. stromatolithes).

Igneous intrusions: Another important feature of the proterozoic formation is the presence of igneous basaltic rocks in the upper strata of the Belt series. The Purcell Lava is a cushion-shaped basalt flow of presumably subaquatic origin that nowadays forms a conspicuous surface in the Boulder Pass and Granite Park areas (the latter being a misnomer for the basalt which has obviously been mistaken for granite which is not present in the area). Of similar age is the Purcell sill, an intrusive, up to $80 \mathrm{~m}$ thick band of diorite which was pressed as a magma in between the sedimentary strata. It forms an obvious band along the Continental Divide through most of the park. Especially its light upper and lower contact zones with dolomitic limestone are easily seen on many mountain walls. The bleaching of the adjacent rock results from contact-metamorphism caused by the heat and pressure of the intruding magma. Except for one typical boulder-field community, igneous substrates do not play an important role for the vegetation of the area.

The Cambrian: Near the end of the Proterozoic about 750 Ma BP, uplift brought about the end of this period of sedimentation. The surface rose above sea-level to initiate a period of erosion causing a major break in the geological record known as an unconformity. After a couple of minor lifts and downward movements, a new syncline developed in the Middle Cambrian initiating the next period of sedimentation. These Cambrian layers covered the older Belt Series layers in the area, but were subsequently completely eroded away. During later periods of uplift, all of the younger sedimentary rocks and even much of the precambrian Belt rocks which almost all of the present mountain ranges consist of, eroded. Being mostly sedimentary in its origin, the Rocky Mountains in Glacier National 
Park are geologically much closer related to the Canadian Rocky Mountains than to the US-American Rocky Mountains further south. As a result of their much different geological history, the latter are mainly dominated by granitic rocks originating from the old continental crust.

The Lewis Overthrust: The next and very important event in the geological history of the study area was the so called Lewis Overthrust. About $85 \mathrm{Ma} \mathrm{BP}$, when the collision of the American continental crust and the Pacific Oceanic crust began (Laramide Orogeny), the latter, being the heavier one, started being subducted under the continental plate and melted off in the depth of the earth's mantle. This resulted in an increased volcanic activity. As opposed to the Central and Southern Rocky Mountains, where the granitic basement rock was crushed and thrust upwards by this collision to partly form todays surface, the continental basement in the Northern Rockies remained mainly intact. Instead, the more surficial layers were separated from the deeper layers by large thrusts and pressed eastwards against each other, adding oceanic crust to the American continent. In this process the whole surface was shoved northeastward over the granitic crust, like a carpet over a floor, causing it to warp, fault, break and thrust (Gadd 1995).

The area that nowadays reaches along the Continental Divide from about $150 \mathrm{~km}$ south of Glacier National Park to a couple of hundred kilometers into Canada was pushed eastward for at least $65 \mathrm{~km}$, as more or less one big, about $4600 \mathrm{~m}$ thick slab of sedimentary rock. Within this slab, only minor thrust faults, normal faults and folds developed (Ross 1959). The entire sedimentary plate slid over younger cretaceous layers rising at a slight angle towards the northeast. Its eastern front currently forms the abrupt drop-off of the mountain front to the Great Plains near the eastern boundary of the park. This tremendous geological formation is known as the Lewis Overthrust. The reversed order of the younger cretaceous rocks underlaying the older overthrusted proterozoic layers can still be seen in the eastern parts of Glacier Park. The cretaceous material that covered the thrust plate was lifted up during the thrusting and was thus exposed to erosion which has long abraded it away.

The Tertiary period of erosion supposedly left a landscape of rolling uplands that underwent further intense shaping during the comparatively short period of the Pleistocene. The change from the dry and warm tertiary climate to colder and wetter conditions of the pleistocene era caused heavy glaciation in the area. Huge masses of ice built up to more than 1000 meters thickness and carved out drainages into deep valleys to create todays impressive landscape within the geologically short period of less than two million years. The melting of the glaciers during the holocene left large amounts of debris behind, which still are an important factor as a landscape element. Moraines frequently occur from the alpine to the montane zone, often holding lakes. Glacial till is a common substrate on valley floors all over the park.

\section{Bedrock materials}

The most important rock formation which today forms the surface in the study area is the middle proterozoic Belt Supergroup. None of its subformations is correlated with one single rock-type only, and delineation of adjacent formations is often obscured by gradational transitions. Many rock-types even reoccur in different formations and the changes within one formation can be considerable over short distances vertically as well as horizontally. Thus local particularities are mainly obscured which is enhanced even more by the fact that many sites, especially in sloping situations, have strongly intermixed colluvial parent materials. This is likely to be one of the reasons why a pronounced difference 
and calcifugal vegetation as it is found in other mountain ranges in the world could not be observed in the area.

Geological formations of the Belt Supergroup listed from younger to older strata downwards (after Earhart et al. 1989):

Shepard Formation: the uppermost Belt formation exposed in Glacier National Park. This formation is exposed on some of the summits in the central part of the Park. It consists of at least $300 \mathrm{~m}$ yellowishgrey to greenish grey dolomitic argillites and siltites and lesser amounts of pale green argillite, light grey quartzite, calcarenite, limestone and dolomite.

Snowslip Formation (formerly called Siyeh Formation p.p. or Helena Formation): Mainly consisting of argillites and siltites of various colors from green to mostly red. Dolomitic siltite, dolomite and stromatolithes are common in the upper part of this about $460 \mathrm{~m}$ thick formation which tends to grade into the above one.

Helena Formation (formerly called Siyeh Formation p.p.): This up to 750 (-1525) m thick formation (Mudge 1977) consists of dark grey argillaceous dolomite, gray limestone and in the lower part calcarenite and quartzite most of which weather tan-colored. Conspicuous are up to $15 \mathrm{~m}$ thick strata of stromatolithes, dolomite structures of various shapes (e.g. 2-3 m wide Conophyton-"cabbageheads") which have been deposited by blue-green algae in a proterozoic shallow sea.

Parts of this formation are forming conspicuous cliffs due to their differential resistance against weathering processes.

Empire Formation (formerly called Siyeh Formation p.p.): Mostly green argillite and siltite with dolomitic character in the upper part. Buff weathering calcareous strata are often interlayered with green argillites and siltite and thus appear banded. With gradational contacts to the neighboring formations this one is about $200-300 \mathrm{~m}$ thick.

Grinnell Formation (equivalent to Spokane Formation): This formation is dominated by the red color of argillites and siltites which give a very characteristic coloration to many mountain-sides in the Park. Coarse quartzite, hardened by metamorphosis, and sandstones are often mixed in with argillite clasts. Thickness is about $750 \mathrm{~m}$.

Appekunny Formation (equivalent to Greyson Formation): This formation consists mainly of green argillites and siltites and is about $1165 \mathrm{~m}$ in thickness. Light grey quartzite and medium-red argillite and siltite occur in some of the the lower parts of the formation.

Altyn Formation: This is the lowermost unit of the Lewis thrust fault plate and its base is not exposed in the area. With a thickness of at least $300 \mathrm{~m}$ it consists of dark-grey to buff, even orange dolomites, argillaceous dolomites and stromatolithic limestones. Its upper parts are thin bedded and argillaceous which leads to the formation of slopes whereas the middle, resistant beds are cliff-forming.

Prichard Formation: This lateral, western facies of the Altyn formation consists of argillites and siltites but occurs only in the western part of the park and thus did not reach any of the sites of this study.

Colluvial parent materials: Due to the strong relief in much of the alpine and subalpine zone of Glacier National Park, the bedrock is often found to be mantled by thick colluvial masses which is the case in practically every valley in the park. In many places the entire valley bottoms are covered by post-glacial colluvial debris unless they are covered by glacial till. The resulting extensive talus slopes 
constitute an important site type for various types of Glacier's alpine and subalpine vegetation. Vegetative cover on those slopes varies greatly in its density depending on the degree of instability of the slopes. The relocation of the parent material by gravitational forces usually leads to a complete mix of the bedrock materials originating from the cliffs above. Therefore the resulting parent material for any initial soil development often is a chemically leveled mix of rocks rather than a reflection of a soil that might be typical for particular a rock type. Thus e.g. pronounced differences in soil-pH were not found. Still ecological differences could be found especially correlated to the talus texture. As an example coarse, platy argillite slopes tend to remain very unstable and unsuitable for vegetative colonization whereas smaller and isodiametrically fractioning sandstones or quartzites are more readily compacted and soil-supporting.

Non-deposited parent materials: On high, unglaciated upland surfaces, which occur mainly on the east side of the area, the exposed bedrock surfaces have not been altered as much by gravitational as by climatical forces. Severe frost action has created gravelly frost-rubble surfaces which often reveal stone stripes, sorted polygones and solifluction features (Washburn 1956). These very stable sites are largely covered by well developed, species-rich alpine fellfield communities.

Alluvial parent materials: Cirques, valley bottoms and other more or less level depressions which have not been covered by colluvium or washed bare are often covered with alluvial material. Some of this is of glacial origin or derives from younger colluvial slopes. Periglacial loess deposition might also account for some of the fine fractioned alluvial material. Much of it derives from various holocene volcanic eruptions near the Pacific coast. Ashes from Mt. Mazama (6845 yr. BP), Glacier Peak G (11200 yr. BP), Mt. St. Helens (11400 yr. BP) have been found in Glacier (Carrara 1989a, 1989b). Alpine cirque snowbed communities can often be found on thick silty depositions which have been washed into the cirque basins and accumulated to various thickness. In some soil profiles a conspicuous orange layer of silty material could be observed which has been attributed to the Mt. Mazama eruption. The Carex nigricans communities were found to be a good indicator for such profiles.

\section{Climate}

The climate of Glacier National Park is classified as "continental with decided Pacific maritime modification" (Dightman 1967). The mountainous character of the area together with the location of the Park on the eastern edge of the western North American Cordillera results in a remarkable degree of variation of the climate within the Park's boundaries. According to Carrara (1986), the climate of the Park is effected by two different climatical systems. A steep climatic gradient cuts through the Park from the moister and milder maritime westside to the drier, cooler and more continental east side. This steep gradient is covered over a distance of less than $50 \mathrm{~km}$ It is strongly reflected in the vegetation of the region.

Four Walter climate diagrams have been compiled which represent stations along this gradient.

West Glacier at the western boundary of the park represents the maritime westside at a montane station within coniferous forest. Flattop Mountain is the highest available weather station with continuous precipitation recordings. It is located in an open subalpine Abies lasiocarpa forest on the westside near the Continental Divide. St. Mary as well as Babb represent the drier conditions on the Eastside. St. Mary is located at the entrance of the major St. Mary drainage which has strong influence on its local climate: Despite its eastern location it is still considerably moister than Babb, 
and its climate diagram does not quite show the difference compared to the West Glacier diagram. Therefore data from Babb, which is not far from the mountain front located in the open foothills has been added to represent the continental climate character of the Eastside. Much of the high country on the eastside which has been included in this study is likely to be influenced by this dry, continental climate.

Unfortunately more detailed climate data of true alpine weather stations to better characterize the environmental conditions which alpine vegetation experiences, are not available from the area. This is largely due to the fact that nearly all of the alpine in Glacier is inaccessible in winter which so far precludes the maintainance of year round weather stations which could provide the needed precipitation data.

Precipitation: According to Dightman, precipitation along the climatic gradient ranges from less than $600 \mathrm{~mm} / \mathrm{a}$ on the plains east of the Divide (Babb) to more than $6000 \mathrm{~mm} / \mathrm{a}$ in the central and northern interior portions of the park. Finklin gives a still high but more realistic figure of $2500 \mathrm{~mm} / \mathrm{a}$ as precipitation maximum for the area. No continuous precipitation measurements have yet been taken from the higher elevation areas except for those from Flattop Mountain presented in the climate diagram which reveals a slightly smaller figure $(1888 \mathrm{~mm} / \mathrm{a})$.

The westside of the Park is among the wettest parts of Montana caused by moist Pacific-maritime air masses that meet the abruptly rising mountains of the Continental Divide. December and January are the moistest months in this region with considerable amounts of snow even down to lower elevations and significantly increasing with altitude. A second marked precipitation maximum is in June.

Winter temperatures are not very extreme due to the leveling effect of the moist air masses coming in from the west which bring about frequent and dense cloud cover through much of the year except for the summer months. Similar on both sides of the Continental Divide is a minimum of precipitation during July and August with a relatively stable, mostly cloudless high pressure period during this short summer season.

The Eastside experiences a more extreme, drier continental climate with colder winters and warmer summers. The wet season is from April to June when the polar air masses are replaced by incursions of moist air masses from the Gulf of Mexico that might also lead to significant amounts of precipitation on the westside during early summer. On the Eastside cold and dry continental polar air masses predominate during the winter with far lesser winter precipitation than on the westside. While average winter temperatures are similar to those on the west side extremes are much more pronounced on the east side. Strong and warm chinook winds ("Föhn") frequently occur in winter when pacific air masses invade the area loosing their moisture upon the ascent on the western mountain sides, warming adiabatically and producing winds up to $160 \mathrm{~km} / \mathrm{h}$ on the east side (Carrara, 1989).

Snow can fall at any time of the year being very rare in July and August when it occurs only in the high country. Snow cover usually continues from November to April at lower elevations, to May at about $1500 \mathrm{~m}$ with few snow patches remaining through mid-August at higher elevations. Perennial snow fields are found above $1800 \mathrm{~m}$. They mostly coincide with present or former glacier surfaces. Average annual snowfall along the edges of the park ranges from 300 to $680 \mathrm{~cm}$ and probably exceeds 1525 to $1775 \mathrm{~cm}$ in favored mountain locations (Finklin 1986). The large amounts of snow that cover much of the high country reveal a problem in terms of accessability of many alpine areas in early summer. The only road reaching the lower alpine in the park, the Going-to-the-Sun Road, usually opens the first or second week of June, sometimes not before July when the higher elevation areas are still covered with snow. Since most of the trails are not open before another two or three weeks later, accessibiliy of the study area is very limited even though vegetative development has long started at 
that time. Snow free areas at high elevations can be found as early as May. Exposed ridges and other locations, where snow cover is removed by wind and intense radiation, can be snow free much earlier. The short growing season, which usually terminates with the first snow by mid-September (sometimes even late August), puts another constraint to the study of alpine vegetation and caused this study to be extended over four summer seasons (1994-1997).

Temperature: Monthly average mean temperatures for July are $14-17^{\circ} \mathrm{C}$ on both sides of the Divide at lower elevations and $10-11^{\circ}$ on Flattop Mtn. The corresponding January temperatures are $-4--7^{\circ} \mathrm{C}$ at lower and about $-9^{\circ} \mathrm{C}$ at higher elevations. Annual means are $2-5^{\circ} \mathrm{C}$ at lower elevations and $-0.2^{\circ} \mathrm{C}$ at Flattop Mtn. Temperature maxima are similar on both sides of the Divide, being slightly higher on the westside (see diagrams, upper left figure). Minima are considerably lower on the continental eastside (lower left figure in the diagrams). Frost can occur at any time during the year. Monthly average mimima below zero ${ }^{\circ} \mathrm{C}$ occur from October to April in West and East Glacier and from October through Mai on Flattop Mtn. According to Finklin (1986) the season between "killing frosts" $\left(-2^{\circ} \mathrm{C}\right)$ is mid or late May through mid-September (= 4 months) on the eastern edge of the Park and 2,5-4,5 months in west side valley locations.

The temperature lapse rate with elevation is $7.5-8^{\circ} \mathrm{C}$ per $1000 \mathrm{~m}$. As common in mountainous areas, temperature inversions are common during summer, mainly at nighttime and from July through early fall. These inversions can persist throughout the daylight hours particularly in the westside valleys.

Wind: Wind conditions are quite dissimilar on the east and westside. The mountain tops and the areas east of the Continental Divide experience a windspeed maximum in winter with 24 hour-averages of $32 \mathrm{~km} / \mathrm{h}$ during November through February and a minimum in summer. The mountain-sheltered west side experiences much less windy conditions throughout the year with a minimum in winter of about $8 \mathrm{~km} / \mathrm{h}$ and a spring maximum (Finklin 1986).

Prevailing wind directions are from west to southwest through much of the year and on both sides of the Continental Divide with much deviation by topographic channeling. Reversed directions are common at night in the westside valleys when cold downslope winds occur. 


\section{Walter Climatic Diagrams from Glacier National Park, Montana, U.S.A.}

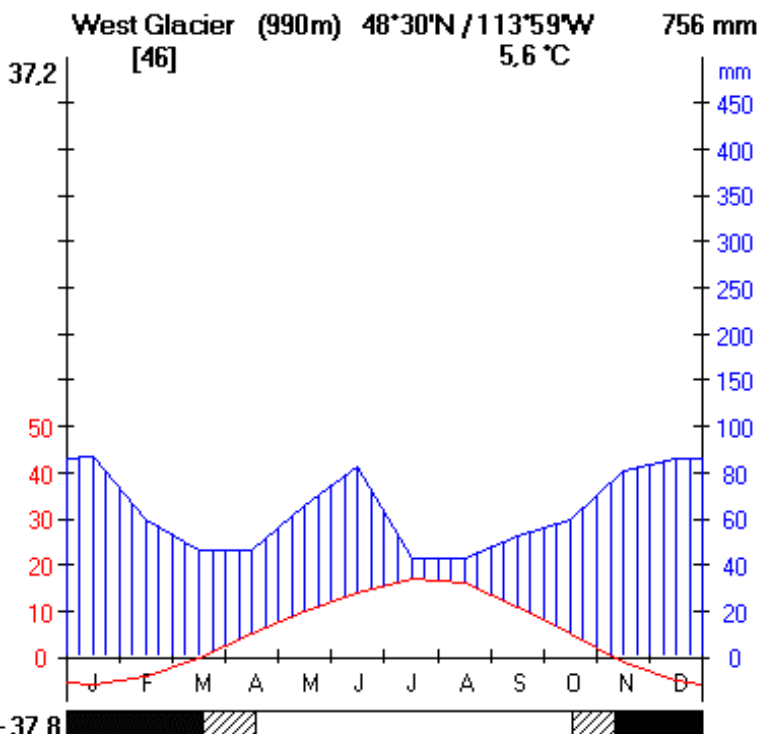

West Glacier: Westside of Glacier NP, montane coniferous forest

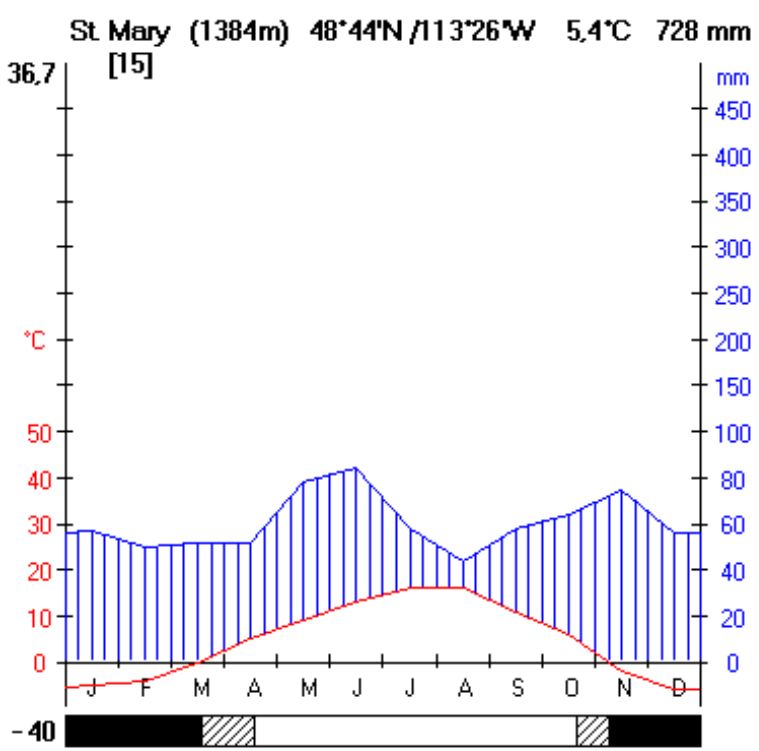

St.Mary: Eastside of the Park at the mountain front towards eastern prairie

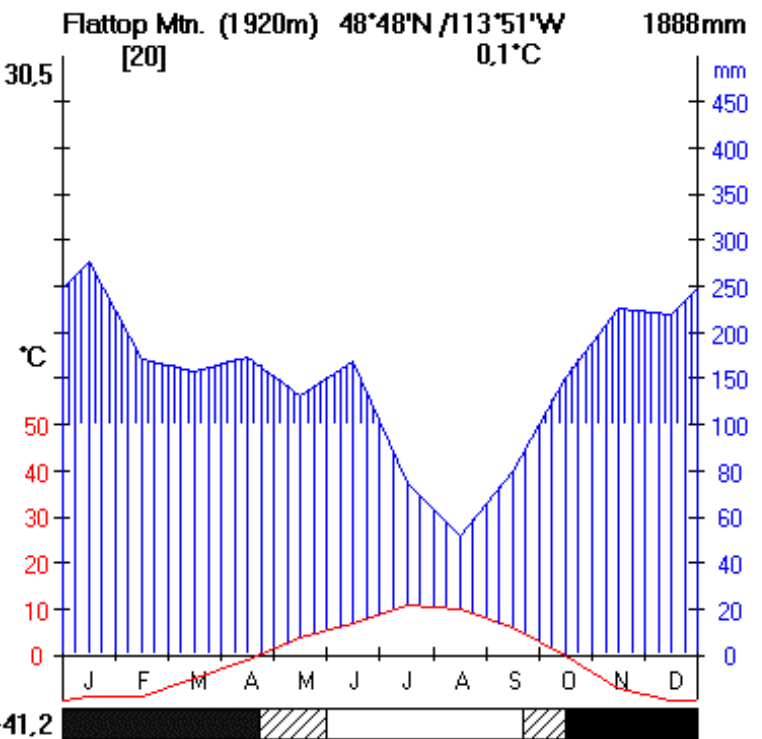

Flattop Mtn: West-central part of the Park; subalpine, open fir-forest

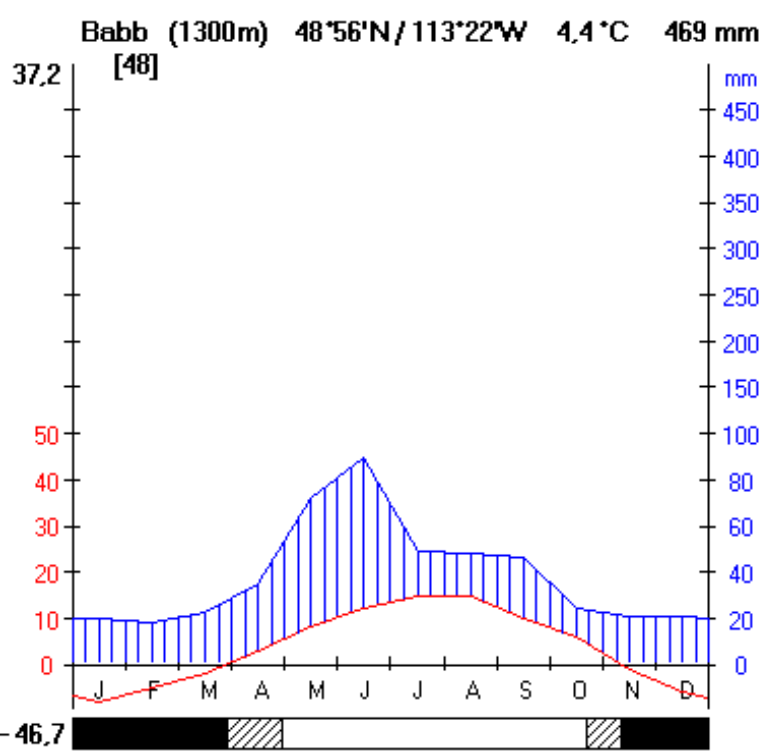

Babb: Eastside of the Park; continental foothills; prairie and aspen forest 


\section{Methods}

\section{Vegetation Sampling}

Most important for this study was the gathering of detailed, quantitative vegetation data using standardized sampling methods which allow the comparison with data from other studies. The widely employed method of Braun-Blanquet as it has been described by various authors (e.g. Becking 1957, Braun-Blanquet 1964, Mueller-Dombois \& Ellenberg 1974, Willard 1979, Dierschke 1994), was chosen for this purpose. The first summer (1994) was spend on reconnaissance trips all through the park, getting an overview over the character and distribution of the vegetation units. Possible sampling areas were chosen in order to organize an efficient field sampling schedule. All plots were sampled above or sometimes near "treeline". This was hard to define in the area.

The main criteria at the lower end of the elevation range of this study was "openness", meaning the absence of closed tree stands and tree islands in the immediate vicinity which would influence the adjacent subalpine or low alpine vegetation. The definition of the alpine and subalpine zones and subzones is a topic disputed intensely by many researchers. For the purpose of this study, and given the great irregularity of "treeline" and "forest line" in Glacier National Park, a more detailed distinction of these zones is not considered necessary. The distribution of subalpine plant communities in the area from well below to above the "treeline ecotone" obviously does not seem to follow the scientific delineations and terminology.

An upper limit of vegetation was not found in the area since the climatic altitudinal limit of vegetation is not reached even on the highest peaks of the park (Mt. Cleveland: $3190 \mathrm{~m}$ ). In most of the area the vegetation becomes more and more scattered at considerably lower elevation already, determined by adverse edaphic conditions like high rock cover and instability of slopes.

Another important factor is extreme wind exposure resulting in a depression of treeline and all higher vegetation zones. A distinction of a nival zone in the area is difficult. Given the constant melting of all remaining glaciers in the area there is hardly any place left where annual snowfall on a horizontal surface would exceed annual snow melt, which is a common definition of the nival zone (Ellenberg 1996).

The distribution of plots in the area was limited only by the distribution of the alpine and subalpine area itself and certain constraints due to inaccessibility and remoteness. Since by far most of the area is roadless backcountry, the accessibility is quite poor, which is likely to be the reason for the little attention much of the area has received from vegetation scientists. On multi-day hiking trips as much of the study area was covered as possible, gathering samples of each vegetation type. This is considered important in order to determine whether vegetation units are reoccurring types or just local particularities.

The definition of the montane, subalpine, alpine and nival vegetation zones follows Meusel et al. 1965 (see Löve \& Löve 1970), Ellenberg (1996) and Dierßen (1996).

\section{Cover Estimates}

Plot locations were chosen after the common criteria of homogeneity (see methodological literature mentioned above) and vegetation cover was estimated using a slightly modified Braun-Blanquetcover-abundance scale with a higher resolution on the lower end of the scale. This was considered useful as well as practical in the often sparsely vegetated alpine types. 
The scale used in the field was defined as follows:

$\begin{array}{ll}\text { ad }=\text { occurring adjacent to the plot } & 1=>5 \% \\ \mathrm{r}=\text { single individual } & 2=>10 \% \\ \mathrm{r}-\mathrm{<}-5 \text { individuals } & 3=>25 \% \\ +-\mathrm{r}<20 \text { individuals or }<1 \% \text { cover } & 4=>50 \% \\ +\quad=<5 \% & 5=>75 \%\end{array}$

In all association tables presented, the data are converted to the standard Braun-Blanquet scale (r, +, 1-5) for easier comparison. Adjacent occurrences in the same unit were converted to " $r$ ". Data on sociability and vitality have not been gathered but the phenological state was recorded for each species.

Estimating vegetation cover presents a problem when striped or patchy vegetation patterns are present as was the case many times in this study mainly on fellfield and talus slope sites. In cases with clearly separated vegetated and unvegetated portions of the plot, the cover classes were first recorded for vegetated patches alone (thus excluding the unvegetated interspaces) and afterwards a separate estimate was given referring to the whole plot. Consequently a $16 \mathrm{~m}^{2}$ Dryas-striped plot with vegetated stripes covering $50 \%\left(=8 \mathrm{~m}^{2}\right)$ of the square plot might have $90 \%$ of the densely vegetated stripes covered by Dryas, resulting in a cover abundance value of " 5 "for the vegetated area alone. The second estimate for the whole plot would refer to the $16 \mathrm{~m}^{2}$ area, resulting in $90 \%$ of $50 \%$ of the plot (= $90 \%$ of $8 \mathrm{~m}^{2}=7.2 \mathrm{~m}^{2}$ ) covered by Dryas. $7.2 \mathrm{~m}^{2}$ is $45 \%$ of the whole plot resulting in a cover value of only 3 .

Differences in cover values resulting from this are limited to the higher cover classes only. The desired consistency could not always be achieved since in many cases the vegetation pattern is not easily identified, frequently being intermediate between patchy and striped or grading into an erratic to even-spread pattern. In the latter cases the cover values referred to the whole plot. Again these differences are important only for the few species which achieve high cover, whereas in the lower cover classes the effect is negligible. The same applies of course for other cover-estimated parameters like litter, bryophyte and lichen cover which have always referred to the whole plot size.

\section{Plot Size}

The minimal area to be sampled in each community was determined a few times by starting out with a square meter plot and enlarging it gradually until further enlargement does not add new species to the species list. This determination was made on species-rich alpine fellfield plots but the resulting size was used as a standard also for other meadow communities. Standard plot size was $4 \times 4 \mathrm{~m}=16 \mathrm{~m}^{2}$. The square plots were sampled as completely as possible for vascular plants, bryophytes and lichens. Rarely on very sparsely vegetated sites, like unstable talus slopes, larger plots of $6 \times 6 \mathrm{~m}=36 \mathrm{~m}^{2}$ were sampled. Certain communities with very small areas (e.g. streambanks, sometimes snowbeds) had to be sampled with irregular, individual shapes following the shape of noticeably homogeneous vegetation. The plot sizes are given in the header data of the particular association tables. Micro-plots have not been used since they require a much larger amount of time per plot resulting in only a slightly higher degree of accuracy concerning the cover and abundance of species. It is considered of much greater value to use the time saved by sampling larger plots - assuming that all species are similarily accurately recorded - to sample a larger number of plots. Statistically the larger number of plots better defines the compositional character of the community sampled rather than putting much 
emphasis on the highly accurate sampling of one particular plot. This methodological question has been amply discussed by many authors (Mueller-Dombois \& Ellenberg 1974).

Species growing adjacent to the plots but apparently in the same kind of homogenous vegetation were also recorded. They have been included in the tables with the lowest cover value "r".

\section{Cryptogam Sampling}

Except for the species easily identified in the field, cryptogams were collected and identified in the laboratory.

Chemical analysis of lichen samples has been done of a number of representative samples of the genera Lepraria and Xanthoparmelia. Thin layer chromatography using the method of Culberson \& Ammann (1979) was applied on 10 samples of each of the two genera.

Cover of cryptogams was not recorded unless the species assumed conspicuous and estimatable cover degrees $\geq 1 \%$. Sampling of bryophytes and lichens was done after the vascular plant sampling was finished. A methodological problem is inherent in the attempt to completely sample mosses, liverworts and lichens on alpine plots. A single $16 \mathrm{~m}^{2}$ plot of alpine fellfield was found to easily have between 30 to 50+ cryptogamic species with most of them occuring in very small amounts. In fact, many of the lichen species were not only identified, but also detected in the first place in the lab under the dissecting scope. Inevitably many species, mainly microlichens and small bryophytes, are overlooked unless a large amount of time is spend on the sampling of each plot. To set a standard, the sampling time for cryptogams had to be limited to about 10 minutes per $16 \mathrm{~m}^{2}$ plot.

An interesting (and somewhat frustrating) result of the intensive sampling of many alpine plots in this study is, that diagnostic species for the resulting vegetation units have not been found among the microlichens. The seemingly even distribution of most bryophyte and lichen species reveals an ecological amplitude which is wider than that of the vascular plants. Only very few species turned out to be diagnostic for certain syntaxonomic units (e.g. Dicranum sp. for Phyllodoce heath communities, Lepraria neglecta and L. caesioalba for certain snowbed units).

Vascular plants inevitably turned out to be the better indicators for vegetation units, at least on the scale of investigation in this study.

It seems safe to say that at least for lichen-rich fellfield vegetation, lichens are diagnostic species on higher syntaxonomic ranks only, if at all. It might have been expected that small organisms like microlichens are inhabiting microsites which are distributed at least partly independent of the site parameters important for the distribution of the vascular plant biocoenosis. Some of the epilithic lichens are almost ubiquitous in the area being dependent solely on rock cover, lacking on very late melting sites only. Such an independence of the lichen synusiae from the vascular plant synusiae is not proven by this study but the current data supports the probability of this assumption. Among the lichens, the distribution of the larger, mainly fruticose and foliose species shows a slightly higher correlation with the vascular plant vegetation units. The more mesophytic bryophytes also show a closer correlation, being more dependent on moisture and winter snow cover, both factors which are important for the distribution of certain alpine plant communities.

It has to be mentioned here that in a number of plots used in the tables, cryptogam data were not sampled. These samples had been made in the beginning of this study as mere species lists which nevertheless are considered to represent the particular vegetation types. The advantage of having more samples to prove the widespread representation of the units was considered greater than the disadvantage of including plots without cryptogam data and minor changes in some synthetic characters. Most data from other authors used in the synoptic tables also lack cryptogams or present obviously incomplete lists of bryophytes and lichens. 


\section{Repeated Sampling}

Since much of the study area is fairly inaccessible, it has not been possible to sample each plot more than once. For alpine vegetation with its short growing season this is considered sufficient. Each species in this harsh environment has to complete its annual cycle in a very short amount of time. Making use of the limited time available from the very beginning to the very end of the often abruptly ending season is essential in the alpine. This results in a complete species presence through most of the season with only the cover degrees changing with their phenological development. Different sampling dates in the season are thus likely to result in the same species composition. Related systematic errors are limited to the very few short living species which appear very early and disintegrate long before the end of the season. Such is the case with e.g. Claytonia lanceolata and sometimes even with Erythronium grandiflorum. These species, at least the former one, might have been overlooked or underestimated in late-season samples.

Repeated sampling has been done on three fellfield plots only (in different years), resulting in neglible differences in species composition as well as cover-abundance values.

\section{Site Description}

With the vegetation data ecological data on each plot was recorded. A standard data-form for the specific situation of alpine vegetation was developed for a consistent sampling precedure (see dataform in the appendix). Parameters noted were date, location, GPS-reading, elevation, aspect, slope, plot-size and shape, topography, geology/parent materials, rock cover, rock size classes, fine soil cover, substrate stability, brief information on soils (for more on soil sampling, see next section), moisture conditions, apparent solifluction/frost features, estimated wind exposure, estimated snow cover. Information on many parameters was gathered using estimate scales. The scales and more information on the data gathered can be taken from the data-form. Detailed ecological measurements have been taken only with $\mathrm{pH}$-measurements in selected soil samples.

Three different GPS-units were used in the course of this study: 1. Rockwell International Precision Lightweight GPS Receiver (PLGR), 2. Trimble GeoExplorer GPS Receiver, 3. Magellan GPS 315. Data gathered with the Geoexplorer was differentially corrected with a Trimble software package using base station data from the Missoula County base station, Missoula, Montana.

\section{Soil Investigations}

Selected plots, covering most vegetation types, were chosen for soil profiles and $\mathrm{pH}$ measurements.

The samples were taken from the A, B (if present) and C horizons. The soil horizons were used according to the definitions provided by Scheffer \& Schachtschabel (1989). According to these authors the A-B-C definitions are nearly identical to those used by the American Soil Taxonomy system (Soil Survey Staff 1975) and have therefore been used to described the soil types.

Three holes were dug on the plot and the three soil samples of each horizon were mixed for an average plot sample. Since most of the plots were located on very rocky sites, the depth of the profiles was fairly limited, rarely exceeding $25 \mathrm{~cm}$ in depth. In order to limit the impact on the natural resource, no further attempts were made for deeper and more complete profiles. This was considered enough in order to get a general idea of the edaphic situation. Also the depth sampled was considered sufficient to describe the part of the pedon which is mostly used by the vegetation acknowledging though that parts of the root systems penetrate much deeper into the ground. 
The value for "soil depth"was taken from probing the plot ten times with a $4 \mathrm{~mm}$ diameter metal probe. A rough average of the depths reached is presented with minimum and maximum values in order to give a general idea of the rock content and penetrability of the solum.

Soil pits were dug with a hand shovel and the profile structure was recorded on a standard data sheet (see appendix). Litter and soil horizons were differentiated and described separately. Skeletal contents, soil texture, organic matter and root contents were estimated in the field. The soil material was taken to the lab and air-dried. $\mathrm{pH}$ measurements were conducted later. The method used was to soak the soil with distilled water creating a liquid soil paste (soil:water volume-relation was about 1:1). The exact amount of water added was found not to affect the resulting $\mathrm{pH}$. After 15 minutes of equilibration and occasional stirring the $\mathrm{pH}$ of the paste was measured (Büttner 1989, Steubing \& Fangmeier 1992).

In order to get an idea of exchangeable proton-saturation, $\mathrm{KCl}$ was added in saturation after the first measurement and a second measurement was taken after another 15 minutes of equilibration and occasional stirring. The $\mathrm{pH}$-unit used was a Hydac Conductivity/Temperature/pH-Tester, Cambridge Scientific Industries.

Soil colors were identified on dry and moistened soil samples using a standard Munsell Soil color chart.

\section{Syntaxonomic work (Synthetic phase)}

The classification system used largely determines the methods and the proceeding of all syntaxonomic work done in the course of this study. The theoretical background of the Braun-Blanquet approach used has been amply laid out in the literature. The syntaxonomy follows the current Code of Phytosociological Nomenclature (Weber et al. 2000) and in some cases its previous version (Barkman et al. 1986). The abbreviation "CPN" has been used occasionally for the "Code of Phytosociological Nomenclature". Even though the consistent implementation of the code has become a difficult task, it is believed to be the only way to develop a comprehensive, standardized classification system. Strict adherence to the Code was therefore practiced throughout this study, which necessarily led to numerous syntaxonomic changes for existing units.

The vegetation classification presented in this study is essentially based on the comparison of quantitative vegetation data by means of vegetation tables. The assemblage of vegetation tables has been sufficiently described by other authors (see list above). Nevertheless, a number of basic syntaxonomic terms should be defined in their present use.

\section{Definitions}

(Plant-)Community: This term is used here in a very broad sense referring to any vegetation unit that has distinctive characters and homogeneity (Willard 1979), without any implications as to its hierarchical classification.

Alliance: a group of similar associations sharing a number of diagnostic species and having similar ecological characters. In the syntaxonomic system developed in this study this level was used frequently to unite floristically and ecologically similar associations from different alpine areas which are differentiated by regional character species. 
Association: This is the basic unit of phytosociology. The association is a recognizable vegetation unit identified by certain floristic and sociologic characters, i.e. the presence of defined character species or a characteristic species combination. It is the abstraction of a community derived from the floristic comparison of a number of stands (Braun-Blanquet 1964, Dierschke 1994).

Unfortunately the term "association"has been widely adopted in North America without any clear definition. So far this has not appeared to be a problem since no coherent floristic vegetation classification system in North America exists that would include many of those units which have been described for very limited areas only. The inconsistent use of the term becomes a problem when a coherent species combination-based classification system is developed which comprises many of those "associations". The main difference in the use of the association is the amplitude of the vegetation units included in the definition. With only a set of defined character species or a group of diagnostic species, the association becomes a widely applicable unit. Braun-Blanquet (1964) added the presence of faithful, selective and preferential species (see below for definitions) as a further criterion for the association. Admittedly, the breadth of an association is still to a certain degree subject to the personal judgment of the author. Nevertheless this judgment is subject to certain constraints, set by the logical hierarchy of the classification system.

The presence of true character species has often been stressed as a main criterion for the association. In vegetation types with relatively few species occuring in different combinations over large areas, as is the case in the alpine vegetation in western North America, certain easily recognizable units might have very few or even no exclusive character species. In these cases a "characteristic species combination" might be defined which has to qualify for an unambiguous identification of the association. In some cases a ratio has been given of how many species out of a set of diagnostic species have to be present in order to assign a plot to a certain association.

Subassociation: associations can be subdivided into subassociations. Unlike the association, they do not need to have exclusive character species. Differential species are enough to separate these units from other subunits of the association. Subassociations are mostly used to separate ecologically, geographically or topographically different subunits of an association. The part of an association which remains, when a subassociation in separated, is called the "typicum subassociation". While the new subassociation has a set of differential species, the "typicum"is characterized solely by the diagnostic species of the association.

Variant: this unit is commonly used to further subdivide subassociations. Variants usually are characterized by constant but not very large floristic differences. In this study, variants were also used as subunits of associations when a constant floristic difference but no ecological difference was apparent and the floristic difference was small. Examples are the Dryas, Festuca idahoensis and Selaginella wallacei variants among the fellfield communities, all of which are obviously different in appearance but differ floristically only in the presence or absence of one dominant species.

Facies: stands with conspicuous differences in dominance patterns but with the same species composition are called "facies" of a given association or subassociation. In most cases one species assumes extraordinarily strong dominance.

\footnotetext{
${ }^{1}$ This applies mainly for the alpine vegetation, given the fact that the system established by Willard $(1963,1979)$ and Komárková was limited largely to their study areas with little applicability beyond. Some other syntaxonomical attempts have been made e.g. for forest vegetation (Krajina 1965, Peinado et al. 1998, RivasMartinez et al. 1999, and others).
} 
Diagnostic species: a general term for species defining a vegetation unit. These can be character species and differential species. Furthermore any species of a character species group for a vegetation unit also belongs here.

Differential species: species occurring in one vegetation unit and lacking in another, mostly similar unit. These species are differentiating the compared units against each other. Differential species only apply for the units compared. Therefore the compared units should be mentioned or be apparant from the context. If no other mention is made, then it can be assumed that the differentiation is against all units of the same rank within the next higher unit.

Character species: species with their main overall distribution within a certain vegetation unit, rarely occurring in other vegetation units. These species best characterize a given vegetation unit. Character species can have different degrees of fidelity to the characterized unit: faithful, selective and preferential. Character species of different quality are:

Faithful species (= Exclusive species): These species occur only in the particular community, with no or only extremely rare occurrence in other vegetation units

Selective species: species occuring most frequently in the particular community and with low constancy in other communities

Preferential species: species present in several communities more or less abundantly but predominantly or with better vitality in the particular community.

The character species is a special case of a differential species: it differentiates not only against a particular adjacent unit but also against all other vegetation units.

The lack of character species has often led to a somewhat looser use of the term. Species with ecologically or phytogeographically disjunct distributions have been used as character species of more than one syntaxonomic unit, even though these may be otherwise completely unrelated. This is possible where no confusion can occur due to the general ecological or geographical distance of the units.

A particular problem exists for the definition of character species and species groups in syntaxonomically incompletely treated areas: for a large number of species their distribution and even more so their occurrence in the vegetation types is poorly known. The diagnostic value of such species for plant communities is very limited. It might well happen that species which are now considered diagnostic taxa for certain units might later on turn out to be much more widespread and not diagnostic at all for that syntaxon or perhaps only in a small geographic area. Thus diagnostic taxa given for any higher syntaxon might be subject to change.

Constancy value: a numerical expression for the number of occurrences of a species in a given set of plots of the same size. It is a measure for the presence of a species in a given community. It is a synthetic character of plant communities and is mainly used in synoptic tables in order to compare vegetation units. 
The following scale of constancy is used in this study (modified after Dierschke 1994):

$$
\begin{array}{ll}
\mathrm{V}=>80-100 \% & \mathrm{II}=>20-40 \% \\
\mathrm{IV}=>60-80 \% & \mathrm{I}=>10-20 \% \\
\mathrm{III}=>40-60 \% & +=0-10 \%
\end{array}
$$

\section{Synoptic tables}

The main tool for the development and definition of the higher units of the syntaxonomic system presented here is the tabular comparison of vegetation data in synoptic tables.

To facilitate the comparison of similar communities over a larger area, in this case the western North American alpine, synoptic constancy tables have been compiled from vegetation data available in the literature. They provide an overview over floristic communalities and differences among these units. In order to keep the tables to a practical size, minor species occurring with low constancy or in a few units only have been omitted from these tables.

An attempt was made to include all data available in literature into the synoptic tables in order to get a broad picture of the respective vegetation units over the geographical area as determined above.

The synoptic tables provide the species in rows, whereas the vegetation units of the various authors are arranged as columns next to each other. Each column represents one plot or, more often, a number of plots belonging into the unit. In the latter case, the data has been condensed into presence/absencecalculated constancy values with the disadvantage of not taking the cover and abundance of the species into consideration.

The sequence of units has been arranged according to floristic similarity and geographical location. Units from the present study area have been included in order to show the syntaxonomic position of these units.

Since a complete understanding of the vegetation from the area covered in these synoptic tables is far from being achieved, care has to be taken when making any calls on the diagnostic value of the socalled diagnostic taxa. Mainly highly constant species (classes IV and V, rarely III) should therefore be considered diagnostic species unless the fidelity of a species to a certain syntaxon is well known.

It has to be kept in mind that the vegetation data provided by different authors in the literature and compared in the synoptic tables is qualitatively heterogeneous. Differences arise from:

- different sampling methods: e.g. micro-plot or line-plots vs. large plots, circular vs. square plots, transects

- various methods of community delineation/classification: e.g. species-based, dominancebased or similarity based

- different thoroughness of sampling: e.g., with or without or with few cryptogams sampled; most important species mentioned only; obviously incomplete samples etc.

- different ways of data presentation: e.g., detailed association tables; constancy tables; tables with various degrees of abbreviation; in some cases species lists

- taxonomy: different taxonomic concepts; a number of likely or clear misidentifications. 
For these reasons the quality of the data sources is apparently quite variable. Still it is believed that even such heterogeneous data is comparable for the present purpose since all sources present quantitative descriptions of the particular types of vegetation'. It is assumed that the structurally most important species as well as the most frequent species are well represented, no matter which sampling method is applied. A better database with standardized data would of course be desirable but is neither likely to be available in the foreseeable future nor is it essentially necessary.

Despite the different approaches used in the various studies, most vegetation units were accepted the way the respective authors presented them. In some instances though, where the original plot data was available and a possible better classification of the units seemed obvious, these tables were rearranged again in order to bring out the improved classification. In this manner some tables were found to lump clearly differentiated subunits. Such re-classified data is presented from Komárková (1979), Polster (1977) and Caicco (1984). Whenever such manipulation of the original data was made - and changes were never very large - this is clearly marked in the synoptic table.

In some cases obvious misidentifications have been corrected or the species have been omitted.

\section{Community descriptions}

The description of all vegetation units described in this study follows a standardized scheme. In the beginning of each description, nomenclatural type, type relevés (if a new syntaxon is introduced) and a list of the plots from the study area is given. Lectotypes are identified where present. Next, the character species are given in approximate order of their quality (including exclusiveness and constancy). Differential species are listed which are differential only within the next higher syntaxon. Character species and differential species presented in brackets are considered to have limited diagnostic value only or have to be re-confirmed in the future. This usually also implies that their exclusiveness is not very pronounced.

The standard description scheme for all syntaxa consists of the following elements:

General aspect: a brief physiognomic description with reference to particularities of the unit;

Topography: Information on the topographical situation and related site-factors with ecological importance: macro-/micro-relief, landforms, exposition, slope, slope stability, elevation range;

Geology/Parent material: Notes on the geological situation, mostly reduced to the parent materials and their structure;

Soils: a brief description of the common soils present in the particular unit;

Wind exposure/Snow cover/Moisture conditions: The wind situation and resulting snow cover, the latter focussing mostly on the snow duration, estimated from topographical location, on site observations and vegetative characteristics. Water availability through the season was recorded based on estimates taken on the sites.;

Floristical differentiation/ Vegetation pattern: The floristic particularities of the units are given in this paragraph. Floristic composition and differentiation as well as vegetation structure and patterns are mentioned including comments on bryophytes and lichens.

\footnotetext{
${ }^{2}$ Some non-quantitative species lists or presence/absence-tables have been included.
} 
Distribution: The occurence of the unit in the study area is given based on the samples taken and observations made in the area during the field seasons. Distributions beyond the area are noted wherever data is available.

Syntaxonomy: The syntaxonomical position of the unit including notes on related units and reasons for differentiation are discussed;

Literature: Cross-references to other studies which mention similar or identical communities are given. Notes on the geographical differentiation to those units are sometimes included.

Wherever possible the topics are given under the higher ranking units, usually on the association level or with unranked "communities", in order to avoid redundant information. In cases where the subunits differ to a larger extent from the higher unit, the differing topics have been laid out in detail under the subunits.

Community names have been given in accordance with the Code of Phytosociological Nomenclature (Weber et al. 2000). Common names have been added which try to combine floristically important species and some ecologically or otherwise characteristic feature of the community.

\section{Plant identification, Taxonomy and Nomenclature}

After a first season of reconnaissance trips throughout the study area, most vascular plant identifications could be done in the field while sampling the vegetation plots. In cases of difficult taxonomic groups, namely the Carex spectabilis group, Poa spp., Arabis spp., Luzula spp. and Draba spp., specimens were taken and identified later in the lab.

Literature used for identification of vascular plants was mainly Hitchcock \& Cronquist (1973) and Hitchcock et al. (1955-1969). Due to the fact that the somewhat outdated nomenclature is widely used in the most of the literature used in this study, these floras where used as the nomenclatural base of the vascular plants in this study. A number of exceptions was made in cases where more recent treatments were employed (See "Taxonomic Remarks", Appendix A ). Other floras used were Moss (1959), Cronquist et al. (1978-1979), Scoggan (1978), Dorn (1984), Lackschewitz (1991) Douglas et al. (1994).

Other more detailed treatments used were: Antennaria: Bayer (1993), Bayer \& Stebbins (1993), Crack (1977), Arabis: Rollins (1993), Carex: Murray (1969, 1970), Ceska \& Spribille (1996, unpublished manuscript); Delphinium: Sawyer (1967); Draba: Rollins (1993); Luzula: Hämet-Ahti (1965, 1971, 1973); Oxytropis: Elisens \& Packer (1980); Sagina: Crow (1978); Senecio: Packer (1972).

Mosses were identified using Grout (1931-1940), Nyholm (1954-1969), Lawton (1971), Smith (1978), Crum \& Anderson (1981), Frahm \& Frey (1987) and Vitt et al. (1988). More detailed treatments used were: Dicranum: Peterson (1979), Bellolio-Trucco \& Ireland (1990); Drepanocladus s.l.: Hedenäs (1993, 1997); Encalypta: Horton (1983); Lescuraea: Lawton (1957); Mnium: Koponen (1968, 1969, 1971, 1972, 1974); Racomitrium: Frisvoll $(1983,1988)$. Schuster $(1953,1966,1969)$ was used for the identification of liverworts.

Lichen identification was done using Poelt (1969), Bird (1970), Thomson (1979, 1984, 1997), Purvis et al. (1992), McCune (1993), Goward et al. (1994), McCune \& Goward (1995), Wirth (1995, 1995a). Specialized treatments included: Caloplaca: Hansen et al. (1987), Cladonia: Hammer (1995); Peltigera: Vitikainen (1985, 1994); Rinodina: Magnusson (1947, 1947a), Timpe (1990, 1991), Ropin \& Mayrhofer (1993); Xanthoparmelia: Hale (1990). 
Notes on accepted and difficult taxa of vascular plants, bryophytes and lichens are given under "Taxonomic Remarks" in the appendix.

It should be mentioned here that some vegetation units have been named after species which have changed their taxonomic names in recent years (see "Taxonomic remarks"). It was debated whether these syntaxa should be named after the most recent taxonomical names in cases where the new names have not yet reached general acceptance or are not commonly used. For the time being it was considered most practical to name the syntaxa after the commonly used names in order to facilitate the use of the syntaxa. This is in accordance with Articles 30 and 45 of the Code of Phytosociological Nomenclature.

\section{Computer software}

The compilation and sorting process of all vegetation tables including the synoptic tables for this study was accomplished using the TABWIN software, a phytosociological program based on an older DOS-version of the program TAB (Peppler 1988). All tabular vegetation data, including the TABentered vegetation data from other author's publications, which has been used for the synoptic tables, is available from the author. Final formatting of the tables was done with Excel 97 (Microsoft 1997). All other text editing was done with Microsoft Word 7.0 (Microsoft 1993).

In a few cases, numerical methods were used to get some ideas about the classification of the vegetation units. The results of those numerical analyses have not been accepted exactly but general trends (similarity ordinations, boundaries of differentiation) have been used to guide the final classification. The program ESPRESSO (Bruelheide \& Flintrop 1994) was used for a first sorting of the vegetation data. Certain subsets of data have also been presorted with TWINSPAN (Hill 1979). Similarity ordination using the Jaccard and Rudzicka formulas has been conducted with SYNTAX (Podani 1993) on the fellfield community data sampled in Glacier National Park. 


\section{Classification of the alpine plant communities of Glacier NP}

The following chapter is giving an overview and the detailed descriptions of all alpine and in part subalpine plant communities treated in the course of this study. The sequence of the communities does not follow a particular rule such as the commonly used phytosociological progression. Within alpine plant communities the latter system being based on structural complexity does not apply well. Therefore no particular effort was given concerning the order of the syntaxa except that the hierarchy within the classes is of course the baseline. The detailed order can be taken from the Classification Summary given below.

\section{Classification Summary:}

1. CLASS: CARICI RUPESTRIS-KOBRESIETEA BELLARDII OHBA 1974

1.1. ORDER: ARENARIO OBTUSILOBAE-FESTUCETALIA BRACHYPHYLLAE

ORD. NOV.

- WESTERN NORTH AMERICAN DRY ALPINE FELLFIELD COMMUNITIES

SUBORDER: GEO ROSSII-SILENENALIA ACAULIS SUBORD. NOV.

- SOUTHERN ROCKY MOUNTAIN FELLFIELD COMMUNITIES.

1.1.1. ALLIANCE: Arenario fendleri-Paronychion pulvinatae all. nov........................................... 41

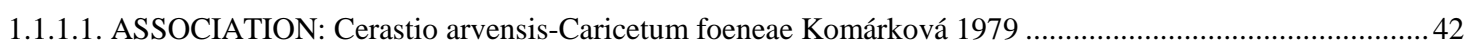

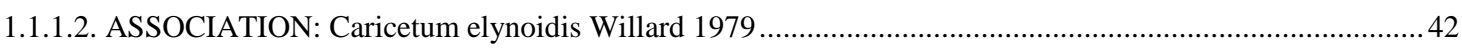

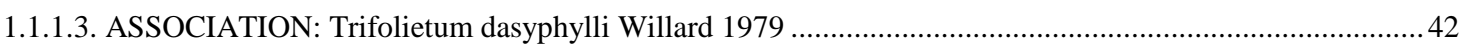

1.1.1.4. ASSOCIATION: Potentillo-Caricetum rupestris Willard 1979 ............................................................. 42

1.1.1.5. ASSOCIATION: Sileno acaulis-Paronychietum pulvinatae Willard 1979 ................................................4 43

1.1.1.6. ASSOCIATION: Eritricho aretioidis-Dryadetum octopetalae Kiener 1939 nom. corr. Komárková 1979 ... 43

1.1.1.7. ASSOCIATION: Selaginello densae-Kobresietum myosuroides Cox 1933 nom. corr. Komárková 1979 ... 43

"ORDER: TRIFOLIO-DESCHAMPSIETALIA KOMÁRKOVÁ 1976" .................................43

1.1.2. ALLIANCE: Deschampsio-Trifolion parryi Komárková ex Damm ...................................44

1.1.2.1. ASSOCIATION: Acomastylidetum rossii Willard (1979)..................................................................... 44

1.1.2.2. ASSOCIATION: Deschampsio caespitosae-Trifolietum parryi Komárková 1979 ..................................... 44

1.1.2.3. ASSOCIATION: Stellario laetae-Deschampsietum caespitosae Willard 1979 ......................................... 45

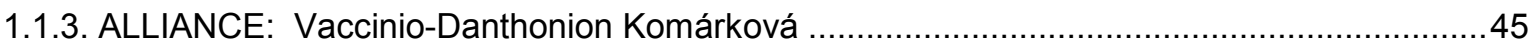

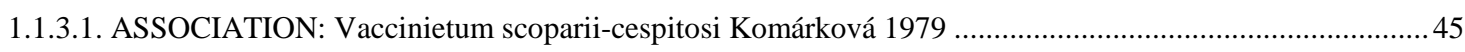

1.1.3.2. ASSOCIATION: Solidagini spathulatae- Danthonietum intermediae Komárková 1979..............................45

1.1.3.3. ASSOCIATION: Artemisietum arcticae-saxicolae Willard 1979 ............................................................ 45 
1.1.4. ALLIANCE: Besseyo wyomingensis-Arenarion obtusilobae all. nov.

- Besseya-Arctic Sandwort fellfield alliance.

1.1.4.1. ASSOCIATION: Myosotido alpestris-Caricetum albonigrae ass. nov.

- Alpine forget-me-not - Black-and-White scaled-Sedge association

SUBASSOCIATION: Myosotido alpestris-Caricetum albonigrae typicum subass. nov.

- High elevation subassociation.

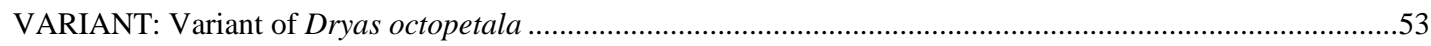

VARIANT: Variant of Dryas octopetala and Salix nivalis .........................................................................53

SUBASSOCIATION: Myosotido alpestris-Caricetum albonigrae polemonietosum viscosi subass. nov.

- Wheatgrass-Jacob's ladder- unstable fellfield slopes..........................................................................54

VARIANT: Campanula rotundifolia-Heuchera parviflora variant ...............................................................56

1.1.4.2. ASSOCIATION: Oxytropido campestris-Bupleuretum americani ass. nov.

- Locoweed-Bupleurum alpine prairie community .................................................................................57

SUBASSOCIATION: Oxytropido campestris-Bupleuretum americani typicum subass. nov.............................59

VARIANT: Oxytropido campestris-Bupleuretum americani variant of Dryas octopetala ....................................59

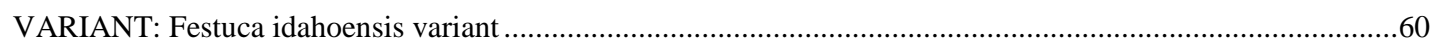

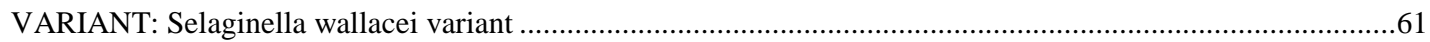

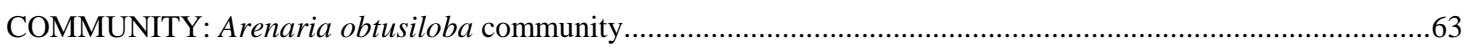

COMMUNITY: Smelowskia calycina-Dryas octopetala community

- Smelowskia-Mountain Avens fellfield community.

1.1.5. ALLIANCE: Antennario umbrinellae-Festucion idahoensis all. nov.

- Umber Pussy-toes - Idaho Fescue high elevation prairie community.

1.1.5.1. ASSOCIATION: Arenario capillaris-Festucetum idahoensis ass. nov.

- Thread-leaved Sandwort - Idaho Fescue late melting high elevation meadow

TYPICUM: Arenario capillaris-Festucetum idahoensis typicum

- Thread-leaved Sandwort - Idaho Fescue late melting meadow

FACIES of Festuca idahoensis ......m. 68

FACIES of Festuca scabrella - Rough Fescue high elevation community ....................................................69

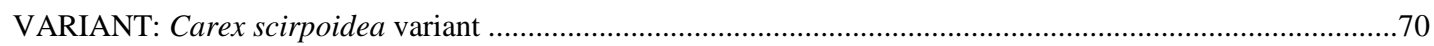

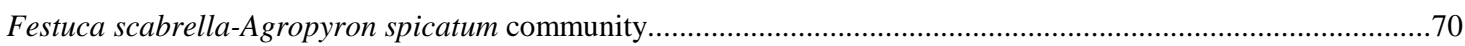

1.1.6. ALLIANCE: Salici nivalis-Dryadion octopetalae all. nov.

- Snow Willow-Mountain Avens alliance.

1.1.6.1. ASSOCIATION: Salici nivalis-Dryadetum octopetalae ass. nov.

- Snow Willow-Mountain Avens association.

SUBASSOCIATION: Salici nivalis-Dryadetum octopetalae typicum subass. nov. ...........................................77

VARIANT: Salici nivalis-Dryadetum octopetalae - poor variant .......................................................................78

VARIANT: Castilleja occidentalis-Cetraria cucullata (local) variant ................................................................79

1.1.6.2. ASSOCIATION: Euphrasio arcticae-Kobresietum myosuroides ass. nov.

- Northern Euphrasia-Kobresia association.

1.1.6.3. ASSOCIATION:Tofieldio pusillae-Kobresietum simpliciusculae ass. nov.

- Tofieldia-Simple Kobresia association . 
SUBASSOCIATION: Zigadeno elegantis-Caricetum scirpoideae typicum subass. nov.

- Death Camas-Single Spike Sedge alpine meadow community

SUBASSOCIATION: Zigadeno elegantis-Caricetum scirpoideae allietosum subass. nov.

- Death Camas-Single Spike Sedge cliffbase community

SUBASSOCIATION: Zigadeno elegantis-Caricetum scirpoideae arnicetosum alpinae subass. nov.

- Alpine Arnica - Single Spike Sedge community

ASSOCIATION: Solidagini multiradiatae-Arctostaphyletum uva-ursi ass. nov.

- Northern Goldenrod-Bearberry association

SUBASSOCIATION: Solidagini-Arctostaphyletum festucetosum scabrellae subass. nov.

- Bearberry-Rough Fescue community

SUBASSOCIATION: Solidagini-Arctostaphyletum dryadetosum subass. nov.

- Bearberry - Mountain Avens community

SUBASSOCIATION: Solidagini-Arctostaphyletum agropyretosum spicati subass. nov.

- Subalpine/low alpine Bearberry-Wheatgrass community....

ASSOCIATION Astragalo bourgovii-Salicetum arcticae ass. nov.

- Bourgeau's Milk-vetch - Arctic Willow fellfield community .96

ASSOCIATION: Artemisio michauxianae - Potentilletum fruticosae ass. nov.

- Artemisia-Shrubby Cinquefoil colluvial slope and cliff-ledge community ........................................... 100

TYPICUM: Artemisio michauxianae - Potentilletum fruticosae typicum........................................................ 102

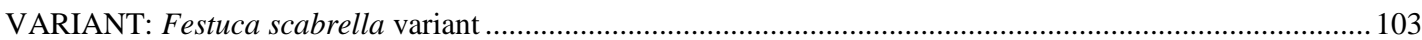

VARIANT: Penstemon ellipticus rock-outcrop variant ..................................................................................... 103

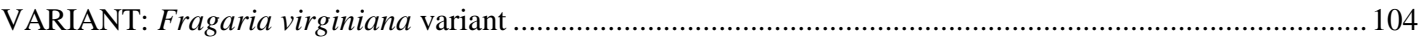

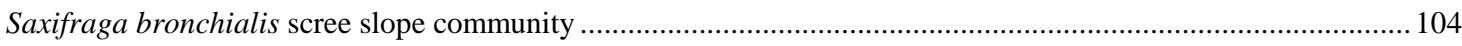

VARIANT: Saxifraga bronchialis scree slope community

- Penstemon albertinus/Woodsia scopulina low alpine variant ......................................................... 106

VARIANT: Saxifraga bronchialis scree slope community

- Potentilla diversifolia fellfield slope variant

\section{CLASS: THLASPIETEA ROTUNDIFOLII BRAUN-BLANQUET 1947: TALUS AND} SCREE COMMUNITIES.

2.1. ORDER: PHACELIETALIA HASTATAE ORD. PROV.

- SILVERLEAF-PHACELIA - SHRUBBY BEARDTONGUE-TALUS COMMUNITY ...113

2.1.1. ALLIANCE: Epilobio alpini-Penstemonion elliptici all. nov.

- Alpine Willow-Herb - Shrubby Beardtongue talus slopes

2.1.1.1. ASSOCIATION: Aquilegio flavescentis-Senecietum megacephali ass. nov.

- Yellow Columbine - Large-headed Groundsel talus slope association.

SUBASSOCIATION: Aquilegio flavescentis-Senecietum megacephali typicum

SUBASSOCIATION: Aquilegio flavescentis-Senecietum megacephali castillejetosum miniatae subass. nov.

- Subassociation of Scarlet Paintbrush. 
2.1.2. ALLIANCE: Phacelio hastatae-Arenarion nuttallii all. nov.

- Phacelia hastata-Arenaria nuttallii talus slope community

2.1.2.1. ASSOCIATION: Phacelio sericeae-Arenarietum nuttallii ass. nov. - Silky Phacelia-Nuttall's Sandwort talus slopes.

SUBASSOCIATION: Phacelio sericeae-Arenarietum nuttallii stellarietosum americanae subass. nov. -

American Starwort unstable scree slope community

THLASPIETEA ROTUNDIFOLII: UNCLASSIFIED ASSOCIATIONS

ASSOCIATION: Cryptogrammo crispae-Athyrietum distentifolii ass. nov. - Rock-Brake-Alpine Lady-Fern

boulder slope community (plate 3, fig. 10)

ASSOCIATION: Saxifragetum mertensianae ass. nov. - Saxifraga mertensiana cliff crevice community

\section{SUBCLASS: JUNCO DRUMMONDII-SIBBALDIENEA PROCUMBENTIS} SUBCLASS. NOV.

- JUNCUS-SIBBALDIA WESTERN CORDILLERAN SNOWBED COMMUNITIES.......132

\subsection{ORDER: CARICETALIA NIGRICANTIS BRETT ET AL. EX DAMM ORD. NOV.}

3.1.1. ALLIANCE: Caricion nigricantis Brooke et al.

- Western Cordilleran Black Sedge snowbeds

3.1.1.1. ASSOCIATION: Caricetum nigricantis Brooke et al. 1970

- Coastal Cordilleran Black Sedge snowbed community

3.1.2. ALLIANCE: Sibbaldio procumbentis-Caricion nigricantis all. nov.

- Sibbaldia-Black Sedge snowbed alliance.

3.1.2.1. ASSOCIATION: Phleo commutati-Caricetum nigricantis (Komárková) Damm

- Interior Cordilleran Timothy-Black Sedge snowbed community..

SUBASSOCIATION Phleo commutati-Caricetum nigricantis typicum subass. nov.

- Typicum Subassociation

SUBASSOCIATION Phleo commutati-Caricetum nigricantis phleetosum (Komárková) Damm stat. nov

- Southern Rocky Mountain Timothy-Black Sedge snowbed community.....

SUBASSOCIATION Phleo commutati-Caricetum nigricantis aulacomnietosum Hämet-Ahti ex Damm...........142

SUBASSOCIATION Phleo commutati-Caricetum nigricantis castillejetosum occidentalis Kuchar ex Damm..143

3.1.3. ALLIANCE: Luzulo piperi-Caricion spectabilis all. nov. 144

3.1.3.1. ASSOCIATION: Arnico diversifoliae-Caricetum spectabilis ass. nov.

3.2. ORDER: SIBBALDIO-CARICETALIA PYRENAICAE KOMÁRKOVÁ 1979 150

3.2.1. ALLIANCE: Polytricho piliferi-Arenarion capillaris all. nov.

3.2.1.1. ASSOCIATION: Sibbaldio-Juncetum parryi typicum ass. nov.

- Sibbaldia-Parry's Rush snowbed community.....

SUBASSOCIATION: Sibbaldio-Juncetum parryi saxifragetosum ferrugineae subass. nov.

- Rusty Saxifrage bedrock-outcrop community.

Polytrichum piliferum-Carex paysonis snow drift community...... .155 
3.2.1.2. ASSOCIATION: Polytricho piliferi-Arenarietum capillaris ass. nov.

- Polytrichum-Arenaria capillaris late melting meadow community

SUBASSOCIATION: Polytricho piliferi-Arenarietum capillaris lomatietosum subass. nov.

- Lomatium sandbergii late melting fellfield meadow community

3.2.1.3. ASSOCIATION: Leprario caesioalbae-Salicetum arcticae ass. nov.

- Lepraria-Arctic Willow snowbed community (plate 4, fig.14)

3.3. ORDER: PHYLLODOCO-CASSIOPETALIA BROOKE ET AL. EM. DAMM. 164

SUBORDER: DRYADO OCTOPETALAE-CASSIOPENALIA TETRAGONAE SUBORD. PROV. 166

3.3.1. ALLIANCE: Dryado octopetalae-Cassiopion tetragonae all. nov. 166

3.3.1.1. ASSOCIATION: Dryado octopetalae-Cassiopetum tetragonae Beder ex Damm

- Mountain Avens-Mountain Heather community

\section{SUBORDER: PHYLLODOCO EMPETRIFORMIS-CASSIOPENALIA MERTENSIANAE SUBORD. PROV.}

- MOUNTAIN HEATHER CASSIOPE SNOWBED COMMUNITIES

3.3.2. ALLIANCE: Phyllodoco-Cassiopion mertensianae Brooke et al. 1970

- Coastal Mountain heather communities

3.3.2.1. ASSOCIATION: Phyllodoco-Cassiopetum mertensianae Brooke et al. 1970

- Coastal Mountain Heather-Cassiope community....

3.3.3. ALLIANCE: Sibbaldio procumbentis-Phyllodocion glanduliflorae all. nov.

- Interior cordilleran Yellow Mountain Heather communities

3.3.3.1.ASSOCIATION: Sibbaldio procumbentis-Phyllodocetum glanduliflorae ass. nov.

- Sibbaldia-Mountain Heather community.....

SUBASSOCIATION: Phyllodocetum glanduliflorae leprarietosum subass. nov.

- Subassociation of Lepraria spp.

SUBASSOCIATION: Phyllodocetum glanduliflorae kalmietosum subass. nov.

- Subassociation of Kalmia microphylla

3.4. ORDER: VALERIANETALIA SITCHENSIS BRETT ET AL. EX DAMM ORD. NOV.

- SITKA VALERIAN ORDER

3.4.1. ALLIANCE: Lupino latifolii -Valerianion sitchensis all. nov.

- Broadleaf lupine - Sitka Valerian alliance

3.4.1.1. ASSOCIATION: Valerianetum sitchensis Archer 1963 ex Damm

- Coastal Sitka Valerian association.

3.4.2. ALLIANCE: Sibbaldio procumbentis-Trollion laxi all. nov.

- Rocky Mountain Sibbaldia-Globeflower alliance

3.4.2.1. ASSOCIATION: Luzulo hitchcockii-Erythronietum grandiflorae ass. nov.

- Smooth Woodrush-Glacier Lily community

SUBASSOCIATION: Luzulo-Erythronietum grandiflorae ranunculetosum

- Woodrush-Glacier Lily community - Ranunculus eschscholtzii subassociation

SUBASSOCIATION: Luzulo-Erythronietum grandiflorae typicum

- Woodrush-Glacier Lily community - Typical subassociation 
3.4.3. ALLIANCE: Philonotido fontanae-Mimulion lewisii all. nov.

- Philonotis-Monkey Flower streambank alliance

3.4.3.1. ASSOCIATION: Senecio triangularis-Mimuletum lewisii ass. nov.

- Arrow-leafed Senecio-Monkeyflower streambank community

SUBASSOCIATION: Senecio-Mimuletum lewisii habenarietosum subass. nov.

- Rich streambank subassociation with Habenaria saccata (and Arnica longifolia)

SUBASSOCIATION: Senecio-Mimuletum lewisii typicum subass. nov.

- Arrow-leafed Senecio-Monkeyflower streambank subassociation.

SUBASSOCIATION: Senecio-Mimuletum lewisii saxifragetosum lyallii subass. nov.

- Lyall's Saxifrage streambank community

3.4.3.2. ASSOCIATION: Epilobio latifolii-Mimuletum lewisii Archer ex Damm

- Alpine fireweed-Monkeyflower streambank community

3.4.3.3. ASSOCIATION: Leptarrheno pyrolifoliae-Calthetum leptosepalae Brooke et al. 1970

- Leatherleaf Saxifrage-Marshmarigold streambank community.

3.4.4. ALLIANCE: Parnassio fimbriatae-Trollion laxi all.nov. 194

3.4.4.1. ASSOCIATION: Aulacomnio-Kalmietum microphyllae ass. nov.

- Aulacomnium palustre - Alpine Laurel moist heath community

SUBASSOCIATION: Aulacomnio-Kalmietum microphyllae phyllodocetosum glanduliflorae

- Yellow Mountain Heather-subassociation.

SUBASSOCIATION: Aulacomnio-Kalmietum microphyllae pedicularetosum groenlandicae

- Elephant's Head streambank subassociation.

SUBASSOCIATION: Aulacomnio-Kalmietum microphyllae salicetosum arcticae

- Arctic Willow-subassociation

3.4.4.2. ASSOCIATION: Trollio-Parnassietum fimbriatae ass. nov.

- Globeflower-Parnassia - wet subalpine and low alpine meadow community

VARIANT: Trollio-Parnassietum fimbriatae typicum

VARIANT: Trollio-Parnassietum fimbriatae - Variant of Palustriella commutata ...

VALERIANETALIA: UNCLASSIFIED COMMUNITY IN THE ORDER: 202

Fragaria virginiana-Carex haydeniana lush subalpine meadow.

UNCLASSIFIED COMMUNITIES:

ASSOCIATION: Hieracio albertini-Caricetum geyeri ass. nov.

- Western Hawkweed-Elk Sedge ravine community

ASSOCIATION: Xerophylletum tenacis

- Subalpine Beargrass slope community

ASSOCIATION: Dodecatheo pulchelli-Suksdorfietum ranunculifoliae ass. nov.

- Suksdorfia-Shooting Star seep community

ASSOCIATION: Tofieldio glutinosae-Caricetum lenticularis ass. nov.

- Tofieldia-Carex lenticularis community 


\section{CLASS: Carici rupestris-Kobresietea bellardii Ohba 1974}

Nomenclatural Type: Not defined in Ohba 1974, needs lectotypification

Diagnostic species (acc. Ohba 1974): Kobresia myosuroides* $(=$ Kobresia bellardii, $=$ Elyna bellardii), Carex rupestris*, Lloydia serotina*, Oxytropis lapponica, Astragalus alpinus*, Pedicularis oederi, Dryas octopetala s.1.*, Gentiana tenella, Potentilla nivea*, Tofieldia coccinea, Erigeron uniflorus, Aster alpinus, Potentilla crantzii, Androsace lehmanniana*, Campanula uniflora*, Carex nardina*, Carex scirpoidea* s.1. etc. (species with an asterisk occur in the Rocky Mountains in this syntaxon)

Although most communities in this study are treated in the more or less regional context of Glacier NP, this unit is treated on a western North American scale. This was necessary in light of the fact that, as will be discussed, the existing syntaxonomy of fellfields did not satisfactorily accommodate the vegetation types described up until the present.

Fellfield communities (for a definition of the term "fellfield" see p.49) in the alpine of western North American mountains have been described under various names and encompass at least four mainly physiognomic or dominance-based groups which have often been treated separately but must be united on a higher syntaxonomic level, as will be shown below. These four groups are

a) alpine cushion plant communities, s.l.,

b) alpine sedge communities of Carex rupestris, Carex elynoides and Carex nardina,

c) Kobresia myosuroides-communities and

d) Dryas octopetala communities.

In his description of the circumpolar class Carici-Kobresietea, Ohba (1974) already mentioned the possibility that there might be an as yet undescribed order of this class in the Rocky Mountains. Due to the lack of vegetation data from the area, he kept the Rocky Mountain communities only tentatively within the circumarctic order Kobresio-Dryadetalia Br.-B1. 1948. He created a provisional alliance "Carici elynoidis-Kobresion bellardii all. prov." with Carex elynoides, Carex chionophylla, Dryas octopetala ssp. hookeriana, Oxytropis campestris var. glabrata and Eritrichum elongatum (=E. aretioides) as diagnostic species. While Ohba had only the data of Cox (1933) to rely on, a much better database is available today for a more all-encompassing classification of the Rocky Mountain fellfield communities. For this purpose all available data on dry alpine fellfield plant communities from the Rocky Mountains into Alberta and the mountain ranges further west were combined into a synoptic table (Tab. 1). The synoptic table reveals that they all belong to the class Carici-Kobresietea Ohba 1974. It furthermore becomes clear that the existing orders of this class could not accommodate the Rocky Mountain fellfield vegetation and that the creation of a new order could not be avoided as had been anticipated by Ohba.

\footnotetext{
${ }^{3}$ In his description of this class, Ohba did not specify a type order. The class is nevertheless accepted widely (e.g. Oberdorfer 1978, Daniels 1982, Dierßen 1991)
} 


\section{Present classification of the dry alpine meadow communities:}

So far, the only existing syntaxonomy of alpine fellfield communities in the Rocky Mountains has been established by Willard $(1963,1979)$ and Komárková $(1976,1979)$ based entirely on samples from the southern Rocky Mountains of Colorado. Their syntaxa need to be discussed in greater detail because some major changes will be proposed here.

Unfortunately many of the syntaxa described by Willard and Komárková are not valid according to the Code of Phytosociological nomenclature (Barkmann et al. 1986, Weber et al. 2000). All of their lower syntaxa are recognized here as well described units. The nomenclatural rules nevertheless require the validation of the formerly unvalidly published higher units which is done in this study for a number of those which are considered important for the system. For a better reference the old author citations as used by Willard and Komárková themselves are used throughout this chapter.

Komárková treated most of the alpine "climax habitats" of "well drained, gently sloping ridgetops" in her order Kobresio-Caricetalia rupestris Komárková 1976 within the European class Elyno-Seslerietea Br.-B1. 1948.

Some of the floristically similar units (mainly the Acomastylidetum rossii Willard 1963) were assigned to her order Trifolio-Deschampsietalia Komárková 1976 in the snowbed class Salicetea herbaceae Br.-Bl. 1947.

Willard furthermore split the alpine meadow communities into two groups which she accommodated in two different classes. Firstly, she put the rockier "fellfield communities" as a separate order SilenoParonychietalia in the European class Thlaspietea rotundifolii Br.-Bl. 1948. Secondly the less rocky, more densely vegetated "alpine turf communities" were treated in the same way as Komárková did, in the class Elyno-Seslerietea under the order Kobresio-Caricetalia rupestris.

Willard placed the Acomastylidetum in the European class Ruderali-Secalinetea Br.-Bl. 1936.

\section{Problems of the present classification:}

At present there seems to be no need to place the alpine fellfield communities in two or three different classes. The synopsis of the alpine meadow communities presented in this study clearly shows that all of these units are floristically similar enough to be accommodated in a single class.

Interestingly, Willard (1979) and Komárková (1979) both mention the great similarity of all of their units with units of the Kobresio-Caricetalia several times. Still they decided to separate these units on the high syntaxonomic level of the class, based predominantly on ecological considerations. Even though some ecological differentiation is indeed present, the floristical comparison clearly shows that the similarities by far outweigh the perceived differences. The separation of ecologically differentiated units can certainly be accomplished on a lower syntaxonomic level.

In addition to this there are other reasons why some of the class-related syntaxonomic assignments of Willard and Komárková in this group are doubtful. Willard uses the European class Thlaspietea, which contains unstable talus communities, to comprise her stabilized fellfield communities mainly because they are similar in their high degree of rock cover. She admits that none of the character species of the European class occur in her study area and that her units are found on much gentler, stabilized and also drier slopes. The use of the Thlaspietea for her order Sileno-Paronychietalia is therefore neither necessary nor appropriate.

The placement of the Acomastylidetum in the European class Ruderali-Secalinetea Br.-B1. 1936, which has not the slightest floristic similarity to the Acomastylidetum and is just based on the factor 
animal disturbance, can not be accepted either. This even more so since the floristic similarity with the Kobresio-Caricetalia is strong and clearly points to the use of that class instead.

Komárková places the Acomastylidetum from Indian Peaks, which is not that much influenced by zoogenic influences, in her Trifolio-Deschampsietalia caespitosae Komárková 1976 within the European snowbed class Salicetea herbaceae. A change of this doubtful syntaxonomic position is proposed here, turning the order into an alliance within the Carici-Kobresietea. Reasons for this treatment are given below under the new syntaxon called Trifolio-Deschampsion (Komárková) Damm stat. nov (see p.44).

\section{The validity of Komárková's Kobresio-Caricetalia rupestris Komárková 1976:}

The single remaining order is the Kobresio-Caricetalia rupestris Komárková 1976. Her provisional placement of the order in the European Elyno-Seslerietea Br.-B1. 1948 is based on the presence of the species Kobresia myosuroides, Carex rupestris, Dryas octopetala, Silene acaulis, Polygonum viviparum, Luzula spicata Cetraria islandica, Cladonia pyxidata, Cetraria nivalis and Cetraria cucullata. Komárková evidently did not take notice of Ohba's creation of the Carici rupestrisKobresietea bellardii Ohba 1974 which is believed to comprise all units within Komárková's Kobresio-Caricetalia rupestris. The latter should thus have been accommodated in Ohba's widely accepted circumpolar class.

The question is, whether Komárková's unit represents Ohba’s anticipated Rocky Mountain order.

The floristic definition of Komárková's Kobresio-Caricetalia very obviously results in a southern Rocky Mountain syntaxon, even though the name Kobresio-Caricetalia rupestris implies a distribution far beyond the southern Rockies. Nine out of the nineteen vascular plants which Komárková lists as diagnostic taxa are restricted to the southern Rockies and according to the synoptic table delineate strictly southern syntaxa on different syntaxonomic levels.

Those nine species are Thlaspi montanum, Oreoxis alpina, Primula angustifolia, Phlox pulvinata, Erigeron pinnatisectus, Trifolium dasyphyllum, Hymenoxys grandiflora, Helictotrichon mortonianum and Hymenoxys acaulis. The remaining species are more or less widespread high elevation species of varying occurrence: Carex rupestris, Poa rupicola, Calamagrostis purpurascens, Potentilla ovina, Arenaria rubella, Mertensia viridis, Campanula uniflora, Allium geyeri, Artemisia borealis and Draba lanceolata .

The fact, that the diagnostic species can be separated into two very different phytogeographical groups, points to the weak definition of this order. With the much larger database available two decades after Komárková's work, the first group inevitably emerges as part of a diagnostic species group of the above mentioned southern Rocky Mountain syntaxon. At least the first four, if not all of the species of the latter group, are diagnostic species of higher and more widespread syntaxa within this class.

Furthermore, Komárková lists species, which she uses as diagnostic species of two orders: this order and her above mentioned order Trifolio-Deschampsietalia. These "two-order-diagnostic species" are Arenaria obtusiloba, Silene acaulis, Lloydia serotina, Selaginella densa agg., Saxifraga rhomboidea, Sedum lanceolatum, Arenaria fendleri, Castilleja occidentalis and Antennaria umbrinella. In fact, the first six species are important common species, even character species, of the widespread alpine Rocky Mountain fellfield order Arenario-Festucetalia brachyphyllae, which will be treated later in this chapter. The fact that these diagnostic species occur constantly in two of Komárková's orders supports the conclusion that both orders should be better united. 
The distribution of these widespread species within the related communities can be taken from the synoptic tables.

Even more important than the mentioned syntaxonomic inconsistencies is the fact, that Komárková's order Kobresio-Caricetalia can not be considered a validly described syntaxon. It has been typified with the alliance Kobresio-Caricion rupestris Komárková 1976. Because this alliance is not a valid syntaxon, the order lacks the necessary typification which is required for syntaxa published after the January 1st, 1979 (Art.3o, Art.5 and Art.17 CPN 2000). The reason for the alliance not being a valid syntaxon is that it is typified with the unpublished, thus invalid association Potentillo-Caricetum rupestris Willard 1963.

The fact that the type alliance was published by Komárková (1979) cannot mitigate this. This applies also to the fact that the Potentillo-Caricetum rupestris was validly published in Willard (1979) a few month after Komárková's publication.

Even if the order would be considered a nomenclaturally valid syntaxon, its definition does not reflect the syntaxonomic reality, and it would consequently need to be emended or better changed in its rank. In this case Komárková's unit would need to be assigned a lower rank, confining it to a southern Rocky Mountain distribution and taking away some of the character species of wider distribution. According to the nomenclatural code it would nevertheless keep its original name containing a rather misleading species combination. With the data now available it becomes obvious that a pan-Rocky Mountain syntaxon which could be described by both Kobresia myosuroides and Carex rupestris does hardly exist. The emendation of this syntaxon is not considered an option.

Like in other cases discussed in this study, the Kobresio-Caricetalia is a high syntaxon which unfortunately has been described without sufficient consideration of the vegetation of a larger area. The alpine areas studied by Willard and Komárková are not necessarily representative for the Rocky Mountains - certainly not as regards the Kobresia communities. Creating higher syntaxa like this order from such local data necessarily results in greater syntaxonomic problems, possibly resulting in nomina ambigua (CPN, Art. 36). The main reason for rejecting the order and alliance is nevertheless the insufficient typification.

\section{Conclusion:}

A comparison of the available fellfield data from the Rocky Mountains reveals that there are a number of communalities among them which justify the creation of higher syntaxa being united floristically as well as ecologically.

The new order Arenario obtusilobae-Festucetalia brachyphyllae of dry, alpine meadow communities is derived from the synoptic comparison of vegetation units from Alberta to New Mexico. This unit is likely identical with the order anticipated by Ohba (1974). As can be taken from the synoptic table it includes many of Willard's and Komárková's syntaxa and replaces the invalid order KobresioCaricetalia rupestris.

The major innovation for the southern Rocky Mountain syntaxonomy is the creation of a new alliance which is now needed to accommodate those southern alpine meadow units.

This alliance Arenario fendleri-Paronychietum pulviantae is introduced below with a floristic definition not much different from the former Kobresio-Caricetalia. It holds all of the associations formerly placed in Komárková's order.

The alliance and association concept used by Willard $(1963,1979)$ and Komárková $(1976,1979)$ is a very narrow one. This practice led both authors to create associations with very few character species 
in a strict sense. The syntaxonomic rank of all such units might have to be reconsidered in the future. For the time being the associations are accepted as such and are presented with the corrected author citations.

The new concepts proposed here are largely based on data gathered and published by other authors including the field data gathered in the course of this study. Admittedly, the author's personal knowledge of much of the vegetation described in the literature from areas beyond the immediate study area is limited. Thus these new ideas are to be viewed as an improved, but not at all final attempt to create a practical classification. Not every single unit included in the synoptic table might after detailed study be retained in this order. So far most of them are not valid syntaxa according to the Code of Phytosociological Nomenclature anyhow and future validation of these syntaxa is necessary.

\subsection{ORDER: Arenario obtusilobae-Festucetalia brachyphyllae ord. nov. - Western North American dry alpine fellfield communities}

Nomenclatural Type: Besseyo wyomingensis-Arenarion obtusilobae all. nov.

Diagnostic species: Arenaria obtusiloba, Silene acaulis, Festuca brachyphylla, Luzula spicata, Erigeron simplex, Carex albonigra (Erigeron compositus, Saxifraga rhomboidea, Potentilla concinna)

Constant species: Trisetum spicatum, Sedum lanceolatum, Selaginella densa s.1., Achillea millefolium, Saxifraga occidentalis/rhomboidea, Polygonum bistortoides, Potentilla diversifolia, Poa rupicola s.l.

Based on a synoptic table of alpine fellfield communities from the southern and central Rocky Mountains Tab. 1), including parts of Alberta and British Columbia, this new order within the CariciKobresietea Ohba 1974 is created here.

General aspect: The physiognomy of fellfield communities has been amply described in other studies and can be taken in this study from the description of the Besseyo wyomingensis-Arenarion obtusilobae (see below).

Syntaxonomy: The only existing syntaxonomy of western North American alpine fellfield communities by Willard and Komárková and its inherent problems have been discussed above.

In addition to the common ecology of all alpine fellfield mats included in this order, a fairly constant set of common species is present. Arenaria obtusiloba turns out to the be most widespread alpine species together with Festuca brachyphylla. Given their high degree of constancy and fairly exclusive occurrence in this unit they are used as the name-giving species for the new syntaxon. It might be inferred that Festuca brachyphylla has a broader ecological amplitude occurring as a widespread high elevation species also in other syntaxa mainly in the subalpine and high montane zone throughout much of the Rocky Mountains and even beyond. Nevertheless, it does have its main occurrence in true alpine meadows and is a structurally very important as well as highly constant constituent of the new order.

The validity of Silene acaulis as an order character species might need to be checked in the future because the species seems to be less frequent in the western part of this order's range. Silene acaulis 
is lacking in the fellfield communities reported from Idaho (Caicco 1984, Moseley 1985, Urbanczyk 1994) but does occur in the Cascades and is very constant in Glacier NP. According to Griggs (1956), both Arenaria obtusiloba and Silene acaulis are ecologically nearly equivalent with very similar competitive abilities in their alpine environment. Within the present order, the circumpolar class character species Carex rupestris seems to be much less frequent further north (Alberta, British Columbia) in the Rocky Mountains, which is even more so the case with Carex elynoides. Erigeron compositus is preliminarily listed as a character species since it does not occur in all alpine studies from the Rocky Mountains. However, it seems to be fairly confined to this vegetation unit if one ignores the species' dealpine occurrence on lower elevation riverbanks. Carex albonigra and Carex nardina might turn out to be characteristic for this order but within the data considered here they are more constant in the northern parts of the order, and in this respect they might belong to a northern subunit as described below. Poa glauca might also turn out to be a character species of the order, but with the different taxonomic concepts used in the data of different studies, this question can not satisfactorily be answered.

An extremely high number of lichens and mosses was constantly found in the samples of the present study, as expected in fellfield communities, and is likely to occur throughout the order's range. However, because data on cryptogams are inconsistent or even lacking in many studies used for the large scale comparison, cryptogams have not been used as character species at this point. Comparing the present studies' results with the detailed samples of Willard (1979) and Komárková (1979) from the southern Rockies it can be assumed that at least the following species are to be considered as character species of this order: Caloplaca ammiospila, Caloplaca stillicidiorum, Caloplaca tetraspora, Caloplaca tiroliensis, Cetraria nivalis, Cetraria tilesii, Megaspora verrucosa, Ochrolechia upsaliensis, Phaeorrhiza nimbosa, Physconia muscigena, Thamnolia subuliformis (incl. T. vermicularis) and Xanthoparmelia sp. Because of the wide, cirumpolar distribution of these species the character species rank is valid for the range of the order only ("local/regional character species").

This new syntaxon is the western North American representative of Ohbas's Carici rupestrisKobresietea bellardii, extending through the Rocky Mountains and the mountain ranges further west.

The southwestern mountains, mainly the Sierra Nevada and scattered Great Basin ranges, are floristically somewhat different and have not been included in this synopsis. Further studies are needed to reveal their relationship to this order.

Differentiated against this order is the fellfield vegetation of higher latitudes in the northern reaches of the Rocky Mountains where, due to the decrease of the altitudinal vegetation belts, alpine and arctic tundra elements more and more intergrade. The definition of an arctic or at least far northern Rocky Mountain order within the Carici-Kobresietea might be a necessary step after the creation of the present order.

The order Arenario-Festucetalia brachyphyllae can be divided into the following subunits:

1. a southern suborder Geo rossii-Silenenalia acaulis, accommodating the southern Rocky Mountain fellfield communities

2. a northern suborder Myosotido alpestris-Silenenalia acaulis

For further details on these units see their descriptions below.

Given the large latitudinal range of this order, the subdivisions suggested are considered to be mainly based on the different regional floristic environments rather than on different ecological conditions. Even though the alpine environments are somewhat changing along this geographical gradient with less of an "arctic character" further south, it is believed that chorological history and the presence of 
different floristical regions in the adjacent areas are responsible for most of the apparent floristic differences. Thus at least the syntaxonomic suborders and alliances are felt to be closely related to phytogeographical units. The boundary between the southern and the northern suborders, for example, coincides with the southernmost extension of the Wisconsinian glaciation, which still demarks a major floristical boundary.

Ecological differentiations will be reflected on the lower syntaxonomic levels.

Distribution: The order is represented in the Rocky Mountains from Alberta to Arizona and New Mexico. Taken from the lack of data from Canada, this order is less widespread north of the $49^{\text {th }}$ degree of latitude especially in the Rocky Mountains. More detailed investigations are necessary to clarify the syntaxonomical relationships with fellfield and tundra vegetation further north. It does most likely occur in the Purcell Mountains, the Selkirks and the Monashee Mountains of southeastern British Columbia. Fellfields from the Mountains of Idaho, Oregon and Washington have been preliminarily included in this order but their syntaxonomy might still be subject to change.

In the area of Glacier National Park the order is represented mainly on the more continental, drier east side.

Literature: Fellfields are probably the most obvious alpine plant communities throughout the Rocky Mountains and have been reported from all true alpine areas. Notwithstanding, detailed accounts are available from only a few areas. Vegetation data in varying levels of detail have been provided by Achuff et al. (1982, 1984, 1984b, 1993, 1997), Andrews (1983), Baker (1983), Bamberg (1961), Bamberg \& Major (1968), Beder (1967), Bryant (1968), Johnson and Billings (1962), Kuchar (1975), Caicco (1983), Cooper \& Lesica (1992, 1997), Crack (1977), DelMoral (1979), Douglas \& Bliss (1977), Eddleman (1967), Eddleman \& Ward (1984), Hamann (1972), Hoefs et al. (1975), Hrapko \& LaRoi (1978), Johnson \& Billings (1962), Kiener (1939), Komárková (1979), Kuchar (1973, 1975), Little (1941), McLean (1970), Moore (1965), Mortimer (1978), Moseley (1985), Moss (1955), Rottman et al. (1985), Polster (1977), Pojar (1991), Thilenius (1985), Timoney (1999), Trottier (1972), Urbancyk (1994) and Willard (1963, 1979). Many of these have been used for the compilation of a synoptic table (Tab. 1) which is the basis for the creation of this new syntaxon.

\section{SUBORDER: Geo rossii-Silenenalia acaulis subord. nov. - Southern Rocky Mountain fellfield communities}

Nomenclatural Type: Arenario fendleri-Paronychietum pulvinatae all. nov.

Character species: Geum rossii ssp. turbinatum, Eritrichum aretioides (=E. nanum), Carex elynoides, Phlox pulvinata, Lloydia serotina, Hymenoxis grandiflora, Artemisia scopulorum, Trifolium nanum, Trifolium dasyphyllum, Trifolium parryi

Within the Rocky Mountains Geum rossii ssp. turbinatum has a fairly restricted range south of central Montana. Within its alpine range the plant seems to occur as a dominant or at least co-dominant species in all fellfield communities. This high degree of dominance seems to be unique among Rocky Mountain alpine plant species. Such a conspicuous and geographically restricted plant is an ideal species to characterize a geographical subdivision.

The species Artemisia scopulorum, Trifolium nanum, Trifolium dasyphyllum and Trifolium parryi have here been used to characterize the present suborder. They are not present in some south western mountain ranges of Montana and in the mountains further west which still belong into the range of this suborder, based on the presence of the other character species. The western and the exact northern 
limit of this suborder will have to be delineated later on when there is more data available on these areas. Artemisia scopulorum and the three clover species mentioned above might also be characteristic for a subset of this suborder, perhaps representing their own alliance. Nevertheless, it seems to be too early with the data available to decide whether such a syntaxon can be set up at an appropriate syntaxonomic level - given the heterogeneity within the unit itself - and to what extent it would differ from the suborder created here.

The species Carex elynoides, Phlox pulvinata, Lloydia serotina and Hymenoxis grandiflora are good differential species of this suborder against the northern syntaxon. Interestingly, they do occur in the stands from Idaho as documented e.g. by Caicco (1983) and Urbanczyk (1994), where Geum rossii and the differential species Artemisia scopulorum, Trifolium nanum and Trifolium dasyphyllum are missing as is the class character species Silene acaulis. It remains to be seen whether the units from Idaho and the mountains further west belong to this suborder or whether they should be placed in a separate subunit. While the first alternative does not seem to be satisfactory, a separate unit seems to be hard to delineate since the available data does not reveal any sufficiently differentiating species groups. Most likely this class is represented in Idaho only with an impoverished set of class character species.

Included into this suborder are a number of units described from the southwestern Montana by Cooper et al. $(1992,1997)$ which seem to represent a transitional zone between the southern and the northern suborder. Based on the constant presence of the structurally important species Carex elynoides, Phlox pulvinata, Lloydia serotina and Hymenoxis grandiflora, Cooper's units seem to rather belong in the southern suborder even though a fairly high number of species of the northern suborder can be present.

\subsubsection{ALLIANCE: Arenario fendleri-Paronychion pulvinatae all. nov.}

Nomenclatural Type: Potentillo-Caricetum rupestris Willard 1979

Diagnostic species: Paronychia pulvinata Gray, Arenaria fendleri Gray, Oreoxis alpina, Thlaspi montanum, Haplopappus pygmaeus, Draba streptocarpa, Helictotrichon mortonianum, (Campanula uniflora, Castilleja occidentalis, Gentiana algida, Erysimum nivale, Primula angustifolia, Artemisia pattersonii)

This new alliance basically replaces Komárková's invalid order Kobresio-Caricetalia rupestris Komárková 1976 (see above p.36). As can be taken from the synoptic table this group combines a number of units from Colorado and most likely includes the fellfield communities reported from New Mexico and Arizona. The alliance thus delineates a syntaxon broader than the former order. For details on the ecology of the communities comprised in this alliance it is referred to the authors of the respective units which can be taken from the synoptic table.

Six species well characterize this alliance in a broader sence. The species group of Castilleja occidentalis, Gentiana algida, Erysimum nivale, Primula angustifolia, Artemisia pattersonii, Hymenoxys acaulis seems to differentiate a subunit within this alliance. They are lacking in the southern part which is here represented by data from Little (1941) and Baker (1983).

According to Komárková five associations belong into the Kobresio-Caricion rupestris alliance. The two assocations Cerastio arvensis-Caricetum foenae and Caricetum elynoidis from her Caricion-

\footnotetext{
${ }^{4}$ Author citations are given only for important diagnostic species of new syntaxa, which do not occur in the present study area and are therefore not referenced in Appendix A
} 
foenae-elynoides Komárková 1976 also have been moved into the present association which now contains the following assocations:

\title{
1.1.1.1. ASSOCIATION: Cerastio arvensis-Caricetum foeneae Komárková 1979
}

\author{
Nomenclatural Type: Komárková (1979): Table 7 relevé 410
}

This association was validly described by Komárková as the Cerastio arvensi-Caricetum foeneae Komárková 1979 (not 1976). Komárková put this association together with the Caricetum elynoides (see below) in a separate alliance. The group of diagnostic species is not nearly strong enough to justify a separate alliance for this unit. Furthermore is the alliance Caricion foeneo-elynoidis Komárková 1976 an invalid syntaxon, being based on the invalid description of the Caricetum elynoides Willard 1963. Therefore this unit has to be placed in the present alliance. An orthographic correction is applied to the old name "Cerastio arvensi-Caricetum foeneae" following Art. 41 of the CPN.

\subsubsection{ASSOCIATION: Caricetum elynoidis Willard 1979}

Nomenclatural Type: Willard 1979: Table 17 relevé 62134 (invalid lectotypification by Komárková 1979, valid typification with the same relevé by Willard 1979)

The author citation has to be referred to Willard 1979, and not to Willard 1963 as formerly done because Willard's thesis is not a valid publication. Komárková's 1979-work can not be considered a validation of the syntaxon because she clearly referred this community to Willard and she even chose a type relevé from Willard's unpublished thesis. A typification with an unpublished relevé is a violation of Art. 17 of the CPN.

The relevés were published a few months later when Willard published the material of her thesis the same year. This publication is the first complete and valid publication of this association. Komárková's selection of a lectotype has been accepted by Willard (1979).

Willard $(1963,1979)$ placed the Caricetum elynoidis in its own alliance Caricion elynoidis. Neither is this syntaxon valid (being based on an invalidly described association) nor seems the rank of an alliance to be warranted for the separation of this unit. It is considered well placed in the present new alliance Arenario-Paronychion.

\subsubsection{ASSOCIATION: Trifolietum dasyphylli Willard 1979}

Nomenclatural Type: Willard 1979: Table 4 relevé 6223 (invalid lectotypification by Komárková 1976, valid typification with the same relevé by Willard 1979)

For the author citation the comment given under the Caricetum elynoidis applies also here.

\subsubsection{ASSOCIATION: Potentillo-Caricetum rupestris Willard 1979}

Nomenclatural Type: Willard 1979: Table 18 relevé 62149 (invalid lectotypification by Komárková 1976, valid typification with the same relevé by Willard 1979)

For the author citation the comment given under the Caricetum elynoidis applies also here. 


\subsubsection{ASSOCIATION: Sileno acaulis-Paronychietum pulvinatae Willard 1979}

Nomenclatural Type: Willard 1979: Table 2 relevé 621 (invalid lectotypification by Komárková 1976, valid typification with the same relevé by Willard 1979)

For the author citation the comment given under the Caricetum elynoidis also applies here.

\subsubsection{ASSOCIATION: Eritricho aretioidis-Dryadetum octopetalae Kiener 1939 nom. corr. Komárková 1979}

Nomenclatural Type: Kiener 1939: "Dryadetum octopetalae" Table 6 relevé 2995/9 (invalid lectotypification by Komárková 1976, considered validated 1979)

The author citation was changed from "Kiener 1939 corr. Komárková 1976" to "Kiener 1939 nom. corr. Komárková 1979", because Komárková’s former work was not published and the correct abbreviation in cases of name changes due to homonymy is "nom. corr." (CPN Art. 48d). The invalid lectotypification from 1976 is here considered healed with the repeated mention of the same type relevé in Komárková's 1979 publication.

\subsubsection{ASSOCIATION: Selaginello densae-Kobresietum myosuroides Cox 1933 nom. corr. Komárková 1979}

Nomenclatural Type: Cox 1933: "Elynetum" Table 11 relevé 1 (lectotypus Komárková 1979)

The author citation was changed for the same reasons described under Eritricho aretioidis-Dryadetum octopetalae (see above).

\section{"ORDER: Trifolio-Deschampsietalia Komárková 1976"}

A particular problem is the placement of the associations and alliances formerly placed in Komárková's invalid order Trifolio-Deschampsietalia Komárková 1976 which Komárková placed in the Salicetea herbaceae Br.-Bl. 1948. The order is considered invalid because the type alliance is invalid, too. It has been typified with the unpublished "Stellario-Deschampsietum cespitosae Willard 1963 corr. Komárková 1976" which has not been a valid association before its valid publication by Willard (1979).

Both former alliances, Deschampsio-Trifolion parryi and Vaccinio-Danthonion are kept as alliances in this suborder until a better system is proposed. The following remarks apply to both alliances until noted otherwise.

The presence of both fellfield species and snowbed species with high constancy, the latter being mainly Sibbaldia procumbens, Ranunculus adoneus and Chionophila jamesii, presumably led Komárková to the placement of the former order within the European snowbed class. The conspicuous common occurrence of fellfield species and snowbed taxa seems to be a southern Rocky Mountain phenomenon which has not been observed in Glacier NP and has not been mentioned by other authors. The number of fellfield species in Komárková's unit is by far higher than the number of snowbed taxa. Even though the chionophilous taxa Sibbaldia, Ranunculus and Chionophila are very constant, the fellfield species dominate these communities physiognomically. Also species-richness, 
vegetative cover and bryophyte cover of these entities likens these units more to the alpine meadows than to any of the snowbed syntaxa. Therefore, the units of the former order TrifolioDeschampsietalia are considered to belong into this suborder within the Carici-Kobresietea. Within the ecological amplitude of the Rocky Mountain order in this class this group is believed to represent the most snow-dependent unit. Its somewhat remote position within the order and suborder, concerning its ecology and its elevational range, is noticed.

Not all lower syntaxa formerly placed in the Trifolio-Deschampsietalia necessarily belong into this alliance. For example, Willard's Stellario laetae-Deschampsietum stands seem to be species poorer and floristically closer to snowbed communities than Komárková's stands of the same association. The former might thus belong into the snowbed class or possibly into another, as yet undescribed moist meadow syntaxon.

\subsubsection{ALLIANCE: Deschampsio-Trifolion parryi Komárková ex Damm}

Nomenclatural Type: Stellario laetae-Deschampsietum cespitosae Willard 1979, unpublished in Willard (1963) Table 11, relevé 6270, published in Willard (1979) Table 10, relevé 6270

Diagnostic species (after Komárková 1979): Deschampsia cespitosa, Erigeron simplex, Trifolium parryi, Agrostis borealis, Gentianella amarella, Stellaria laeta

Differential species: Sibbaldia procumbens, Draba crassifolia, Ranunculus adoneus, Poa alpina, Chionophila jamesii

This alliance is validated here because Komárková was creating an invalid syntaxon when she typified the unit with Willard's invalid "Stellario-Deschampsietum cespitosae Willard 1963 corr. Komárková 1976" (see below).

The diagnostic species were listed by Komárková for the alliance and the invalid order. The alliance itself does not have any differential species as opposed to the better defined neighboring VaccinioDanthonion. Whether the separation of these alliances is appropriate might be reconsidered in the future especially since the present unit lacks the desired floristic characterization. It was nevertheless validated here in order to keep the associations together which Komárková considered to form a distinct unit. The unification of the alliances with the creation of two suballiances would be an option to consider. Following the priority rules of Art. 15 and 27b of the CPN the name VaccinioDanthonion intermediae would have to be kept for this unit.

\subsubsection{ASSOCIATION: Acomastylidetum rossii Willard (1979)}

Nomenclatural Type: Willard (1979): Table 27 relevé 6247 (invalid lectotypification by Komárková 1976, valid typification with the same relevé by Willard 1979)

The author citation is changed from "Willard 1963" (analogous to Caricetum elynoidis, see above).

\subsubsection{ASSOCIATION: Deschampsio caespitosae-Trifolietum parryi Komárková 1979}

Nomenclatural Type: Komárková (1979): Table 8 relevé 417

The author citation is changed from "Komárková 1976". 


\subsubsection{ASSOCIATION: Stellario laetae-Deschampsietum caespitosae Willard 1979}

Nomenclatural Type: Willard (1979): Table 10 relevé 6270 (invalid lectotypification by Komárková 1976 with Willard (1963) Table 11, relevé 6270 [unpublished = invalid], valid typification with the same relevé published by Willard 1979)

The former author citation of this association "Willard 1963 corr. Komárková 1976" is disregarded because it had not been published. This cannot be healed by Komárková's repeated mention of this unit in her 1979 were it remains invalid due to the lack of a published type.

\subsubsection{ALLIANCE: Vaccinio-Danthonion Komárková}

Nomenclatural Type: Solidagini spathulatae-Danthonietum intermediae Komárková 1979,

Komárková (1979) Table 8, relevé 154

Like the Deschampsio-Trifolion this unit is ecologically somewhat remote within the CariciKobresietea. It has considerable affinities to subalpine meadows and snowbed units. Nevertheless does the synoptic tabular comparison (Tab. 1) and the structural importance of the fellfield species in this unit allow for such a treatment. Another option would be to create a new order for this and the neighboring alliance outside the present class which would have the disadvantage of being floristically largely identical with the regional units of the Carici-Kobresietea.

\subsubsection{ASSOCIATION: Vaccinietum scoparii-cespitosi Komárková 1979}

Nomenclatural Type: Komárková (1979): Table 8, relevé 134

The author citation is changed from "Komárková 1976".

\subsubsection{ASSOCIATION: Solidagini spathulatae- Danthonietum intermediae Komárková 1979}

Nomenclatural Type: Komárková (1979): Table 8 relevé 154

The author citation is changed from "Komárková 1976".

\subsubsection{ASSOCIATION: Artemisietum arcticae-saxicolae Willard 1979}

Nomenclatural Type: Willard (1979): Table 26 relevé 6255 (unpublished in Willard (1963): Table 30 relevé 6255)

The author citation is changed from "Willard 1963" (analogous to Caricetum elynoidis, see above). 


\section{SUBORDER: Myosotido alpestris-Silenenalia acaulis subord. prov. - Northern Rocky Mountain fellfield communities}

Nomenclatural Type: Besseyo wyomingensis-Arenarion obtusilobae all. nov.

Character species: Myosotis alpestris, Solidago multiradiata, Oxytropis campestris s.l., Saxifraga occidentalis, Smelowskia calycina, and character species of the Besseyo wyomingensis-Arenarion obtusilobae

Differential species: Poa alpina, Carex albonigra, Antennaria umbrinella, Bupleurum americanum, Saxifraga bronchialis, Antennaria alpina, Astragalus alpinus, Anemone drummondii, Agropyron latiglume, Poa secunda, Pedicularis contorta, Hedysarum sulphurescens, Carex phaeocephala, and differential species of the Besseyo wyomingensisArenarion obtusilobae

This is the northern counterpart of the suborder Geo-Silenenalia (see Tab. 1). One of its most important characters is the lack of any southern and central Rocky Mountain species which define the southern suborder. The diagnostic species of the type alliance well delineate this suborder floristically. A number of additional species have been listed to be diagnostic for this syntaxon even though they do occur with lesser constancy in vegetation which are considered to belong to the southern suborder units as far south as southern Montana. These species are therefore less sharply differentiating, but are still much more characteristic for this unit. They have also been listed separately in the synoptic table. These species characterize the suborder also further north and are likely to comprise further communities not covered by the present alliance. Many of the character species mentioned here are character species only on a regional level since on a larger scale several of them occur in other syntaxa as well. While Solidago multiradiata and Myosotis alpestris are highly constant in this suborder, Oxytropis campestris s.l. seems to occur less often in the Canadian part of the suborder's range. The species is extremely common in the communities within the study area. Due to the uncertainty of the northern limits of this unit, it is here proposed as a provisional unit.

Several communities of this suborder have Dryas octopetala as a constant species and the species is likely to be confined to this unit throughout its range. Mountain Avens is therefore called a character species even though it is not necessarily present in all members of this suborder. This can be seen in the synoptic table of the dry alpine meadow communities (Tab. 1), which lacks the Dryas-Salix nivalis communities. Their alliance has been presented in a separate table.

Smelowskia calycina can also be considered a character species even though it occurs also much further north, south and west of the suborder's range where it seems to be not very constant in communities of this order.

The other differential species commonly occurring in this northern subunit only occur with lesser degrees of faithfulness. 


\subsubsection{ALLIANCE: Besseyo wyomingensis-Arenarion obtusilobae all. nov. - Besseya-Arctic Sandwort fellfield alliance}

Nomenclatural Type: Myosotido alpestris-Caricetum albonigrae ass. nov.

Plots: (see subordinate units)

Character species: Besseya wyomingensis, Taraxacum ceratophorum, Potentilla nivea, Eriogonum ovalifolium, Arenaria rossii, Draba paysonis, Phacelia sericea, Douglasia montana, Heuchera parviflora, (Oxytropis campestris s.1., Antennaria umbrinella)

Differential species: Saxifraga bronchialis, Campanula rotundifolia, Senecio canus, Arnica alpina, Arabis nuttallii, Galium boreale, Linum perenne, Astragalus aboriginum, Silene parryi, Potentilla fruticosa, Pedicularis contorta, Pulsatilla patens, Poa secunda

Not very many accounts of fellfield communities of this order have been found in the literature from northern Montana and western Canada. Reports of such units from Alberta by Achuff et al.(1982, 1984, 1993, 1997), Kuchar (1975) and others seem to refer do heterogeneously delineated, lichen-rich fellfield communities which need to be studied in greater detail before they can be related to the present system.

Consequently, only this one alliance could be established based mainly on the data from the study area in Glacier National Park. All true alpine, high elevation fellfield plant communities in this area turned out to belong into the same order (and suborder). Within this order they represent a floristically distinct regional group identified by the diagnostic species given above. Within the classification system as presented here, it seems most practical at this point to assign this group the rank of an alliance. The number of character species is somewhat uncertain at this point. Due to the lack of information on lower elevation vegetation units, it cannot safely be said how far some of the species are distributed in other vegetation units.

Some of the character species mentioned are local character species only and can occur in various other vegetation units elsewhere. This applies e.g. for Taraxacum ceratophorum, Eriogonum ovalifolium and Heuchera parviflora. Some of the species listed as differential species might later on turn out to be character species. This might, for instance, be the case for Senecio canus and Astragalus aboriginum. The limited number of character species in these alpine units is not surprising, since under the extreme alpine conditions the overall number of species is smaller and most species adapted to these conditions are fairly widespread. This is most likely to be also the reason for the lack of character species in the associations established in this alliance which have been characterized by species groups instead.

The differential species given above differentiate mainly against the other, northern units of the suborder but most of them are also widely lacking in any other southern Rocky Mountain unit which makes them differential species of the suborder. Unfortunately, alpine vegetation data from the adjacent mountain ranges of central and southern central Montana are not available to better define the southern limit of this alliance floristically as well as geographically.

Even though a number of floristically and physiognomically very different entities is found within this alliance, ecological differentiation is not always easy to detect. At least with the limited number of ecological parameters sampled in the course of this study, correlations between these particular types of vegetation and the environment were hard to find. This is not to say that ecological differentiation is not present at all. In fact, the extent of very homogeneous, species-rich expanses of fellfield over larger areas, which border abruptly against other species-rich and homogeneous types - often with very clear-cut delineations - might, suggest that some ecological factors or a combination thereof 
determines the pattern of vegetation here also. Microclimatic measurements, more detailed soil analyses as well as studies of snow melt patterns would be needed to elucidate these relationships.

A striking example of such a major shift in vegetation units with very different physiognomies is the immediate adjacency of fellfield communities with and without Dryas octopetala. The differences in the floristic composition between these units with extremely dissimilar physiognomy are small and in fact limited to the one differential species Dryas octopetala, and a change in cover for certain other species. In the Dryas-units the dwarf shrub assumes a strongly dominant role and often the other species are reduced to scattered occurrences only. Even so, no single species was found to completely drop out under the dominance of Mountain Avens, raising the question where to accommodate the Dryas dominated stands in a floristically rather than physiognomically defined classification system. So far most other authors have separated the Dryas dominated communities from those lacking Dryas on the basis of structural differences, often without taking into account the striking floristic similarity of both groups.

It was debated in the course of this study whether or not to retain the Dryas units, as different as they appear structurally, in the same alliance with non-Dryas units. With one single differential species only - which is Mountain Avens itself - the Dryas units could be treated on the low level of the subassociation. To be consistent with the floristic approach used throughout this study this has indeed be done for three Dryas units. Only the obviously ecologically distinct, moister Dryas units with a larger number of differential species have been placed in a new alliance, Salici nivalis-Dryadion octopetalae.

As far as the ecological significance of the occurrence of Dryas is concerned, no obvious explanation has been found. It might well be that the dominance of the dwarf shrub is merely a matter of dispersal history on the site since any other floristical differentiation is lacking. It needs to be mentioned that the present difference of ecological site conditions - mainly the humus-rich soil profile built up under Dryas mats - is a consequence rather than a prerequisite of the floristic change. Any statements on the ecological site conditions before the establishment of the shrub are rather speculative. This problem of change over time is increasingly hard to solve the slower the changes in vegetation are, as is the case in alpine environments. Studies on the dynamics, dispersal and establishment of Dryas octopetala can be found elsewhere in literature (Aichinger 1957, Anderson 1967, Johnson \& Billings 1962, Kuchar 1975, Lawrence et al. 1967, Elkington 1971 and others).

Subdivisions in this group are mainly drawn after the occurrence and combination of differential species groups derived from the vegetation tables. Only few syntaxa could be identified on the basis of their own characteristic species group as would be needed for the creation of associations in the strict sense. Some of the differentiated syntaxa have therefore been treated as unranked "communities" (German: "Gesellschaften") rather than as associations. Since most of the high elevation species are fairly widespread in this extreme environment, the differential species groups are not always clear-cut and some of the units do not have their own differential species group at all. Main species groups are the Carex albonigra-Myosotis alpestris group, the Carex rupestris-Lupinus lepidus group and the Bupleurum americanum group (see Tab. 7.).

As the table reveals, these three species groups have been found to show an obvious sequence of overlap within the fellfield communities. For the Bupleurum americanum group it can be safely assumed that it represents a lower elevation variant occurring mostly close to the eastern border of the study area with strong floristic influence from the adjacent prairie grasslands. The species of this group rarely occur at very high elevations which is most likely attributable to the lack of adaptation of its prairie species for the extreme conditions of higher altitudes. For the former two groups such a 
clear ecological and geographical correlation has so far not been found. The sequence of overlap suggests a tendency of the Carex albonigra group for higher elevations.

General aspect: The term "fellfield" well describes the appearance of these low to high alpine plant communities. The word "fellfield" is derived from the swedish word "fjäll", meaning "mountain" and "treeless, rocky highland". It is used throughout this study for high elevation vegetation types with an evenly scattered cushion plant and graminoid dominated vegetation layer and a high cover of rocks of pebble or gravel size. The soil surface is usually fairly stable. Some units occur with patterned, striped or patchy vegetation, some with considerable amounts of bedrock surface (see below). The vegetation consists of small, low growing species. Hemicryptophytes are the dominating life-form except for the chamaephyte dominated Dryas- (and dwarf willow-) communities. According to this definition the term "fellfield" is used here for the whole order Arenario-Festucetalia brachyphyllae.

Species diversity in this particular alliance is extremely high which is reflected in different spectacular flowering aspects in summer. Larges expanses of Dryas octopetala appear painted creamy-white. Myosotis alpestris, Douglasia montana, Lupinus lepidus, Smelowskia calycina, Oxytropis campestris, Hedysarum sulphurescens and Erigeron simplex are some of the less dominant but most conspicuous flowering species. Graminoid dominated aspects can occur when Festuca brachyphylla or Carex rupestris assume an important structural role. Even lichens can contribute much to the aspect of some subunits. Especially winter-snowfree sites have larger amounts of blackish species of Umbilicaria, Lecidea s.l., Pseudephebe and other genera.

Topography: Surface reliefs range from step-like rock-outcrops with fine soil-filled vegetation pockets which often cover large expanses of the highest mountain peaks, to unstable scree-covered upper slopes as well as level bedrock- or frost rubble-covered ridges and rolling uplands.

Geology: These fellfield communities are found on green and red argillite, sometimes with smaller amounts of arenite, coarse sandstone or quarzitic components. They were never found on limestone, which does not necessarily mean that they could not occur there. It merely indicates that extensive sufficiently stable scree slopes or frost rubble-covered uplands do not occur in the study area or have at least not been sampled on limestone in this study.

Soils: The organic content of the soils can be high which is mostly the case under Dryas octopetala. The almost pure, dark humus is often visible in cracked vegetation carpets of solifluction slopes. In non-Dryas vegetation organic contents of the soil is much less and is related to soil stability. The latter can range from extremely stable on level, frost-rubble covered uplands to extremely unstable on steeper talus slopes where this type of vegetation can persist only as patches of strongly consolidated turf interrupted by mostly barren scree. Initial soil development in such situations is possible in the stabilized, vegetated patches only. The soil profiles are generally shallow to very shallow with little development of visible horizons. Only little moisture is stored.

Wind exposure/Snow cover/Moisture conditions: Wind exposure is high to very high on ridges and mountaintops, whereas on the slopes it can be less extreme. Accordingly winter snow cover is little in exposed, windswept sites but can be considerable on leeward slopes. Due to the mostly (but not exclusively) southerly to southwesterly aspects of the stands, meltout occurs early in the summer and no extended period of meltwater supply can compensate for the strong dessiccation which these stands experience. Desiccating winds and little water storage results in drought conditions which are likely to occur in summer and fall. Desiccation also presents a problem in winter on sites with little snow cover, where water loss cannot be replenished by root-uptake since the soils are frozen through the root horizons. Other authors have referred to this kind of vegetation as "alpine desert". 
Vegetation pattern and cover: Two physiognomic types can be encountered within this vegetation unit:

1. patchy or evenly spread vegetation on windswept ridgetops, summits and upper slopes. Although this type is mostly open with a high rock and gravel cover it can in some cases be fairly dense when sufficient moisture and surface stability are provided. These carpets of compact vegetation can create an extremely tough turf which perfectly demonstrates the soil- and surface-stabilizing function of the vegetation layer plate 2, fig.7.

2. unstable slopes with patchy or mostly striped vegetation (see plate 2, fig.6, the latter mostly on slopes and running perpendicular to the slope contour lines. The number of species in these patches and stripes can be extremely high within only a few square-decimeters. Especially on slopes with very unstable screes the vegetated patches are very dense and compacted, sometimes even bulging upwards towards their center.

Within both types rock cover often exceeds vegetation cover, even though this is much more so the case in the latter type. Vegetation cover can vary from extremely little (to less than $1 \%$ ) to $75 \%$ or more.

Moss cover can be relatively high (up to $30 \%$ !), mainly near rock outcrops where water is unable to drain into the bedrock or on sites with meltwater supply, but mostly tends to be below $5 \%$ since the prevailing dry conditions are unfavorable for bryophytes; lichen cover varies greatly also, with a nearly complete lichen cover on rocks in compacted, wind-exposed uplands and almost no lichens on unstable talus slopes where lichens are restricted to stabilized vegetation patches.

It is important to note that the vegetation pattern has not been found to be correlated with the floristic vegetation type as might be expected by the completely different appearance of e.g. unstable, patchy slopes and evenly vegetated fellfields.

Floristical differentiation: The syntaxonomic definition of this regional alliance is given above. Within the area of this study this broad alliance has been identified by the "Silene acaulis species group" consisting of Silene acaulis, Arenaria obtusiloba, Festuca brachyphylla, Saxifraga occidentalis, Smelowskia calycina, Selaginella standleyi, Erigeron compositus and Umbilicaria krascheninnikovii. Except for a few sites at least four species of this group are present in most stands.

Distribution: This is by far the most widespread alpine syntaxon, comprising all high and mid-alpine communities in Glacier NP except for steep, very loose talus and scree vegetation and moist sites in the lower alpine. Much of the true alpine areas of the park are covered by various units of this group. The steeper and rockier highest elevations of the western parts of the study area, the Continental Divide and the highest eastern peaks have communities of this order as well as the flat and undulating true alpine uplands of the eastern mountain ridges.

Syntaxonomic relationships: Most of the syntaxonomic questions have been mentioned above. Critical in the area is the position of the regional Kobresia units. They seem to be somewhat different from most Kobresia communities in other Rocky Mountain alpine areas. For the one part they are very rare occurrences in the study area. Furthermore, they seem to be more moisture-dependent in the study area than they are elsewhere and than most other communities of this unit.

At a regional scale the following species have initially been called "alpine generalists": Solidago multiradiata, Oxytropis campestris, Arenaria obtusiloba, Luzula spicata, Besseya wyomingensis, Potentilla diversifolia, Selaginella scopulorum, Sedum lanceolatum, Potentilla fruticosa and Calamagrostis purpurascens. As has been expected, some of these turned out to be character species of higher alpine syntaxa in a wider geographical context. 
Literature: The most similar communities have been described by Polster (1977) in the adjacent Akamina area in British Columbia. Other similar accounts have been provided by Achuff et al. (1982, 1984, 1984b, 1993, 1997) and Kuchar (1973, 1975). The decreasing degree of similarity with vegetation types from other areas can be taken from the synoptic table (Tab. 1).

\title{
1.1.4.1. ASSOCIATION: Myosotido alpestris-Caricetum albonigrae ass. nov. - Alpine forget-me-not - Black-and-White scaled-Sedge association
}

\author{
Nomenclatural Type: Table 6 relevé 49 \\ Plots: $\quad 43,46,47,48,49,50,53,54,57,58,59,60,61,65,66,67,68,69,188,189,190,273,274,275,299$, \\ $302,303,304,359,467,523,636,725,727,728 \quad(n=34)$
}

Diagnostic species group: (Myosotis alpestris, Carex albonigra, Sedum roseum, Potentilla nivea, Trisetum spicatum, Arnica alpina, Arenaria rossii)

General aspect: The most widespread fellfield plant communities of the alpine in Glacier NP are found in this unit. High rock cover and a species-rich, low-growing, often scattered vegetation layer is characteristic for this group. Flowering aspects differ with the various vegetation patterns and with the dominance of Dryas and Salix nivalis, for which subvariants have been separated.

Gentle environmental gradients as well as the phytogeographical gradients create a floristic variability which could not be easily resolved. This unit does not have an exclusive species group but is defined by its combination of species. Furthermore, the species groups which proved to be stable in other communities tend to thin out in some subunits of this association.

The shifting overlap of three species groups is very conspicuous within this unit and divides the association into three subassociations. It is mainly the Carex albonigra species group which best delineates the whole association and differentiates well against the next association. However, the Carex albonigra species group also occurs in much of the ecologically different Salici-Dryadetum octopetalae. The latter fact precludes it from being a good character species group in the strict sense for the present syntaxon which it would otherwise nicely define. Since the delineation against the Dryas-Salix nivalis community is not a problem floristically and ecologically, this community is assigned the rank of an association and the above-mentioned species group is given as a "diagnostic species group". The lack of a character species group in the strict sense as a criterion for an association is accepted in this case, fully recognizing that this practice stretches the definition of an association. The fact that this unit on a landscape scale is very important makes it desirable to include it in the system as a full ranking association rather than as a mere "community". The latter solution would be in closer keeping with the central European protocol.

The other important species group of Carex rupestris is also highly present but overlaps largely with the neighboring Bupleurum group. Thirdly, the Bupleurum group demarcates the lower elevation end of this unit. This latter unit might as well be included in the Bupleurum group which is suggested by its lower elevation range and also supported by the numerical methods which join this group with the lower elevation unit.

Even though the Carex rupestris- and the Bupleurum americanum species groups are mostly lacking in the Agropyron-Polemonium variant, they are kept in this group, which certainly is the closest they could fit in. 
A Dryas octopetala- and a Salix nivalis variant are both weakly differentiatiated by the dominant dwarf shrubs only.

Much of the highest terrain in the mountains along the Continental Divide supports this type of vegetation. It presents the most severe alpine environment encountered in the area. Surprisingly, a strong floristic differentiation between horizontal windswept mountaintops and ridgetops and less exposed and partly very scree-rich slopes could not be found. It is assumed that under these extreme conditions the species composition has already been selected to such a degree that further niche differentiation is not reflected by even more specialized species.

The Myosotis alpestris - Carex albonigra community has five subunits, namely three subassociations and two variants:

SUBASSOCIATION: Myosotido alpestris-Caricetum albonigrae typicum subass. nov. - High elevation subassociation

Nomenclatural Type: Table 6 relevé 49

Plots: $49,50,58,60,67,69,275 \quad(n=7)$

\section{Differential species: see text}

General aspect: Together with the Agropyron-Polemonium community this is the most extreme high elevation community. It often covers large expanses of rolling uplands and frost rubble covered summits. Perhaps unexpectedly (due to its extreme environment) this community is quite species-rich. A very low-growing and mostly scattered vegetation of alpine turf presents a spectacular flowering aspect in early summer when Silene acaulis, Douglasia montana, Myosotis alpestris, Smelowskia calycina and Lupinus lepidus cover the rocky frost rubble expanses with their colorful display.

Topography: This is a high elevation frost rubble community; in some plots patterned ground with obvious polygonal arrangement of rocks was observed, which is a fairly common feature in exposed frost rubble areas in the park (Butler \& Malanson 1989). Sites are often on flat mountain summits, ridges, rolling uplands and prominent upper slopes. Exposure is mainly NW to SW, rarely NE. Elevation of the plots is $2400-2550 \mathrm{~m}$, but possibly reaching higher. This unit occurs on gentle slopes with slope angles between $3^{\circ}-10^{\circ}\left(-17^{\circ}\right)$ and only very little loose surface material, i.e. a high of soil stability.

Geology: Found on green and red argillite, p.p. with high fractions of coarse arenites and quartzite. Exposed rocks and gravel cover the larger part of the plots and are strongly weathered.

Soils: Soils are hardly developed and restricted to soil pockets and vegetation covered patches. Mineral and organic fine soil can be lacking between the rocks which can form frost sorted polygons, with open gaps between the rocks into the ground.

Wind exposure/Snow cover: Due to its extremely exposed situation this community has the least winter snow cover of any alpine vascular plant community, thus it is among the most extreme of all alpine communities. The lack of a protective snow cover facilitates the occurrence of frost action which generates the patterned ground features found in this community. The abundance of chionophobous lichen species is also a result of a lack of winter snow cover.

Moisture conditions: Xeric conditions prevail through much of the year in this extremely exposed and well drained community with drought periods being most obvious in fall. 
Floristical differentiation: Lacking its own differential species group, the presence of the Carex rupestris group and the Carex albonigra group is the most important floristic characteristic of this community together with the lack of the species of the Salici-Dryadion. In addition, all species of the Silene acaulis group and the general alpine species are highly constant. Silene acaulis reaches its highest cover in this association. The lack of the lower elevation Bupleurum species group differentiates this against the Campanula rotundifolia-Heuchera parviflora variant.

Vegetation pattern and cover: The vegetation pattern is usually patchy or striped, rarely even and occasionally with no detectable pattern, thus erratic distribution of clumps of vegetation prevails. The patchiness of the vegetation is a typical feature for the upper elevational limits of vascular plant growth. The extremity of the environmental conditions does not allow for a closed vegetation cover which remains restricted to slightly more favorable microsites.

Moss cover is low (1-4\%), whereas lichen cover is very high (18-85\%) taking advantage of the scarce snow cover and plenty of open and stable rock faces.

Distribution: Most of the plots of this variant except for one have been sampled on one massif only (Otokomi-East Flattop-ridge). Further sampling would be needed to make sure whether this might represent a local variant only.

Syntaxonomic relationships: This typicum variant is closely related to all other variants of this association. Particularly close relations exist to the Myosotis-Dryas- and Myosotis-Dryas-Salix nivalis communities which can be considered variants of this unit but have been moved into the SaliciDryadion for reasons given there (p. 73) On the other hand it

might as well be considered a high elevation variant of the Campanula rotundifolia-Heuchera parviflora unit (or vice versa), mostly lacking the latter unit's lower elevation prairie species.

\section{VARIANT: Variant of Dryas octopetala}

Plots: $43,46,47,48,53,54 \quad(n=6)$

\section{Character species: see Myosotido-Caricetum albonigrae}

Differential species: Dryas octopetala

Except for the pronounced structural differences of a Dryas dominated community, which makes the aspect of this community much different, this variant is very similar to the high elevation typicum subassociation. Silene acaulis and Potentilla fruticosa are less constant and less abundant in this and the following variant, very likely as a result of the structural dominance of the Mountain Avens.

The samples of this variant have all been gathered in a limited area of Otokomi Mountain in the eastcentral portion of the park. This might thus be a locally valid unit only.

\section{VARIANT: Variant of Dryas octopetala and Salix nivalis \\ Plots: $57,59,65,66,68,91,727 \quad(n=7)$}

\section{Character species: see Myosotido-Caricetum albonigrae}

\section{Differential species: Dryas octopetala, Salix nivalis}

This subvariant is differentiated against the typicum solely by the presence of Dryas octopetala and Salix nivalis. The latter can achieve considerable cover. Since the dwarf willow species is entirely lacking in the other variants, this unit cannot be treated as a facies (see p 16). Ecologically the stands are likely to be on the moist side within the association representing a transition to the Salici- 
Dryadetum. They might also belong in the latter association as an impoverished high elevation variant. Due to the lack of the association character species of Salici-Dryadetum and a distribution at higher elevations, they were kept in this unit.

Like the latter unit the samples of this variant have all been gathered in a limited area of East Flattop Mountain, Otokomi Mountain and Mtn. Wynn in the east-central portion of the park. Consequently this might also be a locally valid unit only.

\section{SUBASSOCIATION: Myosotido alpestris-Caricetum albonigrae polemonietosum} viscosi subass. nov.

- Wheatgrass-Jacob's ladder- unstable fellfield slopes

Nomenclatural Type: Table 6 relevé 523

Plots: $61,188,189,190,274,299,302,303,523,636,725,728 \quad(n=12)$

Diagnostic species: Polemonium viscosum, Potentilla quinqueflora, Taraxacum sp., (Agropyron latiglume); species of the Carex rupestris group are almost entirely lacking

General aspect: A typical high alpine fellfield community with high rock cover and a species-rich, low growing, often scattered vegetation layer very similar to the typicum subassociation. It occurs mainly on sites with a high fraction of loose surface, thus is less stable than the typicum frost rubble community.

Topography: Mostly at or near mountain- and ridgetops and on undulating high elevation uplands, outcrops and upper slopes; high in rock and scree cover, sometimes on frost rubble; slopes are mostly steeper than in the typicum variant and therefore stability is usually less in this community except for some almost level ridgetops. Consequently colluvial talus is more common than frost rubble which derives directly from the underlying bedrock. The community was sampled at elevations from 2250 to $2630 \mathrm{~m}$ a.s.l. Thus it is among the highest-reaching communities in the area.

Geology: This community is found mainly on green argillite, sometimes on red argillite. Fractions of quartzite and arenites can be present.

Soils: Like in the other communities of this association, soils are weakly developed and restricted to soil pockets.

Wind exposure/Snow cover: Wind exposure was estimated to be extreme but snow cover is slightly higher than in the typicum variant which might be due to different relief situations.

Moisture conditions: In part surprisingly moist, which be might locally aided by rock outcrops which impede drainage, but most sites are drying out by midsummer or even earlier. The varying abundance of bryophytes is a good indicator of the site-specific moisture conditions in this community.

Floristic differentiation: The characterization of this unit is not very strong but the table reveals two differences in a number of plots:

- the presence of a character species group consisting of Polemonium viscosum, Potentilla quinquefolia, Taraxacum sp. and Agropyron latiglume. Taraxacum sp. also occurs in the Dryas variants and Agropyron occurs scattered in other communities too. Hence the latter two species are only weak character species.

- the apparent lack of the Carex rupestris group 
The differential species group of this syntaxon is not very strong, but it still differentiates a number of relevés from the closely related high elevation fellfield community. Even though cover of the differential species is very low, two out of the four differential species are enough to assign a plot to this unit if the second criterion, less than four species of the Carex rupestris group being present, is met. Further sampling would be needed to prove whether the differentiation of this variant from the typicum variant describes a constant syntaxon.

Vegetation pattern and cover: Vegetation of this unit is almost always patchy and covering about $10-25 \%$, rarely down to $1 \%$ or up to $50 \%$. Moss and lichen cover can vary greatly depending on the local moisture, snow cover and slope stability conditions. Silene acaulis often reaches high cover in this unit. Arenaria obtusiloba and Smelowskia calycina can also be very abundant in this community.

Syntaxonomic relationships: The position of this unit in this association is somewhat tentative. Even though the close relationship to the Myosotido-Caricetum albonigrae typicum is beyond doubt, there are some differences. One is the lack of the Carex rupestris group which is present in the other members of this association. The other is the presence of an independent species group which might call for a separate treatment of the present unit. Due to the overall floristical similarity it was decided to include the Agropyron-Polemonium unit as a subassociation in this association.

Lacking in about half of the samples of this subunit is the Bupleurum americanum group. The lack of these species, including the sparser occurrence of lichens, reflects the extreme alpine conditions added to by the increased instability of the substrate: due to considerable slope in this community a further selection results for species which are tolerant of loose and shifting substrates. Polemonium viscosum and a little less so Agropyron latiglume are good examples for these kinds of adapted species.

The presence of species of the Bupleurum americanum group can obviously not be interpreted as an indicator of lower elevation as it is the case in the following Bupleurum-units. The influence of floristic elements derived from the prairies is not only elevation-related but is also a function of the distance or orographic relation to the prairie.

It needs to be mentioned that close relations exist between this subunit and the Arenaria obtusiloba basal community.

Even though the table shows a differentation of this group against the other Besseyo-Arenarioncommunities, they are ecologically and physiognomically closely related. The ecological significance of the lack of the Carex rupestris group remains to be detected.

Distribution: The community has been observed through much of the park and sampled from Redgap Pass/Yellow Mountain in the north along the Continental Divide down to Mt. Henry near the SE corner of the study area.

Literature: Even though Polemonium viscosum has been noted in other areas as a species of unstable high elevation slope communities (Kuchar 1973) more detailed references to similar vegetation units have not been found. 


\section{VARIANT: Campanula rotundifolia-Heuchera parviflora variant}

Nomenclatural Type: Table 6 relevé 640

Plots: $4,6,55,89,133,143,144,154,155,162,468,470,471,472,640,(469) \quad(n=16)$

Character species: none (see typicum)

Differential species: Bupleurum americanum group: Bupleurum americanum, Campanula rotundifolia, Cerastium arvense, Senecio canus, Antennaria umbrinella, Agoseris glauca, Eriogonum ovalifolium, Achillea millefolium, Arabis nuttallii, Pedicularis contorta, Silene parryi, Galium boreale, Pulsatilla patens

General aspect: see typicum

Topography: This widespread subunit occurs in all aspects, mostly on slopes of medium steepness. It covers large areas on flat summits, ridgetops and more or less steep upper slopes. On steep slopes with considerable instability and shifting scree, perfect vertically striped patterns of vegetation islands are formed. Elevation ranges from 2000-2400 m, which makes this variant the low elevation variant within this community.

Geology: Parent material is mostly green argillite, red argillite, interbedded layers of red argillite and quartzite, pure quartzite or brown arenite. Surface rocks appear as weathered frost rubble on less steep slopes and talus or scree on steeper slopes.

Soils: Surface rock cover is high, as is the skeletal content within the soils

Wind exposure/Snow cover: Depending on the exposure of the sites, wind exposure can be high to extreme on ridgetops and less on upper and middle slopes, with snow cover reacting accordingly. Local topography can allow for slighty higher snow cover resulting in better moisture conditions.

Moisture conditions: Most sites seem to undergo strong seasonal changes in water supply with sufficient moisture after snow melt. By mid-summer dry conditions prevail and drought periods are likely to occur.

Floristical differentiation: Characteristic for this community is the occurrence of the Bupleurum group forming a clearly defined differential species group. Most species of this group are not yet as constant here as they are in the next community. As described in greater detail in the next section (Oxytropis-Bupleurum-alpine prairie) the species of this group are not true alpine species but occur widespread in the lower elevation prairie grasslands to the east not far from the sampling areas.

Vegetation pattern and cover: Within this widespread syntaxon the most extreme vegetation patterns occur. Most obvious on slopes are perfect vertical patches of species-rich vegetation interspersed with loose, mostly barren running scree. The vegetated islands seem to float on the loose matrix of barren, fine-soil-deprived scree, forming a vegetation complex of two strongly differing environments. The overall cover of the vegetated parts rarely exceeds $50 \%$ and is mostly around $10 \%$ to $30 \%$. This is not taking into account the cover within the vegetated patches.

On the other hand, extremely homogeneous, even stands occur on uplands and gentle slopes with more stabilized surfaces.

Lichen cover varies greatly, clearly depending on slope stability. Moss cover is mostly low with few exceptions in places where drainage is impeded.

Syntaxonomic relationships: This community represents the low elevation end of the Myosotis alpestris-Carex albonigra community. It can be can be viewed as an intermediate syntaxon between 
true alpine fellfield and prairie grasslands, concerning its floristic composition, elevational range, geographic location and overall ecology. Since this is even more true for the Oxytropis-Bupleurumalpine prairie treated later in this chapter, the present unit constitutes the upper limit of the stratified intermediate zone in an alpine-to-prairie gradient and at the same time the lowest unit within the syntaxonomic unit of a variant seems to best accommodate this detailed classification.

Greatest similarity exists to the Oxytropis campestris-Bupleurum americanum community if their overall floristical similarity is calculated and compared qualitatively. This is due to the weight of the species-rich Bupleurum group. Nevertheless, the constant presence of a set of true alpine species of the Carex albonigra group marks this as a community with strong alpine affinities. For this reason, the community was retained within the Myosotis alpestris-Carex albonigra association. Nevertheless, being part of a continuous elevational gradient, this vegetation unit could as well have been classified with the Oxytropis campestris-Bupleurum americanum association, since delimiting vegetation units on such continuous vegetation gradients is a matter of definition rather than of naturally-given lines.

Distribution: The distribution of this community is reflected in its floristic composition: as the characteristic Bupleurum species group suggests, which is floristically derived from the prairie vegetation, this community is found on the easternmost mountains of the study area. There, NNEtrending mountain ridges with rolling, alpine uplands are pointing from the Continental Divide towards the prairies.

Literature: No specific reference to this or a similar community has been found in the literature, except that in a very broad sense it might be part of some alpine cushion plant community described elsewhere.

\subsubsection{ASSOCIATION: Oxytropido campestris-Bupleuretum americani ass. nov. - Locoweed-Bupleurum alpine prairie community}

Nomenclatural Type: Table 7 relevé 5

Plots: $3,5,7,8,9,10,14,16,17,18,19,20,21,22,23,28,29,30,31,32,33,79,80,99,102,103,106,107$, $108,109,114,115,116,128,134,135,223,226,237,262,263,280,282,285,469,487,493,515,639$, $(n=49)$

\section{Character species: none}

Differential species (= Bupleurum americanum group): Bupleurum americanum, Campanula rotundifolia, Cerastium arvense, Senecio canus, Antennaria umbrinella, Agoseris glauca, Eriogonum ovalifolium, Achillea millefolium, Arabis nuttallii, Pedicularis contorta, Silene parryi, Galium boreale, Pulsatilla patens

General aspect: Structurally, the stands of this association appear like any other true alpine fellfield community, due to the growth habit of low growing species adapted to the extreme conditions of open high elevation sites. Sedges (mainly Carex rupestris), grasses and forbs form a closed or more often open vegetation layer on very rocky, mostly frost rubble-covered sites. The combination of alpine species and species from lower elevations results in the most species-rich communities found in any alpine vegetation unit. This leads to a colorful rich flowering aspect in early summer with which contrasts this community nicely against the white-tinged areas of flowering Dryas mats. Lichens are 
abundant and rich in species, growing on pebble-sized stones as well as covering the remaining soil surface in between.

Topography: On exposed alpine frost rubble meadows of slightly lower alpine uplands, compared to the Myosotis alpestris-Carex albonigra communities. Also found in presumably wind-channeling valleys (see below). The relief on these gravelly upland surfaces is very even except for protruding larger rocks in some cases.

Most sites are found on slopes steeper than $18^{\circ}$, often steeper than $25^{\circ}$, and only rarely level areas or gentle slopes are found. Even on many of the steeper sites frost rubble was more common in this community than talus, i.e. slope stability regardless of the steepness is high in this community. At least currently shifting scree is rarely present here. The elevation range is from $1800 \mathrm{~m}$ to $2350 \mathrm{~m}$. No clear preference for any exposure was found, except for the Dryas variant which tends to prefer northern to eastern aspects.

Geology: Found on green argillite, red argillite and quartzite often mixed in with coarse arenites. Frost rubble rocks and pebbles cover mostly more then half of the surface, much of them covered with epilithic lichens.

Soils: Soil development is extremely weak on these alpine sites. Fine soil loss by the extreme winds is likely to be an important factor.

Wind exposure/Snow cover: Low growing vegetation structure and very exposed sites point to a high to extreme wind exposure in this community. The first two subunits are mostly found on exposed alpine upland whereas the subassociation of Selaginella was mainly found in valley situations and on lower slopes where channeled winds reach considerable speed. The latter is the case for the Selaginella wallacei community found in the Appistoki Valley, where the depressed and scattered treeline neighboring these open alpine communities seems to be influenced by high valley-winds.

Snow cover is likely to be low or sometimes even absent in winter on the ridgetops and slightly higher in valley situations.

Moisture conditions: Drying winds and good drainage provide mesic to more often xeric conditions, the latter certainly prevailing during the second half of the growing season.

Floristical differentiation: Characteristic for this unit within the Besseyo-Arenarion-unit is the presence of the alpine Carex rupestris group in combination with the lower elevation Bupleurum americanum group. The members of the latter group are all widespread prairie species, which in this area extend well into the immediately adjacent mountains up to elevations far above their usual altudinal distribution.

The Myosotis alpestris-Carex albonigra group as an indicator of high elevation conditions is almost entirely lacking. No unique character species group has been found for this unit. Thus, like the latter unit this is an association defined on the basis of a species group rather than on a group of character species in the strict sense. Nonetheless is this association floristically as well as ecologically quite distinct.

The combiniation of floristic elements of the alpine species group in combination with the relatively large Bupleurum americanum group results in very high species numbers with the maximum species number per plot ever found in this study (93 species of vascular and non-vascular plants on a $16 \mathrm{~m}^{2}$ plot).

Vegetation pattern and cover: All kinds of patterns vegetation occur, with a tendency to more even vegetation cover. Perfect vertical stripe patterns, often on a terraced relief, do occur, as do patchy 
patterns not only on loose scree. Lichen cover is mostly high, between $10 \%$ and $30 \%$, as is common in fellfield communities, but can occasionally be lower. Bryophyte cover is highly variable, from less than $1 \%$ to about $15 \%$.

Distribution: These communities have only been found in the southeastern alpine uplands of the park (Spot Mountain Plateau and south to Firebrand Pass/Calf Robe Mountain). It is likely to occur at least occasionally on the neighboring flat mountains up to the Saint Mary drainage. That area has not been sampled since comparably large expanses of alpine vegetation as those in the southern area were not expected to occur.

Syntaxonomic relationships: The Oxytropis-Bupleurum association is the lowest association within the elevational range covered by the Besseyo-Arenarion. Even though the floristic ties to lower elevation communities have been stressed several times and are a most important character of this community, this is a true fellfield unit with an overall floristic composition much closer to alpine plant communities than to any lower elevation grassland community which is why it has been placed in the present alliance.

Four subunits have been separated within this association, being characterized floristically by the presence of few but very constant and physiognomically very obvious species. The subunits are presented here in order of increasing similarity with the lower elevation units.

\section{SUBASSOCIATION: Oxytropido campestris-Bupleuretum americani typicum subass. nov.}

Nomenclatural Type: Table 7 relevé 5

Plots: $5,7,14,31,32,33,109,116,128,134 \quad(n=10)$

Differential species: none (see above)

\section{VARIANT: Oxytropido campestris-Bupleuretum americani variant of Dryas octopetala Nomenclatural Type: Table 7 relevé 8}

Plots: $3,8,9,10,28,29,30,108,115,469 \quad(n=10)$

\section{Differential species: Dryas octopetala}

Many of the most perfectly striped Dryas stands in the eastern part of the park belong to this community such as those found at Calf Robe Mtn./Firebrand Pass, the Scenic Point Plateau, Spot Mtn. and Otokomi Mtn.

Floristical differentiation: This variant is differentiated against the typicum variant solely by the dominant presence of Dryas octopetala, and some species of the Bupleurum group being less constant, namely Cerastium arvense, Achillea millefolium, Arabis nuttallii, Silene parryi, Galium boreale, Pulsatilla patens. The combination of Dryas and Bupleurum americanum is hardly ever found in any other community. Very conspicuous in this community is the flowering aspect of Oxytropis campestris.

Syntaxonomic relationships: The community is physiognomically as well as ecologically very close to the other xeric Dryas communities. Its floristics reflect its slightly lower elevation distribution with increasing prairie vegetation affinities (increasing Bupleurum species group). 
Sample-number 469, which is somewhat intermediate to the Dryas variant of the MyosotidoCaricetum albonigrae has been included here even though it has four species of the Carex albonigra group.

VARIANT: Festuca idahoensis variant

Nomenclatural Type: Table 7 relevé 106

Plots: $21,106,107,114,135,280,282,285,639 \quad(n=9)$

Differential species: Festuca idahoensis (covering > 10\%, Selaginella wallacei and Festuca scabrella \pm absent; Carex rupestris co-dominant)

General aspect: Among the open alpine fellfield communities, this one is the grass-rich Idaho Fescue variant. With its dense tufts which grow taller than most of the other species, the Fescue considerably changes the aspect of this otherwise hard to differentiate community, almost giving it the appearance of an open shortgrass-prairie. Thus stands of this unit can be singled out easily in the field among the lower-growing fellfield communities.

Topography: This community is growing on high alpine uplands mostly on upper or middle slopes or on open rolling fellfield meadows. The relief is smooth and often slightly depressed or sheltered from extreme winds by a leeward exposure. Sites are mostly restricted to stable situations with no slope movement. Frost action has only rarely been observed. Elevations are from 1870 to $2370 \mathrm{~m}$ a.s.l. Most sites are south to east exposed with none of them facing in northly directions and only one towards the west. This indicates a preference for warmer environments within the alpine, correlating with the occurrence of many prairie species. Slopes are usually between $10^{\circ}$ and $25^{\circ}$.

Geology: Mostly on green argillite with smaller fractions of red argillite, arenite and quartzite. Rock cover is usually far less than $30 \%$.

Soils: Soils undergo considerably more development than in most other fellfield communities. The structure of Festuca idahoensis itself might aid in trapping fine soil and impeding extreme erosion of fine soil fractions. Also the biomass productivity in this community increases the amount of litter which is considerably higher than in most other alpine communities building the base for an unusually well developed humus layer.

Wind exposure/Snow cover: Wind exposure is high but not extreme. Snow cover is higher than in the more exposed ridgetop regions.

Moisture conditions: Moisture conditions in this community are mesic and much better than in the adjacent, more open and rockier fellfield communities. Dry conditions might not occur until late summer.

Floristical differentiation: No other species than Festuca idahoensis was found to floristically separate this variant. The structural change created by this species, correlated with a marked ecological difference, justifies the differentiation of a variant or even a subassociation.

Vegetation pattern and cover: Obviously, all stands of this community are very homogenous in their vegetation pattern evenly covering the smooth relief. Slope stability allows for a higher vascular plant cover (up to $90 \%$ !) than in the other variants. This is at the expense of the moss and lichen cover which tends to be the lowest in this variant.

Distribution: see typicum 
Syntaxonomic relationships: As mentioned under the typicum variant, close relations exist to prairie communities which is especially true for this variant. A number of Festuca idahoensis communities have been reported from lower elevation areas but the overlap is mostly restricted to certain widespread and ecologically adaptable species.

Literature: High elevation communities with Festuca idahoensis have been reported from other, mainly more southern alpine areas in and adjacent to the Rocky Mountains. Looman (1969) described a Festucetum idahoensis from Canada which certainly is a lower elevation community and resembles a "native grassland type" mentioned by Kuchar (1973) from Waterton Lakes National Park adjacent to the area of the present study. Kuchar also reports a species-rich "strange assemblage" as "intermediate meadow" which he suspects might not be a community but part of a broad transitional zone between the prairies and the alpine. This applies in a similar way to the community discussed here which might in some respects be close to Kuchar's. Nevertheless the present community proved to be floristically fairly stable at least for the sampling area and its species are not nearly as ecologically mixed as the ones which are listed by Kuchar.

Caicco (1983) reports relatively lush Festuca idahoensis dominated grasslands among his alpine grasslands on steep slopes of the lower alpine belt in south-central Idaho. Similar is Moseley's Festuca idahoensis grassland (1985). Another similar type was described by Cooper \& Lesica 1997 as Festuca idahoensis-Potentilla diversifolia community type from southwestern Montana as a fairly productive low alpine community. Its floristical composition is though somewhat different from the present studies type.

Kuramoto \& Bliss 1970 describe a Festuca idahoensis mesic grass type and a Festuca idahoensisEriophyllum lanatum grass type, both of which are physiognomically similar but floristically not much related to the community treated here.

\section{VARIANT: Selaginella wallacei variant \\ Nomenclatural Type: Table 7 relevé 493 \\ $\underline{\text { Plots: }} \quad 16,17,18,19,20,22,23,79,80,99,102,103,223,262,263,460,487,493 \quad(\mathrm{n}=18)$ \\ Character species: (local): Selaginella wallacei \\ Differential species: Festuca scabrella}

General aspect: Even more so than other fellfield communities this one has a low-growing, sparse vegetation cover with considerable rock cover. The latter is largely camouflaged by a dense cover of mostly dark colored epilithic lichens which cover almost all of the rocky or gravelly surface. Very conspicuous are the worm-like shoots of Selaginella wallacei which cover considerable portions of this open fellfield community and contribute greatly to stabilize the gravelly soil surface forming a closely appressed network of tough shoots. Even though the appearance of this subassociation is quite unique, its floristic composition is very closely related to the other subunits of this association.

Topography: All sites were found on stabilized and weathered colluvial talus slopes. Occasional debris rolls in to these stands on slopes ranging from $10^{\circ}$ to $30^{\circ}$ in steepness. Slope position is on middle and lower slopes in the low alpine. Among the fellfield communities this is the low elevation variant (see below) occurring from 1750 to about $1900 \mathrm{~m}$ a.s.l. Aspects are mostly NW to SE, which might not be representative since most samples have been gathered in one valley. The directional orientation is important though for the wind effects mentioned below. 
Geology: Found always on green argillite mostly with small amounts of red argillite, arenites, sandstones or quartzite.

Soils: Soils are very rocky and hardly developed.

Wind exposure/Snow cover: The Appistoki Valley seems to be a wind channeling area where the treeline and the whole elevational zonation is obviously depressed by locally high wind speeds. Snow cover therefore is likely to be low which is evidenced by a high cover of a species-rich lichen flora.

Moisture conditions: Dry to mesic conditions dominate in this community. The colluvial sites are well drained but might receive some moisture from the slopes above. Still the xeric element prevails especially in late summer and fall.

Floristic differentiation: As opposed to the typicum subassociation and the Festuca idahonesis variant, this variant is differentiated by the occurrence of Selaginella wallacei and to a lesser extend Festuca scabrella. Selaginella wallacei is a weak character species only, occurring in other communities mostly at lower elevations. Therefore it might better be called a local or elevational character species.

The floristic differentiation of this unit is not strong enough to make it a subassociation. All species of the Bupleurum americanum group are highly constant in this unit with Antennaria umbrinella and Senecio canus often being very numerous.

Even though, this variant is very conspicuous and constant in its composition, similar communities have not yet been described in the literature. Only Selaginella scopulorum and Selaginella standleyi, both mostly called S.densa (s.1.) are reported as constant species from alpine areas. None of these ever becomes as dominant as does S. wallacei. This dominant occurrence of Selaginella wallacei in an alpine community seems to be a regional or even local feature. In much of the Pacific Northwest $S$. wallace i is a widespread species on montane to subalpine boulder slopes and bedrock meadows (T.Spribille, pers. communication). It is also common in the prairies immediately eastward of the study area. Several communities of those habitats will have to be described in the future and will possibly lead to reconsideration of the syntaxonomical relation to the present unit.

Vegetation pattern and cover: Most sites are on fairly stable slopes which are covered evenly with this vegetation type. Only rarely are stripes of shifting scree crossing these sites in vertical, unvegetated runs. This community can cover larger slope areas or can occur in a patchy mosaic with the Arctostaphylos uva-ursi-Juniperus communis community. Well developed patterns of the latter kind are found in the Appistoki Valley in the southern part of the park as well as in the hanging Apikuni Valley near Many Glacier in the eastern central part of Glacier Park.

Lichens growing on rock and on litter, mainly on the abundant dead remnants of Selaginella wallacei are very well developed in this community. Most constant are typical alpine species like Thamnolia subuliformis/vermicularis, Umbilicaria krascheninnikovii, Umbilicaria hyperborea, Physconia muscigena, Coelocaulon muricatum, Cetraria ericetorum and others.

Mosses can be sparse or covering up to $20 \%$ of the plots. Important species are Hypnum revolutum, Abietinella abietina, Polytrichum juniperinum, Polytrichum piliferum, Dicranum spadiceum and Tortula ruralis, most of which are commonly found in alpine fellfield communities of the study area and beyond.

Distribution: By far most of the samples of this conspicuous community have been sampled in the Appistoki Valley in the southeastern portion of the park which in part is due to its easy accessibility. Nevertheless, it was also found further north on the SW-side of Goat Mtn. and in the hanging Apikuni-Valley. 
Syntaxonomic relationships: see typicum

\title{
COMMUNITY: Arenaria obtusiloba community
}

Plots: $173,174,273,304,314,315,359,467 \quad(n=8)$

\section{Character species and Differential species: none}

A number of samples have been lumped into this preliminary unit, which did not have sufficient species of any differential species group to assign them to one of the other communities unless less strict floristic criteria are used for the delineation of the units. The Carex albonigra- and Carex rupestris groups are only weakly represented whereas some species of the Bupleurum americanum group occur quite frequently. The unit does not have its own differential species group and is fairly heterogeneous. It is an assemblage of impoverished stands like they often occur under extreme conditions. Therefore this unit is a basal community of the alliance.

This entity is closest to the Agropyron latiglume-Polemonium viscosum community and the high elevation fellfield community both of which it clusters with in presence/absence and abundance-based numerical analysis. Applying the first method also reveals some floristic similarity with the Smelowskia calycina-Dryas octopetala basal community.

\section{COMMUNITY: Smelowskia calycina-Dryas octopetala community - Smelowskia-Mountain Avens fellfield community}

\author{
Nomenclatural Type: Table 6 relevé 175 \\ Plots: $91,175,186,187,363,364,726,753,801 \quad(n=9)$
}

Diagnostic species: Dryas octopetala, Smelowskia calycina, Potentilla diversifolia, Solidago multiradiata, Oxytropis campestris, Arenaria obtusiloba, Festuca brachyphylla, Selaginella standleyi, Carex nardina

General aspect: Typical for this unit are scattered or more often dense Dryas mats with a relatively low number of vascular plant species being scattered in the dense mats of Dryas. The Dryas-matted areas with their underlaying humus profile differ strongly from the almost unvegetated open scree, boulder or bedrock. Sometimes the rocky areas appear to be places where the vegetation carpet has been torn open by erosional forces and sliding of the vegetation layer on unstable slope surfaces. This unit is fairly species-poor and the floristically least well-defined fellfield type.

Topography: The community always occurs on middle or upper rocky slopes to near ridgetops in the alpine. Stability on those slopes is usually low due to the steepness and loose rocks of different sizes comprising the surface. Elevation ranges from 2200 to $2400 \mathrm{~m}$ a.s.l.. Exposure was mostly found to be NW or SE.

Geology: The community is mostly found on limestone which makes up for much of the alpine in the area, but occurs also on sandstones with small amounts of argillite or on pure argillite. A preference

\footnotetext{
${ }^{5}$ see remarks under "Syntaxonomy" in the Smelowskia-Dryas community
} 
of Dryas octopetala for limestone can nonetheless not be inferred from the distribution of Dryas in the study area as it has been noted for other areas (see Komárková 1979: e.g. Beder 1967, Bamberg \& Major 1968, Braun-Blanquet \& Jenny 1926, McVean \& Ratcliffe 1962 and many others). This is due to the fact that true siliceous rocks are scarce and the widespread argillites are intermediate in their base content and $\mathrm{pH}$.

Soils: The Dryas mats form a tough layer of vegetation which creates its own layer of raw humus. The vegetation layer often appears like a raised, thick carpet that covers the surface of the open rocky areas in a more or less closed, patchy pattern. The development of this raised surface level is caused by the upward growth of the humus layer as well as by downward erosion on the interspersed (fine-) rocky areas.

Wind exposure/Snow cover: Wind exposure is moderate to high and subsequently winter snow cover can differ from little to medium, the latter case being evidenced by the presence of considerable amounts of mosses in some cases which often coincides with lesser amounts of lichens on exposed rocks.

Moisture conditions: The thick humus layer is capable of storing moisture to provide a mesic environment through mid- or late summer. Melt water from above might also aid the moisture supply until about late July. Nevertheless the sites are well drained, drying out by mid- or late summer.

Floristical differentiation: This community is a species-poor variant of the Myosotis-Carex albonigra fellfield. It is differentiated against other related alpine communities mainly by a relatively low number of species. None of the more of less diagnostic species groups which have been identified in the area for alpine fellfield communities occurs in this unit with sufficient constancy.

Conspicuously scarce are also the otherwise widespread species Potentilla fruticosa, Sedum lanceolatum, Besseya wyomingensis, Selaginella scopulorum and Calamagrostis purpurascens. Apparently the same species are also lacking in the poor variant of the Salici-Dryadetum, the only other unit that also occurs mainly on limestone. It might be interesting to investigate to what extend the parent material is responsible for this floristical difference. Species of the Silene acaulis group are present with medium constancy and the species of the Carex albonigra- and Bupleurum americanum groups are often missing. Carex nardina, a species which does not quite follow the distribution pattern of any other species, is more constant than in any other community, except perhaps the species of the high elevation Carex albonigra group. Saxifraga bronchialis, which is believed to be an indicator for unstable surface conditions, is also highly constant. However, it does occur fairly widely in the samples of this study and is not well- correlated with any of the species groups.

Vegetation pattern and cover: Within the dense vegetation carpet of Mountain Avens a high degree of homogeneity is found. These carpets can be very uniform over larger areas or, depending on the degree of slope and exposure to erosive forces, scattered and torn into patches of various sizes. Cracks in the vegetation layer often show the beginning of the distortion of the mats which seem to slide slowly downslope. These cracks give a visual impression of the mechanical stress the sites are exposed to on these unstable slopes. Litter cover easily exceeds $>50 \%$ consisting mainly of the leaves and shoots of Dryas. On sites with stronger erosion, plant cover can be greatly reduced. This reduction is because of the increase in open rock area, whereas the vegetation density in the vegetated patches remains mostly unaltered. Moss cover ranges from 3 to $8 \%$, depending on slope stability and moisture availability with an extreme on a stable site with $20 \%$ moss cover. Lichen cover is lower than in other fellfield communities which points to a longer period of snow cover.

Distribution: This is the widest ranging Dryas community in the area and it has been found on the east and lesser so even on the west side of the Continental Divide. 
Syntaxonomic relationships: This unit is a fragmentary representation of similar, better developed units. This community can be regarded as an impoverished and Dryas dominated variant of the other units of the alliance. As can be seen in table 6, members of the other diagnostic species groups are lacking to a degree that an assignment to those units becomes impossible. The dominance and high competitive power of Dryas is likely to be the reason for the decrease of other species which is also reflected in an overall smaller number of species per plot. The community can also be regarded as a species-poor variety of the Dryas variant of the Myosotido alpestris-Caricetum albonigrae.

In absence of character species or any well represented differential species group, this community fits the definition of a "basal community" (German: "Basalgesellschaft") of this group. It has been separated from the second fragmentary community of Arenaria obtusiloba, based not only on the dominance of Dryas octopetala, but also since a very consistent pattern of other species is missing. Thus two different, species-poor communities have been characterized in this alliance. Both units can be aligned with the definition of a "basal community" of the alliance as well as with a "fragmentary community" (Dierschke 1994). For the time being, they have been treated as basal communities even though the existence of more than one basal community within one alliance is doubted by some authors (Bergmeier et al. 1990, Peppler 1992).

\subsubsection{ALLIANCE: Antennario umbrinellae-Festucion idahoensis all. nov. - Umber Pussy-toes - Idaho Fescue high elevation prairie community}

Nomenclatural Type: Arenario capillaris-Festucetum idahoensis ass. nov.

Plots: see association

\section{Characteristic species group: Arenaria capillaris, Arnica rydbergii, Eriogonum flavum, Cetraria islandica}

In a floristic community gradient from the alpine to the prairie, these communities occupy the low alpine position, sharing a (decreasing) number of alpine species and being dominated by the important Bupleurum americanum species group. The ecological role of this community is that of a later melting meadow in depressions and on leeward slopes of alpine fellfield areas. Snow duration and consequently the moisture supply are higher than in the adjacent Arenario-Festucetalia communities. Notwithstanding, these communities are differentiated from true snowbed communities by their physiognomy, species-richness and productivity.

The syntaxonomical ties with the higher elevation communities are obvious and have been delineated as outlined below. An open question remains as to the relationship to the true prairie communities. Since this study is addressing alpine and high subalpine communities, thus the lower elevation units are beyond the scope of this work. Since I am not familiar enough with prairie vegetation, the syntaxonomic solutions presented here, concerning the delineation against prairie communities, might need to be re-evaluated when a better knowledge on the lower elevation communities is gained.

General aspect: The aspect of these communities is that of open high elevation Fescue grasslands with slightly changing aspects in the subunits. The two quite dissimilar looking Festuca facies are mainly characterized by the increasing cover of their name-giving species. Nevertheless there are a number of other differences which justify the separation of these units.

Floristical differentiation: The presence of the Arenaria capillaris-Arnica rydbergii-Eriogonum flavum species group is a very striking feature in these parts of the alpine fellfield. Arnica rydbergii and Eriogonum flavum both are very conspicuous yellow/orange flowering species which create an outstanding aspect in their otherwise relatively color-poor environment. The three species are 
occurring together with a high degree of faithfullness and indicate very special site conditions. An important compositional feature of this unit is the decreasing presence of the alpine Silene acaulis, Carex albonigra- and Carex rupestris species groups. On the contrary, the Bupleurum americanum species group is highly constant. The line of delineation between the gradually decreasing Silene acaulis communities and this unit was drawn at the beginning occurrence of species of the Arenaria capillaris-Eriogonum flavum species group. Another characteristic used is the marked increase of the name-giving Antennaria umbrinella. In cases of doubt the numerical ordination was used to decide whether a plot is closer to the higher elevation Silene acaulis units or belonging into this group.

Apart from the elevational differentiation, the Arenaria capillaris group also characterizes sites of extended but not extreme snow cover. Even more extreme snow conditions are resulting in the presence of the Sibbaldio-Juncetum parryi and the Polytricho-Arenarietum capillaris. The latter is very close to the units treated here, as can be seen when comparing the diagnostic species groups of both units.

Stands from different subunits of this syntaxon have been found to contain species of the Hedysarum sulphurescens-Zigadenus elegans-Carex scirpoidea-Dodecatheon pulchellum species group which is believed to be a moisture indicating group. More samples would be needed to elucidate the microtopographic-edaphical differentiation suggested by these species' occurrences.

Syntaxonomy: The syntaxonomical position of this new alliance in the order Arenario-Festucetalia brachyphyllae is at this point the most useful solution. The only fact that slightly weakens this assignment is the decreasing presence of order diagnostic species. It is based on the ecological and spatial relationship with that order as well as the physiognomical similarity. Of the order species only Luzula spicata, Sedum lanceolatum and Selaginella scopulorum occur with high constancy. Other important order diagnostic species like Silene acaulis, Arenaria obtusiloba, Polygonum bistortoides, Carex rupestris, Lupinus lepidus and Trisetum spicatum are of moderate to low constancy and Festuca brachyphylla is completely missing. The lack of these is the main reason for treating this unit as a separate alliance rather than keeping this unit together with its closest neighbor, the OxytropidoBupleuretum.

The variants of Festuca idahoensis and F. scabrella are especially poor in diagnostic species of the order. They also are physiognomically somewhat different from the cushion plant communities, a structural detail that adds to the differentiation against the Silene acaulis-fellfield communities. Therefore, the alliance is accommodated in this order with some hesitation. However, until a better understanding of these high elevation units is gained, they might well be kept in this order.

Literature: Looman (1969), in his grassland classification described a Festucetum idahoensis with a subassociation erigonetosum flavi which has a few species in common with the present unit. He also described a Festucetum scabrellae with a subassociation erigonetosum flavi, containing a number of alpine species. Eriogonum flavum thus seems to be a constant species in Fescue grasslands elsewhere. Whereas the species was found to be somewhat chionophilic in the study area, this might not be the case in the prairie areas studied by Looman. Kuchar (1973) mentions an "intermediate meadow" from Sofa Mtn. in the northward adjacent Waterton NP. This fairly heterogeneous assemblage contains a number of species present in this unit and might at least be similar to this alliance. Kuchar described it as intermediate between alpine and prairie communities, a description which also fits the present unit. 


\title{
1.1.5.1. ASSOCIATION: Arenario capillaris-Festucetum idahoensis ass. nov. - Thread-leaved Sandwort - Idaho Fescue late melting high elevation meadow
}

\author{
Nomenclatural Type: Table 8 relevé 26 \\ Plots: $24,25,26,34,81,86,105,129,130,150,160,220,250,255,256,260,283,288,293,306,464,488$, \\ $489,500,641,642 \quad(n=26)$
}

Characteristic species group: Arenaria capillaris, Arnica rydbergii, Eriogonum flavum, Cetraria islandica

General aspect: The aspect of this high elevation grass-rich community is dominated in summer by the yellow and orange flowers of Eriogonum flavum and Arnica rydbergii. The pale flowering Pedicularis contorta as well as Silene parryi can be very abundant too. Much of the ground is often covered by the loose mats of Arenaria capillaris and dotted with its numerous bright-white little starlike flowers. This species, as well as Eriogonum flavum, seems to be good indicators for sites with considerably long snow duration. In some cases snow catching depressions have been found to be nearly completely covered with Arenaria capillaris. This is mainly the case in the Festuca idahoensis facies.

Topography: The unit is found on smooth mid- to low alpine frost rubble plateaus and slopes or on consolidated talus. Only once was a floristically very similar community found on a very unstable talus slope. Elevation ranges from 1700 to $2100 \mathrm{~m}$ with a slight preference for east facing aspects. Slope angle can be everything from level to $20^{\circ}$ and even up to $30^{\circ}$.

Wind exposure/Snow cover: Wind exposure is high and snow cover moderate or in some cases reasonable to long. Despite the openness of the habitat, the particular topography of these sites in depressions or on the leeward side of wind-barriers (convex relief-forms, krummholz-patches, bedrock terraces, leeward slopes) results in a snow catchment situation.

Moisture conditions: Seasonally changing water supply is characteristic for this unit with good moisture conditions through mid-summer and xeric conditions in fall.

Floristical differentiation: (see mainly under the alliance and the subunit)

Vegetation pattern and cover: The vegetation in this community is mostly very homogeneous and evenly spread. Only under rare unstable slope conditions patchy patterns occur. Cracks in the vegetation layer point to some downslope movement on steeper slopes. Lichens and bryophytes are as important as they are in other units of the order.

Syntaxonomical relationships: This community is close the Oxytropis campestris-Bupleurum americanum association particularly its variant of Selaginella wallacei, taken from its low growing fellfield aspect as well as from its floristic composition this community. In fact, it often occurs adjacent to the latter, and transitional stands are frequent. It might even have been placed into that association as a late melting subunit with a different topography. Nevertheless are the main diagnostic groups of that association only inconsistently represented. The constancy of the Silene acaulis group species and the Carex rupestris group species is low and the differential Arenaria capillaris group occur constantly. Therefore it seems appropriate to place it into the Arenario capillaris-Festucetum idahoensis syntaxon. This is so far the only association in this alliance. The association has been subdivided into the typicum, one variant and three facies, none of which is distinct enough to deserve. 
Distribution: This unit was sampled mostly in the southeastern corner of the park in Appistoki Valley, on the adjacent Scenic Point Plateau and on Spot Mtn. Few other plots are from the Many Glacier area in the eastern central part of Glacier NP as well as from Red Gap Pass north of Many Glacier.

\section{TYPICUM: Arenario capillaris-Festucetum idahoensis typicum}

- Thread-leaved Sandwort - Idaho Fescue late melting meadow

Nomenclatural Type: Table 8 relevé 26

Plots: $25,26,220 \quad(n=3)$

Character species: see association

Differential species: none

Three sites have been assigned to this variant only. These sites lack the characteristic dominance patterns which the other facies have been separated for. As usual, no differential species group for the typicum-unit can be defined. Delineation is simply by the presence of the association species group as given above. It is a basal community of the association.

\section{FACIES of Festuca idahoensis}

Nomenclatural Type: Table 8 relevé 306

Plots: $24,81,105,160,283,288,306,500,641,642 \quad(n=10)$

Differentiating species: Festuca idahoensis (>10\% cover), Arenaria capillaris (>10\% cover), (Astragalus bourgovii)

General aspect: The dominance of Idaho Fescue is so prominent in this unit that it is separately treated as a facies. It is a grass dominated fellfield community, often with a conspicuous amount of shrubby cinquefoil (Potentilla fruticosa) and a summer flower aspect of Pedicularis contorta and/or Silene parryi.

Topography: This facies is found on colluvial slopes or rarely on ridgetops in the mid- to lower alpine. Slope stability is varies from very gentle, stable slopes to steep slopes with plenty of running scree. Cracks in the vegetation layer often evidence slope movement even on slopes of little steepness and a compacted surface. Slightly terraced relief surfaces can occur within the plots which are a sign of frost- and gravity-induced soil movement. Given the ample moisture supply from the melting snow in early summer, soils are likely to be saturated at that point with gelifluction being involved the surface-structuring processes. Elevation ranges from 1870 to $2400 \mathrm{~m}$ a.s.l. Exposure is usually E (NE) to SSW.

Geology/Parent material: Parent materials are green argillite, red argillite, often with small amounts of arenites and/or quarzitic rocks. Frost rubble is much more common than unconsolidated colluvial talus.

Wind exposure/Snow cover: Wind exposure is usually high, snow cover moderate to reasonable. This is evidenced by the partly dense vegetation cover, some mesophytic plant species and a mostly low lichen cover. Snow duration is most likely the predominant ecological factor for this mesic plant community. 
Moisture conditions: Continuous or changing strongly through the season, always good through late summer, usually drying later on. The constant occurrence of some bryophytes, most abundantly Tortula ruralis, is a good indicator for fairly continuous moisture supply in this community.

Floristical differentiation: Characteristic for this facies is the dominance of Festuca idahoensis and in most cases also Arenaria capillaris. Some species of the Bupleurum group are apparently missing, like Bupleurum americanum, Senecio canus, and little less so Cerastium arvense, Anemone patens, Eriogonum ovalifolium, Arabis nuttallii and Festuca scabrella. As a differantiating species Astragalus bourgovii is fairly constant. Slightly more constant is Carex phaeocephala. The lack of a number of lichens in this facies is a differentiating character against all other subunits in this association. Since no ecological factor was found to cause this differentiation, this unit was not treated as a variant but rather on the low level of the facies. The lack of lichens and the conspicuous absence of other common species of the association suggest, that extended snow cover might be the differentiating factor, but no ecological measurements have been made to substantiate this assumption.

Syntaxonomical relationships: This Festuca idahoensis facies is clearly different from the Festuca idahoensis-Carex rupestris variant of the Oxytropis-Bupleurum community by the characters of the higher syntaxa they belong to. Somewhat closer ties exist to the Festuca scabrella facies and the Potentilla fruticosa-talus slope communities.

\section{FACIES of Festuca scabrella - Rough Fescue high elevation community}

Nomenclatural Type: Table 8 relevé 260

Plots: $86,130,255,256,260,293,489 \quad(n=7)$

\section{Differentiating species: Festuca scabrella (covering >30\%)}

General aspect: The Rough Fescue itself gives this community its typical appearance of a prairie-like bunchgrass grassland overlaid on a relief-rich high elevation landscape. Sometimes Potentilla fruticosa assumes a co-dominant role. Both these species differentiate the aspect of this facies. The steppe-like appearance can in rare cases be modified by interspersed rock outcrops or steep, unstable slope situations where scree runs cut vertically through the vegetation layer.

Topography: Occurring on overgrown, steep colluvial talus slopes. The steepness is between 15 and $30^{\circ}$ with some slope creep being likely to occur. Large stripes of vegetation are occasionally found on fairly active talus slopes, especially when occurring on upper slopes below cliffs. Elevations range from 1690 to $2200 \mathrm{~m}$ a.s.l. Aspects have been found to be NE to E or S to W.

Geology: The rough Fescue meadow grows on colluvial slopes of green argillite with little red argillite or v.v. and small amounts of arenites of quartzitic rocks.

Soils: Considerable amounts of organic matter point to a slighlty advanced soil development in this unstable environment. Nevertheless is a differentiation of soil horizons not yet visible.

Wind exposure/Snow cover: Wind exposure is usually high with a moderate snow cover slightly lesser than in the Festuca idahoensis facies.

Moisture conditions: The moderate amounts of snow provide sufficient moisture for a mesic situation through mid-summer. On the well drained sites dry conditions are likely to occur later in the season. 
Floristical differentiation: The dominance of Festuca scabrella is the main character of this unit. Potentilla fruticosa can be very important too. Otherwise the composition is mostly similar to the other units of the high elevation Idaho Fescue association. Bryophyte cover is low between $1 \%$ and $5 \%$. Lichens are usually low in cover too, but occasionally Cetraria islandica or some other fruticose species can increase considerably.

Syntaxonomy: Like the Idaho Fescue unit this one has been treated as a facies. Despite a likely small difference in winter snow cover, no obvious ecological differences have been observed nor is there a sufficient floristic difference to treat this unit as a variant or even a subassociation.

Distribution: As a high elevationRough Fescue community with strong floristic relations to lower elevation grasslands, it is distributed in the eastern parts of the study area not far from the adjacent prairies.

\section{VARIANT: Carex scirpoidea variant}

Nomenclatural Type: Table 8 relevé 129

Plots: $34,131,129,150 \quad(\mathrm{n}=4)$

Differential species (= Carex scirpoidea group): Carex scirpoidea, Hedysarum sulphurescens,

Dodecatheon pulchellum, Erigeron simplex, Zigadenus elegans, Polygonum bistortoides, Pohlia sp.

The moisture indicating Carex scirpoidea group, which has also been observed in other units (Zigadeno-Caricetum scirpoidea, Salici-Dryadion) reoccurs in this association. The aspect of this unit does not differ much from the other variants of the association. The differential species of this variant are not easily detected in the field. Because of their low cover values the aspect of this variant does not differ noticeably from that of the association. Nevertheless is their constant presence believed to be a reliable indicator of moister conditions. Already during the field sampling this variant has always been described as a moister variant even though the diagnostic species group was not defined at that time.

\section{Festuca scabrella-Agropyron spicatum community}

Plots: $462,463,475,477,482 \quad(\mathrm{n}=5)$

Differential species: Festuca scabrella covering >30\%, Agropyron spicatum, Sedum stenopetalum, Amelanchier alnifolia, (Aster foliaceus, Calochortus apiculatus, Antennaria microphylla, Penstemon confertus)

Five plots dominated byRough Fescue have been preliminarily lumped into this unranked unit. All of them lack the Arenaria capillaris-Eriogonum flavum group which is why they do not fit into that association of late melting meadows which floristically they are somewhat close to. The presence of species such as Agropyron spicatum, Sedum stenopetalum, Amelanchier alnifolia, Aster foliaceus, Fragaria virginiana, Antennaria microphylla, Calochortus apiculatus, Penstemon confertus are characteristic for this subunit. It is obvious that the first two samples are even closer to the Festuca scabrella variant of the Arenaria capillaris-Eriogonum flavum group, in particular to the slightly moister variant of Carex scirpoidea, Hedysarum sulphurescens, Dodecatheon pulchellum and Zigadenus elegans. The other three samples are most likely identical to other some widespread lower 
elevation Rough Fescue prairie community and should be regarded as the more typical part of this unit.

A more detailed description of this community is not given here since it is believed to be more closely related to low elevation prairie communities than to the alpine vegetation despite the fact that the five plots have been sampled at elevations between 1690 and 1830 m.a.s.1.

Accounts of Festuca scabrella communities have been given by a number of authors (Moss \& Campbell 1947, Coupland 1961, Looman 1963, 1969, Stringer 1969, 1973, Kuchar 1973).

\section{Dryas octopetala - Salix nivalis - Kobresia myosuroides Communities:}

A particular problem in the syntaxonomic treatment of the Rocky Mountain alpine vegetation is the classification of the Dryas octopetala- and the closely related Kobresia myosuroides-communities. The following paragraphs will discuss this problem before the description of this new alliance.

Many authors have described western North American alpine vegetation types as Dryas- (= Mountain Avens-) or Kobresia-types or a combination thereof without relating those units to a larger system.

A preliminary synoptic table has been compiled with all available Dryas- and Kobresia-vegetation units published in literature. The first result from this table is the conclusion that the placement of all Dryas octopetala- and Kobresia-communities in the new order Arenario-Festucetalia brachyphyllae is justified, evidenced by the constant presence of species like Silene acaulis, Arenaria obtusiloba, Festuca brachyphylla, Selaginella densa s.1., Trisetum spicatum and Luzula spicata throughout those units.

Next observation is that the most constant species in all Dryas-units, apart from Dryas octopetala, are Polygonum viviparum and Silene acaulis, occurring in more than $90 \%$ of the compared units.

Thirdly, there is a clear-cut differentiation of the southern Rocky Mountain Dryas- and Kobresia-units that follows the floristic definition of the southern suborder Geo-Silenenalia acaulis (p 40]. Because of this strong floristic differentiation of the southern Dryas units they have been kept separate from the northern ones as a consequence of the establishment of those suborders. This was another reason to keep the present unit as an alliance in the northern suborder, whereas a southern counterpart should later on be created in the southern order Geo-Silenenalia acaulis. It has to be acknowledged though that, e.g., the constant presence of Polygonum viviparum with Dryas octopetala, as well as the constant species combination Kobresia myosuroides - Polygonum viviparum - Campanula uniflora, conspicuously bridge this north-south differentiation. If the latitudinal differentiation were not accepted, a pan-Rocky Mountain syntaxon for the Dryas- and Kobresia-communities could indeed be proposed. In this study the not very abundant southern Dryas- and Kobresia-communities are not treated as a syntaxonomic group.

So far the northern counterpart within the Dryas-communities is differentiated by Salix nivalis, Anemone parviflora, Myosotis alpestris, Oxytropis campestris, Solidago multiradiata, Astragalus alpinus, Saxifraga oppositifolia, Poa arctica and Antennaria alpina. The first two of those are preferential to northern Mountain Avens communities and the next four of the listed species have been identified as differential species for the northern suborder Myosotido-Silenenalia acaulis. One must bear in mind that the following paragraphs only apply to Dryas-Salix nivalis communities which are by far most of the Dryas-communities described in literature - but not necessarily apply to Dryas-communities without Salix nivalis which have been described by some other authors (Bamberg 
1961, Beder 1967, Douglas \& Bliss 1977, Hrapko et al. 1978) and in this study. Their preliminary placement in this group will have to be reconsidered.

The Dryas octopetala-Salix nivalis alliance appears to be a distinct unit in the order ArenarioFestucetalia physiognomically as well as ecologically. Notwithstanding is the floristic differentiation admittedly not very strong. Besides the pan-Rocky Mountain companion Polygonum viviparum there is only a small species group which apparently correlates with Dryas throughout this suborder. Salix nivalis and Anemone parviflora and Anemone drummondii are preferential companions in the central and northern part of the Dryas communities.

Nevertheless, all authors who have been describing alpine vegetation in the Rocky Mountains separated these communities from the non-Dryas fellfield units, which is basically a physiognomical delineation caused by the strong dominance of Mountain Avens itself.

These physiognomically extraordinary communities present a syntaxonomic problem in a classification system that is largely based on floristic composition. The following situation is responsible for these syntaxonomic difficulties:

- the Rocky Mountain alpine environment \pm continuously spans a wide latitudinal range

- the "floristic environment" changes with changing phytogeographical regions

- some structurally important species (e.g. Dryas, Kobresia) \pm constantly occur all along the Rockies

- As a result, structurally and ecologically similar communities occur with different overall floristical compositions.

Two possible ways to solve this problem in a syntaxonomic classification are:

1. The common ecology and physiognomy of samples and vegetation units is given more emphasis, giving the structurally dominant species a greater weight in the floristic analysis

$\Rightarrow$ Dryas and Kobresia communities can be kept together in (higher) syntaxa that span larger geographical areas.

2. The overall floristic composition (similarity indices!), resulting in part from local or regional floristical differences and communalities (regional diagnostic species groups) is given greater weight

$\Rightarrow$ many different (lower) syntaxa dominated by Dryas or Kobresia have to be created within regionally confined alliances or associations which also contain non-Dryas- or non-Kobresia communities.

Whereas the first alternative produces easier to use units, it does somewhat violate the floristic principle which has been said to be the basis of the classification developed in this study. It less so values the overall floristic composition but emphasizes the occurrence of some dominant species. This alternative creates geographically larger higher syntaxa which can be split on lower syntaxonomic levels into regional or local subunits according to regional floristic differences.

The second alternative better uses all the "floristic information" i.e. the overall floristic composition and produces more or less computable similarity groups, while at the same time creating a hierarchy with a large number of lower syntaxa. Ecological and structural similarities of vegetation units over a larger 
geographical areas become much more difficult to detect and thus the applicability of such a system is likely to be lower.

The Dryas- and Kobresia-vegetation treated here perfectly represents such a situation. Most differences in these vegetation units reported by the various authors are based on different local phytogeography with certain regionally diagnostic species groups present. Overall floristic similarities are often greater towards non-Dryas or non-Kobresia communities than among the Dryas- and Kobresia units. If the floristic principle would be adhered to consistently, then those Dryas- and nonDryas fellfield communities would have to be treated together and the Dryas- and Kobresia communities would have to be syntaxonomically spread over different higher syntaxonomic units where they would occur as scattered variants or subassociations among other non-Dryas and nonKobresia communities.

The first alternative has been preferred for this classification in order to stress the ecological and physiognomical similarities of all Dryas- and Kobresia communities treated. For this purpose the new alliance Salici nivalis-Dryadion octopetalae is created here. This way provides a system which is far easier to use, uniting entities which have generally been recognized by many authors as similar vegetation types. It is acknowledged that this separation of the Dryas- and Kobresia communities amounts to the use of a physiognomic rather than floristic criterion. This is, however, not uncommon to do on higher syntaxonomic levels. Due to the considerable overall floristic similarity of these units it seems justified to extend such practice onto the level of the alliance and suballiance.

In a few local cases, Dryas units which are differentiated only by Dryas itself but otherwise are floristically identical with other non-Dryas communities, have been treated as variants within the nonDryas fellfield units. Three such Dryas variants have been described in the Myositido-Caricetum albonigrae and the Oxytropido campestris-Bupleuretum americani (see above).

\subsubsection{ALLIANCE: Salici nivalis-Dryadion octopetalae all. nov. - Snow Willow-Mountain Avens alliance}

Nomenclatural Type: Salici nivalis-Dryadetum octopetalae ass. nov.

Character species: Dryas octopetala, Salix nivalis, Anemone parviflora, Anemone drummondii

Differential species (against southern Dryas-communities): Myosotis alpestris, Oxytropis campestris, Solidago multiradiata, Astragalus alpinus, Saxifraga oppositifolia, Poa arctica, Antennaria alpina

This alliance unites all of the northern Rocky Mountain Dryas octopetala-Salix nivalis communities north of Wyoming and as far north as Jasper NP. Almost all Dryas communities of this unit have Salix nivalis as a constant and structurally important co-dominant. The species thus characterizes this syntaxon well and serves as a good differential species against the southern Dryas-communities. It was therefore used as the second name-giving taxon for this alliance.

Another diagnostic species of this new alliance, apart from the two dwarf shrubs mentioned above, is possibly Anemone parviflora with a much lower constancy and a somewhat lesser faithfulness. The same might apply for Anemone drummondii, but its faithfulness to the alliance needs to be reevaluated later with better knowledge of similar vegetation units throughout the range of the unit. Polygonum viviparum, which is even more faithful in its occurrence with Dryas octopetala than Salix nivalis, behaves so even in the southern Dryas-communities which have been kept separate for reasons given above. Therefore, it does not characterize this alliance exclusively. 
The main ecological characteristic of the Salici-Dryadion communities is most likely an increased amount of moisture as compared with the southern Dryas-communities. This is probably the reason why this unit is distributed further north in the Rocky Mountains, where the average moisture distribution through the season is more mesic than in the southern Rocky Mountains, where dry summer conditions persist longer. It remains to be elaborated with more detailed ecological investigations which other ecological factors separate these Mountain Avens communities from other fellfield types, especially within the study area. A better moisture supply and/or longer winter snow cover are likely to be important ecological factors.

Only two associations have been created in this alliance. A better knowledge of the Dryas-Salix nivalis communities outside the study area is needed to differentiate any further subunits. The synoptic table (Tab. 1) nevertheless shows two species groups which suggest the subdivision of parts of this alliance: One group is the Kobresia myosuroides group, consisting of Kobresia myosuroides, Gentiana prostrata, Gentiana propinqua, Campanula uniflora and possibly Equisetum scirpoides. Due to the low constancy of the gentians in this group, the definition is to a large degree based on the dominant presence of Kobresia. The abundant presence of the sedge led most authors to differentiate the units as Kobresia communities or more often as Dryas-Kobresia communities. The common occurrence of Kobresia myosuroides and the gentian species mentioned has also been reported by other authors (Gjaerevoll 1954, Cooper 1986) and points to a widespread northern distribution of this group.

The second species group taken from the synopsis is the Carex scirpoidea group, which is defined by Carex scirpoidea, Hedysarum sulphurescens, Sedum roseum, Zigadenus elegans, and possibly Potentilla fruticosa and Polygonum bistortoides. All Salix nivalis - Dryas octopetala communities occurring in Glacier NP belong to this unit. Locally this species group indicates sites with good moisture conditions through much of the season. The characteristic species of the Carex scirpoidea group are present with decreasing constancy only in some Dryas-Kobresia communities reported from Alberta by Corns \& Achuff (1982), Beder (1967) and Trottier (1972). It seems that the Carex scirpoidea group gradually loses its ecological indicator value in the increasingly moister alpine environments further north. Nevertheless the communities mentioned by those authors also represent relatively moist Dryas-Kobresia communities, while the Dryas communities without Carex scirpoidea from Alberta, British-Columbia and the Northern Cascades (Douglas \& Bliss 1977) occur as more xeric Dryas-fellfield units. No moist Kobresia-communities have been reported from the southern Rocky Mountains. Dryas communities with Carex scirpoidea are much more widespread in the far northern Rocky Mountains (Hoefs et al. 1975) and Alaska (Gjaerevoll 1954, Cooper 1986, Viereck et al. 1992).

Three other communities with Carex scirpoidea have been found in Glacier NP, which are floristically and ecologically extremely similar to the local Dryas-Kobresia communities. These are the Aster foliaceus - Carex scirpoidea community, the Cirsium hookerianum - (Crepis runcinata - ) Carex scirpoidea community and the Arnica alpina-Carex scirpoidea community ( $\mathrm{p} .83$. They are similar with respect to the above mentioned moisture indicating species group. Nevertheless, they do lack a number of character species of the higher syntaxon treated here and are physiognomically very much different owing to the lack of Dryas and the dominance of the dense Carex scirpoidea-turf. Thus they have been kept as unranked communities at this point. They might as well be treated as units with few or none of the character species present but still belonging into this alliance. 
It was debated whether the Kobresia myosuroides group and/or the Carex scirpoidea group should be used for the definition of subunits, possibly as suballiances, within this alliance. Because both groups show considerable overlap and because of the lack of knowledge concerning possible ecological differences, such syntaxonomical differentiation was not yet proposed.

\title{
1.1.6.1. ASSOCIATION: Salici nivalis-Dryadetum octopetalae ass. nov. - Snow Willow-Mountain Avens association
}

\author{
Nomenclatural Type: Table 9 relevé 153 \\ Plots: $\quad 27,56,73,74,75,90,92,94,95,153,156,157,159,167,278,322,366,367,368,373,377,441,742$ \\ $(\mathrm{n}=23)$
}

\section{Characteristic species: Dryas octopetala, Salix nivalis \\ Differential species: Carex scirpoidea, Hedysarum sulphurescens, Sedum roseum, Zigadenus elegans, (Potentilla fruticosa, Polygonum bistortoides)}

This association comprises the vernally-moist to mesic high elevation Dryas-communities. Salix nivalis, Polygonum viviparum, Hedysarum sulphurescens and Anemone drummondii delineate this syntaxon on a regional scale. Statistically, three out of those four species need to be present to assign a stand to this syntaxon. A similar definition applies to a different unit within the Carex scirpoideaZigadenus elegans group, i.e. the Kobresia community which in some respects is closely related but treated separately for ecological and compositional reasons (see p.83).

General aspect: These communities have the typical Dryas-aspect of a strongly Mountain Avens dominated vegetation matrix with a scattering of other species mixed in. Most of the aspect-related variability lies in the various vegetation patterns ranging from even vegetation mats to stripes and scattered patches. The remaining area is exposed frost rubble, talus or bedrock and can reach high cover or be nearly absent. The striped patterns on gentle slopes are usually correlated with a step-like, terraced surface relief which has been called "Dryas banked terraces" (Bamberg \& Major 1968). The risers of those regularly patterned terraces are covered almost completely with Dryas whereas the treads in between the risers are level frost rubble areas with almost no vegetation at all. A few species like Sedum roseum and Arenaria nuttallii occur on the treads only and cannot successfully compete within the dense Dryas mats. Depending on the snow situation, lichen cover is usually low on the frost rubble in these areas.

The origin of such striped pattern has been discussed in many studies ( Washburn 1956, McVean \& Ratcliffe 1962, Anderson 1967, Bamberg \& Major 1968, Kuchar 1975 Butler \& Malanson 1989 and others). Even though a complete understanding has not yet been gained it seems safe to assume that a combination of gravity, frost action and wind effect is responsible for generating these conspicuous patterns.

Ecological conditions in the Dryas-covered parts and on the rocky open parts of the stands are very much different, which is why this kind of community might as well be treated as a patterned community complex of two different vegetation units. Since the rocky part does not have a very independent species composition, and for practical reasons, these subunits were not treated separately in this study.

Syntaxonomy: Apart from the dignostic species, this community is ecologically as well as floristically close to the non-Dryas fellfield communities, namely to the Agropyron latiglumePolemonium viscosum community, the Arenaria obtusiloba basal community and the high elevation 
fellfield community. This is reflected in the presence/absence-based cluster analysis which results in a number of Dryas clusters interspersed with non-Dryas clusters. The quantitative analysis (Ruzicka formula) unites nearly all Dryas stands based on the species' dominance. An intermediate solution is most useful for the present classification (see "syntaxonomic problem of the Dryas communities" above, p.72).

Due to the presence of a sufficiently characterized, nearly exclusive diagnostic species group, the local Dryas octopetala-Salix nivalis syntaxon was separated and assigned the rank of an association. For the area of Glacier NP, two weakly differentiated subunits are recognized by the presence or absence of the Carex albonigra group and a difference in species-richness. There is also a differentiation in bedrock, the poor variant being found more often on limestone. A third subunit of Cetraria cucullata and Castilleja occidentalis seems to be of local importance in one drainage only. Similar units from adjacent areas (see literature below) can certainly be accommodated in this association on the subassociation level.

Distribution: Within the study area, the Salici nivalis-Dryadetum octopetalae was found all along the Continental Divide and east of it.

Literature: A large number of publications from all over the Rocky Mountains and the western mountain ranges mention communities with Dryas octopetala, in addition to the literature on the subject from all over the northern temperate hemisphere. Within the Rocky Mountians, there are few if any descriptions of alpine areas which do not describe Mountain Avens vegetation types. A synopsis of eleven Rocky Mountain Dryas fellfield communities from literature was presented by Kuchar (1973).

The description of the Salici-Dryadetum as delineated here focusses on the unit as represented in Glacier NP. Nevertheless the syntaxon is more widespread and units given by Achuff (1997, Waterton NP) and Polster (1977, Akamina, B.C.) from areas just north of the study and samples from Cooper \& Lesica (1997, Beaverhead NF) Bamberg (1968, Big Snowy Mtns.) from south-western and southcentral Montana can be assigned to this association (see synoptic table 2). They might be given the rank of regional subassociations. Apart from the diagnostic species they share a number of alpine fellfield species in common. However, many common alpine species present in Glacier NP in this unit are lacking in those species-poorer variants. Carex scirpoidea is obviously missing in Glacier in this Dryas community but is present in other areas.

Vegetation types named after both Salix nivalis and Dryas octopetala - have been described by other authors (Achuff \& Corns 1982, Achuff \& Dudynsky 1984, Achuff \& Dudynsky 1984a, Achuff et al. 1993, Achuff \& Coleman 1997), Crack (1977), Hrapko \& LaRoi (1978), Kuchar (1975), McLean (1970), Trottier (1972). Most of these can be found in the synosis Tab. 2. 
SUBASSOCIATION: Salici nivalis-Dryadetum octopetalae typicum subass. nov.

Nomenclatural Type: Table 9 relevé 153

Plots: $\quad 27,56,90,153,156,157,159,367,368 \quad(\mathrm{n}=9)$

Character species: see association (+ Astragalus aboriginum)

Differential species: see association, (+ Polygonum bistortoides, Lupinus lepidus, Douglasia montana, Pedicularis contorta)

General aspect: see association

Topography: This subassociation is found mostly on upper slopes, ridgetops, saddles and benches; the surface relief is smooth, often rolling or sometimes terraced; the surface mostly consists of stable frost rubble, with frost heave activity likely to be common; site exposure is mostly southerly to westerly. The typicum subassociation occurs on less steep slopes than the other subassociations. Elevation ranges from $2200 \mathrm{~m}$ to $2400 \mathrm{~m}$ a.s.1..

Geology: The typicum unit is found mostly green argillite, often with smaller fractions of quartzite, arenite or little dioritic igneous rock; only one plot was encountered on limestone; average rock cover is significantly higher than in the poor variant.

Wind exposure/Snow cover: Wind exposure is usually extreme to high, snow cover moderate to low, thus parts of the vegetation are exposed in winter. This variant experiences less snow cover than the following species poorer variant.

Moisture conditions: Usually strongly changing during the season from moist in spring and summer to mesic and even dry in fall.

Floristical differentiation: Within the association the differentiation of this variant is based mainly on the lack of differential species of other subunits and the overall species number being greater than in the species-poor variant ( $\geq 42$ species). Species of the Carex albonigra group or of the Carex rupestris group are relatively high in presence with $\geq 5$ species of the former and $\geq 4$ species of the latter group present. The four differential species listed are differential in the area only and might need to be reconsidered with more data.

Vegetation pattern and cover: Vascular plant and litter cover are slightly lower than in the poor variant; bryophyte cover varies greatly from less than .1\% to $20 \%$; lichen cover on average is higher than in the poor variant which can be attributed to the higher rock cover. The litter-rich Dryas-covered areas usually does not bear large amounts of lichens.

Distribution: Sampled on the eastern rolling alpine uplands, less so towards the Continental Divide.

Syntaxonomic relationships: This unit is closely related to the other two variants of the association. 


\section{VARIANT: Salici nivalis-Dryadetum octopetalae - poor variant}

Nomenclatural Type: Table 10 relevé 322

Plots: $\quad 167,278,322,366,373,377,441,742 \quad(n=8)$

\section{Differential species: Carex rupestris, p.p. Salix arctica}

Constant species: Dryas octopetala, Potentilla diversifolia, Solidago multiradiata, Oxytropis campestris, Arenaria obtusiloba, Smelowskia calycina, Festuca brachyphylla

General aspect: Different compared with the other units in this association is a tendency of the vegetated Dryas mats to slide downslope and sometimes create little warps of shoved-up carpet, which is a common sign for unstable, active slopes.

Topography: This variant occurs on mid- to upper, usually steeper slopes than the typicum variant, but sometimes also on flatter benches. Exposure is mostly westerly, rarely in northerly or easterly directions. Elevations range from $2200 \mathrm{~m}$ to $2400 \mathrm{~m}$ a.s.1.

Geology: Most plots were sampled on limestone, only few on argillite.

Wind exposure/Snow cover: Wind exposure is high to moderate, i.e. slightly less exposed than the typicum variant. Snow cover therefore is moderate to sometimes considerable, the highest of the true fellfield communities and probably the most important ecologically differentiating factor. Among the sites snow cover decreases with increasing patchiness and lesser cover of vegetation.

Moisture conditions: Due to lesser wind desiccation and higher snow cover a slightly better moisture supply is encountered and very obvious in some sites with extreme moss cover.

Floristical differentiation: Like in the latter variant of the Salici-Dryadetum, there is no character species group for this syntaxon. On the contrary, this basic variant is identified by its lack of many species common throughout most of the other dry alpine communities. Largely lacking among the alpine generalists are Luzula spicata, Potentilla fruticosa, Sedum lanceolatum, Besseya wyomingensis, Selaginella scopulorum and Calamagrostis purpurascens. Some of the common Silene acaulis group species are also scarce. Except for Carex rupestris, which is highly present in this group, most other species of the Carex rupestris-Lupinus lepidus group are missing. Likewise are the species of the Bupleurum group.

Three of the sites included here have Salix arctica with a high cover degree and can be separated out as a facies or subvariant. The latter might be considered to be more appropriate since the species does not occur in the other samples and thus is not just a variation of dominance patterns which would call for a facies.

Vegetation pattern and cover: Vegetation pattern is even or patchy, and sometimes perfectly striped patterns occur. Average vegetation cover is higher than in the typicum variant, which might be attributed to the slightly lesser exposure of these sites; moss cover is highly variable with very high extremes to $30 \%$, lichen cover considerably lower than in the typicum unit which might be due to the longer winter snow cover and the higher degree of slope instability.

Syntaxonomy: This unit is related also to the species-poor Smelowskia calycina-Dryas octopetala basal community. As a unit without any differential species and being generally poor in species it might be regarded as a basal community of the association. The constant lack of certain sets of species as mentioned above nevertheless implies some ecological difference. Therefore the variant seems to be the more appropriate unit in this case. 
Distribution: Sampled on the eastern mountain ridges mostly a little closer to the Continental Divide than the typicum variant.

\author{
VARIANT: Castilleja occidentalis-Cetraria cucullata (local) variant \\ Nomenclatural Type: Table 9 relevé 74 \\ Plots: $73,74,75,92,94,95 \quad(n=6)$
}

Differential species: Castilleja occidentalis, Cetraria cucullata, Arnica rydbergii, Erigeron lanatus, Dicranum sp., (Astragalus bourgovii)

Constant species: Potentilla diversifolia, Solidago multiradiata, Oxytropis campestris, Arenaria obtusiloba, Smelowskia calycina, Festuca brachyphylla

This floristically well defined variant has only locally been sampled on mostly very steep red argillite slopes in one high elevation drainage (Snow Moon Lake, Falling Leaf Lake and the ridge towards Cracker Lake) It might be a local phenomenon only. For this reason a type relevé was not chosen. It is a very mesic, westerly exposed unit with a fairly lush vegetation and the highest number of species reached in any Dryas-vegetation unit.

Even though Polygonum viviparum is completely lacking and Hedysarum sulphurescens is not very constant, the presence of Salix nivalis and Anemone drummondii and the community structure clearly identify this unit as a member of this association.

\title{
1.1.6.2. ASSOCIATION: Euphrasio arcticae-Kobresietum myosuroides ass. nov. - Northern Euphrasia-Kobresia association
}

\author{
Nomenclatural Type: Table 10 relevé 393
}

Plots: $291,311,313,312,310,309,392,393 \quad(\mathrm{n}=8)$

Character species: Kobresia myosuroides, Gentiana prostrata, (Euphrasia arctica, Aulacomnium palustre)

Constant species: Dryas octopetala, Hedysarum sulphurescens, Solidago multiradiata, Polygonum viviparum, Potentilla fruticosa, Zigadenus elegans,Trisetum spicatum, Potentilla diversifolia, Sedum roseum, Poa alpina, Silene acaulis

Much of the description of this community also pertains to the following association. They have been mostly described together here because the differences among them are relatively small given their ecological and spatial relationships. Since these communities are so rare in the area it has not been possible to gather any more samples. Given the rarity and their limited acreage it might be questioned whether there is a point in describing new syntaxa for such locally restricted units. The merely regional validity at this point needs better foundation with additional relevés preferably from a other areas.

General aspect: These rare plant communities are at the same time some of the floristically richest alpine plant communities in the Park. They form thick mats of dense sedge vegetation carpeting outcrops and terraced high elevation slopes or sometimes extend over colluvial slopes. An important factor for these communities is ample moisture supply which is usually provided by water seeping in from areas above. The layered sedimentary bedrock often aids in channeling water over larger distances even through the mountains themselves creating these sloping but seeped habitats. Slow soil 
creep seems to be common at least on the smoother colluvial slopes where the blankets of vegetation in some places seem to "float" on the bedrock material. Cracks in the vegetation layer as well as bulging and folded portions of the swards evidence the presence of slope movement (German:"Girlanden-Bildung"). The torn-up soil carpet along the cracks exposes the humus-rich soil layers and provides slowly but constantly renewed space for plant species with little competitive advantage. This seems to be one factor for the richness of these communities.

Topography: The slopes are gentle to reasonably steep between $5^{\circ}$ and $30^{\circ}$ and nearly all S-facing. On outcrops and benches almost level sites can be encountered. Aspect is mostly southeast to southwest. Rock cover on these densely vegetated stands is very low.

Geology: Parent materials are mostly red argillite and sometimes limestone.

Snow duration/Wind exposure/Water supply: Estimated snow duration on the sites is moderate only, with an estimated early meltout in June or early July due to sufficient insolation on these Sexposed slopes. Considerable but not extreme wind exposure is likely to remove higher snow accumulations from the sites which mostly occur on bench edges of coarsely terraced outcrops and on convex slopes. Longer lasting snow patches can be present above the sites, providing moisture over an extended period of time. The water supply is good through the year in these mesic to moist communities.

Soils: Soils in these communities are very rich in humus and bear a very tough and dense root turf in the upper horizons which is mostly lacking a skeletal fraction. This firm root-mat is most important for a coherent vegetation layer under unstable slope conditions as found on these sites. The toughness of the turf layer is evidenced by the above mentioned upwarping and folding of the whole soilvegetation layer as a result of slope action. Here the stabilizing function of the vegetation layer becomes very obvious even though in these extreme sites the limits of protective function are also apparent by cracks in the vegetation layer. Soils under the Kobresia-Tofieldia-communities are less densely rooted and more peat-like.

Vegetation: The vegetation layer is very dense being dominated mostly by the sedges Kobresia myosuroides, Kobresia simpliciuscula and Carex scirpoidea. Even though the overall aspect in most cases is that of a sward-like community, dwarf shrubs and herbs do play an important role. Namely Dryas octopetala is highly constant and in most cases reaches the highest cover of any single species. This even though the ecological conditions in the much more widespread Dryas dominated fellfield communities are much different. Thus this species shows a bimodal, "ecologically disjunct" distribution in the area. With Salix nivalis and Arctostaphylos uva-ursi two other dwarf shrub species assume an important but mostly less dominant role in this community.

Among the forbs Hedysarum sulphurescens is by far the most copious mainly in the Kobresia myosuroides community where it is the most covering species in all Red Gap Pass sites. Solidago multiradiata is another herb species with p.p. unusually high cover in this community and high constancy throughout. Like in the other Carex scirpoidea communities, Polygonum viviparum is a numerously represented indicator for high elevation moist site conditions.

Kobresia swards are among the floristically richest communities in the area and are known to contain a number of rare vascular plant species. Among these, Euphrasia arctica, Gentiana prostrata, Tofieldia pusilla and Carex capillaris have high diagnostic value. Gentiana prostrata is very constant in the Kobresia myosuroides community and occasionally occurs in the other Kobresia syntaxon. It has not been found in any other plant community in the area in the course of this study. The species is 
also present in some of the Kobresia communities reported from Alberta (Beder 1967, Hrapko \& LaRoi 1978, Achuff \& Corns 1982).

Mosses play an almost predominant role in both of these moist communities. This is particularly the case in the Kobresia myosuroides community where Aulacomnium palustre is very constant and reaches up to $45 \%$ cover. Bryum sp. is the most common species (or species group) in both communities. Other reasonably constant species in this syntaxon are Brachythecium sp., Campylium chrysophyllum, Tortella fragilis, Hypnum revolutum and Thuidium abietinum. Distichium capillaceum, Myurella julacea, Myurella tenerrima and Cephaloziella sp. have been found mainly in the Kobresia myosuroides community. Lichens are not important concerning their cover but occur in surprising species-richness. Many species from the mostly drier and widespread rocky alpine communities do reach into these moist communities and are responsible for the increase in species numbers.

Syntaxonomy: Several Kobresia myosuroides communities have been described from various areas in the western North American mountains (see below). All such communities from areas in the Rocky Mountains south of Glacier Park are xeric turf communities which differ considerably from the moist to mesic communities encountered in the study area. The clearly moisture-indicating and fairly dominant species Carex scirpoidea, Zigadenus elegans, Hedysarum sulphurescens and Sedum roseum are mostly lacking in the samples reported from those southern areas. The group is very common in Dryas-Kobresia communities from area further north (Gjaerevoll 1954, Cooper 1986).

As can be seen in the synoptic table, the southern Dryas-Kobresia units share a number of differential southern species with Eritrichum aretioides being a very constant one (non-Dryas communities with Kobresia have not been included in that table but can be found in the fellfield synoptic table [Tab. 1]).

It is interesting to note though, that in terms of species numbers most species of this community in Glacier NP are indeed dry fellfield species. Therefore relations to other widespread high elevation fellfield communities are strong also in the Kobresia communities in Glacier NP.

With both, xeric and moisture indicating species present, the Kobresia communities in the area seem to have in intermediate ecological position in the moisture gradient. which is also the case in many of the northern Kobresia communities which the local units share a closer relationship with. Euphrasia arctica has been chosen as a name-giving species even though it also occurs in the other Carex scirpoidea communities. Within the local Kobresia units it defines this particular unit. Gentiana prostrata would also have been an option to use in the name but it is a widespread species in northern Kobresia units which this new syntaxon might not be representing sufficiently.

Common species of all Rocky Mountain Kobresia communities compared here are Kobresia myosuroides, Polygonum viviparum, Silene acaulis, Arenaria obtusiloba, Festuca brachyphylla, Selaginella densa agg. s.l., Luzula spicata, Trisetum spicatum Potentilla diversifolia, Carex rupestris, and a little less so, Cerastium arvense, Poa alpina, Cetraria ericetorum, Peltigera rufescens, Physconia muscigena, Coelocaulon muricatum. Even less common - and among the southern samples just mentioned by Komárková - are e.g. Hypnum revolutum, Xanthoria elegans, Antennaria umbrinella, Polytrichum juniperinum, Lecanora epibryon and Carex albonigra. By far most of these species are widespread high elevation species common to other alpine fellfield communities. Therefore these Kobresia communities perfectly fit into the newly established order ArenarioFestucetalia brachyphyllae. A common species group that would be specific enough to form a separate Rocky Mountain-wide Kobresia syntaxon of order rank does not seem to exist. Regional floristic affiliations differentiate the various, physiognomically similar Kobresia communities 
occurring along the Rocky Mountains. Thus they will have to be accommodated in various alliances following the latitudinal gradient.

Distribution: Both Kobresia syntaxa are among the rarest communities found in Glacier National Park. Their particular environmental requirements restrict them to very few alpine locations east of the Continental Divide. Both have so far been sampled in two locations only. Still they might be present at least in a few other remote locations in the area.

Literature: Kobresia-communities are very widespread throughout the western and eastern holarctic regions. Accounts from Northern American mountain ranges have been given by Kiener (1939), Beder (1967), Baptie (1968), Trottier (1972), Knapik et al. (1973), Kuchar (1975), Crack (1977), Douglas \& Bliss (1977), Hrapko \& LaRoi (1978), Komárková (1979), Willard (1963, 1979), Corns \& Achuff (1982) and Eddleman \& Ward (1984), some of which have been mentioned above already. In the study area Lesica (1988) and Lesica \& McCune $(1990,1992)$ have undertaken transect sampling in a community which clearly belongs into this group (see below).

Other accounts on Kobresia communities have been given from mountain ranges throughout the holarctic region, only a few of which can be mentioned here. Scandinavia: Nordhagen (1928, 1936, 1943), Greenland: Böcher (1954), Barrett (1972), Gelting (1934, 1937), Northwest Territories: Brassard \& Beschel (1968), Iceland: Falk (1940), Spitsbergen: Hadaç (1946), Rønning (1965), Altai: Kuminova (1960), Japan: Ohba (1974).

\subsubsection{ASSOCIATION:Tofieldio pusillae-Kobresietum simpliciusculae ass. nov. \\ - Tofieldia-Simple Kobresia association}

Nomenclatural Type: Table 10 relevé 411

Plots: $234,323,408,411,412,320,321 \quad(n=7)$

Character species: Kobresia simpliciuscula, Tofieldia pusilla, Carex capillaris,

(Anemone parviflora)

The description for this community is included in the description of the similar EuphrasioKobresietum (see above).

Syntaxonomy: For its general similarity with the latter association this unit has been accommodated in this alliance. At least the assignment to the latter is somewhat questionable at this point given the fact that a different Kobresia species replaces Kobresia bellardii and otherwise only Anemone parviflora is a constant character species present. Stands \#320 and \#321 have been included in this community because of their overall floristic and ecological similarity even though they lack some of the character species.

Distribution: This locally rare community has only been sampled in a few locations (Twin Lakes/Mt. Reynolds, Gunsight Pass) but is well defined by the species given above.

Literature: Lesica (1980) and Lesica \& McCune (1990, 1992) have done detailed transect sampling in one of the most species-rich alpine habitats in the park and it turns out that their transects from Lunch Creek and Twin Lakes/Mt. Reynolds belong to this community.

This community might represent a far southern example of a community occurring more commonly much further north. In his description of the "Kobresieto-Dryadion in Alaska", Gjaerevoll (1954) describes such a Kobresia simpliciuscula community which shares Dryas octopetala, Carex 
scirpoidea, Carex capillaris, Carex rupestris, Tofieldia pusilla, Potentilla fruticosa, Polygonum viviparum, Gentianella prostrata, Silene acaulis, Solidago multiradiata, but also has some floristic differences based mainly on the different regional phytogeography. Ecologically the communities appear to be somewhat dissimilar as far as can be taken from Gjaerevoll's short description as xeric communities. Cooper (1986) described a Carici scirpoideae-Kobresietum simpliciusculae from the Arrigetch Valley in Alaska's central Brooks Range. His community occupied trickling springs and waterfalls on limestone slopes resembling the moist sites in the community from Glacier NP. The stands are of similar small extent as the samples found in the present study area. Ecologically and floristically similar communities have been reported from northern Greenland (Bøcher 1954) and Scandinavia (Gjaerevoll 1980).

\title{
Arenario-Festucetalia brachyphyllae: Unclassified Associations of the Order
}

\section{ASSOCIATION: Zigadeno elegantis-Caricetum scirpoideae ass. nov.}

\author{
Nomenclatural Type: Table 10 relevé 242
}

Plots: see subunits

Character species group: Carex scirpoidea, Potentilla fruticosa, Zigadenus elegans, Hedysarum sulphurescens, Euphrasia arctica, Dodecatheon pulchellum

Three subassociations have been united in this association which in the area is very distinct as a community of continuously wet to moist, not very exposed alpine situations. Two other similar units, the Euphrasio-Kobresietum myosuroides and the Tofieldio-Kobresietum simpliciusculae have so far been treated elsewhere in the alliance Salici nivalis-Dryadetum octopetalae, even though they largely share the character species group of this unit. Both of those communities could have been included in this association but they are physiognomically different (dominance of Dryas and Kobresia spp.) and floristically richer. Due to their close similarity they have been presented in the same association table (Tab. 10).

The syntaxonomical placement of this association is provisional. Since both closely related (Dryas-) Kobresia communities have been placed in the order Arenario-Festucetalia brachyphyllae, this association is preliminarily placed in the same alliance within that order. At least the Arnica alpina subassociation has considerable floristic relations to this order whereas at least the other subassociation will most likely have to be moved into a different order in the future. Cooper (1986) described a provisional order Pediculari kanei-Dryadetalia octopetalae where he accommodated his Caricetum scirpoideo-rupestris Cooper 1986 as well as his Carex scirpoidea-Dryas octopetala community. At least the Kobresia communities mentioned above have relationships to these units. Cooper's Carici scirpoideae-Kobresietum simpliciusculae Cooper 1986, which includes Dryas octopetala and Cassiope mertensiana as constant species, was not placed in any higher syntaxon and is likely to belong into the same group. The provisional order Zygadeno elegantis-Elymetalia innovatis Cooper 1986, which by the way does not deserve such a high syntaxonomic rank having not a single constant character species, also has some similarity with this unit.

The common occurrence of Carex scirpoidea with Dryas octopetala or D. integrifolia seems to be a given in almost all communities reported from areas north of the present study area. The complete lack of Dryas in the present unit seems to be quite unusual and might represent an impoverished variant which might ecologically still be close to the Dryas-Carex scirpoidea communities. Adding 
the fact that the whole Carex scirpoidea species group is very constant, the placement of the Carex scirpoidea communities with the Dryas-Kobresia communities might turn out to be appropriate.

Three subassociations have been created in this association. The subassociation cirsietosum has been chosen as the type subassociation. Since a distribution of this association beyond this study area is very likely, other subunits will have to be included here in the future.

Literature: Communities dominated by Carex scirpoidea have been described from various areas in western North America (Douglas \& Bliss 1970, Hoefs et al. 1975, Mortimer 1978, Polster 1980, Cooper 1986, Lesica et al. 1992, Cooper et al. 1997 and many others). Whereas in the far northern parts the single spike sedge seems to occur in a much wider range of communities, its restriction to particularly wet sites seems to be a feature of the units further south, reflecting the overall drier conditions of those mountainous areas. In the Rocky Mountains south of the limits of the Wisconsinian glaciation, the role of Carex scirpoidea seems to be taken over by Carex scopulorum.

\section{SUBASSOCIATION: Zigadeno elegantis-Caricetum scirpoideae typicum subass.} nov.

- Death Camas-Single Spike Sedge alpine meadow community

Nomenclatural Type: Table 10 relevé 242

Plots: $35,36,37,38,39,40,227,230,242,292 \quad(n=10)$

Character species: (Cirsium hookerianum), Crepis runcinata + association character species

Differential species: Cystopteris fragilis, Aquilegia flavescens, Arabis nuttallii, Gaillardia aristata, Astragalus aboriginum, Botrychium simplex

General aspect: Apart from the even higher reaching subassociation allietosum, this subassociation is probably the most productive low-alpine plant community. The stands are dominated by an often dense mat of Carex scirpoidea and scattered stems of Cirsium hookerianum protruding through the lush sedge layer conspicuously mark this community. It almost looks like a dense Festuca scabrella meadow. Festuca also frequently occurs in this unit and with its similar leafage would be easily overlooked if it weren't for its tall flowering culms. A flowering aspect is contributed by Zigadenus elegans and Aquilegia flavescens and locally also by Crepis runcinata. The flowers of Dodecatheon pulchellum and Solidago multiradiata are somewhat hidden in the sedge layer and the tiny, annual species Euphrasia arctica is likely to be overlooked due to its small stature.

Topography: Slopes of 10 to $30^{\circ}$ steepness are the locations of this community. The more or less shallow soil is mostly organic, being derived mainly from sedge litter. Soil and vegetation layer are covering a terraced, irregular relief with occasional argillite outcrops. The community mostly occurs as a more or less broad zone along streamlets. Oftentimes the argillite bedrock layers parallel the slope surface, impeding any deeper drainage and providing seeped conditions downwards along the slope. Westward exposure seems to be favored by this community.

Geology/Parent Material: This community has only been found on green (and rarely on red) argillite which might be due to the fact that most samples stem from the same, geologically uniform valley. The layered bedrock in its particular surface-parallel orientation is likely to be responsible for the special moisture conditions.

Wind exposure/Snow duration: Wind exposure is considerable and snow packs are likely to be limited because of this. Nevertheless a closed snow layer is to be expected through much of the winter. 
Moisture conditions: The vicinity of streamlets and possibly of longer lasting snowfields above, as well as the particular arrangement of the bedrock is responsible for a good moisture supply in this community. Slightly seeped conditions are present through mid-summer and they are the cause for the lush growth of this community in the vicinity of otherwise relatively dry alpine communities. The slope angle provides sufficient drainage to impede waterlocked conditions.

Soils: The soils in this subassociation are strongly organic like it is commonly the case throughout this association.

Vegetation: A somewhat lesser vegetative cover is typical for this unit compared to the subassociation allietosum. The irregular soil surface with bedrock outcrops, scattered rocks and occasional eroded soil results in an increased number of species which invade the otherwise reatively dense community. This results mainly in an increasing number of lichens and mosses but similarily in a higher presence of various species from adjacent alpine communities and prairie species of the Bupleurum americanum prairie species group.

Apart from the Gentiano-Kobresietum myosuroides, this is the only community where Euphrasia arctica has been found with high constancy. The tiny annual is considered rare in the park but this might be largely due to the overall small area of this kind of moist alpine habitat and the minute size of the species which is easily overlooked in these graminoid dominated stands.

The role of Carex rupestris in this association, also in the following subassociation needs to be studied in greater detail. As a species of xeric tundra communities in the area, the occurrence in this syntaxon is somewhat surprising. The species might even have been overlooked in a number of cases since it can be very hard to distinguish from Carex scirpoidea under these conditions. Moister communities with both of these species are known from areas in Canada and Alaska (Cooper 1986).

The constant presence of Crepis runcinata might be a local particularity. Arctostaphylos uva-ursi sometimes occurs in this community but this might be interpreted as an edge effect since stands of the Arctostaphylos uva-ursi community frequently occur in the vicinity, usually further away from the moisture supplying streamlets or seeps.

The rare Suksdorfietum ranunculifoliae can be found growing in more open spots surrounded by this community.

Syntaxonomy: This unit is considered the typicum unit of the association. Even though it has its own character species, it is not considered distinct enough to warrant association rank.

Distribution: Seven out of eight samples have been gathered in one valley (Appistoki Valley) in the southern portion of the park. Only one sample was taken near Red Gap Pass in the northern center of the park. Similar assemblages have been found in other drainages, e.g. S and W of Spot Mtn.

Literature: No other accounts of similar communities have been found in the literature. 


\section{SUBASSOCIATION: Zigadeno elegantis-Caricetum scirpoideae allietosum subass.}

nov.

- Death Camas-Single Spike Sedge cliffbase community

Nomenclatural Type: Table 10 relevé 112

Plots: $112,113,177 \quad(\mathrm{n}=3)$

Character species: see association

Differential species: Allium schoenoprasum, Aster foliaceus, Arnica mollis, Parnassia fimbriata, Deschampsia cespitosa, Castilleja miniata, Carex spectabilis, Phleum alpinum, Senecio cymbalarioides, Tofieldia glutinosa

Even though this subassociation has been sampled in only three locations, it has been found more often in the area and certainly represents a reoccurring type.

General aspect: Steep, sheltered sites at the base of moist to wet rock walls are the typical location for this community. The vegetation is probably the most lush type at elevations above $2000 \mathrm{~m}$, consisting of a dense, high growing sedge meadow with scattered individuals of shrubby cinquefoil. A colorful flowering aspect originates from the interspersed mesophytic forbs Allium schoenoprasum, Zigadenus elegans, Hedysarum sulphurescens, Arnica mollis, Parnassia fimbriata, Castilleja miniata and Senecio cymbalarioides.

Topography: This community occurs on lush vegetated debris slopes immediately at the base of vertical, sometimes even overhanging, seeped cliffs. The step-like ledges are covered with scree and rock debris which is completely overgrown by the dense vegetation layer. This widely visible vegetation stripe occurs only within the upper $10 \mathrm{~m}$ along the cliffbases where sufficient shelter from the rockface above is given. Sometimes even small and inaccessible rock ledges with similar conditions hold this community. Exposure of the few sites sampled was SE and SW in a very narrow elevation range around $2050 \mathrm{~m}$ a.s.l. which coincides in this area with the upper limit of the larger colluvial valley slopes meeting the steeper rock faces and cliffs. These cliffs often dominate the higher elevations up to $3000 \mathrm{~m}$ in the study area. The ground surface on the sites is usually very steep around $30^{\circ}$. The unique topographical situation well characterizes this community. Only occasionally is this unit found growing along streambanks.

Geology/Parent Material: All sites have been found below green argillite cliffs, in one case a marbelized kind of rock was present. The finely disintegrating shale makes up for most of the colluvial material which this community grows on.

Soils: A sometimes thick layer of organic material accumulates on the colluvial debris. The vegetation might well be the most productive one in the alpine resulting in extraordinary amounts of organic built-up.Fine mineral soil fractions seem to be mostly lacking and the boundary between the largely organic top layer and the gravelly scree are rather abrupt.

Wind exposure/Snow duration: The wind- and sun-sheltered locations are likely to accummulate considerable amounts of snow which due to the lack of irradiation melt rather late.

Water/Moisture supply: Snow melt and seepage from the adjacent cliffs results in good water supply through much of the season. Additionally moisture can be supplied seeping out of the cliff face above. Waterfalls and small, trickling streamlets are common in the vicinity of this community. Despite this ample supply, the sites are well drained and water-locked situations do not occur. 
Vegetation: Both the sedge Carex scirpoidea and also Deschampsia cespitosa can reach dominance in this moist graminoid meadow community. A shrubby aspect is contributed by Potentilla fruticosa which also can reach considerable cover. Vegetation cover is always above $90 \%$ of the plot. Cryptogams are mostly lacking. The Saxifraga mertensiana cliff crevice community or fragments of it are often found in the moist cliff faces above this community.

Syntaxonomy: Even though this community is very conspicuous, it represents an assemblage of species which all occur in other communities in the area. The lack of true character species and the physiognomical similarity to the other units of this association where considered sufficient reason to keep this unit as a subassociation within the present association. The community is closely related to the subassociation of Cirsium hookerianum and can be found grading into it.

Distribution: This community occurs in small areas in suitable situations throughout the study area. Stands larger than $500 \mathrm{~m}^{2}$ have not been found, whereas stand of only a few square meters do occur.

SUBASSOCIATION: Zigadeno elegantis-Caricetum scirpoideae arnicetosum alpinae subass. nov.

- Alpine Arnica - Single Spike Sedge community

Nomenclatural Type:Table 10 relevé 148

Plots: $136,137,140+138,139,141,147,148,161 \quad(n=3+6)$

Character species: see association

Differential species: Arnica alpina, Bromus pumpellianus, Erigeron simplex, Lupinus lepidus, Salix commutata, Antennaria umbrinella

Two closely variant with a very close special relationship have been described from the area which are similar enough to be described together in the following paragraphs.

VARIANT: Arctostaphylos uva-ursi variant $\quad(\mathrm{n}=3)$

Plots: $136,137,140$

Differential species: Arctostaphylos uva-ursi, Dryas octopetala, Salix commutata, Danthonia intermedia

VARIANT: Sedum roseum variant $(\mathrm{n}=6)$

Plots: $139,138,141,147,148,161$

Differential species: Sedum roseum, Deschampsia cespitosa, Dodecatheon pulchellum, Arenaria rossii, Erigeron compositus, Artemisia michauxiana, Hypnum revolutum, Rhizocarpon geographicum s.l., Lecidea atrobrunnea, Rhizoplaca melanophthalma, Xanthoria elegans, Collema sp., (Selaginella standleyi) 


\section{Description for both variants:}

General aspect: Two physiognomically quite dissimilar variants belong into this subassociation which have been found in a regular, striped pattern. It is the typical pattern of "turf-banked terraces" like the one known from Dryas-and other fellfield communities plate 2, fig.5. Both variants share the diagnostic species given above which are not known to occur in other Carex scirpoidea communities. The fact that an extremely similar sample could be found in a large stand on East Flattop Mtn. some thirty kilometers to the north was taken as evidence for a repeated occurrence of this community. This resulted in the establishment of a subassociation for this unit rather then an unranked community.

Topography: Eight out of nine samples have been gathered on the Scenic Point plateau in the southeastern corner of the study area. They are forming a striped pattern on a very slightly concave alpine gravel plain with very little slope, the stripes running parallel to the contour lines. The sampling area is only about 0.8 ha and The pattern of the two variants consists of sloping risers covered densely covered with the dwarf shrubs Arctostaphylos uva-ursi, Dryas octopetala and Salix commutata. The horizontal steps (treads) between the adjacent risers are mostly frost-rubble covered.

Geology/Parent Material: All stands were found on green argillite plateaus with some smaller fractions of brown arenite, and white, grainy quartzite. The latter rock-type was predominant in one stand.

Wind exposure/Snow duration: The open plateau situation of all stand most likely results in high wind exposure. Nevertheless are all sites located in wide and shallowly concave situations which are likely to be filled with snow through much of the winter. The presence of a higher number of lichen species in the Sedum roseum-frost-rubble variant point to a lesser snow cover of this gravelly unit.

Moisture conditions: Within the plateau situation, these sites are likely to be fairly moist or mesic compared to the adjacent xeric fellfield communities. Within this subassociation the dwarf-shrub variant rests on thick organic soils as it is commonly the case in Arctostaphylos and Dryas communities. The organic soil material builds a larger water storage compared to the gravelly, highly skeletal soil under the horizontal treads. The latter are thus more xeric and likely to experience drought periods in summer and fall. The lesser occurrence of mesophytic species like Hedysarum sulphurescens on the treads supports this observation.

Soils: see above

Vegetation: An important floristic feature of this subassociation is the occurrence of Arnica alpina, a species which has not been found with a similar constancy in any other community. The same applies for Bromus pumpellianus, a species which certainly has a wider distribution. The two units combined in this subassociation are so dissimilar in appearance that they need to be treated separately here. Variant of Arctostaphylos uva-ursi: Structurally and also concerning much of its floristic composition this unit resembles the Arctostaphylos uva-ursi-Juniperus communis communities. On the one hand it differs in the presence of Salix commutata, Carex scirpoidea, Erigeron simplex. Polygonum viviparum and Festuca brachyphylla and in its presence on turf-banked risers. On the other hand it is so similar with those other kinnikinnik communities that it might indeed be syntaxonomically treated within that group.

Variant of Sedum roseum: This variant is a somewhat impoverished form of a fellfield community. The rocky appearance with a scattered vegetation as well as the occurrence of several fellfield species likens it to those units. 
Syntaxonomy: The variant of Arctostaphylos uva-ursi physiognomically strongly resembles the other Arctostaphylos communities described elsewhere in this study and might be treated as a Carex scirpoidea-subunit under that syntaxon. Ecologically and floristically the ties to the present unit are considered strong enough to justify the present treatment.

The Sedum roseum variant is structurally and to some degree also floristically similar to other fellfield communities. As an open-structured community it is easily invaded by fellfield species from the Arenario-Festucetalia communities widely occurring in the vicinity. Its ecological, floristic and spatial character nevertheless relates it closer to the present association.

Distribution: see above

This community is a local type of vegetation which so far has been found on top of the Scenic Point Plateau only. The two structurally very dissimilar subunits form a very conspicuous striped pattern over a more or less level alpine gravel plain of about 0.8 ha.

\title{
ASSOCIATION: Solidagini multiradiatae-Arctostaphyletum uva-ursi ass. nov. - Northern Goldenrod-Bearberry association
}

\author{
Nomenclatural Type: Table 11 relevé 229 \\ Plots: $1,2,11,12,13,15,41,42,76,77,78,100,101,142,145,146,149,224,225,229,231,234,238,248$, \\ $286,287,372,387,461,474,484,486,514,516,712,714,723,724,800,802 \quad(n=40)$ \\ Character species: Arctostaphylos uva-ursi, Juniperus communis, Shepherdia canadensis, \\ Astragalus aboriginum
}

General aspect: One of the most conspicuous plant communities of the study area is the bearberry heath community found slightly above treeline in the lower alpine zone. Its largest expanses are found in areas where dead trunks of Pinus albicaulis witness the former existence of a subalpine open pine woodland.

Floristical differentiation: The bearberry community has been separated as an association based on the character species Arctostaphylos and Juniperus communis, none of which is highly exclusive. Nevertheless together they form a highly diagnostic species group. This syntaxon reveals the problem that even though it is physiognomically very distinct, it has a high degree of floristic-compositional variation in itself. This is most likely due to the fact that the community often occurs interfingered with other floristically rich plant communities with alpine as well as lower elevation affinities.

The subunits were delineated based on the clusters found in numerical and tabular analysis. It remains to be seen whether these subdivisions can be validated over larger areas or merely represent local effects.

The role of cryptogams for the differentiation of subunits presents a little problem: cover and number of lichen species in the plots vary extremely with the cover of Arctostaphylos uva-ursi itself: high cover of the bearberry leads to a high litter cover which effectively excludes lichens from the sites. On the other hand small scree and rock patches increase lichen diversity tremendously. Thus the diagnostic value of lichens in this group, at least as far as their quantity and species number is concerned, is limited due to the sampling methods used which did not differentiate these microhabitats. The same problem applies to mosses. Still the difference in cryptogam-cover was used in one case to delineate a lichen-poor subunit.

One major consequence of this circumstance is that a floristical classification using the whole species 
composition could generate groups which might differ from a classification based solely on vascular plants. Therefore not too much weigh should be given to the lower units defined here, especially when comparing them to units from other areas.

Syntaxonomy: As a community of the xeric portion of the lower alpine and subalpine zones, it is related to the communities with strong affinities to prairie vegetation. Thus the Bupleurum americanum species group is well represented in this syntaxon. On the other hand the group of high elevation generalists is also well represented. The typicum and Dryas variants additionally have some species of the alpine Carex rupestris group. As mentioned above much of this heterogeneity might be attributed to the spatial closeness of these communities and the other lower alpine fellfield communities which can occur closely patterned. The latter is especially true for the Selaginella wallacei variant of the Oxytropis campestris - Bupleurum americanum association which forms intricate patterns with bearberry heaths e.g. in Appistoki Valley. The Oxytropis campestris Bupleurum americanum association in itself is floristically close to the typicum variant of the Arctostaphylos uva-ursi association. In some cases the floristic composition between the latter two units is so close that certain stands are difficult to assign to one of the two units. In these cases the dominance of Arctostaphylos uva-ursi was considered the main criteria for treating such stands under the present association.

A synopsis of bearberry communities from the western mountains is still lacking and would be needed to clarify the relationship among those heaths. The present community has therefore been called Solidagini-Arctostaphyletum in order to limit its range. A name like "Festuco scabrellaeArctostaphyletum uva-ursi" would certainly apply to a wider ranging unit but the presently available data is not sufficient to allow for a floristic delineation of such a unit.

An alliance to accommodate this association is not yet available. On the order level, the floristic overlap is greatest with the Arenario-Festucetalia brachyphyllae. Even though most members of this association are not fellfield communities, at least the Dryas octopetala subassociation clearly represents a fellfield unit. Thus the bearberry heaths are transitional between subalpine (and low elevation) heath communities and alpine fellfields. Until a better treatment of these heath communities is available, the association is provisionally kept in the fellfield order. Within the order it is closest to the Oxytropido-Bupleuretum americani.

Distribution: This xeric community is found east of the Continental Divide on mostly west-facing slopes. This and similar Arctostaphylos uva-ursi-communities are widespread on xeric subalpine sites along the east slope of the Rocky Mountains from the Yukon Territory (Hoefs et al. 1975) through Colorado (see also under literature).

Literature: The existence of a heath belt in between the subalpine forests and the alpine zone is a character of most temperate holarctic mountain areas and these dwarf shrub formations have been subject of innumerable studies. This xeric heath community in particular has one of the most widespread ranges of any high elevation plant community. Both species, bearberry and creeping juniper, have a holarctic range (subspecific differentiation neglected) and frequently occur together in physiognomically and ecological very similar situations. In fact a Junipero-Arctostaphyletum Br.-Bl. ex Haffter in Br.-Bl. et al. 1939 has been described long ago and reserves the name which otherwise would be perfect for the community treated here. The ecological similarities to the present unit are striking: both occur under xeric continental conditions and accumulate a rawhumus layer which is hardly podzolized. Also the occurrence near or at treeline or at slightly lower elevation under a pinecanopy is a communality. In the European Alps, this community is mostly replacing treeline forests after anthropogenic treeline-depression, which might be analogous to the situation after blister-rust kill in the Rockies. Also both units do not have their own character species but have a fair number of 
grassland species which derive from adjacent Fescue grasslands. It needs to be mentioned of course that almost all other, less dominant species of these vicariant communities are different.

The following Arctostaphylos uva-ursi communities have been reported from western North America: Arctostaphylos uva-ursi -Solidago spathulata association in Mt. Rainier NP (Hamann 1972); Elymus innovatus association steep S-facing colluvial slopes Banff NP (Beder 1967); Dryas octopetala Shepherdia canadensis association, Wrangel Mtns., Alaska (Scott 1971); a rare SE-facing Dryas octopetala subtype of lichen tundra in Jasper NP, Alberta (Kuchar 1975); dry limestone slope community in central Alaska (Gjaerevoll 1967); dry stony fans and warm south facing slopes southwestern Mackenzie (Raup 1947).

From Greenland Böcher (1954) reports a Artemisia borealis- Calamagrostis purpurascens Arctostaphylos uva-ursi complex. Scandinavian units are Loiseleurieto-Arctostaphylion Kalliola 1939 (nom inval.), Loiseleurieto-Arctostaphylion (Nordhagen 1936) and Arctostaphyleto-Cetrarion nivalis (Rondane, Dahl 1954), all of which are wind-exposed and lichen-rich high elevation units. From Scotland McVean \& Ratcliffe (1962) describe a heath community with Calluna vulgaris.

Much more important in this context are descriptions from the Canadian Rocky Mountains: Kuchar (1973) reports a limber pine scrub from adjacent Waterton NP with southern and western exposure and the same elevation range which doubtlessly belongs to the same syntaxon or describes a unit merely different by its additional tree layer which has died or never been part of the community in the present study area. Most of the shrub species he mentions occur in this community in Glacier, namely Juniperus communis, Potentilla fruticosa, Rosa acicularis, Shepherdia canadensis, Amelanchier alnifolia and rarely Symphoricarpus albus. Within the subunits it belongs to the low elevation variant.

Kuchar's unit is synonymous or at least very close to the Juniperus communis - Arctostaphylos uvaursi communities mentioned by Corns \& Achuff (1982), Willoughby et al. (1997), Achuff et al. (1997) and Pinus albicaulis and Pinus flexilis communities of Timoney (1999).

Crack (1977) refers to a steep S to SW-facing Arctostaphylos uva-ursi community in Jasper NP, Alberta. It occurs between krummholz patches with Carex rupestris and Elymus innovatus and probably is closely related. Like in the present study he considers his community to be a high elevation variant of a lower elevation syntaxon.

From the Candian Front Range Mortimer (1978) describes a Arctostaphylos uva-ursi subtype of his Dryas octopetala - Carex rupestris community which is likely to be close to the typicum variant of this study.

Stringer (1969) lists Arctostaphylos uva-ursi for Festuca scabrella- or F. idahonensis dominated prairie grassland communities (see Kuchar 1973). This points to the close relation between these prairie communities and the higher elevation bearberry units.

A close relation exists to the Calamagrostido-Arctostaphyletum uva-ursi described by Hoefs et al. (1975) from southwest Yukon Territory and to a somewhat lesser degree to the "Roso-ShepherdioPopuletum balsamiferae" from the same authors. 


\section{SUBASSOCIATION: Solidagini-Arctostaphyletum festucetosum scabrellae subass.}

nov.

\section{- Bearberry-Rough Fescue community}

Nomenclatural Type: Table 11 relevé 229

Plots: $15,41,42,76,77,78,100,101,149,224,225,229,231,234,238,248,286,287,372,387,461,474$, $484,486,514,516,712,714,723,724 \quad(n=30)$

Differential species: Festuca scabrella, Astragalus aboriginum, Selaginella wallacei, Agoseris glauca

\section{VARIANT: Typicum variant}

Plots: $15,41,76,77,78,100,101,229,234,238,248,387,486,514,516 \quad(n=15)$

Differential species: Cladonia borealis, Ochrolechia upsaliensis, Aspicilia sp., Sporastatia testudinea

General aspect: The typical aspect of this community is that of a slope-covering heath community strongly dominated by the dark green mats of Arctostaphylos uva-ursi. No other species reaches nearly that much cover in this unit. Other important species are tufts of Festuca scabrella, clumps of Potentilla fruticosa and scattered inidivuals of Hedysarum sulphurescens and Astragalus aboriginum. Dead trunks of Pinus albicaulis and Pinus flexilis are often found in this community.

Topography: On steep $\left(11^{\circ}-30^{\circ}\right)$ overgrown talus cones and slopes mostly facing $\mathrm{W}$, rarely $\mathrm{S}$ or $\mathrm{E}$. Elevations are from 1750 to $2050 \mathrm{~m}$ a.s.l. Even though steep, the slopes are stabilized with a compacted surface and a smooth or slightly rolling relief. Scattered larger rocks can be protruding. Cracks in the vegetation layer point to some slope movement and increase the number of species presenting micro-sites for the estabnlishment of invading species. This leads to an increase of floristic heterogeneity in this community; the community is often found between krummholz patches of Abies lasiocarpa, Pinus albicaulis or Pinus flexilis. Less steep stands have been found on windswept colluvial footslopes and weathered ground moraines on the valley bottom in Apikuni Valley.

Geology/Parent material: This community is mostly found on a colluvial mix of green argillite or red argillite talus, with small amounts of arenite and quartzite.

Wind exposure/Snow cover: The stands are always highly wind exposed. Snov cover is moderate or sometimes slightly exposed in winter. Arctostaphylos uva-ursi is one of the most frost hardy dwarf shrubs in the alpine with a tolerance down to $-40^{\circ} \mathrm{C}$ found in European populations of the species (Ellenberg 1986).

Moisture conditions: Sites are well drained, exposed to desiccating winds and mostly drying out by midsummer. These xeric conditions are a main ecological character of the Arctostaphylos communities in general which is reflected in the bearberry's xerophytic growth-form.

Floristical differentiation: Apart from the four lichens listed above, a large diagnostic species group can not be given for this subunit since the differentiation is predominantly based on structural features. Nevertheless this and the Dryas octopetala - Arctostaphylos uva-ursi fellfield community described below are differentiated against the next variant and the low elevation variant by a large number of lichen and moss species which are characteristic for alpine fellfields. These species are mostly restricted to rocky microsites exposed by wind erosion and soil-creep-induced cracks in the vegetation layer. Even though these species are very constant, they - in a strict sense - belong to a 
different rocky micro-habitat ("synusiae" sensu Ellenberg 1956) which has not been separated out in this study (see below). A better separation of the different micro-habitats, resulting in irregular plot shapes, might have reflected the floristic differences more clearly. Trying to maintain a standard plot size and shape, this was not always possible, but care was taken to sample homogenous heath area whenever these were available.

The pattern of vegetation is often a very evenly spread heath over larger areas. In other cases it occurs in larger patches interspersed with more open fellfield communities creating a conspicuous and reoccurring vegetation complex. Krummholz patches frequently abut on this community.

Distribution: This is certainly the most widespread of the Arctostaphylos uva-ursi communities in the study area covering hectars e.g. in Appistoki Valley and in Baring Creek Valley north of Sunrift Gorge.

\section{VARIANT: Lichen-poor variant}

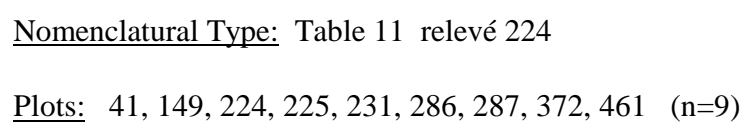

Differential species: none

General aspect: This unit is a typical Arctostaphylos uva-ursi heath with the highest density of the dwarf shrub layer reach in any comparable unit.

Topography: This variant occurs between 1880 and $2230 \mathrm{~m}$ a.s.l. on W to SW exposed, moderately to very steep slopes. Slope angle is from $14^{\circ}$ to $32^{\circ}$.

Floristical differentiation: The differentiation against the typicum variant is merely the lack of lichens in this very dense Arctostaphylos uva-ursi heath. Rock cover is very low whereas bearberry litter covers by far most of the plot surface impeding the establishment of a ground lichen layer. Otherwise there is not much difference to the typicum variant.

Syntaxonomy: Even though this unit breaks out quite apparently in the vegetation table, it does not have its own diagnostic species. It is nothing but an impoverished variant of the typicum and might be lumped with that unit since no ecological differentiation seems to exist.

VARIANT: Carex scirpoidea variant

Nomenclatural Type: Table 11 relevé 39

Plots: $38,39,42 \quad(n=3)$

Differential species: Carex scirpoidea, Polygonum bistortoides, Eriogonum ovalifolium, Arnica rydbergii, Dodecatheon pulchellum, Antennaria anaphaloides, Botrychium simplex

Three stands have been placed into this possibly local variant of Carex scirpoidea. It is a moist type of Arctostaphylos uva-ursi community. Thus it is ecologically different from the other predominantly xeric units. This variant can be interpreted as a transition to adjacent moister areas. Stands \#142 and \#146 could also be placed here but have been treated under the Dryas subassociation. It possibly represents a local unit since it was found only on the Scenic Point plateau. 


\section{SUBASSOCIATION: Solidagini-Arctostaphyletum dryadetosum subass. nov. - Bearberry - Mountain Avens community \\ Nomenclatural Type: Table 11 relevé 12}

Plots: $1,2,11,12,13,142,145,146,800,802 \quad(n=10)$

Differential species: Dryas octopetala, Salix nivalis, Lupinus lepidus, Antennaria alpina, Erigeron compositus, Saxifraga occidentalis, Anemone parviflora

General aspect: This mixed dwarf-shrub-subassociation of apparently higher elevations is much more exposed than the other Arctostaphylos uva-ursi units. Thus it assumes more of a fellfield character which it is transitional to. The shrub layer often is very short growing (to less than $12 \mathrm{~cm}$ tall) and creates a denser mat than in other less exposed bearberry heaths. When in flower, Zigadenus elegans gives this community a particular aspect. Regularly striped and terraced vegetation patterns occur only in this subassocation.

Topography: This high elevation variant among the Arctostaphylos uva-ursi communities occurs at 1920-2220 m a.s.l. Exposures are very variable, the slopes varying from only gently sloping to very steep but usually found on upper slopes and rolling uplands less steep than the other valley slope variants. Terraced surface structure is commonly found in this unit with most sites occurring on fairly stable surfaces.

Geology: Mostly on limestone parent material. Occasionally on green and red argillite but then limestone is frequently mixed in to some amount. This geological substrate is a main ecological difference to the other Arctostaphylos uva-ursi communities. Whereas the other Arctostaphylos uvaursi communities have all been found on talus, this one also occurs on frost rubble surfaces.

Wind exposure/Snow cover/Moisture conditions: Exposure to wind is high to sometimes extreme. Snow cover is moderate to reasonable which is usually due to the topographical position on leeward slopes or in slightly depressed surface situations. Consequently moisture supply is above average when compared to nearby alpine fellfield communities.

Floristical differentiation: The dominance of Dryas octopetala together with Arctostaphylos has been a main reason to differentiate this subassociation. The other association character species area largely lacking as are a number of species of the Bupleurum americanum group, namely Festuca scabrella, Festuca idahoensis, Galium boreale, Campanula rotundifolia, Cerastium arvense, Silene parryi, Selaginella wallacei and Agoseris glauca.

Even though the data suggests that the substrate limestone is a main factor for this community, no single calcicolous species has been found in this community that would support this assumption. In other studies Arctostaphylos uva-ursi as well as Dryas are said to be limestone preferring species. This has not been found in the study area where both species do occur on argillites, which contain much less calcium than limestone and provide a more acidic substrate.

The vegetation pattern in this unit is either evenly spread or patterned in broader stripes which is mostly the case when occurring on terraced slopes.

Two stands (\#142, \#146) have been assigned to this subassocation based on the abundant presence of Mountain Avens. Given their overall floristic composition they are closer to the provisional moist variant. 
Syntaxonomy: Some of the samples are very close to other fellfield communities. Still the Silene acaulis tundra group is not very constantly present. Neither are the fellfield species groups of Carex albonigra and Carex rupestris. On the other hand the Bupleurum americanum group is present with medium constancy and suggesting to keep this group with the other Arctostaphylos uva-ursi communities as a high elevation variant of the latter.

A subunit of Festuca scabrella and Potentilla fruticosa with Festuca idahoensis and Bromus pumpellianus might be differentiated on an even lower syntaxonomical level as more prairie-like subunit.

Some moister samples with Carex scirpoidea, Hedysarum sulphurescens and Polygonum viviparum point some similarity with the Dryas-Salix nivalis community.

Distribution: The samples given in the tables are from Lee Ridge, Scenic Point Plateau and Firebrand Pass, all being locations on the continental eastside of the Park. The first location is not far from the Canadian border whereas the last is close to the southern end of the sampling area, thus the whole N-S range of the study area is covered.

Literature: Dryas octopetala - Arctostaphylos uva-ursi communities have been mentioned in some other studies from areas further north in the Rocky Mountains. Very close is e.g. the Arctostaphylos uva-ursi subtype of the Dryas octopetala - Carex rupestris community given by Mortimer (1978). Also Crack's Arctostaphylos uva-ursi community from Jasper NP (1977) is likely to belong here. The same holds true for the Dryas octopetala subtype of lichen tundra from Jasper NP, Alberta reported by Kuchar (1975).

\section{SUBASSOCIATION: Solidagini-Arctostaphyletum agropyretosum spicati subass. nov. \\ - Subalpine/low alpine Bearberry-Wheatgrass community \\ Nomenclatural Type: Table 11 relevé 474 \\ Plots: $474,484,712,714,723,724 \quad(n=6)$ \\ Differential species: Antennaria microphylla, Agropyron spicatum, Carex geyeri, Heuchera cylindrica, Amelanchier alnifolia, Spiraea betulifolia, Lupinus sericeus, Gentianella amarella, Calochortus apiculatus, Aster foliaceus}

General aspect: Apart from the frequent co-dominance of Juniperus communis this community does look very similar to the other bearberry heath units. Nevertheless it is differentiated by a number of low elevation species. Some low elevation shrub species are frequently found here being very conspicuous when in flower as is the case with Amelanchier alnifolia, Spiraea betulifolia, Rosa acicularis and rarely Prunus virginiana. Shepherdia canadensis is common also and conspicuous with its silverish leaves. Tufts of Carex geyeri and Agropyron spicatum also contribute to modify the character of this heath community. Even though some of the species listed are not very constant in the few samples presented, they are likely to turn out very characteristic for this unit when a larger sample would be gathered.

Topography: Apart from its lower elevation range (1510 to $1850 \mathrm{~m}$ a.s.1.) the topography is as usual for Arctostaphylos uva-ursi units on steep slopes with E to SW exposure. This unit is often found on dry, rocky slopes with large portions of bedrock outcrops.

Wind exposure/Snow cover: High to moderate wind exposure and a snow cover slightly heavier than in the other Arctostaphylos uva-ursi communities characterize this unit. Thus moisture supply is slightly better than in the other variants. 
Floristical differentiation: A varying number and composition of subalpine species clearly differentiates the sites belonging to this unit. None of these taxa is confined to this unit and all are fairly widespread in different types of vegetation in the subalpine, montane and even colline zone along the eastern edge of the Rocky Mountains. Another difference is the lower constancy of high elevation species as well as prairie species of the Bupleurum americanum group. In fact this is the subunit with the smallest diversity of all bearberry communities in the area. Juniperus communis can achieve high cover in this unit. Alpine lichen species are obviously scarce which clearly evidences the elevational difference and the greater amounts of snow shortening the annual growth period in this unit. In places where the bearberry itself does not impede lichen growth, scree movement is likely to be responsible for the sparse lichen cover. Given these ecological and floristic differences, this unit is assigned the rank of a subassociation.

Distribution: The distribution is the same as said for the typicum, except that this unit occurs at slighlty lower elevations. This community is likely to be very widespread on the continental eastern slope of the Rocky Mountains to the north as well as further south.

Literature: Among the bearberry communities mentioned from other areas some clearly refer to this lower elevation variant. This is the case for the communities reported by Stringer (1969) and Kuchar (1973).

\title{
ASSOCIATION Astragalo bourgovii-Salicetum arcticae ass. nov. - Bourgeau's Milk-vetch - Arctic Willow fellfield community
}

\author{
Nomenclatural Type: Table 12 relevé 381
}

Plots: $163,168,361,362,379,380,381,382,415,510 \quad(n=10)$

Diagnostic species: (Salix arctica, Castilleja occidentalis), Astragalus bourgovii, Anemone parviflora, Astragalus vexilliflexus

Differential species: Solidago multiradiata, Erigeron simplex, Sedum lanceolatum, Luzula spicata, Smelowskia calycina, Hedysarum sulphurescens, Myosotis alpestris, Saxifraga occidentalis, Poa cusickii

General aspect: Like all Salix arctica communities this one is dominated by the low mat-forming creeping dwarf shrub. Interspersed and higher growing are scattered individuals or tufts of herbaceous species. They ornament the darkish green willow-mat with various colored flowers in summer. Conspicuous yellow flowering species are Solidago multiradiata, Senecio cymbalarioides, Ranunculus eschscholtzii and the pale yellowish Castilleja occidentalis whereas whitish colors are represented by Anemone parviflora, Hedysarum sulphurescens, Zigadenus elegans, Erigeron simplex, Saxifraga occidentalis and Smelowskia calycina. The only species to add bluish colors are Myosotis alpestris and the very conspicuous Gentiana calycosa. Particular importance has Astragalus bourgovii is some places where it achieves high cover and even co-dominates the stands. Astragalus vexilliflexus has been found on all plots were the other milk-vetch was missing. The more dominating Bourgeau's milkvetch was thus chosen as the name-giving species.

Topography: The community carpets WNW to NE-exposed, gentle to steep $\left(\left(0^{\circ}-\right) 6^{\circ}-24^{\circ}\right)$ slopes; the willow dominated matted vegetation is covering scree/talus slopes and contributes considerably to the stabilization of the slopes. Nevertheless is solifluction a common process on steeper slopes resulting 
in a torn vegetation mats with exposed underlying scree in the cracks. Surface rock cover is usually between 15 and 55\% with some of the rocky material being loose rocks which occasionally roll into the stands from above. Still most of the plot is generally compacted.

Geology: This community is one of the very few communities which seems to be confined to limestone areas. Only minor amounts of quarzite, argillite and arenite have been found in this community.

Wind exposure/Snow cover: Wind exposure is usually middle to high. Reasonable to sometimes large amounts of snow cover the sites and melt out fairly late in the season.

Moisture conditions: The abundant snow on and above the sites usually provides a good moisture supply through much of the season.

Vegetation: In many sites the vegetation forms even carpets covering and stabilizing the mostly sloping landforms. The dominant, structurally important arctic willow is likely to be an early member in the succession towards this community being an important soil builder. The large part of the litter produced in this unit stems from the dwarf shrub providing the material for an initial soil development before the the other herbs are able to establish on these sites.

By its mostly low growing physiognomy this community is easily recognized as a fellfield type, less so on steeper slopes. Certain mesophytic species like Gentiana calycosa, Anemone parviflora, Hedysarum sulphurescens and Astragalus bourgovii point to a better moisture supply in this community than most other fellfields experience. A number of late-melt indicating species like Arenaria capillaris, Arnica rydbergii and Ranunculus eschscholtzii are present in this unit. Together with the location of this community often in the vicinity of Dryas communities, it seems safe to assume that within the fellfield environment this unit replaces Dryas mats in sites with extended snow cover. Lichen and moss cover is usually low in this community. The lack of lichens is attributable to the long snow cover.

Syntaxonomy: As opposed to all other Salix arctica communities this unit lacks most moisture indicating species except perhaps Senecio cymbalarioides and Ranunculus eschscholtzii. On the other hand species of the drier fellfield areas are fairly common even though not all of them with high constancy. Especially diagnostic species of the fellfield communities like Myosotis alpestris, Silene acaulis, Smelowskia calycina or Arenaria obtusiloba are fairly sparse or even lacking like the elsewhere common species Festuca brachyphylla and Erigeron compositus. Nevertheless it seems to be justified to place this unit with the dry fellfield communities into the order Arenario-Festucetalia. Within this order it seems to be so unique and remote that it can at this point not be assigned to a known alliance. It is restrained here from creating a new alliance for this single unit. Nevertheless the Solidago-Salix arctica community itself seems to be stable enough to deserve association rank.

Distribution: The community has been sampled along the Continental Divide from Ahern Pass in the northern center of the park to Pitamakan Pass in the southern parts of the study area. It is likely to occur more widespread beyond the studies geographical limits.

Literature: Most Salix arctica communities mentioned in literature are much different from the one treated here. Closest ties exist to the Salix arctica communities from Alberta mentioned by Trottier (1972, Highwood Pass) and Beder (1967, Snow Creek Valley), the latter author reporting his unit as a Dryas-Salix arctica community. Some similarity also exists to the Dryas- and non-Dryas - Salix arctica communities mentioned by Hrapko (1970) from Signal Mountain in Alberata. As discussed under the Leprario-Salicetum arcticae, the heterogeneity of the Salix arctica units described from various areas is considerable. 


\section{Association Table 12}

\section{Astragalo bourgovii-Salicetum arcticae ass. nov.}

\begin{tabular}{|c|c|c|c|c|c|c|c|c|c|c|c|c|}
\hline & & & & & & & & & & & & \\
\hline & Location & PPE & Pit & Pit & Pit & Pit & PPE & TDP & PPE & PPE & Ahe & \\
\hline & Plot-Number & 168 & 379 & 380 & 381 & 382 & 362 & 510 & 361 & 163 & 415 & \\
\hline & Elevation [m/10] & 221 & 227 & 229 & 233 & 235 & 221 & 201 & 221 & 217 & 206 & \\
\hline & Aspect $\left[{ }^{\circ}\right]$ & 290 & 15 & 45 & 40 & 45 & 290 & 350 & 0 & 300 & 330 & \\
\hline & Slope $\left[{ }^{\circ}\right]$ & 6 & 19 & 23 & 24 & 23 & 15 & 8 & 0 & 7 & 13 & \\
\hline & Parent Material & LiM & $\mathrm{DLi}$ & DLi & DLi & DLi & DLi & $\mathrm{Lm}$ & $\mathrm{DLi}$ & $\mathrm{DLi}$ & DLi & \\
\hline & Rocks $>6 \mathrm{~cm}$ & 10 & 20 & 25 & 35 & 45 & 20 & 3 & 25 & 8 & 25 & \\
\hline & Rocks $<6 \mathrm{~cm}$ & 10 & 2 & 35 & 20 & 15 & 2 & 45 & .1 & 8 & 30 & \\
\hline & Mineral Soil & 8 & 1 & - & 2 & - & 0 & - & - & 1 & - & \\
\hline & Litter Cover [\%] & 65 & 55 & 30 & 25 & 35 & 85 & 25 & 90 & 60 & 50 & \\
\hline & Vasc. Plant Cover [\%] & 55 & 80 & 50 & 45 & 50 & 85 & 80 & 85 & 70 & 55 & \\
\hline & Moss Cover [\%] & 2 & 1 & .1 & 2 & 2 & 2 & 7 & .1 & 3 & 6 & \\
\hline & Lichen Cover [\%] & 4 & .5 & 1 & 1 & 1 & .1 & 5 & 0 & 8 & 15 & \\
\hline & Vegetation Pattern & eve & eve & eve & $\mathrm{e} / \mathrm{s}$ & eve & eve & eve & eve & eve & eve & \\
\hline & Number & 1 & 2 & 3 & 4 & 5 & 6 & 7 & 8 & 9 & 10 & Constancy \\
\hline Asso & iation diagnostic species: & & & & & & & & & & & \\
\hline$(\mathrm{AC})$ & Salix arctica & 3 & 3 & 3 & 3 & 3 & 4 & 3 & 4 & 3 & 3 & v \\
\hline$(\mathrm{AC})$ & Castilleja occidentalis & + & + & + & + & + & + & + & + & + & . & V \\
\hline & Anemone parviflora & + & 1 & + & + & + & . & . & + & + & + & IV \\
\hline AC & Astragalus bourgovii & . & 2 & . & 2 & 3 & 3 & . & + & . & $\cdot$ & III \\
\hline AC & Astragalus vexilliflexus & + & . & + & . & . & . & + & . & 2 & . & II \\
\hline Com & anion species & & & & & & & & & & & \\
\hline & Poa alpina & + & + & + & + & + & + & + & + & + & + & V \\
\hline & Potentilla diversifolia & + & + & . & + & + & 1 & 1 & + & + & . & IV \\
\hline & Ranunculus eschscholtzii & . & + & + & + & + & . & + & . & . & + & III \\
\hline & Antennaria alpina & $\mathrm{r}$ & + & . & + & + & + & + & . & + & . & IV \\
\hline & Solidago multiradiata & + & + & + & + & . & . & + & + & r & + & IV \\
\hline & Hedysarum sulphurescens & 1 & + & + & + & . & . & 1 & + & . & $r$ & IV \\
\hline & Erigeron simplex & + & + & + & + & . & + & + & . & . & + & IV \\
\hline & Saxifraga occidentalis & + & . & + & + & . & . & $r$ & . & + & + & III \\
\hline & Trisetum spicatum & $x$ & . & . & r & + & + & + & . & . & + & III \\
\hline & Sedum lanceolatum & + & + & + & + & + & + & . & . & . & $r$ & IV \\
\hline & Gentiana calycosa & + & 1 & + & + & ad & . & . & + & r & . & IV \\
\hline & Zigadenus elegans & + & + & . & . & . & . & + & + & $r$ & . & III \\
\hline & Phleum alpinum & + & . & . & . & $r$ & + & . & + & + & . & III \\
\hline & Selaginella standleyi & + & + & + & . & . & . & + & . & 1 & . & III \\
\hline & Polygonum bistortoides & . & + & + & + & . & + & . & + & + & . & III \\
\hline & Luzula spicata & + & + & + & + & + & + & + & . & . & . & IV \\
\hline & Smelowskia calycina & + & + & + & + & + & + & $r$ & . & . & . & IV \\
\hline & Myosotis alpestris & + & . & + & + & + & + & + & . & . & . & III \\
\hline & Poa cusickii & + & + & + & + & + & + & . & . & . & . & III \\
\hline & Cerastium arvense & + & . & + & + & + & + & . & + & . & . & III \\
\hline & Silene acaulis & $r$ & . & + & + & + & . & r & . & . & . & III \\
\hline & Arnica rydbergii & . & $r$ & + & + & + & . & + & . & . & . & III \\
\hline & Arenaria capillaris & . & 2 & + & . & + & 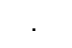 & 1 & . & . & . & II \\
\hline
\end{tabular}


Table 12 (cont.)

\begin{tabular}{|c|c|c|c|c|c|c|c|c|c|c|c|}
\hline Number & 1 & 2 & 3 & 4 & 5 & 6 & 7 & 8 & 9 & 10 & Constancy \\
\hline Arabis nuttallii & + & . & $r$ & $\cdot$ & . & + & + & . & . & . & II \\
\hline Polygonum viviparum & . & + & + & + & . & . & . & . & . & . & II \\
\hline Senecio cymbalarioides & + & . & . & $\cdot$ & . & + & + & + & + & + & III \\
\hline Achillea millefolium & . & . & . & $\cdot$ & . & + & . & + & + & + & II \\
\hline Carex phaeocephala & . & . & . & . & . & r & + & . & + & r & II \\
\hline \multicolumn{12}{|l|}{ Important Bryophytes } \\
\hline Brachythecium sp. & . & $p$ & $\mathrm{p}$ & $\mathrm{p}$ & $\mathrm{p}$ & $p$ & $\mathrm{p}$ & . & $\mathrm{p}$ & $\mathrm{p}$ & IV \\
\hline Tortula norvegica & $\mathrm{p}$ & $\mathrm{p}$ & . & $\cdot$ & $\mathrm{p}$ & $\cdot$ & $\cdot$ & . & $\mathrm{p}$ & . & II \\
\hline \multicolumn{12}{|l|}{ Important Lichens } \\
\hline Cladonia sp. & $\mathrm{p}$ & $\mathrm{p}$ & $\mathrm{p}$ & $\mathrm{p}$ & . & $\mathrm{p}$ & $\mathrm{p}$ & . & $\mathrm{p}$ & $\mathrm{p}$ & IV \\
\hline Peltigera rufescens & $\mathrm{p}$ & $\mathrm{p}$ & $\mathrm{p}$ & $\mathrm{p}$ & $\mathrm{p}$ & $\mathrm{p}$ & $\cdot$ & . & . & . & III \\
\hline Lecanora polytropa & $\mathrm{p}$ & $\mathrm{p}$ & $\mathrm{p}$ & . & . & . & $p$ & . & . & $p$ & III \\
\hline
\end{tabular}

\section{Minor species:}

Vascular plants: Draba sp. 1:+ ; Carex nardina 1:+ ; Carex albonigra 1:+c; Astragalus alpinus 1:r ; Gentiana sp. 1:+ ; Androsace septentrionalis 1:r , 6:r ; Pedicularis contorta 1:+ , 7:+ ; Koeleria cristata 1:+ , 9:+ ; Arenaria rubella 1:+ , 9:rcf; Erigeron sp. 2:x , 9:+ ; Arenaria rossii 3:+ , 4:+ , 10:+ ; Delphinium sp. 3:r , 5:+ ; Agoseris glauca 3:+ ; Arnica diversifolia 4:ad, 5:+ ; Cirsium hookerianum 4:r , 5:+ ; Arenaria obtusiloba 5:r , 6:+ ; Penstemon ellipticus 5:+ ; Agropyron latiglume 5:+ , 9:r ; Poa secunda 6:+ ; Draba crassifolia 6:+ ; Allium schoenoprasum 7:+ , 8:+ ; Festuca idahoensis 7:+ ; Anemone drummondii 7:+; Carex scirpoidea 7:+ ; Aster alpinus 8:+; Erigeron peregrinus 8:+ ; Carex podocarpa 8:1 ; Aster foliaceus 8:+ , 9:r ; Pedicularis groenlandica 9:+ ; Carex haydeniana 9:r ; Carex epapillosa 9:+ ; Sibbaldia procumbens 10:+ ; Antennaria umbrinella 10:+ ; Bryophytes: Bryum sp. 2:p , 6:p , 9:p ; Pohlia sp. 1:p ; Hypnum revolutum 1:p , 2:p , 6:p ; Tortula ruralis 1:p , 8:p ; Desmatodon latifolius 1:p ; Tortella tortuosa 1:p ; Bryum caespiticium 1:p , 7:p ; Cephalozia? sp. 1:p , 7:p ; Lophozia sp. 2:p ; Mnium arizonicum 2:p ; Brachythecium sp. 6:p ; Ceratodon purpureus 7:p ; Bryum capillare 7:p ; Distichium capillaceum 7:p ; Polytrichastrum alpinum 10:p ; Lichen sp. 1:p ${ }^{\mathrm{cf}}, 2: \mathrm{p}^{\mathrm{cf}}$;

Lichens: Rhizocarpon geographicum agg. 10:p ; Peltigera lepidophora 1:p ; Lecidea auriculata 1:p ; Caloplaca sp. 1:p ; Catapyrenium daedaleum 1:pcf; Psora decipiens 1:p ; Caloplaca stillicidiorum 1:p ; Aspicilia sp. 2:p , 10:p ; Peltigera venosa 2:p ; Psora sp. 2:p $p^{\text {cf }}$ Peltigera kristinssonii 2:p; Catapyrenium cinereum 2:p , 7:p ; Lecideine epilithic crust 1:p , 2:p , 7:p ; 3:p ; Placynthiella sp. 5:p , 7:p ; Rinodina sp. 7:p ; Rinodina mniaraea 7:p ; Caloplaca fraudans 7:p ; Lecidella wulfenii 7:p ; Lepraria sp. 9:p ; Peltigera sp. 9:p , 10:p ; Lecidea atrobrunnea 10:p 


\title{
ASSOCIATION: Artemisio michauxianae - Potentilletum fruticosae ass. nov. - Artemisia-Shrubby Cinquefoil colluvial slope and cliff-ledge community
}

\author{
Nomenclatural Type: Table 13 relevé 308 \\ Plots: 44, 45, 72, 84, 104, 110, 111, 215, 216, 217, 218, 221, 243, 244, 249, 258, 308, 375, 376, 389, 390, 391, \\ $460,466,483,494,551,701,715,722,741 \quad(n=31)$
}

\section{Character species: Artemisia michauxiana, Potentilla glandulosa, (Eriogonum androsaceum)}

Differential species (against other Arenario-Festucetalia brachyphyllae units): Linum perenne, Heuchera cylindrica, Chrysopsis villosa, Penstemon albertinus, Gaillardia aristata, (Arenaria nuttallii, Allium cernuum, Heuchera parviflora, Phacelia hastata)

General aspect: Precipitous rocky terrain covers much of the alpine and subalpine area in the steep mountain landscape of the study area. Large expanses of the unstable, steep slopes are covered with this heterogeneous, shrub dominated, patterned vegetation. Potentilla fruticosa, even though one of the most widespread species in the alpine in general, tends to predominante this community more than any other unit. The commonly used name is used here instead of the taxonomically more recent Pentaphylloides floribunda (see Taxonomic Remarks, Appendix A). The shrubby cinquefoil often makes up for much of the vertical, parallel running vegetation stripes which become very obvious when dotted with thousands of the species' yellow flowers plate 3, fig. 10. On less stable slopes the vegetation occurs in scattered patches, sometimes consisting of only a few or just one species. Potentilla glandulosa and the greyish leaved Artemisia michauxiana are typical for these slopes. While P. fruticosa is more conspicuous and structurally important, P. glandulosa is more restricted and thus more diagnostic for this community. The aspect of this unit is not as much that of an alpine community but that of a scattered, rocky shrub formation. The typicum variant belongs to this type. A second structural type differs mainly in that it occurs in more stable situations on cliffs and rockoutcrops which are an abundant habitat type in the study area. The Zigadenus variant entirely belongs to this type.

Topography: This community occurs on very unstable, steep talus slopes with coarse rock debris or smaller scree covering the larger part of the slopes. The platy shape of the rock fragments of sedimentary origin enhances the instability of the rocky slope surfaces with smaller and larger shales sliding singly or in larger masses downslope. Resulting is a vegetation mostly confined to stable rock outcrops or vertical stripes of vegetation islands which seem to float on the completely unvegetated talus. The vertical shape of the patches is a result of the slope movement. This pattern provides relatively large undisturbed areas which can be inhabited by plants while offering the least area of contact for the moving debris hitting the vegetated patches from up-slope.

Steep, rugged cliffs are commonly found above the slopes continually supplying the slopes with new rock debris from the ongoing weathering processes. Apart from these unstable sites the community also covers more stable rock outcrops and cliffs where it is found on smaller and larger the fine soil pockets.

Geology/Parent material: The unit if found mostly on green, sometimes on red argillite. Small amounts of arenites and quartzite can occur, rarely is a little limestone present. Rock cover on the slopes is usually very high between $80 \%$ and $95 \%$. 
Wind exposure/Snow cover: Wind exposure is high, rarely extreme, and snow cover is reasonable to moderate. Almost uncovered, exposed sites occur were wind exposure is extreme. This can be the case in the outcrop variants in the vicinity of summits and ridgetops.

Moisture conditions: The steep slopes are well drained and exposed to drying winds. Thus dry conditions are likely to prevail at least in the later part of the summer. On the other hand it has been observed that the soil under the vegetation as well as the finer fraction most always present under the upper layer of unvegetated talus holds considerable amounts of moisture even after longer periods without precipitation. This effect has already been observed by Harshberger (1929). One factor contributing to this is the presumably little evaporation on the talus minimized by shaly rocks covering the surface like multiple layers of shingles. Harshberger compared this effect with the principle of "dry farming". Ecological measurements would be desirable to confirm this observation.

Floristical differentiation: As a widespread low to mid-alpine community in the study area, it shares almost the whole group of alpine generalist species, which are Potentilla fruticosa, Potentilla diversifolia, Solidago multiradiata, Sedum lanceolatum, Arenaria obtusiloba, Calamagrostis purpurascens, Besseya wyomingensis and Oxytropis campestris. The other mid- to high-alpine species groups, which have been defined in the order Arenario-Festucetalia brachyphyllae, are not as well represented in this unit. Species of the Silene acaulis group occur in some samples reflecting the spatial closeness to true alpine fellfield communities. Even less represented are the species of the Carex albonigra and Carex rupestris groups.

On the contrary, members of the Bupleurum americanum group like Galium boreale, Achillea millefolium, Cerastium arvense, Eriogonum ovalifolium and Campanula rotundifolia are very common in this unit. Thus a lower elevation affinity can be assumed based on the floristic composition, especially when weighing the constancy and abundance of the species. The presence or even complete absence of high elevation species creates some heterogeneity in the samples of this community. The unstable habitat with considerable disturbance by erosion and soil movement is probably accounting for this kind of floristic variation. The disturbance frequently creates open microsites for the establishment of species originating from adjacent communities. The main distribution of this community is most likely at lower elevations. Thus all samples gathered in this study represent high elevation variants. For a better understanding of this talus community more data from subalpine and montane lower elevation sites would need to be included here. Such similar communities have been observed in the mountain ranges west of Glacier National Park.

The character species Artemisia michauxiana and Potentilla glandulosa are a small but highly diagnostic species group to identify this community in the area. At least the latter species has a much wider ecological amplitude in other areas. It therefore is a local character species only.

Syntaxonomy: Only very few species are occur exclusively in this community. Most species are constituents of other vegetation units as well which results in relationships with a number of other communities. The floristic heterogeneity adds to the diversity of floristic links.

However, closest ties exist to the Bupleurum americanum species group with its low alpine, prairierelated communities. The constant presence of most of the species of this group in addition to the presence of the alpine generalist species is the reason for the provisional placement of this association in the order Arenario-Festucetalia brachyphyllae. Physiognomically these Potentilla fruticosa communities are somewhat different from the fellfield communities of that order, even though there are sites which intergrade to units of that order. A separate alliance and order to hold this unit is not in sight and cannot be created with the little data available. In fact some authors even refused to classify similar rock-ledge communities: Kuchar (1973) was probably pointing to similar vegetation types in 
the adjacent Waterton National Park when he wrote: "Considering the effort it seems no worth to study the inaccessible cliff habitat in great detail".

As a community of very unstable, dry slopes there is a close relation of this association to the even more extreme Arenaria nuttallii-Phacelia hastata talus slope community. The scattered presence of Phacelia hastata and Arenaria nuttallii themselves as well as Phacelia sericea, Crypthantha celosioides and Agropyron latiglume evidence this relationship. Another community of unstable colluvial slopes which is similar to the present unit is the unranked Saxifraga bronchialis community. Its variant of Penstemon albertinus in particular shares the diagnostic species Artemisia michauxiana, Potentilla glandulosa, Penstemon albertinus and Heuchera cylindrica among others. The Saxifraga bronchialis community described below is very close to this association and transitions between both units occur occasionally.

The subunits of this association are somewhat weakly defined floristically. A greater set of relevé would be needed to underline their validity and better understand their ecological relations. Therefore the lower rank of variants was at this point favored rather than assigning the subassociation rank.

Distribution: This association was found mostly east of the Continental Divide, rarely along the Divide itself on the western slope. The range of this community is likely to extend beyond the boundaries of Glacier NP.

Literature: Even though this community is likely to be more widespread, only few records have been found in the literature. Kuchar (1975) mentions a "Cliff-ledge subtype" of his Dryas-Lichen tundra unit with Artemisia michauxiana that might be similar to this association. Crack (1977) mentions a so far undescribed unit occurring on rocky ledges and outcrops that contains Artemisia michauxiana, Cystopteris fragilis, Saxifraga bronchialis and a number of fellfield species.

\section{TYPICUM: Artemisio michauxianae - Potentilletum fruticosae}

Nomenclatural Type: Table 13 relevé 45

Plots: $243,244,249,218,460,216,72,722,45,44,466,308 \quad(n=12)$

\section{Differential species: none}

General aspect: This widespread talus community has the typical aspect of a patchy shrub community on largely open, unstable talus slopes. In many cases the shrubby cinquefoil is much reduced in cover or dwarfed in its growth form. This results in an aspect which is more like a cushion plant or small herbaceous community.

Topography: On very steep and unstable talus slopes with no or only little stabilizing rock outcrops. Slope angles range from $17^{\circ}$ to $36^{\circ}$ at elevations from 1740 to $2380 \mathrm{~m}$; exposure is $\mathrm{E}$ to $\mathrm{S}$, only sometimes westerly. The sites are mostly on middle or upper slopes with a smooth surface relief interrupted only by occasional outcrops and the sometimes bulging vegetation stripes.

Wind exposure/Snow cover/Moisture conditions: see above

Floristical differentiation: Within the Artemisia michauxiana-Potentilla glandulosa communities this unit is not much characterized floristically beyond the presence of the association character species. Together with the Festuca scabrella variant it shares the alpine generalist species Arenaria obtusiloba, Calamagrostis purpurascens, Besseya wyomingensis, Cladonia pocillum and Peltigera rufescens and the Bupleurum group species Bupleurum americanum, Campanula rotundifolia. Agoseris glauca and Festuca idahoensis. Both units are very similar floristically and differ mainly in the diagnostic species group given below. Another difference is in the fact that the Festuca scabrella 
variant often has a less pronounced striped pattern which does not quite correlate with the slightly steeper slopes of this unit. The dominance of Potentilla fruticosa can vary greatly in both units, which is not changing the overall floristic composition but changes the aspect of these communities to some degree. As expected for an unstable community, lichen cover is very low. The same applies to the bryophyte cover except for some cases where Tortula ruralis, Tortella fragilis, Hypnum revolutum or Bryum caespiticium reach higher cover within the limits of the vegetated patches which are less susceptible to disturbance.

This and the following Festuca scabrella variant could be separated based on a fairly well characterized species group. Due to the so far limited area where these units have been sampled in, this is not yet attempted.

Distribution: This widespread syntaxon has been sampled evenly dispersed from Red Gap Pass to Appistoki Valley always on the continental east side of the Park and mostly away from the Continental Divide.

\section{VARIANT: Festuca scabrella variant \\ Nomenclatural Type: Table 13 relevé 215 \\ Plots: $84,104,110,111,215,217,221,258,483,494 \quad(n=10)$ \\ Differential species: Festuca scabrella, Gaillardia aristata, Silene parryi, Chrysopsis villosa, Senecio canus, Penstemon albertinus, Lupinus sericeus, Mertensia viridis}

This variant is very similar to the typicum variant. Details have been discussed under that unit (see above).

\section{VARIANT: Penstemon ellipticus rock-outcrop variant}

Nomenclatural Type: Table 13 relevé 390

Plots: $375,376,389,390,391,551 \quad(\mathrm{n}=6)$

Differential species: Penstemon ellipticus, Zigadenus elegans, Hedysarum sulphurescens, Aster meritus, Agropyron latiglume, Cystopteris fragilis, Saxifraga adscendens, Candelariella vitellina (Trisetum spicatum, Crypthantha celosioides, Poa alpina, Lecanora thompsonii, )

General aspect: As opposed to the typicum this variant occurs on more stabilized cliffs and rock outcrops where talus movement is impeded by protruding bedrock outcrops and scattered boulders.

Topography: On high elevation cliffs and rock outcrops, partly scree covered and very steep from 12 to $35^{\circ}$; sometimes largely covered with loose scree; elevation from $1880 \mathrm{~m}$ to $2270 \mathrm{~m}$ with an slightly higher average elevation than the typicum variant. Exposure has been found to be S to rarely SW.

Geology/Parent material: Bedrock material is green or red argillite, in some cases limestone or dolomite.

Moisture conditions/Wind exposure/Snow cover: Wind exposure is high and snow cover is likely to vary strongly with the very irregular outcrop-relief. This variant is slightly moister than the other Potentilla fruticosa communities. This is evidenced by the presence of mesophytic species like Zigadenus elegans and Hedysarum sulphurescens. The good moisture supply is most likely caused by the impermeable underlaying bedrock which largely impedes drainage. In addition, surface parallel bedrock layers often channel water towards the sites from the areas above. 
Floristical differentiation: Penstemon ellipticus, Zigadenus elegans and Hedysarum sulphurescens are the most diagnostic species of this community. The latter two in combination with Hypnum revolutum point to the preference of somewhat mesic sites. Penstemon ellipticus, Agropyron latiglume and Crypthantha celosioides indicate the unstable conditions on these talus slope which are steeper than in the other variants. Cystopteris fragilis indicates both, rocky, often unstable conditions and a good moisture supply at least through much of the season.

Syntaxonomy: This moister variant has some affinity to the Carex scirpoidea community which is evidenced by the presence of Zigadenus elegans, Hedysarum sulphurescens and sometimes Carex scirpoidea.

Distribution: Five out of six samples of this variant have been gathered on the south slope of Pitamakan Pass in the southern part of Glacier Park which suggests a local variant. Neverthelss it has also been found in the center of the Park and further north to Fifty Mountain, where the community was found on the western slope of the Continental Divide.

\section{VARIANT: Fragaria virginiana variant}

Nomenclatural Type: Table 13 relevé 701

Plots: $701,715,741 \quad(n=3)$

Differential species: Fragaria virginiana, Carex scirpoidea, Carex geyeri, Polygonum bistortoides, Cirsium hookerianum, Castilleja miniata

Three plots (nos. 701, 741, 715) have been provisionally placed here as a loosely associated variant. Despite the lack of most of the differential species of this association they are spatially and ecologically related and have a closer relation to this association than to any other unit. This variant is floristically and ecologically very close to the subassociation allietosum of the Zigadeno-Caricetum scirpoideae. Even though the present variant is structurally closer to that subassociation, it is retained here because there are a number of differentiating species which point to a somewhat drier character of this unit. The allietosum receives a more constant moisture supply indicated by a number of high elevation wetland species. The fact that this kind of vegetation was found in three locations far apart from each other is considered a hint that the unit represents more than a merely coincidential species assemblage.

\section{Saxifraga bronchialis scree slope community}

Table: 14

Plots: $173,174,235,236,246,277,314,315,432,481,522,541,648,713,735 \quad(n=15)$

\section{Character species: (Saxifraga bronchialis)}

\section{Differential species: none}

Various scree slopes dominated strongly by Saxifraga bronchialis have been lumped into this syntaxon. It is even more heterogeneous than the Artemisia michauxiana-Potentilla glandulosa/fruticosa-talus communities which it is closely related to. The spotted saxifrage is a typical scree slope species being highly adapted to the unstable conditions of these sites. Among the growth-forms of talus-inhabiting species which have been described by Schroeter (1926, see also Harshberger 1929), this one follows the scree-blocking strategy ("screedammers/scree-bankers" according to Harshberger). This can easily be seen on most of these plots. The dense mats of the 
species create a barrier, blocking the scree which subsequently piles upslope against the sturdy cushion plant. Oftentimes well established u-shaped walls of this species form the lower end of vertical vegetation stripes on steep unstable slopes, suggesting that the entire vegetation island is dependent on the stabilizing function of the saxifrage and might even have developed on the material settled after a first establishment of the little cushion plant. Thus this species is likely to be of high structural importance for talus slope communities.

General aspect: This group of floristically not very well defined talus slope communities occurs as a mostly patchy, steeply sloping scree community similar in aspect to the Artemisio-Potentilletum. Loose and unvegetated sliding scree covers much of the slopes in between the vertically streched vegetation patches. The light green, often yellowish-tinged bulging low walls and carpets of Saxifraga bronchialis are the most conspicuous vegetation feature.

Topography: This community occurs on very steep talus slopes and on partly scree covered outcrops from $20^{\circ}$ to $34^{\circ}$ slope. The variant of Woodsia scopulorum occupies the steeper and less stabilized sites. Two stands of the fellfield slope variant have been found on level ridges. Thus stability in this unit is extremely variable. The ecological factor disturbance is usually related to gravitational mass wasting processes on steep and unstable slopes. It might nevertheless be replaced by erosional disturbance and possibly frost activity on exposed level summits and ridgetops.

Exposures were quite different among the two variants. The Woodsia variant was found on $\mathrm{S}$ to $\mathrm{W}$ (NW exposed sites whereas the Solidago multiradiata variant was found in NE to southerly exposed or even level situations.

Both variants are strongly differentiated by their elevational range. The Woodsia scopulina variant is the lower elevation unit, occurring between $1500 \mathrm{~m}$ and $2000 \mathrm{~m}$ whereas the fellfield slope variant occurs only above $2000 \mathrm{~m}$.

Geology/Parent material: Both variants where found mostly on green or red argillite.

Soils: As expected under these strongly disturbed high elevation conditions, there is hardly any soil development to speak of. Mention should be made of the saxifrage's characterisitic to accumulate organic as well as inorganic material under its mats. Much of the organic material is like to be derived from old remains of the species itself.

Wind exposure/Snow cover/Moisture conditions: Wind exposure is high, snow cover moderate or reasonable but melting by approximately mid-July. The sloping sites, particularly the ones with southerly inclined exposure receive maximum amounts of solar radiation. Moisture conditions are mesic to dry in summer and mostly dry in fall. A differentiation of the variants concerning this parameter has not been observed.

Floristic differentiation: As can been seen from the list of diagnostic species this unit is not very well characterized floristically. Except for the constant and often abundant presence of Saxifraga bronchialis, which conspicuously dominates this community in many cases, there are no other exclusive species. Penstemon albertinus, Penstemon lyallii and Woodsia scopulina are more constant in the low elevation variant than in any other unit of the area but the species are also occurring in the Artemisio-Potentilletum. The outstanding ecological situation of these unstable slopes in combination with the diagnostic occurrence of the name-giving species is nevertheless considered reason enough to define this unit as a separate community.

Syntaxonomy: This community is very close to the Artemisio-Potentilletum described above. Still, the tabular comparison reveals enough constant differences to keep both units separate. Another close relationship exists to the fellfield communities of the Arenario-Festucetalia order, which often are 
found in the vicinity of these talus slope on more stable sites. This is more obvious in the Solidago multiradiata high elevation variant. It seems that the Saxifraga bronchialis community is intermediate between these two types of habitat.

In terms of its floristic composition this results in a diminished set of species of the fellfield order due to the increasingly unstable conditions. The characteristic species of the Artemisio-Potentilletum on the other hand are also fairly rare in this unit, resulting in a floristically poorly defined unit. For this reason it has not been created as its own association. For the same reason given above under the Artemisio-Potentilletum, this unit is treated under the order Arenario-Festucetalia brachyphyllae.

Apart from the occasional presence of Penstemon ellipticus there is surprisingly little similarity to the talus communities of the Phacelion hastatae which are talus slope with an ever lesser degree of slope stability.

Two elevationally differentiated variants of this community have been found, the first of which is closer to the Potentilla fruticosa/glandulosa talus slopes. The other one occurs on slightly more stabilized talus and is closer to the fellfield communities.

Distribution: Talus communities with Saxifraga bronchialis have been observed in the study area from the north central part of the Park to its southern boundary near Marias Pass.

Units similar to the low elevation variant have been observed in other mountain ranges just west of the study area on subalpine rock outcrops (T.Spribille, pers. comm.). Whereas those outcrops are somewhat similar to the European class Sedo-Scleranthetea Br.-B1. em. Th.Müller 1961, the higher elevation variants are closer to the talus slopes of the Thlaspietea rotundifolii Br.-Bl. 1947.

\section{Saxifraga bronchialis scree slope community \\ - Penstemon albertinus/Woodsia scopulina low alpine variant}

Plots: $235,236,246,481,713 \quad(\mathrm{n}=5)$

Character species: Penstemon albertinus, Woodsia scopulina, Penstemon lyallii

Differential species: Calamagrostis purpurascens, Eriogonum ovalifolium, Potentilla fruticosa,

Selaginella wallacei, Artemisia michauxiana, Potentilla glandulosa, Agropyron spicatum, (Heuchera cylindrica, Rhizoplaca chrysoleuca, Allium cernuum, Antennaria microphylla, Cryptogramma acrostichoides)

Sites \#314 and 315 are transitional between the two variants. Due to their low elevation and the occurrence in the vicinity of other communities typical for these elevations, their were assigned to this variant despite the presence of some alpine fellfield species which are characteristic of the neighboring variant. 


\section{Saxifraga bronchialis scree slope community - Potentilla diversifolia fellfield slope variant}

Plots: $200,269,277,432,541,648,735 \quad(n=7)$

Differential species: Potentilla diversifolia, Poa secunda, Poa alpina, Solidago multiradiata, Trisetum spicatum, Carex phaeocephala, Silene acaulis, Poa glauca, Hypnum revolutum, Peltigera sp., Cladonia pyxidata, Pseudephebe pubescens, (Selaginella standleyi, Arenaria obtusiloba, Festuca brachyphylla, Erigeron compositus, Luzula spicata, Antennaria umbrinella, Smelowskia calycina, Antennaria alpina, Sibbaldia procumbens, Penstemon ellipticus)

Within this community this variant represents the mid- to high alpine unit. Due to the presence of a number of typical species of the fellfield order Arenario-Festucetalia brachyphyllae it was also called fellfield slope unit in order to emphasize the floristic gradation into the true fellfield units. Both the group of alpine gerneralist species and the Silene acaulis group are rather well represented. It might be considered in the future to treat this subunit as a Saxifraga bronchialis variant of unstable slopes within another Arenario-Festucetalia brachyphyllae unit or as a (slightly modified) basal community of this order. 


\section{Association Table 14}

Saxifraga bronchialis colluvial slope community

\begin{tabular}{|c|c|c|c|c|c|c|c|c|c|c|c|c|c|c|}
\hline \multirow{5}{*}{ Location } & \multirow{2}{*}{\multicolumn{12}{|c|}{ Saxifraga bronchialis community }} & & \\
\hline & & & & & & & & & & & & & & \\
\hline & \multicolumn{5}{|c|}{ Penstemon variant } & \multicolumn{7}{|c|}{ Potentilla variant } & & \\
\hline & Gri & $\mathrm{ApV}$ & $\mathrm{ApV}$ & $\mathrm{ApV}$ & AIS & Spo & Cha & Sw & $\mathrm{HiT}$ & Hea & LoS & Spo & & \\
\hline & 713 & 236 & 235 & 246 & 481 & 269 & 541 & 200 & 432 & 735 & 648 & 277 & & \\
\hline Elevation [m/101] & 152 & 174 & 172 & 197 & 176 & 232 & 235 & 212 & ele & 213 & 225 & 238 & & \\
\hline Aspect $\Gamma^{\circ} 1$ & 150 & 245 & 250 & 180 & 180 & 120 & 0 & 110 & 335 & 54 & 75 & 30 & & \\
\hline Slope $\left[{ }^{\circ} 1\right]$ & 34 & 25 & 28 & 34 & 28 & 26 & 1 & 23 & 30 & 22 & 24 & 28 & & \\
\hline Parent Material & $\mathrm{RG}$ & GA & GA & GA & GA & GA & GA & GA & GA & Lim & RA & RA & & \\
\hline Rocks $>6 \mathrm{~cm}$ & 5 & 65 & 80 & 60 & $55 b$ & 60 & $85 b$ & 23 & 40 & 90 & 35 & 20 & & \\
\hline Rocks $<6 \mathrm{~cm}$ & 25 & 30 & 15 & 20 & 20 & 10 & 10 & 27 & 20 & 0 & 50 & 30 & & \\
\hline Fine Soil $<1 \mathrm{~mm}$ & 8 & 0 & .1 & 1 & 3 & 2 & 0 & 3 & .5 & - & - & - & & \\
\hline Litter Cover $[\%]$ & $5+$ & 3 & 2 & 15 & 8 & 10 & 5 & 12 & 6 & 8 & 4 & 14 & & \\
\hline Vascular Plant Cover $[\%]$ & $20-$ & 4 & 5 & 12 & 12 & 25 & 6 & 25 & 25 & $<10$ & 10 & 30 & & \\
\hline Moss Cover $[\%]$ & $<10$ & 0 & $<.1$ & 1 & 8 & $<.1$ & 2 & 5 & 7 & $<1$ & .2 & 2 & & \\
\hline Lichen Cover $[\%]$ & lic & 0 & $<.1$ & 2 & 1 & 3 & 2 & 6 & 5 & 0 & .5 & 0 & & \\
\hline Veqetation Pattern & - & $\mathrm{p} / \mathrm{s}$ & spo & $\mathrm{p} / \mathrm{e}$ & $\mathrm{p} / \mathrm{e}$ & vst & spo & $\mathrm{p} / \mathrm{e}$ & $\mathrm{p} / \mathrm{s}$ & - & $\mathrm{p} / \mathrm{s}$ & - & & \\
\hline Plot-size $\left[\mathrm{m}^{2} 1\right.$ & 30 & 36 & 36 & 16 & 16 & 16 & 15 & 16 & 16 & 25 & 36 & 16 & & \\
\hline Number & 1 & 2 & 3 & 4 & 5 & 6 & 7 & 8 & 9 & 10 & 11 & 12 & \multicolumn{2}{|c|}{ Constancy } \\
\hline Saxifraqa bronchialis & 1 & $r$ & $r$ & $r$ & 1 & + & 1 & 1 & 2 & + & 5 & 1 & $\mathrm{~V}$ & V \\
\hline \multicolumn{15}{|c|}{ VARIANT of Penstemon albertinus } \\
\hline Penstemon albertinus & r & + & r & r & $\mathrm{ad}$ & . & . & . & . & . & . & . & V & . \\
\hline Selaginella wallacei & 1 & + & + & 2 & $r$ & . & . & . & . & . & . & . & $\mathrm{V}$ & . \\
\hline Agropyron spicatum & + & $r$ & $r$ & + & + & . & . & . & . & . & . & . & $\mathrm{V}$ & . \\
\hline Woodsia scopulina & r & r & r & + & . & . & . & . & . & . & . & . & IV & . \\
\hline Penstemon Iyallii & $r$ & $r$ & $r$ & . & $r$ & . & . & . & . & . & . & . & IV & . \\
\hline Calamagrostis & + & + & + & + & . & $r$ & . & . & . & . & . & . & IV & 1 \\
\hline Artemisia michauxiana & . & + & + & $r$ & $r$ & . & . & . & . & . & . & . & IV & . \\
\hline Potentilla glandulosa & . & + & + & + & + & . & . & + & . & . & . & . & IV & I \\
\hline Heuchera cylindrica & . & r & + & . & . & . & . & . & . & . & . & . & II & . \\
\hline Rhizoplaca chrysoleuca & . & $\mathrm{p}$ & $\mathrm{p}$ & $\mathrm{p}$ & . & . & . & . & . & . & . & . & III & . \\
\hline Umbilicaria & . & $\mathrm{p}$ & $\mathrm{p}$ & $\mathrm{p}$ & . & $p$ & . & . & . & . & . & . & III & I \\
\hline Rhizoplaca melanophthalma & . & $\mathrm{p}$ & $\mathrm{p}$ & $\mathrm{p}$ & . & $\mathrm{p}$ & . & . & . & . & . & . & III & I \\
\hline Xanthoria elegans & . & $\mathrm{p}$ & $\mathrm{p}$ & $\mathrm{p}$ & . & . & $\mathrm{p}$ & . & . & . & . & . & III & 1 \\
\hline Caloplaca tiroliensis & & & $\mathrm{p}$ & $\mathrm{p}$ & $\mathrm{p}$ & $\mathrm{p}$ & . & . & . & . & . & . & III & 1 \\
\hline \multicolumn{15}{|c|}{ VARIANT of Potentilla diversifolia } \\
\hline Potentilla diversifolia & . & . & . & . & . & + & . & $r$ & + & + & $r$ & + & . & V \\
\hline Poa alpina & . & . & . & . & . & + & + & . & + & + & . & + & . & IV \\
\hline Erigeron compositus & . & . & . & . & . & + & + & $r$ & . & + & $r$ & . & . & IV \\
\hline Solidago multiradiata & . & . & . & . & . & + & . & $\mathrm{r}$ & + & + & . & + & . & IV \\
\hline Luzula spicata & . & . & . & . & . & + & . & r & + & . & + & + & . & IV \\
\hline Carex phaeocephala & . & . & . & . & . & + & . & + & + & . & + & $r$ & . & IV \\
\hline Silene acaulis & . & . & . & . & . & r & . & . & + & . & $r$ & + & . & III \\
\hline Sibbaldia procumbens & . & . & . & . & . & . & $r$ & $r$ & . & + & . & + & . & III \\
\hline Arenaria obtusiloba & . & . & . & . & . & 1 & $r$ & r & + & . & . & . & . & III \\
\hline Festuca brachyphylla & . & . & . & . & . & + & $+^{\mathrm{cf}}$ & r & + & . & . & . & . & III \\
\hline Arenaria capillaris & . & . & . & . & . & + & . & + & + & + & . & . & . & III \\
\hline Penstemon ellipticus & . & . & . & . & . & . & . & 2 & + & + & 2 & . & . & III \\
\hline Hypnum revolutum & . & . & . & . & . & $\mathrm{p}$ & $\mathrm{p}$ & $\mathrm{p}$ & $\mathrm{p}$ &. & . & $\mathrm{p}$ & . & IV \\
\hline
\end{tabular}




\begin{tabular}{|c|c|c|c|c|c|c|c|c|c|c|c|c|c|c|}
\hline Number & 1 & 2 & 3 & 4 & 5 & 6 & 7 & 8 & 9 & 10 & 11 & 12 & \multicolumn{2}{|c|}{ Constancy } \\
\hline \multicolumn{15}{|l|}{ Companion species } \\
\hline Sedum lanceolatum & + & $\mathrm{r}$ & $r$ & + & & + & $\mathrm{r}$ & $\mathrm{r}$ & + & + & $r$ & . & IV & $\mathrm{V}$ \\
\hline Achillea millefolium & . & + & $\mathrm{ad}$ & + & $\mathrm{r}$ & + & . & + & + & + & . & + & IV & IV \\
\hline Eriogonum ovalifolium & + & $\mathrm{r}$ & $r$ & $\mathrm{r}$ & + & + & . & + & . & . & . & + & $\mathrm{V}$ & III \\
\hline Potentilla fruticosa & 1 & $\mathrm{r}$ & $r$ & + & . & + & . & . & . & + & . & . & IV & $\|$ \\
\hline Cerastium arvense & & $r$ & + & + & . & $\mathrm{r}$ & - & . & + & . & . & + & III & III \\
\hline Poa secunda & . & . & . & $\mathrm{r}$ & + & + & + & . & + & + & + & . & ॥ & IV \\
\hline Festuca idahoensis & . & . & . & + & + & 1 & . & + & . & . & + & 2 & ॥ & III \\
\hline Selaginella scopulorum & . & . & . & $x$ & + & + & . & + & . & + & $r$ & . & II & III \\
\hline \multicolumn{15}{|l|}{ Important Bryophytes } \\
\hline Polytrichum piliferum & . & . & $\mathrm{p}$ & $\mathrm{p}$ & . & . & $\mathrm{P}$ & $\mathrm{p}$ & $\mathrm{p}$ & . & $\mathrm{p}$ & . & II & III \\
\hline Tortula ruralis & . & . & . & $\mathrm{p}$ & $\mathrm{p}$ & $\mathrm{p}$ & . & $\mathrm{p}$ & . & . & . & $\mathrm{p}$ & II & III \\
\hline \multicolumn{15}{|l|}{ Important Lichens } \\
\hline Lecidea atrobrunnea & 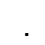 & $\mathrm{p}$ & $\mathrm{p}$ & $\mathrm{p}$ & $\mathrm{p}$ & $\mathrm{p}$ & $\mathrm{p}$ & $\mathrm{p}$ & $\mathrm{p}$ & . & $\mathrm{p}$ & . & IV & IV \\
\hline Rhizocarpon geographicum & . & $\mathrm{p}$ & $\mathrm{p}$ & $\mathrm{p}$ & $\mathrm{p}$ & $\mathrm{p}$ & $\mathrm{p}$ & . & $\mathrm{p}$ & . & . & . & IV & III \\
\hline Cladonia pocillum & . & . & $\mathrm{p}$ & $\mathrm{p}$ & $\mathrm{p}$ & $\mathrm{p}$ & . & $\mathrm{p}$ & $\mathrm{p}$ & . & . & . & III & III \\
\hline Aspicilia sp. & 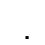 & $\mathrm{p}$ & $\mathrm{p}$ & & $\mathrm{p}$ & $\mathrm{p}$ & . & . & $\mathrm{p}$ & . & . & . & III & ॥ \\
\hline Lecanora polytropa & & $\mathrm{p}$ & $\mathrm{p}$ & & $\mathrm{p}$ & $\mathrm{p}$ & . & . & . & . & $\mathrm{p}$ & . & III & $\|$ \\
\hline Cladonia pyxidata & . & . & . & . & $\mathrm{p}$ & $\mathrm{p}$ & $\mathrm{p}$ & $\mathrm{p}$ & . & . & $\mathrm{p}$ & . & I & III \\
\hline Coelocaulon muricatum & 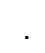 & $\sigma^{\circ}$ & $\mathrm{p}$ & $\mathrm{p}$ & . & $\mathrm{p}$ & $\mathrm{p}$ & $\mathrm{p}$ & . & . & . & 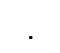 & II & III \\
\hline Peltigera rufescens & & & $\mathrm{p}$ & & $\mathrm{p}$ & $\mathrm{p}$ & & $\mathrm{p}$ & $\mathrm{p}$ & . & . & . & ॥ & III \\
\hline
\end{tabular}

\section{Minor species:}

Vascular Plants: Allium cernuum 1:r , 3:r , 10:+ ; Galium boreale 2:ad, 3:ad; Antennaria microphylla 1:+ , 5:r ; Cryptogramma acrostichoides 1:+ , 5:+ ; Sedum stenopetalum 5:+ , 12:r ; Antennaria alpina 5:x , 10:+ , 11:r ; Danthonia intermedia 5:+ , 8:+ , 10:+ ; Poa interior 4:r , 6:r , 8:+ , 11:r ; Saxifraga occidentalis 4:r , 6:+ , 10:r ; Eriogonum flavum 4:r , 5:ad, 6:r , 8:r ; Trisetum spicatum 6:r , 7:+ , 9:+ ; Epilobium angustifolium 1:r ; Agrostis scabra 1:+ ; Selaginella densa agg. 1:1 ; Carex sp. 1:+ ; Campanula rotundifolia 2:+ , 6:+ ; Spiraea betulifolia 2:+ ; Arabis lemmonii 4:r ; Mertensia viridis 4:r ; Heuchera parviflora $5:+$; Botrychium simplex $5:+$; Polygonum minimum $5:+$; Cheilanthes gracillima $5: r$; Potentilla gracilis $5: r$; Polygonum engelmannii 5:r ; Polygonum bistortoides 6:+ ; Silene parryi 6:+ ; Antennaria umbrinella 6:+ ; Carex albonigra 6:r ; Dodecatheon conjugens 6:r ; Oxyria digyna 7:r ; Erigeron acris 7:r ; Fragaria virginiana 8:+ ; Antennaria racemosa 8:r ; Luzula hitchcockii 8:r ; Draba paysonis 8:r ; Polemonium pulcherrimum 9:+ ; Anemone drummondii 9:+ ; Epilobium latifolium 9:+ ; Arabis nuttallii 9:+ ; Festuca vivipara 9:r ; Arabis sp. 9:r ; Poa sp. 10:+ ; Aster sibiricus 10:+ ; Lomatogonium sp. 10:+ ; Selaginella standleyi 10:+ ; Anemone multifida 10:+ ; Agoseris glauca 6:+ , 12:+ ; Besseya wyomingensis 6:+ , 12:r ; Astragalus alpinus 12:+ ; Arnica rydbergii 12:+ ; Lupinus lepidus 12:+ ; Oxytropis campestris 12:r ; Polemonium viscosum 12:r ; Selaginella sp. 12:r;

Bryophytes: Bryum capillare 3:p , 4:p ; Cephalozia? sp. 4:p , 5:p , 8:p ; Grimmia sp. 4:p , 5:p , Moss sp. 4:p ; Tortella tortuosa 4:p ; Orthotrichum sp. 4:p ; Encalypta affinis 4:p ; Bryum sp.2 7:p ; 4:p ; Racomitrium sp. 5:p ; Grimmia sp.2 5:p ; Bryum sp. 3:p , 9:p ; Ceratodon purpureus 4:p , 8:p ; Racomitrium canescens 5:p , 8:p ; Desmatodon latifolius 5:p , 8:p ; Pohlia sp. 5:p , 9:p ; Lophozia sp. 9:p ; Eurhynchium pulchellum 9:p ; Mnium arizonicum 9:p ; Lescuraea radicosa 9:p ; Dicranum spadiceum 9:p ; Hypnum sp. 9:p ; Brachythecium sp. 9:p ; Mnium sp. 9:p ; Barbilophozia hatcheri 9:p ; Tortula speM 11:p

Lichens: Peltigera sp. 7:p , 9:p , 11:p ; Cladonia chlorophaea 5:p , 7:p , 9:p ; Umbilicaria hyperborea 4:p , 5:p , 6:p , 7:p ; Thamnolia subuliformis 4:p , 7:p , 8:p ; Brodoa oroarctica 4:p , 7:p ; Xanthoparmelia wyomingica 4:p , 7:p ; Rhizocarpon sp. 5:p , 7:p ; Dermatocarpon reticulatum 4:p , 5:p ; Phaeophyscia decolor 4:p , 5:pcf; Lepraria sp. 5:p , 9:p ; Cladonia sp. 4:p , 5:p ; Xanthoparmelia sp. 4:p , 5:p ; Physcia caesia 4:p , 5:p ; Diploschistes muscorum 3:p , 4:p ; Peltigera didactyla 5:p , 6:p , 8:p ; Stereocaulon sp. 7:p , 8:x ; Peltigera aphthosa 7:p , 9:p ; Cetraria islandica 6:p , 9:p ; Psoroma hypnorum 9:p , 11:p ; Candelariella vitellina 2:p, 11:p ; Physcia sp. 4:p , 11:p ; Peltigera lepidophora 4:p , 8:p ; Lecanora cf. thomsonii 2:p ; 11:p ; Acarospora schleicheri 3:p ; Lecidella wulfenii 3:p ; Rinodina cf. archaea 3:p, 6:p; Megaspora verrucosa 3:P Ochrolechia upsaliensis 3:p ; Rinodina spec3 4:p ; Lecidoma demissum 4:p ; Acarospora fuscata 4:p; $\quad$ Melanelia sp. 4:p ; Umbilicaria polyphylla 4:p ; Rinodina sp.1 4:p ; Diploschistes sp. 4:p ; Cladonia sp.2 4:p ; Rinodina sp.2 4:p ; Caloplaca fraudans 4:p ; Sporastatia testudinea 4:p ; Cladonia borealis 4:p ; Trapeliopsis granulosa 4:p ; Psora sp. 4:p ; Collema sp. 4:p ; Dermatocarpon sp. 4:p ; Candelariella sp. 4:p ; Physconia muscigena 4:p ; Pseudephebe minuscula 4:p ; Umbilicaria virginis 4:p ; Umbilicaria deusta 5:p ; Dermatocarpon miniatum 5:p ; Lichen sp. 5:p; Leptogium sp. 5:p ; Massalongia carnosa 5:p ; Aspicilia contorta agg. 5:p , 6:p ; Physcia aipolia 5:p ; Endocarpon sp. 5:p ; Lecanora sp. 5:p ; Lecanora behringii 5:p ; Lecanora cf. badia 5:p; Lecanora muralis 5:p ; Cetraria ericetorum 6:p ; Bryanora castanea 6:p ; Rinodina mniareae 6:p ; Lecidea sp. 7:p ; Lecanora rupicola 7:p ; Cetraria commixta 7:p ; Pseudephebe pubescens 7:p ; Cladonia borealis 8:p ; Peltigera horizontalis 9:p ; Rinodina mniaraea 9:p ; Rinodina sp. 9:p ; Pannaria sp. 9:p ; Cladonia cf. macroceras 9:p ; Lecideine epilithic crust 11:p ; 


\section{Class: Thlaspietea rotundifolii Braun-Blanquet 1947: Talus and Scree communities}

Talus slope communities cover more than any other alpine plant communities in the study area. The pronounced, glacier-carved, steep relief of the mountains together with readily weathering, sedimentary parent materials provides ideal conditions for the development of extensive talus slopes. Thus long reaches astride the continental divide are covered by acres of colluvial talus slopes of highly unstable to increasingly stabilized screes and taluses. Being constantly fed with rock debris falling down from the weathering cliffs above, these sites provide the most unstable growing conditions among the alpine plant communities of the area. This is added to by mass wasting processes like soil creep, soil slide, sliding talus and rock avalanches. It needs to be mentioned though that not all talus slope experience frequent disturbance and settled colluvial slopes with little slope activity over long periods do occur allowing for more advanced stages of plant community establishment. These stabilized colluvial slopes are less common though and main emphasis is put on unstable slopes in this chapter.

A horizontal differentiation of disturbance levels can be found along most of the talus slopes like e.g. along the Continental Divide. Gaps in the debris-producing cliffs above funnel the streams of talus, resulting in sections with strong colluvial activity often characterized by horizontally-convex surfaceprofiles called "talus cones". The sections between those cones have a concave profile due to the smaller amount's of debris reaching these sites. Much of the falling debris reaching these concave surfaces is funneled towards the depressions whereas the cone-crests are much less exposed to colluvial disturbance.

In general, this differential colluvial activity results in horizontally undulating slopes with differentiated ecological conditions. Resulting are sites with different exposure to wind and the differences in snow duration, as well as varying degrees of mechanical disturbance. These gradients are reflected in the vegetation. Great examples of this can be seen e.g. along the Continental Divide at Fifty Mountain, which is the most extensive continuous talus slope studied: the convex talus cones appear conspicuously greener here than the more active depressed parts which can also be detected by their fans of fresh talus at their footslopes.

Mechanical disturbance is the most prominent ecological factor and requires extreme adaptation to these unstable environments, reducing the comparatively small high elevation flora to even less plant species. The remaining set of species represents a selection of highly adapted organisms, which for this reason form very well defined plant communities with good character species. These species are prominent in this special environment but hardly occur under more stable conditions. The latter fact seems to reflect their little competitive power of these species. Inter- and intraspecific competition is not a major concern in these often sparsely vegetated environments. The adaptive strategies of plants from this kind of instable slope habitat have been characterized as belonging to three main strategies which have frist been described by Schroeter (1926) from the European Alps (see also Harshberger (1929) who also gave the translations of the following terms:

1. passively "migrating" (German: "Schuttwanderer" = scree-wanderers),

2. scree-blocking (German: "Schuttstauer" = scree-dammers/scree-bankers),

3. over-running (German: "Schuttüberkriecher" = scree-creepers/trailers).

The first kind of plants are usually of small size (e.g. Arenaria rossii, Stellaria americana) and do not send much of their root system down into the lower soil horizons. They therefore are not anchored 
firmly to the non-moving deeper parts of the talus but move with the active upper layers (Ellenberg 1996). Because water storage in the upper substrate layers on talus slopes is very limited, most plants need to reach deeper into the colluvial material. Schroeter (1926) and other authors interpret screewanderers as species which follow the scree movement by growth of elongated, horizontal shoots through the rocky material. Other authors refer to this more active strategy as scree-stretchers (German: "Schuttstrecker"). Examples for this strategy in the area are Cryptantha celosioides, Phacelia hastata and many other species in their younger stages.

The second group of plants follows the movement of the substrate by growth of superficial shoots which are prostrate, i.e. loosely appressed to the slope surface. The most conspicuous Penstemon ellipticus, Juniperus communis as well as Arenaria nuttallii are perfect examples of this scree-creeper strategy.

The third type are the scree-bankers which are rooting deeply in the stable lower body of the talus slope by means of strong, often fibrous roots. These sturdier plants are creating a barrier for the moving screes and dam the debris upslope. Oftentimes this results in little humps which subsequently facilitate the establishment of other less resistant species. These slope-stabilizing plants are capable of initiating successional seres on not too extreme talus slopes. Poa secunda, Agropyron spicatum, Cryptogramma acrostichoides and Saxifraga bronchialis (the latter on finer scree only) belong to this group.

Transitional strategies do of course occur, and sometimes within the lifetime of a plant individual it changes its type of strategy. E.g. a plant that starts out as a small individual following the movement of the substrate might later on block of considerable amounts of substrate.

Successional development is possible only if the supply of new rock debris ceases which is not the case on most of the talus slopes. Therefore these specialized communities have been called "permanent pioneer communities" (Dierschke 1994) referring to their ability to colonize these sites despite the constant disturbance which nevertheless hinders progressing to further stages of succession. Even the more consolidated foot slopes with their denser vegetation are not necessarily an indication of currently advancing succession as long as disturbance remains an important factor. Like the more impacted sites further upslope, these sites might be in equilibrium with the environmental conditions and remain relatively stable for extended periods of time.

Succession on unstable talus slopes towards dry tundra communities can occur. It usually results in stripes of vegetation that extent vertically downslope - or better upslope, since the development most likely proceeds in that direction (see plate 2, fig. 6. The soil conditions in the consolidated vegetation stripes with their large amounts of fine material are very different from the alternating, vertical scree runs and so is the vegetation. Accordingly, this will be treated in this study with the tundra communities from which it is unseparable by its plant composition.

Parent materials: Most of the talus slopes in the study area consist of platy, shaly green or red argillite, occasionally mixed with fragments of sandstones of various coarseness, limestone shales, quarzitic material or rarely dioritic rock fragments. It reflects the often highly diverse stratigraphy of the sedimentary layers. The colluvial process creates a highly mixed material leveling any differences in chemical contents of the various parent materials. Talus of pure igneous origin or pure limestone have not been found in the area. Resulting is a lack of differentiation of the talus communities according to different local bedrock materials. Any differentiation that can be found is most likely caused by differences in stability of the substrate, slope aspect, moisture supply, and exposition to the sun and desiccating winds. Snow duration as the most important factor for the vegetation in the alpine also plays a role, as is indicated by the lusher developement of talus vegetation below late melting 
snow patches and the complete absence of vascular plants and often even lichens on late melting talus.

The texture of the colluvial surface materials ranges from coarse talus to stands with high proportions of finer material. The coarser textured substrates are mainly to be found covered by more extreme, less species-rich communities like the Arenaria nuttallii and Stellaria americana communities. Slopes with finer substrate are covered by the Penstemon ellipticus community which also seems to be more snow tolerant.

Moisture conditions: Concerning available moisture, talus slopes are not nearly as harsh an environment as the rocky surface suggests. This is also reflected by the many mesomorphic, productive species inhabiting these sites, a situation which can also be found in similar habitat in the Alps (Ellenberg 1986). As has been mentioned under the Artemisio-Potentilletum, Harshberger (1929), moisture is well retained under the cover of the shingle-like rocks of the upper rock layers which effectively diminishes the evaporation rates. Quite frequently a fine textured, well moisturesupplied substrate can be found a few centimeters below the shale-covered surface. Surprisingly, many talus slopes have been found to show occasional patches of silty fine soil all the way to the surface.

Syntaxonomy: Talus communities have hardly been studied in North America to this point. This is likely due to their little vegetative cover which at first glance might lead to the conclusion that these habitats bear no plant communities at all. This, as will be shown below, is far from being true. As mentioned before, some very diagnostic species inhabit these sites. The lack of recognition for these communities might also be caused by the very different aspects that similar communities might display, mainly due to the extreme differences in vegetative cover and a considerable degree of heterogeneity of the stands. The range in vegetative cover can be from less than $1 \%$ to more than $70 \%$. Widely differing degrees of substrate stability account for this great variability. The same factor also results in the floristic heterogeneity of the stands. Sparsely covered slopes reveal scattered open microsites for the establishment of new individuals. Diaspores of new species take their chances and increase the species diversity of the stands even though some of them might get established temporarily only. Furthermore at the lower end of the vegetative cover scale, correlated with increasing disturbance, more and more species drop out resulting in communities of only a few highly adapted species. The last species to wane are Arenaria nuttallii and Stellaria americana in the area. The latter sometimes occurs in pure, very scattered stands on otherwise barren talus and scree slopes. Whether these one species stands still constitute "communities" should not be discussed here but they certainly deserve recognition as distinct, recurring units.

All of these different variations of plant cover, as different as they might appear, accommodate a very stable array of species and thus can be syntaxonomically united.

The talus and scree slope communities in the Rocky Mountains are ecologically equivalent to those occurring in other high-mountain areas in the world, especially the European Alps. For this reason, they have been included in the European class Thlaspietea rotundifolii as it was provisionally done by Willard $(1963,1979)$ and Komárková 1979. However, those two authors mentioned already, that none of the European class character species occurs in these communities in their study areas which also applies for the area covered in this study. Therefore, a new class will have to be created on this continent. Far too little research has been done on North American talus slope communities to even suggest a provisional name and delineation for this new syntaxon at this point.

Some syntaxonomical relations of the communities described here to other local units exist. Successional development on SE exposed, moister talus is towards tall herb meadow communities 
which are closely related to the Aster foliaceus-Aquilegia flavescens community described below, mainly to the richer variant of Cirsium hookerianum. Somewhat related to these communities are the hetereogeneous vegetation types of fresh moraines and other fine soil bearing sites on younger glacier forefields, as have been described by Baden (1952), Viereck (1966) and Given \& Soper (1975). Such assemblages might indeed be too heterogeneous and subject to the coincidential processes of initial colonisation to be called communities. Nevertheless, some of the characteristic species of the following order are frequently found on such sites.

\subsection{ORDER: Phacelietalia hastatae ord. prov. - Silverleaf-Phacelia - Shrubby Beardtongue-talus community}

Nomenclatural Type: Epilobio alpini-Penstemonion elliptici all. nov.

Plots: (see subordinate units)

Character species: Phacelia hastata, Penstemon ellipticus, Phacelia lyallii, Epilobium latifolium, Senecio fremontii, (Viola nuttallii, Physaria didymocarpa, Arabis lemmonii)

The constant occurrence of extensive talus communities with a very constant set of characteristic species throughout the study area warrants the creation of this new, floristically and ecologically distinct order. Only very few species are shared with the Aquilegio-Cirsietalia scopulorum Komárková 1979 and the overall floristic difference to that order clearly calls for a separate order for the northern-central Rocky Mountains. However, due to the limited study area and the lack of similar habitats from areas beyond, this order is established as a provisional unit at this point.

The character species given for this syntaxon are characterized by a high degree of fidelity. By far the most common species in stands of this alliance is Phacelia hastata. It is a most faithful species occurring with a wide range of cover degrees. Penstemon ellipticus is also characteristic for this syntaxon with an apparantly higher fidelity in the alliance which was named after this species. The remaining species Phacelia lyallii, Epilobium latifolium, Senecio fremontii, Viola nuttallii, Physaria didymocarpa and Arabis lemmonii have little constancy but again are hardly ever found outside this syntaxon. At least in the area they are highly diagnostic for this unit. Senecio fremontii is known to occur in other vegetation units too but most reports refer it to scree habitats (Scott 1966, van Vechten 1960, Hamann 1972, Polster 1977, Thilenius 1985).

\subsubsection{ALLIANCE: Epilobio alpini-Penstemonion elliptici all. nov. \\ - Alpine Willow-Herb - Shrubby Beardtongue talus slopes}

Nomenclatural Type: Aquilegio flavescentis-Asteretum foliacei ass. nov.

Plots: (see under the subunits)

\section{Character species: Penstemon ellipticus, (Senecio megacephalus)}

Differential species: Epilobium alpinum, Poa cusickii, Valeriana sitchensis, Thalictrum occidentale

As a unit of steep, unstable slopes this alliance fits into this talus slope order. On the other hand there are some vegetative traits, mainly the richness in tall herb species, which show a close relationship to the tall herb communities. This is added to by the presence of some conspicuous tall herbs like Senecio megacephalus, Valeriana sitchensis and Thalictrum occidentale. The large group of rich tall 
herb communities, which are found mainly at the lower end of the alpine zone and in the subalpine, has not yet been studied at all. With a better understanding of these units the relation to the present alliance should be re-evaluated in the future. Differentiating against those lush and productive subalpine communities is the higher elevation range of the present alliance.

For its ecological characters, its more open stand structure and its floristic affiliations this community is placed into this talus and scree-slope alliance. Furthermore Senecio megacephalus itself is a differentiating species since it hardly ever occurs in the denser stands of subalpine tall herb communities.

\title{
2.1.1.1. ASSOCIATION: Aquilegio flavescentis-Senecietum megacephali ass. nov. \\ - Yellow Columbine - Large-headed Groundsel talus slope association
}

\author{
Nomenclatural Type: Table 15 relevé 420
}

Plots: $169,170,171,172,178,179,384,385,386,403,416,418,419,420,429,716,717,718,721 \quad(\mathrm{n}=19)$

\section{Character species: Senecio megacephalus, Aquilegia flavescens,}

Differential species: Aster foliaceus, Epilobium angustifolium, Sedum lanceolatum, Arabis drummondii, Tortula norvegica

General aspect: A reasonably constant set of species defines this conspicuous scree-slope community which structurally resembles an open tall herb community. Still the slope position with the resulting unstable slope surface, the openness with a lot of visible mineral soil surface and the wide-spaced vegetation structure differ from the denser and lusher subalpine tall herb stands. A higher number of plant species in the latter units seems to be correlated with their advanced successional development.

During much of the summer this is the most flower-rich talus community in the area with the Cirsium hookerianum variant being even more spectacular. The conspicuous flowering tufts of Senecio megacephalus, Aquilegia flavescens and Epilobium angustifolium overtop the lower growing mats of the showy Penstemon ellipticus and its even more constant, but less dominant companion, the most characteristic Phacelia hastata. The latter and Sedum lanceolatum are characteristic for talus slopes far down to lower elevations.

Topography: Stands of this community are found on extremely steep low- to mid-alpine talus slopes from $25^{\circ}$ to $35^{\circ}$ steepness with a remarkably narrow elevation range from 2000 to $2200 \mathrm{~m}$. This altitudinal zone along the Continental Divide holds most of the extensive talus areas and forms a prominent belt between the rocky summit region above and the upper limits of continuous vegetation below. Aspect is S to W, mostly SW and thus perpendicular to the main direction of the Divide. For topographical reasons this talus belt is less well developed on the NE-facing side of the Divide where the community has not been found. The latter might also be contributable in part to the inaccessability of those areas. It might occur there locally but the drier E and SE exposed talus slopes on the continental side of the Divide are less likely to host this mesic type of vegetation.

Geology: Parent material is mostly green argillite which predomintates at this altitude along the Continental Divide. Occasionally small amounts of red argillite, sandstone or limestone are mixed in. Red argillite and Siyeh limestone do occur as the main parent material in areas off the Divide (Lincoln Pass, Lunch Creek). 
Soils: Soil development with little humus accumulation is restricted to initial stages around clumps of vegetation. Still the mostly pure mineral substrate over most of the sites is not yet altered by the development of a soil profile. Any edaphic stratification is disturbed by the ongoing soil action (soil creep, soil slides). Soil develoment initiated by the open vegetation is not able to change this situation. Only few sites with a higher fraction of fine soil show marked soil consolidation correlating with a lesser degree of disturbance.

Wind exposure/Snow cover: The exposure to wind is quite high in these open high elevation communities. Not much is known about the snow duration on talus slopes in the area. Obviously snowbanks often persist long into July and sometimes August at the upper reaches of the talus slopes right below the cliffs above. These snowpacks through much of the season provide ample water supply for the vegetation below. On the other hand, convex parts of the talus slopes might get blown almost free of snow in winter resulting in much earlier snow melt and somewhat drier conditions.

Moisture conditions: The mesomorphic growth-form of many tall herbs in this community is a visible sign of the good water situation. Rock cover is high (70-100\%) on these slopes. The concentration of the larger rock fraction on the surface might be one factor contributing to the mesic moisture conditions. Larger rocks, namely slabs of argillite-shale, cover the finer mineral soil and act as a barrier against evaporation as has been mentioned before. This is evidenced by the moist fine soil which can easily be dug up a few centimeters below the surface even in late summer. Given the high exposure to wind and the good drainage of the sites this amount of water availability is quite surprising. Moisture supply by melting snow can be very different among the sites.

Vegetation: This plant community can be considered the higher elevation variant of those yet undescribed subalpine tall herb communities. Apart from its diagnostic species, it is quite heterogeneous in its composition which is commonly the case in such unstable environments which get easily invaded by "accidental" species. On the one hand these slopes are subject to enough disturbance as to allow for the establishent of new, mostly subalpine meadows species, which are increasing the heterogeneity of the stands. On the other hand conditions are stable enough to allow for more than just temporary establishment of these herbs. Woody species are most likely excluded due to the prolonged snow duration and the destructive forces of soil movement.

Owing to the unstable substrate, lichens are mostly lacking, whereas a few mosses are present although with very little cover. Nevertheless Tortula ruralis and T. norvegica are highly constant species on stable micro-sites, adding to the mesic character of this community.

\section{SUBASSOCIATION: Aquilegio flavescentis-Senecietum megacephali typicum \\ Nomenclatural Type: Table 15 relevé 429}

Plots: $171,172,178,179,403,416,429 \quad(n=7)$

\section{Character species: none}

Without any differentiating character species the typicum variant comprises slightly more extreme and species poorer stands compared to the subassociation of Cirsium hookerinanum. The most obvious difference visible at first glance is the dominance of Penstemon ellipticus with can achieve considerable cover. As with all talus slope communities the degree of homotony is not very high. 


\section{SUBASSOCIATION: Aquilegio flavescentis-Senecietum megacephali castillejetosum}

miniatae subass. nov.

- Subassociation of Scarlet Paintbrush

Nomenclatural Type: Table 15 relevé 384

Plots: $169,170,384,385,386,418,419,420,716,717,718,721 \quad(n=12)$

Differential species: Castilleja miniata, Cirsium hookerianum, Aquilegia flavescens, Hackelia floribunda, Aster foliaceus, Lomatium dissectum, Eriogonum flavum, Phleum alpinum

This variant is the most conspicuous of all talus communities. It is dominated by a number of relatively high growing tall herbs most of which usually occur in subalpine meadows. Thus this community might be looked at as an impoverished variant of a subalpine meadow community or an early successional stage in a sere towards a stable meadow community. The latter option seems doubtful though, since one main character of consolidated meadow is a less steep and thus less disturbed slope position. Therefore it seems to be more likely that these meadow assemblages are floristically quite stable despite their heterogeneity, without the chance of a progression into a more advanced meadow stage.

Vegetational structure and ecological conditions are much different from the more consolidated meadows even though this community is on the more stabilized end within the talus communities. The subassociation has close affinities to the Carex geyeri ravine community. Compared to the typicum variant this subassociation has more fine mineral soil at the surface and coarse talus is less important. This is an important difference in that mechanical disturbance is much reduced with the absence of larger sliding rocks which are particularly detrimental to mesophytic tall herbs which after mechanical damage do not recover easily.

\section{Phacelia hastata-Penstemon ellipticus basal community plate 3, fig. 8,}

Plots: $326,332,417,549,553,554,555,602,617,618,638,720,775,780,783 \quad(n=15)$

Character and differential species: none

This syntaxon combines a number of heterogeneous species assemblages which apart from the character species of the alliance do not have a common diagnostic species group. Due to the heterogeneous nature of these talus communities a much larger sample of plots would be needed to better define subtypes. These would be determined by various combinations of the dominant ecological factors substrate-stability, snow duration and meltwater-supply. At this point the only differentiating characters found are differences in dominance which creates striking differences in aspect. Greatest dominance can be reached by Penstemon ellipticus, rarely Epilobium latifolium assumes the same role. Since no ecological differentiation can be correlated to these variations I restrain from the attempt to create separate syntaxa.

A species suggesting ecological differentiation is Epilobium alpinum on sites with better water supply. Together with Poa cusickii it creates a group at the mesic end of this syntaxon. Until separate study of talus communities elucidates the finer relationships in this groups it is retained a basal community

Topography: On alpine talus slopes from $2000 \mathrm{~m}$ to $2400 \mathrm{~m}$. The slopes are very steep from $25^{\circ}$ to $34^{\circ}$ facing SW or S to E. Rock cover is high from $65 \%$ to usually more than $90 \%$ with scattered larger rocks and even boulders occasionally present. Fine soil is mostly not visible except for scattered 
patches of silty material protruding after disturbance. The rocks and pebbles at the surface are loose and scree runs are very common on these most unstable sites.

Geology: Most sites have been sampled on green and red argillite with small amount of other quarzitic and dioritic rocks mixed in. In a few plots a fraction of limestone was present.

Soils: see under Aquilegio flavescentis-Asteretum foliacei

Wind exposure/Snow cover: Winds are high to middle on these sites with snow accumulating to a degree that results in a reasonable and sometimes even longer snow cover.

Moisture conditions: Mostly mesic conditions are encountered on the sites. Even though the rocky surface easily makes the impression of a very dry community, considerable moisture is present in the lower fine soil richer horizons being protected against evaporation by the surface layer of larger screes and rocks.

Vegetation: The vegetation occurs mostly as scattered tufts of single species or little patches of few species clumped together. Only rarely are patches of coherent vegetation developed on slightly less unstable sites.

Litter is mostly lacking completely or restricted to the immediate remains of the scattered clumps of tall herbs. Only Penstemon ellipticus is capable of generating considerable amounts of litter under its single-species patches which sometime can reach remarkable cover.

Lichens and bryophytes are mostly absent on these unstable slopes.

Distribution: Most of the sites have been encountered on the extensive talus slopes along the Continental Divide from the Hole-in-the-Wall area near the Canadian border to Dawson Pass in the south. Only few sites have been observed far east of the Divide which might hint to the fact that this community does not tolerate extremely dry conditions.

\subsubsection{ALLIANCE: Phacelio hastatae-Arenarion nuttallii all. nov. \\ - Phacelia hastata-Arenaria nuttallii talus slope community}

Nomenclatural Type: Phacelio sericeae-Arenarietum nuttallii

As a second alliance in this order this unit was created to accommodate the communities of extremely mobile scree slopes. It is so far represented by one association only.

\subsubsection{ASSOCIATION: Phacelio sericeae-Arenarietum nuttallii ass. nov. - Silky Phacelia-Nuttall's Sandwort talus slopes}

Nomenclatural Type: Table 15 relevé 261

Plots: $82,219,261,276,305,495,643 ; 771 \quad(n=8)$

Character species: Arenaria nuttallii, Phacelia sericea, Cryptantha celosioides

Differential species: Eriogonum ovalifolium, Agoseris glauca, Artemisia michauxii, Penstemon lyallii, Saxifraga bronchialis, Rhizocarpon geographicum s.l., Lecidea atrobrunnea, Lecanora polytropa, Umbilicaria krascheninnikovii, Rhizoplaca melanophthalma

General aspect: The general aspect of this community is not very showy since most species are of small stature and conspicuously flowering species are growing widely spaced or lacking entirely. Furthermore the hairy coat of many of those plants almost camouflages them on the scree-patterned 
grayish-green argillite surface. Compensating for this can be the various colored rock assemblage with small amounts of red argillite, brown weathered arenitic sandstone debris, whitish quartzite and other rock types present. This spectacularly coloured inorganic surface almost perfectly hides its vegetative cover. This might have lead many people to the wrong assumption that these talus slopes lack any plant life at all.

Outstanding plants in this assemblage during flowering time are Crypthantha celosioides with its white ball-shaped inflorescences, Eriogonum ovalifolium and the beautiful purple Phacelia sericea. Less constant are the yellowish flowering Agoseris glauca, the white flowering Saxifraga bronchialis and the tall and showy pale violet flowering Penstemon lyallii.

Topography: Apart from the following subunit this is the most extreme talus-scree community found in the study area. It occurs at elevations from $1800 \mathrm{~m}$ to $2500 \mathrm{~m}$ on steep slopes from $24^{\circ}$ to $37^{\circ}$ and is not restricted to any slope aspect. The steepness and the loose scree results in unstable conditions with scree run at the surface and other mass wasting processes like rock slides of the whole upper talus layers. The total of rock surface is between 90 and $98 \%$. Fine soil at the surface is negligible and confined to soil pockets around tufts of plants.

Geology: Parent material is mostly green or red argillite with small amounts of other proterozoic rock types.

Soils: Almost no soil development is found in this unit. Most plants are rooted in the fine fraction of the abundant mineral soil. Disturbance by slope movement and frost action prevents the establishment of discernible soil horizons. Nevertheless slighlty darkened upper layers of mineral soil can be found under clumps of vegetation resulting from decomposed organic matter.

Wind exposure/Snow duration: Exposure to wind is high in most cases with wind being also likely to account for some erosion of mineral and organic material. Snow duration in this community is hard to estimate and measurements are not available. Whereas often the cover and species composition of lichens give a good hint as to how long the sites are snow covered during the year, this does not apply for these unstable sites. Here the constant but little abundance of lichens is likely to be a consequence of surface movement rather than a result of long snow cover. It is assumed that most stands are snow free by late June, some might be melting off even earlier giving an estimated snow free period of 5 to 6 months. The absence of mesomorphic species points to possibility of water stress in these stands. High exposure to wind and the presence of tomentose leaf and stem surfaces on most of the important species of this community in combination with the low growing habit adds to this assumption.

Vegetation: A relatively low number of plant species with a constant diagnostic species groups and a additional heterogeneous set of more of less accidental species is typical for this syntaxon.

Species-richness varies quite a bit thus the degree of homotony is low. Succession in not likely to occur in this most extreme kind of habitat. In fact the present vegetation is permanently struggling with the constant disturbance and this is a good example for a permanent pioneer community. The size of stands varies from a couple of ten square meters to almost a hectar. In some areas it forms mosaic-like complexes with vertical stripes of tundra-like vegetation often dominated by Potentilla fruticosa (see p.100. The rich tundra type forms its own densely vegetated narrow lines, which seem to float in the loose surrounding scree slope, perpendicular to the contour lines of the slope. The Arenaria-Phacelia-scree community covers most of the area in between the vegetation stripes building the "matrix" of the vegetation complex. The latter function is even more often assumed by the following subassociation. 
Surprisingly, a differential group of lichen species is present in this unstable talus community. These lichen species might be regarded as a separate synusia representing a variant of the widespread circumpolar Rhizocarpon geographicum community of non-calcareous substrates. In this context they are included, being good indicators of the overall site conditions. It can be inferred from the presence of a number of those epipetric lichens in most of the stands of the association that the rock sliding activity is not as intense as it is in the subassociation of Stellaria americana. This, as will be mentioned below, is the most important difference between those communities. Mosses are most entirely lacking on these fine-soil poor, unstable sites.

Distribution: The community is most common in this kind of habitat and was found through much of the alpine in the park.

Literature: As mentioned above, talus slope communities have so far not received much attention by researchers. Caicco (1984) reports talus slopes as locally common in the White Knob Mtns. and Pioneer Mtns. of Idaho, developing on all rock types. Common species with talus slopes from Glacier NP are Phacelia hastata, Arenaria nuttallii, Polemonium viscosum and Agropyron scribneri. Differentiating and lacking in Glacier are the less frequent species Penstemon montanus Greene, Chaenactis evermannii Greene, and Anelsonia eurycarpa (Gray) Macbr. \& Pays. Oxyria digyna is restricted to moist and late melting talus sites in the study area.

Polster (1977) mentions a community with Arenaria nuttallii, Phacelia sericea and Agropyron latiglume which he calls Draba-Agropyron Ridge Community. In the light of the present study which has been conducted just south of Polster's study area in southeastern British Columbia, the constant occurrence of those species with species of much more stable tundra communities on consolidated ridgetops might seem odd. Together with the information that Arenaria nuttallii and Phacelia sericea are dominant on scree and Arenaria obtusiloba and Erigeron compositus are dominant in vegetation stripes it becomes obvious that Polster sampled two interfingering, complex-building communities together which have been kept separate in this study (see above).

\section{SUBASSOCIATION: Phacelio sericeae-Arenarietum nuttallii stellarietosum americanae subass. nov. - American Starwort unstable scree slope community \\ Nomenclatural Type: Table 15 relevé 388}

Plots: $71,83,281,365,388,465,793,797 \quad(n=8)$

\section{Character species: Stellaria americana, Agropyron scribneri (Polemonium viscosum, Claytonia megarhiza)}

General aspect: This is by far the most extreme and often most species-poor talus community. Very unstable soil conditions with intense scree run is the predominant site factor. Any plants colonizing these sites have to be able to withstand these conditions by means of their adapted growth strategies (see above). Stellaria americana often gets overrun by mid-sized screes and manages to survive by its lax, "floating" growth of its elongate shoots through the scree masses. Arenaria nuttallii on the other hand with its more compact-prostrate stature remains on top of the scree and manages to stay there even if scree shifts around it. Under these extreme conditions many species are not able to survive which is why with increasing severity of site conditions the number of species in the community drops dramatically. The most unstable vegetated screes are inhabitat solely by Stellaria or Arenaria nuttallii forming single-species fragment communities (sensu Brun-Hool 1966). Looked at in a successional context, of course, these taxa are the first to colonize these site with other species not being able to invade. Even more so than in the association the sites of this community look almost unvegetated at 
frist glance. Vegetation cover indeed is the least of all communities treated in this study ranging from $5 \%$ to less than $1 \%$. The mosaic-building function mentioned for the typicum-subassociation is taken even more so by this unit.

Topography: This community occurs on very loose, smaller textured talus and scree slopes facing NNE to SSW. The slopes are extremely steep from $28^{\circ}$ to $38^{\circ}$. The elevation range is in the alpine from $1900 \mathrm{~m}$ to $2300 \mathrm{~m}$. It seems that this community is very much dependent on a certain scree texture. All stands sampled and further observations revealed that the medium rock size classes (2$5 \mathrm{~cm}, 5-10 \mathrm{~cm}$ ) predominated on the sites. Fine soil is hardly visible thus the scree particles are not bedded in a stabilizing finer matrix but loosely covering the surface. Vertical scree runs are very common as can be easily observed when crossing these slopes, sliding and stumbling on the loose surface. The scattered vegetation is easily damaged by trampling on this loose scree, which at a first thought seems to contradict the natural adaptation of this vegetation type. But trampling by humans causes localized stress on the long shoots and roots weaving through the loose scree much more so than does the slow and more evenly distributed scree movement.

Geology: Parent material is green and red argillite, sometimes with smaller amounts of other rock types mixed in.

Soils: No apparant soil development has been found in this extremely rocky plant community.

Floristics: This variant is floristically an impoverished version of the former unit. Whereas Stellaria americana and Agropyron scribneri are almost completely exclusive species for this community, the other two character species listed above do occur in other communities with very low constancy also.

Syntaxonomy: This community could be treated as an unranked fragmentary variant of the latter association and not - as done here - as a subassociation. Still the diagnostic species Stellaria americana does occur only in few samples of the association and structurally it is restricted there to the most unstable micro-environments of the sites which have not been differentiated in this classification. Furthermore these most extreme sites are differentiated by the absence of a number of epipetric lichens typical for the typicum association. Due to the intense scree-run, rock lichens can not establish on the periodically moving rocks. Mechanical abrasion and the rocks being turned over completely impede the establishment of these species which thus are good indicators for stable soil surface conditions.

The delineation of this unit towards the latter one is somewhat doubtful. The presence of Stellaria americana has so far been used as a criterion but might be replaced by using the species-richness of the plots as a criterion.

Distribution: This subassociation has been found on talus slopes along the Continental Divide and in the eastern parts of the study area. A distribution far beyond the study area is to be expected. 


\title{
Thlaspietea rotundifolii: Unclassified associations
}

\section{ASSOCIATION: Cryptogrammo crispae-Athyrietum distentifolii ass. nov. - Rock-Brake-Alpine Lady-Fern boulder slope community plate 3, fig. 11]}

Nomenclatural Type: Table 16 relevé 556

Plots: $556,557,591,592,593,327,331,354 \quad(n=8)$

\author{
Character species: Athyrium distentifolium var. americanum, Cryptogramma acrostichoides \\ Constant species: Juncus parryi, Carex phaeocephala, Epilobium alpinum, Penstemon \\ ellipticus, Bryum sp., Polytrichum piliferum
}

General aspect: The typical community of alpine and subalpine boulderfields is the azonal rockbrake-alpine lady-fern community. This often is not a very obvious vegetation type since most of the plants of this community can be hidden in gaps between large rocks of extensive boulder slopes. The most apparent species is the name-giving Athyrium distentifolium which is in most cases visible, with its bright green fronds protruding between the rocks. Cryptogramma acrostichoides can also be very conspicuous in places where it occurs abundantly. Penstemon ellipticus is the only constant species giving some flowering color to this community when in summer.

Topography: The Alpine Lady Fern community is a typical boulder-slope community occurring on mostly steep low- to mid-alpine boulder slopes from $2000 \mathrm{~m}$ to $2200 \mathrm{~m}$. Aspect is mainly S to SE with a slope of $30^{\circ}$ to $35^{\circ}$ or less than $20^{\circ}$ on foot slopes. The size of the rock debris is considerably larger than in other talus communities, ranging from a couple of decimeters in diameter to huge blocks measuring more than $5 \mathrm{~m}$ across. Smaller fractions of talus can accumulate in the interstices where the necessary fine soil fractions create pockets of substrate which are essential for the establishment of vascular plants in this adverse rocky environment. All vascular plants and bryophytes (except for Grimmia sp.) grow in these fine soil accumulations.

It is well known from other areas that boulder slopes experience a particular microclimate catching and retaining downslope moving cold air in the extensive system of interstices which is where most of the vegetation is found. This particular micro-environment often holds azonal vegetation with species commonly occurring in colder climates.

Parent material: Parent material is mostly red argillite or ignous dioritic and gabbroic rocks of the Purcell sill intrusion, sometimes mixed talus with considerable amounts of green argillite. The argillite types of boulder slopes show a different, isodiametric debris texture, whereas mostly the argillites in the study area are fine-layered and fracturing into platy shales creating a much different kind of scree.

Soils: Soil development in the limited space of soil pockets is slow due to the cool temperatures of the sites and the relatively short growing season. Under such conditions organic matter does accumulate in some sites especially around denser patches of vegetation, namely surrounding the often dominant tufts of Athyrium. More open fine soil pockets with little biomass production hardly show any soil development. Thus sandy and silty accumulations can be found to be the only substrates available for colonization. Mosses play an important role in the initial soil building process on fine soil. Frost heave and soil creep might be important factors to limit plant establishment. 
Wind exposure/Snow duration/Moisture conditions: These microsites do not experience much drought since drying winds do not reach into the gaps between the boulders. Neither does direct solar radiation. Mesomorphic plants thus dominate in this species poor, moist to mesic community. For the same reasons snow melt is occurring late in the season which is why this community has similarities to snowbed sites, a fact which was also observed in analogous Athyrium distentifolium communities in Europe (Nordhagen 1928). Other species with a tendency to occur in later melting sites are Juncus parryi, Carex phaeocephala and Penstemon ellipticus.

Vegetation: Athyrium distentifolium makes a perfect character species for this community since it is hardly ever found in any other vegetation unit. Cryptogramma acrostichoides has a slightly wider distribution but seems to have an optimum in this unit too. Plant cover in this type of vegetation is very scattered and patchy, being limited to the above mentioned fine soil accumulations which often cover only a very small percentage of the talus slope surface. Much of the soil pockets is hidden under overhanging boulder-faces. Rock cover is usually between $90 \%$ and $98 \%$ with mostly sparse lichen cover due to long snow duration. Mosses can form considerable cushions on the moist mineral soils and are less well developed on unstable slopes.

The community is relatively homotonous and constancy of the diagnostic and companion species is high. The comparatively extreme conditions with long snow cover, short growing season and often unstable, frost-affected soils limits the overall number of species. Further succession is not likely to take place since no other community is known to occur in this particular environment. Competition for the spatially limited fine soil can be important. Athyrium distentifolium is the most competitve species outcompeting other species in its immediate surroundings by the mere abundance of litter it produces. This community often occurs in species-poor fragments which is common among units of extreme environments which in addition are restricted to spatially limited sites.

Neighboring communities are mostly talus communities, beargrass slopes and tall herb meadows which often encroach the boulder slopes from their moist and often increasingly fine-soil rich lower end.

Syntaxonomy: The syntaxonomical position of this distinct community is not easily assigned. On the one hand the ecological conditions and some of the constant taxa point to a position near the moderate snowbed communities. This is why in this study this community has tentatively been kept in the snowbed class Salicetea herbaceae. On the other hand similar Athyrium-communities have mostly been assigned to the European class Betulo-Adenostyletea as did e.g. Komárková (1979). The floristic similarity of the present syntaxon to Komárková's Ligustico filicini-Athyrietum distentifolii is relatively small though and mostly based on the dominance of Athyrium distentifolium itself. Other lady fern communities assigned to the Betulo-Adenostyletea e.g. in Scandianvia and the European Alps are floristically much different and consistently have a number of tall herbs which justifies their placement in the tall herb class Betulo-Adenostyletea. The other option to place the present unit would be with the talus slope communities, with Penstemon ellipticus as the only but very frequent indicative talus species. Other combinations would not be justified on floristical grounds given the poor species list of this community.

Distribution: This community is limited to parts of the extensive talus slopes along the Continental Divide and to similar slopes of neighboring mountain chains. It is expected to occur in the Livingston Range west of the Divide as well as in other areas influenced by the moister western climate conditions. Two factors might be responsible for its limited local occurrence. The first is its preference for a cold and moist microclimate which is why it was not found on highly exposed slopes and in the drier mountains of the eastern reaches of the park. For the same reason concave landforms as given in cirque basins and on footslopes are favored. Secondly, the isodiametric fracturing pattern 
which is necessary to produce boulder-sized debris does occur only locally since most of the area's rock types disintegrate into a shaly manner creating a different and smaller sized kind of talus. A larger range of this syntaxon exceeding the area of this study is to be expected.

Literature: The only other North American syntaxon dominated by Athyrium distentifolium is the Ligustico filicini-Athyrietum distentifolii Komárková 1976 from the southern Rockies. It is ecologically different, growing on southeast-exposed, stabilized, mesic scree. Komárková herself states the difference of her community to the more chionophilic lady-fern communities from e.g. Europe (see below) which the Athyrium community described in this study is ecologically closer to. Structurally and ecologically very similar boulder slope communities with (a different variety of) Athyrium distentifolium as a character taxon have been described from other areas mainly in Europe (Nordhagen 1936, 1928(Scandinavia, Gjaerevoll (1956), Dierßen 1996 (Scandinavia), Schmid 1923 (Alps), Philippi 1989 (Black Forest), Schlüter 1966 (Thuringian Forest), Wendelberger 1960 (Alps), Damm 1994 (Harz Mountains)). It should be mentionend that much of the accompanying vegetation is different in these examples as is the subspecific variety of Athyrium distentifolium. Nevertheless are the structural and ecological similarities striking and make this community another good example for vicariant circumpolar syntaxa. 


\section{Association Table 16}

\section{Cryptogrammo crispae-Athyrietum distentifolii ass. nov.}

\begin{tabular}{|c|c|c|c|c|c|c|c|c|c|c|}
\hline Location & Cha & Cha & LiP & LiP & LiP & LE & Spe & Spe & Spe & \\
\hline Plot-Number & 556 & 557 & 591 & 592 & 327 & 593 & 331 & 779 & 354 & \\
\hline Elevation $[\mathrm{m} / 10]$ & 219 & 218 & 210 & 202 & 211 & 203 & 212 & 205 & 204 & \\
\hline Aspect $\left[{ }^{\circ}\right]$ & 160 & 170 & 190 & 160 & 160 & 100 & 130 & 140 & 240 & \\
\hline Slope $\left[{ }^{\circ}\right]$ & 33 & 14 & 16 & 30 & 32 & 30 & 35 & 32 & 31 & \\
\hline Parent material & DiM & DiM & $\mathrm{RA}$ & $\mathrm{RA}$ & $\mathrm{RA}$ & RA & $\mathrm{RA}$ & $\mathrm{RA}$ & RA & \\
\hline Rocks $>6 \mathrm{~cm}$ & 82 & 93 & 73 & 92 & 92 & 70 & 80 & 10 & 74 & \\
\hline Rocks $<6 \mathrm{~cm}$ & 11 & 4 & 1 & 2 & 4 & 2 & 6 & 75 & 1 & \\
\hline Fine Soil $<1 \mathrm{~mm}$ & 2 & .5 & .1 & - & .1 & .5 & .2 & - & 0 & \\
\hline Litter Cover [\%] & 3 & 4 & 2 & 1 & 0 & 3 & 7 & 5 & 3 & \\
\hline Vascular Plant Cover [\%] & 9 & 8 & 4 & 5 & 5 & 9 & 10 & 15 & 20 & \\
\hline Moss Cover [\%] & 2 & - & 1 & .5 & 0 & 2 & .1 & - & 0 & \\
\hline Lichen Cover [\%] & .1 & .1 & 2 & .1 & 0 & 0 & 0 & - & 0 & \\
\hline Plot-size $\left[\mathrm{m}^{2}\right]$ & 16 & 16 & 36 & 36 & 16 & 36 & 16 & 36 & 16 & \\
\hline Number & 1 & 2 & 3 & 4 & 5 & 6 & 7 & 9 & 8 & Constancy \\
\hline \multicolumn{10}{|l|}{ Character species } & \\
\hline AC Athvrium distentifolium & 4 & 4 & 3 & 4 & + & 3 & + & $x$ & 5 & V \\
\hline AC Cryptogramma & + & $r$ & + & + & + & 2 & + & $\mathrm{x}$ & + & V \\
\hline \multicolumn{11}{|l|}{ Constant species } \\
\hline Epilobium alpinum & + & + & + & + & $r$ & + & $r$ & $x$ & + & V \\
\hline Carex phaeocephala & + & $r$ & + & $r$ & $r$ & $r$ & + & $x^{c f}$ & . & V \\
\hline Penstemon ellipticus & 1 & . & $r$ & + & $r$ & + & + & $x$ & . & IV \\
\hline Juncus parryi & 1 & 1 & 3 & + & $r$ & + & . & . & . & IV \\
\hline Polytrichum piliferum & $\mathrm{p}$ & $\mathrm{p}$ & $\mathrm{p}$ & . & . & $\mathrm{p}$ & $p$ & . & . & III \\
\hline Bryum sp. & $\mathrm{p}$ & . & $\mathrm{p}$ & $\mathrm{p}$ & $\mathrm{p}$ & . & $\mathrm{p}$ & . & . & III \\
\hline Ceratodon purpureus & . & $p$ & $\mathrm{p}$ & $\mathrm{p}$ & . & . & $\mathrm{p}$ & . & . & III \\
\hline \multicolumn{11}{|l|}{ Other species } \\
\hline Arnica sp. & . & + & + & + & . & . & . & $x$ & . & III \\
\hline Hypericum formosum & + & . & . & + & + & . & . & . & . & II \\
\hline Hieracium gracile & $r$ & $r$ & + & . & . & . & . & . & . & II \\
\hline Arnica longifolia & r & + & . & . & . & . & . & . & . & II \\
\hline Carex pyrenaica & $r$ & + & . & . & . & . & . & . & . & II \\
\hline Trisetum spicatum & $r$ & $r$ & . & . & . & . & . & . & . & II \\
\hline Xerophyllum tenax & . & . & $r$ & $r$ & . & . & . & . & . & II \\
\hline Phacelia hastata & . & . & . & $r$ & $r$ & . & & . & . & II \\
\hline Achillea millefolium & . & . & . & r & r & . & . & . & . & II \\
\hline Juncus drummondii & . & . & + & . & . & + & + & $x$ & . & II \\
\hline Poa secunda & . & . & . & . & . & $r$ & $r$ & $x$ & . & II \\
\hline Veratrum viride & r & . & . & . & . & . & . & $r$ & 1 & II \\
\hline Polytrichum alpinum & . & $\mathrm{p}$ & $\mathrm{p}$ & $\mathrm{p}$ & . & . & . & . & . & II \\
\hline Grimmia sp. & $\mathrm{p}$ & . & $\mathrm{p}$ & $\mathrm{p}$ & . & . & . & . & . & II \\
\hline Brachythecium sp. & . & $\mathrm{p}$ & . & $\mathrm{p}$ & . & $\mathrm{p}$ & . & . & . & II \\
\hline Hepaticae sp. & . & $\mathrm{p}$ & . & . & . & $\mathrm{p}$ & . & . & . & II \\
\hline Lescuraea radicosa & . & . & $\mathrm{p}$ & . & . & $\mathrm{p}$ & . & . & . & II \\
\hline Lichen sp. & $\mathrm{p}$ & . & $\mathrm{p}$ & . & . & . & . & . & . & II \\
\hline Preissia quadrata & . & . & . & $\mathrm{p}$ & $\mathrm{p}$ & . & . & . & . & II \\
\hline
\end{tabular}




\section{Table 16 (cont.):}

\section{Minor species:}

Lepraria sp. 2:p , 3:p ; Poa cusickii 1:r ; Sambucus racemosa 1:ad ; Marchantia polymorpha 2:p ; Ranunculus eschscholtzii 2:r ; Cystopteris fragilis 2:r ; Oxyria digyna 2:r , 8:r ; Veronica wormskjoldii 2:r ; Senecio triangularis 2:r ; Arenaria capillaris 2:r ;Carex nigricans 3:+ ; Rhizocarpon geographicum agg. 3:p ; Cladonia chlorophaea 3:p ; Cephalozia? sp. 3:p ; Tortula norvegica 3:p ; Polytrichum sp. 3:p ; Saxifraga bronchialis 3:r ; Poa sp. 4:r ; Arabis lyallii 4:r ; Racomitrium canescens 5:P ; Luzula hitchcockii 5:+ ; Arnica diversifolia 5: $\mathrm{r}^{\mathrm{cf} ;}$ Heuchera cylindrica 6:r ; Carex paysonis 7:r , 8: $\mathrm{x}^{\mathrm{cf}}$; Thalictrum occidentale 9:2 ; Viola canadensis 9:+m; Elymus glaucus 9:+ ; Calamagrostis inexpansa 9:+; Pogonatum urnigerum 9:p ; Poa arctica 9:x ; Poa alpina 8:r ; Luzula parviflora 8:x ; Carex tenera 8:x ; Carex scirpoidea 8:x ; Valeriana sitchensis 8:x ; Taraxacum officinale 8:x ; Arabis lemmonii 8:x

\section{ASSOCIATION: Saxifragetum mertensianae ass. nov. - Saxifraga mertensiana cliff crevice community}

Nomenclatural Type: Table 17 relevé 517

Plots: $491,492,517,524,550,552,600 \quad(n=7)$

Character species: Saxifraga mertensiana, Cryptogramma stelleri, Saxifraga occidentalis, Saxifraga cernua, Saxifraga debilis, Marchantia polymorpha, Collema sp., Dermatocarpon sp., (Cystopteris fragilis, Ribes lacustris, Salix vestita, Oxyria digyna)

Constant species: Bryum sp., Epilobium alpinum, Poa secunda, Cerastium beeringianum, Philonotis fontana var. americana, (Sedum roseum, Draba lonchocarpa, Poa alpina, Brachythecium sp.)

Large and moist crevices in subalpine to more often alpine cliff faces are the typical environment for this community. Often these deep fissures reach from a few decimeters to more that a meter into vertical rock walls and thus have a very particular cool, moist and shaded microclimate. Moist overhanging cliffs can hold the same type of vegetation.

The elevation range for this azonal community is reasonably large ranging from 1600 to $2400 \mathrm{~m}$. It was found in SW to W exposures with only one exception in a SE-facing cliff. Slope is difficult to determine in these longitudinal, mostly vertically or horizontally stretching plots. Measurements ranged from $56^{\circ}$ to overhanging cliffs with $100^{\circ}$ (!) slope angle. Parent material is mostly green or red argillite, sometimes ignous diorite of the Purcell sill intrusion. Plants are growing in pockets of fine soil which get trapped in the narrower parts of the crevices. Due to the cool and moist environment, soil development is limited and raw mineral soils are common. Layers of organic soil deriving from extensive moss cushions which often thrive in these hygric habitats, can accumulate in some sites or get washed out in others. Especially on vertical or overhanging, seeped rock faces, moss cushions develop into extensive pads which enable higher plants to establish.

Much of the area at these elevations is extremely exposed to severe environmental impact, periodical drought and strong mechanical stress reducing the vascular plant cover more and more resulting in a dominance of cryptogams, mainly lichen species. On the contrary, these protected sites are fresh to moist at least in their inner reaches, some are even wet with water running through the crevices during and even after periods of snow melt. Thus water is never in short supply, and the vegetation consists of mesomorphic and even hygromorphic species. Light conditions vary extremely from very light at 
the entrance to dark in the deeper parts of the crevices with decreasing vegetation for that reason. Snow cover is hard to estimate but it can be assumed that the gaps are catchment areas which are filled with snow during the winter. Meltout will most certainly be delayed in these cool, windprotected and shaded habitats. But in the steeper and larger crevices the snow might early in the season slide down clearing much of the gaps. Overhanging crevices will not be snow covered but some might remain sheltered in "snow-caves". Still even these vertical and overhanging sites are well moisture supplied through much of the year by water pouring in through cracks in the bedrock.

Due to the reduced light conditions vegetation is usually scattered and many, mainly larger plant species do not develop to their usual vigor. The occurrence of the diagnostic species is pretty constant whereas the number of accidential species can be high: more than $60 \%$ of all species found in the plots were found only once in this community.

The group of character species is outstandingly well delineating this azonal syntaxon. Saxifraga is the dominant genus with three species which are highly specialized for this kind of unusual habitat. Cryptogramma stelleri is a rare species in Montana and is also confined to these sites. Cerastium beeringinanum has its local optimum in this community but sometimes occurs in more open, wet and rocky alpine habitats. The other constant species are common also in other wet communities.

Mosses are very important in this community and reach high cover. Main species are Philonotis fontana var. americana, Brachythecium sp. and Bryum sp., three taxa which also are common in other moist communities. Moss cover ranges from 5\% to $90 \%$. Lichens are mostly confined to rock surfaces and strictly speaking do belong to a different synusiae. Since these occur immediately adjacent to the community treated here and experience the same micro-environmental conditions they are here included. Furthermore some of them, namely Collema sp. and Dermatocarpon sp. are good indicator species.

Like many other communities of cold micro-environments this community is not floristically saturated. The vegetation often does not cover the available substrate completely thus invasion of accidental species with little potential for long-time establishment does occur and slightly increases heterotoneity and species-richness. Succession could not be observed. Disturbance occurs as rocks, snow and water occasionally slide down through the crevices.

Adjacent communities are mainly rock lichen communities on the extensive rock faces and talus slopes at the lower ends of crevices ending above colluvial slopes. Stand size is always very limited most sites being of vertical or less often horizontal elongate shape. Delineation of such communities does present a problem. It was tried to relate cover estimates to the vertically projected fine-soil surface. Since floristic composition is valued much more important, not too much effort was invested on this methodological issue in this case and the resulting cover estimates should be regarded as relative values.

Occurrence of the community is very scattered but regular through much of the study area.

Similar crevice communities dominated by Saxifraga species have been described from other alpine areas in North America and Europe (Dierßen 1996) mostly occurring in similar ecologically distinct micro-environments. These are true vicariants of this community.

It seems noticeable that dry rock crevice communities, as have been described from many other mountain ranges, do not or only rarely occur in the area. This might be attributed to the continental, dry summer climate with extended periods of water stress. Rocky environments with little water holding capacity and limited amounts of fine soil are particularly adverse to plant growth under such conditions. The Scandinavian Mountains as well as the Alps receive considerable more continuous 
precipitation throught the summer season allowing for a richer development of comparable vegetation types under the such site conditions.

Literature: Choate (1963) reports a type of "wet rocky ledges" in his study on the Logan Pass area in Glacier NP which has a number of Saxifraga species. This unit is almost certainly idenitcal with the one described here.

Similar cliff communities with Cystopteris fragilis, Saxifraga cernua, Saxifraga cespitosa have been reported by Mortimer (1978), who found these at the base of limestone cliffs. Similar units have also been reported from other temperate mountain ranges (Ellenberg 1996, Dierßen 1996). It seems indeed, that this unit is representated by vicariant representations 


\section{Association Table 17}

\section{Saxifragetum mertensianae ass. nov.}

\begin{tabular}{|c|c|c|c|c|c|c|c|c|c|}
\hline & Location & ApV & $\mathrm{ApV}$ & $\mathrm{HiS}$ & Spe & ReW & Fif & Fif & \\
\hline & Plot-Number & 491 & 492 & 517 & 600 & 524 & 550 & 552 & \\
\hline & Elevation $[\mathrm{m} / 10]$ & 194 & 193 & 162 & 206 & 237 & 200 & 222 & \\
\hline & Aspect $\left[{ }^{\circ}\right]$ & 280 & 275 & 320 & 165 & 250 & 220 & 250 & \\
\hline & Slope $\left[{ }^{\circ}\right]$ & 72 & 100 & 90 & 56 & 74 & 60 & 68 & \\
\hline & Parent Material & GA & GA & Dio & RA & GA & $\mathrm{RA}$ & GA & \\
\hline & Rocks $>6 \mathrm{~cm}$ & $80 b$ & $50 b$ & $95 b$ & $95 b$ & - & $99 b$ & $88 b$ & \\
\hline & Rocks $<6 \mathrm{~cm}$ & 0 & 0 & - & 2 & - & .2 & 3 & \\
\hline & Fine Soil $<1 \mathrm{~mm}$ & 0 & - & 0 & .5 & - & - & 15 & \\
\hline & Litter Cover $[\%]$ & 3 & - & 0 & 5 & 2 & 1 & 2 & \\
\hline & Vascular Plant Cover [\%] & 45 & 15 & 15 & 50 & - & 60 & 35 & \\
\hline & Moss Cover $[\%]$ & 90 & 10 & 50 & 60 & - & 50 & 20 & \\
\hline & Lichen Cover [\%] & .1 & $50 r$ & $40 r$ & $40 r$ & 2 & 0 & 0 & \\
\hline & Number & 1 & 2 & 3 & 4 & 5 & 6 & 7 & Constancy \\
\hline ASSC & CIATION diagnostic species & & & & & & & & \\
\hline $\mathrm{AC}$ & Saxifraqa mertensiana & 1 & 1 & + & + & 1 & 2 & $r$ & $\mathrm{~V}$ \\
\hline$A C$ & Cryptogramma stelleri & + & + & + & . & + & $\mathrm{ad}$ & . & IV \\
\hline (AC) & Cystopteris fragilis & + & + & + & $r$ & + & + & . & V \\
\hline$(\mathrm{AC})$ & Saxifraga cernua & + & . & $r$ & + & + & r & . & IV \\
\hline$(\mathrm{AC})$ & Saxifraga debilis & 1 & . & + & $++^{\mathrm{cf}}$ & r & . & 3 & IV \\
\hline (AC) & Cerastium beeringianum & $r$ & . & $r$ & $r$ & + & . & $r$ & IV \\
\hline (AC) & Oxyria digyna & . & . & $r$ & . & . & + & $r$ & III \\
\hline$(\mathrm{AC})$ & Salix vestita & . & + & ad & . & . & . & . & II \\
\hline$(\mathrm{AC})$ & Ribes lacustris & . & . & ad & $r$ & . & . & . & II \\
\hline$(\mathrm{AC})$ & Sagina saginoides & . & . & . & . & + & . & $r$ & II \\
\hline$A C$ & Mimulus floribunda & & & & & & + & $\mathrm{ad}$ & II \\
\hline Impo & tant cryptogams & & & & & & & & \\
\hline & Bryum sp. & $\mathrm{p}$ & $\mathrm{p}$ & $\mathrm{p}$ & $\mathrm{p}$ & . & $\mathrm{p}$ & $\mathrm{p}$ & V \\
\hline & Philonotis fontana & $P$ & $\mathrm{p}$ & . & $\mathrm{p}$ & . & $\mathrm{p}$ & $P$ & IV \\
\hline & Brachythecium sp. & $\mathrm{p}$ & $\mathrm{p}$ & $\mathrm{p}$ & . & . & $\mathrm{p}$ & . & III \\
\hline & Ditrichum flexicaule & $\mathrm{p}$ & . & $\mathrm{p}$ & $\mathrm{p}$ & . & . & . & III \\
\hline & Marchantia polymorpha & $\mathrm{p}$ & . & $\mathrm{p}$ & . & . & $\mathrm{p}$ & . & III \\
\hline$(\mathrm{AC})$ & Collema sp. & $\mathrm{p}$ & . & . & $\mathrm{p}$ & $\mathrm{p}$ & . & . & III \\
\hline (AC) & Dermatocarpon sp. & $\mathrm{p}$ & . & . & $\mathrm{p}$ & $\mathrm{p}$ & . & . & III \\
\hline Com & anion species & & & & & & & & \\
\hline & Poa secunda & + & . & $r$ & 1 & r & + & + & V \\
\hline & Saxifraga occidentalis & $r$ & . & ad & $r$ & $r$ & r & + & V \\
\hline & Epilobium alpinum & . & 1 & + & + & . & + & + & IV \\
\hline & Sedum roseum & + & . & ad & + & + & . & . & III \\
\hline & Draba lonchocarpa & $r$ & + & $r$ & . & $r$ & . & . & III \\
\hline & Poa alpina & $r$ & . & . & . & + & r & + & III \\
\hline & Dodecatheon pulchellum & + & + & . & ad & . & . & . & III \\
\hline
\end{tabular}




\section{Association Table 17 (cont.):}

\section{Minor species:}

Achillea millefolium 1:7 , 4:+ ; Deschampsia cespitosa 1:7 , $2: 7$; Arnica mollis 2:7 , 4:ad ; Aster foliaceus 2:7 , 3:ad; Poa sp. $5: 6$ , $7: 7$; Hepaticae sp. 1:p , 4:p ; Bryum pseudotriquetrum 2:p , 6:p ; Moss sp. 1:p , 2:p ; Rhizocarpongeographicum agg. 3:p , 4:p ; Rhizocarpon sp. 3:p , 4:p ; Xanthoria elegans 1:p , 3:p ; Solidago multiradiata 1:7 ; Aster sibiricus 1:7 ; Artemisia michauxiana 1:6 ; Bryum argenteum 1:p ; Caloplaca cladodes 1:p ; Endocarpon sp. 1:p ; Verrucaria sp. 1:p ; Cerastium arvense 2:7 ; Festuca scabrella 2:7 ; Bromus pumpellianus 2:7 ; Carex scirpoidea 2:7 ; Parnassia fimbriata 2:6 ; Suksdorfia ranunculifolia 2:6 ; Potentilla fruticosa 2:r ; Poa interior 2:6 ${ }^{\text {cf; }}$ Myurella julacea 2:p ;Campanula rotundifolia 3:6 ; Carex nardina 3:6 ; Arnica diversifolia 3:6 ; Saxifraga caespitosa 3:6 ; Saxifraga bronchialis 3:6 , 7:6 ; Tortula ruralis 3:p ; Megaspora verrucosa 3:p ; Black dots on rock 3:p ; Lecidea umbonata 3:p ; Solorina sp. 3:p ; Aspicilia sp. 3:p ; Epilobium latifolium 3:ad; Osmorhiza depauperatum 3:ad; Petasites sagittatus 3:ad; Draba aurea 3:ad; Carex haydeniana 4:7 ${ }^{\text {cf }}$; Agrostis scabra 4:7 ; Penstemon ellipticus 4:6 ; Carex sp. 4:+-; Saxifraga ferruginea 4:+ ; Cephalozia? sp. 4:p ; Leproloma subalbicans 4:p ; Grimmia sp. 4:pc; Spiraea densiflora 4:r ; Claytonia megarhiza 5:6 ; Festuca brachyphylla 5:+ ; Collema sp2 5:p ; Potentilla quinquefolia 5:r ; Arnica longifolia 6:6 ; Polystichum lonchitis 6:6 ; Agropyron latiglume 6:6 ; Poa arctica 6:x ; Mniaceae sp. 6:p ; Agrostis sp. 7:x ; Phleum alpinum $7: 7$; Leptarrhena pyrolifolia $7: 6$ 


\section{Class: Salicetea herbaceae Br.-Bl. 1947}

The originally European snowbed class Salicetea herbaceae has generally been used in North America under the same name for it perfectly represents the ecological vicariant of the European entity. The units on both continents share the following phanerogamic character species:

$\begin{array}{lll}\text { Sibbaldia procumbens } & \text { Sagina saginoides } & \text { Veronica alpina } \text { s.l. } \\ \text { Carex lachenalii } & \text { Ranunculus nivalis } & \text { Phippsia algida } \\ \text { Saxifraga rivularis } & \text { Ranunculus pygmaeus } & \end{array}$

(assuming that subspecific differentiations within the taxon Veronica alpina can be neglected for this matter, i.e. treating V. alpina var. unalaschcensis as synonymous with Veronica wormskjoldii and the Eurasian taxon). Only the first three species have been found in this study.

Some of the common European and North American species occur only in parts of the class. According to Dierßen (1984) only few snowbed taxa show a very large geographical distribution, suggesting a large area for the class. Phanerogams with a complete holarctic range, according to Dierßen, are Ranunculus pygmaeus, Carex lachenalii and Sibbaldia procumbens only. More holarctic species are to be found among the bryophytes. Circumpolar representatives of the class (Dierßen 1984, Ellenberg 1986) are the following bryophytes:

$\begin{array}{lll}\text { Anthelia juratzkana } & \text { Conostomum tetragonum } & \text { Pleuroclada albescens } \\ \text { Marsupella brevissima } & \text { Kiaeria falcata } & \text { Tayloria froelichiana } \\ \text { Pohlia drummondii } & \text { Kiaeria starkei } & \text { Athalamia hyalina } \\ \text { Polytrichum norvegicum }(=\text { P. sexangulare }) & \text { Solorina crocea }\end{array}$

Looking at the vascular plants, Sibbaldia procumbens is the only frequent snowbed species in the study area and thus seems to remain as the only unifying circumpolar taxon of the snowbed class Salicetea herbaceae. In fact in Europe Sibbaldia procumbens has been used as a character species not of the whole class but of the order Salicetalia herbaceae, occurring on siliceous substrates, whereas it does not represent the second order Arabidetalia caeruleae of calcareous soils (Oberdorfer 1957, Ellenberg 1986). It needs to be mentioned that according to some authors the Arabidetalia are no longer to be placed into the Salicetea herbaceae at all (Razzhivin 1994, Dierßen 1984, 1992, Daniels 1994).

Character species of the North American part of the class Salicetea herbaceae according to Willard (1979) and Komárková (1979) are:

$\begin{array}{lll}\text { Chionophila jamesii } & \text { Draba crassifolia } & \text { Sibbaldia procumbens } \\ \text { Lewisia pygmaea } & \text { Ranunculus adoneus } & \text { Sagina saginoides }\end{array}$

Veronica alpina var. unalaschcensis (= treated here as synonymous with $V$. wormskjoldii)

Lepraria arctica (= treated here as synonymous with L. neglecta and L. caesioalba, see below).

Chionophila jamesii, Lewisia pygmaea, Draba crassifolia and Ranunculus adoneus are most likely of regional importance only for this class. Komárková adds Poa alpina, Carex phaeocephala, Agoseris glauca, Agrostis variabilis and Senecio crassulus plus the cryptogams Pohlia obtusiloba, Stereocaulon rivulorum and Lecidoma demissum. The five vascular plant species added by Komárková are here considered doubtful character species for this class since they are much more widespread than this syntaxon. Except for Sibbaldia, Veronica, Sagina saginoides and Lecidoma 
demissum all other taxa added by Willard and Komárková are unlikely to represent this class on a larger geographical scale. They might nevertheless be of diagnostic value for the classes units on a regional level.

The present study, including data from Alberta and British Columbia suggests that the best set of character species for an all Rocky Mountain snowbed syntaxon would consist of

Sibbaldia procumbens

Juncus drummondii

Lepraria neglecta/caesioalba.

Polytrichastrum alpinum might have to be included whereas Polytrichum piliferum and Cladonia pyxidata are very constantly present but certainly more widespread than this syntaxon. Nevertheless they belong to the most constant species in this group.

As implied by Dierßen (1984) it might be questioned whether a class like the Salicetea herbaceae should be allowed to span several continents, especially when the name giving species is not nearly covering that area completely, and when the overlap in species becomes very poor over much of such a broadly defined class. Salix herbacea does not occur in western North America at all and most of the other European character species of that class do not either. Among the cryptogams, circumpolar distributions are certainly more common but more detailed data would be needed to evaluate their diagnostic value throughout the range of this class.

Furthermore it has to be taken into account that the communities accommodated in this class are ecologically strikingly similar over its whole range. A better consideration of cryptogams in the future might even strengthen the floristic relationships between the classes' members.

Whether or not to use the European Salicetea herbaceae in North America cannot be resolved without a broader study of the snowbed vegetation throughout the continent in the future. For the time being the class Salicetea herbaceae is therefore accepted to comprise much of the North American snowbed vegetation.

However, an interesting and obvious difference turns up between arctic and alpine North American snowbed communities: looking at western North American alpine snowbed vegetation, it appears that considerable and consistent differences exist compared to the vast group of arctic snowbed communities on this continent as well as to the whole class in general. A similar difference between arctic-oroarctic snowbed communities of Scandinavia and those of the high mountains of temperate Europe has been emphasized by Dierßen (1984). Cooper (1986) reported a similar difference between units from Alaska and Colorado. The cool and moist conditions with long snow cover typical for snowbed situations occur very localized only in the temperate mountain regions like the European Alps (and the Rocky Mountains) whereas in the higher, arctic latitudes of Scandinavia (and arctic North America) such conditions prevail over larger areas. Wide amplitudes of radiation and temperature are characteristic for the temperate alpine regions with strongly changing evapotranspiration and soil moisture through the season. Exposition and relief become important factors, resulting in very obvious delineations of vegetation types. On the contrary, high latitude oroarctic and arctic regions experience relatively low temperatures throughout the season with smaller diurnal amplitudes in radiation. Frost action and solifluction become more important processes which are less important in temperate snowbed situations. Consequently the ecological gradients are much steeper in the alpine snowbeds and floristic differentiations are much more clear cut than they are in the oroarctic and arctic regions where transitions to other communities are much broader. Thus the indicative value of the diagnostic species is diminished (Dierßen 1984).

Based on a similar ecological and floristic differentiation of arctic-oroarctic and alpine regions in North America the necessity of a syntaxonomical separation of alpine against arctic snowbed communities within the class is postulated. The creation of a new western North American alpine 
snowbed subclass is proposed in the following paragraphs, named after the only all-encompassing snowbed species Sibbaldia procumbens and the more specific, western North American Juncus drummondii.

\section{SUBCLASS: Junco drummondii-Sibbaldienea procumbentis subclass. nov. - Juncus-Sibbaldia Western Cordilleran snowbed communities}

Nomenclatural Type: Sibbaldio-Caricetalia pyrenaicae Komárková 1979

\section{Character species: Sibbaldia procumbens, Juncus drummondii, Lepraria neglecta s.1., (Polytrichum piliferum, Cladonia pyxidata, Carex nigricans, Ranunculus eschscholtzii)}

Since the European snowbed class is accepted here, the differentiation of the western North American alpine snowbed units from other snowbeds of higher latitudes has to be expressed on a lower syntaxonomical level. The creation of this new subclass is considered the appropriate tool. If the separation of the North American snowbeds on the class level were the favored solution, this unit could represent such a class unless the study of the arctic and eastern North American snowbed vegetation would call for a different delineation of the pan-continental snowbed class.

The western North American alpine snowbeds share a number of species which serve fairly well as differentiating species against the arctic snowbed communities. First and foremost, these are Carex nigricans, Juncus drummondii and Ranunculus eschscholtzii. Another differentiating character is the lack of a numher of arctic snowbed character species which do not reach far down the western North American Cordillera. Examples are Carex bigelowii, Ranunculus pygmaeus and Salix polaris.

Members of this new subclass presently are the orders

- Sibbaldio-Caricetalia pyrenaicae Komárková 1979 and

- Caricetalia nigricantis Brett et al. ex Damm.

The order Trifolio-Deschampsietalia Komárková 1979, which has been carried as member of the Salicetea herbaceae, is not likely to belong into this subclass. Willard 1979 used the European order Arabidetalia caerulea Rübel 1933 for the Salicetum arcticae which is also considered doubtful. Despite the moderate presence of some snowbed species like Chionophila jamesii, her Salicetum arcticae is likely to belong as a subunit of later melting habitats in the new fellfield order Arenario obtusilobae-Festucetalia brachyphyllae within the Carici-Kobresietea.

A problem for the definition of this subclass is the taxonomical uncertainty of the Lepraria species used as a diagnostic taxon. Several authors list Lepraria arctica, Lepraria neglecta, Leproloma cacuminum or just Lepraria sp. in their vegetation samples of units belonging into this syntaxon. Since these species are morphologically almost identical, differentiation in the field is impossible. Possibly all three species and Lepraria caesioalba can occur in such communities but for reasons of feasibility have been lumped here. Thin Layer Chromatography performed on a number of specimens from the current study revealed the occurrence of Lepraria neglecta and L. caesioalba, the latter of which had not yet been reported from Montana. 
Furthermore other grayish crusts like Trapeliopsis granulosa or Lecidoma demissum might in some cases have been mistaken for one or the other of these species. Nevertheless, most of those grayish soil crusts seem to be fairly exclusive members of units within this subclass.

\subsection{ORDER: Caricetalia nigricantis Brett et al. ex Damm ord. nov.}

Nomenclatural Type: Caricion nigricantis Brooke et al. 1970

Character species: Carex nigricans, Juncus drummondii, (Antennaria lanata, Vahlodea atropurpurea, Erigeron peregrinus, Epilobium alpinum, Carex spectabilis); Brooke et al.: Polytrichum sexangulare, Cephaloziella ambigua, Pohlia drummondii, Pleuroclada albescens

Other diagnostic species ${ }^{6}$. (Luetkea pectinata, Phyllodoce empetriformis, Cassiope mertensiana)

The existence of a Carex nigricans-order for black sedge dominated snowbed communities has first been established by Brett et al. (1998) without using the correct name "Caricetalia nigricantis"or typifying the unit. According to Article $3 \mathrm{~h}$ and 14 of the Code of Phytosociological Nomenclature (Weber et al. 2000) such a publication is not valid. Nevertheless is the creation of a Carex nigricansorder considered the best solution at this point to accommodate the widespread North American snowbed syntaxa even though Brett et al. did not consider such a wide use of the unit. A validation of the order of Brett et al. is not possible. Instead the unit is replaced here with the new order Caricetalia nigricantis in agreement with the nomenclatural rules.

Brooke et al. (1970) placed their validly published Caricion nigricantis (see below) and the Caricetum nigricantis in the European order Salicetalia herbaceae Br.-Bl. in Br.-Bl. et Jenny 1926. In consequence of the creation of the new subclass Sibbaldienea procumbentis and the creation of the present order, the European order Sibbaldietalia herbaceae need no longer be used for the North American syntaxa. Despite the ecological similarity, the floristic overlap with the European unit is relatively small and restricted to bryophytes.

None of the character species given above occurs exclusively in this order. For this species poor unit, true character species s.str. are not be found for the same phytogeographical and historical reasons which are given later in this chapter. Nevertheless, the species combination is believed to circumscribe a stable, ecologically distinct order. Relying on species groups rather than on character species has to be increasingly applied when ecologically distinct vegetation units can be separated in floristically impoverished vegetation types.

The character species given above do occur in other communities, sometimes even in similar combinations, which is mainly the case in moist meadow communities (Valerianetalia sitchensis). Nevertheless, a number of lush forb species do differentiate those units from the present one. For certain intermediate chionophilous meadow units it has to be decided in each case which order they are closer to. Ecologically this order holds the most extreme, but still vascular plant dominated snowbeds as well as some moderately chionophilous communities.

\footnotetext{
${ }^{6}$ These three dwarf shrubs might later be used to define a northern subunit within the order. It needs to be checked to what extend the presence of these species in the samples is dependent on the different community delineation practises of the various authors.
} 


\subsubsection{ALLIANCE: Caricion nigricantis Brooke et al. - Western Cordilleran Black Sedge snowbeds}

Nomenclatural Type: Caricetum nigricantis Brooke et al. 1970

Character species: (acc. Brooke et al. $1970=$ character species of their Caricetum nigricantis): Carex nigricans, Polytrichum norvegicum (=P. sexangulare), Vahlodea atropurpurea, Kiaeria blyttii, Juncus drummondii, Cephaloziella ambiguaDifferential species: Vaccinium deliciosum, Potentilla flabelliformis, Aster alpigenus, Pedicularis ornithorhyncha, (Luetkea pectinata, Phyllodoce empetriformis, Cassiope mertensiana)

The name "Caricion nigricantis" was first used by Brooke et al., who studied subalpine vegetation in southwestern British Columbia. No nomenclatural type was mentioned explicitely in that study but the Caricetum nigricantis was validly described in the same publication, even though no type relevé was chosen from the vegetation table provided. The valid Caricetum nigricantis automatically becomes the type of the alliance being at that point the only association in the alliance (Code of Phytosociological Nomenclature Art. 18).

Since nothing except its presence was said about this alliance in Brooke et al., some ideas about the delineation of the unit should be given here using the synoptic table of the currently available data of western North American Carex nigricans snowbeds (Tab. 3).

Theoretically all western North American Carex nigricans snowbeds could be included into the alliance of Brooke et al. but Brooke et al. did not take any other Carex nigricans snowbeds from outside British Columbia into account. As the synopsis reveals, the coastal cordilleran Carex nigricans snowbeds constantly differ from those of the interior mountain ranges. Hence, the alliance represents the western coastal units only and the interior snowbeds should be accommodated in a separate, new alliance which is described below. The floristic characters of the present unit are given with the coastal species listed under "differential species" above. Unfortunately no exclusive character species can be found for this alliance. Given the floristic differentiation of the coastal against the interior snowbed units, it is nevertheless considered to be appropriate to separate them on the alliance level.

Only Vaccinium deliciosum and Potentilla flabelliformis are strict differential species whereas the other three dwarf shrub species can also occur in black sedge communities further east as was reported by Broad (1973), Kuchar (1975), Achuff \& Dudynski (1984) and others. This is attributed to the fact that the ecologically related heath communities often occur immediately adjacent to the sedge snowbeds, sometimes forming interfingering patterns with snowbed communities. A clear separation of the stands is often not possible and largely determined by the different authors' concept of community delineation. It is obvious though that the presence of Luetkea pectinata, Phyllodoce empetriformis and Cassiope mertensiana is considerably more common in the maritime western unit than in the Rocky Mountain black sedge communities.

None of the differential species is present in all western studies included in the present synopsis nor is any one of them strictly confined to this kind of vegetation. In general, the western snowbed communities seem to be poorer in vascular plant species than the Rocky Mountain black sedge snowbeds. 
It does not seem appropriate to keep the Rocky Mountain unit as a subunit of the western syntaxon. Indeed the Rocky Mountain syntaxon is defined by a distinct and large group of species. This warrants the separation on the alliance level. For this reason a new alliance Sibbaldio-Caricion nigricantis is created later in this chapter.

Literature: Communities belonging into this alliance have been described by Archer (1963), Brooke et al. (1970), Fraser (1970), Kuramoto \& Bliss (1970), Douglas \& Bliss (1977), DelMoral (1979), Hamann (1972), Henderson (1974) and Brett et al. (1998). All of these units are ecologically and structurally very similar to the ones described here.

\title{
3.1.1.1. ASSOCIATION: Caricetum nigricantis Brooke et al. 1970 - Coastal Cordilleran Black Sedge snowbed community
}

\author{
Nomenclatural Type: Brooke et al. 1970 Table 2b relevé 59 (lectotype!)
}

Character species: (acc. Brooke et al. 1970) Carex nigricans, Polytrichum norvegicum (=P. sexangulare), Vahlodea atropurpurea, Kiaeria blyttii, Juncus drummondii, Cephaloziella ambiguaApart from some general mention that was made of black sedge communities earlier during the 20th century (Cooper 1908, Shaw 1916, Ramaley 1919, Cox 1933), the first detailed account of a Carex nigricans association has been given by Archer (1963) from Garibali Provincial Park. Since Archer's type-written thesis is not considered a valid publication in the sense of Article 1 of the Code of Phytosociological Nomenclature, the authorship of the Caricetum nigricantis has to be changed from "Archer 1963" to "Brooke et al. 1970". Brooke et al. included more samples and the definition of character species, but did not assign a type relevé. Therefore a lectotypification is done here selecting plot no. 59 from table $2 \mathrm{~b}$ from Brooke et al. as a lectotype. Even though Archer's Caricetum nigricantis is basically accepted and by its composition represents the unit sufficiently, his effort can not even be recognized with an "ex"-authorship (which would be "Caricetum nigricantis Archer ex Brooke et al.1970"), because Brooke et al. do not refer their black sedge unit specifically to Archer's work. Because Archer's original data has not been published it is presented again in Tab. 18.

For a detailed description of the Caricetum nigricantis it is referred to Archer 1963 and Brooke et al. (1970). Archer's original table is reproduced here since it has not yet been published in its original form. 


\section{Association Table 18}

\section{"Caricetum nigricantis Archer 1963"}

= Original data from Archer (1963), p.58a (sociability and vigor neglected)

\begin{tabular}{|c|c|c|c|c|c|}
\hline Location/Region & Ring & Diamond & Numatak & Viking & Ridge \\
\hline Plot-Number & 56 & 82 & 61 & 57 & 84 \\
\hline Elevation [ft] & 4300 & 6300 & 6000 & 6400 & 6400 \\
\hline Aspect & SE & W & SE & SW & SW \\
\hline Slope $\left[{ }^{\circ}\right]$ & 0 & 35 & 0 & 0 & 0 \\
\hline Soil-type & Ranker & Ranker & Ranker & Ranker & Ranker \\
\hline Parent Material & Dacitic & Dacitic & Quartz & Quartz & Quartz \\
\hline & Lava & Tuffs & Diorite & Diorite & Diorite \\
\hline Shrub cover [\%] & 0 & 5 & 0 & 1 & 1 \\
\hline Herb cover [\%] & 80 & 90 & 95 & 90 & 95 \\
\hline Moss-cover [\%] & 20 & 0 & 2 & 30 & 10 \\
\hline Plot-size $\left[\mathrm{m}^{2}\right]$ & 5 & 10 & 4 & 5 & 4 \\
\hline Phyllodoce empetriformis & . & . & . & 2 & 2 \\
\hline Phyllodoce glanduliflora & . & 1 & . & . & . \\
\hline Cassiope mertensiana & . & 1 & . & . & . \\
\hline Carex nigricans & 9 & 5 & 9 & 6 & 9 \\
\hline Antennaria alpina & . & 4 & . & . & . \\
\hline Vahlodea atropurpurea & 1 & 1 & . & . & . \\
\hline Luetkea pectinata & . & . & 2 & . & 1 \\
\hline Luzula piperi & . & 3 & 1 & . & . \\
\hline Lupinus arcticus & . & 1 & . & . & . \\
\hline Carex spectabilis & . & 1 & 1 & . & . \\
\hline Hieracium gracile & 1 & . & . & . & . \\
\hline Saxifraga tolmiei & 2 & . & . & . & . \\
\hline \multicolumn{6}{|l|}{ Bryophytes: } \\
\hline Juncus drummondii & 1 & . & 2 & . & 1 \\
\hline Polytrichum norvegicum & 3 & 1 & 3 & . & 1 \\
\hline Racomitrium canescens & . & . & . & 4 & . \\
\hline Gymnomitrium varians & . & . & . & . & 1 \\
\hline Marsupella ustulata & . & . & . & 3 & 1 \\
\hline Sphagnum compactum & . & . & . & 2 & . \\
\hline
\end{tabular}

Notice:The cover abundance scale used is the "species significance" scale by Krajina (1933) 


\title{
3.1.2. ALLIANCE: Sibbaldio procumbentis-Caricion nigricantis all. nov. - Sibbaldia-Black Sedge snowbed alliance \\ Nomenclatural Type: Phleo commutati-Caricetum nigricantis ass. nov.
}

\section{Character species: (Carex nigricans [covering >50\%])}

Differential species: Sibbaldia procumbens, Ranunculus eschscholtzii, Veronica wormskjoldii, Salix arctica, Phleum alpinum, Epilobium alpinum, Potentilla diversifolia, Polytrichum juniperinum, Polytrichastrum alpinum

This new alliance has been created as the interior cordilleran counterpart of the existing alliance Caricion nigricantis Brooke et al. 1970 which, as a clearly coastal unit, differs consistently from the interior black-sedge snowbeds. It is thus proposed here to keep the existing alliance as a western subunit of the order whereas the Sibbaldio procumbentis-Caricion nigricantis is the interior, Rocky Mountain counterpart within the western North American black sedge communities.

So far, all units in this alliance belong into the following, broadly defined association. Thus the diagnostic species of this alliance do not differ from those of the association until new subordinate syntaxa are described. The lack of exclusive character species follows the explanation given under the Caricion nigricantis.

\subsubsection{ASSOCIATION: Phleo commutati-Caricetum nigricantis (Komárková) Damm - Interior Cordilleran Timothy-Black Sedge snowbed community plate 4, fig. 12}

\author{
Nomenclatural Type: Table 19 relevé 201 \\ Character species?: (Carex nigricans [covering >50\%]) \\ Constant species: Sibbaldia procumbens, Veronica wormskjoldii, Juncus drummondii, \\ Ranunculus eschscholtzii, Erigeron peregrinus, Antennaria lanata (not in Glacier NP), \\ Phleum alpinum ${ }^{\checkmark}$, Epilobium alpinum
}

The Carex nigricans-communities of the Rocky Mountains can all be accommodated in this broadly defined association which is evidenced by the synopsis of similar communities from all over western North America (Tab. 3). The floristic and ecological similarity of the Carex nigricans snowbeds in this large area seems to be sufficient for such a comprehensive treatment.

The differences which can be observed in the various floristic regions within the association's range are not considered large enough to justify the separation on the association level, but are believed to be better accommodated by means of geographical subassociations.

General aspect: The typical aspect of a strongly Carex nigricans dominated turf is shared by all Carex nigricans communities which have been reported from all over the association's range. Only exception is the extraordinarily species-rich unit reported from Kuchar (1975).

Usually the darkish green and dense sedge mat is interupted only in a few places by other species which add some color to this very uniform, low growing sedge community.

\footnotetext{
${ }^{7}$ characteristic is not just the presence, but the dominance of the species

${ }^{8}=$ Phleum commutatum Gaudin
} 
Distribution: As can be taken from the data presented in the synoptic table of the northwestern North American Carex nigricans communities (Tab. 3), this syntaxon is widespread in the Rocky Mountains from central Alberta down to Colorado. The unit possibly extends into Arizona and New Mexico.

Syntaxonomy: The present treatment implements the use of an existing syntaxon, changing its delineation and combining it with similar units from a much larger geographical area. It units the Rocky Mountain Carex nigricans communities, which are now syntaxonomically separated from the Caricetum nigricantis of the western cordilleran mountains on the alliance level. Given todays incomplete knowledge of the Rocky Mountain plant communities and the species-poverty of this unit, exclusive character species cannot be given at this point. In fact all of the constant species listed above as well as Carex nigricans itself do occur in other plant communities which is why truely exclusive character species are not likely to exist for this community. Nevertheless, the conspicuous dominance pattern and the constant species combination in combination with the extreme ecology of these snowbeds sufficiently characterize this syntaxon.

The geographical range of this community assumes the inclusion of Komárková 's Phleo-Caricetum nigricantis into this association. Given the floristic composition and the fact, that Komárková's southern Rocky Mountain unit is certainly a representation of a marginal unit in this alliance, it seems to be consequent to place Komárková's unit as a southern Rocky Mountain subassociation into this association. The group of southern differential species consists of Ligusticum filicinum var. tenuifolium, Erigeron melanocephalus, Erigeron simplex, Polygonum douglasii, Carex scopulorum, Agrostis borealis, Viola adunca and Bryum turbinatum. Not all of these might indeed belong into this differential group but at this point no other detailed tables than Komárková's are available for a better delineation of this unit in the southern Rocky Mountains.

The name Phleo commutati-Caricetum nigricantis has to be used following the CPN (art. 25), because the validily described Phleo-Caricetum by Komárková has priority if the units are to be united in one association as proposed here. A more appropriate name for a pan-Rocky Mountain Carex nigricans unit might have taken a different first name-giving species (e.g. "Sibbaldio-Caricetum nigricantis"), because Phleum alpinum is not quite a very characteristic species in much of the units' northern and central range. The above mentioned priority rules do not allow to create a different name though.

The other option would have been to keep Komárková's unit separate on the association level and create a separate association for the unit found in Glacier NP, uniting them on the alliance level in the Sibbaldio-Caricion nigricantis. Thus, the broadly defined Rocky Mountain Carex nigricans unit would be split into several regional associations. The first option using geographical subassociations is favored here, stressing the ecological, physiognomical and floristical similarity of these units and the constant difference to the western Caricetum nigricantis.

As can be seen in the synoptic table, other areas also have well delineated regional differential species groups. E.g. Hämet-Ahti's Carex nigricans units from Wells Gray Park in British Columbia are united by the species group of Vaccinium caespitosum, Dicranum scoparium, Barbilophozia floerkii and Calamagrostis canadensis. One of her units certainly belongs into this association and might be separated as the subassociation Phleo-Caricetum nigricantis aulacomnietosum palustre (see below). A number of other subassociations than those described here will have to be created in the future.

Literature: Descriptions of interior cordilleran Carex nigricans communities have been given from all through the Rocky Mountains and the coastal ranges. Similar communities have been reported from British Columbia (Shaw 1916, Eady 1971), Alberta (Beder 1967, Crack 1977, Broad 1973, Trottier 1972, Kuchar 1975, Polster 1977, Achuff \& Corns 1982, Achuff \& Dudynsky 1984, 1984a, 
Achuff et al. 1997, Timoney 1999), Montana (Cooper \& Lesica 1992) and Colorado (Cox 1933, Komárková 1979, Willard 1979. All available tabular data from these sources have been included in the synoptic table (Tab.3). According to these data available, the Carex nigricans snowbed community from Glacier NP belongs to a northern type of this community. The southern type is represented by the above mentioned Phleo-Caricetum nigricantis Komárková 1976 from northern Colorado. Floristically, it does share some basic species with the northern type but otherwise is well differentiated by a number of southern Rocky Mountain species. A new combination of this association changing its rank into a subassociation is provided below.

\title{
SUBASSOCIATION Phleo commutati-Caricetum nigricantis typicum subass. nov. - Typicum Subassociation
}

\author{
Nomenclatural Type: Table 19 relevé 201 \\ Plots: $125,164,184,185,194,197,198,201,207,209,252,316,329,330,333,342,343,356,395,506,614$, \\ $729,731,748,749,750,752 \quad(n=27)$ \\ Character species: (Carex nigricans) \\ Differential species: Senecio cymbalarioides, Luzula hitchcockii, Oxyria digyna, Juncus \\ parryi, Carex cf. paysonis
}

General aspect: All local black sedge communities have be placed into this subassociation. The aspect of this community is that of a very simple structured, usually extremely dense, relatively low growing sedge turf. It is filling the bottoms of the latest melting alpine and sometimes even subalpine snowbed depressions. Scattered in this sedge-matrix, which in some cases becomes almost inpenetrable through the presence of a thick and firm sedge litter layer, are only few individuals of other snow-tolerant species. Conspicuous are the flowering species Senecio cymbalarioides, Ranunculus eschscholtzii, sometimes Senecio triangularis and little less so Epilobium alpinum. All of these are adding scattered dots of color to this uniform greenish community which turns into a monotonous straw-colored meadow in fall.

Topography: Most sites are found on little exposed high elevation benches, on the valley bottoms of hanging valleys and along streambanks. The surface relief is most often concave with this community filling the bottom of the depression. Often less extreme snowbed communities occur zoned around the sedge meadow. The elevation range is subalpine to mid-alpine from 2000 to $2400 \mathrm{~m}$ and no preference for any aspect could be observed, many of these wetland sites being level or only slightly sloping anyhow. Concerning its acreage this is one of the less important plant communities in the alpine of the study area which nevertheless occurs frequently through the whole study area. Dominant ecological factor, as the name implies, is the duration of snow and among the vascular plant dominated units this community represents the most extreme end of the vegetational gradient created by snow duration.

Parent material: The bedrock type does not seem to have any significance for this community. The soil developement is mostly based on colluvial, mostly air- and water-deposited material (see below). The soils are usually developing on more or less thick deposits of silty material which have accumulated over time in relief depressions. The rock fraction in these profiles is smaller than in any other community treated in this study. 
Soils: The catchment situation of the sites results in the deposition of sometimes considerable layers of fine silty material which serves as the major substrate. In many sites much of the silty deposits consists of washed-in material of volcanic ashes that have been deposited following the far-reaching late pleistocene and holocene eruptions of the volcanoes along the Pacific coast. Especially the bright orange material of the Mt. Mazama ash (6.845 B.P., Carrara 1986) is a conspicuous marker in soil pits dug in this community (B. Dutton, pers. comm.). Sceletal contents of the soil is mostly neglectable. In streambank situations much of the fine sediments are recent deposits from springtime flooding. Aerial deposition of silty material blown-in from periglacial areas (=loess) during the later pleistocene period might also have contributed to these accumulations. Thick humus horizons, fed by large amounts of sedge litter, are usually found on top of the silty mineral layers. The wet and cold root environment in this community delays decomposition of organic matter and results in the built-up of rich organic upper horizons. Brooke et al. (1970) mentioned these soils as Snow Basin Anmoor soils.

Wind exposure/Snow duration: Exposure to wind is usual medium to little due to the depressed relief situation. The depressed landforms inhabited by this community work as catchment area. This results in the longest snow durations found anywhere in the study area except for even more extreme unvegetated or merely cryptogam covered areas. The growing season often does not start before midJuly, sometimes even later than that. The first snow is usually falling by late September, thus plants have to deal with a snow free period of 10 to 12 weeks only.

Moisture: The water regime in this vegetation type is that of a true wetland community and has even been called "semi-terrestrial" (Brooke et al. 1970). Springtime flooding during melt-off periods and flooding can also occur after heavy rainfall throughout the summer. Due to the flat or concave relief, run-off is delayed and drainage is furthermore impeded by the fine-silty texture of the soil.

Vegetation: Most conspicuous vegetational feature of this community is the dense turf of Carex nigricans that usually covers the entire plot. Often every spot not covered by living parts of the sedge is covered by a thick layer of its previous years litter forming such a dense cover that establishment for other species becomes very difficult. The more extreme the conditions are, the more dominant becomes the sedge, resulting in very species poor, monotonous stands in many cases, with mosses often lacking completely or being confined to areas of disturbance like cracks in the sedge-turf and little rivulets. With slightly decreasing snow duration or increased disturbance by meltwater action during periods of flooding, other species can invade resulting in slightly richer communities. Nevertheless, the overall number of species generally stays below 25 including cryptogams.

Constant species in this community are Epilobium alpinum, Juncus drummondii, Senecio cymbalarioides, Phleum alpinum and Sibbaldia procumbens in the richer variants. All of these species are widespread in high elevation wet communities in the area which is why this community does not have a well defined group of character species. Even though its ecological role is extremely distinct and the community itself is easily made out in the landscape, its floristical definition is limited to the pronounced dominance of Carex nigricans and the absence of a defined group of any diagnostic species that would refer this community to a different syntaxon. In fact this community could be looked at as an impoverished variant of other alpine communities with one species assuming strong dominance.

This snowbed community borders most commonly against the next less chionophilous community which is the Phyllodoce glanduliflora-heath. The slightly earlier melting heath often forms a band around the sedge-filled depressions or covers boulders and other slightly elevated microsites. Other communities which can occur in the immediate vicinity are Erythronium-Luzula hitchcockii meadows and Trollius-Tofieldia wetland communities with or without Salix arctica. The arctic willow itself can 
reach considerable cover in this community.

In other areas Carex nigricans communities have been described with considerable amounts of mosses (e.g. Brooke et al. 1970). A similar constant presence of any bryophyte species could not be found in the study area. Still in some stands certain moss species can achieve importance, mainly Aulacomnium palustre, Polytrichastrum alpinum, Brachythecium sp. and Bryum sp. Philonotis fontana, Polytrichum sexangulare and Kiaeria blyttii do occur, but not very constantly so. Lichens are more or less absent from this community.

Syntaxonomy: Being the most extreme snowbed community, the syntaxonomical position of this community in the Salicetea herbaceae, as has been commonly practised by other authors (Brooke et al. 1970), is not questioned. The presence of Sibbaldia procumbens, Juncus drummondii, Veronica wormskjoldii and Antennaria alpina with high or at least moderate constancy supports this practice. On the other hand considerable similarity exists with the moderately late melting Erythronium-Luzula hitchcockii meadows as well as to other mesic high elevation meadow communities with less affinity to snowbed communities. It is interesting to note that appart from the strong dominance of Carex nigricans the floristics reveal no single exclusive character species. This might in fact be not surprising, given the ecological extreme which this community experiences. Two local variants are differentiated in this subassociation.

Distribution: Snowbed communities due to their extreme environment are azonal communities and this one occurs very widespread throughout the alpine of Glacier National Park. Individual stands are rarely larger than $400 \mathrm{~m}^{2}$ and many are much smaller down to a few square meters in depressions of undulating glacier scoured bedrock surfaces.

Literature: The only other literature source that mentions a community belonging to this subassociation is Polster (1977), who found this unit immediately to the north of the current studies' area in the Akamina Pass region in the very SE British Columbia.

VARIANT: Juncus mertensianus

- Mertens' Rush-Black Sedge snowbed community

Nomenclatural Type: Table 19 relevé 395

Plots: $122,125,142,184,185,330,342,395,731,748,749 \quad(n=11)$

Differential species: Juncus mertensianus, Veronica wormskjoldii, Hypericum formosum, (Senecio triangularis, Arnica diversifolia, Arnica mollis, Veratrum viridis)

This variant is merely differentiated by the presence of a number of other high elevation wetland species. The increased species-richness is interpreted as an indication of slighlty less severe conditions in these snowbeds. The unit can be interpreted as transitional to other alpine-subalpine wetland communities sharing the differential species given above. 


\title{
SUBASSOCIATION Phleo commutati-Caricetum nigricantis phleetosum (Komárková) Damm stat. nov. \\ - Southern Rocky Mountain Timothy-Black Sedge snowbed community
}

Nomenclatural Type: Komárková 1979 Table 9 relevé 203

\author{
Differential species: Stellaria umbellata, Ligusticum filicinum, Erigeron simplex, Carex \\ scopulorum, Polygonum douglasii, Agrostis borealis, Erigeron melanocephalus, Bryum \\ turbinatum, Viola adunca
}

The concept of this new combination, subdividing the pan-Rocky Mountain Carex nigricansassociation into regional subassociations, is explained under the association Phleo-Caricetum nigricantis above. The description and type of the original Phleo-Caricetum nigricantis can be found in Komárková's work (1979). The subassociation epithet "phleetosum", referring to the widespread Phleum commutatum, is not using a very characteristic species for this unit and is likely to be a local differential species only. Deschampsia cespitosa, Ligusticum filicinum or Caltha leptosepala would perhaps have been better name-giving species on a larger geographical scale to separate a southern Carex nigricans snowbed, but they cannot be used according to Art. 29 of the CPN.

The differential species given above occur with constancy classes II and III only. No exclusive character species exists for this unit which is another reason to not accept its former association rank. The only constant species are Carex nigricans, Juncus drummondii, Deschampsia cespitosa and Phleum alpinum. Caltha leptosepala is also common but occasionally occurs in other subassociations as well.

\section{SUBASSOCIATION Phleo commutati-Caricetum nigricantis aulacomnietosum Hämet-Ahti ex Damm}

Nomenclatural Type: Hämet-Ahti (1978) Table V relevé 1

Differential species: Aulacomnium palustre, Barbilophozia kunzeana, (Sphagnum compactum, S. russowii)

Taking the data from Hämet-Ahti's "moist oligotrophic meadow" community from Wells Gray Provincial Park in British Columbia, this regional subassociation with a very distinct physiognomy is validated here. Hämet-Ahti's syntaxon is somewhat different ecologically in that she describes it not as a snowbed community but as a unit of wet, seasonally flooded habitats. Therefore some of the typical species of snowbeds occur with lesser constancy. Nevertheless, there is no doubt that this community is part of the Phleum-Carex nigricans-association. Two other communities mentioned from Wells Gray Park by Hämet-Ahti, namely the "dry meadows" and the "moist mesotrophic meadows" are floristically somewhat similar to this unit except that Carex nigricans is not as dominant. The former unit might be considered another association in the Caricion nigricantis with at least one subunit defined by its lichen richness, whereas the latter is closer to the lush meadow communities of Valeriana sitchensis. 


\section{SUBASSOCIATION Phleo commutati-Caricetum nigricantis castillejetosum occidentalis Kuchar ex Damm}

Nomenclatural Type: Kuchar (1975) Table 18 relevé 25

Differential species: Castilleja occidentalis, Polygonum viviparum, Sanionia uncinata, Luzula spicata, Peltigera rufescens, Petasites vitifolius, Brachythecium salebrosum, Bryum pseudotriquetrum, Trisetum spicatum, Tortula ruralis, Luzula parviflora, (Pedicularis bracteosa, Arabis lyallii)

A number of Carex nigricans units from the Canadian Rocky Mountains have been organized in this subassociation based on the common occurrence of the diagnostic species listed. Conspicuous is a high number of bryophytes which is correlated with a less dense cover of the dominant Carex nigricans. The presence of Peltigera rufescens, Trisetum spicatum, Luzula spicata, Festuca brachyphylla and other tundra species indicates slightly less extreme snowbed conditions of these continental snowbeds, compared to the snowbeds occurring further west. The units comprised in this subassociation have been described by several authors from different areas in the Rocky Mountains of Alberta. They do show some minor floristic differences which are interpreted as local particularities rather than profound ecological differences. The creation of different variants is considered appropriate for these low ranking units.

Carex nigricans communities of this subassociation have been described by Beder (1967), Broad (1973), Trottier (1972), Kuchar (1975), Crack (1977) and Timoney (1999) (see synoptic table 3).

VARIANT: Phleo commutati-Caricetum nigricantis castillejetosum, Variant of Artemisia norvegica Kuchar ex Damm

Nomenclatural Type: Kuchar (1975) Table 18 relevé 25

Differential species: Artemisia norvegica, Stereocaulon alpinum, Cladonia ecmocyna, Lophozia sp., Lepraria neglecta, Peltigera aphthosa, Gentiana glauca, (Poa grayana, Cetraria islandica, Psoroma hypnorum)

Like the subassociation itself, this variant is based on the data given by Kuchar (1975) from Jasper National Park. Even though the table provided by Kuchar is somewhat heterogeneous with at least one apparent subunit. The variant seems to be the appropriate rank for this unit. Floristically, it is different in the comparatively low cover of Carex nigricans to the advantage of a large number of lichen and bryophyte species which reach considerable cover. The unit is somewhat similar to the above "subassociation aulacomnietosum" reported by Hämet-Ahti from British Columbia. The stronger continental character of this unit is expressed in the larger number of lichens and other fellfield species, even more so than it is the case in the other units of subassociation polygonetosum.

As a typical snowbed species the lichen Cladonia ecmocyna constantly occurs in this variant, a species which is also present is the snowbeds reported by Hämet-Ahti (1989) and Eady (1971) from British Columbia.

The Carex nigricans community type provided by Timoney (1999) from various locations in Alberta clearly belongs into this unit. 


\subsubsection{ALLIANCE: Luzulo piperi-Caricion spectabilis all. nov.}

Nomenclatural Type: Arnico diversifoliae-Caricetum spectabilis ass. nov.

\section{Diagnostic species: Carex spectabilis, Oxyria digyna, Sagina saginoides, Luzula piperi}

This alliance unites alpine and sometimes upper subalpine pioneer plant communities of recently deglaciated, rocky areas on cirque bottoms and talus slopes with considerable snow duration.

This new alliance is created to accommodate the following single association. I formerly considered to place that association into the Sibbaldio-Caricion nigricantis. Ecologically and floristically though it is more different from the Phleo-Caricion alliance than it is from the neighboring western coastal Carex nigricans alliance. Therefore a separate alliance had to be created.

The very similar "Carex spectabilis association" of Brett et al. (1998) is likely to belong into this new alliance but it is also close to the Valerianetalia order. The comparison with the present unit from Glacier reveals that both units are floristically different in a number of species (see Tab. 3). Nevertheless, besides the dominating sedges are the ecology and physiognomy of both units extremely similar. Brett et al. proposed a new "Carex spectabilis order" for their association (which apparently had previously been presented in an unpublished paper by Klinka et al. (1997)) but it is believed that these units are neither ecologially nor floristically distinct enough to warrant the creation of a separate order. As is common in young successional stages these communities are not very rich in species and they are far from being floristically saturated. Such early stages are necessarily quite hetereogenous in their species composition which largely explains the difficulties to find enough constant species to assign the unit to any higher syntaxon. So far the close relationship of this unit with parts of the Valerianetalia communities is acknowledged as well as its relations to the Caricetalia nigricantis. At this point a placement in the latter order is favored.

Luzula piperi was chosen as a name-giving species because it is probably more constant in this community than Oxyria digyna which also characterizes this syntaxon well. The occurrence of Oxyria in this kind of rocky and late melting habitat is known not only from other areas in the Rocky Mountain but also from the European Alps, the Himalayas and other temperate mountains.

\subsubsection{ASSOCIATION: Arnico diversifoliae-Caricetum spectabilis ass. nov.}

\section{- Arnica-Showy Sedge pioneer community (plate 4, fig 15)}

Nomenclatural Type: Table 20 relevé 615

Plots: $117,615,625,627,628,647 \quad(n=6)$

Diagnostic species: Carex spectabilis, Arnica diversifolia, Oxyria digyna, Sagina saginoides, Arabis lyallii, (Luzula piperi)

Constant species: Epilobium alpinum, Ranunculus eschscholtzii, Poa alpina, Phleum alpinum, Poa cusickii, Erigeron peregrinus, Juncus drummondii, Carex nigricans

General aspect: The appearance of this chionophilic pioneer community can be fairly different depending on the successional stage the site has reached. Thus earlier and somewhat advanced stages of this community have been accommodated within this syntaxon. Most easily recognized are the earlier stages with scattered tufts of Carex spectabilis, Oxyria and Arnica on mostly open, gently 
sloping or level talus or frost rubble. Most other species also occur in scattered single-species clumps. With advanced successional development, more soil has accumulated and species-richer patches characterize these later stages.

Topography: This community is a typical pioneer community of fairly recently deglaciated areas with initial soil development in rocky, glacier-scoured cirque basins or on morainal and other talus slopes. The marginal cirque bottoms are usually gently sloping. Slope angles up to $10^{\circ}$ occur on colluvial slopes or morainal walls. Elevations range from 2000 to $2400 \mathrm{~m}$ in the area, in the lower to mid-alpine.

Parent material: Parent material is mostly green and red argillite often with a fraction of limestone or igneous rock.

Soils: Characteristic for this chionophilic pioneer community is the patchy distribution not only of the vegetation but also of the soil, which accumulates in clearly delineated spots with large barren rock or gravel areas in between. Total rock cover is often about $90 \%$ of the plot but can be diminished in later successional stages with an increasing soil and vegetation development. By far most of the rock cover is found in between the vegetated soil patches whereas the latter are dominated by an often humusrich fine soil.

The young soils are rich in rocky fragments like sand, pebbles and gravel throughout the profile but can also contain considerable amounts of humus in the black to dark brown fine soil fraction. High silt content is also common, especially at moraine sites.

Wind exposure/Snow duration/Moisture conditions: Medium to high wind exposure is found on most sites. All sites investigated have a long to reasonable winter snow cover resulting in a mesic to moist water regime. Water supply from nearby snowbanks is common and lasts through much of the summer. Some sites occur under conditions very similar to true snowbeds. The constant presence of Caricetalia nigricantis species shows the close relation to those communities.

Vegetation: This vegetation type is dominated by conspicuous clumps of Carex spectabilis which seems to first colonize the rocky slopes and gravel barrens, producing its own humus layer which is supplied and well protected by the previous year's considerable amounts of sedge litter. It needs to be mentioned that, not only in the field, the identification of the name-giving sedge created considerable problems

which could not be resolved entirely in this study. Even sending some of the critical material to specialists in the taxonomically difficult Carex atratae group did not result in conclusive answers on this group (see taxonomy chapter). Therefore all occurrences in this community are attributed here tentatively to Carex spectabilis even though some of them had the more phyllopodic stature of Carex paysonis. It would be interesting to re-examine material from other occurrences of this community e.g. in Canada and see whether some trends in the occurrence of species can be found.

Noteworthy is the constancy of Arnica diversifolia, Epilobium alpinum, Ranunculus eschscholtzii, Oxyria digyna, Luzula piperi, Poa alpina, Phleum alpinum, all of which are typical colonizer species in this type of habitat and can also be found on many moraines in the study area as the first species to invade. Juncus drummondii and Carex nigricans are good indicators of late melting conditions in this community.

The homotony within this syntaxon is diminished by a large degree of variablity in species-richness ranging from 20 to more than 40 species per plot. Presumed earlier stages have a much smaller number of species whereas the richer samples can have more than 40 species presenting a very diverse and flower-rich aspect and always correlating with a higher soil cover. This could be surprising for a 
community which here is still called a "pioneer" community. The richer variants might indeed better be called "advanced stages" but do nevertheless belong into this syntaxon. They do not yet have another indepent characteristic group of species that would warrant separation as a distinct syntaxon, differentiating against the earlier stages as well as against other known vegetation types in the area.

This example illustrates the difference between a classification which values characteristic species groups higher than the total species composition as opposed to qualitative classification systems which take all species into account with the same weight. Diverse, "floristically growing" stands like these would be confusing in a classification system like the latter if species from syntaxonomically different units occur. Some stands might not even be classifiable in such a system. Using diagnostic species groups on the other hand more easily identifies the position of succesional stages in the system and correlates with the ecological interpretation of the groups.

The large rocky expanses in between the vegetation patches of this vegetation type are lacking any noticable lichen cover, which is either due to long snow cover or unstable substrate in case of gravelly material or on steeper slopes. Bryophyte cover is only little higher for similar reasons. In some cases bryophytes can assume importance for the stabilization of soil surfaces against wind and water erosion mainly on the margins of the soil pockets.

Since this unit was called a pioneer community the question of succession needs to be addressed. Floristic relations do exist with a number of moist meadow units but a definite developmental direction is not easily detected. Given the fact that deglaciation in these cirque basin and hanging valley areas has taken place mostly hundreds of years ago, vegetational succession has not advanced very far and is not likely to do so any quicker in the future. On the other hand the number of species is already reasonably high even in a stage when much of the stand surface is not even soil covered. It becomes very obvious in these sites that the primary environmental parameters themselves are not the limiting factors for the plants, but the development of appropriate soils. These sites also reveal clearly how much time the soil development takes in such a hostile environment.

Still this community is not a permanent pioneer community like e.g. the constantly disturbed steep colluvial talus slopes. A permanently or intermittently destructive agent like falling rock debris on talus slopes can not be detected here. Successional trends are - as expected at these high elevation sites - just taking place exceedingly slow, which is in part caused by the short growing season as well as by the general low temperature environment.

Depending on the local snow and moisture situation, the most likely successional stages to follow are lush herb communities (e.g. Luzulo-Erythronietum), heath communities (Phyllodocetum) or wet meadow and streambank communities (e.g. Trollio-Parnassietum, Senecio-Mimuletum). Even though many of the species of the Carex nigricans snowbeds are present it is doubtful that such an ecologically extreme and species poor community could be a successor of this relatively rich unit. I.e. if snowbed conditions would prevail in those sites, such a relatively lush vegetation as is present would not have been able to develop in the first place.

Syntaxonomy: This unit has floristic affinities to a number of other syntaxa. As can be derived from the successional status of this community outlined above, relations exist to snowbed communities as well as to herb meadows of the Valerianetalia. The Arnico-Caricetum might be looked at as early variant of a Valerianetalia community. But except for Carex spectabilis and less so Erigeron peregrinus and Senecio triangularis no other diagnostic species of that order are important in this unit and all of those also occur in snowbed communities. The Carex spectabilis association reported from Brett et al. (1998) from British Columbia is ecologically extemely similar in that it also colonizes recently deglaciated, rocky areas with considerable snow accumulation. Also the physiognomy of 
both communities seems to be almost identical. But except for a few common species there are quite a number of differentiating species. Whereas the Canadian unit clearly belongs into the Valerianetalia order (and does not deserve its own order as proposed by Brett et al.), the present unit is closer to the Caricetalia nigricantis as defined in this study. As can be expected if two fairly closely related orders exist, certain communities will most likely occur which are not readily assigned to one or the other unit. In this case, despite several similarities with Brett et al.'s unit, the Arnico-Caricetum is placed as a new association with the snowbed communities. The creation of its own alliance takes into account that this community is indeed ecologically distinct from the other chionophilic units.

Distribution: Even though this community has been sampled in two areas only, it has been observed to be more widespread in the Park. It is very likely to be found in many of the hanging valleys and cirque basins throughout the Park under suitable conditions.

Literature: Brett et al. (1998) describe three very similar communities from subalpine and alpine sites in British Columbia in their Carex spectabilis order. Their ecological description seems to closely match the findings in this study's area. It is not possible to say which of the three associations given by Brett et al. the Glacier community corresponds to most closely. The characteristic common occurrence of Oxyria digyna points to the Oxyria digyna-Carex spectabilis association. Since the tables in Brett et al. do only contain species present in at least one order with a presence class higher or equaling 3 , it is difficult to say whether species-richness is different, which nevertheless seems to be the case at least taken from the species groups reported. At least some of the relatively large number of very constant species in Glacier are missing in the Canadian community. This might be due to younger successional stages or more extreme conditions of the sites. Also the overall climatic difference provides a different floristic background which results in some specific differences like the absence of Luetkea pectinata, Cassiope mertensiana and Lupinus arcticus from the study area. Other species are not being present in this type of vegetation in Glacier, like e.g. Phyllodoce empetriformis, Vahlodea atropurpurea, Racomitrium canescens, Anaphalis margaritacea and Petasites frigidus but do occur elsewhere in the Park.

Schlatterer (1972) mentions a "Rocky slope-Boulderfield type" from southwestern Montana with Oxyria, Carex sp. (most likely Carex spectabilis), Hulsea algida, Potentilla diversifolia, Carex pelocarpa $(=C$. nova) and Sitanion hystrix occurring as a pioneer community on sites with little soil available. This community is likely to be another representative of these pioneer communities on rocky sites which seem to be floristically fairly heterogenous but ecologically similar. Floristically, Oxyria digyna and Carex spectabilis seem to be the unifying elements. The occurrence of this unit in Britsh Columbia and southwestern Montana suggests that this kind of vegetation is more widespread. 


\section{Association Table 20}

\section{Arnico diversifoliae-Caricetum spectabilis ass. nov.}

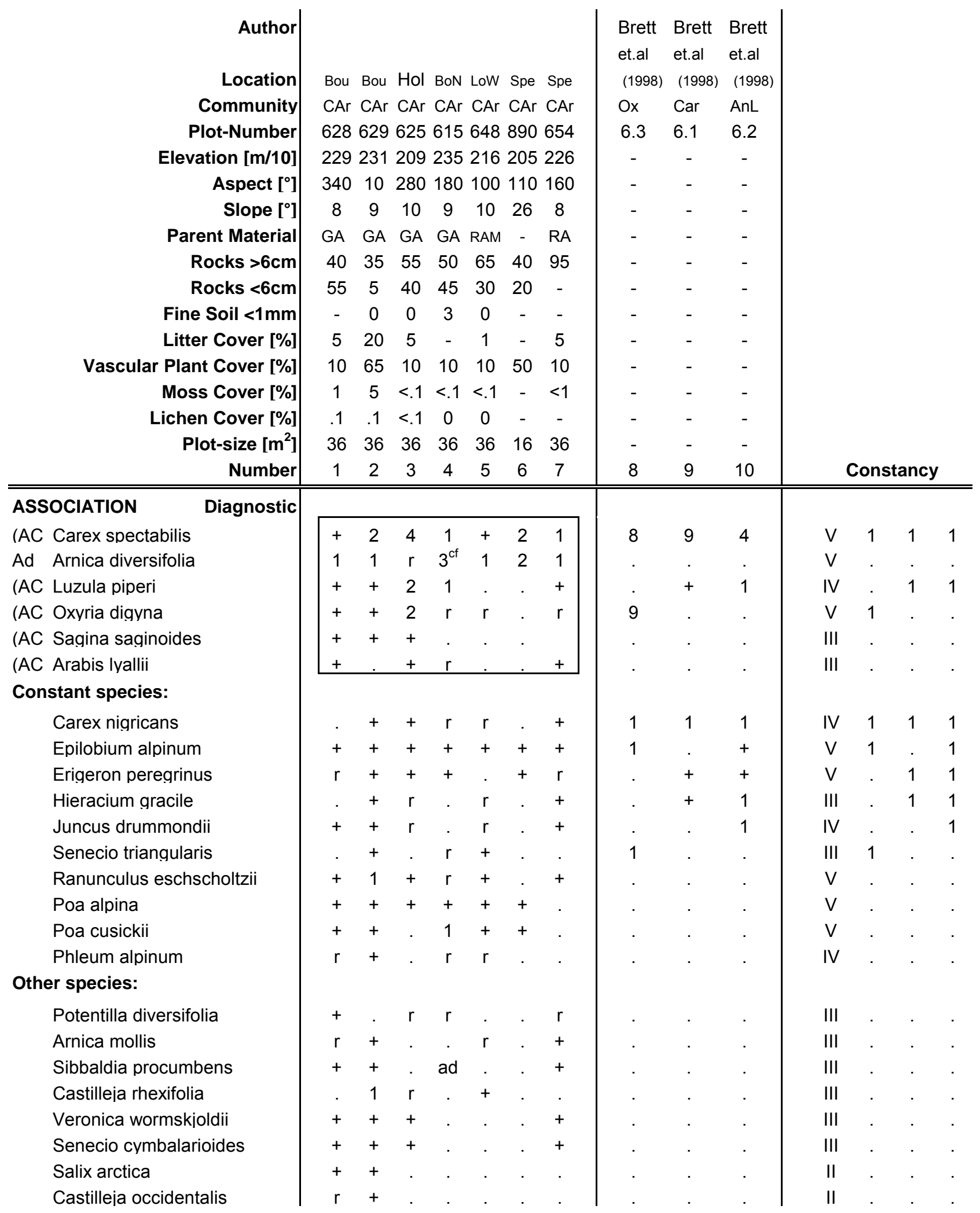


Association Table 20 (cont.):

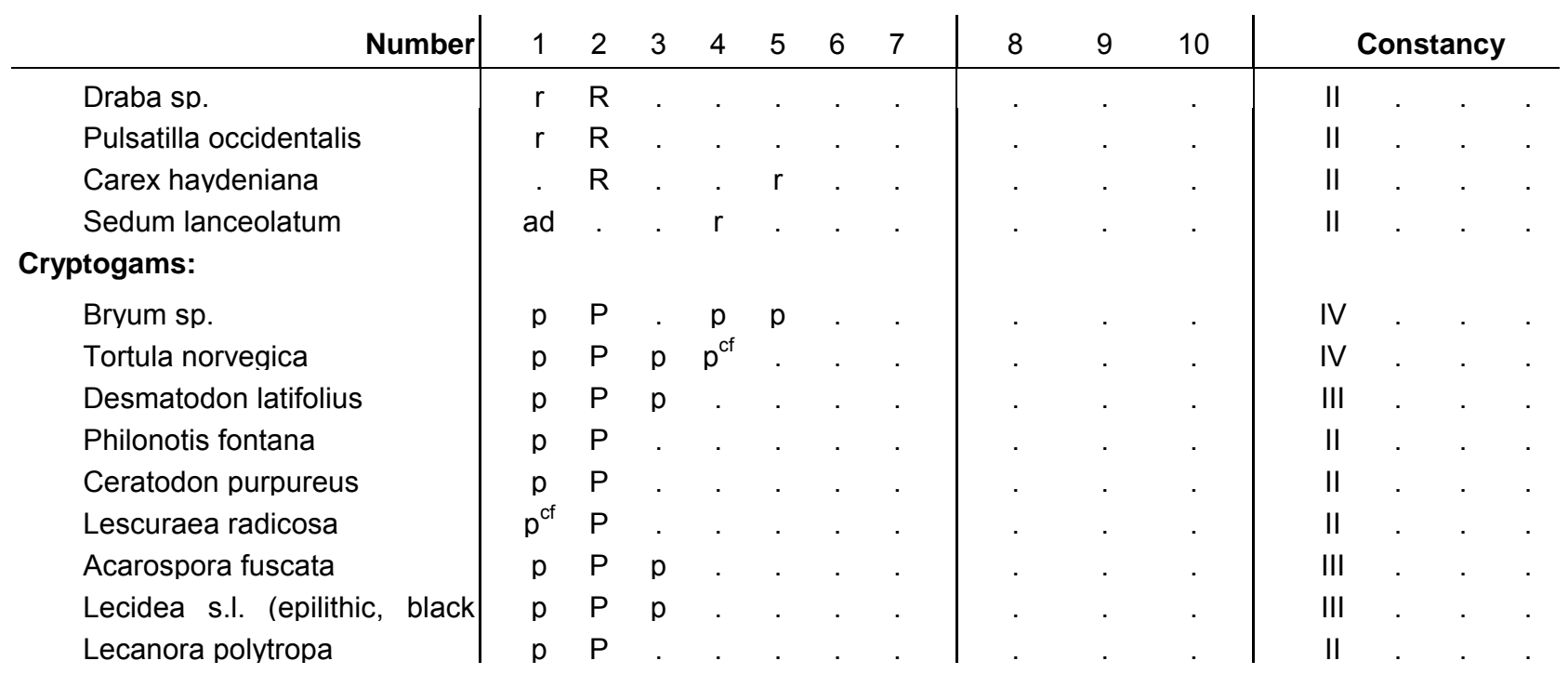

British Columbia-Differential species (Brett et al.):

Lupinus latifolius

Luetkea pectinata

Phyllodoce empetriformis

Cassiope mertensiana

Arnica latifolia

Racomitrium canescens

Vahlodea atropurpurea

\section{Minor species:}

Saxifraga lyallii 1:+ ; Antennaria alpina 1:r , 7:+ , 9:1 ; Leptogium sp. 1:p ; Peltigera rufescens 1:p ; Barbilophozia hatcheri 1:p ; Pohlia sp. 1:p , 10:03 ; Cladonia sp. 1:p ; Brachythecium albicans 1:p ; Pseudoleskella nervosa 1:p ; Phacelia lyallii 1:r ; Larix occidentalis 1:r ; Arnica longifolia 2:+ , 8:+ ; Mitella breweri 2:+ ; Brachythecium sp. 2:p , 3:p ; Bryum weigelii 2:p ;

Polytrichastrum alpinum 3:p ; Claytonia lanceolata 3:+ ; Verrucaria sp. 3:p ; Myurella tenerrima 3:p ; Astragalus bourgovii 4:+ ; Agoseris aurantiaca 4:r ; Mimulus lewisii 5:+ ; Sedum roseum 5:r ; Phacelia hastata 5:ad, 6:+ ; Arabis sp. 5:+ ; Bryum argenteum 5:p ; Carex pyrenaica 7:ad ; Carex phaeocephala 7:+ ; Poa arctica 7:ad ; Polytrichum piliferum 7:p ; Cardamine oligosperma 8:+ , 10:+ ; Dicranum fuscescens 9:+ ; Kiaeria falcata 9:+ ; Anaphalis margaritacea 9:r ; Epilobium latifolium 9:2 ; Valeriana sitchensis 9:1; Petasites frigidus 10:3 ; Penstemon ellipticus 6:1 , 8:+ ; Athyrium distentifolium 6:r, 7:r

Notice:

For comparison, all three units of the "Carex spectabilis order" by Brett et al. (1998) from British Columbia have been added. Their data are in "species significance classes" (see loc.cit.). 


\subsection{ORDER: Sibbaldio-Caricetalia pyrenaicae Komárková 1979}

Nomenclatural Type: Sibbaldio-Caricion pyrenaicae Komárková 1979

Character species (acc. Komárková [1979] and Willard [1979]): Juncus drummondii, Antennaria alpina, Carex pyrenaica, Poa arctica, Erigeron melanocephalus, Rorippa alpina

The most important ecological factor for the spatial arrangement of vegetation units in alpine landscapes is the distribution pattern of the snow. This fact has been stressed by almost any author who ever published on alpine vegetation. Since snow depth and snow duration are factors which like most other ecological parameters occur with gradual changes in space, a number of different ecological situations result which give rise to the development of different snow-dependent vegetation types. These are mostly referred to as snowbed communities. In this study the snowbeds have been treated in two different orders: Firstly, the moister snowbeds with Carex nigricans are treated in the order Caricetalia nigricantis which has a mostly northwestern North American Range with much lesser occurrences further south. Secondly, the present order Sibbaldio-Caricetalia pyrenaicae Komárková 1979, which has a predominantly central and southern Rocky Mountain distribution.

This order is preliminarily used here until a better unterstanding of the large-scale organization of the snowbed orders is worked out with additional data to be collected in the future. In Colorado, both Willard and Komárková classified snowbed communities with Sibbaldia procumbens and Lepraria sp. in the order Sibbaldio-Caricetalia pyrenaicae Komárková 1979 of the class Salicetea herbaceae. The samples from the present study area differ from those of the southern Rocky Mountains mainly in the constant occurrence of Arenaria capillaris.

Besides some other minor floristic differences, these communities are similar enough to be placed in Komárková's order. Within this order they are accommodated in a new and fairly broad alliance Polytricho piliferi-Arenarion capillaris. Compared to the snowbed order Caricetalia nigricantis, the differences to this unit are mostly due to the drier conditions which these communities experience. This order is likely to be confined to more continental areas or locally to more xeric, often better drained or more exposed conditions.

Literature: Snowbed communities with Sibbaldia procumbens have been reported from British Columbia by Archer (1963: Sibbaldietum procumbentis) and Brett et al. (1998: Sibbaldia procumbens association). A number of other Antennaria lanata snowbed communities have been given from Alberta (Kuchar 1973, Kuchar 1975, Crack 1977, Achuff \& Corns 1982). They seem to be somewhat intermediate between the snowbed communities of Carex nigricans and the alpine heath communities of Phyllodoce empetriformis and P. glanduliflora, but are likely to be closer to the latter.

A Juncus drummondii-Antennaria lanata type was described from southwestern Montana by Cooper et al. 1997. Komárková (1979) lists a number of snowpatch communities with Carex pyrenaica from all over the northern hemisphere and from New Zealand which have some similarities with communities in this unit. 


\title{
3.2.1. ALLIANCE: Polytricho piliferi-Arenarion capillaris all. nov.
}

Nomenclatural Type: Sibbaldio-Juncetum parryi ass. nov.

Plots: see lower syntaxa

Character species: Arenaria capillaris Poir. var. americana, (Polytrichum piliferum, Cladonia sp., Lepraria neglecta, Lepraria caesioalba, Sibbaldia procumbens)

This new alliance contains three associations (Sibbaldio-Juncetum parryi, Polytricho-Arenarietum capillaris and Leprario-Salicetum arcticae) and one unranked community, all of which are communities of moderate snowbed environments. I.e., these communities are not extreme in their annual length of snow duration but the snow cover is considerably longer than in the adjacent alpine fellfield and meadow communities. This also represents the most important ecological factor for the differentiation of these units. Often these communities can be found zoned around even longer snow covered catchment areas on the lee-side of wind-breaking relief prominences, but they can also cover larger areas with less steep ecological gradients in shallowly rolling uplands.

The diagnostic species of this group form a very constant group and except for Arenaria capillaris are a more widespread group of snowbed indicator species. Except for Arenaria capillaris which has a more limited western cordilleran distribution, the species have a circumpolar range and are only local character species. Cladonia sp. is likely to be Cladonia pyxidata. The specimens unfortunately have not been determined to the species level because they were always occurring without podetia. Some of them might have been Cladonia ecmocyna, a species being characteristic for snowbeds in much of its northern hemisphere range. A very similar ecological position is known from Lepraria neglecta, Lepraria caesioalba and Sibbaldia procumbens. For notes on the Lepraria species see the "Taxonomic Remarks" in Appendix A.

The placement of this alliance in the order Sibbaldio-Caricetalia pyrenaicae is in fact tentative only until a more thorough large-scale study of alpine snowbed elucidates the orders' validity, delineation and its geographical range.

\subsubsection{ASSOCIATION: Sibbaldio-Juncetum parryi typicum ass. nov. - Sibbaldia-Parry's Rush snowbed community}

\author{
Nomenclatural Type: Table 21 relevé 526 \\ Plots: $191,203,204,206,324,338,346,406,430,440,507,525,526,540,558,566,582 \quad(\mathrm{n}=17)$
}

Character species: Juncus parryi, (with high cover: Sibbaldia procumbens, Antennaria alpina)

Differential species: Hieracium gracile, Claytonia lanceolata

General aspect: This late melting meadow type can vary from a very open structured, moss and soillichen dominated type, exposing some open soil and plenty of Polytrichum piliferum, to a denser, grass and forb richer type with up to $80 \%$ vegetation cover, depending on the local snow situation. The dominant rush and Sibbaldia give this community a darkish, slightly bluish green aspect which contrasts with the greyish-green coloration of the sometimes dominant alpine Antennaria. Very conspicuous for this community are the straight and erect, scattered tufts of Juncus parryi and often also the very similar clumps of Juncus drummondii. A presumed early stage of succession is represented by stands with a high cover of Polytrichum piliferum on shallow soils over bedrock. The community usually does not occur in larger areas. It is commonly found in limited patches or as a 
linear border zone against other communities. The unit is considered a pioneer community, at least on the sites with shallow soils. Due to the little productivity and the occurrence of wind and meltwater erosion, soil development is very slow. Therefore this unit might be considered a "permanent pioneer community" (Dierschke 1994) at least for long periods of time.

A chionophilous tendency in this community is obvious by its topographical position often adjacent to true snowbeds. In fact a common catenal sequence has been observed from Caricetum nigricantis in the most extreme center of the snowbeds through this community towards other fellfield communities. A similar snowbed-sequence from Caricetum nigricantis is through Phyllodoce and Kalmia microphylla-communities to other moist or wet meadow types. The former (Sibbaldio-Juncetum-) sequence seems to be confined to more exposed situations on sites with better drainage and drier fall conditions. This community occurs under slightly less chionophilous conditions and sometimes even in somewhat exposed ridge situations on terraced valley bottoms. The drier conditions of these sites are evidenced by the presence of prairie species like Danthonia intermedia and Carex phaeocephala.

Topography: On smooth to mostly slightly rolling meadows, in slight depressions or on the leeward side of shallow ridges in the low- to mid-alpine, and down also into the subalpine krummholz zone. Also common on benches and terrace edges in the often step-like surface relief of the glacier-carved sedimentary landscape. Sites in depressions usually have considerable soil profiles whereas sites on ledges tend to be extremely shallow with profiles to less than $10 \mathrm{~cm}$, blanketing the bedrock with an initial soil cover. Often occurring not far from smaller krummholz areas, which also tend to occur on the terrace edges due to the lesser snow cover in these slightly raised relief-situations. Slope is none to gentle from $0^{\circ}-10^{\circ}\left(-17^{\circ}\right)$. All samples were gathered in the narrow elevation belt from 2000 to 2050 $\mathrm{m}$ a.s.l., where most gentle sloping areas, hanging valleys and benches occur in the study area.

Geology: The unit is found on Siyeh limestone, red and green argillite, sometimes with little red quartzite or Purcell diorite. Flat, shallow outcrops, which are typical for the slightly inclined sedimentary rocks in the area, provide ideal conditions for the shallow, soil-filled depressions and adjacent flat outcrops occupied by this community.

Soils: Soil development in this community is mostly in an early stage, this community being a pioneer type at least on shallow soil sites. Strongly changing water supply during the season and almost saturated conditions for a long time lead to slow soil building processes, but also impede mineralisation and decomposition of organic material. The resulting soils are dark and rich in humus, occasionally with large amounts of pebbles, gravel and sand. Larger fractions of silt, as are common in other snowbed communities, do occur in depressions and are found increasingly in the lower horizons. Profile depth varies extremely from less than $10 \mathrm{~cm}$ near bedrock surfaces and fairly deep profiles in larger depressions.

Wind exposure/Snow cover/ Moisture conditions: Being situated in slightly wind sheltered, often leeward positions, these sites are snow catchment areas with a long winter snow cover and a good moisture supply in most of the sites. Other sites with shallow soil on rock ledges and ridges can be more exposed resulting in lesser snow cover. Nevertheless drainage in these sites is often impeded by the shallow bedrock surface resulting in wet to moist conditions through mid-summer. Dry conditions occur in late summer and fall, subjecting these sites to an extreme seasonal change in moisture availability. 
Floristical differentiation: Within the Polytricho-Arenarion, this unit is characterized by the importance of Juncus parryi, Antennaria alpina, Juncus drummondii and the constant presence of Hieracium gracile. The latter species, together with Erigeron peregrinus, Claytonia lanceolata, Polytrichastrum alpinum and Erythronium grandiflorum, shows some relationship to the Valerianetalia wet meadow communities and the snowbed order Caricetalia nigricantis. Especially some sites lacking Arenaria capillaris and having Senecio cymbalarioides, Epilobium alpinum, Carex nigricans and Phleum alpinum, are so close to the latter order that they can be considered transitional.

None of the character species of this community as given above is exclusive to this unit. More characteristic is the constant species combination.

With Juncus parryi and Juncus drummondii two morphologically very similar rushes are important in this community. Apart from the fact that Juncus parryi was found to be more constant, no other clear ecological differention between the two closely related species has been found, an observation that was also reported by Willard (1979).

Vegetation cover on the sites is usually evenly spread. Larger patches with pure Polytrichum piliferum can occur mainly on shallow soils over bedrock and in disturbed areas. This moss species is most likely one of the most important colonizer species with high importance for the initial soil development, gradually encroaching over exposed bedrock and trapping soil in their dense mats. The positive effect of bryophyte carpets as soil traps facilitating soil development has been described by Longton (1992).

Polytrichastrum alpinum plays a similar but less important role in this community.

Lichen cover can be little or considerable to $40 \%$, with much of it being covered by the chionophilous Lepraria species growing on bare soil. Another widespread snowbed species common to this community is Cladonia ecmocyna. Also Cladonia pocillum has often been found to be important.

Syntaxonomy: A close relationship exists between the forb-richer variants of this community and the wet Erigeron peregrinus-Erythronium grandiflorum meadows. It was at this point restrained from separating subunits emphasizing this relationship. The floristic similarities are considered to be largely determined by the spatial proximity of the two units whereas ecologically they are quite well separated.

The shallower and drier variants, often characterized by the presence of Danthonia intermedia and Carex phaeocephala are closer to the Festuco-Arenarietum capillaris.

Distribution: The unit occurs on both sides of the Continental Divide. It has not been found in the drier eastern parts of the study area.

Literature: A very similar community was described as Juncus parryi association by Eady (1971) from southern British Columbia. Somewhat similar is her Antennaria lanata association which she also describes as a snowbed unit. Cooper et al. (1997) report a Juncus parryi-Erigeron ursinum community type from southwestern Montana, which is a moderate snowbed unit. Apart from Erigeron ursinum, which does not occur in the study area, some other floristic differences exist. Holway and Ward (1963) reported snow bed vegetation with Juncus parryi from Rocky Mountain NP, Colorado, which is closer though to Willard's Juncetum drummondii. 


\section{SUBASSOCIATION: Sibbaldio-Juncetum parryi saxifragetosum ferrugineae subass. nov. \\ - Rusty Saxifrage bedrock-outcrop community \\ Nomenclatural Type: Table 21 relevé 619}

Plots: $347,348,349,619,633,706,733,734 \quad(n=8)$

\section{Character species: Saxifraga ferruginea, Oligotrichum sp., Racomitrium canescens}

\section{Constant species: Danthonia intermedia, Poa secunda}

General aspect: This community is easily recognized as a community of usually flat shallow-soil rock outcrops with mostly some open bedrock and a moss-rich soil-layer covering the bedrock from the edges. The dense moss carpet is dotted with the scattered rosettes of Saxifraga ferruginea, the bluish-green plants of Sibbaldia procumbens and small tufts of grasses. Open soil areas are largely covered by the grey crust-forming soil lichens Lepraria neglecta and L. caesioalba. In fall most vascular plants, except Saxifraga ferruginea, dry up almost completely and their crumbled remains can be found lying on the moss carpet. The moss layer is most conspicuous when Racomitrium canescens achieves higher cover with its outstanding bright whitish-green color.

Topography: The unit is well characterized as a community of early drying rock ledges and shallow outcrops in the subalpine and low alpine zones. Elevation ranges from 2000 to $2120 \mathrm{~m}$. The sites are mostly level or slightly sloping, only one site was found with a slope angle of $12^{\circ}$.

Geology: see association.

Soils: The shallow accumulations of mineral- and various amounts of organic material can barely be called soils. Within the 20 or less centimeters of fine material almost no soil differentiation can be found. Much of the material is likely to originate from blown-in fine materials and an organic fraction contributed by the vegetation. Most important among these are mosses which first colonize the bare bedrock exposures and help trapping fine material in the spaces between their vegetative parts.

Wind exposure/Snow cover: Wind exposure is moderate to high. Most likely, snow cover in this community is about the same or slightly lesser than in the typicum association. Very little lichen cover on the open bedrock adjacent to the plots indicates a reasonably long winter snow cover.

Moisture conditions: Among the outcrop communities this one seems to be the most extreme one concerning the water availability. The shallow soil profile has only a limited water storage capacity which results in dry conditions early in the summer, sometimes by the end of July. It is assumed that the moss species intercept considerable amounts of moisture from atmospheric water. Interestingly, two of the most dominant species (Polytrichum piliferum, Racomitrium canescens) have prominent leaf hairtips which are considered here to be important devices as condensation surfaces to catch the dew from the air when the soil is already dried out later in the summer. The conspicuous hairy leaves of Saxifraga ferruginea suggest a similar function. Whereas water condensation on the hairy leafsurface certainly happens, the question remains to what extend this vascular plant can make use of the intercepted water. Apart from a decreased evapotranspiration by a thin layer of moistened air on the leaf surface there is no evidence that the saxifrage is capable of taking the water up into the leaf. Even though the possibility might exist, that certain hair-types of vascular plants might be able to accomplish this, no evident cases of such a mechanism have been found in literature.

In this respect the bryophytes have an adaptive advantage, being able to absorb water through their above-ground parts. 
Floristical differentiation: The occurrence of Saxifraga ferruginea is the main floristic difference of this community. Otherwise it is a fairly species poor unit in this association which is likely to be caused by the drought conditions which commonly occur in late summer and fall.

Syntaxonomy: Due to the easily recognized aspect of this community and its extraordinary position on rock ledges it was debated as to whether it should be given association rank. In order to not create too many new syntaxa and due to the fact that only one species differentiates this unit, it was decided to treat it as a subassociation of the Sibbaldio-Juncetum. The latter often occurs right adjacent to this community in the better moisture supplied areas with deeper soil profiles. This community is most likely related to a yet undescribed bedrock community of the subalpine and possibly even montane region (T. Spribille, pers. comm). Similar rock outcrops covered with moss carpets of Polytrichum piliferum and Racomitrium canescens and scattered vascular plant species are found far beyond this study area and are ecologically related to the European Sedo-Scleranthetea class. Nevertheless the impoverished community of the higher elevations presented here is different by the extended snow cover it experiences and the overall extremer conditions provided by the high elevation environment.

Distribution: This community occurs only very scattered and always in small patches being confined to the limited extend of flat rock ledges. It has been observed in the northern and central portions of the study area not far from the Continental Divide. It is likely to be much more widespread further north and south in the Rocky Mountains.

\title{
Polytrichum piliferum-Carex paysonis snow drift community
}

\author{
Nomenclatural Type: Table 21 relevé 195 \\ Plots: $96,97,192,193,195,199,407 \quad(n=7)$
}

\section{Character species: (Carex paysonis, Cladonia ecmocyna, Solorina crocea), Carex pyrenaica}

General aspect: This is a very open structured cryptogam-sedge community of Carex paysonis, Carex pyrenaica often accompanied by Carex phaeocephala. Among the sedge dominated grass-layer most plants do not become much higher than $10 \mathrm{~cm}$, mostly much less than that. Sibbaldia procumbens is an important species growing almost appressed to the ground. Polytrichum piliferum covers much of the surface and soil lichens play an important role in this moderately chionophilous community. Rock cover in this stabilized community is low but can in cases exceed $30 \%$, representing different stages of soil development and vegetation establishment.

Topography: Even though a (moderately) chionophilous community, this unit occurs in fairly exposed high elevation locations. Snow is accumulating in drifts on these sites which can lie in shallow depressions as well as on shallowly convex ridges. Surface relief is smooth and often slightly rolling. Slope is none to usually less than $10^{\circ}$, rarely more with no exposure being favored. A better data base for this unit is desirable to verify the environmental requirements of this community.

Geology: Found on green and red argillite with some quartzite mixed in.

Wind exposure/Snow cover/Moisture conditions: Wind exposure is high to very high but snow can accumulate in drifts due to the leeward orientation of the sites. Resulting is a reasonably long snow duration in early summer. Water availability changes strongly from meltwater-seeped in early summer to quickly drying later on due to the often good drainage of the sites and strongly desiccating winds resulting in dry fall conditions. 
Floristical differentiation: The dominance of the two name-giving species is diagnostic for this unit. Carex pyrenaica has been found mainly in this community and might turn out to be a good character species at least on a local scale. As a character species of the order, Carex pyrenaica of course has a much wider distribution in the snowbed communities of the Rocky Mountains. Carex phaeocephala has even higher constancy but is far more widespread. Agrostis variabilis has been found frequently in one of the locations. Antennaria alpina and/or Antennaria umbrinella are very constant in this snowbed community. The identifications of Antennaria umbrinella are questionable in these cases and it might well be that all of the specimens from this community belong to Antennaria alpina or represent an apomictic hybrid.

Moss cover is highly important with Polytrichum piliferum being the predominant species with up to $45 \%$ cover. As described with the association, it is the most important colonizer and soil builder in this community. Next important in cover are Polytrichastrum alpinum and sometimes Tortula ruralis.

Given the reasonably long winter snow cover, soil lichens are fairly important too, covering 10 to $30 \%$ of the plots. Most of the cover is by circumpolar species typical for such late melting sites, like the highly constant Cladonia ecmocyna and the yellowish Cladonia borealis. Lepraria neglecta and L. caesioalba also belong to this group. Another conspicuous species indicating long snow duration is the colorful foliose soil lichen Solorina crocea.

Syntaxonomy: This distinct unit has been found in two locations only. No syntaxonomic rank is assigned to this community until a more widespread distribution can be validated with more plot samples.

Distribution: The community was found in the north-central part of the study area. It is likely to occur more often in the high elevation valleys were glacial retreat constantly creates new sites for the establishment of similar vegetation. At this point more locations are needed to validate the community itself and delineate its distribution.

Literature: Communities with some similarities have been described elsewhere in the literature. Notwithstanding, none of these would fit into the same association. Some similarity exists to the Caricetum pyrenaicae of Willard and Komárková, even though Carex paysonis does not play a role in those southern Rocky Mountain communities and the rushes Juncus drummondii and Juncus parryi are not well represented in the present community. Komárková's Solorino-Polytrichetum piliferi is similar in regard to the name giving species and the importance of cryptogams. Nevertheless it differs in that the present community is much more dominated by vascular plants. The "dry meadow" among the "chionophilic meadows" described by Kuchar (1973) has some species with this unit in common but seems to be much broader defined than this unit. 


\title{
3.2.1.2. ASSOCIATION: Polytricho piliferi-Arenarietum capillaris ass. nov. - Polytrichum-Arenaria capillaris late melting meadow community
}

\author{
Nomenclatural Type: Table 21 relevé 272 \\ Plots: 51, 52, 87, 152, 158, 200, 253, 254, 264, 267, 268, 271, 272, 279, 284, 295, 298, 358, 360, 371, 508, 590, \\ $637 \quad(n=23)$ \\ Diagnostic species: Arenaria capillaris $>10 \%$, Polytrichum piliferum, Eriogonum flavum, \\ Arnica rydbergii \\ Differential species: Festuca idahoensis, Silene parryi, Pedicularis contorta, (Polygonum \\ bistortoides, Astragalus bourgovii, Erigeron simplex, Achillea millefolium, Antennaria \\ umbrinella, Agoseris glauca, Sedum lanceolatum)
}

General aspect: This kind of late melting meadow can be quite variable from its aspect, largely depending on the different topographical positions which have in common the extended period of snow-cover. Most dominant in all cases is Arenaria capillaris, being exceeded in cover and structural importance occasionally by Festuca idahoensis which does occur in most but not all samples. The latter species is much less common in the subassociation of Lomatium sandbergii. In most cases Arenaria capillaris is the dominant species forming a loose mat of its loosely needle-leaved shoots. Bright green as well as bluish-green forms of the species have been observed but no distributional or ecological pattern separating the two forms has been detected. The Fescue dominated stands have an open grassy meadow aspect with the bluish-green tufted Fescue making up for much of the aspect.

The vegetation layer is mostly evenly spread covering from $20 \%$ to $90 \%$ of the plot surface. This community is quite similar in its aspect to the closely related Arenario-Festucetum idahoensis of the Arenario-Festucetalia brachyphyllae (for differentiation against this unit see below).

Topography: The unit occurs on smooth to rolling upper slopes, in shallow depressions, and most often on leesides of ridgetops where some snow accumulation takes place in the winter. Elevations are from $1850 \mathrm{~m}$ to $2420 \mathrm{~m}$ with $\mathrm{NE}$ to $\mathrm{S}$ exposure. The slopes are gentle to moderately steep, only rarely very steep: $\left(2^{\circ}\right) 8^{\circ}-24^{\circ}\left(-32^{\circ}\right)$. The surfaces mostly consist of stabilized talus or sometimes of frost rubble. Unstable conditions can exist on steeper slopes. Considerable amounts of open mineral soil, often as cracks in the evenly spread vegetation layer point to some frost action which is most likely represented by soil creep on steeper slopes and frost churning in the rockier frost rubble sites. Rock cover in this unit can be none to $40 \%$ with some mineral soil usually being exposed. Pocket gopher activity has been commonly observed in this community.

Geology: This unit was sampled on green argillite, red argillite with small amounts of quartzite and arenites, rarely on limestone.

Wind exposure/Snow cover/Moisture conditions: Wind exposure is high to middle with snow accumulations in drifts behind wind-breaking ridgetops and other raised relief features. Water availability is changing strongly through the season with ample supply after melt-out and strong desiccation later on in the summer.

Floristical differentiation: This unit, even though floristically well differentiated, does not have a single exclusive character species. The differential species as given above are all taken from the Bupleurum americanum prairie species group in the Arenario-Festucetalia fellfield order. A close floristic relationship to that syntaxon exists and spatial closeness is often found between the two, this 
one representing the unit with longer snow cover. In fact it is often not easy to assign certain plots to one of the two orders. The presence of the chionophilous diagnostic species usually decides this question.

Moss as well as lichen cover can vary extremely in this community from being largely absent to covering more than a third of the plot surface.

Syntaxonomy: The syntaxonomical position of this unit in a snowbed group is chosen despite the fact that a fairly large number of taxa diagnostic for the adjacent fellfield communities are present and even constant in many stands of this unit. The increasing lack of fellfield species along the snow gradient is obviously very differently developed among the fellfield species. In other words, some of them like Luzula spicata, Selaginella scopulorum, Potentilla diversifolia, Solidago multiradiata and Polygonum bistortoides are more tolerant of increasing amounts of snow and reach well into this snowbed unit. On the contrary, others like Arenaria obtusiloba, Oxytropis campestris s.1., Besseya wyomingensis, Calamagrostis purpurascens, Silene acaulis and Saxifraga occidentalis are almost completely lacking in the stands of this community which is interpreted as an intolerance for extended snow cover.

The same difference in snow tolerance exists among the species of the Bupleurum americanum group. Out of this group Silene parryi, Pedicularis contorta and little less so Achillea millefolium and Antennaria umbrinella are present in these late melting communities whereas Bupleurum americanum, Senecio canus, Cerastium arvense, Arabis nuttallii. Campanula rotundifolia, Anemone patens, Eriogonum ovalifolium and Galium boreale are snow intolerant enough to be almost entirely lacking. Those missing species serve as negative differential species against the fellfield order Arenario-Festucetalia brachyphyllae.

The large number of species of the Bupleurum americanum group raises the question, why this unit has not been treated as the most late melting variant in the latter association. In order to stress the snowbed character of this unit and due to the constant presence of character species of the snowbed order and alliance, it was decided to treat this unit within the snowbed communities. The almost complete lack of many fellfield character species as well as the lack of eight out of thirteen species of the Bupleurum americanum group supported this decision.

The closest relative of the present association among the fellfields is the Arenario capillarisFestucetum idahoensis. It is indeed so similar, mainly in the characteristic Arenaria capillaris-Arnica rydbergii-Eriogonum flavum group, that the present unit could be given the same name

The name Polytricho-Arenarietum emphasizes both the relation to the snowbed species of the Polytrichum piliferum-Lepraria sp.-Sibbaldia procumbens group and to the Arenaria capillaris group. Less similar but still related is the Oxytropido-Bupleuretum americani.

Within this alliance this community is closest to the Lomatium sandbergii-Juncus parryi community. A few plots were even considered transitional to the Lomatium-unit which is treated as a subassociation in the present syntaxon.

Distribution: This association was found only east of the Continental Divide and has a similar distribution as the units of the Oxytropido-Bupleuretum americani, which is often found in the immediate vicinity frequently grading into this community. 
Literature: No other literature citations of similar communities have been found. A Phlox diffusa / Arenaria capillaris association was described by Hamann (1972) from Mt. Rainier NP but the floristic overlap with the present unit as well as the ecological similarity is very small. The occurrence of Arenaria capillaris in some of the Salix arctica association samples of Trottier (1972) might point to some similarity with that moderately chionophilous community from Alberta.

\section{SUBASSOCIATION: Polytricho piliferi-Arenarietum capillaris lomatietosum subass. nov. \\ - Lomatium sandbergii late melting fellfield meadow community}

Nomenclatural Type: Table 21 relevé 509

Plots: $268,270,284,289,290,296,297,431,509 \quad(n=9)$

\section{Character species: Lomatium sandbergii}

Differential species (against typicum): Juncus parryi, Antennaria alpina, Hieracium gracile, Danthonia intermedia

General aspect: Among the chionophilous Polytricho-Arenarion communities this one has very constant floristic composition which was repeatedly found in various locations of the study area. As the name of the community indicates this unit combines characters of herbaceous meadows and fellfield communities. The average species number is slightly higher than in the latter two Juncus parryi communities with some conspicuous prairie species becoming very constant in this unit. The homogeneous but still fairly open and low growing vegetation is found on gravelly to rocky sites giving it the fellfield character of the vegetation often adjacent above this community. A spectacular flowering aspect of Pedicularis contorta and Arnica rydbergii and sometimes Eriogonum flavum is similar to that of the closely related Arenaria capillaris-Eriogonum flavum association of the Silene acaulis-alliance.

Topography: Mid- to low alpine, sometimes subalpine slopes at elevations from $2050 \mathrm{~m}$ to $2350 \mathrm{~m}$ are inhabited by this community. The slopes have moderate steepness from $4^{\circ}$ to $15^{\circ}\left(-28^{\circ}\right)$ with surfaces often slightly concave, sometimes as depressions on slope-benches. All exposures are found except NW. The talus slopes are mostly stabilized; slow slope creep can be indicated by slight slopeparallel undulating surface.

Geology: The unit occurs mostly on green or red argillite, with small amounts of quartzite, arenite and sometimes diorite.

Wind exposure/Snow cover: Wind exposure is middle thus snow can accumulate considerably in winter. The snow cover is long to reasonable in this chionophilous community. This community often occurs in the immediate vicinity of krummholz areas, sometimes even forming a zone along to lower edges of those fir and pine dominated wooded patches. The wind-breaking krummholz in such situations is one of the main factors for the accumulation of snow drifts which are essential for this community.

Moisture conditions: Water supply in this community is very seasonal. Mesic to moist conditions prevail after snowmelt and in summer with drier conditions being likely to occur on these often well drained sites in fall. Compared to the Sibbaldio-Juncetum this community seems to be drier in fall, thus the extreme between ample moisture after snow melt and and drought in fall create more extremely seasonal conditions. 
Floristical differentiation: Lomatium sandbergii and Juncus parryi are the most characteristic species of this unit. Arenaria capillaris is mostly very dominant and so can be Sibbaldia procumbens. Species of the wet mesic meadows like Erythronium grandiflorum, Hypericum formosum, Vahlodea atropurpurea etc., which are occurring in the Juncetum parryi, are missing in this unit. Nevertheless Juncus parryi itself as well as Antennaria alpina, Hieracium gracile, Danthonia intermedia and Erigeron peregrinus are well represented. All except the last one are differential against the typicum variant. The prairie species Arnica rydbergii, Silene parryi, Eriogonum flavum and Pedicularis contorta point to the drier conditions, differentiating against the Juncetum parryi and uniting it with the typicum variant.

Compared to the Festuco-Arenarietum capillaris typicum, this subassociation largely lacks Polygonum bistortoides, Sedum lanceolatum, Achillea millefolium, Antennaria umbrinella and Potentilla diversifolia. Astragalus bourgovii, Agoseris glauca, Solidago multiradiata, Erigeron simplex and Festuca scabrella are also lacking.

Syntaxonomy: This community is syntaxonomical transitional between the Sibbaldio-Juncetum parryi and the Polytricho-Arenarietum capillaris typicum. Therefore it was debated as to whether it would be better accommodated as a subunit of the Sibbaldio-Juncetum parryi or - as finally done here - as a subassociation of the Polytricho-Arenarietum. The latter's diagnostic species Antennaria alpina, Hieracium gracile and Erigeron peregrinus relate this unit to the Sibbaldio-Juncetum. On the other hand the presence of Arnica rydbergii, Silene parryi, Eriogonum flavum and Pedicularis contorta as well as the numerical analysis show a closer relationship to the Polytricho-Arenarietum capillaris. Furthermore is the dominance of Arenaria capillaris so striking in most of this unit's samples that it seems appropriate to keep it in the Polytricho-Arenarietum. Some ecological factors like mean elevation, exposure, steeper slope and other structural criteria support this decision.

Distribution: The community has been found scattered in the study mainly but not exclusively on the east side of the Continental Divide at five locations from the northern parts at Red Gap Pass through the central portion at Siyeh Pass, Highline Trail and Medicine Owl Basin to Spot Mountain in the southern quarter.

Literature: Community descriptions with similar species assemblages have not been found in literature. 


\title{
3.2.1.3. ASSOCIATION: Leprario caesioalbae-Salicetum arcticae ass. nov. - Lepraria-Arctic Willow snowbed community plate 4, fig.13
}

\author{
Nomenclatural Type: Table 21 relevé 196 \\ Plots: $196,208,396,405,414,434,529,571,609 \quad(n=9)$
}

Character species: (Salix arctica $>10 \%$ cover, Lepraria caesioalba, Lepraria neglecta)

General aspect: This is one of the most extreme and structurally simple plant communities. Much of the stands is dominated by very low growing, sometimes loose mats of Salix arctica which usually do not grow higher than $3 \mathrm{~cm}$. Much of the soil surface is covered with cryptogams, mainly with the conspicuous grey soil crusts of Lepraria neglecta and Lepraria caesioalba. The light patches of these lichens are the most outstanding feature of this community which is therefore easily found as soon as the snow has been melting off in Juli or even early August. Very constant in this community is also Castilleja occidentalis which grows as a hemiparasite on the arctic willow. This paintbrush is hardly ever found in the area without Salix arctica as its host species.

Topography: The community is found on level to slightly inclined bedrock outcrops or sometimes covering colluvial footslopes. Most sites are moderately protected by their relief position which usually has a depressed surface rather than being convex and exposed. Rock cover is relatively high ranging from 30 to $50 \%$ in the samples presented. Loose pebbles on top of the humus-rich soil as well as protruding bedrock both account for the rock cover. Much of the smaller rock fractions is probably blown-in or churned up by frost heaving. No exposition seems to be favored. Elevations are from $2000 \mathrm{~m}$ to $2400 \mathrm{~m}$.

Geology: Sampled on green argillite, red argillite and Siyeh limestone.

Soils: It is very obvious that this community is bound to shallow soils which are underlain by unweathered bedrock about 10 to $20 \mathrm{~cm}$ below the soil surface. The soils are hardly developed, often found as soil pockets on shallow, almost level outcrops of the layered bedrock. Despite the slow soil developement they can consist largely of organic material originating from willow litter, cryptogamic material as well as wind-blown organic and inorganic material.

Wind exposure/Snow cover: Wind exposure is high to middle which increases the likelyhood of desiccation in later summer and fall. Nevertheless snow is accumulating considerably on the depressed or protected sites and snow duration is always long, being the most predominant ecological site factor of this true snowbed community.

Moisture conditions: Water supply is good through about mid-August and might dry later on in sites without moisture supply from other snowmelt or seepage areas above. The shallow soil profile itself does not store large amounts of water. Thus dry conditions in fall might be an important factor for the reduced productivity of this plant community adding to the short season after the late snow melt.

Floristic differentiation: The apparent dominance of Salix arctica, joined by Castilleja occidentalis and Lepraria spp. are very good indicators of this community. So are Polytrichum piliferum and Polytrichastrum alpinum which are very constant species import for stabilizing the soil surface. They cryptogamic biomass production is likely to contribute considerably to the accumulation of the humus layer. Typical for this community is the low growing, often scattered vegetation exposing much of the lichen and moss covered or sometimes bare soil surface. Sibbaldia procumbens, Carex nigricans, Antennaria alpina, Juncus drummondii and Arenaria capillaris underline the snowbed character of this unit. Otherwise there is quite some hetereogeneity in the floristic composition as is common in 
Salix arctica communities, especially when gaps of open soil are present to be colonized by accidential invading species. Senecio cymbalarioides points to the wet conditions which prevail at least through the first two thirds of the season. Some more floristic connections exist to the mesic meadows with Luzula hitchcockii, Hieracium gracile and Carex paysonis in some samples, others show a greater relationship to tundra communities. Salix nivalis which has been found to occur in communities with Salix arctica in other areas does not play an important role in this community. Good differential species against the other Salix arctica communities in the area are Carex paysonis, Juncus parryi, Selaginella scopulorum, Polytrichum piliferum, Polytrichastrum alpinum, Polytrichum juniperinum, Psoroma hypnorum, Cladonia pocillum and Lecidoma demissum. All of those cryptogams also point to the long snow duration in this unit. (Concerning the treatment of Lepraria spp., see notes under "Taxonomic Remarks", Appendix A).

Syntaxonomy: Even though Salix arctica and Castilleja occidentalis are the only constant species to differentiate this unit within this alliance, it is considered structurally and ecologically distinct enough to be separated as an association. It is an outstanding but still typical representative of the PolytrichoArenarion capillaris, representing the most chionophilous community in this alliance. Close relationships exist to the structurally different Sibbaldio-Juncetum parryi, as well as to the Polytrichum-Carex paysonis snow drift community. A number of species common to the Caricetalia nigricantis do occur.

Distribution: This community has been found all along the Continental Divide from Boulder Pass in the north to Logan Pass in the central parts of the study area. It is likely to be found in a larger area far beyond the Park.

Literature: Several alpine plant communities with Salix arctica have been described from western North America. An overview of those communities has not been carried out so far. A synopsis of these units reveals a group of southern Rocky Mountain communities and a very much different group existing in the northern Rockies.

Fairly constant common species among the southern Rocky Mountain units are five widespread alpine fellfield species which are Geum rossii, Festuca brachyphylla, Silene acaulis, Luzula spicata and Polygonum bistortoides. Diagnostic common species on a regional scale are only Carex scopulorum and Chionophila jamesii, which indicate well moisture supplied sites and a prolonged snow cover. On the other hand a large number of differential species exist for all three associations. In case it is decided to create a southern Rocky Mountian Salix arctica syntaxon, which might be named after Geum rossii and Salix arctica, these three units would make well differentiated, locally restricted subunits, possibly local subassociations. Even though only Sibbaldia procumbens and Chionophila jamesii are more or less constantly present as class character species, the ecological role as moderate snowbed communities unites these groups, and together with the occurrence of the two species allows for a placement in that class.

None of the Salix arctica units from Colorado is very similar to the current Leprario-Salicetum, which therefore does not belong to the validly described Salicetum arcticae. Among those southern communities it is closest to the unit presented by Willard.

Besides those southern Rocky Mountain Salix arctica communities, there are a number of units described from the northern Rockies, mainly from Alberta. These are united with the southern Salix arctica units by the species Castilleja occidentalis, Polygonum viviparum and Sibbaldia procumbens. Ecologically they are somewhat similar in that the northern samples also represent moderate snowbed communities. Nevertheless have almost all of those stronger ties to moister high elevation communities, which reflects the overall moister conditions in the northern Rocky Mountains. Poa 
alpina, Ranunculus eschscholtzii, Veronica wormskjoldii, Antennaria lanata, Antennaria alpina and Epilobium alpinum are common species in most of those communities and show a close relationship with communities of the Caricetalia nigricantis.

Such communities have been mentioned by Johnson \& Billings (1962) in frost boils within Deschampsia caespitosa meadows in the Beartooth Mountains, but detailed vegetation information is not given. From Alberta, Beder (1967) describes a Salix arctica association which is a somewhat similar moderate snowbed community of gentle slopes differing in the presence of Antennaria lanata, Carex microptera and Festuca brachyphylla and in its occurrence on deep soils. Ogilvie (1976) also reported a Salix arctica community with Carex microptera, resembling Beder's unit. Among the three community types with Salix arctica mentioned by Hrapko \& LaRoi (1978), only the Salix arcticaAntennaria lanata type has some resemblance to the unit studied here. Nevertheless it seems fairly heterogeneous with strong ties to heath communities and has a very different cryptogamic vegetation. Another Salix arctica association was given by Crack (1977) from Wilcox Pass, Alberta, which shares a number of species with the Salix arctica association reported by Trottier (1972) from Highwood Pass. Both are heterogeneous units again and do not have too much in common with the present unit.

It needs to be stressed that vegetation units with Salix arctica generally are very heterogeneous in their floristic composition. The mere fact that communities dominated by this physiognomically dominant dwarf shrub are very conspicuous and easily delineated in the field might mislead to the assumption that communities of this species would characterize one or only a few related syntaxa. The naming of the above mentioned "Salicetum arcticae" for Salix arctica dominated communities from Colorado as delineated by Willard seems to be such a case and it is to be called somewhat unfortunate. Communities with Salix arctica which would similarily deserve this name can be found all along the Rocky Mountains from the high arctic (e.g. Polunin 1948) to New Mexico (Baker 1983). Willard's validly described community represents a locally restricted variant with a high number and abundance of species not typical for this species' communities over a larger area. A better name for this southern syntaxon would have been e.g. "Geo rossii- Salicetum arcticae" (if this rank would be agreed on), based on Kiener's syntaxon and incorporating Willard's and Komárková's as subassociations, stressing the regional character of these variants. According to arcticle 29 of the Code of Phytosociological Nomenclature, a renaming in such cases is not allowed, even though it would result in a considerable improvement of the syntaxonomical system. It seems appropriate to suggest that new syntaxa which most likely have a restricted geographical range should be named after two species. This even more so when one of the name-giving species has a very large distribution range. The other species would then hold the information of the localized character of the unit.

If a widely distributed Salix arctica-syntaxon does not exist, which in fact is revealed by the comparison of Salix arctica communities over a larger area resulting in a considerable floristic heterogeneity, then several smaller Salix arctica-syntaxa will have to be defined within different higher syntaxa, one of which is presented here.

Another community of interest with slightly lesser floristic ties but strong physiognomic and ecological similarity is the Salix herbacea-Lepraria neglecta community described by Daniels (1982) from Greenland. He found his syntaxon to be a strongly chionophytic, psychrophytic, meso- to xerophytic and moderately acidophytic community. Apart from the fact that Salix herbacea does not occur in western North America where it is replaced by Salix arctica, the similarities are striking. This applies also to the common occurrence of some cryptogams, namely Polytrichum piliferum, Polytrichastrum alpinum, Psoroma hypnorum, Solorina crocea and Lophozia sp. Daniels also 
mentions the good moisture supply in this community in spring followed by dry surface conditions in summer and fall which cause shrinkage cracks resulting in conspicuous polygon patterns of the lichen crust covered soil. The same can be observed in the respective community in Glacier NP.

\title{
3.3. ORDER: Phyllodoco-Cassiopetalia Brooke et al. em. Damm
}

\author{
Nomenclatural Type: Phyllodoco-Cassiopion mertensianae Brooke et al. 1970
}

Character species: Phyllodoce glanduliflora, Phyllodoce empetriformis, Cassiope mertensiana, Kalmia microphylla, Gaultheria humifusa; additional species acc. Brooke et al.: Luetkea pectinata, Vaccinium deliciosum, Lycopodium sitchense (=Diphasiastrum s.), (Leproloma membranacea, Stereocaulon tomentosum, Orthothecium floerkii, Kiaeria falcata, Dichodontium olympicum, Solorina crocea)

This western North American heath order was described by Brooke et al. (1970) based on data from British Columbia. The type alliance was the only one to be described at that time. It is suggested here to extend the order much beyond its original range to include the floristically and ecologically similar interior heath communities with Phyllodoce spp. and Cassiope spp. and open it for the creation of other alliances. This extension is considered a significant change of the order which is this treatment is considered and emendation in the sence of the Phytosociological Code (Barkmann et al. 1986).

Even though very few other species occur through the whole range of this order, the unit is considered to be physiognomically and ecologically distinct enough to warrant separation on this high syntaxonomic level. The detailed organisation of the order and the subordinate units can be taken from the synoptic table Tab. 4.

The placement of this order in a class is yet an open question. The creation of a new class for the chionophilous heath communities of the western North American mountains is not an unlikely option, given the little similarity this unit has to other existing classes and other communities in general. The investigation of the relationship of these heath communities to the even more widespread heath communities further north will have to be accomplished before taking this step. For now the order is provisionally kept in the snowbed class Salicetea herbaceae.

Although the dominance of Phyllodoce and Cassiope spp. is very common in many communities of the western north American cordillera all the way into the North American arctic (Gjaerevoll 1954, Hoefs et al. 1975, Cooper 1986), these communities of higher latitudes are floristically and possibly also ecologically somewhat different. According to use of the term "heath communities" by Gjaerevoll in the limestone-dominated White Mountains of Alaska, they are referred to mainly as somewhat xeric Dryas communities with lesser amounts of ericaceous species in that area. Cooper on the other hand mentions his Cassiope tetragonae-Dryadetalia alaskensis from the central Brooks Range as snowbed communities which are ecologically more similar to the units treated in this study. Cooper made the important statement that he observed a smaller ecological distance between snowbeds and less chionophilic sites in Alaska compared to alpine areas of the southern Rocky Mountains. This results in a lesser floristic differentiation between those snowbeds and less snow impacted sites in the northern regions. Consequently it can be assumed that the relationship between snowbed heath communities and Dryas communities will be much different in the high latitude arctic and alpine areas compared to the central and southern Rocky Mountains and also compared to the coastal ranges. A synoptic comparison of these areas is necessary before a reasonable system of 
classes can be given.

The ecological and floristic relation of the chionophilic heath communities to the snowbeds of the order Caricetalia nigricantis should also be taken into consideration while developing the organisation of the class level.

The synopsis of heath communities reveals, that the present treatment of the Phyllodoco-Cassiopetalia includes a number of communities dominated by Dryas octopetala and Cassiope tetragona. This group has a somewhat marginal position in the order, largely lacking most of the otherwise constant species of the unit. All of these Dryas-Cassiope heaths have nevertheless been described by their authors as chionophilic heath communities. This group best describes the shrinking ecological distance between snowbeds and drier alpine communities which has been mentioned in the previous paragraph. The large number of tundra species in these communities is referred to the spatial proximity of these communities which oftentimes are described to occur under the leeward snow accumulations of ridges covered with drier, exposed fellfield vegetation. These northern Rocky Mountain heath communities largely lack Phyllodoce empetriformis as well as Cassiope mertensiana, both of which are characteristic for the order in the western and central/southern parts of its range. As Trottier (1972) and Mortimer (1978) pointed out, the genera Cassiope and Phyllodoce each have two nearly vicariant species, one of each having a more coastal/oceanic distribution (Cassiope mertensiana, Phyllodoce empetriformis) whereas the other is restricted to the more continental areas (C. tetragona, P. glanduliflora).

Rather then keeping the Dryas-Cassiope tetragona unit separate outside this order, it is suggested to retain it as a provisional suborder Dryado-Cassiopenalia. The remaining part of the order is placed in the provisional suborder Phyllodoco-Cassiopenalia. These suborders might be abolished if later studies reveal the Dryas-Cassiope tetragona units to warrant their own higher unit.

Literature: According to Kuchar (1975) mountain heathers (Cassiope spp. and Phyllodoce spp.) "are the most important low alpine ground cover in the Canadian Rockies except towards the US border where dry sedge meadows seem to replace them (Baig 1972, Kuchar 1973)". These timberline heaths are considered the unifying element with the far western alpine areas (e.g. Brink 1964, Douglas 1972). Almost all vegetation studies from these areas mention mountian heath communities, a fact that makes this vegetation type the most well recognized one of all high elevation units. The following reports have been found in the literature and are included in the synoptic table Tab. 4:

Brink (1959): subalpine heath; Beder (1967): Cassiope tetragona association, Phyllodoce glanduliflora-Vaccinium scoparium association; Baptie (1968): Phyllodoce glanduliflora association, Cassiope tetragona association; Brooke et al. (1970): Phyllodoco-Cassiopetum mertensianae; Kuramoto \& Bliss (1970): Phyllodoce empetriformis-Vaccinium deliciosum-heath type;

Eady (1971): Phyllodoce empetriformis - Antennaria lanata association; Hamann (1972): Phyllodoce empetriformis-Cassiope mertensiana association, Cassiope mertensiana-Phyllodoce empetriformis association, Phyllodoce glanduliflora-Aster alpigenus association; Trottier (1972): Phyllodoce association, Cassiope tetragona association; Broad (1973): Cassiope mertensiana heath, Phyllodoce association; Kuchar (1973): "Phyllodoce glanduliflora-patches"; Knapik et al. (1973): Phyllodoce glanduliflora - Antennaria lanata; Henderson (1974): Phyllodoce empetriformis-Vaccinium deliciosum community type; Kuchar (1975): Phyllodoce glanduliflora-Cassiope mertensiana type, Cassiope tetragona-Phyllodoce glanduliflora subtype, Cassiope tetragona-Dryas octopetala type; Douglas \& Bliss (1977): Cassiope mertensiana community, Phyllodoce empetriformis community, Phyllodoce glanduliflora community; Crack (1977): Phyllodoce association, Cassiope tetragona association; Hrapko \& LaRoi (1978); Cassiope mertensiana-Phyllodoce glanduliflora, Cassiope tetragona-Dryas octopetala community type; Mortimer (1978): Dryas integrifolia-Cassiope 
tetragona community, Salix arctica-Cassiope tetragona community, Phyllodoce glandulifloraCassiope mertensiana community; Hämet-Ahti (1978): Phyllodoce empetriformis heath community; Achuff et al. (1982): Cassiope tetragona-Dryas octopetala community, Phyllodoce glandulifloraCassiope mertensiana-Antennaria lanata community; Caicco (1983): Phyllodoce empetriformis community; Achuff et al. (1984): Phyllodoce glanduliflora-Cassiope mertensiana-Antennaria lanata community, Antennaria lanata-Cassiope mertensiana-Phyllodoce empetriformis community; Cooper \& Lesica (1992), Cooper et al. (1997): Phyllodoce empetriformis-Antennaria lanata community type, Cassiope mertensiana-Carex paysonis community type; Achuff et al. (1997): Cassiope tetragonaDryas octopetala-Salix nivalis community, Phyllodoce glanduliflora-Cassiope mertensianaAntennaria lanata community; Timoney (1999): Phyllodoce glanduliflora association, Phyllodoce empetriformis association.

The geographical distribution of these studies reveals the lack of heath communities in the drier southern parts of the Rocky Mountains. A similar pattern is found for other moist alpine and subalpine communities, mainly the tall herb meadows which are almost characteristic for the coastal mountains (Kuramoto \& Bliss 1970).

\section{SUBORDER: Dryado octopetalae-Cassiopenalia tetragonae subord. prov.}

Nomenclatural Type: Dryado octopetalae-Cassiopion tetragonae all. prov.

Diagnostic species: Dryas octopetala, Cassiope tetragona

This provisional suborder is introduced to unite the following Dryas-Cassiope tetragona units: Cassiope tetragona-Association (Beder 1967, Trottier 1972), Cassiope tetragona-Association and Phyllodoce glanduliflora-Association (Crack 1977), Cassiope tetragona-Dryas octopetala community type and Dryas octopetala-Empetrum nigrum community type (Hrapko \& LaRoi 1978), Cassiope tetragona-Dryas octopetala type and Phyllodoce glanduliflora-Cassiope mertensiana type (Kuchar 1975, Mortimer 1978), Cassiope tetragona-Dryas octopetala-Salix nivalis vegetation type (Achuff \& Corns 1982).

The provisional status of this suborder has been discussed above.

\subsubsection{ALLIANCE: Dryado octopetalae-Cassiopion tetragonae all. nov.}

Nomenclatural Type: Dryado octopetalae-Cassiopetum tetragonae Beder 1967

Diagnostic species: Dryas octopetala, Cassiope tetragona, Phyllodoce glanduliflora, Salix nivalis

All units listed under the suborder certainly belong into one syntaxonomical unit which is created here as a new alliance.

\subsubsection{ASSOCIATION: Dryado octopetalae-Cassiopetum tetragonae Beder ex Damm \\ - Mountain Avens-Mountain Heather community}

Nomenclatural Type: Beder (1967) Table 27: "Cassiope tetragona association", relevé 10

Diagnostic species: Dryas octopetala, Cassiope tetragona, Salix nivalis, Kobresia myosuroides (=K. bellardii), Astragalus alpinus, Carex atrosquama, Saussurea densa, Saxifraga oppositifolia 
As a basis for the alliance Dryado octopetalae-Cassiopion tetragonae this unit reported by Beder is validated as an association. Even though Beder's thesis was available on interlibrary loan as a microfilm, it is not considered a valid publication in the sense of the CPN, since it has never been available in printed format. The units by Trottier (1972), Crack (1977) and Mortimer (1978) most likely belong into this association whereas more detailed studies are needed to clarify, whether this unit should also encompass the units of Hrapko \& LaRoi (1978), Kuchar (1973) and Achuff et al..

All communities in this association are Phyllodoce glanduliflora-heaths with close affinity to the drier fellfield communities of the area.

In Glacier NP there is only one known location of Cassiope tetragona. It grows in a moist heath community with Dryas octopetala and dominant Salix arctica. For its overall difference in floristic composition it is not considered to belong into this association but rather be a local assemblage at the edge of the species' range. Future finds of similar units might call for a different treatment of this unit.

Literature: Hoefs et. al. (1975) described a "Arctostaphylo (rubrae)-Cassiopo (tetragonae)-Salicetum reticulatae-lanatae-glaucae" which has only little similarities with this community. Only a little closer is their "Salico (reticulatae)-Cassiopo (tetragonae)-Dryadetum integrifoliae".

Cooper (1986) described a provisional order Cassiopo tetragonae-Dryadetalia alaskensis from the Brooks Range in Alaska which also has Cassiope tetragona, Dryas octopetala (spp. alaskensis) and Salix nivalis as dominant species. Even though it is ecologically related to this unit, its overall floristic composition seems quite different from the present unit. However, a future treatment of the heath communities should investigate these relationships. A closer syntaxonomical treatment of these units cannot completely be ruled out at this point.

\title{
SUBORDER: Phyllodoco empetriformis-Cassiopenalia mertensianae subord. prov. \\ - Mountain Heather Cassiope snowbed communities
}

Nomenclatural Type: Phyllodoco-Cassiopion Brooke et al. 1970

\author{
Character species: Phyllodoce empetriformis, Cassiope mertensiana \\ Differential species: Valeriana sitchensis, Vahlodea atropurpurea, Hieracium gracile, \\ Luzula piperi
}

In order to create a counterpart for the provisional suborder Dryado octopetalae-Cassiopenalia tetragonae, this suborder is established and likewise considered provisional. From the synoptic table it can be taken, that it contains the western coastal alliance Phyllodoco-Cassiopion Brooke et al. 1970 and the interior alliance Sibbaldio-Phyllodocion glanduliflorae. Following the CPN, the oldest existing alliance becomes the type of this unit. 


\subsubsection{ALLIANCE: Phyllodoco-Cassiopion mertensianae Brooke et al. 1970 - Coastal Mountain heather communities}

Nomenclatural Type: Phyllodoco-Cassiopetum mertensianae Brooke et al. 1970

Diagnostic species (acc. Brooke et al.): Phyllodoce empetriformis, Cassiope mertensiana, Luetkea pectinata, Vaccinium deliciosum, Lycopodium sitchense (= Diphasiastrum s.), (Leproloma membranacea, Stereocaulon tomentosum, Orthothecium floerkii, Kiaeria falcata, Dichodontium olympicum, Solorina crocea)

This alliance was described by Brooke et al. (1970) based on data from coastal British Columbia with little consideration of the physiognomically similar heath vegetation of other western North American mountain ranges. The synoptical comparison of all Phyllodoce and Cassiope heath communities known today from the coastal mountains as well as the Rocky Mountains reveals, that like in other orders the coastal communities differ consistently from their interior counterparts (see Tab. 4). Apart from the differential species of this alliance there is a conspicuous lack of many species which are common in the interior heath communities. The coastal heath units should be kept together as a distinct syntaxon. The character species for the alliance given by Brooke et al. clearly show that their Phyllodoco-Cassiopion mertensianae circumscribes this coastal heath unit. The species given in parenthesis are character species given by Brooke et al. which are probably not confined to this alliance.

Unfortunately both name-giving species of this alliance occur also in some of the interior heath communities where they largely overlap with the structurally and ecologically similar but floristically different Phyllodoce glanduliflora communities. The occurrence of the hybrid Phyllodoce mertensiana $\mathrm{X}$ glanduliflora $(=P$. intermedia $)$ is a good indicator for this area of overlap.

The name "Luetkeo-Cassiopion mertensianae" would have been more descriptive for the western alliance but the older name given by Brooke et al. has priority.

The synoptic table of the heath communities shows that a number of species, namely Hieracium gracile, Antennaria lanata, Pedicularis bracteosa, Arnica latifolia, Epilobium alpinum, Polytrichum piliferum, Vahlodea atropurpurea and Lepraria sp. occur in the western heath communities as well as in parts of the Rocky Mountains. Still this floristic similarity is not considered large enough to give up the separation of the coastal and the western unit on the alliance level.

\subsubsection{ASSOCIATION: Phyllodoco-Cassiopetum mertensianae Brooke et al. 1970 \\ - Coastal Mountain Heather-Cassiope community}

Nomenclatural Type: Phyllodoco-Cassiopetum mertensianae Brooke et al. 1970, Appendix I, Table 3b, Plot 62 (lectotype)

Character species s.str.: Phyllodoce empetriformis, Cassiope mertensiana, Lycopodium sitchense (=Diphasiastrum s.), (Luetkea pectinata, Vaccinium deliciosum)

Differential species: Marsupella brevissima, (Phyllodoce glanduliflora)

This association has been validly published by Brooke et al. without selecting a type relevé. Therefore plot-no. 62 is chosen as a lectotype here. 
It might be questioned whether the other two associations described by Brooke et al., the NanoTsugetum mertensianae Brooke et al. (1970) and the Vaccinietum deliciosi Brooke et al. (1970), deserve association rank or would better be kept as subassociations or even variants under this association. The differences between these units are largely due to varying degrees of dominance and the differential species groups are rather small.

\subsubsection{ALLIANCE: Sibbaldio procumbentis-Phyllodocion glanduliflorae all. nov. - Interior cordilleran Yellow Mountain Heather communities}

Nomenclatural Type: Sibbaldio-Phyllodocetum glanduliflorae ass. nov.

Character species: Phyllodoce glanduliflora (dominant)

Differential species: Sibbaldia procumbens, Antennaria lanata, Salix arctica, Juncus drummondii, Ranunculus eschscholtzii, Cladonia ecmocyna, Veronica wormskjoldii, Pedicularis bracteosa, Luzula parviflora, Epilobium alpinum, Phleum alpinum, (Solorina crocea, Pulsatilla occidentalis, Arenaria capillaris, Arnica latifolia)

Constant companion species: Polytrichum juniperinum, Potentilla diversifolia, Polygonum viviparum

The counterpart to the western Phyllodoco-Cassiopion is this new, interior cordilleran heath unit. Even though the heath character of this unit is very uniform, it comprises units with very different affiliation to moist and late melting communities on the one hand and dry tundra communities on the other hand. This is a result of the specific climatic situation in the northern Rockies.

Compared to the southern Rocky Mountains, this region receives larger amounts of snow. Compared to the coastal mountains, the climate is more continental. This combination creates conditions which on the one hand are moist and snow-rich enough to support heath communities and on the other hand are dry enough to hold certain fellfield species. The ecological differences and consequently the spatial distances between dry fellfields and mesic heath communities are fairly small in this region. A similar effect has been found by Cooper (1986) when he compared the similar vegetation types from the Alaskan Brooks Range and Colorado. The result is a greater presence of fellfield species in heath communities, a combination which would hardly ever be found in the coastal mountains or in the central or southern Rockies. In the moister coastal mountains fellfield species are generally less present and in the southern Rockies the gradients between dry fellfields and snowbeds are so steep that the great ecological difference largely precludes the occurrence of species all the way along such a wide ecological amplitude. In the present alliance many of these fellfield species can be used as differential species against the coastal unit. Because they are not strictly characteristic for chionophilic vegetation types, they have not been listed with the differential species.

Some differential species of this alliance occur also in the western alliance but most always with much lower constancy or structural importance. Usually a difference of two constancy classes among the units compared is accepted for a species to be called differential (Dierschke 1994). This criterion is met in all of the present species.

So far only one association has been described in this alliance. Some other units included in the synoptic table are likely to deserve validation as associations also. 


\title{
3.3.3.1.ASSOCIATION: Sibbaldio procumbentis-Phyllodocetum glanduliflorae ass. nov. \\ - Sibbaldia-Mountain Heather community
}

\author{
Nomenclatural Type: Table 22 relevé 530
}

Plots: $121,124,203,317,334,335,339,341,345,530,531,532,581,604,653,744,747 \quad(n=17)$

\author{
Character species (local): Phyllodoce glanduliflora, Phyllodoce intermedia, Phyllodoce \\ empetriformis, (Kiaeria blyttii) \\ Differential species: see alliance
}

This association is the most common regional Phyllodoce community found in Glacier National Park. Both mountain heather species occur in the area and with them their hybrid Phyllodoce intermedia. For some unknown reason Antennaria lanata, an important species of the alliance, does not occur in Glacier NP. It is found not far north of the park in the adjacent Akamina area (Polster 1977) as well as in Waterton National Park.

General aspect: The Mountain heather community is a moderately chionophilous community found in two slightly different situations: a common situation is on the edges of snowbed depressions often bordering right against the even longer snow-covered Carex nigricans community. The dark bands of the ericaceous community form a conspicuous belt around the sedge dominated snowbed center. A similar zonation has also been observed for closely related communities in other areas too (Brooke et al. 1970, Mortimer 1978).

A slightly drier variant of the community grows on more or less exposed ridges of terraced landscapes like e.g. in the Hanging Garden area at Logan Pass. These sites melt out earlier than the adjacent depressions and are pointing through the receeding snow very obviously as dark bands in June or July when all other less exposed stands of the area are still snow covered. Bedrock ridges with even lesser snow cover and somewhat deeper soil cover are oftentimes occupied by stripes of subalpine fir or sometimes Engelmann spruce.

Topography: The subalpine to low alpine elevation range of this community is found between 1900 $\mathrm{m}$ and $2350 \mathrm{~m}$. The slope varies from $0^{\circ}$ to $20^{\circ}$. Most sites in the area are less than $7^{\circ}$ steep. Exposure of this mesic to hygric community is mostly northerly ranging from $220^{\circ}$ to $70^{\circ}$.

Parent material: The community seems to be indifferent concerning the parent material and occurs on limestone as well as on the more common argillites. The accumulated organic peat horizons insolate the root sphere sufficiently against chemical influences by the bedrock (see next paragraph).

Soils: The soils are very humus-rich and mostly consist of pure ericaceous peat. Frost heave is likely to occur and is probably the cause for scattered gravel in the solum. The development of a considerable peat layer is likely to be responsible for the independence of this community from the underlaying bedrock material, an effect that has also been observe for heath communities in Europe (Ellenberg 1986).

Snow cover/Wind exposure: As a consequence of the relatively long snow cover, moisture supply is ample through much of the summer. The exposed and better drained stands of the Lepraria subassociation experience considerable drought periods in late summer. Wind exposure is little in the moister, less exposed snowbed sites and can be strong on exposed slopes and little ridges. 
Vegetation: The chamaephytic Phyllodoce species are by far the most dominant constituents of this heath community. The pattern which could be found in the Phyllodoce subassociation of the Aulacomnio-Kalmietum regarding the occurrence of Phyllodoce glanduliflora and P. empetriformis was less obvious in this case. Still it is apparent that the hybrid $P$. intermedia was considerably more constant in the Kalmia-variant and Phyllodoce empetriformis was slightly higher in cover.

In general, P. glanduliflora is more common in the area. According to Crack (1977) Phyllodoce empetriformis is more common in the wetter Main Ranges of the Canadian Rockies whereas P. glanduliflora predominates in the drier Front Ranges. Similarily Broad (1973) observed P. empetriformis on moister, protected sites. This is also reflected in the total distribution range of the two species with $P$. empetriformis being common all the way to the coastal mountains. As has been mentioned before a similar pattern is also found in the heath species Cassiope tetragona and Cassiope mertensiana.

Locally, Kiaeria blyttii is very much restricted to this community and can thus be called a local character species despite its circumpolar range. This bryophyte was also listed by Brooke et al. (1970) as a diagnostic species of one of their Phyllodoce empetriformis communities.

The other constant species are mostly common ones occurring also in other moderately late melting high elevation communities. An interesting case in this unit is the occurrence of the difficult taxa Carex spectabilis and C. paysonis. As mentioned elsewhere, the differentiation of the these two taxa is difficult in the area. Looking at the tentative results it becomes obvious that the taxa referred to as Carex spectabilis was markedly more often found in the drier variant and might turn out to be a differential taxon. Similarily, specimens attributed to the more phyllopodic taxon Carex paysonis have more often been found in the moister Kalmia-variant and might be taken as a differential taxon for that unit. Until a clear solution for this difficult taxonomic group is found, the differential value of these taxa remains uncertain and they have been lumped in the tables.

Mosses and lichens are very common in this community and contribute considerably to the species diversity of the unit. As expected, the moist Kalmia-variant of the community is characterized by a higher moss cover but the species number of mosses and liverworts is similar in both units. The number of lichens is much higher in the dry Lepraria-variant.

At one site in the Feather Woman Lake basin this community was found on very conspicuous frost hummocks which at the first glance look like overgrown boulders. The mountain heather completely covers the hemispheric hummocks, each of which has a diameter of 0.5 to 1 meter, being ca. 30-50 cm high. The narrow interspaces of the closely neighboring hummocks are carpeted with a Carex nigricans dominated community not differing much in its overall floristic composition.

The name Sibbaldio-Phyllodocetum was chosen in order to differentiate this heath community from other Phyllodoce-dominated heath communities. Sibbaldia procumbens is about the most common companion species of this community in the area and characterized the unit as a chionophilic community.

Two subassociations have been differentiated based on floristic and ecological differences, the latter being mostly moisture related (see below). 


\section{Association Table 22}

Sibbaldio procumbentis-Phyllodocetum glanduliflorae ass.nov.

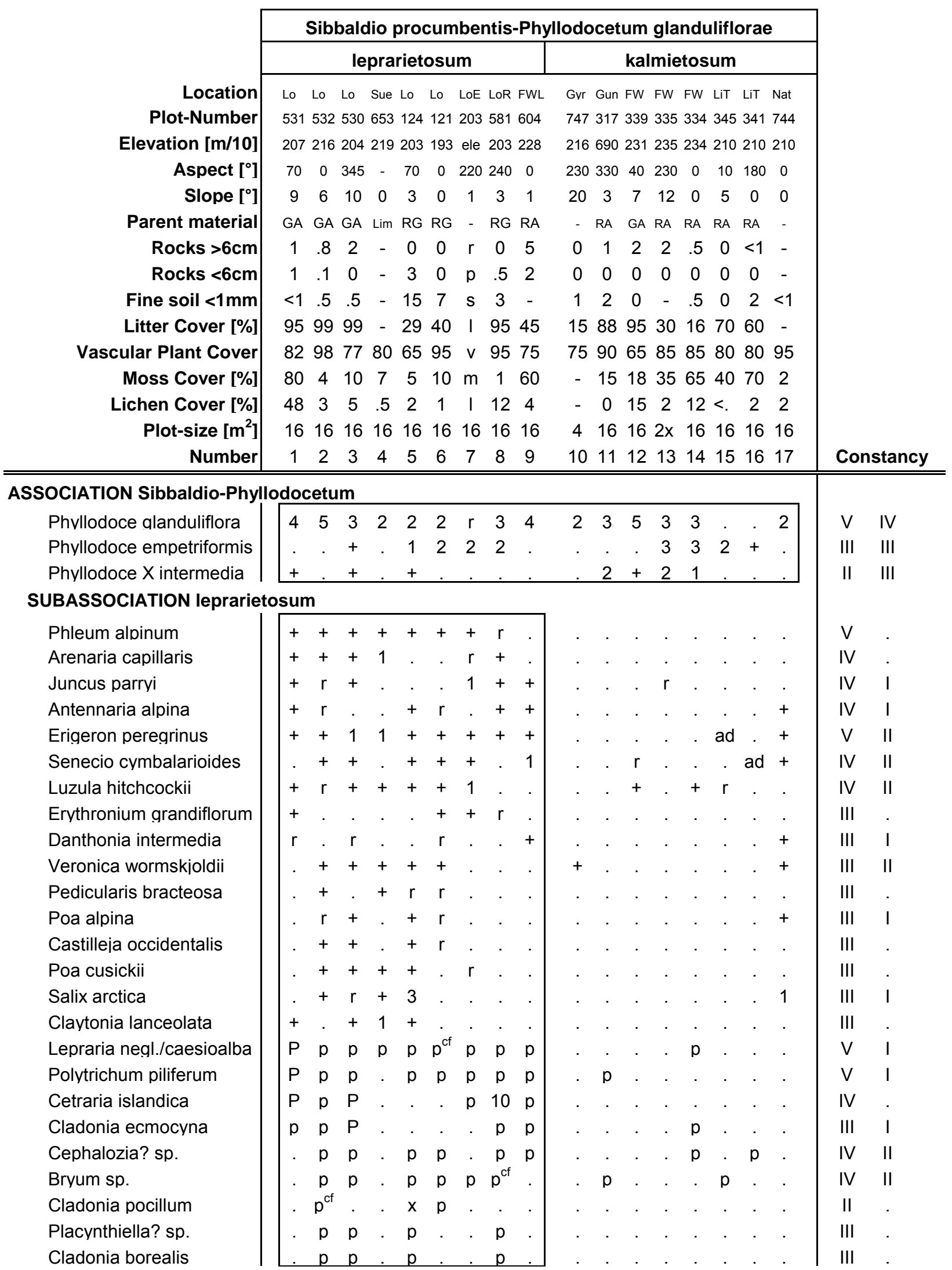


Association Table 22 (cont.):

\begin{tabular}{|c|c|c|c|c|c|c|c|c|c|c|c|c|c|c|c|c|c|c|}
\hline Number & 1 & 2 & 3 & 4 & 5 & 6 & 7 & 8 & 9 & 10 & 11 & 12 & 13 & 141 & 151 & 1617 & \multicolumn{2}{|c|}{ Constancy } \\
\hline \multicolumn{19}{|l|}{ SUBASSOCIATION kalmietosum } \\
\hline Kalmia microphylla & . & . & + & . & . & $r$ & . & . & . & . & + & + & 2 & 2 & 44 & 41 & II & $\mathrm{V}$ \\
\hline Vaccinium scoparium & . & . & 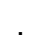 & . & . & 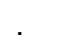 & . & . & $r$ & & . & $r$ & 1 & + & ++ & + & I & IV \\
\hline Gaultheria humifusa & . & . & . & . & . & . & . & . & . & . & . & . & . & . & $3+$ & + & . & II \\
\hline Diphasiastrum alpinum & . & . & . & . & . & . & . & . & . & 4 & . & . & . & . & . 2 & 2. & . & II \\
\hline Barbilophozia floerkii & . & . & . & . & $\mathrm{p}$ & . & . & . & . & . & $\mathrm{p}$ & . & . & $p 3$ & 302 & 20 . & I & III \\
\hline Sphagnum sp. & . & . & . & . & . & . & . & . & . & & &. & $\mathrm{p}$ & & .24 & 4 & . & II \\
\hline \multicolumn{19}{|l|}{ Companion species } \\
\hline Sibbaldia procumbens & + & + & + & 1 & + & + & 1 & + & + & + & $r$ & $r$ & . & 1 & . + & +1 & V & IV \\
\hline Hieracium gracile & . & + & + & + & . & + & + & + & + & + & . & + & + & + & $r+$ & + & IV & IV \\
\hline Carex & . & + & + & 1 & + & + & + & + & + & + & + & + & + & + & . + & $+r$ & V & V \\
\hline Carex nigricans & . & . & + & 1 & 1 & + & . & . & + & + & 1 & + & $r$ & + & 22 & $2+$ & III & V \\
\hline Juncus drummondii & . & . & . & + & & + & + & . & + & + & + & . & . & + & ++ & + & III & IV \\
\hline Vahlodea atropurpurea & r & . & + & . & . & . & + & + & + & + & . & . & . & + & ++ & ++ & III & IV \\
\hline Epilobium alpinum & . & . & . & . & + & + & + & . & + & + & . & . & . & . & ++ & ++ & III & III \\
\hline Hypericum formosum & . & . & $r$ & . & . & + & + & ad & . & + & . & . & . & . & . . & . 1 & III & II \\
\hline Luzula piperi & + & . & $x$ & . & . & . & . & + & + & . & $x$ & . & . & $x$ & . . & . & III & II \\
\hline Polytrichastrum alpinum & . & . & . & $\mathrm{p}$ & . & $\mathrm{p}$ & $x$ & 10 & $\mathrm{p}$ & . & . & $\mathrm{p}$ & . & $\mathrm{p}$ & 56 & 6. & III & III \\
\hline Cladonia sp. & . & . & . & . & $\mathrm{p}$ & $p$ & $\mathrm{p}$ & $\mathrm{p}$ & $\mathrm{p}$ & . & . & . & $\mathrm{p}$ & $\mathrm{p}$ & . $p$ & $\mathrm{p}$. & III & ॥ \\
\hline Dicranum scoparium & . & $\mathrm{p}$ & $\mathrm{p}$ & . & $\mathrm{p}$ & $p^{c f}$ & . & . & $\mathrm{p}$ & . & $\mathrm{p}$ & . & $\mathrm{p}$ & $\mathrm{p}$ & . $p$ & . & III & III \\
\hline Pohlia sp. & . & $\mathrm{p}$ & $\mathrm{p}$ & . & . & . & $\mathrm{p}$ & . & $p$ & . & $\mathrm{p}$ & . & $\mathrm{p}$ & $\mathrm{p}$ & . $p$ & $\mathrm{p}$. & III & III \\
\hline Kiaeria blyttii & . & . & $\mathrm{p}$ & . & $\mathrm{p}^{\mathrm{cf}}$ & $p$ & . & . & $P$ & . & $\mathrm{p}$ & . & . & $\mathrm{p}$ & 43 & 35 . & III & III \\
\hline Polytrichum juniperinum & $\mathrm{p}$ & . & $\mathrm{p}$ & . & . & $x$ & . & . & . & . & . & . & . & . & $p \quad p$ & $\mathrm{p}$. & II & II \\
\hline Cladonia chlorophaea & $\mathrm{p}$ & $\mathrm{p}$ & & . & . & . & . & . & $\mathrm{p}$ & . & . & . & $\mathrm{p}$ & $\mathrm{p}^{\mathrm{cf}}$ & . . & . & II & ॥ \\
\hline Lophozia sp. & . & $\mathrm{p}$ & $\cdot$ & . & . & $p$ & . & . & $\mathrm{p}$ & . & . & . & . & $\mathrm{p}$ & $\mathrm{p}$. & . & II & II \\
\hline Trapeliopsis granulosa & . & . & $\mathrm{p}$ & . & . & . & . & $\mathrm{p}$ & $\mathrm{p}$ & . & . & . & $\mathrm{p}$ & $\mathrm{p}$ & . . & . & II & II \\
\hline Polytrichum sexangulare & . & . & 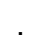 & . & $\mathrm{p}$ & . & . & . & . & . & $\mathrm{p}$ & . & . & 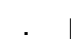 & $\mathrm{p}$. & . & I & II \\
\hline Lescuraea radicosa & . & . & $\mathrm{p}$ & . & $\mathrm{p}$ & . & . & . & . & . & . & . & . & & & $\mathrm{p}$. & II & 1 \\
\hline
\end{tabular}

\section{Minor species:}

Pedicularis groenlandica 2:ad, 5:r ; Potentilla diversifolia 2:+ , 3:+ , 17:+ ; Castilleja rhexifolia 2:+ , 3:r ; Bryum sp. 5:p , 11:p ; Lophoziaceae sp. 3:p , 8:p ; Arnica latifolia 3:+ , 7:r ; Ceratodon purpureus 1:p , 5:p ; Arenaria obtusiloba 2:r , 8:r ; Cetraria ericetorum 2:p , 9:p ; Lecidoma demissum 3:p , 9:p ; Peltigera rufescens 3:p , 8:p ; Lecanora polytropa 1:p , 2:p , 3:p ; Rhizocarpon geographicum agg. 1:p , 2:p , 3:p ; Abies lasiocarpa 1:r , 2:r , 10:+ ; Selaginella scopulorum 2:r , 3:x ; Rinodina mniaraea 2:p , 3:p ; Lecidea atrobrunnea 2:p , 3:p ;Campanula rotundifolia 1:r ; Grimmia sp. 1:p ; Aspicilia sp. 1:p ; Lecidea umbonata 2:p ; Arnica diversifolia 2:+ , 17:+ ; Koeleria cristata 2:+ ; Poa secunda 2:r ; Barbilophozia hatcheri 3:p ; Antennaria sp. 3:+ ;Arnica rydbergii 3:+ ; Lecidea sp. 3:p ; Caloplaca stillicidiorum 3:p ; Antennaria lanata 4: + ; Ranunculus eschscholtzii 4:+m ; Cladonia pyxidata 5:p ; Desmatodon latifolius 5:p ; Pogonatum sp. 5: $x^{\mathrm{cf}}$; "Black dots on rock" 5:p ; Bryum argenteum 6:p ; Carex haydeniana 7:r ; Pulsatilla patens 7:r ; Mitella breweri 7:+ ; Carex pyrenaica 8:r ; Lichen sp. 9:p; Cladonia phyllophora 9:p ${ }^{\text {cf }}$; Valeriana sitchensis 10:r , 17:+ ; Agrostis sp. 10:+ ; Barbilophozia lycopodioides 11:p ; Luzula parviflora 11:+ ; Cladonia gracilis 13:p ; Saxifraga ferruginea 14:r ; Stereocaulon sp. 15:p ; Veratrum eschscholtzii 15:r ; Racomitrium canescens 16:p ;Cladonia carneola 16: $p^{\text {cf }}$; Aulacomnium palustre 16:02; Brachythecium sp. 16:05; Tofieldia glutinosa 17:1 ; Parnassia fimbriata 17:1 ;Aster foliaceus 17:+ ; Trollius laxus var. albiflorus 17:+ ; Trisetum spicatum 17:+ ; Agrostis variabilis 17:+ ; Juncus mertensianus 17:+ ; Leptarrhena pyrolifolia 17:+; Senecio triangularis 17:r ; Gentiana calycosa 17:r 
Syntaxonomy: Locally this well defined community is floristically and spacially related to the Phyllodoce subassociation of the Aulacomnio-Kalmietum which in some areas borders this community towards the wetter, later melting depressions. These communities represent neighboring segments in a ecological sequence from snowbeds to drier, less chionophilic conditions. Some transitional samples are hard to classify especially when the presence of differential species and the dominance of diagnostic taxa call for opposite assignments.

Due to the ecologically extreme nature of these units as snowbed communities, there are strong floristic and ecological similarities with communities of the order Caricetalia nigricantis. The spatial closeness of these units underlines this relationship. Physiognomically and by the presence of the heath species both are easily told apart. It has to be mentioned though that the delineation of these units in the field can be difficult since they are oftentimes growing together in mosaic-like patterns. Different sampling practices might lead to dissatisfying results when these units have to be differentiated.

Distribution: Similar mountain heaths are found through much of the Park in subalpine uplands and glacial cirques mostly in the vicinity of snowbeds. Despite their widespread occurrence they rarely achieve greater spatial extend in the area. They are common in similar ecological situations in the northern Rocky Mountains north of Glacier National Park and all the way west to the coastal mountain ranges. Only one account of a heath community was been found from Rocky Mountain areas south of Glacier NP (Cooper et al. 1997) even though both species occur south through Wyoming. The sparse occurrence of these species in the southern Rockies is likely due to the fact that the species' requirements of cool temperature and sufficient moisture are not met in those more continental southern mountains. More occurrences of heath communities are expected to be found at least a little ways further south from this studies' area if sought for in the future.

Several of the mountain heather communities included in the alliance in the synoptic table are likely to belong to this association.

Literature: All reports of similar heath communities in literature have been included in the synoptic table in the alliance Sibbaldio-Phyllodocion glanduliflorae (see Tab. 4. .

\section{SUBASSOCIATION: Phyllodocetum glanduliflorae leprarietosum subass. nov. - Subassociation of Lepraria spp.}

Nomenclatural Type: Table 22 relevé 530

Plots: $121,124,203,530,531,532,581,604,653 \quad(\mathrm{n}=9)$

Differential species: Erigeron peregrinus, Senecio cymbalarioides, Lepraria neglecta, Lepraria caesioalba, Polytrichum piliferum, Antennaria alpina, Juncus parryi, Cetraria islandica, Cladonia ecmocyna, Bryum sp., Cephaloziella sp., Hypericum formosum, (Carex spectabilis/paysonis)

This is the drier of the two subassociations mostly occurring on better drained sites often in convex relief situations with better water run-off and stronger exposure to desiccating winds. Therefore it is the more ecologically extreme variant in terms of waterstress whereas winter snow cover is considerable but not on the extreme end within the chionophilic units. Average moss cover is smaller compared to the moist variant but a much higher number of lichen species is found in this subassociation. 
Some of those lichen species are good differential species and a few might even turn out to be character species which most likely is the case for the chionophilic Cladonia ecmocyna which is best developed in this community. Both Lepraria species listed above have been found in this community. Until a larger sample is available it can not be said which one is more characteristic for this community.

\section{SUBASSOCIATION: Phyllodocetum glanduliflorae kalmietosum \\ - Subassociation of Kalmia microphylla}

Nomenclatural Type: Table 22 relevé 334

Plots: $317,334,335,339,341,345,744,747 \quad(n=8)$

Differential species: Kalmia microphylla, Vaccinium scoparium, Hepaticae sp., (Carex paysonis)

The moist subassociation is intermediate between the dry subassociation leprarietosum and the richer Aulacomnio-Kalmietum, mainly its subassociation of Phyllodoce glanduliflora. The latter is different primarily in the constant presence of a number of high elevation wet meadow species which are missing in this heath community (e.g. Veronica wormskjoldii, Parnassia fimbriata, Tofieldia glutinosa, Trollius laxus). This obvious difference was also the reason for assigning samples to this syntaxon which are not dominated by Phyllodoce species but do belong here for their overall floristic composition (e.g. no. 341).

In nearly all cases has this syntaxon been found adjacent to the Caricetum nigricantis forming patches and bands adjacent to the sedge snowbeds.

The Carex spectabilis-group species found in this unit was identified as Carex paysonis in the field, based on the presence of a strong tuft of basal leaves. Given the taxonomic difficulties in this group the species is lumped here with Carex spectabilis.

The clubmoss Diphasiastrum alpinum has only been found in this subassociation and can reach high cover classes. It is regarded as a facies-building species. Since it seems to be confined to this association, it might be a character species at least locally. Its occurrence in this units is somewhat vicariant to the occurrence of Diphasiastrum sitchense in the coastal Phyllodoco-Cassiopetum mertensianae.

Gaultheria humifusa is also largely restricted to this association and might in fact be a local character species. It nevertheless does occur occasionally in the closely related Aulacomnio-Kalmietum microphyllae. 


\title{
3.4. ORDER: Valerianetalia sitchensis Brett et al. ex Damm ord. nov. - Sitka Valerian order
}

Nomenclatural Type: Sibbaldio procumbentis-Trollion laxi all. nov.

\author{
Diagnostic species: Valeriana sitchensis, Pulsatilla occidentalis, Veratrum viride, Pedicularis \\ bracteosa, Thalictrum occidentale, (Carex spectabilis)
}

In order to elucidate the syntaxonomical position of the Luzulo-Erythronietum described below, a synoptic table for the lush subalpine forb communities of the Rocky Mountains and the western mountain ranges was compiled Tab. 5. The available literature was searched for subalpine and low alpine meadow communities without bias towards any presumed species combinations. It turned out that Valeriana sitchensis seems to be the most constant tall herb species occurring in most of these ecologically related western North American high elevation meadow communities. Together with this species a number of constant species occur which form the floristic base for a common syntaxon. Given the large geographical area covered by the units comprised in this unit and considering their floristic variability, the rank of an order is considered appropriate for this unit.

A "Valeriana sitchensis order" has indeed already been mentioned by Brett et al. (1998) but like in the case of their "Carex nigricans order" their syntaxon has not been published in accordance with the Code of Phytosociological Nomenclature. Therefore the order Valerianetalia sitchensis has to be validated here.

Like in other higher syntaxonomic units in northwestern North American high elevation vegetation, exclusive character species are not very numerous in this entity. Furthermore the knowledge of the complete vegetation is too limited at this point to determine how wide the species are distributed through this and related vegetation units. Therefore, the assignment of exclusive character species s.str. as done here has to be looked at with care.

The new order of lush, mainly subalpine or in a few cases low alpine meadows is well defined by a very strong species group consisting of Valeriana sitchensis, Erigeron peregrinus, Pulsatilla occidentalis, Pedicularis bracteosa, Carex spectabilis, Veratrum viride and Thalictrum occidentale.

Senecio triangularis is so far treated as an order diagnostic species even though it seems to be almost confined to the eastern alliance within this order. Only the occurrence in Brett et al.'s tables points to a wider distribution of the species which has to be looked for in later studies. Other, slightly less constant species are Arnica latifolia, Vahlodea atropurpurea, Luzula hitchcockii, Carex nigricans, Antennaria lanata, Erythronium grandiflorum, Mitella breweri and Phyllodoce empetriformis, some of which are missing in parts of the units range. Only the species listed as diagnostic species in the header are at this point considered more or less faithful species, whereas the other species are constant but more widespread companions which typically occur in this community with medium degrees of constancy.

This order is floristically very close to the snowbed order Caricetalia nigricantis which at this point is a member of the snowbed class Salicetea herbaceae. The reason for keeping both orders separate needs to be discussed here. The constant presence of snowbed species like Sibbaldia procumbens, Juncus drummondii, Ranunculus eschscholtzii and Veronica wormskjoldii likens the Valerianetalia units to the snowbed order, namely to its new suborder Junco-Sibbaldienea. In fact all of the diagnostic species of the Caricetalia nigricantis do occur with different degrees of constancy in this unit. However, a placement of the tall herb meadows into the snowbed class would require a greater 
ecological, physiognomical and floristic similarity of both units. 
In all of these parameters the snowbed class differs consistently from the tall herb meadows which should probably be accommodated in their own, yet undescribed class. A better knowledge of the northwestern North American tall herb community is needed to create such a new class in the future.

Whereas all of the Caricetalia units most obviously are true low growing and often species-poor snowbed communities, the Valerianetalia units are physiognomically much different. They consist of lush, highly productive vegetation types which the name "tall herb meadows" is indicative for. Whereas the species-poorer but ecologically distinct Caricetalia nigricantis do not have an exclusive character species group, the Valerianetalia are fairly well characterized by a number of tall herb species. For this reason these two units have been kept apart on the order level, even though it is acknowledged that very strong floristical ties exist between both groups. The widespread occurrence of chionophilous species through both different units might be explained as follows:

Large amounts of snow resulting in short growing seasons are common in the Pacific Northwest as well as in the northern and central Rocky Mountains where both units occur. Therefore, it is not surprising that chionophilic communities are widespread. The difference between sites of low snow cover and long covered sites is levelled by an overall higher snow pack. Consequently adaptation to these snow rich conditions are more widespread throughout the different vegetation types. For this reason, the meadow communities are floristically and ecologically closer to snowbed communities than it is the case elsewhere in drier, more continental mountain areas.

Great similarity exists not only to snowbed communities but also to other units of moist to wet alpine and subalpine environments, like streambank and seep communities as well as to the abundant northwestern heath communities.

Like in the order Caricetalia nigricantis, there is a clearly differentiated western subunit in this order which is proposed as a separate alliance.

The relationship of other, p.p. still undescribed subalpine tall herb communities, which are well developed in many western North American mountain ranges, to this syntaxon will have to be studied in the future and might result in some changes of the syntaxonomy suggested here.

Literature: Lush meadow communities with Valeriana sitchensis have been described by several alpine and subalpine studies in northwestern North America. Units of this order occur in the western coastal cordilleran mountains as well as in the Rocky Mountains as far south as northern Colorado.

Many vegetation types with Erythronium grandiflorum belong into this order. The species though has not only been reported from forb-meadow communities but from Phyllodoce- and Cassiope-heath communities and Carex nigricans snowbeds. Erythronium-meadows which probably belong into this order have been reported by Achuff (1982, 1997), Broad (1973), Butters (1914), Heusser (1956), Lewis (1917), Polster (1972), Shaw (1916), Trottier (1972). The coastal species Erythronium montanum occurs in similar communities and also reaches into the same neighboring units like snowbeds and heath communities.

The sitka valerian communities described from Mt. Rainier NP (Hamann 1972, Henderson 1974) are similar to the tall herb communities discussed here. They nevertheless differ in the constant presence of Lupinus latifolius and Festuca viridula belonging into the western, coastal alliance. Four variants of similar Valeriana sitchensis-Lupinius latifolius communities have been reported by Evans and Fonda (1990) slighly further north in the Cascades. They might represent subassocations or maybe even better variants of a western Valeriana sitchensis-Lupinus latifolius-association. 
Association rank is given to the Valerianetum sitchensis described by Archer (1963) from Garibaldi Provincial Park which is validated here. It is also a floristically very similar community being dominated by Valeriana sitchensis, accompanied by Carex spectabilis and Pulsatilla occidentalis. Besides this, the unit seems fairly heterogeneous among the five relevés presented by Archer. This association certainly shows close ties to the snowbed units with Carex nigricans.

Brinks (1959) describes a similar, perhaps even identical type of lush meadow vegetation from Garibaldi Park which again belongs to the coastal alliance. The species list given by this author for the heath communities and for the "flower meadow type" both show some relation to the present order and demonstrate the closeness of this order not only to snowbeds but also to the western cordilleran heath communities.

Brinks also cites Lewis (1917) with a "mat grassland" that might be the same type. Some similarity exists to the "Saussurea forb type" and even more so to the "Valerian forb type" which Kuramoto and Bliss (1970) reported from the Olympic Mountains.

Eady's Valeriana sitchensis-Castilleja elmeri association from the British Columbian Big White Mountains (1971) is physiognomically similar to other tall herb communities. Apart from the lack of Erythronium grandiflorum and the lesser occurrence of Luzula hitchcockii (assuming that "Luzula sp." is Luzula hitchcockii), there is also a very constant similarity to other chionophilic communities with Carex nigricans and Sibbaldia procumbens.

Certainly a member of this order in possibly the same alliance is Kuchar's chionophilic moist forb meadow (Kuchar 1973) which shares many of the most important species of this order and alliance. The Anemone occidentalis - Thalictrum occidentale community reported by (Broad 1973) undoubtedly belongs into the same alliance, too. Likewise do Hämet-Ahti's mesic meadow, Trottier's Thalictrum occidentale -association (at least p.p.), Polster's Arnica-, Arnica-Valeriana- and JuncusValeriana-communities and the Erigeron peregrinus-Valeriana sitchensis community types of Achuff et al. $(1982,1984,1994)$.

Two units which have been reported by Shaw (1916) from the Selkirk Mountains in British Columbia have been added to the synoptic table. At least one of these "mesophytic grasslands" is likely to belong into this order following Shaw's rough textual descriptions, even though the list of species is largely incomplete.

All three units of the above mentioned "Valeriana sitchensis order" by Brett et al. (1998) are good representatives of the coastal alliance Lupino-Valerianion. Two lush subalpine grass-forb meadows described from northern British Columbia by Pojar (1991) have been added to the synoptic table for comparison. They are likely to belong to a different syntaxon being more of a Festuca altaicagrassland type with a large quantity of tall herbs associated.

The southern Rocky Mountain Ligustico-Trollietum Komárková 1979 is similar to this unit and at this point seems to be the most southern member of this order if it is accepted as a member of this order. Komárková placed her Ligustico-Trollion laxi into the European class Betulo-Adenostyletea Br.-Bl. and Tüxen 1943. This, however, does not have much floristic similarity with any western North American unit and should better be replaced by a new, continent specific class. Komárková's order Salici-Trollietalia laxi and the included alliance Ligustico-Trollion cannot be extended further north to include the central Rocky Mountain and western coastal tall herb communities. It rather seems an option to include Komárková's meadows into a wider defined Sibbaldio-Trollion laxi.

Interestingly, no other similar tall herb communities have so far been described in literature from the Rocky Mountains south of Glacier NP. 


\subsubsection{ALLIANCE: Lupino latifolii -Valerianion sitchensis all. nov. - Broadleaf lupine - Sitka Valerian alliance}

Nomenclatural Type: Valerianetum sitchensis Archer 1963

\section{Diagnostic species: Lupinus latifolius (treated here as synonymous with L. arcticus), Polygonum bistortoides, Potentilla flabelliformis}

Based on the synoptic table Tab. 5 this alliance is created here to accommodate the western cordilleran sitka valerian communities. A distinct species combination differentiates this unit against the Rocky Mountain alliance Sibbaldio procumbentis-Trollion laxi which is described later in this work. The complete lack of the differential species of the latter alliance also characterizes this syntaxon.

Several "associations" and "communities" have been described by Archer (1963), Kuramoto \& Bliss (1970), Bockheim (1972), Hamann (1972), Henderson (1974), Douglas \& Bliss (1977), Evans and Fonda (1990) and Brett et al. (1998) which do belong into this alliance. Reports of Valeriana sitchensis community by VanVechten (1960) and Hickman (1976) are likely members of this unit. Whether these communities deserve association rank or should better be treated as subassociations of a broader association remains to be seen. An obvious subunit in this alliance consists of the units from Mt. Rainier National Park as can be seen in the synoptic table. Whether this unit is to be treated as a broader local association or as a suballiance with a number of associations is beyond the scope of this study.

\subsubsection{ASSOCIATION: Valerianetum sitchensis Archer 1963 ex Damm - Coastal Sitka Valerian association}

Nomenclatural Type: Archer 1963, p.70: Plot 90 (lectotype!) (reprinted in Tab. 23)

Plots: (Archer 1963, p.70: plot numbers 90, 50, 25, 75, 80; Garibaldi Provincial Park, B.C.)

Diagnostic species: Valeriana sitchensis, Lupinus arcticus (=Lupinus latifolius) and Carex spectabilis

Part of this order is the Valerianetum sitchensis first described by Archer (1963) from Garibaldi Park, B.C. Since his masters thesis is not considered a valid publication, this association is validated here. Archer's original data (Archer 1963 p.70) is cited in Tab.23. Plot 90 is chosen as a lectotype. The data is also included in the order's synoptic table Tab. 5. Diagnostic species according to Archer are Valeriana sitchensis, Lupinus latifolius and Carex spectabilis. None of these can be considered a character species in a strict sence. This community could as well be considered a basal community of the alliance since no distinct character species are present. 


\section{Valerianetum sitchensis Archer ex Damm}

= Original Table from Archer (1963, p. 70; sociability and vigor omitted)

\begin{tabular}{|c|c|c|c|c|c|c|}
\hline $\begin{array}{r}\text { Location/Region } \\
\text { Plot-Number } \\
\text { Elevation [ft] } \\
\text { Aspect } \\
\left.\text { Slope [ }{ }^{\circ}\right] \\
\text { Parent Material } \\
\text { Soil-type } \\
\text { Vascular Plants [\%] } \\
\text { Cryptogams [\%] } \\
\text { Plot-size [m }{ }^{2} \text { ] }\end{array}$ & $\begin{array}{c}\text { Opal } \\
\text { Cone } \\
90 \\
4900 \\
\text { SW } \\
30 \\
\text { Dacitic } \\
\text { Lava } \\
\text { Organic } \\
\text { Ranker } \\
90 \\
2 \\
5\end{array}$ & $\begin{array}{c}\text { Opal } \\
\text { Cone } \\
50 \\
5300 \\
\text { SW } \\
40 \\
\text { Dacitic } \\
\text { Lava } \\
\text { Organic } \\
\text { Ranker } \\
90 \\
2 \\
5\end{array}$ & $\begin{array}{c}\text { Opal } \\
\text { Cone } \\
25 \\
5250 \\
\text { SW } \\
40 \\
\text { Dacitic } \\
\text { Lava } \\
\text { Organic } \\
\text { Ranker } \\
90 \\
- \\
5\end{array}$ & $\begin{array}{c}\text { Opal } \\
\text { Cone } \\
75 \\
5300 \\
\text { W } \\
35 \\
\text { Dacitic } \\
\text { Lava } \\
\text { Organic } \\
\text { Ranker } \\
100 \\
- \\
5\end{array}$ & $\begin{array}{c}\text { Opal } \\
\text { Cone } \\
80 \\
5200 \\
\text { W } \\
30 \\
\text { Dacitic } \\
\text { Lava } \\
\text { Organic } \\
\text { Ranker } \\
95 \\
- \\
5\end{array}$ & Constancy \\
\hline Phyllodoce empetriformis & & 2 & & & & 1 \\
\hline Valeriana sitchensis & 7 & 8 & 7 & 7 & 5 & 5 \\
\hline $\begin{array}{l}\text { Antennaria alpina } \\
\text { Phleum alpinum }\end{array}$ & . & i & 1 & . & . & 1 \\
\hline $\begin{array}{l}\text { Phleum alpinum } \\
\text { Lupinus latifolius }\end{array}$ & $i$ & $\begin{array}{l}1 \\
3\end{array}$ & $\dot{1}$ & $\dot{1}$ & 3 & $\begin{array}{l}1 \\
5\end{array}$ \\
\hline Arnica latifolia & 1 & & 2 & . & 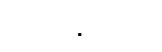 & 2 \\
\hline Luetkea pectinata & 4 & 1 & . & . & 4 & 3 \\
\hline Vahlodea atropurpurea & 1 & . & . & . & . & 1 \\
\hline Hieracium gracile & 1 & . & . & . & 3 & 2 \\
\hline Carex nigricans & 4 & . & 3 & . & 5 & 3 \\
\hline Carex spectabilis & 1 & 4 & 2 & 6 & 2 & 5 \\
\hline Luzula piperi & 1 & . & . & . & . & 1 \\
\hline Pulsatilla occidentalis & 2 & 3 & 4 & 2 & . & 4 \\
\hline Potentilla flabelliformis & 1 & $\cdot$ & 1 & . & . & 2 \\
\hline Ranunculus eschscholtzii & 1 & . & . & . & . & 1 \\
\hline Diphasiastrum sitchense & . & . & . & . & 2 & 1 \\
\hline Bryophytes: & & & & & & \\
\hline Polytrichum piliferum & . & . & 1 & . & . & 1 \\
\hline Racomitrium canescens & . & . & . & . & 1 & 1 \\
\hline Lichens: & & & & & & \\
\hline Solorina crocea & & & 1 & 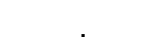 & & 1 \\
\hline Trapeliopsis granulosa & & 1 & & 1 & & 2 \\
\hline
\end{tabular}

Notice: The cover-abundance scale used is the "species significance" scale by Krajina (1933) 


\subsubsection{ALLIANCE: Sibbaldio procumbentis-Trollion laxi all. nov. - Rocky Mountain Sibbaldia-Globeflower alliance}

Nomenclatural Type: Luzulo hitchcockii-Erythronietum grandiflorae ass. nov.

\section{Character species: none}

Differential species: Sibbaldia procumbens, Trollius laxus, Juncus drummondii, Aquilegia flavescens, Vaccinium scoparium, Castilleja rhexifolia, Mitella breweri, Claytonia lanceolata, Caltha leptosepala, Potentilla diversifolia, Epilobium angustifolium, Fragaria virginiana, Phleum alpinum, Trisetum spicatum, Arnica mollis, Salix arctica, Castilleja occidentalis

This alliance is the eastern counterpart of the coastal-cordilleran Lupino-Valerianion occurring from central BC east through the Rocky Mountains into Colorado. A large differential species group differentiates this syntaxon but character species in a strict sence have so far not been found, except perhaps for the low constancy species Aquilegia flavescens and Mitella breweri (see synoptic table 5. Many of the differential species of this alliance (mainly Sibbaldia procumbens, Juncus drummondii) and some other species occurring predominantly in this alliance within this order (Ranunculus eschscholtzii, Veronica wormskjoldii, Vahlodea atropurpurea, Antennaria lanata), are also common species in the neighboring Caricetalia nigricantis and show the above mentioned close relation to the snowbed communities, even more so than it is the case in the coastal Lupino-Valerianion. Interestingly, these affiliations are missing in the moister western mountains. Based on this differentiation the new alliance has been established. The following association from the study area is the new type for this unit.

\subsubsection{ASSOCIATION: Luzulo hitchcockii-Erythronietum grandiflorae ass. nov.}

\section{- Smooth Woodrush-Glacier Lily community plate 5, fig. 17}

Nomenclatural Type: see typicum subassociation

Plots: 47, 49, 73b, 94, 95, 120, 126, 205, 210, 211, 212, 213, 214, 257, 344, 404, 435, 438, 439, 542, 543, 544, $545,548,567,568,570,575,576,577,578,585,586,587,621,624,634,635,700,705,706,754$ $(\mathrm{n}=41)$

Character species: Erythronium grandiflorum, (Pulsatilla occidentalis, Luzula hitchcockii)

Constant species: Erigeron peregrinus, Hieracium gracile, Vahlodea atropurpurea, Epilobium alpinum, Carex nigricans, Phleum alpinum, Arnica diversifolia, Polytrichastrum alpinum

General aspect: The woodrush-glacier lily community is perhaps the most well known plant community in the area to anybody who has ever in mid-summer visited the prime touristic site of Glacier National Park, the Hanging Gardens at Logan Pass. Around the end of July, large expanses of the terraced, slightly undulating subalpine to low alpine meadows in the Pass area are covered by this showy community and reveal an impressive floral display of millions of yellow flowering glacier lilies which can even be seen from miles away looking down from the surrounding mountains.

The general aspect is that of a lush forb community with a pronounced phenological sequence. Right after snow melt in July, the first green to appear are the spear-shaped lily-shoots emerging from the 
brownish snow-compacted last year's litter. At the same time the short-lived spring-beauty (Claytonia lanceolata) unfolds and is already at its flowering peak when the glacier lily's flowers open. Both species can sometimes be found emerging right at the edge of the receding snow-patches or sometimes even working their way through the waning snow cover.

The spectacular aspect of hectares of bright yellow lily flowers covering the subalpine meadows is certainly one of the highlights of Glacier's botanical summer. This mountain-spring aspect is followed by a short period of lesser flowering dominated by the emerging of Luzula hitchcockii with its wide and soon reddish-turning leaves. By mid-August a new wave of intense flowering approaches with a number of various-colored species starting to bloom. Most dominant is the subalpine fleabane (Erigeron peregrinus) with its light pinkish tinge that stains the meadows like the glacier lilies did before except that the dominant color is different.

Important contributors to the rich aspect are also different species of Arnica, namely Arnica diversifolia, A. latifolia and A. mollis with their yellow to orangish large ray-flowers. Each of those species can reach considerable cover, with $A$. diversifolia being the most constant and most covering species. A red, sometimes pinkish, whitish or yellowish tinge is added by the various forms of subalpine indian-paintbrush (Castilleja rhexifolia). Overtopping much of the forb layer are the white corymbs of sitka valerian (Valeriana sitchensis) and the yellow ray flowers of the arrow-leafed groundsel (Senecio triangularis). Not nearly as showy but nevertheless very constant are the smaller species Sibbaldia procumbens, Hypericum formosum, Epilobium alpinum, Ranunculus eschscholtzii, Senecio cymbalarioides, Mitella breweri and Veronica wormskjoldii, adding their share to the luxury of this community.

Topography: The glacier scoured, slightly sloping Logan Pass region as well as other similar sites in the Park on large benches mostly below talus slopes or in former glacier basins are the main landforms to find this community on. The slopes are gentle from level to mostly below $20^{\circ}$ (rarely to $28^{\circ}$ ) with no detectable preference of aspect. The subalpine to low alpine elevation range is relatively narrow, from $1900 \mathrm{~m}$ near timberline to about $2200 \mathrm{~m}$ with by far most of the plots between $2000 \mathrm{~m}$ and $2100 \mathrm{~m}$. In some areas (e.g. Preston Park), openings in the subalpine Abies lasiocarpa-forests are dominated by this community but all sampling within this study has been done in areas above closed timberline which is why the definition of this community does not include the subalpine variants below forest line. They are though likely to fall within the delineation of this syntaxon as given here.

Parent material: The bedrock material does not seem to be very differentiating within this community which was found to grow on limestone as well as on green and red argillite.

Soils: Given the high elevation and the resulting harsh environment of this community, the soils found in this unit are quite well developed. A dark, almost black $A_{h}$ horizon can reach considerable thickness but is often only gradually differentiated against the underlaying B or sometimes immediately the $\mathrm{C}$ horizon.

Wind exposure/Snow duration: The gentle slopes of this community are often found in slightly wind-protected areas of undulating landforms, on the lee-side of bedrock-outcrops or on long consolidated colluvial footslopes sites where considerable amounts snow accumulate. For this reason the community has affinities to true snowbed communities with which it shares a number of species. The late laying snow allows for a growing season no longer than an estimated 3.5 to 4 months. Water supply is hardly a problem throughout the season on these mesic sites.

Vegetation: Vegetative cover is mostly above $80 \%$ to almost complete cover. Accordingly the large amount of biomass results in a considerable litter cover. The latter varies greatly though with the floristic composition. Graminoids, mainly Luzula hitchcockii and Carex nigricans, seem to be 
important for the accumulation of litter whereas the easily decomposing forb litter seems to not correlate in this regard. The weathered remains of the leaves of Claytonia and Erythronium are often hard to find by late August and especially the first species might for that reason have been overlooked in the plots sampled later in the season.

Even though Erythronium grandiflorum does occur in a number of other related subalpine meadow communities, which mainly pertains to areas other than the one studied here, the syntaxon as outlined certainly is the central syntaxonomical unit for the species regionally. A larger number of samples would be needed to ensure that the stands with mountain pasqueflower (Pulsatilla occidentalis) make a separable variant of this community. The species does not occur in other communities in the area, hence it is a good though not very constant regional character species. A number of relevés (nos.47, $49,73 b, 94,95,700,706,754$ ) have been included in the association table which originate from species lists gathered in the reconnaissance phase of this study. Those plots lack cryptogam data and some of the less conspicuous vascular plant species. Still they have been included in the table.

Whereas homotoneity within this community is fairly high, variability exists in the pattern of species dominance. Resulting are floristically defined units consisting of in some cases very differently looking stands that appear to belong to different units at a first glance. This quantitative and also the qualitative variability is at least in part due to the intensity of disturbance which the sites experience. Most intense disturbance is caused by the digging of grizzly bears (Ursus arctos) which frequently visit the areas on their search for high energy food being provided by the carbohydrate-rich tubers of Erythronium grandiflorum. Disturbed meadow patches are often almost completely dug up with much of the turf sods being turned upside down by the grizzly bears in their pursuit of the lily corms (plate 5 , fig.18.

This disturbance increases available soil nutrients through the stimulation of mineralisation processes and initiates new succession (Tardiff \& Stanford 1998). Resulting is a patchy pattern of different successional stages with differing soil and vegetation development. One of the conspicuous stages of the sequence are patches with a dominance of Luzula hitchcockii which is considered to be an early stage after digging disturbance. Vegetative colonization of the open mineral soil under the harsh subalpine and snow-rich conditions starts with species of mosses (mainly Polytrichastrum alpinum). First and most dominant vascular plant species is Hitchcock's woodrush and only gradually can other species invade the dense Luzula-stands. These patches of dominant Luzula hitchcockii can easily be picked out in the landscape by their intense reddish coloration in late summer. Other animals to cause disturbance on a smaller scale but nevertheless very frequent in this community are gophers, marmots, voles and other rodents. Disturbed patches around gopher holes and marmot burrows in this community often have a distinct vegetation with single species such as Carex spectabilis assuming dominance. It needs to be mentioned though that some of the variability in species dominance might as well be determined by other biotic or abiotic parameters.

Bryophytes do constantly occur in this community, with Polytrichastrum alpinum being one of the most constant species. Other fairly common species are Pohlia sp., Brachythecium sp., and Bryum sp.. Lichens do not play an important role except for the frequently occurring vegetative thallus squamules of one or more unidentified Cladonia species.

The spatial occurrence of this meadow community is clearly correlated with the snowmelt gradient and can easily be studied in the repeating patterns of the terraced landscape at Logan Pass. Adjacent communities towards the longer snow covered depressions are Caricetum nigricantis or Salix arctica dominated snowbeds. Much of the intermediate positions is covered by this unit, whereas the drier, better drained and elevated ridges with their shallower soils are covered with bands of subalpine fir or Phyllodoce heath communities. This pattern is repeated a number of times in the Hanging Garden area 
and represents a spatial as well as a phenological sequence.

Within each of the treeless communities, a continuous phenological sequence follows the melting snow front resulting in a phenological wave of flowering belts moving parallel to the relief terraces over the landscape. The most conspicuous aspect being within the Erythronium belt which also is by far the widest covering the largest proportion of the meadow areas. The community seems to occur through much of the study area without local differentiation. Thus it can be called widespread and common. It is though confined to areas not much east of the Continental Divide being bound to the moister parts of the mountains.

Syntaxonomy: It has been debated whether to place this unit together with the snowbed units into the Caricetalia nigricantis. Again the tool of the synoptic table was used to solve this problem. Such a table was compiled with data from similar lush subalpine communities throughout the Rocky Mountains and the western mountain ranges Tab. 5.

There is no doubt as to the placement of the glacier lily-meadows into the class Salicetea herbaceae. It turns out that the new Luzulo-Erythronietum fits better into the Valerianetalia than into the Caricetalia nigricantis. Floristical ties to both units are strong, but being structurally and ecologically closer to other forb meadows, the present solution was favored.

Two variants of this community have been separated mainly based on their species-richness and completeness of the diagnostic species group. Ecological differentiation is not quite clear among these variants which is why they are not called subassociations at this point. There is a slightly higher percentage of limestone soils among the richer sites which points to a difference in soil nutrients. As mentioned above, successional processes also has its impact on species-richness and will contribute to this difference.

Distribution: This community has been found in much of the alpine along the Continental Divide not reaching the drier mountains towards the prairies. It is known to occur in other north western Montanan mountain ranges (e.g. Cabinett Mountains - observed by the author) and is certainly ranging into Canada as well as further south in Montana. Other occurrences of the same association have not been found in literature. A distribution pattern centered around this study's area can be assumed.

\section{SUBASSOCIATION: Luzulo-Erythronietum grandiflorae ranunculetosum - Woodrush-Glacier Lily community - Ranunculus eschscholtzii subassociation}

Nomenclatural Type: Table 24 relevé 576

Plots: 47, 49, 73b, 94, 95, 126, 211, 212, 213, 214, 438, 439, 544, 545, 568, 570, 575, 576, 578, 585, 586, 621, $624,634,635,700 \quad(n=26)$

\section{Character species: none}

Differential species: Ranunculus eschscholtzii, Veronica wormskjoldii, Sibbaldia procumbens, Senecio cymbalarioides, Valeriana sitchensis, Poa cusickii, Senecio triangularis, Castilleja rhexifolia, Arnica mollis, Mitella breweri

The Ranunculus eschscholtzii variant is considerably richer in taxa and usually has a species number above 25 (mostly $>30$ to 50 species). The differential species group allows for a clear separation from the following variant. In addition to these differential species a number of others have a higher constancy in this variant (e.g. Hypericum formosum, Arnica diversifolia, Juncus drummondii and others) but have not been called differential species since the difference in constancy is less than two 
classes. Further subdivision of this syntaxon might be possible, with a syntaxon comprising the richest samples. It includes Pulsatilla occidentalis, Aster foliaceus and Potentilla diversifolia. It is restrained from separating this subgroup here, since more samples would be needed to validate this division. Nevertheless, on a local scale a differentiation within this subassociation along a snow-melt gradient is obvious and would most certainly reveal some variants.

\section{SUBASSOCIATION: Luzulo-Erythronietum grandiflorae typicum \\ - Woodrush-Glacier Lily community - Typical subassociation}

Nomenclatural Type: Table 24 relevé 543

Plots: $120,205,210,257,344,404,435,542,543,548,567,577,587,705,706,754 \quad(n=15)$

\section{Character species: none}

Differential species: none (see text)

This community lacks any particular differential species, which commonly is the case in a typicum, has less than six out of ten species of the diagnostic species group of the Ranunculus variant and/or has a total of less than 25 species. Plots with Ranunculus eschscholtzii and Pulsatilla occidentalis have been assigned to the richer Ranunculus eschscholtzii variant. It needs to be mentioned that the term typicum is used here in the derived sense as a variant lacking a set of differential species rather than having the "typical" composition. I.e., this is a subassociation without differential species sensu Dierßen (1990).

Apart from a trend of this subunit to occur on argillite bedrock rather than limestone, no other dominant ecologically differentiating factor has so far been found. The impoverished set of species is most likely caused by a variety of reasons which might result in further subdivisions in the future. A larger number of samples together with detailed site-ecological investigations would be needed to verify these differentiations. A possible syndynamic variant has already been mentioned in the stands with dominant Luzula hitchcockii following animal disturbance. Sites with pronounced dominance of Carex nigricans are most likely indicating longer snow cover and can be considered transitional to the Carex nigricans snowbed community.

\subsubsection{ALLIANCE: Philonotido fontanae-Mimulion lewisii all. nov. - Philonotis-Monkey Flower streambank alliance}

Nomenclatural Type: Senecio triangularis-Mimuletum lewisii ass. nov.

\section{Character species: Mimulus lewisii, Stellaria calycantha, Leptarrhena pyrolifolia}

\section{Constant species: Philonotis fontana, Juncus drummondii, Senecio triangularis, Epilobium alpinum, Parnassia fimbriata, Bryum sp.}

This new alliance is created in order to unite the distinct streambank communities of Mimulus lewisii which have been reported from different mountain areas in the Pacific Northwest. The similarities and differences of the units included can be taken from table 25. Included in this new syntaxon are the members of the unvalidly published "Philonotis fontana alliance" by Brett et al. (1998) which was established to accommodate their Epilobium latifolium-Mimulus lewisii association and the Leptarrheno-Calthetum leptosepalae Brooke et al. 1970. Even though Mimulus lewisii is not very constant in the latter community, it was still used as the name giving species of the alliance since it 
better describes the tall herb character of this unit than does e.g. Leptarrhena pyrolifolia. Stellaria calycantha is so far considered a local character species of the association and the alliance. It might turn out that it is more diagnostic for the association only.

The placement of this alliance in an order is not yet resolved. The creation of the above mentioned Philonotis fontana order for this purpose can not be evaluated at this point.

\subsubsection{ASSOCIATION: Senecio triangularis-Mimuletum lewisii ass. nov. - Arrow-leafed Senecio-Monkeyflower streambank community plate 5, fig. 19)}

Nomenclatural Type: Table 25 relevé 616

Plots: $318,350,351,352,353,501,559,560,562,589,603,616,623,630,644,646,730,737,738 \quad(\mathrm{n}=19)$

Character species: Mimulus lewisii, Stellaria calycantha, Poa leptocoma

Diagnostic species: Arnica mollis, Leptarrhena pyrolifolia, (Pohlia wahlenbergii)

Constant species: Senecio triangularis, Epilobium alpinum, Philonotis fontana, Parnassia fimbriata, Brachythecium sp., Bryum sp.

General aspect: The most typical subalpine and low alpine streambank community is also perhaps the most conspicuous and flower-rich of all plant communities in Glacier National Park (see plate 5 . appendix). A brief glance at some of the most common postcards and posters sold in the park gives a good unterstanding of how this spectacular community looks like. Unshaded streambanks in the upper reaches of the subalpine conifer forests as well as streambanks in open meadow areas are lined by this lush forb and tall herb community throughout the park, forming a band often not wider than one meter on streambanks widening only with increasing seepage, like in the spray-water zone at the base of waterfalls.

Topography: Like in many other communities of the timberline zone, the elevation range is very small from $1900 \mathrm{~m}$ to $2300 \mathrm{~m}$ with most sites between $2000 \mathrm{~m}$ and $2100 \mathrm{~m}$. By far the most predominant ecological factor in this community is abundant moisture. Some of the sites are constantly seeped or in the spray zone of adjacent waterfalls. Other ecological factors are much less important: There is no correlation with aspect, and the slope angle varies from level sites to very steep rock outcrops $>45^{\circ}$. Slope relief can be smooth which is the case mostly along little inclined streams or very rough along bouldery cascades and rocky slopes.

Geology: There is no preference for certain types of bedrock and most stands are found on the widespread green and red argillites. Rock cover varies from none to $40 \%$ of the plot, much of it being bedrock outcrops in many cases.

Wind exposure/Snow duration/Moisture supply: Moderate wind exposure of the sites allows for considerable accumulation of snow resulting in a relatively short growing season of about 3.5 to 4.5 months. Fast running water and/or constantly water saturated soils create a cool microenvironment.

Vegetation: Even though the topography of these sites can be extremely diverse, from level meadow streambanks to edges of rocky waterfalls, their common ecology results in a very constant set of plant species which is mostly dominated by some tall forb species making up for a vascular plant cover often greater than $80 \%$ and sometimes even more than 95\%. Mimulus lewisii and Senecio triangularis are the structurally dominant species giving this unit the aspect of a lush and productive herb 
community. They are very constantly joined by the much smaller but very numerous Epilobium alpinum. Juncus mertensianus and Parnassia fimbriata are two other constant companions and common wetland species all through the subalpine and lower alpine.

Litter cover varies greatly from less than $10 \%$ to $90 \%$. Due to the cool microclimate decomposition of organic matter is retarded and much of the litter accumulates if it does not get washed away by periodical flooding. The high amounts of litter seems to contradict the high bryophyte cover of the communities but the bryophytes are often confined to the wettest parts of the stands close to the shoreline and not spread out evenly through the plots.

Dense carpets of bryophytes dominate this community more than any other community except for the related Saxifraga lyallii streambanks. Moss cover is mostly above $50 \%$ and can exceed $75 \%$ in some cases. Most important moss species are Philonotis fontana, Brachythecium spp. and Bryum spp. Unfortunately the latter have not been identified to species in many cases. The most frequent Bryum species is B. pseudotriquetrum followed by B. weigelii. Pohlia wahlenbergii also is common in this syntaxon. Lichens are mostly lacking or present in very small amounts on rocks only.

Successional trends have not been observed in this community. It is believed to be a stable vegetation unit despite its partly unstable sites along fast running streams. Considerable changes in the water level does occur with spring meltwater run-off and erosion along the shorelines is a common process.

A number of other communities occur adjacent to this one. Common neighbors are snowbed communities with Carex nigricans and/or Salix arctica. Erythronium meadows and Phyllodoce heaths do border the streambanks, as well as subalpine forests, Saxifraga mertensiana rock crevice community or the related Saxifraga lyallii streambank community which frequently grades into the typicum variant of the present unit.

Syntaxonomy: This association is divided here into two subassociations which might later on be subdivided further. This is not attempted here, because additional samples would be needed to better define a more detailed differentiation.

Following the treatment of similar communities reported by Brooke et al. (1970) and Brett et al. (1998), this community could be placed into the European order Montio-Cardaminetalia Pawl. in Pawl. et al. 1928. At least a placement in the European class Montio-Cardaminetea Br.-Bl. et Tx. 1943 seems possible if such a wide-ranging use of European classes is to be accepted. Even though the ecological similarities are beyond doubt, floristic similarities with the European order and class are poor. Besides the obvious ecological similarities, only the structurally often important species Philonotis fontana and Bryum weigelii would built a close tie between the European syntaxon and its North American counterpart.

Floristically the Senecio-Mimuletum is also similar to the Caricetalia nigricantis but again not enough species-overlap exists to include it in that order. Also structural differences to that order are considerable. Very close similarity exists to the wet meadows with Parnassia fimbriata.

Distribution: The community is very widespread along streams at the respective elevations in the park and certainly has a much larger range. Local variation is limited as would be expected for an azonal community.

Literature: A similar community has been described by Brett et al. (1998) as the Epilobium latifolium-Mimulus lewisii association, partly based on the "Mimuleto-Epilobietum latifolii" described by Archer 1963 and validated below. It has some floristic differences which are mainly the presence of Epilobium latifolium as a most important constituent and the presence of Saxifraga nelsoniana, Mitella pentandra, Luetkea pectinata, Petasites frigidus, Luzula piperi, Arnica latifolia, Hieracium 
gracile, Phyllodoce empetriformis, Racomitrium canescens. Even though all of these species are lacking in the samples of this study and some others are occurring with different constancy, the overall floristic similarity reflects the ecological closeness of the two communities. Due to their geographical difference and the resulting floristic differences, they are maintained as different associations but should most likely be kept in the same alliance. Floristic differences seem too strong to keep them separate at the subassociation level only.

The Leptarrheno-Calthetum leptosepalae Brooke et al. 1970 has some affinities in the presence of Philonotis fontana, Parnassia fimbriata and rarely Mimulus lewisii, but differences seem to prevail including ecological differences which result from a little less water- influenced micro-sites with slightly better soil development. Still, this unit might also be placed in an alliance with the Mimulus lewisii associations.

For comparison the constancy columns of Epilobium latifolium-Mimulus lewisii association, the "Mimuleto-Epilobietum latifolii" and the Leptarrheno-Calthetum leptosepalae are added in table 25).

\section{SUBASSOCIATION: Senecio-Mimuletum lewisii habenarietosum subass. nov. - Rich streambank subassociation with Habenaria saccata (and Arnica longifolia)}

Nomenclatural Type: Table 25 relevé 350

Plots: $350,351,352,353,559,560,562,589,603 \quad(\mathrm{n}=9)$

Character species: Habenaria saccata, Arnica longifolia

Differential species: Veratrum viride, Aster foliaceus, Achillea millefolium, Elymus glaucus, Tofieldia glutinosa, Mitella breweri, Agrostis thurberiana, Montia parviflora, Spiraea densiflora, Carex mertensiana, Athyrium filix-femina

This unit comprises the species-rich stands assigned to the association. Very conspicuous and maybe in need of further separation are the plots with a markedly higher number of species which are describing the subassociation habenarietosum in a strict sense. The less species-rich plots in this dataset have not yet been separated from those and are all dominated by Aster foliaceus. They could be separated as a variant named after this species.

This subassociation has stronger affinities to the Parnassia-Philonotis group of the TrollioParnassietum.

It seems to occur on slightly more stable, protected sites than the latter unit. Comparing the soil development this subassociation has deeper and more differentiated profiles with higher amounts of organic matter derived from a denser lower herb layer. Whereas the Saxifraga lyallii-subassociation does not show a preferred directional aspect, this variant was sampled mainly with westerly to southerly exposure, suggesting higher importance of solar radiation.

Even though this community was sampled mainly at two locations (Sperry Glacier Trail, Fifty Mountain meadows) it is certainly more widespread and has been found in other places e.g. along Highline- and Iceberg Lake Trails. 


\section{SUBASSOCIATION: Senecio-Mimuletum lewisii typicum subass. nov. - Arrow-leafed Senecio-Monkeyflower streambank subassociation \\ Nomenclatural Type: Table 25 relevé 630}

Plots: $318,501,616,623,630,644,646,730,737,738 \quad(\mathrm{n}=10)$

Differential species: Carex nigricans, Ranunculus eschscholtzii, Veronica wormskjoldii, Saxifraga lyallii, Oxyria digyna, Mimulus tilingii

The typicum subassociation is defined on the basis of the differential species set given above. It is certainly the more widespread of the two subunits having been sampled in a variety of locations all through the study area. It is floristically closer to the snowbed communities than the following subassociation. The samples with Mimulus tilingii and Saxifraga lyallii are closely related to the Philonotis-Saxifraga lyallii community which is very similar ecologically, but more extreme and entirely lacking the lush tall herb structure (see under that community). This subassociation might be a successional follower of the structurally much simpler Saxifraga lyallii community.

SUBASSOCIATION: Senecio-Mimuletum lewisii saxifragetosum lyallii subass. nov. - Lyall's Saxifrage streambank community

Nomenclatural Type: Table 25 relevé 626

Plots: $202,230,265,512,597,626 \quad(n=6)$

Character species: Saxifraga lyallii, (Mimulus tilingii, Oxyria digyna)

Constant species: Philonotis fontana var. americana, Bryum pseudotriquetrum, Brachythecium sp., Senecio triangularis, Epilobium alpinum, Carex podocarpa, Senecio cymbalarioides, Carex nigricans, Ranunculus eschscholtzii, Luzula piperi

Due to the much different physiognomy of this unit compared to the typicum variant, it was considered to keep this community as a separate association. Since there are no exclusive species and the overall floristic composition is so similar - even though with a reduced species number - this unit is kept as a subassociation of the Senecio-Mimuletum. The overlap of the diagnostic species group with Saxifraga lyallii, Oxyria digyna, Mimulus tilingii and Poa alpina into the typicum unit strongly supports this treatment (see table).

General aspect: Seeped or spray water supplied streambanks and fine soil-filled meltwater pools are the sites of this lush wetland community. The often dominant Saxifraga lyallii more or less completely covers lush green and often extensive moss cushions, which bulge over rocks and banks of little streams in the alpine and sometimes in lower alpine regions.

Topography: Aspect of this community was found to be mostly northerly, ranging from WSW to E with an elevation range from $2000 \mathrm{~m}$ to $2300 \mathrm{~m}$. As a streambank habitat it commonly grows in concave landforms, thus catching considerable amounts of snow. Moisture supply is copious with frequent flooding during spring melt-off and extensive rainfall. In fact, the wettest parts of this community might almost be considered semi-aquatic since they are well water-supplied through the whole season. 
Geology: The bedrock does not seem to have any influence on this community. The running or seeping water is likely to wash out any soil-chemical differences caused by the underlaying bedrock.

Soils: Soils are rich in silty and sometimes sandy material which gets trapped in the interstices of the moss carpets. In cases with deeper silty substrate some of the material might also have been deposited prior to vegetative colonization of the sites. This might especially be the case in alpine meltwater depressions which partly dry out later in the summer. Humus contents can be reasonably high since decomposition of organic material is delayed in this cold and wet environment. Instead of forming a surface peat layer the organic material is embedded in the frequently deposited silt material.

Vegetation: The dense vegetative cover is based on a high moss cover of Philonotis fontana and Bryum sp., mainly B. pseudotriquetrum, and is added to by different amounts of vascular plants ranging from scattered individuals to almost closed stands of Saxifraga lyallii. Often impoverished variants of this community occur which can consist of pure cryptogam synusiae and might be treated separately as Philonotis-Bryum bryophyte communities.

Due to the small number of stands, the list of constant species is only tentative. Differential taxa were not assigned since the data on related communities is scanty. This unit is certainly the most conspicuous low growing streambank community of this kind. Highly characteristic are Mimulus tilingii and less so Oxyria digyna, both of which do occur only in a few other communities. Senecio triangularis, Epilobium alpinum, Carex spectabilis s.1., Senecio cymbalarioides, Carex nigricans and Ranunculus eschscholtzii are species of moist to wet sites at these altitudes and constant occurring in, but not entirely confined to this azonal community. Again, this community shows the taxonomic difficulties in the Carex spectabilis group, some of the specimens being closer to Carex spectabilis, others to Carex podocarpa.

Moss cover often exceeds $90 \%$ with only the aquatic portions of the plots lacking the bryophyte cover. Lichens are completely lacking.

Only a small number of stands was sampled since this type of habitat occurs only very scattered in the study area. The stands also are relatively small, forming narrow bands along streamlets, occurring on the basal edges of waterfalls or covering constantly seeped flat rock-surfaces. The community is considered a pioneer community of these streambank habitats representing the stage of first establishment of vascular plants on alluvial, already moss-covered silt deposits. Unless water erosion prevents any further development, the community is likely to merge into Senecio-Mimuletum lewisii, the unit which most often can be found in the vicinity of this community.

Disturbance by small mammals was observed with dried grass clippings as a sign of vole activity. Voles have been trapped in the vicinity. Meltwater flooding impacts the sites mainly with the deposit of fine material. Erosion can occur on fast running streambanks when the water undercuts the bulging carpets of shoreline vegetation. Signs of succession have not been found in this simple structured community.

A zonal pattern is often found with this syntaxon at the waterline and the Mimulus lewisii-Senecio triangularis community bordering immediately after. Both are sometimes forming mixed patterns where delineation is hardly possible anymore.

Syntaxonomy: Floristic ties exist to Valerianetalia tall herb communities (namely SenecioMimuletum lewisii), Carex nigricans snowbeds, and to Trollius-Parnassia wet meadows. The syngenetic relationship seems to be closest to the first, which was the reason to place this unit into that order. Pronouncing the importance of mosses in this unit, a placement with the Philonotis fontana communities seems possible, but has to await further syntaxonomical studies. The use of the 
European order Montio-Cardaminetalia Pawl. in Pawl. et al. 1928 as done by Brooke et al. (1979) should await a better treatment of these high elevation wetland communities with a broader geographical scope.

The presence of Oxyria digyna and Carex spectabilis s.l. reveals great similarity with the ArnicoCaricetum spectabilis, which generally is a more chionophilic and less hydric pioneer community though. Brett et al. cited Douglas (1970) with a Saxifraga lyallii community resembling their OxyriaCarex spectabilis community.

Literature: Crack (1977) mentions similar Saxifraga lyallii stands in meltwater channels through Carex nigricans snowbeds. Structurally somewhat similar are the Saxifraga tolmiei communities mentioned from British Columbia by Brooke et al. (1970), Brett et al. (1998), and others. Despite their richness in other bryophyte species, they are less water dependend though and are likely to be closer to snowbed communities.

\subsubsection{ASSOCIATION: Epilobio latifolii-Mimuletum lewisii Archer ex Damm}

\section{- Alpine fireweed-Monkeyflower streambank community}

Nomenclatural Type: Archer (1963): "Mimuleto-Epilobietum latifolii" p.67(a) plot 9 ( =lectotype), reproduced in Table 26

\section{Diagnostic species: Mimulus lewisii, Epilobium latifolium}

This community is validated here from Archer's unpublished paper cited above. Brett et al. (1998) present a somewhat incomplete synoptic table, including Archer's plots and adding a few relevés. The publication by Brett et al. is not a validation of Archer's syntaxon since they did not use the correct form of the name which would have been necessary for a validation after 1.1.1979 (Code of Phytosociological Nomenclature Article 3h).

\subsubsection{ASSOCIATION: Leptarrheno pyrolifoliae-Calthetum leptosepalae Brooke et al. 1970 - Leatherleaf Saxifrage-Marshmarigold streambank community}

Nomenclatural Type: Brooke et al. 1970 : "Leptarrheno pyrolifoliae-Calthetum leptosepalae" Table 30, p.245 plot 73 (lectotype!)

Diagnostic species: (acc. Brooke et al.): Rhytidiadelphus squarrosus, Leptarrhena pyrolifolia, Drepanocladus aduncus, Caltha leptosepala, Erigeron peregrinus, Philonotis fontana, Parnassia fimbriata, Equisetum palustre, Petasites frigidus, Arnica latifolia, Cratoneuron commutatum, Campylium stellatum, Salix commutata, Mimulus lewisii

This association is added here for a better understanding of this alliance. A lectotypification is also done. The diagnostic species given by Brooke et al. were called "Alliance and Association character species" referring to the Leptarrhenion pyrolifoliae Brooke et al. 1970, an alliance which is likely to have a very weak delineation according to its original diagnosis. It is defined be a number of widespread species of wet and mesic conditions without any nearly exclusive species except perhaps the leatherleaf saxifrage itself. 


\section{Epilobio-Mimuletum lewisii Archer ex Damm}

"Mimuleto-Epilobietum latifolii Archer 1963"

= Original Table from Archer (1963, p. 67a; sociability and vigor omitted)

\begin{tabular}{|c|c|c|c|c|c|c|}
\hline Location/Region & Moraine & Ring & Ring & Ring & Diamont & \\
\hline & Lake & Creek & Creek & Creek & Head & \\
\hline Plot-Number & 92 & 66 & 29 & 9 & 6 & \\
\hline Elevation [ft] & 5350 & 4300 & 4400 & 4600 & 5900 & \\
\hline Aspect & NW & NW & SW & $E$ & W & \\
\hline Slope $\left[^{\circ}\right]$ & 0 & 0 & 5 & 2 & 10 & \\
\hline Parent Material & $\begin{array}{c}\text { Dacitic } \\
\text { Lava }\end{array}$ & $\begin{array}{l}\text { Dacitic } \\
\text { Lava }\end{array}$ & $\begin{array}{c}\text { Dacitic } \\
\text { Lava }\end{array}$ & $\begin{array}{c}\text { Dacitic } \\
\text { Lava }\end{array}$ & $\begin{array}{c}\text { Dacitic } \\
\text { Lava }\end{array}$ & \\
\hline Soil-type & Lithosol & Lithosol & Lithosol & Lithosol & Lithosol & \\
\hline Vascular Plants [\%] & 50 & 80 & 70 & 30 & 20 & \\
\hline Bryophytes [\%] & 70 & 10 & 70 & 50 & 50 & \\
\hline Plot-size $\left[\mathrm{m}^{2}\right]$ & 10 & 5 & 5 & 5 & 5 & Constancy \\
\hline Mimulus lewisii & . & 8 & 7 & 2 & 1 & 4 \\
\hline Epilobium latifolium & 5 & 7 & 7 & 4 & 4 & 5 \\
\hline Philonotis fontana & 8 & 2 & 6 & 5 & 7 & 5 \\
\hline Juncus drummondii & 2 & 1 & 1 & 1 & 1 & 5 \\
\hline Scapania undulata & . & 3 & 2 & 1 & 4 & 4 \\
\hline Leptarrhena pyrolifolia & 1 & . & 3 & 3 & . & 3 \\
\hline Salix drummondiana & 6 & 1 & 2 & . & . & 3 \\
\hline Juncus mertensianus & 3 & . & . & 1 & . & 2 \\
\hline Gymnomitrium varians & 3 & . & . & 1 & . & 2 \\
\hline Carex spectabilis & . & 3 & . & 1 & . & 2 \\
\hline Arnica latifolia & . & 1 & . & 2 & . & 2 \\
\hline Marchantia polymorpha & . & . & 6 & 4 & . & 2 \\
\hline Valeriana sitchensis & . & . & 1 & 1 & . & 2 \\
\hline Racomitrium canescens & . & . & 1 & 1 & . & 2 \\
\hline Epilobium alpinum & . & . & 4 & 1 & . & 2 \\
\hline Luzula piperi & . & . & . & 1 & . & 1 \\
\hline Hieracium gracile & . & . & . & 1 & . & 1 \\
\hline Athyrium filix-femina & . & . & 2 & . & . & 1 \\
\hline Luetkea pectinata & . & . & 1 & . & 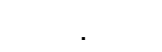 & 1 \\
\hline Phyllodoce empetriformis & . & . & 1 & . & . & 1 \\
\hline Polytrichum juniperinum & . & . & 1 & . & . & 1 \\
\hline Diranoweisia crispula & . & . & 1 & . & . & 1 \\
\hline Saxifraga arguta & . & 1 & 1 & . & . & 2 \\
\hline Kiaeria blyttii & . & 1 & 1 & . & . & 2 \\
\hline Kiaeria starkei & . & 2 & . & . & . & 1 \\
\hline Saxifraga ferruginea & . & 1 & & . & . & 1 \\
\hline Athyrium distentifolium & . & 1 & . & . & . & 1 \\
\hline Mimulus tilingii & & & & & 2 & 1 \\
\hline
\end{tabular}

Notice: The cover-abundance scale used is the "species significance" scale by Krajina (1933) 


\title{
3.4.4. ALLIANCE: Parnassio fimbriatae-Trollion laxi all.nov.
}

Nomenclatural Type: Trollio-Parnassietum fimbriatae ass. nov.

Character species: Trollius laxus, Parnassia fimbriata, Tofieldia glutinosa

Diagnostic species: Agrostis thurberiana, Carex podocarpa, Philonotis fontana

This alliance comprises some widespread and vigorous subalpine to low alpine moist to wet meadow communities. The diagnostic species group is considered strong enough to be kept as a unit even though a division separates the two member associations:

The Aulacomnio-Kalmietum has closer affinities to the snowbed communities of the Caricetalia nigricantis (and to Phyllodoce heath communities), whereas the Trollio-Parnassietum fimbriatae is more similar to the Valerianetalia moist meadow communities. Diagnostic species of both orders are frequent and even among the more constant species of this alliance. Ecologically, the unit is considered to be slightly closer to the Valerianetalia where this alliance is placed for now. The available data from similar vegetation types of the Rocky Mountains and beyond is not considered enough to create a third order, which would separate the Tofieldia-Parnassia fimbriata meadows from both orders mentioned above. However, such a differentiated treatment might be considered the preferred solution in the future. The diagnostic species Parnassia fimbriata and Philonotis fontana do occur outside this unit, relating it to the Senecio-Mimuletum lewisii.

In the mountain ranges west of Glacier NP, Tofieldia glutinosa apparently does not occur in vegetation units belonging into this alliance. Therefore it might be an alliance character species in the area of this study only.

\subsubsection{ASSOCIATION: Aulacomnio-Kalmietum microphyllae ass. nov. - Aulacomnium palustre - Alpine Laurel moist heath community (plate 5, fig.16)}

\author{
Nomenclatural Type: Table 27 relevé 588
}

Plots: 73, 122, 123, 127, 253, 266, 394, 409, 413, 527, 563, 565, 569, 572, 574, 579, 580, 584, 588, 610, 611, $612,613,622,631,645,649 \quad(n=27)$

Character species: Kalmia microphylla, Aulacomnium palustre, (Gaultheria humifusa)

Differential species: Salix arctica, Castilleja occidentalis, Sibbaldia procumbens, Potentilla diversifolia; Danthonia intermedia

General aspect: The Aulacomnio-Kalmietum is a moist and floristically rich, subalpine heath community of reasonably late melting, undulating upland slopes and basins. The subassociation of Salix arctica is much different in aspect, even though its somewhat impoverished floristic composition is basically similar. It is not a heath community but a dwarf willow snowbed unit. Its position in this association is discussed below. Most of the description given for this association pertains to the two subassociations of Kalmia, whereas the subassociation salicetosum is somewhat different in a number of parameters.

Topography: Within the rolling or terraced land-surfaces this association occupies the moister, lower ends of depressions, bench-like terrace edges or often streambanks. Accordingly, the surfaces are flat or only gently sloping from $0^{\circ}$ to $14^{\circ}$. Aspects are various, with most sites being easterly exposed since much of the sampling of this community has been done in the Hanging Garden area at the Logan 
Pass which is predominantly east-exposed. Elevation of the sites is between $2000 \mathrm{~m}$ to $2320 \mathrm{~m}$, close to the altitudinally irregular timberline.

Parent material: Parent material was found to be mostly green and red argillite but limestone is also represented.

Snow cover: This unit is a moderately chionophilic community with a reasonable to long winter snow cover occurring often immediately adjacent to snowbed depressions. Being located on the edges of the depressions, snow duration in these heath communities is not as long as in the snowbeds themselves. The latter provide a reliable water source through midsummer and together with the good storage capacity of the peaty organic soils, water supply is ample throughout the year.

Wind exposure: Wind exposure was found to be middle to reasonable, especially on the raised parts of the undulating topography. Such sites might experience considerable wind desiccation in winter, when the protective snow cover gets blown away and even more so when the soils are still frozen, the latter being the case through much of early summer since water saturated soils take much longer to thaw than dry soils. This is most likely to be one of the reasons for the dominant occurrence of the "xeromorphic" heath species Kalmia microphylla and Phyllodoce spp.. This is best represented by the Phyllodoce subassociation occurring on drier sites. Another important cause for the occurrence of these ericaceous species is the well known adaptation of these so called "peinomorphic" (=starvationshaped) plants for nitrogen poor conditions (Ellenberg 1986), which are likely to be found in these stands. What seems to be an adaptation to drought conditions is at least in part a morphological reaction to the low nitrogen level in the cold and wet peat soils which have little microbiotic activity to recycle available nitrogen. On the contrary much of the nitrogen gets trapped in the accumulating organic layer. The floristic richness of these stands seems to contradict the presumed poor nutrient situation. Detailed investigation of the available nutrients would be needed to solve this question.

Soils: Soils in this unit are mostly pure organic heath peats. In this respect, the two Kalmia subassociations are somewhat different. The pedicularetosum-streambank variant has a much higher silt content through all horizons which is resulting from springtime flooding of the sites, with subsequent deposition of mineral materials getting trapped in the vegetation layer. Therefore, a slightly better overall nutrient supply is likely to be present in this variant, even though the limiting nitrogen is not likely to be influenced noticeably by this. Still the number of species in this variant suggests some influence. The streambank soils are usually developing on top of silty, sandy or gravelly C-horizons. Soils of the Phyllodoce variant are more purely organic peats with no or little noticable mineral contents in the $\mathrm{A}_{\mathrm{h}}$-horizon and often are based on shallow bedrock.

Vegetation: This community is a floristically rich heath community, dominated by the dwarf shrub species Kalmia microphylla, Phyllodoce glanduliflora and Phyllodoce empetriformis. It is noteworthy, that Phyllodoce glanduliflora is a differential taxon for the drier variant whereas Phyllodoce empetriformis turned out to be more constant in the moss rich variant. This pattern reflects the general distribution pattern of the two species, with P. empetriformis being more westerly oriented in the moister parts of the northern Rockies and the western Mountains whereas P. glanduliflora is mainly found in the eastern part of the northern Rockies. It needs to be mentioned that the heath character of this community is not as pronounced as it is in some other units. The number of species is high in the present unit and many of them, mainly graminoids and forbs, attribute a meadow-like character to this community.

Especially in the wetter variant, Salix arctica becomes very important and dominates some of the sites. It has observed that the occurrence of the hemiparasitic Castilleja occidentalis is strongly correlated with the presence of its presumed host Salix arctica, this couple being characteristic for the 
Aulacomnio-Kalmietum. Adding to the floristic richness of this community is the presence of many of the widespread, non-diagnostic high elevation wetland species. A good but not very constant character species is Gaultheria humifusa which has only been found in this community and the closely related Sibbaldio-Phyllodocetum kalmietosum.

Mosses are a predominant element of this unit with Aulacomnium palustre being the most frequent and often most covering species. It can make up for more than half of the plot surface and in those cases strongly dominates the aspect of the plots with its typical bright yellowish green coloration. Other important moss species are Bryum spp. which are represented by B. pseudotriquetrum and $B$. weigelii. The other important moss species are restricted to the moss-rich variant and will be treated later on. Lichens do not assume greater importance except for some Cladonia species in the Phyllodoce variant.

Successional trends have not been observed in the Kalmia-bearing communities and disturbance is not important except for spring-time flooding in the moister variant and occasional rodent activity.

Syntaxonomy: The community has strong affinities towards Trollio-Parnassietum on the one hand, and towards the drier Phyllodoce heaths, mainly Sibbaldio-Phyllodocetum kalmietosum, on the other hand. Also some resemblance exists towards the Caricetum nigricantis into which all of these variants can grade locally. The Salix arctica variant without Kalmia was included here for reasons given below.

Distribution: Most samples of this community have been gathered in the well developed and easily accessible subalpine meadows at Logan Pass in the center of Glacier National Park. Few others have been gathered not much further south in the Twin Lakes basin and some in the northern reaches of the Park at Gyrfalcon Lake and in the Boulder Pass area. This moisture dependent community is thus found mainly in the less continental, western parts of Glacier's subalpine and low alpine zones. Similar rich heath communities have not been described in literature so far, but the community's range very likely goes beyond the area of this study, especially to the north. I have observed very similar, if not identical communities in the Cabinet Mountains near the Idaho border. This community is also similar to the Sphagno-Kalmietum microphyllae described from northwestern Montana (T. Spribille, in press).

Literature: Even though this type is most likely more widespread in the Rockies, it has not received much attention in the literature so far.

Archer (1963), Brooke et al. (1970) and Brett et al. (1998) mention ecologically similar moderately chionophilous Cassiope-Phyllodoce communities from the coastal mountains which share surprisingly few species. Those are mainly Phyllodoce empetriformis, Gaultheria humifusa, Bryum sp., Hieracium gracile, Carex nigricans and Vahlodea atropurpurea. Antennaria alpina, Juncus drummondii and Leptarrhena pyrolifolia occur in smaller quantities. The species number per plot is also much smaller in the Canadian samples. The same applies for the Cassiope-Phyllodoce communities given by Achuff \& Corns (1982), Achuff \& Dudynski (1984), Achuff et al. (1984), Achuff et al. (1993) for Albertan and British Columbian National Parks. The sedge meadow species list given by Brink (1959) from Garibaldi Provincial Park, B.C., has some of the species present here, but can not be compared exactly. The Salix barrattiana association reported by Beder (1967) has some affinities to the Philonotis variant of this community. 


\section{SUBASSOCIATION: Aulacomnio-Kalmietum microphyllae phyllodocetosum glanduliflorae \\ - Yellow Mountain Heather-subassociation \\ Nomenclatural Type: Table 27 relevé 413}

Plots: $127,394,413,610,612,645,649,744 \quad(n=8)$

\section{Differential species: Phyllodoce glanduliflora}

This subassociation is conspicuously dominated by mountain heather. It occupies the more exposed sites within the moist subalpine meadows with Tofieldia and Parnassia. These are the edges and ridges of the mostly terraced subalpine landscapes. These ever so slightly raised microsites get blownoff their snow cover earlier, a fact easily observed every summer during the melting period on the Hanging Gardens at Logan Pass. The dark dwarf shrub-covered ridges are the first to emerge from the receeding snow cover. The most exposed edges belong to more xerophytic true Phyllodoce community, whereas this syntaxon comprises the moister parts forming a transition towards the moister and later melting concave parts of the terraced or undulating slopes.

This subassociation is very close to the Phyllodocetum glanduliflorae kalmietosum (Kalmia microphylla subassociation of the Sibbaldio-Phyllodocetum glanduliflorae), which was separated from this syntaxon for reasons discussed under that vegetation unit.

\section{SUBASSOCIATION: Aulacomnio-Kalmietum microphyllae pedicularetosum groenlandicae - Elephant's Head streambank subassociation}

Nomenclatural Type: Table 27 relevé 622

Plots: $122,123,527,569,572,573,574,579,580,584,588,622 \quad(\mathrm{n}=12)$

Differential species: Leptarrhena pyrolifolia, Pedicularis groenlandica, Vahlodea atropurpurea, Salix commutata, Sanionia uncinata, Bryum weigelii, Brachythecium sp., Scapania paludosa, Pohlia sp., (Equisetum arvense, Philonotis fontana)

The Pedicularis subassociation is confined mainly to streambank sites and is wetter than the Phyllodoce subassociation. Spring flooding is likely to occur here and might result in a different nutrient situation due to washed-in material. As mentioned earlier, Phyllodoce empetriformis largely replaces $P$. glanduliflora in this subunit. With Salix commutata, another shrubby species is frequently present in this syntaxon. The common subalpine Salix thickets which have been observed at Logan Pass and Fifty Mountain have not been sampled, but very likely have strong ties to this unit. They might represent a shrubby and less forb species-rich facies of this community. A highly diagnostic species of the present syntaxon is Leptarrhena pyrolifolia with its conspicuous dark-green and shiny creeping rosettes.

Mosses are very important in this subassociation, and even though the total moss cover is similarily variable in this subassociation and in the Phyllodoce variant, bryophyte diversity is much higher in this unit. The table shows a weak subdivision of this unit into a floristically richer subvariant differentiated by Senecio triangularis, Arnica diversifolia, Pedicularis bracteosa, Arnica mollis, Vahlodea atropurpurea, Castilleja rhexifolia, and Campylium stellatum. This seems to grow on slightly steeper sites with a denser vascular plant cover resulting in a higher litter cover. It is restrained here from subdividing the subassociation since more data would be needed for this attempt. 


\section{SUBASSOCIATION: Aulacomnio-Kalmietum microphyllae salicetosum arcticae - Arctic Willow-subassociation}

Nomenclatural Type: Table 27 relevé 611

Plots: $266,409,563,565,611,613,631 \quad(n=7)$

Diagnostic species: Salix arctica, Aulacomnium palustre, Philonotis fontana, (Polygonum viviparum, Ranunculus eschscholtzii)

This subassociation is an impoverished subassociation, even lacking the character species Kalmia microphylla which is replaced by a highly present Salix arctica dwarf shrub layer and an aspect dominated by an almost complete moss cover. Most important mosses are again Aulacomnium palustre, Philonotis fontana and Bryum species. The physiognomical difference is very obvious, because, lacking Kalmia and mostly also Phyllodoce species, this subassociation is not a heath community.

Syntaxonomy: The syntaxonomical position of this unit as a subassociation of the AulacomnioKalmietum is somewhat unusual, if one considers the vegetation table given. It is unusual is that the three species Kalmia, Gaultheria and Danthonia, which characterize the association, are missing in the present subassociation salicetosum. Uncommon is furthermore, that all species characterizing the subassociation constantly occur throughout the association. This should normally result in the creation of an association being defined by this species group (e.g. as an "Aulacomnio-Salicetum"). The Kalmia dominated heath communities would consequently be treated as subassociation.

The unit is nevertheless retained in this association since no exclusive characteristic species for a separate association are present and the overall floristic composition does not differ noticeably from the association.

The dominance of the arctic willow and the overall different physiognomy of this community are strong, differentiating characters. This applies also for the lack of Kalmia and Gaultheria (and a number of other species), which drop out under the longer snow covered conditions to the competitive advantage of Salix arctica. But in a floristic classification this alone does no suffice as a base for a well defined association. The treatment as an ecologically more extreme, species-poor chionophilic subassociation is considered appropriate.

Furthermore, at least some of the site individuals of this subassociation are likely to represent early stages of the other two subassociations, thus they are syngenetically related. This is likely to be the case for those stands which have relatively little developed young soils on wet scree, sand, loam or silt, whereas some stands of this syntaxon already bear considerable humus layers reflecting a more advanced soil development. The number of vascular plant species sometimes but not always reflects the developmental stage within this unit. For this reason, the creation of an unranked "AulacomnioSalicetum arcticae" is considered unnecessary and not justified. The decreased number of plant species in this unit is most likely due to the more extreme snow conditions. This subassociation is the most chionophilic one within this association and it is transitional to the Caricetalia nigricantis.

The Kalmia heath units on the other hand are floristically and physiognomically distinct enough to warrant recognition above the level of a subassociation which is why this association has been named after them. 


\title{
3.4.4.2. ASSOCIATION: Trollio-Parnassietum fimbriatae ass. nov. - Globeflower-Parnassia - wet subalpine and low alpine meadow community
}

\author{
Nomenclatural Type: Table 27 relevé 425 \\ Plots: $117,118,398,410,421,422,423,424,425,427,518,528,546,547,561,629,732 \quad(\mathrm{n}=17)$
}

\begin{abstract}
Character species: (Allium schoenoprasum)
Differential species: Aster foliaceus, Zigadenus elegans, Veratrum eschscholtzii, (Carex podocarpa)

Constant species: Tofieldia glutinosa, Hypericum formosum, Senecio triangularis, Aster foliaceus, Bryum sp., Allium schoenoprasum, Arnica mollis, Arnica diversifolia, Veronica wormskjoldii, Philonotis fontana
\end{abstract}

General aspect: This lush and densely vegetated forb community is moderately common in the subalpine to lower alpine along streambanks and other wet, often seeped areas like springs, seeped slopes or outcrops and benches with somewhat impeded drainage. It is one of the richer communities with a very colorful flowering aspect in late July and August. It is most easily recognized by the bright flower display of the white buttercup-shaped Trollius flowers in combination with the yellow stars of Senecio triangularis, the Arnicas and the conspicuously contrasting purplish-black, drooping spikelets of Carex podocarpa. As opposed to the higher growing tall shrub communities, this one is much lower in stature and a number of smaller species like Parnassia fimbriata, Tofieldia glutinosa, Hypericum formosum and Veronica wormskjoldii contribute greatly to the flowering aspect.

Topography: This meadow type occurs at elevations from $1960 \mathrm{~m}$ to $2320 \mathrm{~m}$. Most sites have southerly to westerly aspects. As a strongly moisture dependent community it is mostly restricted to the west slope of the Continental Divide but occurs scattered in appropriate habitat east of the Divide, mainly in glacial cirques.

Wind exposure/Moisture conditions: Since moisture is the predominant factor, slope steepness does not play a major role and varies from $1^{\circ}$ to $47^{\circ}$. Bedrock material can be limestone as well as green argillite, red argillite or igneous diorite. Winter snow cover of the sites is reasonable owing to the concave relief forms or little exposure to wind. Resulting is a snow pack that contributes to the ample water supply which these habitats receive.

Soils: Soils are rich in humus in the $\mathrm{A}_{\mathrm{h}}$-horizon as a result of cool, water saturated soil conditions which impede decomposition of organic matter. Often these soils have a peaty, soapy, dark black consistence with little to no skeletal content. Root density in the $A_{h}$ can be very high, adding a fibrous texture. The silt content is hard to estimate in the field but is likely to be quite high which often becomes more obvious towards the lower, less humus-darkened part of the $A_{h}$. As in other streambank communities the silt content most likely results from washed-in material deposited during spring flooding of the sites. C-horizons in streambank situations are usually sandy to gravelly layers which can be water-saturated through much of the year, resulting in quickly water-filled soil pits.

Vegetation: This community is not very well defined in terms of good character species. Locally Allium schoenoprasum is somewhat characteristic for this community but the species also occurs in a subassociation of the Zigadeno-Caricetum scirpideae, which in fact has been named for it.

The structurally important species Trollius laxus, Parnassia fimbriata and Carex podocarpa all occur in other syntaxa as well and thus are not exclusive for this unit. Even so, they are much more constant 
and dominant in this community. As a species group they are highly diagnostic for this syntaxon and are therefore given here as character species.

Vegetation usually covers more that $80 \%$ in an evenly spread layer, and litter cover varies from very little to $80 \%$. Annual biomass production is estimated to be reasonably high for this elevation. As expected for a wetland forb community, moss cover is mostly very high with the most important species being Bryum spp., Philonotis fontana, Brachythecium sp., Campylium stellatum and Palustriella commutata, the latter two being confined to what is considered to be a subunit. Lichens are mostly lacking. Like most wetland communities, being dominated by moisture as the overruling factor, this is considered an azonal community. Disturbance is not important and successional trends have not been observed.

Most sites of this community are fairly small, often as a band along a creek or as patches filling seepage areas. Adjacent communities can be other streambank communities, Salix arctica meadows, willow- or green alder thickets or Carex lenticularis wetland. Delineation is often difficult since gradual transitions are frequent.

Syntaxonomy: Synsystematically, this community has close ties to all other wet meadow communities which share Parnassia fimbriata and Philonotis fontana. As can be seen from the synoptic table Tab. 5 these are the Mimulus lewisii streambank communities on the one hand and the Tofieldio-Trollion meadow communities sharing Trollius laxus, Tofieldia glutinosa, Agrostis thurberiana and Carex podocarpa on the other hand. Compared with the neighboring AulacomnioKalmietum this association does not have any exclusive character species. Nevertheless, it almost completely lacks all of the dwarf shrub species diagnostic for the Aulacomnio-Kalmietum. Presumably a more constant moisture supply results in the dominance of the name-giving mesophytic forb species.

Literature: Moist meadow types have been mentioned by a number of authors from the Rocky Mountains and the Cascades. Still most of those types are based on very little data and the definitions of the units seem to be too broad to reveal a detailed insight in the relationships with the community treated here. A table presented by Broad (1973, Tab. 25) at least partly seems to represent a similar syntaxon.

A part of Komárková's Ligustico-Trollietum laxi (Komárková 1979), which according to Komárková's table (Komárková: Tab. 12) seems to be in need of further subdivision, also has ties to the unit treated here, even though the overall floristic similarity is diminished by a number of different species. A list of species presented by Brink (1959) from sedge meadows with high water table but without flooding has some common species with this community.

A study from the Akamina Pass area in southeastern BC, not far from the area of the present study, has one sample in the so called Arnica cirque community which is most likely belonging to this syntaxon (Polster 1972, plot no.63). Also a subunit of the Arnica-Valeriana cirque community of the same study is very close to this syntaxon, despite some differences possibly resulting from the subalpine setting of Polster's study.

The table presented here suggests a subdivision of this association into a unit of presumably slightly richer sites being characterized by Palustriella commutata, Campylium stellatum, Zigadenus elegans and Deschampsia cespitosa and a typicum variant. The differential species groups seem too heterogeneous to make these units subassociations. 


\section{VARIANT: Trollio-Parnassietum fimbriatae typicum}

Nomenclatural Type: Table 27 relevé 425

Plots: $410,422,425,528,546,547,561,629,732 \quad(n=9)$

Differential species: Mimulus lewisii, Castilleja rhexifolia, Habenaria saccata, Erigeron peregrinus, (Aulacomnium palustre)

The typicum variant does have few differential species only. Mimulus lewisii, Castilleja rhexifolia and Habenaria illustrate the close relation to the Valerianetalia communities, in particular the Senecio -Mimuletum lewisii streambank community. The subassociation habenarietosum of the latter association is in fact very close to this association.

Slightly differentiating is also the higher cover of Carex podocarpa s.1., Trollius laxus var. albiflorus, Aster foliaceus and Arnica diversifolia, giving this variant a lusher forb meadow aspect. Juncus mertensianus, Phleum alpinum and Aulacomnium palustre are differentiating but not very constant species in this subunit. Carex nigricans is more constant in this unit but can also occur as an important constituent in the other variant. The typicum variant is most commonly found along or near streamlets.

\section{VARIANT: Trollio-Parnassietum fimbriatae - Variant of Palustriella commutata Nomenclatural Type: Table 27 relevé 421}

Plots: $117,118,398,421,423,424,427,518 \quad(\mathrm{n}=8)$

Differential species: Palustriella commutata, Campylium stellatum, Zigadenus elegans and Deschampsia cespitosa.

Even though this variant is clearly differentiated by its differential species group, an ecological difference is not easily detectable. The variant tends to be more confined to rocky outcrop seepages in the subalpine often not far from or at timberline or even below it. The plots with Carex scirpoidea (nos. 117, 118, 518) represent a facies of this community which is related to the Zigadenus elegansCarex scirpoidea community. 


\section{Valerianetalia: unclassified community in the order:}

\section{Fragaria virginiana-Carex haydeniana lush subalpine meadow}

Nomenclatural Type: Table 28 relevé 182

Plots: $176,180,181,182,397,399,40,401,402 \quad(n=9)$

Character species: Fragaria virginiana, Carex haydeniana,

Other Diagnostic species: Arnica diversifolia, Poa cusickii, Poa alpina, Achillea millefolium. Trisetum spicatum, Ranunculus eschscholtzii, Sibbaldia procumbens, Hypericum formosum, Phleum alpinum, Aster foliaceus, Poa secunda, Epilobium alpinum, Pedicularis contorta, Penstemon ellipticus

General aspect: This unit is a very lush meadow type which can be found as a vividly green border at the lower end of subalpine to low alpine colluvial slopes. An irregular vegetation cover with some lower growing areas and even open spots and scattered boulders is typical for this community.

Topography: The sites of these meadows are lower slopes and slope bases with prolonged snow cover. Boulders and smaller rocks in and around these meadows evidence a high degree of disturbance by rock debris falling from the cliffs above. Bedrock outcrops are also common on or near the plots. The slopes are of varying steepness from 5 to $36^{\circ}$, mostly above $25^{\circ}$. Aspect has been found to be westerly along the west slope of the Continental Divide and with the same exposition also in the adjacent Lunch Creek Valley.

Geology/Parent Material: This community has been found on limestone in the Lunch Creek basin and on green argillite along the Continental Divide. Whether the few observed floristic differences can be attributed to the difference in bedrock cannot be said without more data from other locations. Continuous supply of fresh rock debris is likely to provide these sites with sufficient amounts of nutrients. Together with a good moisture availability this results in very favorable growing conditions.

Wind exposure/Snow duration: Wind exposure of most sites is estimated to be high to moderate. Due to the position in the lower half of the slopes, large amounts of snow are likely to accumulate added to by avalanche deposition. A reasonable to long snow cover was estimated for all sites, evidenced by the constant presence of some chionophilic species like Sibbaldia procumbens and Ranunculus eschscholtzii which dominate the early aspects of this community during June and July.

Moisture conditions: Moisture availability in this community is ample as long as snow is available on the slopes above, which can be the case until late July or even into August. Dry conditions are likely to occur not before late fall. The amount of organic material in the soils is fairly variable, resulting in different moisture storage capacities of the stands. Especially sites with less organic soil content and better drainage are likely to be subject to dry conditions in precipitation poor highpressure periods in late summer. 
Soils: The relatively long snow cover on the sites together with a moderate to high degree of disturbance slows down soil development processes. Even though the vegetation in this community has developed to an advanced stage with a complex vegetation structure, soils are not well developed. Soil movement on the steep and periodically well water-supplied soils probably contributes to the weak profile development.

Vegetation: A floristic mix of species which are diagnostic for different orders characterizes this meadow type. It does not have any exclusive character species. For a vegetation type of reasonably late melting sites, the productivity is quite remarkable at least in years with normal snow duration. The late development still allows for a pronounced change in aspect through the season with a lower growing early summer aspect dominated by the small chionopilous species and a lush and tall growing late summer and fall aspect. As opposed to true tall herb communities this one usually is quite irregular in its cover, which is interpreted as a result of disturbance. Gaps in the vegetation are common but they do not result in a higher cryptgam cover, as could be expected under less disturbed conditions.

Tortula norvegica is the only common bryophyte and lichens occur very sparsely only, being mostly limited to epilithic species on larger boulders.

Syntaxonomy: This meadow type has relations to different communities in the area and can hardly be placed closer to one or the other unit. Most important are ties to the late melting Valerianetalia meadows which are represented in the area by the Luzulo-Erythronietum. On the other hand there are ties to the snowbed meadows with Sibbaldia procumbens and Ranunculus eschscholtzii. Disturbance as an important agent in this community results in similarities with talus slope communities, which is evidenced not only by the boulder strewn aspect, but floristically by the presence of Penstemon ellipticus, Juncus drummondii and Agropyron latiglume.

Based on the forb rich physiognomy of the stands this community is placed in the order Valerianetalia sitchensis. Because of its local distribution it has so far not been assigned association rank. The absence of exclusive character species supports this treatment.

Distribution: This meadow type has been found on both sides along the Continental Divide. All samples are from a very limited area though in the central portion of the park not far from Logan Pass (Highline Trail, Lunch Creek). At least fragments of this community have been found elsewhere in the study area. Until a wider distribution has been ascertained, this unit is considered a local community.

Literature: Similar vegetation types have not been found in the literature. Some similarity exists to the "intermediate meadow" described by Kuchar (1973) which is probably closer to other, more widespread Valerianetalia meadows. Cooper et al. (1997) mention Carex haydeniana ("C. haydenii") from a number of community types which are also somewhat similar in their tendency to favor chionophilic conditions. All of these community are nevertheless different in their overall floristic composition. 


\section{Association Table 28}

\section{Fragaria virginiana-Carex haydeniana community}

\begin{tabular}{|c|c|c|c|c|c|c|c|c|c|c|}
\hline Location & GOT & $\mathrm{HiT}$ & HiT & $\mathrm{HiT}$ & Lun & Lun & Lun & Lun & Lun & \\
\hline Plot-Number & 176 & 180 & 181 & 182 & 397 & 399 & 400 & 401 & 402 & \\
\hline Elevation $[\mathrm{m} / 10]$ & 227 & 212 & 214 & 215 & 202 & 207 & 207 & 207 & 209 & \\
\hline Aspect $\left[{ }^{\circ}\right]$ & 230 & 230 & 210 & 240 & 170 & 220 & 225 & 210 & 162 & \\
\hline Slope $\left[{ }^{\circ}\right]$ & 36 & 18 & - & 26 & 3 & 26 & 32 & 29 & 15 & \\
\hline Paremt Material & GAM & GAM & Mix & Mix & LmM & LmM & DLi & DLi & Lim & \\
\hline Rocks $>6 \mathrm{~cm}$ & 5 & 70 & 85 & 70 & .5 & 15 & 55 & 25 & 13 & \\
\hline Rocks $<6 \mathrm{~cm}$ & 2 & 5 & 10 & 10 & 0 & 20 & 25 & 20 & 2 & \\
\hline Fine Soil $<1 \mathrm{~mm}$ & - & 10 & 4 & 4 & 1 & - & 5 & 8 & .5 & \\
\hline Litter Cover [\%] & 80 & 23 & 2 & 10 & 75 & 30 & 10 & 25 & 75 & \\
\hline Vascular Plant Cover [\%] & 90 & 25 & 18 & 30 & 85 & 55 & 18 & 35 & 80 & \\
\hline Moss Cover [\%] & 20 & 15 & 3 & 10 & 0 & .1 & 2 & 2 & .5 & \\
\hline Lichen Cover $[\%]$ & 0 & 3 & $<.1$ & 0 & 0 & .1 & 0 & .5 & 0 & \\
\hline Vegetation Pattern & eve & eve & eve & eve & eve & eve & $\mathrm{e} / \mathrm{e}$ & eve & eve & \\
\hline Plot-size $\left[\mathrm{m}^{2}\right]$ & 16 & 16 & 16 & 16 & 16 & 16 & 16 & 16 & 16 & \\
\hline Number & 1 & 2 & 3 & 4 & 5 & 6 & 7 & 8 & 9 & Constancy \\
\hline Fragaria virginiana & + & 1 & 1 & 1 & 2 & 1 & . & + & 2 & V \\
\hline Carex haydeniana & r & + & + & + & + & + & . & + & + & V \\
\hline Arnica diversifolia & 2 & + & 1 & 2 & 2 & 1 & 1 & 2 & + & $\mathrm{V}$ \\
\hline Poa cusickii & + & + & + & + & + & + & + & $x$ & + & V \\
\hline Poa alpina & + & + & + & + & + & + & + & + & + & $\mathrm{V}$ \\
\hline Achillea millefolium & + & + & + & + & + & + & + & + & 1 & $\mathrm{~V}$ \\
\hline Trisetum spicatum & . & + & + & + & + & + & + & + & + & V \\
\hline Ranunculus eschscholtzii & . & + & + & + & + & . & + & + & $r$ & IV \\
\hline Sibbaldia procumbens & . & + & . & ad & + & + & + & + & + & IV \\
\hline Hypericum formosum & . & + & . & 1 & + & 1 & 1 & 2 & + & IV \\
\hline Phleum alpinum & + & + & . & + & + & $r$ & + & . & + & IV \\
\hline Aster foliaceus & 1 & . & . & . & 1 & 2 & + & 1 & + & IV \\
\hline Poa secunda & + & . & . & + & . & + & + & + & $r$ & IV \\
\hline Epilobium alpinum & + & + & + & + & . & . & r & + & . & IV \\
\hline Pedicularis contorta & . & $r$ & . & + & + & . & ad & ad & r & IV \\
\hline Penstemon ellipticus & . & $r$ & + & ad & . & $r$ & $r$ & ad & . & IV \\
\hline Juncus parryi & . & 2 & + & . & + & + & . & + & . & III \\
\hline Erigeron peregrinus & + & . & . & . & 1 & + & . & . & + & III \\
\hline Sedum lanceolatum & . & + & + & + & . & . & r & . & $r$ & III \\
\hline Senecio cymbalarioides & + & + & + & + & . & . & . & . & . & III \\
\hline Agropyron latiglume & + & + & + & + & . & . & . & . & . & III \\
\hline Veronica wormskjoldii & + & + & + & + & r & . & . & . & . & III \\
\hline Anemone multifida & . & + & + & + & $r$ & . & . & . & . & III \\
\hline Valeriana sitchensis & . & + & + & + & + & + & . & . & . & III \\
\hline Carex rossii & . & + & + & + & + & r & . & . & . & III \\
\hline Senecio triangularis & + & . & + & . & . & + & $\mathrm{ad}$ & . & . & III \\
\hline Potentilla diversifolia & . & . & . & + & + & + & + & . & + & III \\
\hline Luzula hitchcockii & . & . & . & $r$ & 1 & 2 & . & . & 1 & III \\
\hline Juncus drummondii & . & . & . & + & $r$ & $r$ & . & r & . & III \\
\hline
\end{tabular}




\section{Association Table 28 (cont.):}

\begin{tabular}{|c|c|c|c|c|c|c|c|c|c|c|}
\hline Number & 1 & 2 & 3 & 4 & 5 & 6 & 7 & 8 & 9 & Constancy \\
\hline \multicolumn{11}{|l|}{ Cryptogams: } \\
\hline Tortula norvegica & $\mathrm{p}$ & $\mathrm{p}$ & $\mathrm{p}$ & $p$ & . & $\mathrm{p}$ & $\mathrm{p}$ & $\mathrm{p}$ & $\mathrm{p}$ & V \\
\hline Bryum sp. & . & $\mathrm{p}$ & $p$ & $p$ & . & . & $\mathrm{p}$ & $\mathrm{p}$ & . & III \\
\hline Brachythecium sp. & $\mathrm{p}$ & . & . & $p$ & . & . & $\mathrm{p}$ & $\mathrm{p}$ & . & III \\
\hline Cladonia sp. & . & $p$ & $p$ & $p$ & . & $\mathrm{p}$ & . & $\mathrm{p}$ & . & III \\
\hline
\end{tabular}

\section{Minor species:}

Arabis cf. drummondii 3:r, 6:+ , 7:+ ; Hedysarum sulphurescens 5:+ , 6:r , 7:r ; Gentiana calycosa 5:+ , 6:r , 9:+ ; Salix arctica $1: 1$; Parnassia fimbriata 1:1 ; Carex spectabilis $1: 1$; Zigadenus elegans 1:+ ; Anemone parviflora 1:+ ; Sagina nivalis 1:+ ; Polygonum viviparum 1:+ ; Taraxacum sp. 1:r ; Saxifraga lyallii 1:ad; Androsace septentrionalis 2:r , 3:r ; Salix nivalis 2:+ ; Botrychium simplex 2:+ , 9:r ; Antennaria alpina 2:+ ; Polystichum lonchitis 2:r , 4:r ; Arnica cf. mollis 2:+; Antennaria cf. microphylla 2:r; Vaccinium scoparium 2:ad; Vaccinium membranaceum 2:ad; Castilleja miniata 3:+ , 5:+ ; Phacelia lyallii 3:r , 7:ad; Carex podocarpa 5:2 , 9:2 ; Arenaria capillaris 5:+ , 9:r ; Pulsatilla occidentalis 5:+ , 9:r ; Carex phaeocephala 5:+ , 6:+ ; Aquilegia flavescens 5:+ , 7:+ ; Arabis nuttallii 5:r , 7:+ ; Veratrum viride 5:r , 7:ad; Elymus glaucus 5:+ ; Danthonia intermedia 5:+ ; Erythronium grandiflorum 5:+ ; Castilleja rhexifolia 4:+ , 8:+ ; Galium boreale 5:+ , 9:+ ; Hackelia floribunda 6:r , 8:r ; Luzula spicata 7:+ ; Allium schoenoprasum 7:r ; Epilobium latifolium 7:r ; Carex scirpoidea 7:r , 8:r ; Senecio cymbalarioides 7:r ; Cirsium hookerianum 7:ad, 9:r ; Mitella breweri 7:ad; Draba sp. 8:r ; Saxifraga occidentalis 8:r ; Eriogonum flavum 8:+ ; Thalictrum occidentale 9:r ; Carex cf. paysonis/spectabilis 9:x ; Carex nigricans 9:+ ;

Bryophytes: Barbula sp. 1:p , 7:p , 8:p ; Lophozia sp. 1:p ; Marchantia polymorpha 1:p ; Bryum pseudotriquetrum 1:p ; Tortula ruralis 1:p ; Philonotis fontana 1:p ; Brachythecium cf. albicans 1:p; Cephalozia? sp. 2:p , 4:p ; Lescuraea patens 2:p , 4:p ; Desmatodon latifolius 1:p ; Bryum caespiticium 2:p , 4:p ; Brachythecium cf. collinum 2:p

Lichens: Peltigera sp. 3:p , 9:p ; Psora sp. 2:p ; Acarospora fuscata 2:p ; Placynthiella sp. 2:p ; Peltigera rufescens 2:p ; Lecideine epilithic crust 5:p ; Lecidea atrobrunnea 5:p ; Lecanora cf. thomsonii 5:p ; Lecanora polytropa 5:p ; Rhizocarpon geographicum agg. 5:p ; Umbilicaria krascheninnikovii 5:p ; Lecidea umbonata 5:p ; 


\section{Unclassified communities:}

\section{ASSOCIATION: Hieracio albertini-Caricetum geyeri ass. nov. - Western Hawkweed-Elk Sedge ravine community}

Nomenclatural Type: Table 29 relevé 251

Plots: $233,239,240,241,247,251,252,294,478,761 \quad(n=10)$

Character species: Carex geyeri, Hieracium albertinum, Lomatium dissectum, (Sedum stenopetalum, Antennaria microphylla)

Differential species: Senecio megacephalus, Calochortus apiculatus, Erigeron speciosus, Cirsium hookerianum, Aquilegia flavescens, Spiraea betulifolia, Peltigera didactyla, Galium boreale, Selaginella wallacei

General aspect: The aspect of this community is dominated by varying amounts of relatively tall forb species, building a layer above the Carex geyeri dominated lower herb/grass-layer which is sometimes co dominated by Festuca idahoensis. Besides the conspicuous vegetative cover, a high percentage of open soil or rock is typical for this community. Noteworthy is the spectacular flowering aspect of this unit in summer, stressing the yellowish and orange flower colors of Hieracium albertinum, Senecio megacephalus, Arnica rydbergii, Eriogonum flavum, Sedum stenopetalum, Lomatium dissectum, Cirsium hookerianum and Aquilegia flavescens. Whitish colors are presented by Calochortus apiculatus, Arenaria capillaris, Antennaria microphylla, Achillea millefolium, Cerastium arvense, Galium boreale and Silene parryi.

Topography: This community is typically found on the steep gully-slopes of intermittent or perennial streamlets in the lower alpine and subalpine zones. The streambeds often cut deeply into the colluvial valley-slopes, having steep slope angles from $18^{\circ}$ to $33^{\circ}$, resulting in unstable surface conditions. Scree and smaller rock fractions cover up to $50 \%$ of the surface and open soil can be present up to $10 \%$. Scattered loose talus-rocks are common and represent a recurring source of disturbance. The vegetation-layer can be very even but tends to be cracked and fragmented to various degrees, depending on the stability conditions of the particular site. Even patchy vegetation patterns can occur with increasing instability. The vegetation covers between $15 \%$ and $75 \%$, depending mostly on slope stability.

Aspect of this community has been found to be mostly SSW to W, sometimes E. The elevation in the area ranges from 1770 to $2200 \mathrm{~m}$ a.s.1.

Geology: Found on colluvial slopes with mostly loose scree of green and red argillite with little other rock types mixed in.

Soils: Soil development is very little in this community. Much of the organic and fine mineral deposition is washed of the steep ravine slopes leaving little material for an advanced soil development. Pockets of soil can accumulate around tufts of vegetation, mainly around grass- and sedge tufts or clusters of tall herb. 
Wind exposure/Snow cover: Wind exposure is little to medium due the sheltered position of the gullies below the surface level of the slope which the gullies cut into. Larger growing plants, unusual for most other high elevation communities, can establish under such protected conditions and account for many of the typical plants of this community. The stream-cuts represent depressions in the valley slopes, which in winter-time largely fill up with snow or at least bear large snow-drifts accumulating on the upper and middle parts of the cut-slopes. Snow accumulation is guaranteed and prolonged on these sites making this the predominant ecological factor for this plant community.

Moisture conditions: Very seasonal moisture conditions are characteristic for this unit. After the late snow melt and mostly well into August moisture supply is ample by snow melt and saturated fine soil storage. Later in fall drier conditions can occur especially on sites exposed to strong solar radiation which often is the case given the southerly aspect of many sites. Wind desiccation is not likely to be an important factor in the sheltered site situations. Good drainage is expected on the sites. The role of water storage in deeper fine soil horizons might be important.

Floristical differentiation: With Carex geyeri, Hieracium albertinum and Lomatium dissectum a highly constant and diagnostic species group identifies this community through much of the study area. Hieracium albertinum and Lomatium dissectum are very much confined to this community in the area, thus making good character species at least in the study area. Many other species of the differential species group are common in the subalpine plant communities of the study. Unfortunately these subalpine units, often dominated by tall growing mesophytic species, have not been included in the present study. Thus further research is necessary on this subject in order to elucidate the floristic relationships with these tall herb communities.

Sedum stenopetalum is very characteristic for this community but does occur in other open colluvial slope units. Comandra umbellata has also been found only in this community but is not as exclusive as it seems in the present dataset. The diagnostic value of the tiny species Polygonum minimum, which has been found in this unit more constant than in any other, remains doubtful at this point.

Most other species of the differential species group do occur in other communities and differentiate mainly against other slope communities and against communities of the Arenario-Festucetalia brachyphyllae.

As expected for this unstable and reasonably winter-snow covered community, lichen cover is negligible even though Cladonia pyxidata is commonly present. Moss cover in most cases is low also, but the fairly constant Polytrichum piliferum and sometimes Tortula ruralis and Desmatodon latifolius can reach considerable cover under stable surface conditions. 


\section{Association Table 29}

\section{Hieracio albertini-Caricetum geveri ass. nov.}

\begin{tabular}{|c|c|c|c|c|c|c|c|c|c|c|c|c|c|c|}
\hline & Location & Red & ApV & ApV & ApV & ApV & $\mathrm{ApV}$ & $\mathrm{ApV}$ & AIS & ApV & Bou & Pit & GNP & \\
\hline & Plot-Number & 294 & 252 & 251 & 241 & 233 & 239 & 240 & 478 & 247 & 761 & 702 & 650 & \\
\hline & Elevation $[\mathrm{m} / 10]$ & 219 & 190 & 191 & 183 & 188 & 178 & 179 & 177 & 203 & 192 & 219 & 215 & \\
\hline & Aspect $\left[{ }^{\circ}\right]$ & 200 & 90 & 75 & 200 & 180 & 200 & 200 & 170 & 200 & - & 180 & - & \\
\hline & Slope $\left[{ }^{\circ}\right]$ & 27 & 33 & 32 & 32 & 18 & 25 & 29 & 33 & 28 & - & 34 & - & \\
\hline & Parent material & $\mathrm{RAQ}$ & GA & GA & GAQ & GA & GA & GA & RG & $\mathrm{GA}$ & - & - & - & \\
\hline & Rocks $>6 \mathrm{~cm}$ & 6 & 3 & 9 & 10 & 6 & 3 & 9 & 1 & 3 & - & - & - & \\
\hline & Rocks $<6 \mathrm{~cm}$ & 11 & 4 & 12 & 28 & 25 & 45 & 35 & 2 & 53 & - & - & - & \\
\hline & Fine Soil & 7 & 10 & 10 & 1 & - & 4 & 5 & 2 & 10 & - & - & - & \\
\hline & Litter Cover [\%] & 67 & - & 50 & 35 & 58 & 7 & 8 & 65 & 25 & - & - & - & \\
\hline & Vascular Plant Cover [\%] & 70 & 62 & 33 & 60 & 30 & 20 & 25 & 75 & 15 & - & - & - & \\
\hline & Moss Cover [\%] & 4 & - & $<.1$ & 1 & 12 & 4 & 2 & .5 & 7 & - & - & - & \\
\hline & Lichen Cover [\%] & 1 & - & 0 & $<1$ & 8 & 1.5 & 10 & 0 & 1 & - & - & - & \\
\hline & Number & 1 & 2 & 3 & 4 & 5 & 6 & 7 & 8 & 9 & 10 & 11 & 12 & Constancy \\
\hline \multicolumn{14}{|c|}{ ASSOCIATION: Hieracio-Caricetum geyeri } & \\
\hline$A C$ & Carex qeveri & 2 & 3 & 3 & 3 & 3 & + & + & 4 & 2 & $x$ & 1 & $x$ & $\mathrm{~V}$ \\
\hline$A C$ & Hieracium albertinum & + & + & + & . & + & . & + & + & + & . & . & $x$ & IV \\
\hline$A C$ & Lomatium dissectum & + & . & + & + & 1 & + & + & 2 & . & . & 1 & $x$ & IV \\
\hline $\mathrm{AC}$ & Antennaria microphylla & . & $r$ & + & + & + & $r$ & + & . & $r$ & . & . & . & III \\
\hline Ad & Senecio megacephalus & + & $\mathrm{r}$ & + & + & . & . & . & + & + & . & + & . & II \\
\hline Ad & Sedum stenopetalum & $r$ & + & + & $r$ & + & + & + & + & + & . & . & $x$ & IV \\
\hline Ad & Calochortus apiculatus & . & + & + & + & + & + & + & . & . & $x$ & . & $x$ & IV \\
\hline $\mathrm{Ad}$ & Agropyron spicatum & . & + & + & + & + & 1 & + & + & . & . & . & . & III \\
\hline Ad & Aquilegia flavescens & . & $r$ & + & + & . & ad & ad & . & . & . & . & . & II \\
\hline Ad & Cerastium arvense & . & + & + & . & + & $r$ & $r$ & + & . & . & . & . & III \\
\hline $\mathrm{Ad}$ & Spiraea betulifolia & . & + & + & $r$ & . & . & + & + & . & . & . & . & II \\
\hline Ad & Cirsium hookerianum & . & ad & + & + & $r$ & $r$ & . & . & . & $r$ & $r$ & . & III \\
\hline $\mathrm{Ad}$ & Selaginella wallacei & & & $r$ & + & + & + & + & & & & & & 2 \\
\hline \multicolumn{15}{|c|}{ Provisional VARIANT of Silene parryi } \\
\hline (SAd) & Poa cusickii & + & & + & & . & . & . & . & 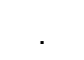 & . & . & . & 4 \\
\hline (SAd) & Silene parryi & + & + & + & $r$ & . & . & . & . & . & . & . & . & 4 \\
\hline (SAd) & Potentilla diversifolia & + & + & + & + & . & . & . & . & . & . & + & $x$ & 4 \\
\hline (SAd) & Arnica rydbergii & 2 & . & $r$ & + & . & . & . & . & . & . & . & . & 3 \\
\hline (SAd) & Castilleja miniata & . & + & + & 1 & . & . & . & . & . & . & . & . & 3 \\
\hline (SAd) & Pedicularis contorta & + & + & + & . & . & . & . & . & . & . & . & . & 3 \\
\hline & Sedum lanceolatum & + & + & r & . & . & . & . & . & + & . & . & . & 3 \\
\hline & Selaginella scopulorum & + & $r$ & r & . & + & . & . & . & . & . & . & . & 3 \\
\hline & Erigeron peregrinus & + & + & . & . & . & . & . & $r^{c f}$ & . & . & r & . & 2 \\
\hline & Aster foliaceus & & 1 & 1 & & . & . & . & . & . & $x$ & + & . & 2 \\
\hline \multicolumn{15}{|c|}{ Companion species } \\
\hline & Arenaria capillaris & 2 & + & + & 1 & + & $r$ & + & . & 1 & . & + & $x$ & IV \\
\hline & Eriogonum flavum & + & + & + & + & 1 & 1 & + & . & + & . & . & . & III \\
\hline & Achillea millefolium & + & + & + & $r$ & + & + & + & + & + & $x$ & + & $x$ & 4 \\
\hline & Campanula rotundifolia & . & + & + & + & + & . & + & + & + & . & . & . & III \\
\hline & Galium boreale & + & + & $r$ & + & + & . & + & + & + & . & + & $x$ & $4 \quad$ IV \\
\hline
\end{tabular}




\section{Association Table 29 (cont.):}

\begin{tabular}{|c|c|c|c|c|c|c|c|c|c|c|c|c|c|c|}
\hline Number & 1 & 2 & 3 & 4 & 5 & 6 & 7 & 8 & 9 & 10 & 11 & 12 & \multicolumn{2}{|c|}{ Constancy } \\
\hline Festuca scabrella & $r$ & 2 & + & . & . & . & . & $r$ & + & . & . & $x$ & 3 & II \\
\hline Festuca idahoensis & 1 & . & 1 & + & 1 & . & 1 & . & . & . & + & $x$ & 3 & III \\
\hline Erigeron speciosus & . & . & + & + & . & . & + & . & + & . & . & . & 2 & II \\
\hline Polygonum minimum & . & . & . & . & . & + & $r$ & + & . & . & . & . & . & II \\
\hline $\begin{array}{l}\text { Comandra umbellata } \\
\text { Important Cryptogams }\end{array}$ & . & . & . & + & + & . & + & . & . & . & . & . & 1 & 1 \\
\hline Cladonia sp. & $\mathrm{p}$ & $\mathrm{p}$ & $\mathrm{p}$ & $\mathrm{p}$ & $\mathrm{p}$ & $\mathrm{p}$ & $\mathrm{p}$ & . & $\mathrm{p}$ & . & . & . & 4 & III \\
\hline Tortula ruralis & $\mathrm{p}$ & . & $\mathrm{p}$ & $\mathrm{p}$ & $\mathrm{p}$ & $\mathrm{p}$ & . & $P$ & . & . & . & . & 3 & II \\
\hline Polytrichum piliferum & $\mathrm{p}$ & $\mathrm{p}$ & $\mathrm{p}$ & . & $\mathrm{p}$ & $\mathrm{p}$ & . & . & $\mathrm{p}$ & . & . & . & 3 & II \\
\hline Desmatodon latifolius & $\mathrm{p}$ & . & $\mathrm{p}$ & $\mathrm{p}$ & $\mathrm{P}$ & $\mathrm{p}$ & . & . & . & . & . & . & 3 & II \\
\hline Ceratodon purpureus & $\mathrm{p}$ & . & $\mathrm{p}$ & . & $\mathrm{p}$ & $\mathrm{p}$ & . & . & $\mathrm{p}$ & . & . & . & 2 & II \\
\hline Peltigera didactyla & . & . & $\mathrm{p}$ & 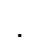 & $\mathrm{p}$ & $\mathrm{p}$ & . & . & $p$ & . & . & . & 1 & II \\
\hline Peltigera rufescens & $\mathrm{p}$ & . & $\mathrm{p}$ & . & $\mathrm{p}$ & . & . & . & . & . & . & . & 2 & 1 \\
\hline
\end{tabular}

\section{Minor species:}

Luzula spicata 2:+ , 3:+ ; Lupinus sericeus 3:+ , 8:r , 11:r ; Agoseris aurantiaca 1:+ , 3:r , 7:r ; Lomatium sandbergii 1:+ , 3:+ , 9:+ ; Danthonia intermedia 2:+ , 4:+ , 5:+ ; Senecio canus 2:r , 3:x , 7:ad; Aster engelmannii 2:+ , 3:+ ; Erigeron sp. 5:r , 6:ad; Calamagrostis purpurascens 4:+ , 9:+ ; Eriogonum umbellatum 5:r , 8:+ ; Penstemon albertinus 8:ad, 10:x ; Bromus pumpellianus 6:r , 10:x ; Tortula norvegica 1:p , 3:p ; Bryum sp. 5:p , 7:p ; Cephalozia? sp. 5:p , 6:p ; Racomitrium canescens

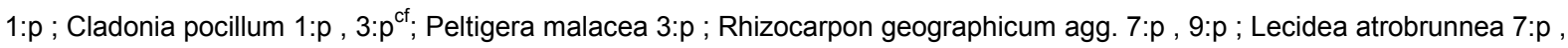
9:p ; Lecanora polytropa 1:p ; Astragalus bourgovii 1:+ ; Castilleja rhexifolia 1:r , 10:x ; Phleum alpinum 2:+ , 12:x ; Antennaria racemosa 2:+ ; Heuchera cylindrica 3:+ , 8:r ; Osmorhiza occidentalis 3:r ; Oxytropis campestris 3:r ; Valeriana sitchensis 3:r , 11:+ ; Brachythecium sp. 3:p ; Hypericum formosum 4:+ ; Gaillardia aristata 4:+ ; Arnica mollis 4:+ ; Xerophyllum tenax 4:r ; Hieracium gracile 4:+ ; Carex petasata 5:r ; Polytrichum juniperinum 5:p ; Cladonia pyxidata 5:p ; Cladonia chlorophaea 5:p ; Poa secunda 6:1 ; Collinsia parviflora 6:x ; Antennaria umbrinella 7:+ ; Lomatium triternatum 8:r , 12:x ; Arnica longifolia 8:r ; Orobanche uniflora 8:+ ; Antennaria anaphaloides 8:+ ; Amelanchier alnifolia 8:ad; Selaginella standleyi 9:+ ; Clematis columbiana 9:+ ; Penstemon lyallii 9:r ; Lepraria sp. 9:p ; Heracleum lanatum 10:r ; Rubus parviflorus 10:x ; Viola glabella 10:x ; Angelica dawsonii 10:x ; Arnica latifolia 10:r ; Erythronium grandiflorum 10:x ; Arnica sp. 11:+ ; Hedysarum sulphurescens 11:+ ; Hackelia floribunda 11:+ ; Poa alpina 11:+ ; Viola nuttallii 11:+ ; Valeriana occidentalis 11:+ ; Thalictrum occidentale 11:+ ; Arabis drummondii 11:r ; Carex sp. 11:r ; Liliaceae sp. 11:r ; Pinus albicaulis 11:ir; Stipa sp. 12:x ; Penstemon confertus 12:x 
Syntaxonomy: Although this community is well differentiated and ecologically distinct, its syntaxonomical position is not quite clear. As a community of late melting sites in the lower alpine it was decided to keep it with the snowbed communities at this point. It does not belong into the Salicetea herbaceae though. An appropriate class that would sufficiently consider its ecological and floristic position in between late melting communities, low alpine meadow communities and talus slopes is not yet available. Nevertheless strong ties exist with other higher syntaxa. The presence of Arenaria capillaris, Eriogonum flavum and in some plots also Selaginella wallacei and Arnica rydbergii likens this unit to the late melting subunits of the Arenario-Festucetalia brachyphyllae, namely the Arenario-Festucetum idahoensis.

As can be taken from the association table, a provisional variant of Silene parryi has been created for plot-nos. 241, 251, 252 and 294). Species of the Bupleurum americanum prairie group are wellrepresented in these stands, pointing to a closer relationship to those meadow communities. These sites have been put in a provisional variant. Many species also evidence a relation to the Festuca scabrella-communities and this community might only be a variant of those prairie meadows differentiated elevationally and by its more extreme snow conditions. This relationship is also underlined by the distribution of this community in the eastern parts of the study area. Relations to other low elevation communities, possibly prairie communities, should be looked for.

Senecio megacephalus reveals a floristic connection with talus and scree communities which is however not much supported by other species. >Similarity to those units exist in that the present community does occur on quite steep slopes. These are nevertheless much richer in fine soil and are genereally much more stable, which is evidenced by the constant presence of a number of lichen and bryophyte species.

Distribution: This community has only been found on the drier east side of the Continental Divide in valleys not too far from the easterly adjacent prairie areas. It is also present in the adjacent Whitefish Range on similar sites (T.Spribille, pers. comm.).

Literature: Communities with Carex geyeri have been described from several other montane and subalpine areas (Hall 1973, Forcella \& Weaver 1977, Timoney 1999). Nevertheless most of these seem to be different in their floristical composition as well as ecologically. No descriptions have been seen from areas above treeline.

VARIANT of Silene parryi var. prov.

Plots: 241, 251, 252, 294

Differential species: Silene parryi. Poa cusickii, Potentilla diversifolia, Arnica rydbergii, Castilleja miniata, Pedicularis contorta, Sedum lanceolatum, Selaginella scopulorum, (Erigeron peregrinus, Aster foliaceus)

The association table reveals a group of stands with a differnential species group as listed above. An ecological differentiation of these plots has not yet been observed. The units is merely separated for its floristic distinctness. 


\section{ASSOCIATION: Xerophylletum tenacis - Subalpine Beargrass slope community}

Nomenclatural Type: Table 30 relevé 512

Plots: $183,259,521,594,595,596,601,607,608,620, \quad(n=10)$

\section{Character species: Xerophyllum tenax}

Constant species: Valeriana sitchensis, Erigeron peregrinus, Luzula hitchcockii, Brachythecium sp., Carex geyeri, Vaccinium membranaceum, Vaccinium scoparium, Epilobium angustifolium, Arnica latifolia, Silene parryi

General aspect: In Glacier NP, the extensive subalpine to low alpine beargrass slopes are one of the most well known high elevation habitat types to high elevation hikers. Large expanses of the slopes right above timberline mostly west of the Continental Divide are covered by these beargrass dominated mats. Well known are the several-year flowering cycles, which about every seven years cover entire slopes with the intense display of thousands of the large, white candle-like inflorescences of this showy lily species plate 4, fig.15.

Topography: The upper reaches of this vegetation unit roughly coincides with the upper treeline in the western parts of the area. The community was sampled at elevations from $1790 \mathrm{~m}$ to $2150 \mathrm{~m}$ mostly on E (NE) to SW-facing, reasonably to very steep slopes. The steepness results in gravitational instability which is an important ecological factor in this vegetation unit giving the better adapted beargrass an ecological advantage over the tree species, which could otherwise still occur at these elevations and are in fact present on suitable, stablilized sites on rock ledges.

It has to be mentioned, that forested communities with an important quantity of beargrass in the herb layer are common at montane and lower subalpine elevations and have been described from adjacent mountain ranges as Xerophyllo-Abietetum bifoliae Spribille 1999 (Spribille 1999, Stachurska-Swakon \& Spribille, unpubl. manuscript). Apart from the tree component they can be fairly similar in composition and it has been suggested that these communities represent an impoverished, "treeless phase" of those forest communities (Kuchar 1973). Given the slope-specific ecology of the sites as described below, the differences seem strong enough to keep them separate from forested communities. Further floristic comparison might elucidate the relation of these units in the future. Another species with such a forest/non-forest occurence pattern near timberline is Carex geyeri at least in the western mountains. A similar phenomenon does occur in other mountain areas of the world, e.g. the dominant occurence of the tall grass Calamagrostis villosa above and below timberline in some central European mountain ranges (e.g. Issler 1942, Damm 1994).

Geology/Parent material: Parent materials of the stands samples are colluvial, fine soil rich materials derived from argillite, diorite or limestone.

Soils: Mineral content of the fine soils is high with considerable amounts of gravel and coarser rock fractions. Organic content is mostly represented by a dense but not tough network of fine roots that extends at least 12 to $15 \mathrm{~cm}$ into the ground. This network provides the protective function which the beargrass sward brings about for the stabilization of the slopes.

The beargrass' extensive fibrous rootsystem and its conspicuously prostrate growing basal shoots are extremely resistant against soil creep and erosion and make it the most successful and by far most dominant species of this community. Not only the occurrence, but also the dominance of the beargrass is important for the stability of the slopes, because only a coherent network of root-systems from different individual Xerophyllum plants covering the slope without larger gaps can provide sufficient 
stability against erosive and gravitational impact, stabilising of the whole community. Thus the species' dominance is also important to all other plant species of this steep slope community, which except for Vaccinium membranaceum never achieve greater cover in this unit. If Xerophyllum were less dominant, slope stability would be decreasing with negative consequences for most other species present.

Wind exposure/Moisture conditions: Steep slopes furthermore provide good drainage leading to fairly dry conditions in late summer and fall, to which Xerophyllum is perfectly adapted, as its name implies. The rigid, sedge-like leaves of the species are an adaptation not only to summer drought, but also to wind desiccation and mechanical damage due to large amounts of snow which can accumulate on the plants.

Snow cover: Snow cover is estimated to be high, but melting relatively fast due to the southerly inclined position of the beargrass-meadows. Observation of snow melt patterns in the adjacent Swan Range in spring shows that exposed slopes covered by Xerophyllum tenax are usually among the earliest to melt, occasionally as early as late April.

The impact of snow avalanches which frequently occur on these steep high elevation slopes is a particular stress factor for this community. The long and slender, rigid leaves of the species are built to resist the abrasive forces of large masses of snow, sliding downhill over the slippery surface of the Xerophyllum covered steep slopes. As a species with an evergreen survival strategy, which provides an advantage by a much quicker start of springtime assimilation, the beargrass has evolved an unusual but successful set of characters to withstand the harsh climatic conditions in its habitat. Carex geyeri, which also is important in this community, has a similar kind of adaption. Among the dicots, Vaccinium scoparium seems to morphologically well-adapted adapted to resist snow avalanches with its broom-like, flexible branches.

Vegetation: Other species important in this community are Vaccinium membranaceum and Vaccinium scoparium, pointing to the heath character of this community. Ericaceous heath communities assume a similar position at and above timberline in many temperate mountain ranges of the world. This function seems to be filled by the beargrass community in this summer-dry part of the Rocky Mountains. In the moister northern and western ranges, Phyllodoce and Cassiope communities apparently fill this niche. 


\section{$\underline{\text { Xerophylletum tenaci ass. nov. }}$}

\begin{tabular}{|c|c|c|c|c|c|c|c|c|c|c|c|c|c|c|}
\hline Location & LEW & LEW & $\mathrm{HiS}$ & Pit & Bro & ApV & LEW & Spe & HoW & LiP & BrW & Hay & TML & LD \\
\hline Plot-Number & 595 & 596 & 521 & 770 & 607 & 259 & 594 & 601 & 620 & 784 & 608 & 183 & 768 & 776 \\
\hline Elevation $[\mathrm{m} / 10]$ & 195 & 192 & 200 & 218 & 194 & 179 & 202 & 213 & 213 & 211 & 205 & 219 & 170 & 187 \\
\hline Aspect & 120 & 120 & 230 & 200 & 225 & 50 & 150 & 120 & 160 & 230 & 160 & 230 & 160 & - \\
\hline Slope & 27 & 11 & 32 & 30 & 10 & 22 & 21 & 32 & 20 & 33 & 30 & 33 & - & - \\
\hline Soil-type & RAQ & RAQ & Lim & - & - & GA & RAQ & $\mathrm{RA}$ & RAQ & GAM & - & Dio & - & - \\
\hline Rocks $>6 \mathrm{~cm}$ & 22 & 10 & 0 & - & - & $<1$ & 15 & 18 & 0 & 0 & - & 0 & - & - \\
\hline Rocks $<6 \mathrm{~cm}$ & 1 & 1 & 0 & - & - & 0 & .5 & 2 & 0 & 4 & - & 0 & - & - \\
\hline Fine Soil $<1 \mathrm{~mm}$ & 0 & $\mathrm{n}$ & $\mathrm{n}$ & - & - & 0 & 0 & $\mathrm{n}$ & $\mathrm{n}$ & $\mathrm{n}$ & $\mathrm{n}$ & 0 & - & - \\
\hline Litter & 85 & 99 & 95 & - & - & 92 & 85 & 82 & 98 & 95 & - & 100 & - & - \\
\hline Vascular plants [\%] & 98 & 98 & 98 & - & - & 95 & 98 & 98 & 95 & 95 & - & 98 & - & - \\
\hline Mosses [\%] & $<1$ & $<.1$ & 1 & - & - & 3 & 1 & 4 & $<.1$ & - & - & $<.1$ & - & - \\
\hline Lichens [\%] & 0 & 0 & $<.1$ & - & - & 0 & 0 & 1 & 0 & - & - & 0 & - & - \\
\hline Plot-Size $\left[\mathrm{m}^{2}\right]$ & 16 & 16 & 16 & 16 & 16 & 16 & 16 & 16 & 16 & 16 & 16 & 16 & 16 & - \\
\hline Number & 1 & 2 & 3 & 4 & 5 & 6 & 7 & 8 & 9 & 10 & 11 & 12 & 13 & 14 \\
\hline \multicolumn{15}{|l|}{ Character species } \\
\hline AC Xerophyllum tenax & 4 & 5 & 5 & 5 & 5 & 5 & 4 & 5 & 5 & 5 & 5 & 5 & $x$ & $x$ \\
\hline \multicolumn{15}{|l|}{ Constant companion species } \\
\hline Valeriana sitchensis & + & 1 & + & $x$ & 1 & + & + & + & + & $x$ & 1 & . & . & . \\
\hline Erigeron peregrinus & $r$ & $r$ & $r$ & $x$ & $r$ & + & + & + & + & $x$ & + & . & . & $x$ \\
\hline Luzula hitchcockii & 1 & + & $\cdot$ & . & + & + & 2 & 1 & + & $x$ & . & + & . & $x$ \\
\hline Carex geyeri & + & . & $\mathrm{r}$ & . & + & + & + & + & . & $x$ & 1 & . & $x$ & . \\
\hline Vaccinium scoparium & . & . & $r$ & . & . & . & 1 & 3 & . & $x$ & 1 & r & . & $x$ \\
\hline Vaccinium membranaceum & 3 & 2 & 2 & $x$ & 1 & + & 3 & . & + & . & . & . & $x$ & . \\
\hline Epilobium angustifolium & . & + & + & $x$ & + & . & . & . & . & $x$ & + & + & . & . \\
\hline Arnica latifolia & + & . & ${ }^{\circ}$ & $x$ & + & + & 1 & + & . & $x$ & + & . & - & . \\
\hline $\begin{array}{l}\text { Brachythecium sp. } \\
\text { Other species }\end{array}$ & $\mathrm{p}$ & $\mathrm{p}$ & . & . & $\mathrm{p}$ & $\mathrm{p}$ & $\mathrm{P}$ & $\mathrm{p}$ & $\mathrm{p}$ & . & . & . & . & . \\
\hline Silene parryi & + & + & . & . & + & r & + & + & . & . & . & . & . & . \\
\hline Lescuraea radicosa & $\mathrm{p}$ & $\mathrm{p}$ & . & . & . & . & $\mathrm{p}$ & $\mathrm{p}$ & . & . & . & . & . & . \\
\hline Thalictrum occidentale & + & $r$ & + & $x$ & 1 & . & . & . & . & . & . & . & $x$ & . \\
\hline Elymus glaucus & $r$ & + & + & . & + & . & . & . & + & . & . & . & . & . \\
\hline Juncus parryi & . & . & . & . & . & . & . & + & $r$ & . & $r$ & . & . & . \\
\hline Arnica sp. & . & . & . & . & . & . & . & + & . & . & + & + & . & . \\
\hline Aster foliaceus & . & . & . & . & $r$ & . & . & . & . & $x$ & + & + & . & . \\
\hline Hypericum formosum & + & + & . & . & . & . & . & . & + & $x$ & . & $r$ & . & . \\
\hline Trisetum spicatum & . & . & . & . & $r$ & + & . & + & + & $x$ & + & . & . & . \\
\hline Achillea millefolium & . & . & + & . & $r$ & + & . & . & $r$ & . & . & $r$ & . & . \\
\hline Fragaria virginiana & . & . & + & . & + & . & . & . & . & . & . & + & $x$ & . \\
\hline Erythronium grandiflorum & . & $r$ & . & . & + & . & . & . & . & $x$ & + & . & . & . \\
\hline Campanula rotundifolia & + & . & . & . & r & . & . & . & $r$ & . & . & . & . & . \\
\hline Calochortus apiculatus & . & . & . & . & r & + & . & $r$ & . & . & . & . & $x$ & . \\
\hline Potentilla diversifolia & . & . & . & . & r & + & . & + & . & . & . & . & . & . \\
\hline Galium boreale & . & . & . & . & + & + & . & . & . & . & . & . & . & . \\
\hline Pedicularis bracteosa & . & . & . & . & $r$ & + & . & . & . & . & . & . & . & $x$ \\
\hline Castilleja miniata & 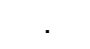 & 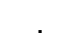 & - & . & + & $r$ & . & . & - & . & . & . & . & . \\
\hline
\end{tabular}


Association Table 30 (cont.):

\begin{tabular}{|c|c|c|c|c|c|c|c|c|c|c|c|c|c|c|}
\hline Number & 1 & 2 & 3 & 4 & 5 & 6 & 7 & 8 & 9 & 10 & 11 & 12 & 13 & 14 \\
\hline Phleum alpinum & . & . & . & . & . & + & . & . & r & . & . & $r$ & . & . \\
\hline Arenaria capillaris & . & . & . & . & ${ }^{\circ}$ & + & . & 1 & . & $x$ & . & . & . & . \\
\hline Hieracium gracile & . & . & . & . & . & . & $r$ & + & . & . & . & . & . & . \\
\hline Cryptogams: & & & & & & & & & & & & & & \\
\hline Tortula ruralis & . & . & . & . & $\mathrm{p}$ & $\mathrm{p}$ & . & . & . & . & . & . & . & . \\
\hline Bryum sp. & $\mathrm{p}$ & . & . & . & ${ }^{\circ}$ & . & $\mathrm{p}$ & . & . & . & . & $\mathrm{p}$ & . & . \\
\hline Cladonia chlorophaea & $\mathrm{p}$ & . & . & . & . & . & $\mathrm{p}$ & $\mathrm{p}$ & . & . & . & . & . & . \\
\hline Polytrichum piliferum & . & . & . & . & . & $\mathrm{p}$ & $\mathrm{p}$ & $\mathrm{P}$ & . & . & . & . & . & $\mathrm{p}$ \\
\hline Cladonia sp. & . & . & . & . & . & $\mathrm{p}$ & $\mathrm{p}$ & $\mathrm{p}$ & . & . & . & . & . & . \\
\hline Tortula norvegica & . & . & . & . & . & . & $\mathrm{p}$ & $\mathrm{p}$ & . & . & . & $\mathrm{p}$ & . & . \\
\hline Ceratodon purpureus & . & . & . & . & . & . & $\mathrm{p}$ & $\mathrm{p}$ & . & . & . & . & . & . \\
\hline Polytrichum sp. & . & . & . & . & . & . & . & $\mathrm{p}$ & . & . & $\mathrm{p}$ & $\mathrm{p}$ & . & . \\
\hline
\end{tabular}

Notice: This table is abbreviated. Species with minor constancy (usually occurring in less than three plots) have been omitted

Syntaxonomy: At a glance this community does not seem to have very close ties to any other of the communities described so far in the area and beyond. This is mainly due to the dominance of the beargrass. Nevertheless, some floristic affinities do exist to different subalpine to low alpine meadow types. In many of these adjacent meadow types beargrass can be a reasonably constant companion species, though never being nearly so dominant as in the community described here. The several tall herb species occurring in this community suggest a syntaxonomic placement with other tall herb communities. Therefore the association is accommodated in the Valerianetalia order.

The community might have to be subdivided later on but this is not attempted here since the dataset is believed to be too small for that purpose. It appears from the table even now, however, that there is a tendency of a Vaccinium membranaceum- Silene parryi variant and a less species-rich variant. The first comprises some stands with typical subalpine and montane tall herbs like Thalictrum occidentale, Elymus glaucus and Epilobium angustifolium. The latter variant has fewer tall growing, mesophytic species and might be related to a longer snow cover or stronger mechanical impact. Accordingly, Vaccinium scoparium seems to be more common in this variant.

Distribution: Beargrass slopes are most common in the central and northern portions of the Park mainly on the west slope of the Continental Divide. Stands on the east side are never far from the Continental Divide. This distribution points to a preference of this community for the moister maritime to subcontinental climate type. The community is not found in the drier, easternmost reaches of the mountains. Communities which are likely to belong int this association occur very abundant in the mountain ranges of western Montana and northern Idaho in subalpine to alpine localities. However, Xerophyllum tenax does not extend far north in Canada.

Literature: The same "monoculture"-dominance-community has been described by Kuchar (1973) from the northerly adjacent Waterton National Park where the community is reported to occur only in smaller patches within other meadow communities on S-facing slopes from $1830 \mathrm{~m}$ to $2200 \mathrm{~m}$ a.s.1.. Kuchar considers beargrass the successful competitor which replaces subalpine fir and whitebark pine on the drier slopes. Deep snow cover with relatively early meltout in June and late summer drought 
are also mentioned by Kuchar as important factors. He also points to the fact that these plants are "not much utilised by animals", which is at least true for its forage value for larger mammals.

Some of the samples of the Valeriana-types reported by Polster (1977) point to the occurrence of Xerophylletum stands in the Akamina area north of Glacier NP.

\section{ASSOCIATION: Dodecatheo pulchelli-Suksdorfietum ranunculifoliae ass. nov. - Suksdorfia-Shooting Star seep community}

Nomenclatural Type: Table 31 relevé 513

Plots: $88,98,228,232,479,513 \quad(n=6)$

Character species: Suksdorfia ranunculifolia, (Dodecatheon pulchellum, Botrychium simplex)

Constant species: Carex scirpoidea, Festuca idahoensis, Potentilla fruticosa, Danthonia intermedia, Festuca scabrella, Saxifraga occidentalis, Zigadenus elegans, Potentilla diversifolia, Philonotis fontana, Ditrichum flexicaule, Tortella tortuosa, Tortula fragilis, Polytrichum juniperinum

General aspect: Moist rock outcrops on large mountain-sides covered with a thin layer of dark organic open soil are typical for this community. Vegetation on these areas is scattered and very seasonal. The hydrophytic dominant Suksdorfia as well as the prominently flowering Dodecatheon pulchellum are withering away by mid-summer leaving only their yellowish remains which characterize the sites from late July into fall.

Topography: This rare community occurs on low alpine and subalpine wet rock ledges and outcrops and on seeping, consolidated talus at elevations from 1700 to $2000 \mathrm{~m}$. Overall slope angle was found to be $20^{\circ}-30^{\circ}$ mostly facing SW but surfaces within the often micro-terraced or otherwise roughsurface plots are often less steep. Flat outcrops of the layered, sedimentary red and green argillite create surfaces where organic humus layer accumulates which retains enough moisture to provide the conditions for the establishment of this community.

Geology: On flat outcropping banks of green and red argillite. The sedimentary, impermeable rocks collect water in distinct layers, providing localized seepages where through much of early summer permanently moist areas exist even on drier mountain-sides.

Soils: Soils are very humus-rich sometimes completely lacking mineral contents even though they are directly covering bedrock outcrops. They have accumulated as shallow layers in situ from pioneering moss-carpets and subsequent vascular plants which have established on those originally barren rock surfaces.

Wind exposure/Snow cover: Snow duration is reasonable and exposure to wind is moderate. Most important factor is an extremely variable moisture regime. During spring and early summer the sites are seeped and water might run over parts of the stands whereas later in the summer the water supply ceases and the shallow, humus-rich soils dry out rather fast. Variation in the vegetation is mostly caused by the differences in the water regime, some sites drying earlier whereas others stay moist through much of the season. 
Vegetation: The vegetation of these sites is rather open with much of the humus soil exposed and susceptible to water and wind erosion. Eroded edges of the humus layer are often visible and create open space for the establishment of humus-dwelling lichens and mosses.

Most important and also most conspicuous species is Suksdorfia ranunculifolia with its name-giving buttercup-shaped leaves often covering much of the plot surface. The prominent flowers of Dodecatheon pulchellum make these stands resemble other low elevation wetlands. Constant in the six plots sampled is Botrychium simplex, which might even be a local or regional character species of this community, and is also known from similar communities in the Salish Mountains.

A loose cover of Carex scirpoidea is very diagnostic for this community but the sedge cannot be called a character species since it also occurs in other units. The species is generally a good indicator of seasonally moist, humus-rich sites at these elevations. The other Carex scirpoidea-communities are often found adjacent to and intergrading with this unit. Cystopteris fragilis points to the relationship to the moist and cool rock crevice communities which sometimes occur with rocky outcrops in the vicinity. Philonotis fontana and Bryum pseudotriquetrum point to the close relation to continuously wet streambank communities and cover mostly more than $10 \%$ of the plot, sometimes up to $40 \%$. On the other hand there are a number of typical dry community species which reflect the periodically dry conditions in fall. Some of these are Festuca idahoensis, Danthonia intermedia, Festuca scabrella, Saxifraga occidentalis, Poa secunda, Tortula fragilis and Peltigera sp.

As a very rare species Cryptogramma stelleri occasionally occurs in this unit.

Heterotoneity within the plots samples is quite high which is attributed to the small size of the stands allowing for a considerable influence of bordering communities. Furthermore the openness of the stands with moist humus surface being present through much of the year creates a good seedbed for the establishment of invading species. Together these two causes lead to an obvious increase in species-richness based on a number of species with little constancy, a fact that needs to be reconfirmed with a bigger data set than the small one used here. Nevertheless a constant set of species is maintained by the selective impact of the strongly changing water conditions eradicating many solely drought-adapted species in spring and summer and moisture-adapted species during the dry fall period.

Syntaxonomy: The placement of this unit in the syntaxonomic system is still unresolved. It most likely belongs into a yet undescribed alliance, order and possibly even class together with other communities of lower elevations. In the study area it has some connection to the Carex scirpoidea alliance of moist to wet alpine meadows. Species pointing to a relationship in other directions do occur in this community which is not surprising given the large patches of open soil which can easily be colonized by invasive species. Nevertheless a long-term establishment does not seem to happen very often resulting in a persisting open structure of this community.

Distribution: The Suksdorfietum is very rare in the area since it is highly dependent on the unusual combination of flat outcropping rock surfaces and its particular moisture regime. In the study area it has so far been found in four different locations. An extremely similar community likely belonging to the same association is known from low elevation rock outcrops near Stryker, Montana and in the northern Salish Mountains (T.Spribille, pers. comm.). Published reports of a similar community from other areas have not been found even though the community is likely to be more widespread. 
Dodecatheo-Suksdorfietum ranunculifoliae ass. nov.

\begin{tabular}{|c|c|c|c|c|c|c|c|c|}
\hline & $\mathrm{ApV}$ & Bar & Ice & ApV & ApV & $\mathrm{ApV}$ & AIS & \\
\hline Plot-Number & 232 & 513 & 479 & 228 & 88 & 98 & 480 & \\
\hline Elevation $[\mathrm{m} / \mathbf{1 0}]$ & 187 & 200 & 171 & 182 & 212 & 185 & 179 & \\
\hline Aspect $\left[{ }^{\circ}\right]$ & 200 & 204 & 220 & 240 & 206 & 240 & 216 & \\
\hline Slope $\left[{ }^{\circ}\right]$ & 29 & 20 & 22 & 29 & 29 & 27 & 24 & \\
\hline Parent Material & GAM & RA & RA & GA & GA & GA & GA & \\
\hline Rocks $>6 \mathrm{~cm}$ & .5 & 16 & 1 & - & 2 & 40 & 25 & \\
\hline Rocks $<6 \mathrm{~cm}$ & 3 & 2 & 22 & - & .5 & 10 & 10 & \\
\hline Litter Cover [\%] & 35 & 25 & 10 & 4 & 55 & 20 & 1 & \\
\hline Vascular Plant Cover [\%] & 25 & 25 & 20 & 18 & 55 & 20 & 30 & \\
\hline Moss Cover [\%] & 10 & 40 & 20 & $15+$ & 5 & 10 & 40 & \\
\hline Lichen Cover [\%] & 15 & 4 & $10+$ & $1+$ & 15 & 12 & 0 & \\
\hline Plot-Size $\left[\mathrm{m}^{2}\right]$ & 8 & $3 \times 3$ & $1 \times 4$ & $3 \times 4$ & 16 & 12 & 6 & \\
\hline Number & 1 & 2 & 3 & 4 & 5 & 6 & 7 & Constancy \\
\hline Association Diagnostic species & & & & & & & & \\
\hline AC Suksdorfia ranunculifolia & 1 & 1 & 3 & 1 & + & 1 & 1 & V \\
\hline Ad Dodecatheon pulchellum & 1 & + & + & 1 & 1 & + & + & V \\
\hline Ad Cystopteris fragilis & + & + & . & + & . & + & $\mathrm{ad}$ & IV \\
\hline Carex scirpoidea & 1 & + & + & + & 3 & 1 & & V \\
\hline Constant species & & & & & & & & \\
\hline Festuca idahoensis & + & 1 & + & r & + & + & r & V \\
\hline Potentilla fruticosa & + & + & + & + & + & + & . & V \\
\hline Danthonia intermedia & + & + & + & + & 1 & $r$ & . & V \\
\hline Festuca scabrella & + & + & $r$ & + & + & $r$ & . & V \\
\hline Saxifraga occidentalis & + & $r$ & $r$ & + & + & $r$ & . & V \\
\hline Zigadenus elegans & + & . & r & $r$ & + & + & . & IV \\
\hline Potentilla diversifolia & + & + & . & + & + & $r$ & . & IV \\
\hline Achillea millefolium & + & + & . & + & . & r & + & IV \\
\hline Selaginella standleyi & + & $x$ & + & . & . & + & . & III \\
\hline Botrychium simplex & + & . & $r$ & . & $r$ & + & . & III \\
\hline Allium cernuum & . & + & . & + & + & + & . & III \\
\hline Cirsium hookerianum & . & + & . & $r$ & . & $r$ & . & III \\
\hline Poa secunda & . & + & + & + & . & . & 1 & III \\
\hline Agrostis scabra & . & + & + & . & . & + & . & III \\
\hline Sedum roseum & . & . & . & + & $r$ & + & . & III \\
\hline $\begin{array}{c}\text { Montia parviflora } \\
\text { Important Cryptogams }\end{array}$ & . & . & + & . & . & . & 3 & ॥ \\
\hline Philonotis fontana & $\mathrm{p}$ & $\mathrm{p}^{\mathrm{cf}}$ & $\mathrm{p}$ & $\mathrm{p}$ & $\mathrm{p}$ & $\mathrm{p}$ & $\mathrm{p}$ & $\mathrm{V}$ \\
\hline Tortella tortuosa & $\mathrm{p}$ & $\mathrm{p}$ & . & $\mathrm{p}$ & $\mathrm{p}$ & $\mathrm{p}$ & . & IV \\
\hline Cephalozia? sp. & $\mathrm{p}$ & $\mathrm{p}$ & $\mathrm{p}$ & . & $\mathrm{p}$ & $\mathrm{p}$ & . & IV \\
\hline Ditrichum flexicaule & . & $P$ & $\mathrm{p}$ & . & $\mathrm{p}$ & $\mathrm{p}$ & . & III \\
\hline Cladonia pocillum & $\mathrm{p}$ & . & . & $\mathrm{p}$ & $\mathrm{p}$ & $\mathrm{p}$ & . & III \\
\hline Tortella fragilis & $\mathrm{p}$ & $\mathrm{p}$ & $\mathrm{p}$ & $\mathrm{p}$ & . & . & . & III \\
\hline Polytrichum juniperinum & $\mathrm{p}$ & $\mathrm{p}$ & $\mathrm{p}$ & . & $\mathrm{p}$ & . & . & III \\
\hline Preissia quadrata & $\mathrm{p}$ & . & . & . & $\mathrm{p}$ & $\mathrm{p}$ & . & III \\
\hline Ceratodon purpureus & $\mathrm{p}$ & $\mathrm{p}$ & $\mathrm{p}$ & . & . & . & . & III \\
\hline
\end{tabular}




\section{Association Table 31 (cont.)}

\begin{tabular}{lc|ccccccc|c} 
& Number & 1 & 2 & 3 & 4 & 5 & 6 & 7 & Constancy \\
\hline Bryum sp. & $\mathrm{p}$ &. & $\mathrm{p}$ & $\mathrm{p}$ &. &. &. & & III \\
Peltigera sp. &. & $\mathrm{p}$ & $\mathrm{p}$ & $\mathrm{p}$ &. &. &. & & III \\
Cladonia pyxidata & & $\cdot$ & $\mathrm{p}$ & $\mathrm{p}$ &. & $\mathrm{p}$ &. &. & \\
Cladonia sp. & $\mathrm{p}$ & $\mathrm{p}$ &. &. & $\mathrm{p}$ &. &. & & III
\end{tabular}

\section{Minor species:}

Vascular Plants: Poa alpina 4:r , 5:r , 6:r ; Solidago multiradiata 1:+ , 5:r , 6:r ; Cerastium arvense 1:+ , 2:+ , 6:r ; Arabis nuttallii 1:+ , 2:+ , 6:+ ; Polygonum bistortoides 2:r , 4:r , 6:r ; Potentilla gracilis 2:r , 5:r , 6:r ;Luzula spicata 1:r , 2:+ , 5:+ ; Senecio canus 1:r , 3:r ; Galium boreale 1:+ , 3:+ ; Deschampsia cespitosa 2:+ , 3:+ ; Calochortus apiculatus 1:+ ; Antennaria anaphaloides 1:+ ; Agrostis sp. 1:+ ; Campanula rotundifolia 1:+ , 6:+ ; Crepis runcinata 1:+ ; Oxytropis campestris 1:r , 6:r ; Orobanche uniflora 1:r , 7:+ ; Lithophragma parviflora 1:r , 7:r ; Erigeron sp. 1:r ; Bupleurum americanum 1:r ; Prunus virginiana 2:1 , 3:+ ; Polygonum minimum 2:+ , 7:ad ; Danthonia uniflora 2:+ ; Arnica fulgens 2:+ ; Koeleria cristata 2:+ ; Penstemon confertus 2:+ ; Arnica rydbergii 2:+ ; Selaginella wallacei 2:+ ,6:+ ; Besseya wyomingensis 2:+ ; Phleum pratense 2:+ ; Antennaria microphylla 2:+ , $5: \mathrm{x}^{\mathrm{cf}}$;Sedum stenopetalum 2:+ , 5:+ ; Agropyron spicatum 2:r ; Phleum alpinum 2:x ; Polemonium pulcherrimum 2:r ; Zigadenus venenosus 3:+ ; Rhinanthus crista-galli 3:+ , 7:ad; Geum triflorum 3:r ; Potentilla hippiana 3:r ; Allium schoenoprasum 3:r ; Rosa sp. 4:+ , 7:r ; Calamagrostis purpurascens 4:r , 6:r ; Selaginella sp. 4:r ; Gentiana sp. 4:r ; Linum perenne 4:r , 6:r ; Selaginella scopulorum 5:+ ; Pedicularis contorta 5:+ ; Hypericum formosum 5:+ ; Saxifraga mertensiana 5:+ ; Silene parryi 5:+ ; Botrychium paradoxum 5:r ; Heuchera cylindrica 5:r ; Astragalus bourgovii 5:r ; Juniperus communis 5:r ; Collinsia parviflora 6:+ , 7:r ; Euphrasia arctica 6:+ ; Poa sp. 6:+ ; Carex rupestris 6:+ ; Woodsia scopulina 6:r ; Hedysarum sulphurescens 6:r ; Hieracium sp. 6:r ; Draba sp. 6:r ; Sedum lanceolatum 6:r ; Arctostaphylos uva-ursi 6:r ; Barbarea vulgaris 7:+ ; Delphinium sp. 7:r ; Linanthus septentrionalis 7:ad; Mimulus tilingii 7:+

Bryophytes: Racomitrium canescens 3:p , 5:p ; Tortula ruralis 3:p , 4:p ; Bryum pseudotriquetrum 4:pc, 7:p ; Moss sp. 2:P ; Aulacomnium palustre 5:p ; Bryum argenteum 5:p ; Marchantia polymorpha 5:p , 6:p ; Encalypta rhabdocarpa 6:p ; Polytrichum piliferum 6:p ; Encalypta affinis 6:p ; Bryum caespiticium 6:p ;

Lichens: Caloplaca tiroliensis 1:p , 6:p ; Bryanora castanea 1:p ; Caloplaca sp. 1:p ; Peltigera rufescens 1:p , 2:p ; Rhizocarpon sp. 2:p ; Xanthoria elegans 2:p , 4:p ; Rhizocarpon geographicum agg. 2:p , 4:p ; Peltigera lepidophora 3:p , 6:p ; Lecanora polytropa 3:p ; Placynthiella sp. 3:p ; Umbilicaria virginis 4:p ; Collema sp. 4:p ; Caloplaca cladodes 4:p ; Physconia muscigena 4:p ; Lecanora rupicola 4:p ; Sporastatia testudinea 4:p ; Xanthoparmelia coloradoensis 4:p ; Lecanora thomsonii cf. 4:p ; Lecidea atrobrunnea 4:p ; Xanthoparmelia sp. 4:p , 6:p ; Umbilicaria krascheninnikovii 4:p , 6:p ; Rinodina spec1 5:p ; Cetraria ericetorum 5:p , 6:p ; Cetraria islandica 5:p ; Cladonia cervicornis 5:pcf; Cladonia borealis 5:p ; Ochrolechia upsaliensis 6:p ; Umbilicaria hyperborea 6:p ; Xanthoparmelia wyomingica 6: $\mathrm{p}^{\mathrm{cf}}$; Umbilicaria polyphylla 6: $\mathrm{p}^{\mathrm{cf}}$ 


\title{
ASSOCIATION: Tofieldio glutinosae-Caricetum lenticularis ass. nov. - Tofieldia-Carex lenticularis community
}

\author{
Nomenclatural Type: Table 32 relevé 564
}

Plots: $426,428,564,583,743 \quad(\mathrm{n}=5)$

\section{Character species: Carex lenticularis, Equisetum variegatum}

Other Diagnostic species: Tofieldia glutinosa, Salix commutata, Leptarrhena pyrolifolia, Equisetum arvense

General aspect: This community is a subalpine to low alpine wetland community with a typical bryophyte dominated bog aspect. The thick, peat soil is partially visible and otherwise largely covered by mosses. Vascular plant cover is usually little and very scattered. Only the small flowers of Tofieldia glutinosa, Senecio cymbalarioides and sometimes Pedicularis groenlandica and Dodecatheon pulchellum add some color to this uniformly green community. The first of those species has been used for the name of this community, also in order to differentiated this community from other Carex lenticularis communities.

Topography: This high elevation wetland occurs exclusively on more or less level peat flats along streambanks assuming more sloping positions only occasionally in seepage areas. It has been sampled at elevations between 2000 and $2080 \mathrm{~m}$ but is likely to have a wider elevation range especially to lower altitudes.

Geology/Parent Material: The bedrock material seems to be not important for this community. Like in all seeped communities, particularly those with considerable humus accumulations, the abundantly percolating water influences the soil chemistry more than the relatively negligible influence of the local lithology.

Wind exposure/Snow duration: Wind exposure on the sites can be quite reasonable or just very moderate without being an important factor in this community. Snow cover is likely to be high on the level high elevation sites.

Moisture conditions: Seeped to floated moisture conditions are met in this unit almost throughout the season. Standing water has been found even in August. Abundant water is the predominant ecological factor in this unit, which is the wettest unit encountered in the study area.

Soils: Purely organic profiles are one of the most characteristic features of this unit. The peat is derived partly from the well developed moss layer and partly from the sedges which most likely do not contribute nearly as much as the bryophytes. Given the cool conditions under which these high elevation fens exist, the time of development has probably been quite long within the quarternary period. The low temperature of the soils reduces nutrient availability to an extend that species with little competitive power and little biomass production can dominate these sites (Dierßen 1996). The little productivity results in relatively shallow profiles with depths that have been found to be never more than $25 \mathrm{~cm}$, often much less than that.

Vegetation: The dominance of Carex lenticularis is the most important character of this among the vascular plants. Together with Tofieldia glutinosa and Equisetum variegatum this is a very constant diagnostic species group. Equisetum arvense is also limited to this community in the alpine of the study area. The other prominent sedge Carex nigricans points to an extended snow cover in this community as do the other chionophilic species Juncus drummondii, Salix arctica and Senecio 
cymbalarioides. Juncus mertensianus, Epilobium alpinum, Deschampsia cespitosa and Dodecatheon pulchellum are widespread high elevation wet meadow species. Most important for this unit is the dominating bryophyte cover which consists mainly of Philonotis fontana, Bryum pseudotriquetrum, Bryum weigelii and possibly other unidentified Bryum species. Sphagnum sp., Aulacomnium palustre, Calliergon stramineum, Scapania undulata, Sanionia uncinata and Drepanocladus aduncus have been found on one plot and are likely to be common in this unit. The cryptogams have not been sampled completely in all of the plots presented in the table.

Lichens have not been found at all in this community.

Syntaxonomy: This wetland community has not been assigned to a higher unit. It does most likely belong into a widespread lower elevation unit of sedge dominated wetlands. Among the units represented in the alpine in Glacier NP relationships exist to the snowbed communities with Carex nigricans and to the wet meadows of the Trollio-Parnassietum. However, this unit is different in that it is neither a snowbed nor a wet meadow but quite distinct in its fen character. The dominance of Philonotis fontana likens this community to also to the Philonotido-Mimulion streambank alliance. Relationships also exist to other, lower elevation spring communities which are related to the European class Montio-Cardaminetea Br.-Bl. et Tx. 1943.

Distribution: The community has been found in the western Livingston Range as well as in the main Lewis Range. Similar assemblages have been found at Sue Lake, Kootenai Lakes, No Name Lake and other locations. The community is likely to be found althrough the park and much beyond it. Its main distribution is likely to be at lower elevations.

Literature: Cooper et al. 1997 describe a Carex scopulorum/Caltha leptosepala community type from southwestern Montana which has considerable amounts of Carex lenticularis as well as Senecio cymbalarioides and occurs under similar wet meadow to fen conditions with continuously water saturated soils. Other species in common are Poa alpina, Deschampsia cespitosa, Juncus drummondii, Juncus mertensianus, Dodecatheon pulchellum, Pedicularis groenlandica and Veronica wormskjoldii. 
Tofieldio glutinosae-Caricetum lenticularis ass. nov.

\begin{tabular}{|c|c|c|c|c|c|c|c|}
\hline & $n$ & LoR & Fif & TrP & $\mathrm{HiT}$ & $\mathrm{HiT}$ & \\
\hline & Plot-Number & 583 & 564 & 743 & 426 & 428 & \\
\hline & Elevation [m/10] & 201 & 208 & ele & 206 & 206 & \\
\hline & Aspect $\left[{ }^{\circ}\right]$ & 0 & 180 & 0 & 285 & 270 & \\
\hline & Slope $\left[^{\circ}\right]$ & 0 & 4 & 0 & 12 & 13 & \\
\hline & Parent Material & RG & DiM & - & GA & GA & \\
\hline & Rocks $>6 \mathrm{~cm}$ & 1 & 0 & 0 & 0 & 0 & \\
\hline & Rocks $<6 \mathrm{~cm}$ & 0 & 0 & 0 & 0 & 0 & \\
\hline & Fine Soil $<1 \mathrm{~mm}$ & 0 & 2 & 5 & 20 & 40 & \\
\hline & Litter Cover [\%] & 3 & 3 & 30 & 50 & 40 & \\
\hline & Vascular Plant Cover [\%] & 25 & 30 & - & 30 & 60 & \\
\hline & Moss Cover [\%] & 90 & 90 & 60 & 1 & 3 & \\
\hline & Number & 1 & 2 & 3 & 4 & 5 & Constancy \\
\hline ASSC & CIATION Diagnostic species & & & & & & \\
\hline & Carex lenticularis & 2 & 3 & 1 & 3 & 3 & 5 \\
\hline$(\mathrm{AC})$ & Tofieldia glutinosa & + & + & + & + & 2 & 5 \\
\hline & Salix commutata & + & 1 & + & . & . & 3 \\
\hline$A C$ & Equisetum variegatum & . & 2 & + & . & . & 2 \\
\hline & Leptarrhena pyrolifolia & $r$ & + & . & . & . & 2 \\
\hline & Equisetum arvense & + & $r$ & & & & 2 \\
\hline Com & Janion species: & & & & & & \\
\hline & Carex nigricans & $2 n$ & + & 3 & $x$ & $r$ & 5 \\
\hline & Juncus mertensianus & + & + & + & + & 3 & 5 \\
\hline & Senecio cymbalarioides & . & $r$ & + & + & 1 & 4 \\
\hline & Deschampsia cespitosa & . & . & . & $\mathrm{ad}$ & + & 2 \\
\hline & Epilobium alpinum & + & + & + & . & . & 3 \\
\hline & Salix arctica & 1 & . & + & . & . & 2 \\
\hline & Juncus drummondii & $r$ & . & $r$ & . & . & 2 \\
\hline & Dodecatheon pulchellum & . & . & . & ad & + & 2 \\
\hline Bryo & ohytes: & & & & & & \\
\hline & Philonotis fontana & 80 & 85 & $\mathrm{p}$ & $\mathrm{p}$ & $\mathrm{p}$ & 5 \\
\hline & Bryum pseudotriquetrum & $\mathrm{p}$ & . & . & $\mathrm{p}$ & $\mathrm{p}$ & 3 \\
\hline & Bryum sp. & $\mathrm{p}$ & $\mathrm{p}$ & . & $\mathrm{p}$ & . & 3 \\
\hline & Oncophorus virens & . & $p^{c f}$ & . & . & $\mathrm{p}$ & 2 \\
\hline & Brachythecium sp. & . & . & . & $\mathrm{p}$ & $\mathrm{p}$ & 2 \\
\hline & Bryum sp2 & 5 & . & . & . & . & 1 \\
\hline & Sphagnum sp. & 3 & . & . & . & . & 1 \\
\hline & Calliergon stramineum & 1 & . & . & . & . & 1 \\
\hline & Aulacomnium palustre & $\mathrm{p}$ & . & . & . & . & 1 \\
\hline & Hepaticae sp. & $\mathrm{p}$ & . & . & . & . & 1 \\
\hline & Scapania sp. & $\mathrm{p}$ & . & . & . & . & 1 \\
\hline & Campylium stellatum & . & $\mathrm{p}^{\mathrm{cf}}$ & . & . & . & 1 \\
\hline & Sanionia uncinata & . & $p^{c f}$ & . & . & . & 1 \\
\hline & Drepanocladus aduncus & . & $\mathrm{p}$ & . & . & . & 1 \\
\hline & Scorpidium cossoni & . & . & . & $p$ & . & 1 \\
\hline
\end{tabular}




\section{Association Table 32 (cont.):}

\section{Minor species:}

Pedicularis groenlandica 1:+ ; Agrostis thurberiana 1:+ , 3:+ ; Senecio triangularis 1:+ ; Veronica wormskjoldii 1:r ; Mimulus lewisii 1:ad; Habenaria saccata 2:r ; Eriogonum sp. 4:ad; Parnassia fimbriata 4:ad; Poaceae sp. 4:+ ; Carex spectabilis 3:+ ; Phleum alpinum 3:+ ; Poa alpina 3:+ 


\section{Acknowledgements}

A large number of people have been contributing to this study to a larger of lesser degree. First of all my sincere thanks go to to Prof. F.-G. Schroeder (Göttingen) for supervising this project and leaving me all the freedom a doctorate candidate could possibly desire. Many thanks are also due to Prof. H. Dierschke (Göttingen) for valuable advice and his willingness to act as a co-referent.

For launching the initial spark as well as for getting this project started I am indebted to Dr. R. Callauch (Göttingen, Germany) and Dr. Cliff Martinka (Boulder, CO).

My deep thanks is to the National Park Service, mainly the Staff of Glacier National Park, where about everybody I had to deal with contributed to a great experience not only of well-supported scientific work, but also of enriching personal interactions with numerous people. Many thanks are also due to the colleagues of the Science Center in West Glacier, of whom I have to mention my local supervisors Laurie Kurth and Tara Williams as well as Richard Menicke, Jen Asebrook, Dr. Dan Fagre, Karen Holzer, Lisa McKeon, Fritz Klasner, Dr. Kate Kendall, the Whitebark Project Crew, Dr.Carl Key and others.

Jen and Richard I would like to thank especially for providing a home whenever I needed a place.

My deepest thanks are to Toby Spribille (Fortine, MT), who contributed a wealth of information and support to this study, probably more than anybody else mentioned herein. Not only did we become great friends in the course of the years. With his ever-excited way, he made me interested in lichen and moss taxonomy, also beyond the alpine flora of the study area. He accompanied me through all steps of this study with his incredible amount of knowledge, encouragement, most productive discussions and a good sense of humor. Last but not least, Toby was also the one to suggest corrections and smoothen much of the English.

Of particular importance for the syntaxonomical part of this work were discussions with Dr. F. Daniels (Münster, Germany), Dr. H.E. Weber (Vechta, Germany), Dr. J. Moravec (Pruhonice, Czech Republic) and Dr. Jens Pallas (Münster)

For the verification and identification of specimens, I am indebted to Prof. T. Ahti (Helsinki, Finland), Dr. G. Douglas (Vancouver, BC), Dr. U. Drehwald (Göttingen), Dr. L. Hedenäs (Stockholm, Sweden), Dr. M. Hauck (Göttingen), J. Heinrichs (Göttingen), P. Lesica (Missoula, MT), Dr. H. Mayrhofer (Graz, Austria), Dr. B. McCune (Corvallis, OR), Dr. D. Murray (Fairbanks, AS), Dr. Elena Reiner-Drehwald (Göttingen), Dr. A. A. Reznicek (Ann Arbor, MI), R. Rosentreter (Boise, ID), Dr. H. Sipman (Berlin, Germany), Dr. R. J. Soreng (New York), Dr. D. H. Vitt (Edmonton, AB), Prof. W. A. Weber (Boulder, CO), and to Dr. V. Wirth (Stuttgart, Germany).

Vegetation data were provided by the Alberta Environment Data Conservation Center (Edmonton, AB), Lorna Allan (Edmonton, AB), D. Polster (Duncan, BC), M. Ketcheson (Nelson, BC), and Dr. K. Klinka \& H. Qian (Vancouver, BC). Of particular importance for the syntaxonomical part of this work were fruitful discussions with Dr. F. Daniels (Münster, Germany), Dr. H. E. Weber (Vechta, Germany), Dr. J. Moravec (Pruhonice, Czech Republic) and Dr. J. Pallas (Münster). Karen Golinski (Vancouver, BC) and K. Schulz (Boulder, CO) were helpful in making available additional literature. Valuable miscellaneous information was provided by Jerry DeSanto (Babb, MT), Dr. A. Ceska (Victoria, BC), Barry Dutton (Missoula, MT), Dr. C. Peppler (Oldenburg, Germany), and T. Becker (Göttingen). 
Thanks are to Dr. W. B. Dickoré (Göttingen) for his intense and constructive proofreading. Im am particularly grateful to A. Berg (Göttingen) for his technical and moral support on finalizing the manuscript.

Cordula Theil was and is a great inspiration. I deeply appreciate her encouragement, patience and care. Her way to manage to get along with a dedicated doctoral candidate was quite important for this study.

This study was supported by grants of Evangelisches Studienwerk Villigst e.V. (Schwerte, Germany) and Deutscher Akademischer Auslandsdienst e.V. (Bonn, Germany), which are gratefully acknowledged. 


\section{References}

Achuff P. L.; McNeil R. L.; Coleman M. L. (1997): Ecological Land Classification of Waterton Lakes National Park, Alberta. Soil and Vegetation Resources. Unpublished Report, 220 pp.

Achuff, P. L.; Corns, I. G. W. (1982): Vegetation. Vol.1. In: Holland, W. D.; Coen, G. M.: Ecological (biophysical) land classification of Banff and Jasper National Park. Alberta Institute of Pedology Publication No. SS-82-44.

Achuff, P. L.; Dudynski, H. A. (1984): Vegetation. Vol. I. Integrated Resource Description. In: Achuff, P. L.; Holland, W. D.; Coen, G. M.; Van Tighem, K. (eds.): Ecological Land Classification of Kootenay National Park, British Columbia. Alberta Institute of Pedology Publication No. M-84-10. University of Alberta, Edmonton.

Achuff, P. L.; Dudynski, H. A. (1984a): Vegetation. Vol. I. In: Achuff, P. L.; Holland, W. D.; Coen, G. M.; Van Tighem, K. (eds.): Ecological Land Classification of Mount Revelstoke and Glacier National Parks, British Columbia. Integrated Resource Description. Alberta Institute of Pedology Publication No. M-84-11. University of Alberta, Edmonton.

Achuff, P. L.; Taylor, W. S.; Knapik, L. J. (1993): Ecological Land Classification of Yoho National Park, British Columbia. Prepared for Yoho National Park, Canadian Parks Service, Environment Canada. Achuff Consulting, Canmore, Alberta and Pedocan Land Evaluation Ltd. Edmonton, Alberta

Aichinger, E. (1957): Die Silberwurzteppiche als Vegetationstypen (Dryas octopetala-Heiden). Angewandte Pflanzensoziologie 14: 156-171.

Anderson, D. J. (1967): Studies on structure in plant communities. IV. Cyclical succession in Dryas communities from north-west Iceland. J. Ecol. 55: 629-635.

Anderson, L. E.; Crum, H. A.; Buck, W. R. (1990): List of the Mosses of North America north of Mexico. The Bryologist 93(4): 448-499.

Anderson, M., P. Bourgeron, M. T. Bryer, R. Crawford, L. Engelking, D. FaberLangendoen, M. Gallyoun, K. Goodin, D. H. Grossman, S. Landaal, K. Metzler, K. D. Patterson, M. Pyne, M. Reid,L. Sneddon, and A. S. Weakley. (1998): International Classification of Ecological communities: Terrestrial Vegetation of the United States. Volume II. The National Vegetation Classification System: List of types. The Nature Conservancy, Arlington, Virginia, USA.

Andrews, T. (1983): Subalpine meadow and alpine vegetation of the upper Pecos River. USDA Forest Service Report RM-51. Southwestern Region, Albuquerque, N.M.

Archer, A. C. (1963): Appendix J. Plant successional studies in the alpine zone of Garibaldi Park. In: Krajina, V. J. (ed.): Ecology of the Forests of the Pacific Northwest. 1962 Progress Report. Dept. of Biology and Botany, University of British Columbia, Vancouver, pp. 78-82.

Archer, A. C. (1963): Some synecological problems in the alpine zone of Garibaldi Park. Unpublished M. Sc. Thesis, Dept. of Biology and Botany, University of British Columbia, Vancouver, $129 \mathrm{pp}$.

Baden, M. G. (1952): Plant succession following glacial recession in Glacier National Park, Montana. Research paper, Dept. Bot. Pomona College. 
Baig, N. M. (1972): Ecology of timberline vegetation in the Rocky Mountains of Alberta. Ph. D. Thesis, Dept. of Botany, University of Calgary, Alberta, 444 pp.

Baker, W. L. (1983): Alpine vegetation of Wheeler Peak, New Mexico, U. S. A.: gradient analysis, classification and biogeography. Arct. Alp. Res. 15: 223-240.

Bamberg, S. A. (1961): Plant Ecology of Alpine Tundra areas in Montana and adjacent Wyoming. unpublished M. A. Thesis, University of Colorado, Boulder, 163 pp.

Bamberg, S. A.; Major, J. (1968): Ecology of the Vegetation and Soils associated with calcareous Parent Materials in three alpine Regions of Montana. Ecological Monographs 38: 127-167.

Baptie, B. (1968): Ecology of the alpine soils of Snow Creek Valley, Banff National Park, Alberta. M.Sc. thesis, Dept. of Biology, University of Calgary Calgary, Alberta. 134 pp.

Barkman, J.; Moravec, J.; Rauschert, S. (1986): Code of Phytosociological Nomenclature. Vegetatio 67: 145-195.

Barrett, P. E. (1972): Phytogeocoenosis of a coastal lowland ecosystem, Devon Island, N. W. T, Ph. D. Thesis, University of British Columbia, Vancouver, 292 pp.

Bayer, R. J. (1993): A taxonomic revision of the genus Antennaria of Alaska and Yukon Territory, northwestern North America. Arct. Alp. Res. 25 (2): 150-159.

Bayer, R. J.; Stebbins, G. L. (1993): A Synopsis with keys for the genus Antennaria of North America. Can. J. Bot. 71(12): 1589-1604.

Becking, R. W. (1957): The Zurich-Montpellier School of Phytosociology. Botanical Review 23: 411-488.

Beder, K. (1967): Ecology of the alpine vegetation of Snow Creek Valley, Banff National Park, Alberta. Unpublished M. Sc. Thesis, University of Calgary, Alberta, 243 pp.

Bell, K. L.; Bliss, L. C. (1973): Alpine disturbancy study, Olympic National Park, United States. Biol. Conserv. 5: 25.

Bell, K. L.; Bliss, L. C. (1979): Autecology of Kobresia bellardii: Why winter snow accumulation limits local distribution. Ecol. Monogr. 49: 377-402.

Bellolio-Trucco, G.; Ireland, R. R. (1990): A taxonomic study of the moss genus Dicranum (Dicranaceae) in Ontario and Quebec. Can. J. Bot. 68: 867-909.

Bergmeier, E.; Härdtle, W; Mierwald, U.; Nowak, B.; Peppler, C. (1990): Vorschläge zur syntaxonomischen Arbeitsweise in der Pflanzensoziologie. Kieler Not. z. Pflanzenk. SchleswigHolst. Hamburg 20 (4): 92-103.

Billings, W. D. (1969): Vegetational pattern near alpine timberline as affected by fire-snowdrift interaction. Vegetatio 19: 192-207.

Billings, W. D.; Bliss, L. C. (1959): An alpine snowbank environment and its effects on vegetation, plant development, and productivity. Ecology 40: 388-397.

Billings, W. D.; Clebsch, E. E. C.; Mooney, H. A. (1966): Photosynthesis and respiration rates of Rocky Mountain alpine plants under field conditions. Am. Midl. Nat. 75: 34-44. 
Billings, W. D.; Mooney, H. A. (1968): The ecology of alpine and arctic plants. Biol. Rev. 43: 481-530.

Billings, W.D.; Bliss, L.C. (1959): An alpine snowbank environment and its effects on vegetation, plant development, and productivity. Ecology 40: 388-397.

Bird, C. D. (1970): Keys to the Lichens of West-Central Canada. Unpublished Manuscript, 170 pp.

Bliss, L. C. (1956): A comparison of plant development in microenvironments of arctic and alpine tundra. Ecol. Monog. 26: 303-337.

Bliss, L. C. (1958): Seed germination in arctic and alpine species. Arctic 11: 180-188.

Bliss, L. C. (1962): Adaptations of arctic and alpine plants to environmental conditions. Arctic 15: 117-144.

Bliss, L. C. (1969): Alpine community patterns in relation to environmental parameters. In: Greenridge, K. N. H.: Essays in plant geography and ecology. Nova Scotia Museum. Halifax, N. S., pp. 167-184.

Bøcher, T. W. (1954): Oceanic and continental vegetational complexes in southwest Greenland. Meddel. om Gronl. 148: 1-336.

Bockheim, J. G. (1972): Effects of alpine and subalpine vegetation on soil development, Mount Baker, Washington. Unpublished Ph. D. Thesis, University of Washington, Seattle, 171 pp.

Brassard, G. R.; Beschel, R. E. (1968): The vascular flora of Tanquary Fiord, Northern Ellesmere Island, N. W. T., Can. Field Natur. 82: 103-113.

Braun-Blanquet, J. (1964): Pflanzensoziologie. Grundzüge der Vegetationskunde. Springer Verlag, Wien, $865 \mathrm{pp}$.

Braun-Blanquet, J.; Jenny, H. (1926): Vegetationsentwicklung und Bodenbildung in der alpinen Stufe der Zentralalpen. Neue Denkschrift der Schweiz. Naturf. Ges. 63: 175-349.

Brett, R. B.; Klinka, K.; Qian, H. (1998): Classification of high-elevation, non-forested plant communities in coastal British Columbia. Scientia Silvica. Forest Service Deprtment, University of British Columbia, Vancouver, 58 pp.

Brink, V. C. (1964): Plant establishment in the high snowfall alpine and subalpine regions of British Columbia. Ecology 45: 431-438.

Brink, V.C. (1959): A directional change in the subalpine forest-heath ecotone in Garibaldi Park, British Columbia. Ecology 40: 10-16.

Broad J. (1973): Ecology of alpine vegetation at Bow Summit, Banff National Park. M. Sc. Thesis, University of Calgary

Brooke, R. C.; Peterson, E. B.; Krajina, V. J. (1970): The subalpine Mountain Hemlock Zone. Vol. 22, No. 2. In: Ecology of Western North America. Department of Botany, University of British Columbia, Vancouver, pp. 151-349.

Bruelheide, H.; Flintrop, T. (1994): Ordnen von Vegetationstabellen nach Arten-AufnahmenGruppen mit dem Programm ESPRESSO. Tuexenia 14: 493-502. 
Brun-Hool, J. (1966): Ackerunkraut-Fragmentgesellschaften. In: Tüxen, R. (ed.): Anthropogene Vegetation. Ber. Internat. Sympos. IVV Stolzenau 1961. Junk, Den Haag, pp. 38-50.

Bryant, J.P. (1968): Vegetation and frost activiy in an alpine fellfield on the summit of Plateau Mountain, Alberta. M.Sc. thesis, Dept. of Biology, University of Calgary.

Bryant, J.R.; Scheinberg, E. (1970): Vegetation and frost activity in an alpine fellfield on the summit of Plateau Mountain, Alberta. Can. J. Bot. 48: 751-772.

Butler, D. R. (1979): Snow avalanche path terrain and vegetation, Glacier National Park, Montana. Arct. Alp. Res. 11: 17-32.

Butler, D. R. (1985): Vegetational and geomorphic change on snow avalanche paths, Glacier National Park, Montana, USA. Great Basin Naturalist 45 (2): 313-317.

Butler, D. R.; Malanson, G. P. (1989): Periglacial patterned ground, Waterton-Glacier International Peace Park, Canada and USA., Z. Geomorph. N. F. 33 (1): 43-57.

Butler, D. R.; Malanson, G. P. (1994): Stability of alpine treeline in Glacier National Park, Montana, USA. Phytocoenologia 22(4): 485-500.

Butters, F. K. (1914): The Vegetation of the Selkirk Mountains. Mountaineering and Exploration in the Selkirks. Putnam, New York: 352-362.

Büttner, G. (1989): Der Boden als Teil des forstlichen Standorts. Institut für Bodenkunde und Waldernährung der Univeristät Göttingen, 134 pp.

Caicco, S. L. (1983): Alpine Vegetation of the Copper Basin Area, South-central Idaho. M. Sc. Thesis, University of Idaho, Moscow, 99 pp.

Cain, S.A. (1943): Sample-plot techniques applied to alpine vegetation in Wyoming. Amer. Jour. Botany 30: 240-247.

Carrara, P. E. (1986): Holocene and latest Pleistocene glacial chronology, Glacier National Park, Montana. Can. J. Earth Sciences 24: 387-395.

Carrara, P. E. (1989): Late quarternary Glacial and Vegetative History of the Glacier National Park Region, Montana. USGS Bulletin 1902. US Government Printing Office, Washington.

Carrara, P. E. (1989a): Map showing distribution of moraines and extent of glaciers from the mid-19th century to 1979 in the Mount Jackson area, Glacier National Park, Montana. US Geological Survey Miscellaneous Investigations Map 1:24000 I-1508-C.

Carrara, P. E. (1989b): Surficial Geologic Map of Glacier National Park, Montana. US Geological Survey Miscanllaeneaous Investigations Map 1:100000 I-1508-D.

Carrara, P. E., McGimsey, R. G. (1981): The late neoglacial histories of Agassiz and Jackson Glaciers, Glacier National Park, Montana. Arct. Alp. Res. 13: 183-196.

Ceska A; Spribille T. (1996): Key to the Genus Carex in Montana. Unpublished Manuscript, 25 pp.

Choate, C. M. (1963): Ordination of the Alpine Plant Communities at Logan Pass, Glacier National Park, Montana. M. A. Thesis, Univ. Montana Missoula, Montana, 106 pp.

Choate, C. M.; Habeck, J. R. (1967): Alpine Plant Communities at Logan Pass, Glacier National Park, Montana. Proc. Mont. Acad. Sci. 27: 36-54.

Cooper, D. (1986): Arctic-alpine tundra vegetation in Arrigetch Creek Valley, Brooks Range, 
Alaska. Phytocoenologia 14(4): 467-555.

Cooper, S. V.; Lesica, P. (1992): Plant Community Classification for Alpine Vegetation on Beaverhead National Forest, Montana. Ecological Study prepared for Beaverhead National Forest, $80 \mathrm{pp}$.

Cooper, S. V.; Lesica, P.; Page-Domroese, D. (1997): Plant Community Classification for Alpine Vegetation on Beaverhead National Forest, Montana. USDA Forest Service General Technical Report INT-GTR-362

Cooper, W.S. (1908): Alpine vegetation in the vicinity of Long's Peak, Colorado. Bot. Gaz. 45: 319-337.

Corns, I. G. W.; Achuff, P. L. (1982): Vegetation type descriptions in Banff and Jasper National Parks. In: Holland, W. D., Coen, G. M., (eds.): Ecological (Biophysical) Land Classification of Banff and Jasper National Parks, Vol. II. Soil and Vegetation Resources. Alberta Institute of Pedology, University of Alberta, Edmonton.

Coupland, R. T. (1961): A reconsideration of grassland classification in the Northern Great Plains of North America. J. Ecol. 49: 135-167.

Cox, C. F. (1933): Alpine plant succession on James Peak, Colorado. Ecol . Monog. 3: 299-372.

Crack, S. N. (1977): Flora and vegetation of Wilcox Pass, Jasper National Park, Alberta. M. Sc. Thesis, University of Calgary, 284 pp.

Cronquist A.; Holmgren A. H.; Holmgren N. H.; Reveal J. L.; Holmgren P. K. (1972-1977): Intermountain Flora. Vascular Plants of the Intermountain West, USA. Vol. 1-6. Published for the New York Botanical Garden by Hafner Pub. Co., New York, London.

Crow, G. E. (1978): A taxonomic revision of Sagina (Caryophyllaceae) in North America. Rhodora 80: 1-91.

Crum, H. A.; Anderson, L. E. (1981): Mosses of Eastern North America. Vol. 1+2. Columbia University Press, New York, 1328 pp.

Culberson, Ch. F.; Ammann, K. (1979): Standardmethode zur Dünnschichtchromatographie von Flechtensubstanzen. Herzogia 5: 1-24.

Damm, C. (1994): Vegetation und Florenbestand des Brockengebietes. Hercynia N. F. 29: 5-56.

Daniels, F. J. A. (1994): Vegetation classification in Greenland. J. Veg. Sci. 5(6): 781-790.

Daubenmire, R. F. (1943): Vegetational zonation in the Rocky Mountains. Bot. Rev. 9: 325-393.

Debolt, A.; McCune, B. (1993): Lichens of Glacier National Park, Montana. Bryologist 96(2): 192-204.

Del Moral, R. (1979): High elevation vegetation of the Enchantment Lakes Basin, Washington. Can. J. Bot. 57 (10): 1111-1130.

Dierschke, H. (1994): Pflanzensoziologie - Grundlagen und Methoden. Ulmer, Stuttgart. 683 pp.

Dierßen, K. (1984): Vergleichende Untersuchungen an Schneeböden (Zur Abgrenzung der Klasse Salicetea herbaceae). Ber. Deutsch. Bot. Ges. 97: 359-382.

Dierßen, K. (1990): Einführung in die Pflanzensoziologie (Vegetationskunde). Wiss. Buchgesellschaft, Darmstadt, 241 pp. 
Dierßen, K. (1992): Zur Synsystematik nordeuropäischer Vegetationtypen. 1. Alpine Vegetation und floristisch verwandte Vegetationseinheiten tieferer Lagen sowie der Arktis. Ber. Reinh.Tüxen-Ges. 4: 191-226. Hannover.

Dierßen, K. (1996): Vegetation Nordeuropas. Ulmer, Stuttgart. 838 pp.

Dightman, R. A. (1967): Climate of Glacier National Park, Montana. Glacier Natural History Association Bulletin No.79.

Dorn, R. D. (1984): Vascular Plants of Montana. Mountain West Publishing, Cheyenne, Wyoming.

Douglas G. W.; Straley, G.B.; Meidinger, D. (1994): The Vascular Plants of British Columbia.

Vol. 4. B.C. Ministry of Forests, Victoria. 257 pp.

Douglas, G. W. (1972): Subalpine plant communities of the Western North Cascades, Washington. Arct. Alp. Res. 4: 147-166.

Douglas, G.W.; Bliss, L.C. (1977): Alpine and high subalpine plant communities of the North Cascades Range, Washington and British Columbia. Ecol. Monogr. 47 (2): 113-150.

Eady, K. (1971): Ecology of the alpine and timberline vegetation of Big White Mountains, British Columbia. Unpublished Ph. D. Thesis, University of British Columbia, Vancouver, 329 pp.

Earhart, R. L.; Raup, O. B.; Whipple, J. W.; Isom, A. L.; Davis, G. A. (1989): Geologic Maps, Cross Section and Photographs of the central part of Glacier National Park, Montana. USGS Miscellaneous Investigations Map, 2 sheets I-1508-B

Eddleman, L. E.; Ward, R. T. (1984): Phytoedaphic relationships in alpine tundra of north central Colorado, USA. Arct. Alp. Res. 16: 343-359.

Elisens, W. J.; Packer, J. G. (1980): A contribution to the taxonomy of the Oxytropis campestris complex in northwestern North America. Can. J. Bot. 58: 1820-1831.

Elkington, T. T. (1971): Studies on the variation of the genus Dryas in Greenland. Medd. om Gronl. 178 (1): 1-56.

Ellenberg, H. (1956): Aufgaben und Methoden der Vegetationskunde. :Ulmer Verlag, Stuttgart. $156 \mathrm{pp}$.

Ellenberg, H. (1986): Vegetation Mitteleuropas mit den Alpen. 4. Aufl. Ulmer, Stuttgart, 989 pp.

Ellenberg, H. (1996): Vegetation Mitteleuropas mit den Alpen in ökologischer, dynamischer und historischer Sicht. 5th ed. Ulmer, Stuttgart, 1096 pp.

Esslinger, T. S. (1997): A Cumulative Checklist for the Lichen-forming, Lichenicolous and Allied Fungi of the Continental United States and Canada. URL: http://www. ndsu. nodak. edu/instruct/esslinge/chcklst/chcklst7. htm. Most Recent Update 15 May 2000 Fargo, North Dakota.

Evans, R. D.; Fonda, R. W. (1990): The influence of snow on subalpine community pattern, North Cascades, Washington. Can. J. Bot. 68: 212-220.

Ewan J. A. (1950): Rocky Mountain naturalists. University Denver Press, Denver, CO, 358 pp.

Falk, P. (1940): Further observations on the ecology of Central Iceland. J. Ecol. 28: 1-41.

Finklin, I. A. (1986): A climatic handbook for Glacier National Park - with data for Waterton 
Lakes National Park. USDA Forest Service Intermountain Research Stn. General Technical Report INT-204 Ogden, Utah, 124 pp.

Frahm, J. P.; Frey, W. (1987): Moosflora. 2. ed. Ulmer, Stuttgart, 525 pp.

Franklin, J.F.; Dyrness, C.T. (1969): Vegetation of Oregon and Washington. USDA Forest Service Research Paper PNW-80, Pacific Northwest Forest \& Range Experimental Station. Portland, Oregon. 216 pp.

Fraser, B. E. C. (1970): Vegetation Development on recent Alpine Glacier Forelands in Garibaldi Park, British Columbia. Ph. D. Thesis, University of British Columbia, Vancouver, 259 pp.

Frisvoll, A. A. (1983): A Taxonomic revision of the Racomitrium canescens Group (Bryophyta, Grimmiales). Gunneria 41, 181 pp.

Frisvoll, A. A. (1988): A Taxonomic revision of the Racomitrium heterostichum Group (Bryophyta, Grimmiales) in N. and C. America, N. Afrika, Europe and Asia. Gunneria 59, 289 pp.

Gadd, Ben (1991): Handbook of the Canadian Rockies. Corax Press, Jasper, Alberta, 831 pp.

Gelting, P. (1934): Studies on the vascular plants of east Greenland between Franz Josephy Fjord and Dove Bay (Lat. $73^{\circ} 15^{\prime}-76^{\circ} 20^{\prime}$ ). Med. om Gronl. 101 (2): 1-340.

Gelting, P. (1937): Studies of the food of the East Greenland ptarmigan, especially in its relation to vegetation and snow cover. Med. om Gronl. 116 (3): 1-373.

Given, D. R.; Soper, J. H. (1975): Pioneer vegetation on moraines near Clachnacudainn Snowfield, British Columbia. Syesis 8: 349-354.

Gjaerevoll, O. (1954): Kobresieto-Dryadion in Alaska. Nytt. Mag. Bot. 3: 51-55.

Gjaerevoll, O. (1956): The plant communities of the Scandinavian alpine snowbeds. Norske Vidensk. Selsk. Skrift, 405 pp.

Gjaerevoll, O. (1980): A Comparison between the alpine plant communities of Alaska and Scandinavia. Acta Phytogeogr. Suec. 60: 83-88.

Goward, T.; McCune, B., Meidinger, D. (1994): Lichens of British Columbia. Part 1 - Foliose and Squamulose Species. B. C. Ministry of Forests, Victoria, 181 pp.

Griggs, R. F. (1956): Competition and succession in a Rocky Mountain fellfield. Ecology 37: 820.

Briggs, G. M.; MacMahon, J. A. (1983): Alpine and subalpine wetland plant communities of the Uinta Mountains, Great Basin Naturalist 43(4): 523-530.

Grossman, D. H.; Faber-Langendoen, D.; Weakley, A. S.; Anderson, M.; Bourgeron, P.; Crawford, R.; Goodin, K.; Landaal, S.; Metzler, K.; Patterson, K. D.; Pyne, M.; Reid, M.; Sneddon, L. (1998): Terrestrial Vegetation of the United States, Vol. 1. The National Vegetation Classification System: Development, Status and Applications. The Nature Conservancy, 139 pp.

Grout, A. J. (1931-1940): Moss Flora of North America north of Mexico. Vols. I-III, 264, 285 and $275 \mathrm{pp}$. 
Habeck, J. R. (1963): The composition of several climax communities in the Lake McDonald area of Glacier National Park. Proc. Montana Acad. Sci. 23: 37-44.

Habeck, J. R. (1968): Forest succession in the Glacier Park cedar-hemlock forests. Ecol. 49: 872880.

Habeck, J. R. (1969): A Gradient Analysis of a Timberline Zone at Logan Pass, Glacier Park, Montana. Northw. Sci. 43: 65-73.

Habeck, J. R. (1970): The Vegetation of Glacier National Park. Missoula, Montana, 132 pp.

Habeck, J. R.; Choate, C. M. (1963): An analysis of Krummholz Communities at Logan Pass, Glacier National Park. Northwest Science 37 (4): 165-166.

Hadac (1946): The plant communities of Sassen Quarter, Vestspitsbergen. Stud. Bot. Czechosl. 7: $127-164$.

Hale, M. E. (1990): A Synopsis of the Lichen Genus Xanthoparmelia (Vainio) Hale (Ascomycotina, Parmaliaceae). Smithsonian Contributions to Botany 74, 250 pp.

Hall, F. C. (1973): Plant communities of the Blue Mountains in eastern Oregon and southeastern Washington. USDA Forest Service Pacific Northwest Region R6 Area Guide: 3-162 pp.

Hamann, M.J. (1972): Vegetation of alpine and subalpine meadows at Mount Rainier National Park, Washington. M.Sc. thesis, Washington State Univ., unpubl. Pullman. 120 pp.

Hämet-Ahti, L. (1965): Luzula piperi (Cov.) M. E. Jones, an overlooked Woodrush in western North America and eastern Asia. Aquilo, Ser. Botanica 3: 11-21.

Hämet-Ahti, L. (1965a): Notes on the vegetation zones of western Canada, with special reference to the forests of Wells Gray Provincial Park, British Columbia. Ann. Bot. Fenn. 2: 274-300.

Hämet-Ahti, L. (1971): A synospsis of the species of Luzula, subgenus Anthelaea Griseb. (Juncaceae) indigenous in North America. Ann. Bot. Fenn. 8 (4): 368-381.

Hämet-Ahti, L. (1973): Notes on the Luzula arcuata and L. parviflora groups in eastern Asia and Alaska. Ann. Bot. Fennici 10: 123-130.

Hämet-Ahti, L. (1978): Timberline Meadows in Wells Gray Park, B.C. and their comparative geobotanical interpretation. Syesis 11: 187-211.

Hammer, S. (1995): A Synopsis of the genus Cladonia in the Northwestern United States. The Bryologist 98(1): 1-28.

Hansen, E. S.; Poelt, J., Soechting, U. (1987): Die Flechtengattung Caloplaca in Grönland. Medd. om Gronland, Bioscience 25: 3-51.

Hansen, H. P. (1948): Postglacial forests of Glacier National Park. Ecol. 29 (2): 146-152.

Harshberger (1929): The vegetation of the screes, or talus slopes of western North America. Amer. Phil. Soc. Proc. 68: 13-25.

Hartley, E. A. (1976): Man's effect on the stability of alpine and subalpine vegetation in Glacier National Park, Montana. Ph. D. Thesis., Duke University, Durham, North Carolina

Hedenäs, L. (1993): Field and microscopic keys to the Fennoscandian species of the CalliergonScorpidium-Drepanocladus Complex. Biodetektor AB, Märsta, Schweden, 79 pp.

Hedenäs, L. (1997): A partial generic revision of Campylium (Musci). The Bryologist 100(1): 65- 
88

Heidel, B. (1999): Plant species of special concern. unpublished list Natural Heritage ProgramHelena, Montana.

Henderson, J. A. (1974): Composition, distribution and succession of subalpine meadows in Mount Rainier National Park, Washington. Ph. D. Thesis, Oregon State University, Corvallis, Oregon, $153 \mathrm{pp}$.

Heusser, C. J. (1956): Postglacial environments in the Canadian Rocky Mountains. Ecol. Monog. 26: 263-302.

Hickman, J. C. (1976): Non-Forest Vegetation of the Central Western Cascade Mountains of Oregon. Northwest Science 50 (3): 145-155.

Hill, M. O. (1979): TWINSPAN - a FORTRAN program for arranging multivariate data in an ordered two-way table by classification of the inidividuals and attributes. Cornell University Ithaca, New York, 60 pp.

Hitchcock, C. L.; Cronquist, A. (1973): Flora of the Pacific Northwest. (6th printing, 1987). University of Washington Press, Seattle, London, 730 pp.

Hitchcock, C. L.; Cronquist, A.; Ownbey, M.; Thompson, J. W. (1955, 1959, 1961, 1964, 1969): Vascular Plants of the Pacific North West. University of Wash. Publ. Biol. 17 Vol. I-V. University of Washington Press, Seattle, London.

Hoefs, M.; Cowan, I. McT.; Krajina, V. J. (1975): Phytosociological analysis and synthesis of Sheep Mountain, southwest Yukon Territory, Canada. Syesis 8, Suppl. 1: 125-228.

Holway, J. G.; Ward, R. T. (1965): Phenology of alpine plants in northern Colorado. Ecol 46: 7383.

Hopson, R.E. (1961): The arctic-alpine zone in the Three Sisters Region. Mazama 43: 14-27.

Horton, D. G. (1983): A revision of the Encalyptaceae (Musci) with particular reference to the north American taxa. Part II. J. Hattori Bot. Lab. 54: 353-532.

Hrapko, J. O.; LaRoi, G. H. (1978): The alpine tundra vegetation of Signal Mountain, Jasper National Park. Can. J. Bot. 56: 309-332.

Issler, E. (1942): Vegetationskunde der Vogesen. Pflanzensoziologie 5. Jena. 192 pp.

Ives, J. D. (1974): Biological refugia and the nunatak hypothesis. In: Ives, J. D. \& Barry, R. D. (eds)., Arctic and alpine environments. Methuen \& Co. Ltd., London, pp. 605-636.

Ives, J. D. (1977): Remarks on the stability of timberline. Erdwissenschaftliche Forschung. Steiner, Wiesbaden.

Ives, J. D.; Barry, R. G.(eds.) (1974): Arctic and Alpine Environments. Methuen, London, 999 pp.

Jaques , D.R.; Legge, A.H. (1974): Living environment: vegetation. The mountain environment and urban society, Kananaskis Project. Environmental ceiences Centre, University of Calgary. Calgary. pp. 193-280.

Johnson, P.L.; Billings, W.D. (1962): The alpine vegetation of the Beartooth Plateau in relation to cryopedogenic processes and patterns. Ecol. Monog. 32: 105-135.

Kiener, W. (1939): Sociological studies of the alpine vegetation on Longs Peak. Ph.D. thesis, 
Univ. Nebraska, Lincoln, Nebraska. 68 pp.

Kiener, W. (1967): Sociological Studies of the alpine vegetation on Long's Peak. Univ. Nebraska Stud. new series 34, Lincoln, Nebraska. 75 pp.

Kirby, C.L.; Ogilvie, R.T. (1969): The forests of the Marmot Creek Watershed Research Basin. Department of Fisheries and Forestry. Candian Forestr Service Publication. Publication 1259

Klinka, K. H.; Qian, H., Ceska, A. (1997): Provisional classification of non-forested plant communities in coastal British Columbia. For. Sci. Dep., University of British Columbia, Vancouver

Knapik, L. J.; Scotter, G. W.; Pettapiece, W. W: (1973): Alpine soil and plant community relationsships of the Sunshine area, Banff National Park. Arct. Alp. Res. 5 (3) part 2: A161A170.

Kondla, N. et al. (1978): An overview vegetation survey of Kananaskis Provincial Park. Alberta Recreatiion, Parks and Wildlife. Edmonton.

Komarkova, V. (1976): Alpine vegetation of the Indian Peaks area, Front Range, Colorado Rocky Mountains. Ph. D. Thesis, University of Boulder Colorado, 655 pp.

Komárková, V. (1979): Alpine Vegetation of the Indian Peaks Area, Front Range, Colorado Rocky Mountains. Flora et Vegetatio Mundi 7: J. Cramer, Vaduz, 591 pp.

Komárková, V. (1993): Vegetation type hierarchies and landform disturbance in arctic Alaska and alpine Colorado with emphasis on snowpatches. Vegetatio 106(2): 155-181.

Koponen, T. (1968): The moss genus Plagiomnium Kop. sect. Rosulata (Kindb.) Kop. in northwestern Europe. Ann. Bot. Fenn. 5 (4): 213-224.

Koponen, T. (1969): Generic revision of Mniaceae Mitt. (Bryophyta). Ann. Bot. Fenn. 5 (4): $117-$ 151.

Koponen, T. (1971): A monograph of Plagiomnium sect. Rosulata (Mniaceae). Ann. Bot. Fenn. 8 (4): 305-367.

Koponen, T. (1972): Notes on Mnium arizonicum and Mnium thomsonii. Lindbergia 1 (3-4): 161165.

Koponen, T. (1974): A guide to the Mniaceae in Canada. Lindbergia 2 (3/4): 160-184.

Koterba, W. D.; Habeck, J. R. (1971): Grasslands of the North Fork Valley, Glacier National Park, Montana. Can. J. Bot. 49: 1627-1636.

Krajina, V. J. (1933): Die Pflanzengesellschaften des Mlynica-Tales in den Vysoke Tatry (Hohe Tatra) mit besonderer Berücksichtigung der ökologischen Verhältnisse. Bot. Centralbl. Beih. (Abt.2) 51: 1-224.

Krajina, V. J. (1965): Bioclimatic zones and classification of British Columbia. In: Ecology of Western North America. Vol. 1. Dept. of Botany, University of Britsh Columbia, Vancouver, pp. 1-17.

Krajina, V. J. (1965): Bioclimatic zones and classification of British Columbia. Ecology of Western North America 1: 1-17.

Krajina, V. J.; Brooke, R. C.; Peterson, E. B. (1970): The Subalpine Mountain Hemlock Zone. Ecology of Western North America 2/2: 151-349. 
Kuchar, P. (1973): Habitat types of Waterton Lakes National Park. Indian \& N. Affairs, Parks Canada, Unpublished Report, 301 pp.

Kuchar, P. (1975): Alpine tundra communities and Dryas octopetala ssp. hookeriana in the Bald Hills, Jasper National Park. Ph. D. Thesis. University of Calgary

Kuminova, A. V (1960): Rastitel 'nyi pokrov Altaya (The vegetation of the Altai). Izd. Sibirsk. Otd. Akad. Nauk SSSR Novosibirsk, 450 pp.

Kuramoto, R. T.; Bliss, L. C. (1970): Ecology of subalpine meadows in the Olympic Mountains, Washington. Ecol. Monog. 40: 317-347.

Lackschewitz K. (1991): Vascular Plants of West-Central Montana. USDA Forest Service, Intermountain Research Station General Technical Report INT-277, 648 pp.

Langenheim, J.H. (1962): Vegetation and environmental patterns of Crested Butte Area, Gunnison County, Colorado. Ecol. Monogr. 32: 249-285.

Lawrence, D. B; Schoenike, R. E.; Quispel, A.; Bond, G. (1967): The role of Dryas drummondii in vegetation development following ice recession at Glacier Bay, Alaska, with special reference to its nitrogen fixation by root nodules. J. Ecol. 55: 793-813.

Lawton, E. (1957): A revision of the genus Lescuraea in Europe and North America. Bull. Torr. Bot. Club 84: 281-307.

Lawton, E. (1971): Moss Flora of the Pacific Northwest. Journal of the Hattori Botanical Laboratory Suppl.1. Miyazaki, Japan.

Lesica, P. (1988): Monitoring the Effects of Global Warming Using Peripheral Rare Plants in Wet Alpine Tundra in Glacier National Park, Montana. Unpublished Progress Report for the National Park Service Missoula, Montana.

Lesica, P. ; McCune, B. (1990): Monitoring the Effects of Global Warming Using Peripheral Rare Plants in Wet Alpine Tundra in Glacier National Park, Montana. Unpublished Progress Report for the National Park Service Missoula, Montana.

Lesica, P.; McCune, B. (1992): Monitoring the Effects of Global Warming Using Peripheral Rare Plants in wet Alpine Tundra in Glacier National Park, Montana. 1990 Progress Report prepared for Glacier National Park Research Division, 36 pp.

Lesica, P.; Shelly, S. J. (1991): Sensitive, threatened and endangered vascular plants of Montana. Montana Natural Heritage Program Occasional Publication 1Helena, Montana. 88pp.

Leuckert, C.; Kümmerling, H.; Wirth, V. (1995): Chemotaxonomy of Lepraria Ach. and Leproloma Nyl. ex Crombie, with particular reference to Central Europe. In: Farkas, E. E.; Lücking, R.; Wirth, V. (eds.): Scripta Lichenologica - Lichenological Papers Dedicated to Antonín Vezda. Bibliotheca Lichenologica. J. Cramer. Berlin, Stuttgart, pp. 245-259

Lewis, F. J. (1917): Vegetation distribution in the Rocky Mountains Park. Canad. Alpine J. 8: 8795.

Little, E. L. (1941): Alpine Flora of San Francisco Mountain, Arizona. Madrono 6: 65-81.

Longton, R.E. (1992): In: J.W. Bates; A.M. Farmer (1992): Bryophytes and Lichens in a changing environment :Oxford Science Publications,

Looman, J. (1963): Preliminary Classification of Grasslands in Saskatchewan. Ecol. 44: 15-29. 
Looman, J. (1969): The Fescue Grasslands of Western Canada. Vegetatio 19: 128-145.

Loope, L. L. (1969): Subalpine and Alpine Vegetation of Northeastern Nevada. Ph. D. Thesis, Department of Botany Duke University Durham, N. C., 307 pp.

Löve, A., Löve, D.; Kapoor, B. M. (1971): Cytotaxonomy of a century of Rocky Mountain orophytes. Arct. Alp. Res. 3 (2): 139-165.

Löve, D. (1970): Subarctic and subalpine: where and what? Arct. Alp. Res. 2(1): 63-73.

Magnusson, A. H. (1947): Rinodina in North America. Botaniska Notiser 1: 32-54.

Magnusson, A. H. (1947a): Studies on non-saxicolous species of Rinodina mainly from Europe and Siberia. Acta Horto Gothob. 17: 191-338.

Marr, J. W.; Willard, B. E. (1970): Persisting Vegetation in an Alpine Recreation Area in the Southern Rocky Mountains. Biol. Conserv. 2: 97-104.

McClelland, B. R. (1970): Ecosystems of Glacier National Park. Unpubl. part of Glacier National Parks Resource Management Plan

McCune, B. (1993): Key to the lichen genera of the Pacific Northwest. Unpublished Manuscript, $47 \mathrm{pp}$.

McCune, B.; Goward, T. (1995): Macrolichens of the Rocky Mountains. Mad River Press Inc., $208 \mathrm{pp}$.

McLean, A. (1970): Plant communities of the Similkameen Valley, British Columbia, and their relationships to soils. Ecol. Monogr. 40: 403-424.

McVean, D. N.; Ratcliffe, D. A. (1962): Plant communities of the Scottish Highlands. Nature Conservancy Monograph 1. H. M. S. O., London. 445 pp.

Meusel, H., Jäger; E.; Weinert, E. (1965): Vergleichende Chorologie der zentraleuropäischen Flora. Vol. 1+2. Fischer, Jena. 583 and 258 pp.

Michener-Foote, J.; Hogan, T. (1999): The Flora and Vegetation of the Needle Mountains, San Juan Range, southwestern Colorado. Natural History Inventory of Colorado 18:Univ. of Colorado Museum, Boulder, CO.

Mooney, H. A.; Billings, W. D. (1960): The annual carbohydrate cycle of alpine plants as related to growth. Am. J. Bot. 47: 594-598.

Moore, T. C. (1965): Origin and disjunction of the alpine tundra on the San Franzisco Mountain, Arizona. Ecol. 46: 860-864.

Mortimer, P. R. (1978): The alpine vascular flora of Prospect Mountain, Front Range, Rocky Mountains, Alberta. M. Sc. Thesis, University of Alberta

Mortimer, P.R. (1978): The alpine vascular flora of Prospect Mountain, Front Range, Rocky Mountains, Alberta. MS thesis Univ. Alberta

Moseley, R.K. (1985): Synecological relationships of alpine spike-Fescue grasslands in eastcentral Idaho. M.S. thesis, University of Idaho, Moscow.

Moss, E. H. (1955): The vegetation of Alberta. Bot. Rev. 21: 493-567.

Moss, E. H. (1959): Flora of Alberta. University of Toronto Press, 545 pp.

Moss, E. H.; Campbell, J. A. (1947): The Fescue grassland of Alberta. Canad. J. Res. C 25: 209- 
Mudge, M. R. (1977): General Geology of Glacier National Park and adjacent areas, Montana. Bulletin of Canadian Petroleum Geology 25(4): 736-751.

Mueggler, W.F.; Stewart, W.L. (1980): Grassland and shrubland habitat types of western Montana. USDA Forest Service General Technical Report INT-66 Ogden, Utah.

Mueller-Dombois, D.; Ellenberg, H. (1974): Aims and Methods of Vegetation $\quad$ Ecology. John Wiley and Sons, Toronto, Ontario.

Murray, D. F. (1969): Taxonomy of Carex section Atratae (Cyperaceae) in the southern Rocky Mountains. Brittonia 21: 55-76.

Murray, D. F. (1970): Carex podocarpa and its allies in North America. Can. J. Bot. 48: 313-324.

Nordhagen, R. (1928): Die Vegetation und Flora des Sylenegebietes. Eine pflanzensoziologische Monographie. Skr. utgitt av det norske Vidensk.-Akad. i Oslo. I. Mat.-naturv. Klasse 1927 1: 1612. Oslo.

Nordhagen, R. (1936): Versuch einer neuen Einteilung der subalpinen-alpinen Vegetation Norwegens. Bergens Mus. Arbok, Naturv. rekke 7: 1-88.

Nyholm, E. (1954-1969): Illustrated Moss Flora of Fennoscandia II. Musci. Fasc. 1-6. CWK Gleerup, Lund and Natural Science Research Council, Stockholm, Sweden, 799 pp.

Oberbauer, S. F.; Billings, W. D. (1981): Drought tolerance and water use by plants along an alpine topographic gradient. Oecologia 50: 325-331.

Ogilvie, R. T. (1976): The alpine and subalpine in the Rocky Mountains of Alberta. In: Luttmerding, H. A., Shields, J. A., (eds.): Proc. Workshop on alpine and subalpine environments, Victoria, British Columbia, Prov. of British Columbia, Min. Environ. Res., Anal. Br.

Ohba, T. (1974): Vergleichende Studies über die alpine Vegetation Japans. 1. Carici rupestrisKobresietea bellardii. Phytocoenologia 1 (3): 339-401.

Packer, J. G. (1972): A taxonomic and phytogeographical review of some arctic and alpine Senecio species. Can. J. Bot. 50: 507-518.

Peinado, M.; Aquirre, J. L.; de la Cruz, M. (1998): A phytosociological survey of the boreal forest (Vaccinio-Piceeta) in North America. Plant Ecology 137: 151-202.

Peppler, C. (1988): TAB - Ein Computerprogramm für die pflanzensoziologische Tabellenarbeit. Tüxenia 8: 393-406.

Peppler, C. (1992): Die Borstgrasrasen (Nardetalia) Westdeutschlands. Diss. Bot. 193: J. Cramer, Berlin, Stuttgart, 404 pp.

Peterson, K. M.; Billings, W. D. (1982): Growth of alpine plants under controlled drought. Arct. Alp. Res. 14: 189-194.

Peterson, W. (1979): A Revision of the Genera Dicranum and Orthodicranum (Musci) in North America north of Mexico. Ph. D. Thesis. University of Alberta, Edmonton, 453 pp.

Philippi, G. (1989): Die Pflanzengesellschaften des Belchengebietes im Schwarzwald. In: Der Belchen - Geschichtlich-naturkundliche Monographie des schönsten Schwarzwaldberges. Natur- und Landschaftsschutzgebiete Baden-Württemberg. Vol. 13. Karlsruhe, pp. 747-890. 
Podani, J. (1993): SYNTAX-PC. Computer Programs for multivariate Data Analysis in Ecologyadn Systematics. Version 5. Users Guide. Scientia Publishing, Budapest, 104 pp.

Poelt, J. (1969): Bestimmungsschlüssel europäischer Flechten. J. Cramer, Lehre, 757 pp.

Pojar, J. (1991): Subalpine and alpine vegetation of the Gladys Lake Ecological Reserve, Northern British Columbia. Contributions to Natural Science. British Columbia Provincial Museum 12: 1-28.

Polster, D. F. (1977): Plant communities of the alpine and meadow areas of southeastern British Columbia. Unpublished M. Sc. Thesis, University of British Columbia, Vancouver, 160 pp.

Polunin, N. (1948): Botany of the Canadian Eastern Arctic. Part III. Vegetation and Ecology. Nat. Mus. Can. Bull., 104, Biol. Ser. 32: 1-304.

Purvis, O. W.; Coppins, B. J. et al. (1992): The Lichen Flora of Great Britain and Ireland. Natural History Museum Publications in association with The British Lichen Society, 710 pp.

Ramaley, F. (1919): The role of sedges in some Colorado plant communities. Amer. J. Bot. 6: 120-130.

Raup, H.M. (1947): The Botany of southwestern Mackenzie. Sargentia 6: 1-275.

Raup, O. B.; Earhart, R. L.; Whipple, J. W.; Carrara, P. E. (1983): Geology along Goint-tothe-Sun-Road, Glacier National Park, Montana. Glacier Natural History Association West Glacier, Montana.

Razzhivin, V. Yu. (1994): Snowbed vegetation of far northeastern Asia. J. Veg. Sci. 5 (6): 829842.

Rivas-Martínez, S.; Sánchez-Mata, D.; Costa, M. (1999): North American boreal and western temperate forest vegetation (Syntaxonomical Synopsis of the potential natural plant communties of North America II.) Itinera geobotanica 12: 4-316.

Rollins, R. C. (1993): The Cruciferae of continental North America: systematics of the mustard family from the Arctic to Panama. Stanford University Press, Stanford, CA.

Rønning, O. I. (1965): Studies on Dryadion of Svalbard. Norsk Polarinstitutt Skrifter 134, 52 pp.

Ropin, K.; Mayrhofer, H. (1993): Zur Kenntnis corticoler Arten der Gattung Rinodina (lichenisierte Ascomyceten) in den Ostalpen und angrenzenden Gebieten. Herzogia 9: 779-835.

Ross, C. P. (1959): Geology of Glacier National Park and the Flathead Region Northwestern Montana. Geological Survey Professional Paper 296. United States Government Printing Office, Washington $123 \mathrm{pp}$.

Rottman, M.L.; Hartman, E.L. (1985): Tundra vegetation of three cirque basins in the northern San Juan Mountains, Colorado. Great Basin Naturalist 45: 87-93.

Sammons, I. (1959): Flora of Logan Pass, Glacier National Park, Montana. Unpublished Report, Department of Botany, University of Montana Missoula, 16 pp.

Sawyer, P. T. (1967): Taxonomic study of Montana Delphiniums. Proc. of the Montana Acad. Sci. 27: 20-25.

Scheffer, F.; Schachtschabel, P. (1989): Lehrbuch der $\quad$ Bodenkunde. $\quad 12 . \quad$ Aufl.:Enke, Stuttgart. 491 pp. 
Schlatterer, E.F. (1972): A preliminary description of plant communities found in the Sawtooth, White Cloud, Boulder, and Pioneer Mountains. USDA For. Serv., Region 4, mimeo report. 111 pp.

Schlüter, H. (1966): Vegetationsgliederung und -kartierung eines Quellgebietes im Thüringer Wald als Grundlage zur Beurteilung des Wasserhaushaltes. Archiv für Naturschutz und Landschaftsforschung $6(1 / 2)$

Schmid, E. (1923): Vegetationsstudien in den Urner Reusstälern. Ansbach.

Schroeter, C. (1926): Das Pflanzenleben der Alpen. Eine Schilderung der Hochgebirgsflora. A. Raustein, Zürich. 1288 pp.

Schuster, R. M. (1953, reprint 1977): Boreal Hepaticae. A manual of the liverworts of Minnesota and adjacent regions. Amer. Midl. Naturalist 49(2): 257-684. reprint: J. Cramer, Vaduz, Notre Dame, Indiana.

Schuster, R. M. (1966): The Hepaticae and Anthoceratae of North America east of the hundredth meridian. Vol. 1. Columbia University Press, New York.

Schuster, R. M. (1969): The Hepaticae and Anthoceratae of North America east of the hundredth meridian. Vol. 2. Columbia University Press, New York, 1062 pp.

Scoggan, H. J. (1978-1979): The Flora of Canada. National Museums of Natural Science. Publications in Botany 7(1-4), Ottawa.

Scott, D.; Billings, W. D. (1964): Effects of environmental factors on standing crop and productivity of an alpine tundra. Ecol. Monog. 34: 243-270.

Scott, R. W. (1966): The alpine flora of northwestern Wyoming. M. A. Thesis, University of Wyoming Laramie, $219 \mathrm{pp}$.

Scott, R.W. (1971): Ecology and Phytogeography of Alpine Vegetation in the southeastern Wrangell Mountains, Alaska. Ph.D. Thesis. University of Michigan. Ann Arbour, Michigan. $314 \mathrm{pp}$.

Shaw, C. H. (1916): The Vegetation of the Selkirks. The Botanical Gazette 6/6: 477-494.

Smith, A. J. E. (1978): The Moss Flora of Great Britain and Ireland. Cambridge University Press 706.

Soil Survey Staff (1975): Soil Taxonomy: A basic system of soil classification for making and interpreting soil surveys. Agricultural Handbook 436, U. S. Government Printing Office, Washington D. C., 756 pp.

Spribille, T. (1999): Forest vegetation in the northern Salish Mountains of northwestern Montana (U.S.A.). Phytocoenologia 29 (4): 503-577.

Stachurska-Swakon, A.; Spribille, T. (2001): Syntaxonomy and ecology of forest vegetation in the Whitefish Range (northwestern Montana, U.S.A.). unpublished manuscript

Steubing, L., Fangmeier, A. (1992): Pflanzenökologisches Praktikum. Eugen Ulmer, Stuttgart, $205 \mathrm{pp}$.

Stotler R.; Crandall-Stotler B. (1977): A checklist of the liverworts and hornworts of North America. The Bryologist 80(3): 405-428.

Stringer, P. W. (1969): An ecological study of grasslands at low elevations in Banff, Jasper and 
Waterton Lakes National Park. Ph. D. Thesis, University of Alberta, Edmonton, 342 pp.

Stringer, P. W. (1973): An ecological study of grasslands in Banff, Jasper and Waterton Lakes National Park. Can. J. Bot. 51 (2): 383-411.

Tardiff, S. E.;Stanford., J. A. (1998): Grizzly bear digging: Effects on subalpine meadow plants in relation to mineral nitrogen availability. Ecol 79 (7): 2219-2228.

Thilenius, John F; Smith, Dixie R. (1985): Vegetation and soils of an alpine range in the Absaroka Mountains, Wyoming. USDA Forest Service general technical report. RM 121. Fort Collins, Colorado. 18 pp.

Thomson, J. W. (1979): Lichens of the Alaskan Arctic Slope. University of Toronto Press, 314 pp.

Thomson, J. W. (1984): American Arctic Lichens: I. The Macrolichens. Columbia University Press, 504 pp.

Thomson, J. W. (1997): American Arctic Lichens: II. The Microlichens. University of Wisconsin Press, Madison, 675 pp.

Timoney, K. (1999): Limber Pine, Whitebark Pine, Alpine Heath, and terricolous alpine lichen vegetation Alliances in Alberta. Compilation of Information on Selected Alberta Plant Communities 1998-1999; K. Timoney, Treeline Ecological Research, Alberta Environmental Protection Resorce Data Division Edmonton, Alberta. 197 pp.

Timpe, E. B. (1990): Untersuchungen an muscicolen, arktisch-alpin verbreiteten Arten der Gattung Rinodina (Physciaceae, Lichenes). Diploma-Thesis. Karl-Franzens Universität Graz.

Timpe, E. B. (1991): Schlüssel der muscicolen Sippen der Flechtengattung Rinodina in den Alpen. In: J. Hafellner (ed.): 6. Österreichisches Botanikertreffen in Graz, Tagungsbericht. Graz, Austria.

Trottier, G. C. (1972): Ecology of the Alpine Vegetation of Highwood Pass, Alberta.

Urbanczyk, S.M.; Henderson, D.M. (1994): Classification and Ordination of alpine plant communities, Sheep Mtn., Lemhi County, Idaho. Madrono 41 (3): 205-223.

van Vechten, G. W. (1960): The Ecology of the Timberline and Alpine Vegetation of the Three Sisters, Oregon. Ph. D. Thesis, Oregon State University, Corvallis, $111 \mathrm{pp}$.

Viereck, L. A. (1966): Plant succession and soil development on glacial outwash of the Muldrow Glacier, Alaska. Ecol. Monogr. 36: 181-199.

Viereck, L. A.; Dyrness, C. T.; Batten, A. R.; Wenzlick, K. J. (1992): The Alaska vegetation classification. USDA For. Serv. Gen. Tech. Rep. PNW-GTR-268 Portland, Oregon.

Vitikainen, O. (1985): Three new species of Peltigera (lichenized Ascomycetes). Ann. Bot. Fenn. 22: $291-298$.

Vitikainen, O. (1994): Taxonomic revision of Peltigera (lichenized Ascomycotina) in Europe. Ann. Bot. Fenn. 152

Vitt, D. H.; Marsh, J. E., Bovey, R. B. (1988): Mosses , Lichens and Ferns of Northwest North America. Lone Pine Publishing, 296 pp.

Washburn, A. L. (1956): Classification of patternd ground and review of suggested origins. Bulletin of the Geological Society of America 67: 823-865. 
Webber, P. J.; Komárková; V, Walker, D. A.; Werbe, E. (1979): Geobotanical studies along a latitudinal gradient between the Yukon River and Prudhoe Bay, Alaska. Final Rep. to U. S. Army Corps of Engineers, CRREL, Internal Report 551

Weber, H. E.; Moravec, J.; Theurillat, J.-P. (2000): International Code of Phytosociological Nomenclature. 3rd Edition. J. Veg. Sci. 11: 739-768.

Wendelberger, G. (1960): Farnhalden im Amertal. In: Botanische Exkursionen nach dem Märchenwald im Amertal (Hohe Tauern). Verh. Zool. Bot. Ges. Österreich Bd. 100, Wien, pp. 140-144.

Willard, B. E. (1963): Phytosociology of the Alpine Tundra of Trail Ridge, Rocky Mountain National Park, Colorado. Ph. D. Thesis, University of Colorado, Boulder, 245 pp.

Willard, B. E. (1979): Plant Sociology of the Alpine Tundra, Trail Ridge, Rocky Mountain National Park, Colorado. Quarterly of the Colorado School of Mines 74/4: 1-119.

Willard, B. E.; Marr, J. W. (1970): Effects of Human Activities on Alpine Tundra Ecosystems in Rocky Mountain National Park, Colorado. Biol. Conserv. 2: 257-265.

Willoughby, M.G.; Smith, D. (1997): Range plant community types and carrying capacity for the subalpine and alpine subregions. First approximation.. Alberata Environmental Protection, Land and Forest Service Edmonton, Alberta.

Wirth, V. (1995): Die Flechten Baden-Württembergs. Vol. 1+2, Ulmer, Stuttgart.

Wirth, V. (1995a): Flechtenflora: Bestimmung und ökologische Kennzeichnung der Flechten Südwestdeutschlands und angrenzender Gebiete. 2. Aufl., 661 pp. 


\section{Appendix}

Table of contents (Appendix)

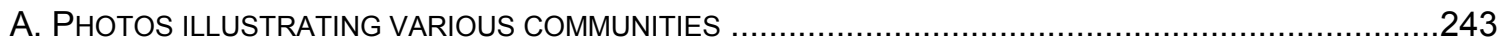

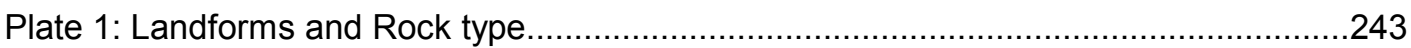

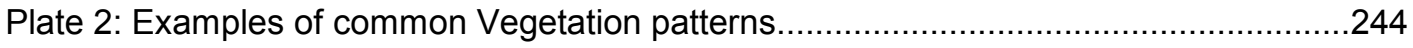

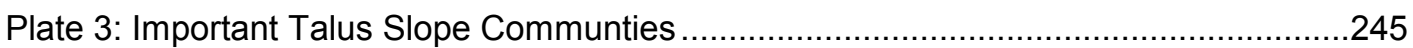

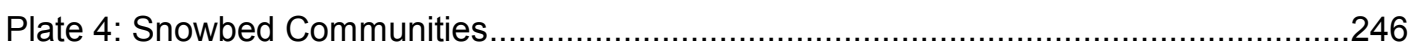

Plate 5: Mesic and wet Meadow Communities .............................................................247

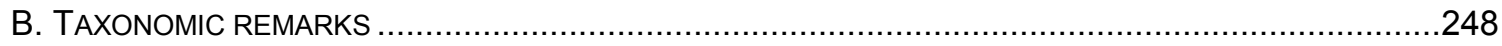

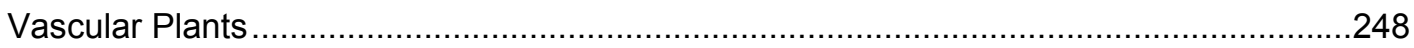

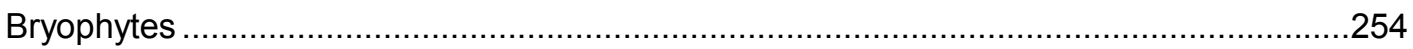

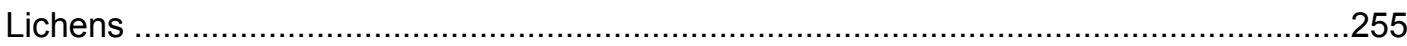

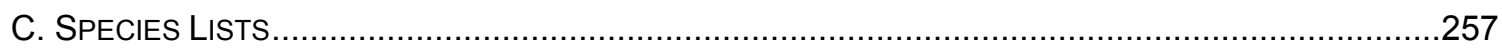

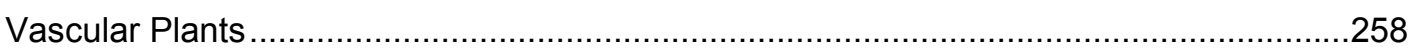

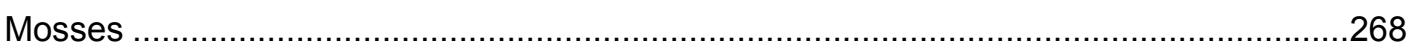

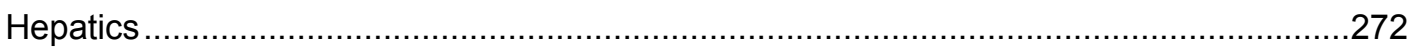

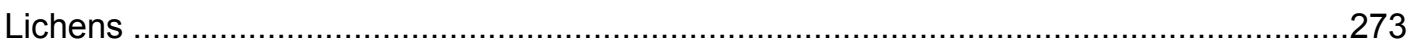

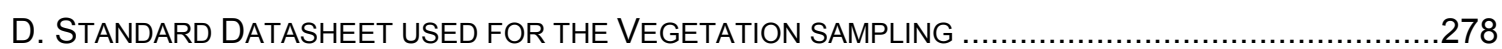

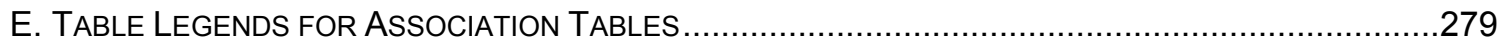

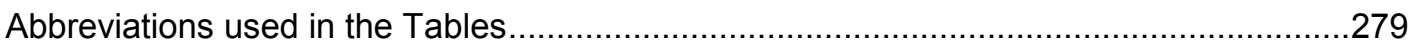

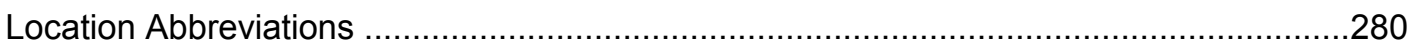

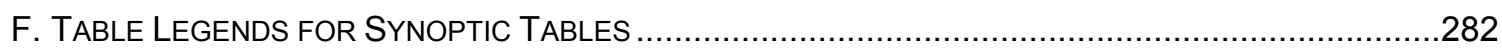

Legend Table 1: Synopsis of Western North American Fellfield units ...........................282

Legend Table 2: Synopsis of Western North American Salix nivalis, Dryas octopetala and

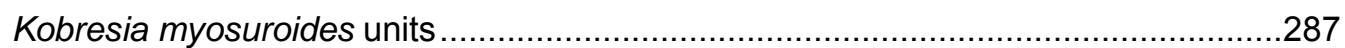

Legend Table 3: Synopsis of Western North American Carex nigricans units...................290

Legend Table 4: Synopsis of Western North American Phyllodoce-Cassiope units ..........292

Legend Table 5: Synopsis of Western North American Valeriana sitchensis units............295

G. Vegetation TABles: SEE SEPARATE FOLDER 


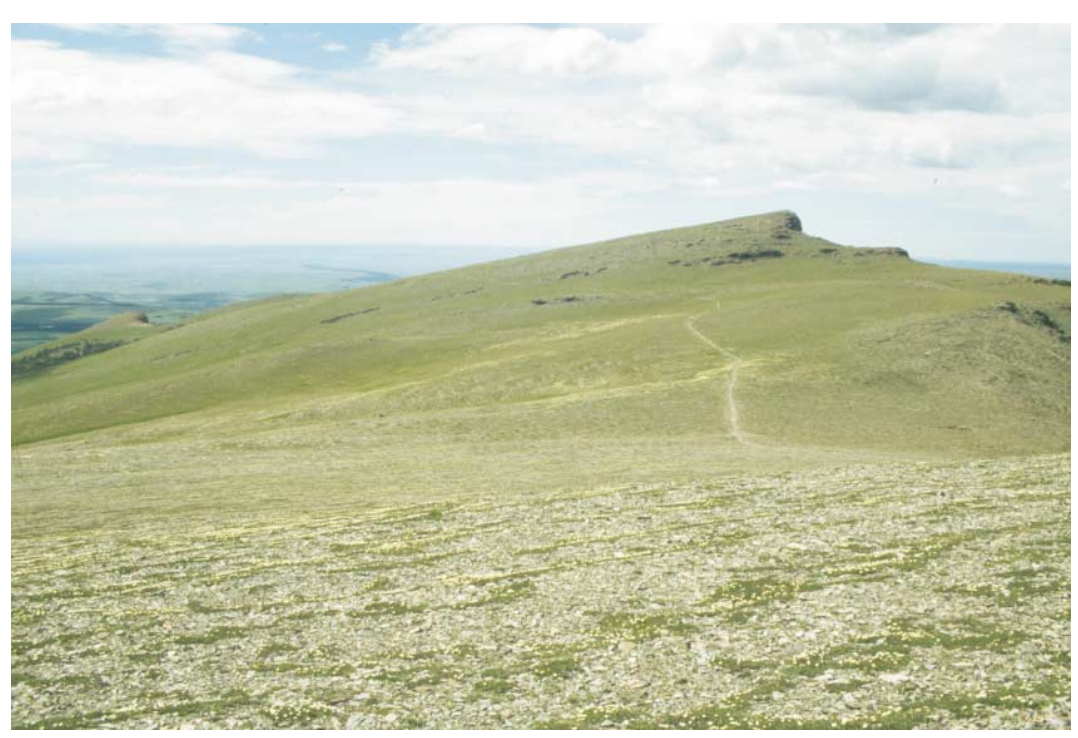

Photo 1: Rolling uplands on the east side of the Continental Divide hold the greatest expanses of alpine vegetation. Eastside prairie in the background (Scenic Point Plateau, ca. 2100-2300 m, Aug. 1994)

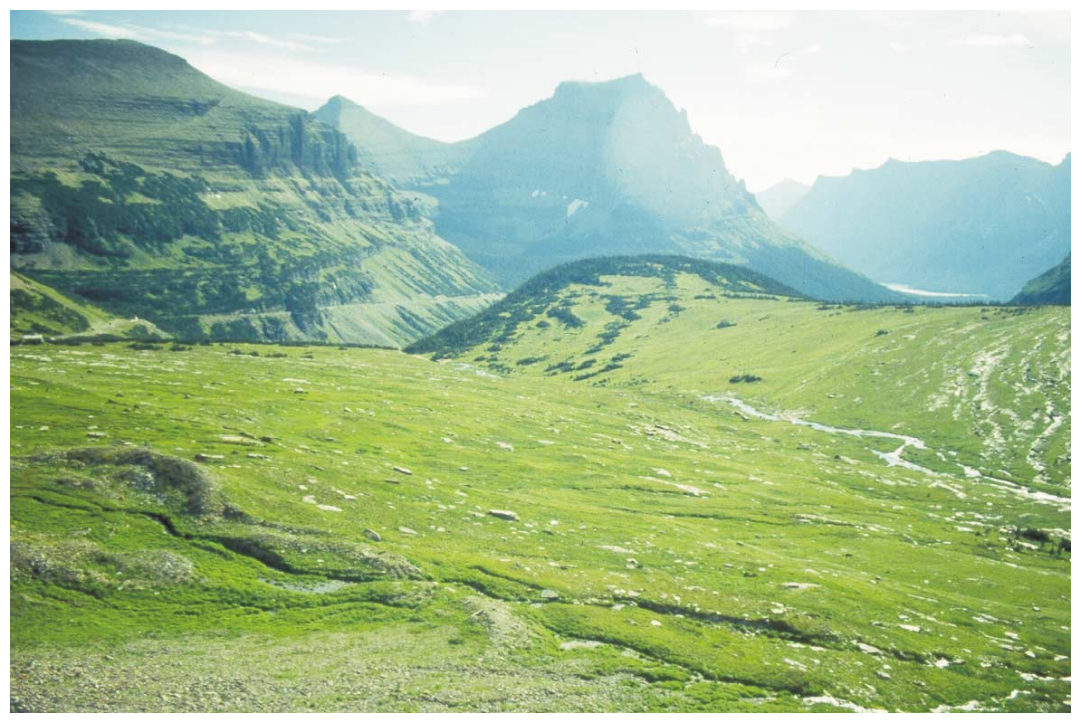

Photo 3: The Hanging Gardens, a subalpine to low alpine meadow area on the Continental Divide with a large diversity of chionophilic communities. (Logan Pass, ca. 2000-2250 m, July 1997)

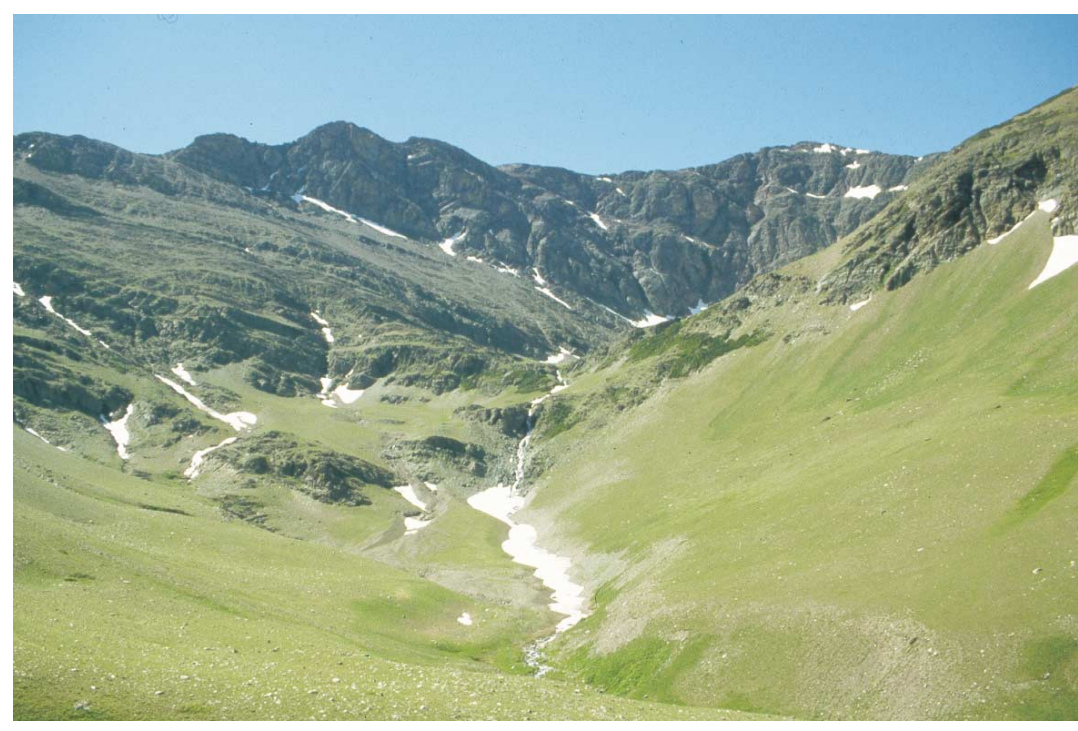

Photo 2: Appistoki Valley, a typical high elevation side-valley on the eastside of the Continental Divide, and one of the major sampling areas (July 1996)

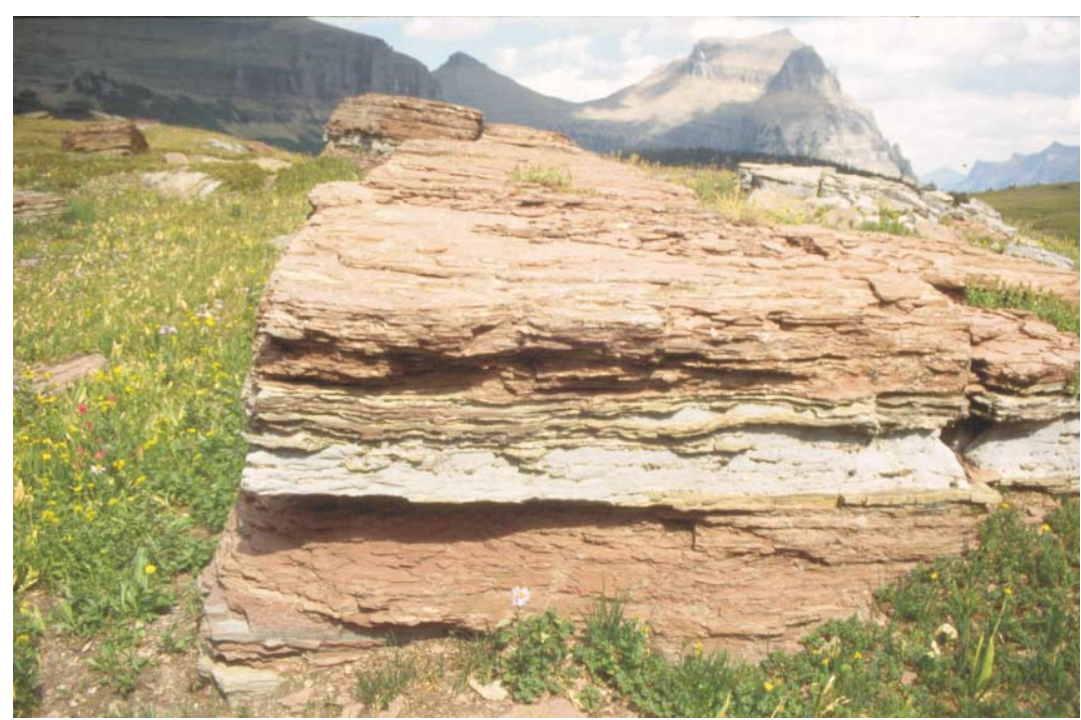

Photo 4: Red argillite, the most common rock-type, bedded with limestone, exposed in a bedded boulder (Logan Pass, July 2000) 


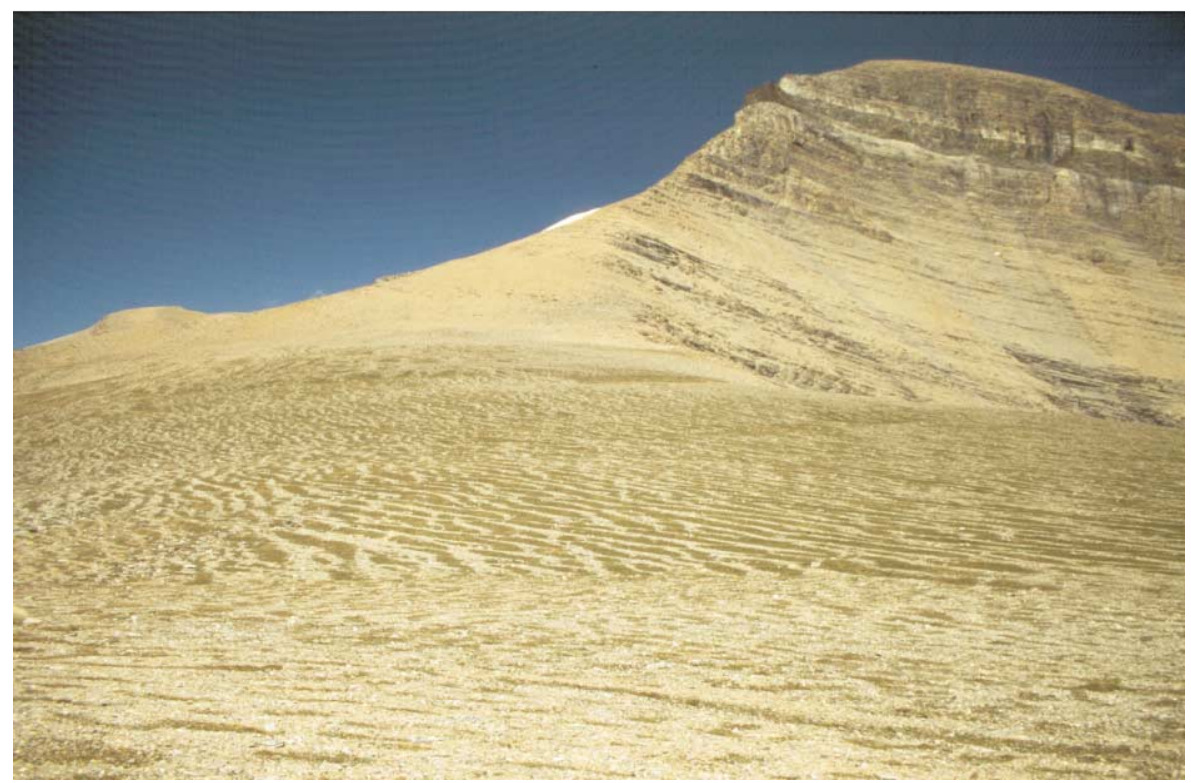

Photo 5: Striped vegetation pattern of Dryas octopetala ("turf banked terraces") at Siyeh Pass

(ca. 2400 m, Aug. 1996)

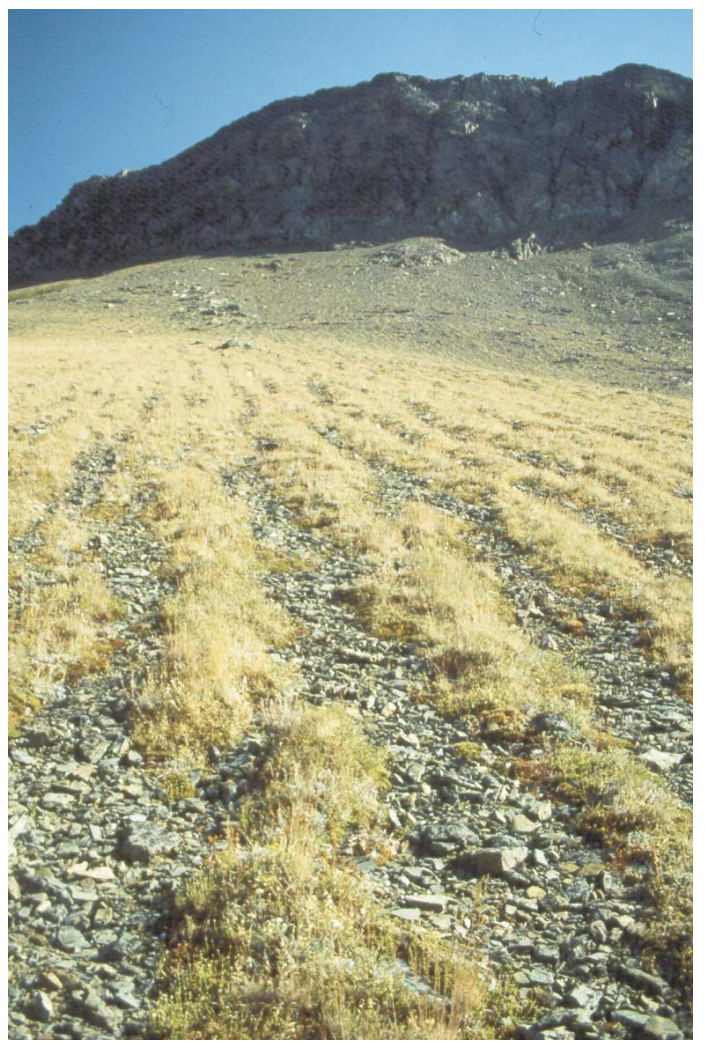

Photo 6: Vertically striped pattern of the Myosotido-Caricetum albonigrae (Firebrand Pass, 2100 m, Aug. 2000)

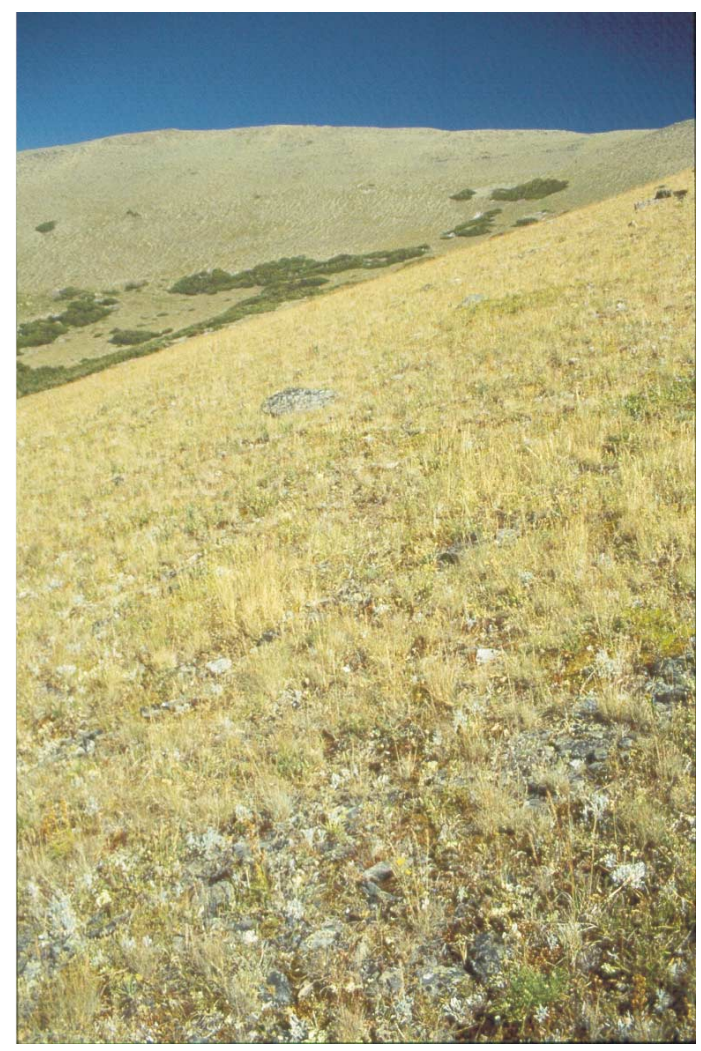

Photo 7: The same community as in photo 6 with a closed turf pattern

(Firebrand Pass, 2050 m, Aug. 2000) 


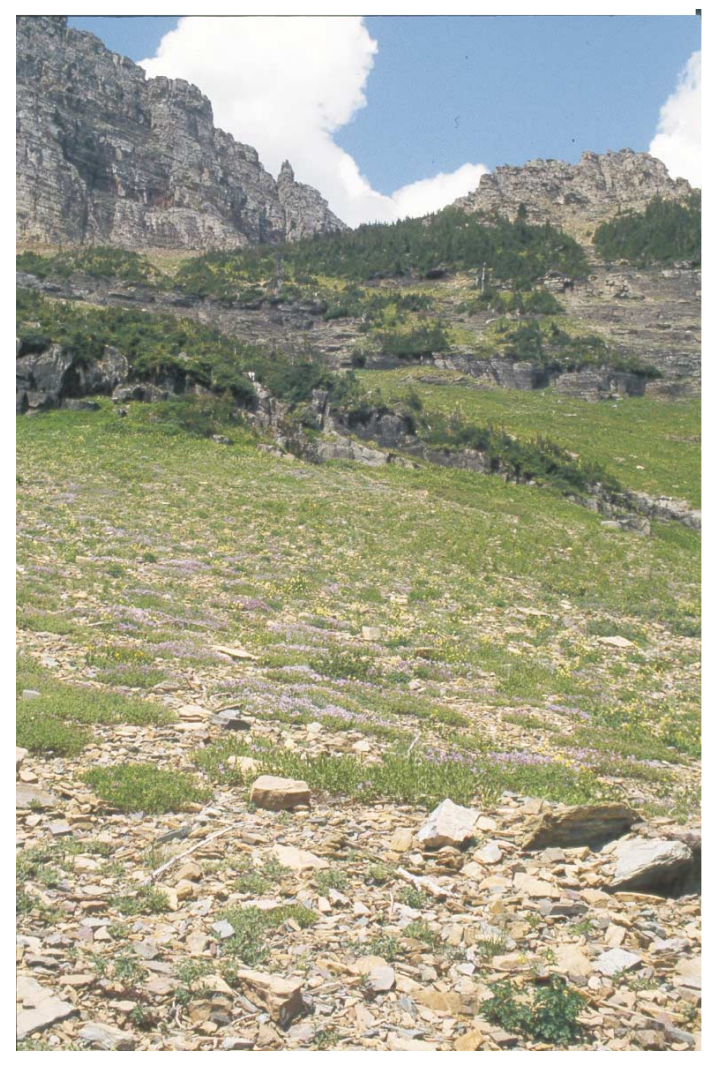

Photo 8:Talus slope with Phacelia hastataPenstemon ellipticus community.

(Sperry Glacier Trail, 2200 m, Aug. 1997)

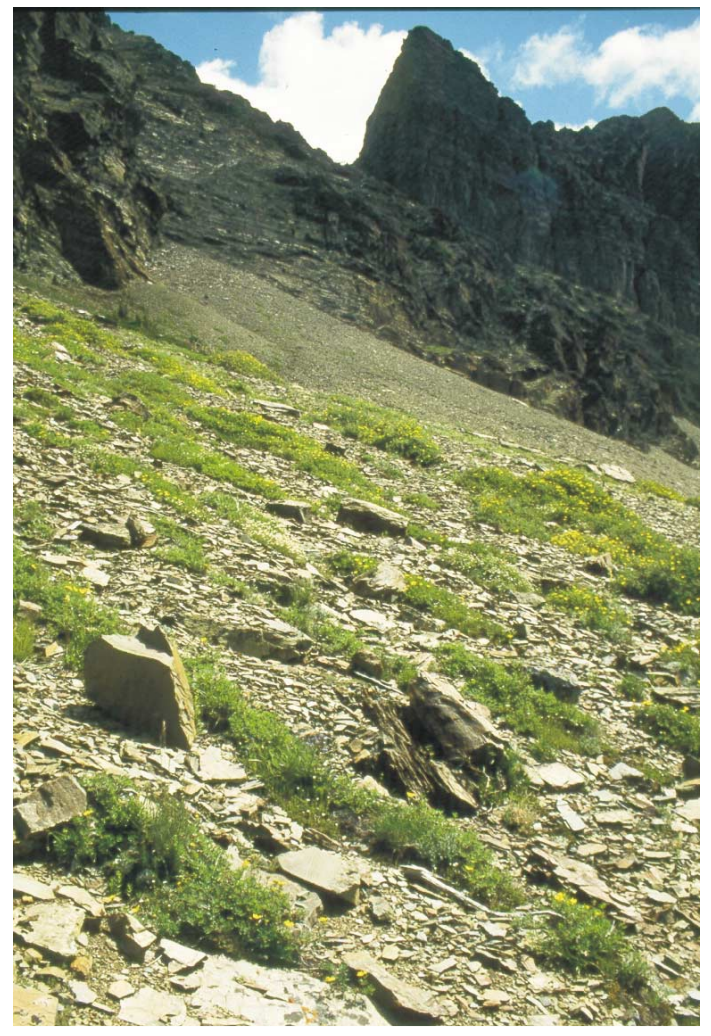

Photo 10: Artemisio-Potentilletum fruticosae, a common association of loose talus slopes east of the continental divide

(Appistoki Valley, 1950 m, July 1997)

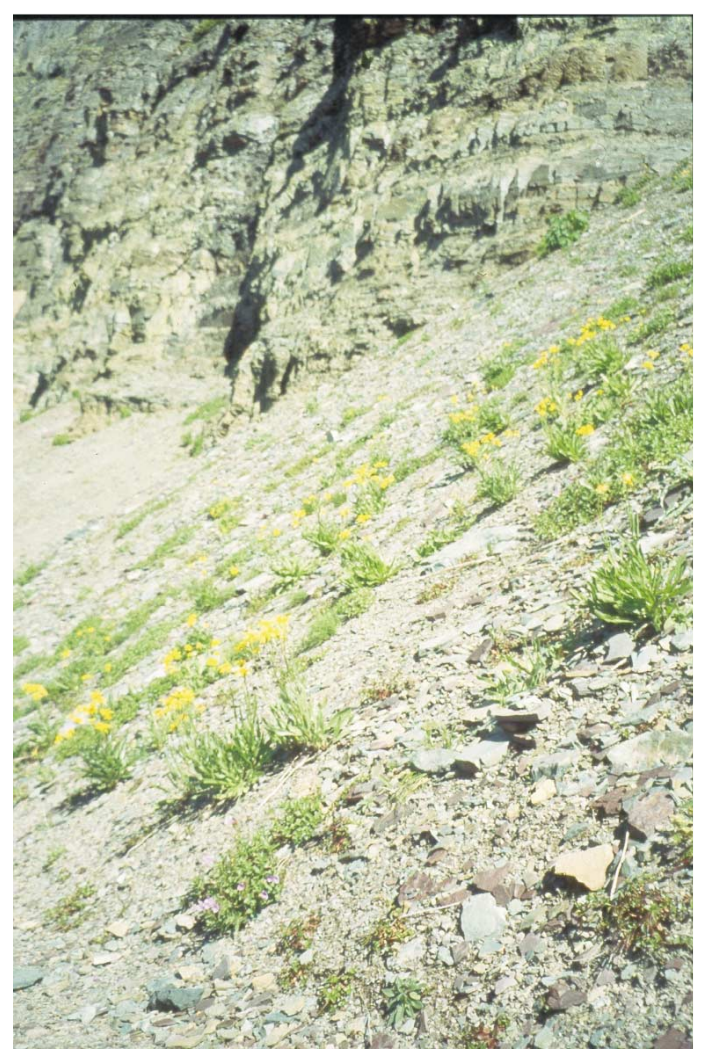

Photo 9: Aquilegio flavescentis-Senecietum megacephali talus slope community (Hole-in-the-Wall, 2200 m, Aug. 1997)

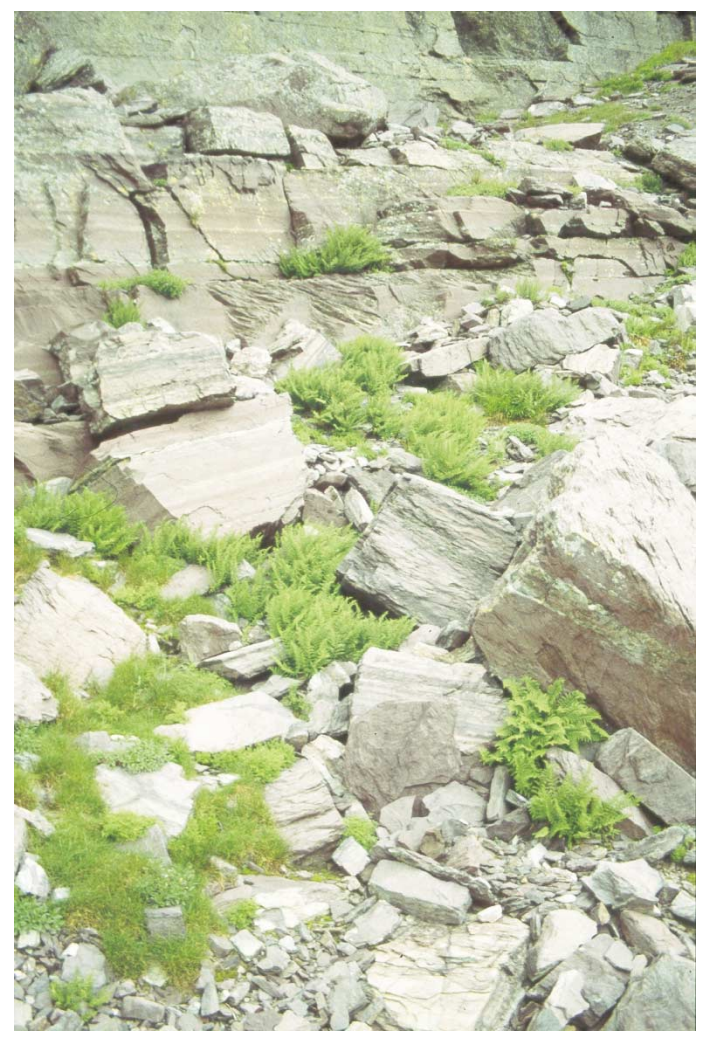

Photo 11: The Cryptogrammo crispae-Athyrietum distentifolii is found on coarse talus and boulder slopes

(above Lake Ellen Wilson, 2030 m, Aug. 1997) 


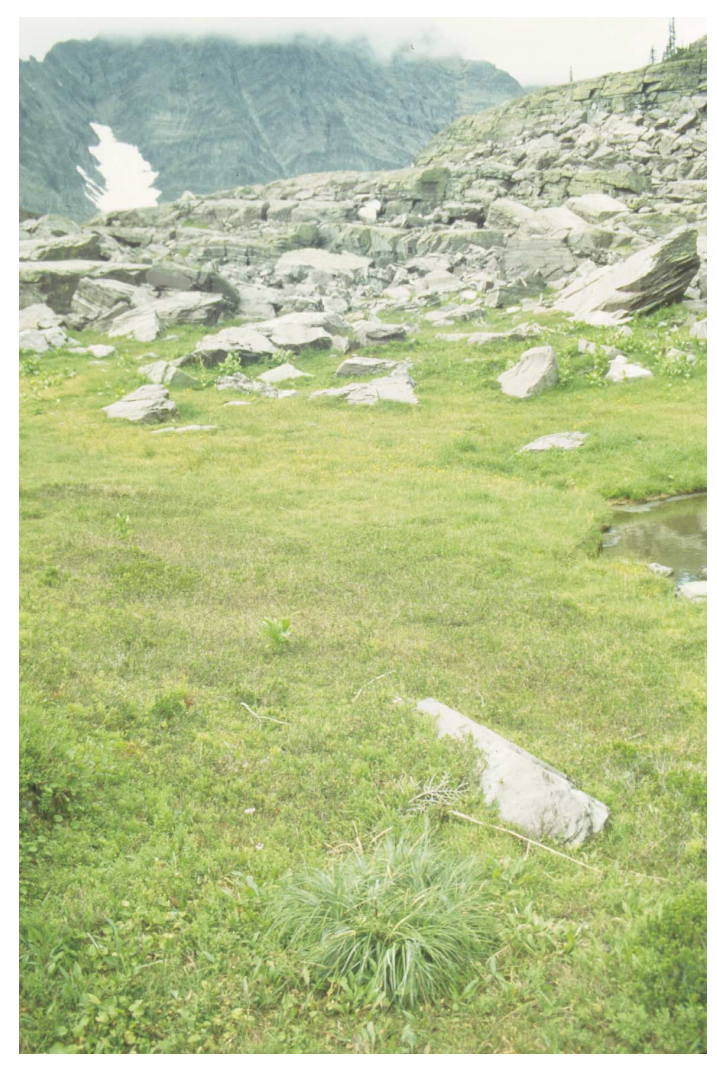

Photo 12: Aulacomnio-Kalmietum with PhleoCaricetum nigricantis in the background Lincoln Pass Terraces, 2100m, July 1996 )

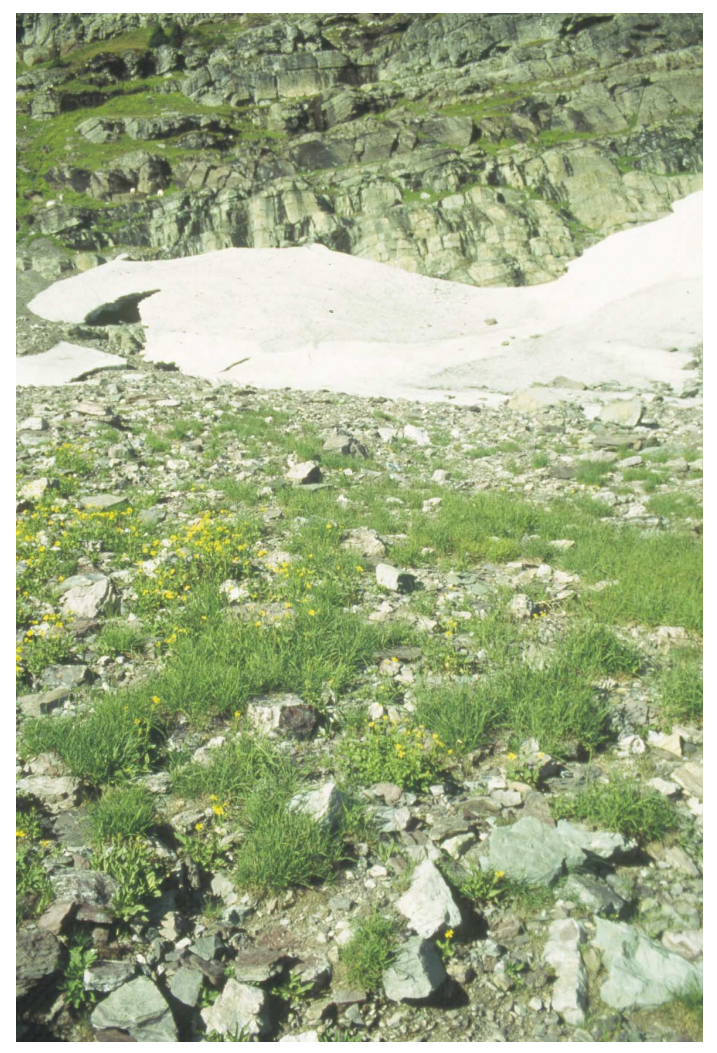

Photo 14: Arnico-Caricetum, a pioneer community most often found in the vicinity of snowbanks (Sperry Glacier Trail, 2070 m, July 1997)

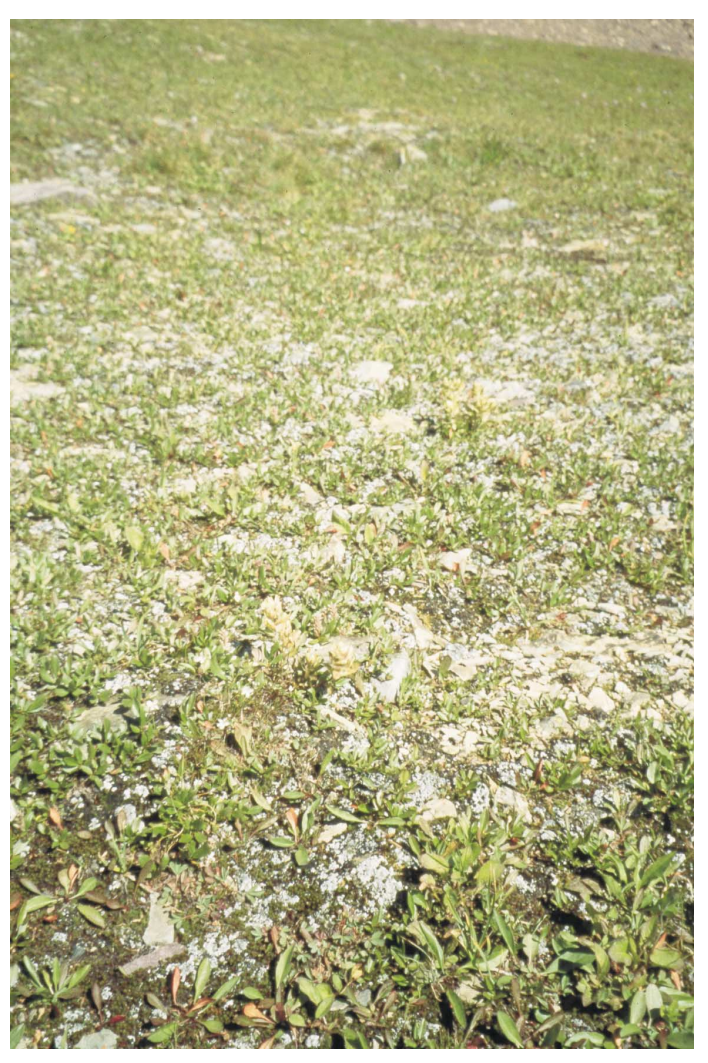

Photo 13: The gray soil crusts of Lepraria sp. dominate the Leprario-Salicetum arcticae (Logan Pass, 2100 m, July 1997)

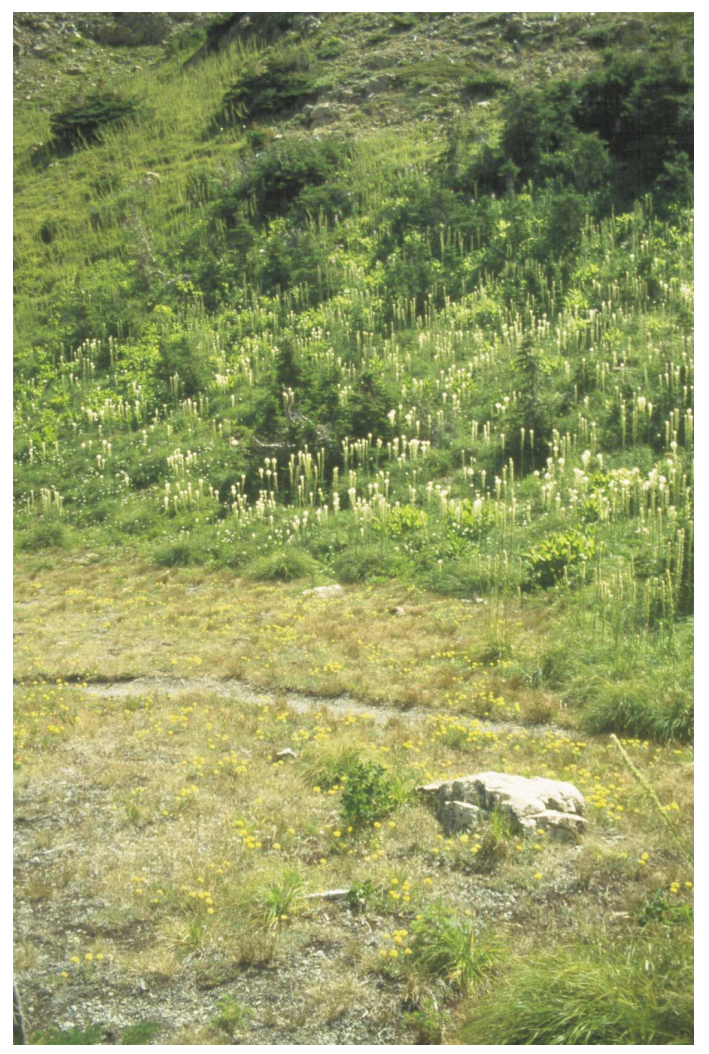

Photo 15: The chionophilic Arenario-Festucetum with its typical Eriogonum aspect; Xerophylletum in the background (Firebrand Pass Trail, $2000 \mathrm{~m}$, Aug. 2000) 


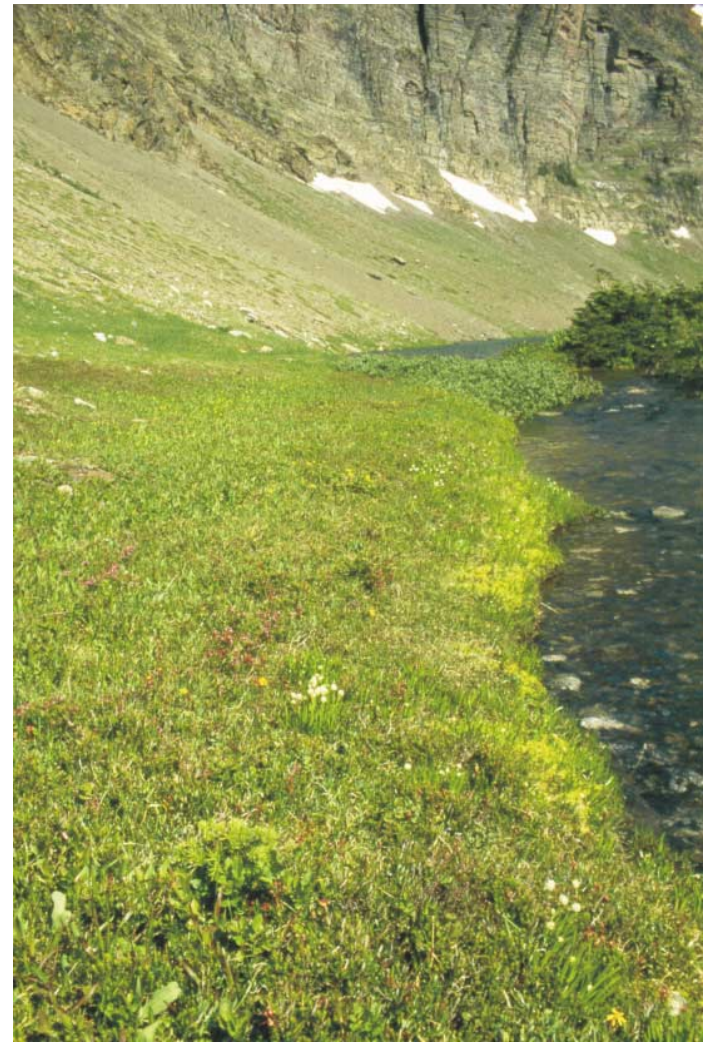

Photo 16: the Aulacomnio-Kalmietum is a community of streambanks and seeped meadows (Falling Leaf Lake, 2030 m, July 1995)

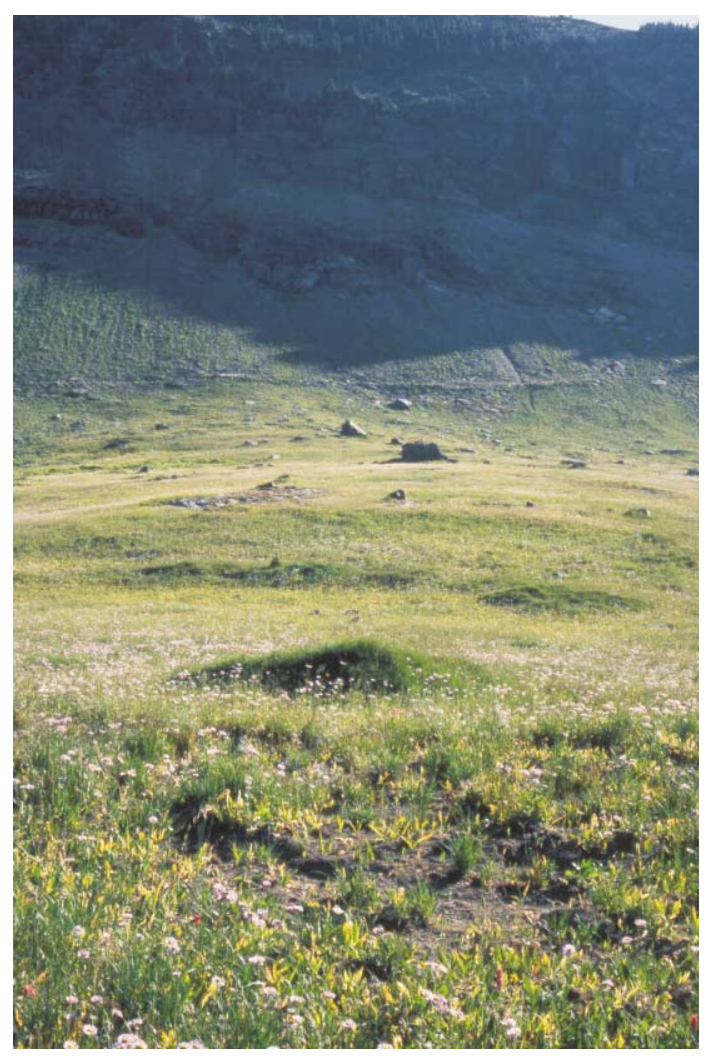

Photo 18: Grizzly digging in a Luzulo-Erythronietum - Summer aspect with Erigeron peregrinus (Fifty Mountain, 2070 m, July 2000)

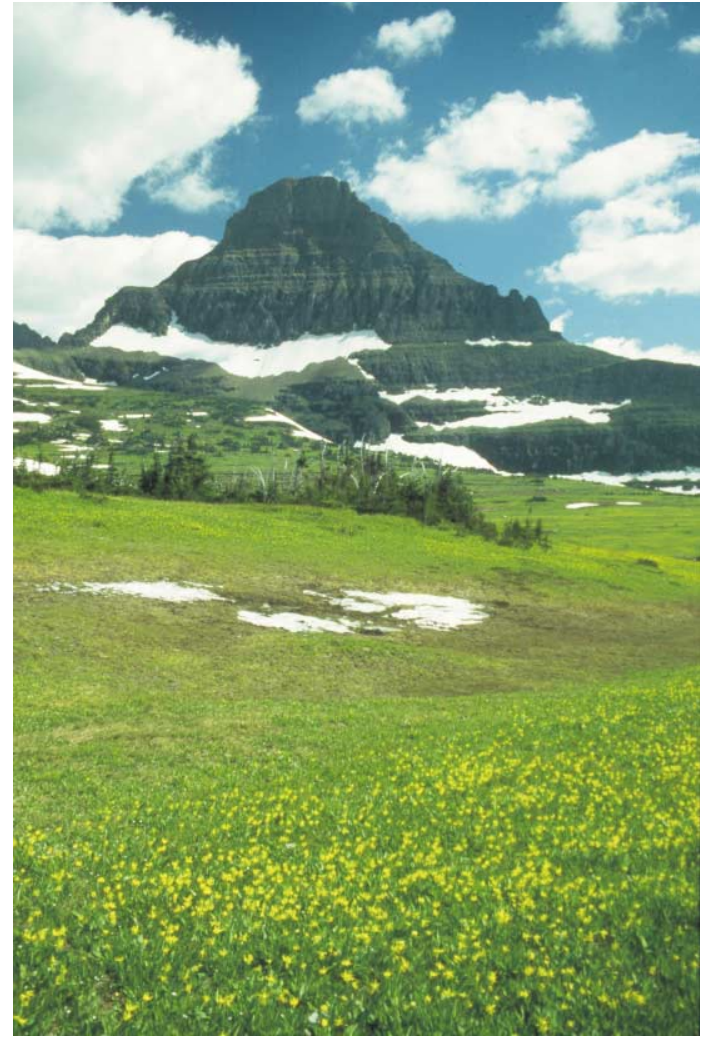

Photo 17: Early summer aspect of a subalpine Erythronium grandiflorum meadow (Logan Pass, 2100 m, July 1997)

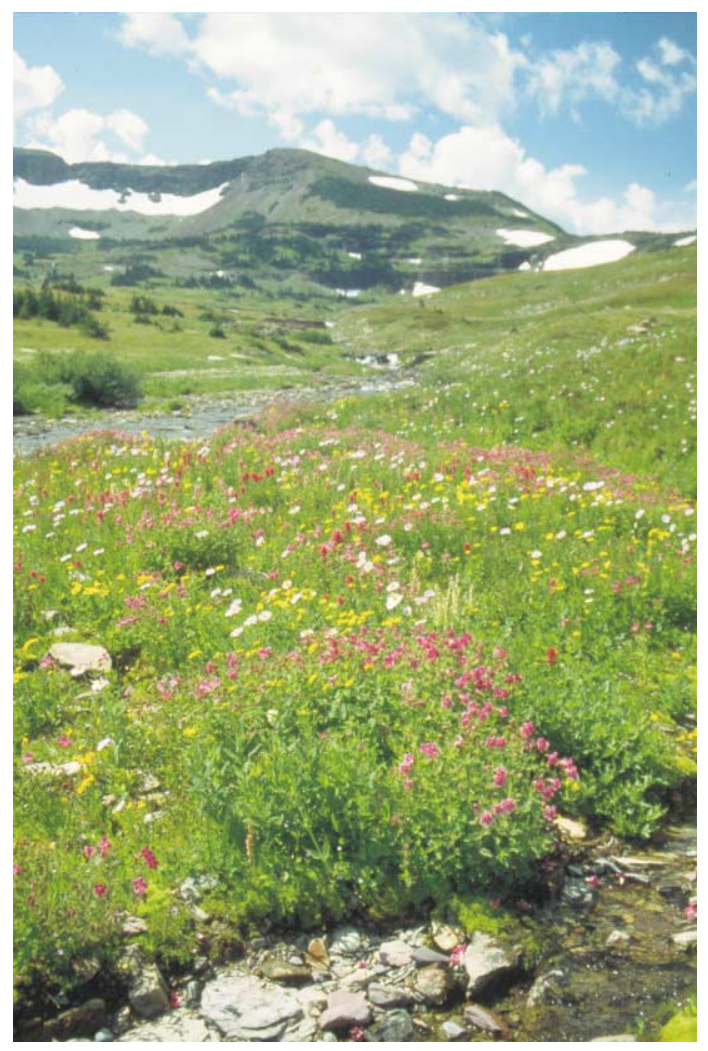

Photo 19: The Senecio triangularis-Mimuletum lewisii, a typical lush, low alpine and subalpine streambank community

(Logan Pass, Reynolds Creek, 2000 m, Aug. 2000) 


\section{Appendix B. Taxonomic remarks}

A number of taxa found in the course of this study are taxonomically critical in that they are either difficult to identify (in the field or even with better tools in the lab) or in that their taxonomic status is under discussion, has been changed recently and/or is unresolved. Notes on the taxonomic concepts accepted in this study will be given in this chapter.

As has been mentioned before, most identifications of vascular plants have been based on the keys provided by Hitchcock \& Cronquist (1973). A large number of taxa has been taxonomically revised since the issue of that flora and are now considered to belong to different species or genera. Therefore the most recent names available have been used except for a certain cases where the more commonly used, but older names have been kept in order to facilitate the use of texts and tables. The latter applies mainly to the frequent species Arenaria obtusiloba (instead of Minuartia o. or. Lidia o.), Arenaria capillaris (instead of Eremogone c. ), Arenaria rubella (instead of Minuartia r. or Tryphane r. ), Arenaria rossii (instead of Minuartia r. ), Agropyron latiglume (instead of Elymus alaskanus), Festuca scabrella (instead of F. campestris), Oxytropis campestris (instead of $O$. cusickii) and Potentilla fruticosa (instead of Pentaphylloides $f$.).

Taxonomic remarks on bryophytes and lichens are also included in this chapter.

\section{Vascular Plants}

Agropyron latiglume: This name has been changed to Elymus alaskanus (Scribn. \& Merr.) A.Löve ssp. latiglumis. For reasons given above the old name is used in this study.

Agropyron scribneri: This species might in some cases have been confused with Elymus elymoides (Raf.) Swezey ( = Sitanion hystrix (Nutt.) J.G. Smith). By far most of the specimens found are Elymus elynoides. According to Lesica (2000, unpublished manuscript), all reports from Glacier NP belong to Elymus elynoides.

Amelanchier alnifolia: vegetatively in some cases very similar to Spiraea betulifolia and S. densiflora. Stunted forms as they are most often encountered on alpine plots are sometimes hard to tell and might have been confused in earlier samples.

Anemone multifida Poiret: Due to great similarity of the basal leaves the differentiation of this species and Pulsatilla patens presents a problem in vegetation samples when the plants are not flowering or fruiting. The presence of a small tuft of hairs on the very leaf-tips of Pulsatilla patens was used to separate the species in those cases.

According to Lesica (2000, unpublished manuscript), our high elevation variety is A. multifida var. tetonensis (Porter) Hitchc.

Anemone occidentalis: see Pulsatilla.

Anemone patens: see Pulsatilla.

Antennaria alpina: This species seems to intergrade with Antennaria umbrinella in some cases. Specimens with obviously dark-greenish involucral bracts and/or with flagged stem leaves have been placed here. See also under A. umbrinella and A. media.

Antennaria media: This species has clearly been overlooked in this study. It has not been differentiated from A. alpina which it resembles closely. According to Lesica (2000, unpublished 
manuscript) it is much more common in the area than A. alpina. The collections made during this study nevertheless seem to have more A. alpina when using the keys provided by Bayer (1993) and Bayer \& Stebbins (1993).

Antennaria microphylla: Some specimens have been found in the alpine which resemble this low elevation taxon grading into A. umbrinella.

Antennaria umbrinella: This species seems to intergrade with Antennaria alpina on the one hand and A. microphylla on the other. Specimen with obviously brownish involucral bracts and without flagged leaf-tips have been called A. umbrinella. Sometimes a clear differentiation was not possible.

Arenaria obtusiloba (Rydb.) Fern. (= Alsinopsis obtusiloba Rydb., Minuartia obtusiloba (Rydb.) House Lidia obtusiloba (Rydb.) Löve \& Löve [1971]: In the tabular comparison of vegetation data from literature A. obtusiloba, A. sajanenis Willd. and A. biflora (=Minuartia biflora (L.) Schinz \& Thell. = Lidia biflora $($ L.) Löve \& Löve) were combined since the identifications do not seem very reliable and the taxonomic distinction is doubtful anyways (acc. Weber [pers. communication], WWWTropicos [2000]). A. congesta Nutt. was mentioned in Thilenius et al. (1985), tables but the floristical composition makes it extremely likely the it was also a misidentified A. obtusiloba. Therefore it was changed in the synoptic table (Tab. 1).

Arnica amplexicaulis: The differentiation of this species against A. longifolia seemed to be problematic in some cases. Also affinities to some long-leaved forms of what has been called $A$. mollis seem to exist and might have led to confusion.

Arnica cordifolia: All of the low alpine and subalpine specimen resembling A. cordifolia have been called A. latifolia based on the partly glabrous achene and the typical sessile upper leaf-pair. The occurrence of A. cordifolia remains doubtful and is likely to be restricted to lower elevations.

Arnica diversifolia: Even though this taxon is said to be very heterogeneous, most specimens found in the area are quite homogeneous. Very obvious for the taxon as used here is the lowest stem-leafpair with a long petiole and a wider-than-long leaf-blade of almost kidney-shaped form and the turbinate, relatively small flower-heads.

Arnica mollis: The strongly broad-hemispheric heads, abundant sticky-glandular hairs and sessile leaves have been used to differentiate this species from the less sturdy-appearing $A$. diversifolia.The range of (stem-)leaf-shapes nevertheless seemed to vary considerably with longlanceolate entire leaves (appoaching A. longifolia and A. amplexicaulis) to almost rhomboid, conspicuously denticulate leaves.

Aster foliaceus: This species vegetatively resembles Erigeron peregrinus to such a degree that specific distinction is hardly possible without flowers or buds. Cover estimates in vegetation plots where both species occur vegetatively are therefore to be taken as rough guesses. For the same reason one or the other species might have been missed in plots where only one of them has been recorded.

Astragalus vexilliflexus: This species might have been confused with the similar A. microcystis in some cases.

Calamagrostis purpurascens: This species might in some cases have been confused with Calamagrostis koelerioides. It is believed though that by far most of the alpine material belongs to the former species.

Cardamine spp. : The oftentimes tiny specimens of Cardamine are in most cases likely to be Cardamine oligosperma. 
Carex elynoides: Only rarely was this species found, which is easily confused with the much more common Carex nardina and, if only superficially, also with Kobresia myosuroides. Based on the non-denticulate upper margins of the perigynia only few specimens were assigned to this taxon. Similar problems have been described by Langenheim (1962) from the Crested Butte area: "It is difficult, too, to distinguish between Kobresia bellardii [=Kobresia myosuroides], Carex hepburnii $[=$ Carex nardina $]$ and Carex elynoides in vegetative condition."

Carex nardina: see under C. elynoides

Carex microptera: This species might in some cases have been confused with the very similar Carex haydeniana, which was differentiated mainly by the size of the perigynia.

Carex phaeocephala: Large specimens of this species have been found to be somewhat intermediate to $C$. petasata. Based on the size of the perigynia and partly on the color of the female scales the larger specimens were attributed to $C$. petasata.

Carex rupestris: Only rarely did this species occur on moist sites. In these cases and with Carex scirpoidea present, cover estimates might be considerably inaccurate since both species can be vegetatively very similar .

Carex spectabilis: The difficult Section Atratae-group of Carex spectabilis, C. paysonis and C. podocarpa was the most intricate one in the course of this study. The members of this group are very common as well as often structurally important in the plant communities. Nevertheless, it has not been possible to solve the taxonomical problems caused by these species. Specimens identified by T. Reznicek and D. Murray did not change that situation markedly and the uncertainty in this group seems to continue or even grow. Therefore in most tables these species were lumped into an even more artificial taxon "Carex spec".

Carex podocarpa: Among the species of the difficult group mentioned under Carex spectabilis, this one seems to be (at least in some cases) the most particular one with its strictly pendular black to blackish-red spikelets. It consistently occurs on streambanks and in other very wet places and has conspicuously dark, reddish-black, strongly pendular spikes and an aphyllopodic culm-base.

Cerastium beeringianum: The differentiation of this taxon against $C$. arvense was not always easy. The former is considered quite rare in the area and was found only very few times, whereas $C$. arvense is very abundant in many drier alpine communities.

Claytonia lanceolata: This species dries out very early in the season and its remains can be almost completely gone by early August. Thus it is easily missed when sampling is accomplished later in the season. In some sites which have been repeatedly visited it turned out to occur almost always when it was expected as is the case in Erythronium grandiflorum-communities. Nevertheless might it have been missed in some samples.

Delphinium spp.: This genus seems to be very difficult in the area and the available keys have not always been used with confidence. Most specimens were identified as D. bicolor, some of which might in fact belong to $D$. nuttallianum or to the recently described $D$. sutherlandii (Flora of North America 1998)

Dodecatheon spp.: Shooting stars are common, sometimes even abundant species in moist high elevation meadows and occur even in some types of fellfield vegetation. Presumably only two species were found which were identified as Dodecatheon pulchellum and Dodecatheon conjugens. The conspicuously glandular surface of the rosette-leaves of the latter species was used to separate the species since other characters were not found to be useful. Dodecatheon cusickii has not been found and does not occur in Glacier NP according to P. Lesica (pers. comm.). 
Epilobium alpinum: Epilobium alpinum L., E. anagallidifolium Lam. and E. hornemannii Hauskn. have been lumped in the synoptic tables of this study. Taxonomic treatment of this group is very different by different authors and further studies are needed on the distribution of the taxa of this group in the wet high elevation meadow communities of western North America.

Erigeron caespitosus: In a few cases this species might have been overlooked vegetatively and recorded as Erigeron simplex.

\section{Erigeron peregrinus: see Aster foliaceus}

Eriogonum ovalifolium: Vegetative young rosettes of this species are almost impossible to tell from the rosettes of Senecio canus. Especially in the earlier days of this study this difference might have led to misidentification. Revisiting some of the earlier plots proved that most identifications in fact have been quite reliable.

Eritichum spp.: The species E. aretioides does not occur in the study area but it has been mentioned in some of the synoptic tables. According to Lechner-Pock (1956) the genus name is not "Eritrichium" as it is most commonly used.

Festuca brachyphylla: The small fescues of the Festuca ovina-group presented a problem in this study. There is no doubt that $F$. brachyphylla is the most common representative of this group, being so widespread that it is proposed as the name giving species for a syntaxonomic order. Uncertain though is the occurence of F. minutiflora Rydb. and F. saximontana Rydb. (=Festuca ovina subsp. saximontana (Rydb.) St.-Yves = Festuca brachyphylla subsp. saximontana (Rydb.) Hultén). While the first species has never been found, mid-sized, glaucous-leaved tufts sometimes seemed to belong to the latter species, being obviously taller than $F$. brachyphylla and smaller than most $F$. idahoensis specimens from similar sites. In some cases such plants have been observed in flower and those in the end turned out to belong to $F$. idahoensis rather than $F$. saximontana. Many plants found in the plots have been encountered vegetatively only, making identification even more difficult. Also in a dense alpine turf not all tufts in a plot can be identified separately. Since $F$. saximontana was not positively found, all very small, non-glaucous specimens (tufts $<5 \mathrm{~cm}$ ) were identified as $F$. brachyphylla, whereas taller specimens were called $F$. idahoensis. Recordings of non-flowering $F$. saximontana were thus lumped with $F$. idahoensis. Non-flowering $F$. baffinensis might also have been overlooked and thus lumped with $F$. brachyphylla, but that species seems to be rare in the area and has been found in flower only twice.

Festuca campestris: The old and still more widespread name $F$. scabrella was used in this study for practical reasons.

Festuca scabrella: See F. campestris

Lloydia serotina: This species has been reported from Siyeh Pass by Bamberg \& Major (1968). It has not been found there again and the record seems to be erroneous.

Lupinus lepidus: According to some specimens in the herbarium of Glacier NP this species resembles L. argenteus var. depressus. The latter might have been overlooked in this study.

Luzula piperi: This species has been reported from Glacier as being synonymous with L. wahlenbergii, which does not agree with the findings of Hämet-Ahti (1971), who calls L. wahlenbergii an arctic species not occuring in the lower US. Following the detailed studies of Hämet-Ahti $(1965,1971)$, L. piperi proved to be difficult to tell from L. parviflora in the area and might have been confused with it in a number of cases in this study, esp. when occurring vegetatively only. Vegetative plants with dull leaves have been assigned to L. piperi, thus L. parviflora is likely to have been overlooked occasionally. The records from the literature of all 
three species occurring in the comparison tables have most likely been based on different taxonomic concepts and are to be viewed with caution.

Mertensia viridis: Acc. to Lesica (2000, unpublished manuscript), M. viridis and M. oblongifolia are almost indistinguishable in our area except for the ring of hairs in the corolla tube of M. viridis, which was used as the main character in this study.

Mimulus tilingii: All stolon-forming, yellow-flowering monkey-flowers occuring in alpine and higher subalpine seeped meadows and on streambanks have been called M. tilingii. The similar but usually smaller and annual Mimulus floribundus has only been found outside the plots on seasonally wet rocky sites.

Myosotis alpestris: This commonly used name was used instead of more recent M. sylvatica var. alpestris (F.W.Schmidt) Koch.

Oxytropis campestris: No good traits have been found to separate this species from $O$. sericea. The consistency of the pod did not seem to work well as a trait and flowers were not always present (to measure their size). Thus all specimen encountered were assigned to O. campestris. According to Elisens \& Packer (1980) the widespread taxon of the Oxytropis campestris group occurring in this part of the Rocky Mountains is O. cusickii Greenm. For reasons of practicability the name Oxytropis campestris is nevertheless used throughout this study.

Phleum alpinum: Vegetatively P. alpinum L. and Vahlodea atropurpurea are very difficult to distinguish in the field. One or the other might therefore have been overlooked in some cases and cover estimates in mixed stands will most likely be somewhat inaccurate: This will not result in big changes though since both species occur with fairly low cover values. According to Weber (1987) Phleum alpinum does not occur in North America and this species is Phleum commutatum Gaudin.

Phyllodoce spp.: Since both species $P$. glanduliflora and $P$. empetriformis are somewhat difficult to identify vegetatively - which is possible though by the dorsal midnerves of the leaves - cover estimates in mixed stands might be inaccurate in some cases. The hybrid $P$. $x$ intermedia can not be differentiated vegetatively at all.

Poa spp.: Poa specimens have not reliably been identified during the first two field seasons. Later on, aided by a set of specimens identified by R.J. Soreng (Ithaca, NewYork), better acquaintance with the Poa-flora of the area was reached and a surprisingly sharp ecological distinction of the species was found: The conspicuously small-flowered Poa glauca Vahl turned out to be by far the most common species in fellfield communities. Poa interior Rydb. and Poa rupicola Nash reported by other authors from similar fellfield communities are likely to belong to the same taxon, Poa glauca.

Poa secunda J.Presl. ssp. secunda is the species of different types of dry rocky slopes, rock ledges and outcrops. Poa arctica R.Br. ssp. arctica and Poa leptocoma Trin. were found only in subalpine to low alpine moist, forb-rich meadows. Poa cusickii Vasey var. epilis is the common species in subalpine mesic meadows and low alpine fine-soil rich slopes.

Potentilla fruticosa: The accepted name Pentaphylloides floribunda (Pursh) Löve was not used here being aware of the inconsistency of such a conservative but pragmatic use.

Potentilla nivea: The triternate, mostly cushion forming alpine cinquefoils have all been assigned to this taxon. According to the degree of density of the densely clustered cushion-plant growth-form, i.d. the degree of elongation of the stems and petioles, at least two syntaxa seem to be present. Nevertheless no consistant characters seemed to distinguish these forms. Hair-types, which have 
been used for the differentiation by other authors, have not been found to be useful traits in this area. Thus no attempt has been made to differentiate P. villosa Pall.and P. ledebouriana Porsild (=P. uniflora Ledeb.). Further studies will have to be undertaken to elucidate the taxonomy of this difficult group.

Potentilla diversifolia: Two obvious forms of this taxon, a glaucous one and a shiny-leaved one, both with similar leave-shapes, have been observed. Furthermore a wide range of leave-dissection patterns occur in the area, ranging from normal palmate leaves to ones with additional two to six pinnae down the rachis.

Pulsatilla spp.: This genus has been used instead of the commonly used genus Anemone for the species P. occidentalis (S. Watson) Freyn and P. patens (L.) Miller following Weber (1987).

Rosa spp.: Rosa species can be found mainly in some east-side communities with prairie affinities. In the alpine the specimens are usually less than $2 \mathrm{dm}$ tall, often not well developed and hard to identify. Thus they have mostly been called "Rosa sp. ". They belong most likely to Rosa acicularis or possibly in some cases to Rosa woodsii.

Salix commutata: This is by far the most common species in subalpine and low alpine wetlands. Some specimen seemed to approach $S$. eastwoodii and $S$. wolfii Bebb but were still identified as $S$. commutata.

Salix nivalis: Oftentimes this species is listed as Salix reticulata or S. reticulata ssp. nivalis (Hook.) A.Löve, D.Löve \& Kapoor.

Saxifraga occidentalis and Saxifraga rhomboidea were not separated in the field. The occurrence of the latter species in the study area is doubtful.

Selaginella spp.: $S$. densa s.str. has only been found rarely outside the plots. S. scopulorum and $S$. standleyi in most cases proved to be readily distinguishable and are both very common. Following Wallace (in Flora of North America Vol.1) they were accepted here as separate species as opposed to subspecies of $S$. densa. Since a reliable distinction could not be made before 1996, the earlier identifications are tentative only.

Within the constancy tables all Selaginella species except $S$. wallacei were lumped into Selaginella densa s.l.

Senecio canus: see remarks under Eriogonum ovalifolium

Senecio conterminus Greenman: This species of dry rocky alpine slopes was formerly mistaken for the very similar but ecologically different Senecio cymbalarioides. The morphological similarity is large enough to base identifications on habitat rather than on morphology. This conclusion was adhered to in this study since the tomentum characteristic did not seem to work to separate the species.

See also remarks under Senecio cymbalarioides.

Senecio cymbalarioides Buek.: Very different treatments exist on the taxonomy of this species and its close and very similar relatives Senecio resedifolius Lessing and Senecio conterminus Greenman. Following the treatment of Packer (1972), S. resedifolius does not occur in the study area and the common species of wet subalpine and alpine meadows is Senecio cymbalarioides. Since $S$. resedifolius is a northern species, all records in the literature of $S$. resedifolius are here considered to be $S$. cymbalarioides and have been edited in the comparison tables accordingly.

Sitanion hystrix: This name was used rather than the recent name Elymus elymoides. 
Spiraea: S. densifolia and S. betulifolia both occasionally occur in the study area and might have been confused since it is hard to differentiated small and stunted alpine specimen of the species. See also under Amelanchier alnifolia.

Taraxacum: Only very rarely good specimens of this genus have been found. Most likely all of them belonged to T. ceratophorum.

Vahlodea atropurpurea: see Phleum alpinum

Veronica wormskjoldii: For the syntaxonomic treatments the species of the Veronica alpina-group, i.e., V. alpina var. unalaschcensis, V. wormskjoldii and V. cusickii have been considered as one taxon. This is not to deny taxonomical differences but misidentifications in many of the literature tables are likely to be present. A treatment of this group is currently worked out by L.Ansbach, Vienna.

Woodsia spp.: The more common $\boldsymbol{W}$. scopulina has not been differentiated from $\boldsymbol{W}$. oregana in some of the veg-samples. But both have been found on some plots, esp. in the Many Glacier area (Sslope of Altyn Peak). Standley (1921) did not differentiate those two species in the field but notes that both are present and suspects that $W$. oregana is more common at lower elevation which he studied much less intensive. Very crumpled fragments of Cystopteris fragilis might in some cases, especially in very late, dry or very young stages have been mistaken for Woodsia.

Zigadenus elegans: Z. elegans was is far more common than Z. venenosus in the study area. The latter might or night not have been overlooked in the vegetative state.

\section{Bryophytes}

Methodological problems in collecting bryophytes on alpine vegetation plots resemble those encountered and described for the lichens (see chapter "Methods" p.\#\#). This applies mainly to the species occurring in small amounts and as fragmentary, poor specimens. Many of these samples have not been identified beyond the genus level.

Anthelia juratzkana: Unfortunately this inconspicuous species was overlooked through much of this study. It is likely to be present in some of the snowbed communities and has been found in different areas.

Barbula: The members of this genus were identified to genus only since material was mostly poor and no capsules were found.

Brachythecium: Like in the latter genus this one was found vegetative only. Thus species could only be safely identified to the genus level

Bryum specs: Only B. argenteum, B. caespiticium, B. pseudotriquetrum and B. weigelii have been identified to species within this genus. All of them might have been included in "Bryum sp." on several plots, where specific identification was not carried out.

Cephaloziella sp.: The species within this genus have not been identified due to the poor material but most common among them seem to be C. arctica Bryhn et Douin var. alpina (Douin) Schust. and C. grimsulana (Jack.) Lacouture.

Distichium inclinatum: Never was a fertile specimen found: the specimens might all be $D$. capillaceum, but the leaves were never found as spreading as in typical D. capillaceum. 
Ditrichum flexicaule: Many specimen were very stunted and hard to recognise as a Ditrichum which might be due to the species' morphological plasticity as a result of the harsh environmental conditions.

Hepaticae spp.: Oftentimes very small fragments of hepatics were encountered which could not be identified, some of them not even on the genus level.

Hypnum: Mainly in the earlier phase of the study $H$. vaucheri was probably overlooked in a number of samples

Kiaeria: specimens with short, mostly square upper laminal cells were called $K$. blyttii. All of them had the true dark, almost blackish green color typical for that species. Based on the alar cells a differentiation against $K$. starkei was not possible. Most of the here called $K$. blyttii had at least some well defined brown alar groups, sometimes even with nearly inflated cells.

Pohlia specs: Species not differentiated since by far most of them were found in sterile condition only.

Sanionia uncinata: Especially in earlier samples this species might have been confused with Scorpidium cossoni and perhaps other "Drepanocladus s.l." species

Scorpidium cossoni: The nomenclature of the Calliergon-Scorpidium-Drepanocladus complex follows Hedenäs (1993).

Tortella fragilis: A common species that was often found in cushions together with Tortella tortuosa as if these two species might grade into each other. Rarely was it found separately. Maybe those tortuosa -like forms are in fact young $T$. fragilis specimen but even microscopic examination revealed no good traits to differentiate the two taxa.

Tortella tortuosa: Some confusion exists concerning the frequent occurrence in densely intermingled cushions with $T$. fragilis.

\section{Lichens}

Considerable methodological difficulties are involved in sampling lichens on alpine vegetation plots. These have been discussed in the "Methods"-chapter.

Aspicilia contorta agg. : All areolate dark-olive-green species on rock have been assigned to this taxon.

"Black-brown soil crusts": Some soil lichens are almost impossible to identify in the field and have most likely been overlooked in many cases. This applies most certainly to a number of brown and blackish crustose species which oftentimes are hard to tell from the soil itself. Some of these have been identified as Placynthiella (or Pannaria) species, but others remain as unidentified taxa (e.g. an unidentified species with scattered black \pm shiny apothecia on soil or litter without an apparent thallus). These species were collectively called "Black-brown soil crusts".

"Black dots on rock": This aggregate term has been used for a group of very widespread saxicolous, mostly lecideine lichens which could not be separated within the scope of this study. Since the obligate saxicolous lichens are considered members of a different synusium and are not part of the same plant community in a strict sence, this does not effect the syntaxonomic objectives of this study.

The large number of samples made a closer examination of all of these specimens impossible. 
Examples of this group turned out to include Lecidella stigmatea, Lecidea auriculata and Porpidia crustulata.

Buellia geophila: In most cases at least a few 3-4 celled spores occur which acc. to Knoph (University of Jena, pers. communication) refers them to B. geophila. In some cases only 2celled spores occur. Specimens with that condition were called Buellia papillata. Since the presence of 3-4 celled spores was very scarce in all cases, it does not seem to be a very convincing character to tell these species apart.

Caloplaca cf. fraudans.: A common taxon with distinct dark-orange apothecia mostly occurring on arenitic rock and usually without any discernable thallus was called $C$. fraudans $\mathrm{cf}$.

Caloplaca jungermanniae: In some cases specimen with smaller apothecia might have been confused with $C$. tiroliensis. Both species are very common in the study area.

Caloplaca sinapisperma: This species closely resembles $C$. tetraspora and might have been confused with it occasionally.

Candelariella vitellina: Only occasionally have the apothecia of this species been sectioned. Thus in some cases other Candelariella species might have been confused with this taxon, most likely at least in some cases Candelariella aurella.

Candelariella terrigena: The frequently occuring scattered-fine-grainy lemon-yellow Candelariella species on litter, humus and mineral soil was called $C$. terrigena even though it might include C. xanthostigma and possibly other taxa. Apothecia were not found.

Catapyrenium daedaleum: differentiation between this species C. lachneum and C. cinereum was not always easy especially in poor specimens. These have nothing to do with Lecidoma.

Cetraria hepatizon: This species was sometimes hard to tell from C. commixta, which seems to be more common in the area.

Coelocaulon muricatum: No differentiation has been attempted between this species and $C$. aculeatum. According to DeBolt \& McCune (1993) both species intergrade in the area and do follow the distinct species concept presented by Kärnefelt (1986). In the tables the taxa were therefore combined.

Cladonia borealis: All yellowish, vegetative specimen of Cladonia were assigned to this very common alpine species. Other species of the genus containing usnic acid could be differentiated.

Cladonia pocillum: The differentiation of this species, which is a doubtful taxon according to some authors, against $C$. pyxidata was based on the presence of continuous brown rosettes of thallussquamules. Nevertheless clear separation was not always easy.

Cladonia pyxidata: This species seems to occur most often vegetatively only. Nevertheless good identification requires podetia. Thus many findings of this species might have been recorded under "Cladonia sp." where all vegetative records of non-yellowish Cladonia were kept. See also under Cladonia pocillum.

Lepraria spp.: Two species of this genus are very common in snowbed situations in the study area. Both species, Lepraria neglecta and L. caesioalba are morphologically identical and can only be separated by chemical characters. For this reason thin layer chromatography (TLC) has been done on representative specimens. Specimens containing atranorin and alectoronic acid have been called Lepraria neglecta, species with atranorin, norstictic acid and stictic acid have been called L. caesioalba, following the chemical characters as given by Leuckert et al. (1995). $L$. 
caesioalba has not yet been reported from Montana. Among the ten samples analyzed with TLC, seven samples proved to be $L$. caesioalba, which points to a fairly widespread distribution of this species. Since a detailed treatment of northwestern North American Lepraria species is still lacking, the possibility exists that this species is not conspecific with the European L. caesioalba.

The literature on alpine vegetation in North America uses the names L. neglecta, L. arctica and oftentimes just "Lepraria sp." for soil dwelling species in chionophilic environments. Most likely many of those identifications will have to be revised. Therefore these taxa have been lumped in the synoptic tables. In some cases Trapeliopsis granulosa might also have been confused with these taxa, mainly in the earlier samples of this study.

Psora spp.: The members of this genus plus other squamulose soil lichens presented a great challenge in this study. Most often specimens found on the plots were too small or bearing no apothecia. Thus identifications of the genera Psora and Toninia are likely to be erroneous in several cases.

Rhizocarpon geographicum agg.: The species within this complicated group have not been differentiated.

Rinodina spp.: Species of this genus are very common in different types of alpine vegetation in the study area. Identification to species proved to be very difficult even though cross-sections of apothecia were made in many cases. A key provided by H. Mayrhofer (Graz) on the musciculous species (mainly $R$. mniaraea, $R$. turfacea, $R$. roscida) did not always work. Thus identifications should be viewed with caution. The very common species occurring as separate black apothecia on litter and shrub-bases was consistently called $R$. archaea, based on material identified by Mayrhofer.

Thamnolia spp.: The two chemical variants $T$. subuliformis and $T$. vermicularis have not been separated in this study.

Toninia spp.: see under Psora

Xanthoparmelia spp.: Among the frequently occurring Xanthoparmelia species only X. coloradoensis and $X$. wyomingica have been identified with confidence. The combination of usnic acid, norstictic acid and salacinic acid was the only one to be found with TLC, pointing to the two species mentioned which have to be furthermore separated by the morphological character of "degree of attachment to the substrate" (Hale 1990, Goward et al. 1994). This turned out to be impossible in a number of cases because the degree of attachment can hardly be meaningfully categorized on the different substrates (rock, gravel, litter, cushion plants). For this reason the species have been lumped in the tables. Xanthoparmelia lineola with the same chemical substances might also have been among the samples. 


\section{Appendix C. Species Lists}

All lists include species found in the alpine as well as in treeless subalpine areas. Separate alphabetical species lists are given for vascular plants, mosses, hepatics and lichens. The taxa printed in bold type are those used in the text and tables throughout this study followed by the recent accepted names after the "="-sign. Other synonyms are identified by "Syn.:".

For reasons given under "Taxonomic Remarks", older names commonly used have been used in the tables. More detailed comments on the taxonomic concepts adhered to are given in the previous chapter ("Taxonomic Remarks").

The authority citations follow the VAScular Tropicos Database (URL: http://www.mobot.org) for vascular plants, Anderson et al. (1990) for mosses, Stotler \& Stotler (1977) for hepatics and Esslinger 1997 (URL: http://www.ndsu.nodak.edu/instruct/esslinge/chcklst/chcklst7.htm, updated Febuary 2001) for lichens.

Species with an asterisk are on the Red List for Montana (Lesica \& Shelly 1991, Heidel 1999).

\section{Vascular Plants}

Abies lasiocarpa (Hook.) Nutt. = A.bifolia A. Murray

Achillea millefolium L.

Actaea rubra (Aiton) Willd.

Agoseris aurantiaca (Hook.)

Agoseris glauca (Pursh) Raf.

Agropyron latiglume (Scribn. \& J.G. Sm.) Rydb. = Elymus alaskanus ssp. latiglumis (Scribn. \& Merr.) A. Löve

Agropyron scribneri Vasey

Agropyron spicatum (Pursh) Scribn. \& J.G. Sm. = Pseudoroegneria spicata (Pursh) Á. Löve

Agrostis humilis Vasey

Agrostis scabra Willd.

Agrostis thurberiana Hitchc.

Agrostis variabilis Rydb.

Allium cernuum Roth

Allium schoenoprasum L.

Alnus sinuata (Regel) Rydb. = A. viridis var. sinuata Regel

Amelanchier alnifolia (Nutt.) Nutt.

Anaphalis margaritacea L.

Androsace chamaejasme Wulf. = A. lehmanniana Spreng.

Androsace septentrionalis $\mathrm{L}$.

Anemone drummondii S. Watson

Anemone multifida Poir. Syn.: A. globosa Nutt.

Angelica arguta Nutt. ex Torr. \& A. Gray

Angelica dawsonii S. Watson 
Antennaria alpina (L.) Gaertn.

Antennaria anaphaloides Rydb.

Antennaria aromatica Evert

Antennaria lanata (Hook.) Greene

Antennaria media Greene

Antennaria microphylla Rydb.

Antennaria neglecta Greene

Antennaria racemosa Hook.

Antennaria rosea (Eaton) Greene ssp. confinis (Greene) R.J. Bayer

Antennaria rosea ssp. pulvinata (Greene) R.J. Bayer

Antennaria umbrinella Rydb.

Apocynum androsaemifolium $\mathrm{L}$.

Aquilegia flavescens S. Watson

Aquilegia formosa Fisch. ex DC.

Aquilegia jonesii Parry

Arabis drummondii A. Gray

Arabis glabra (L.) Bernh.

Arabis hirsuta (L.) Scop.

Arabis holboellii Hornem.

Arabis lemmonii S. Watson

Arabis lyallii S. Watson

Arabis nuttallii B.L. Rob.

Arctostaphylos uva-ursi (L.) Spreng.

Arenaria capillaris L. = Eremogone capillaris (Poiret) Fenzl

Arenaria lateriflora $\mathrm{L}$.

Arenaria nuttallii Pax

Arenaria obtusiloba (Rydb.) Fernald = Lidia o.(Rydb.) Á. Löve \& D. Löve;

Syn.: Minuartia o.(Rydb.) House

Arenaria rossii R. Br. in Richards. = Alsinanthe rossii (R. Br.) Á. Löve \& D. Löve

Arenaria rubella (Wahlenb.) Sm. = Tryphane r. (Wahlenb.) Reichb.;

Syn.: Minuartia r. (Wahlenb.) Hiern

Arnica alpina (L.) Olin \& Ladau

Arnica amplexicaulis Nutt.

Arnica cordifolia Hook.

Arnica diversifolia Greene

Arnica fulgens Pursh

Arnica latifolia Bong.

Arnica longifolia D.C. Eaton

Arnica mollis Hook.

Arnica rydbergii Greene 
Artemisia ludoviciana Nutt.

Artemisia michauxiana Besser

Artemisia campestris ssp. borealis (Pall.) H.M. Hall \& Clem. Syn.: A. borealis Pall.

Aspidotis densa (Brack.) Lellinger

Aster conspicuus Lindl.

Aster engelmannii (D.C. Eaton) A. Gray

Aster foliaceus Lindl.

Aster laevis L.

Aster sibiricus $\quad$ L. var. meritus (A.Nelson) Raup Syn.: Aster m. A. Nelson

Astragalus aboriginum Richardson ex Sprengel

Astragalus adsurgens Pall.

Astragalus alpinus L.

Astragalus bourgovii A. Gray

Astragalus cf. microcystis A. Gray

Astragalus vexilliflexus $\quad$ E. Sheldon

Athyrium distentifolium Tausch ex Opiz var. americanum

Athyrium filix-femina (L.) Roth

Balsamorhiza sagittata (Pursh) Nutt.

Besseya wyomingensis (A. Nelson) Rydb.

Betula glandulosa Michx.

*Botrychium hesperium (Maxon \& R.T. Clausen) W.H. Wagner \& Lellinger

Botrychium lunaria (L.) Sw.

Botrychium minganense Vict.

*Botrychium paradoxum W.H. Wagner

Botrychium simplex E. Hitchc.

Bromus pumpellianus Scribn.

Bupleurum americanum J.M. Coult. \& Rose

Calamagrostis inexpansa A. Gray

Calamagrostis purpurascens $\mathrm{R}$. Br.

Calochortus apiculatus Baker

Campanula rotundifolia $\mathrm{L}$.

Campanula uniflora Gorter

Cardamine bellidifolia L.

Cardamine oligosperma Nutt.

Carex albonigra Mack.

Carex aurea Nutt.

Carex backii Boott

Carex capillaris $\mathrm{L}$.

Carex elynoides T. Holm

Carex garberi Fernald 
Carex geyeri Boott

Carex haydeniana Olney

Carex lenticularis Michx.

Carex leptalea Wahlenb.

Carex media R.Br.

Carex microptera Mack.

Carex nardina Fr. Syn.: C. nardina ssp. hepburnii (Boott) Á. Löve, D. Löve \& B.M. Kapoor

Carex nigricans C.A. Mey.

Carex obtusata Lilj.

Carex oederi Retz.

Carex paysonis Clokey

Carex petasata Dewey

Carex phaeocephala Dewey

Carex podocarpa $\mathrm{R}$. Br.

Carex preslii Steud. (new for Montana)

Carex pyrenaica Wahlenb.

Carex raynoldsii Dewey

Carex rossii Boott

Carex rupestris All. Syn.: C. drummondiana Dewey

Carex scirpoidea Michx. var. stenochlaena T.Holm

Carex scirpoidea Michx. var. pseudoscirpoidea (Rydb.) Cronquist

Carex spectabilis Dewey

Cassiope tetragona (L.) D.Don

Castilleja miniata Dougl. ex Hook.

Castilleja occidentalis Torr.

Castilleja rhexifolia Rydb.

Cerastium arvense $\mathrm{L}$.

Cerastium beeringianum Cham. \& Schltdl.

Cheilanthes gracillima D.C.Eat.

Chrysopsis villosa (Pursh) Nutt. ex DC.

Cirsium hookerianum Nutt.

Claytonia lanceolata Pursh

Claytonia megarhiza (A. Gray) Parry ex S. Wats.

Clematis columbiana (Nutt.) Torr. \& A. Gray

Collinsia parviflora Douglas ex Lindl.

Comandra umbellata (L.) Nutt.

Crepis nana Richardson

Crepis runcinata (E. James) Torr. \& A. Gray

Cryptantha celosioides (Eastw.) Payson

Cryptogramma acrostichoides R.Br. 
Cystopteris fragilis (L.) Bernh.

Danthonia intermedia Vasey

Danthonia unispicata (Thurb.) Munro ex Macoun

Delphinium bicolor Nutt.

Deschampsia cespitosa (L.) P. Beauv.

Diphasiastrum alpinum (L.) Holub

Diphasiastrum complanatum (L.) Holub

Dodecatheon conjugens Greene

Dodecatheon pulchellum (Raf.) Merrill var. pulchellum

Douglasia montana A. Gray

Draba aurea Vahl ex Hornem.

Draba crassifolia Graham

*Draba densifolia Nutt.

Draba incerta Payson

Draba lonchocarpa Rydb.

Draba oligosperma Hook.

Draba paysonii J.F. Macbr.

Draba praealta Greene

Dryas drummondii Richards.

Dryas octopetala (Juz.) Breit. var. hookeriana (Juz.) Breitung

Dryopteris expansa (C. Presl) Fraser-Jenkins \& Jermy

Dryopteris filix-mas (L.) Schott

Eleocharis tenuis (Willd.) Schult.

Elymus elymoides (Raf.) Swezey Syn.: Sitanion hystrix (Nutt.) J.G. Sm.

Elymus glaucus Buckley

Epilobium alpinum $\quad$ L.

Epilobium angustifolium $\mathrm{L}$.

Epilobium latifolium L.

Equisetum arvense $\mathrm{L}$.

Equisetum variegatum Schleich. ex F. Weber \& D. Mohr

Erigeron acris $\mathrm{L}$.

Erigeron caespitosus Nutt.

Erigeron compositus Pursh

Erigeron lanatus Hook.

Erigeron peregrinus (Pursh) Greene

Erigeron simplex Greene

Erigeron speciosus (Lindl.) DC.

Eriogonum androsaceum Benth.

Eriogonum flavum Nutt.

Eriogonum ovalifolium Nutt. 
Eriogonum umbellatum Torr.

Eriophorum angustifolium Honckeny

Eritrichum aretioides (Cham.) DC.

Erythronium grandiflorum Pursh

*Euphrasia arctica Lange ex Rostrup

Festuca baffinensis Polun.

Festuca brachyphylla Schult. \& Schult.

Festuca idahoensis Elmer

Festuca saximontana Rydb.

Festuca scabrella Torr. ex Hook.

*Festuca vivipara (L.) $\mathrm{Sm}$.

Fragaria virginiana Mill.

Gaillardia aristata Pursh

Galium boreale L.

Galium triflorum Michx.

Gaultheria humifusa (Graham) Rydb.

Gentiana calycosa (Koch) Wettst.

Gentianella amarella (L.) Borner

Gentianella propinqua (Richards.) Gillett Syn.: Gentiana p. Richards.

Gentianella prostrata Haenke $=$ Ciminalis p. Löve \& Löve \& Kapoor

Geum triflorum Pursh

Goodyera oblongifolia Raf.

Gymnocarpium dryopteris $\quad$ (L.) Newman

Habenaria dilatata (Pursh) Hook. = Platanthera d. (Pursh) Lindl. ex L.C.Beck

Habenaria hyperborea (L.) R. Br.

Habenaria saccata Greene = Platanthera s. (Greene) Hultén

Habenaria viridis (L.) R.Br. = Platanthera v. (L.) Lindl.

Hackelia floribunda (Lehm.) I.M. Johnst.

Hedysarum sulphurescens Rydb.

Helictotrichon hookeri (Scribn.) Henrard

Heracleum lanatum Michx.

Heuchera cylindrica Douglas ex Hook.

Heuchera parviflora Nutt.

Hieracium albertinum Farr

Hieracium albiflorum Hook.

Hieracium gracile Hook.

Huperzia haleakalae (Bracken.) Holub

Hydrophyllum capitatum Douglas ex Benth.

Hypericum formosum Kunth

Juncus castaneus Sm. 
Juncus drummondii $\quad$ E. Meyer

Juncus mertensianus Bong.

Juncus parryi Engelm.

Juncus triglumis $\mathrm{L}$.

Juniperus communis L.

Juniperus horizontalis Moench

Kalmia microphylla (Hook.) Heller = K. polifolia ssp. microphylla (Hook.) Löve et al.

Kobresia myosuroides (Vill.) Fiori \& Paol. Syn.: K. bellardii (All.) Degl., Elyna myosuroides (Vill) Fritsch ex Janchen

*Kobresia simpliciuscula (Wahlenb.) Mack.

Koeleria macrantha (Ledeb.) Schult. Syn.: Koeleria cristata Pers.

Larix lyallii Parl.

Leptarrhena pyrolifolia (D. Don) R. Br. ex Ser. in DC.

Lewisia pygmaea (A.Gray) B.C.

Linum perenne $\mathrm{L}$.

Lithophragma bulbifera (Rydb.) Jeps.

Lithophragma parviflora (Hook.) Nutt.

Lithospermum ruderale Douglas ex Lehm.

Lomatium dissectum (Nutt. ex Torr. \& A. Gray) Mathias \& Constance

Lomatium macrocarpum (Hook. \& Arn.) J.M. Coult. \& Rose

Lomatium sandbergii (J.M. Coult. \& Rose) J.M. Coult. \& Rose

Lomatium triternatum (Pursh) J.M. Coult. \& Rose

Lonicera involucrata (Richardson in Franklin) Banks

Lupinus argenteus Pursh

Lupinus lepidus Douglas ex Lindl.

Lupinus sericeus Cooper

Luzula hitchcockii Hämet-Ahti

Luzula parviflora (Ehrh.) Desv.

Luzula piperi (Coville) M.E. Jones

Luzula spicata (L.) DC.

Lychnis apetala $\mathrm{L}$.

Melica spectabilis Scribn.

Menziesia ferruginea Sm. ssp. glabella (A. Gray) Calder \& Roy L. Taylor

Mertensia viridis A. Nelson

Mimulus floribundus Douglas ex Lindl.

Mimulus lewisii Pursh

Mimulus tilingii Regel

Mitella breweri A. Gray

Myosotis alpestris F.W. Schmidt $=$ M. sylvatica var. alpestris

Orthilia secunda (L.) House = Pyrola secunda L. 
Osmorhiza depauperata Phil.

Osmorhiza occidentalis (Nutt.) Torr.

Oxyria digyna (L.) Hill

Oxytropis campestris (L.) DC. ours $=$ O. cusickii Greenm.

Papaver pygmaeum Rydb.

Parnassia fimbriata K.D. Koenig

Pedicularis bracteosa Benth. ex Hook.

Pedicularis contorta Benth. ex Hook.

Pedicularis groenlandica Retz.

Pedicularis racemosa Douglas ex Hook.

Penstemon albertinus Greene

Penstemon confertus Douglas ex Lindl.

Penstemon ellipticus J.M. Coult. \& E. Fisch.

Penstemon lyallii A. Gray

Phacelia hastata Douglas ex Lehm.

Phacelia lyallii (A. Gray) Rydb.

Phacelia sericea (Graham) A. Gray

Phleum alpinum L. = P. commutatum Gaud. (acc. Löve et al. 1971)

Phlox hoodii Richards.

Phyllodoce empetriformis (Smith) D. Don

Phyllodoce glanduliflora (Hooker) Coville

Phyllodoce intermedia Rydb.

Physaria didymocarpa (Hook.) A. Gray

Picea engelmannii Parry ex Engelm.

Pinguicula vulgaris $\mathrm{L}$.

Pinus albicaulis Engelm.

Pinus contorta Douglas ex Loudon

Pinus flexilis E. James

Poa alpina L.

Poa arctica R.Br. ssp. arctica

Poa cusickii Vasey ssp. epilis (Scribner) Weber

Poa cusickii ssp. pallida Soreng

Poa glauca Vahl

Poa interior (Rydb.) Syn.: P. nemoralis ssp. interior (Rydb.) W.A.Weber

Poa leptocoma Trin.

Poa pratensis L. (approaching ssp. alpigena (Fr. ex Blytt) Hiit., det. R.J.Soreng)

Poa secunda J.Presl.

Polemonium pulcherrimum Hook.

Polemonium viscosum Nutt.

Polygonum bistortoides Pursh = Bistorta b. (Pursh) Small 
Polygonum engelmannii Greene

Polygonum minimum S. Watson

Polygonum viviparum L.

Polystichum lonchitis (L.) Roth

Potentilla concinna Richards.

Potentilla diversifolia Lehm. var. diversifolia

Potentilla diversifolia var. perdissecta (Rydb.) Hitchc.

Potentilla fruticosa L. = Pentaphylloides floribunda (Pursh) Löve

Potentilla glandulosa Lindl.

Potentilla gracilis Douglas ex Hook. var. gracilis

Potentilla gracilis var. brunnescens (Rydb.) Hitchc.

Potentilla hippiana Lehm.

Potentilla nivea L.

Potentilla ovina Macoun

*Potentilla quinquefolia Rydb.

Potentilla villosa Pall.

Prunella vulgaris L.

Prunus virginiana L.

Pulsatilla occidentalis (S. Watson) Freyn Syn.: Anemone occidentalis S. Watson

Pulsatilla patens (L.) Miller ssp. hirsutissima Zamels Syn.: Anemone patens L.

Ranunculus eschscholtzii Schlecht.

*Ranunculus verecundus Robins.

Rhinanthus crista-galli $\mathrm{L}$.

Ribes lacustre (Pers.) Poir.

Ribes viscosissimum Pursh

Rosa acicularis Lindl. Syn.: R. sayi Schweinitz (acc. Löve et al. 1971)

Rosa cf. woodsii Lindl.

Rubus idaeus L. var. strigosus

Rumex acetosa $\quad$ L.

*Sagina nivalis (Lindblom) Fr.

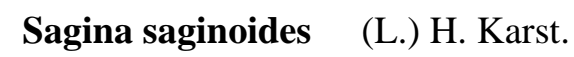

Salix arctica Pall. Syn.: S.arctica ssp. petraea (Anderss.) A.Löve, D.Löve \& Kapoor

Salix brachycarpa Nutt.

Salix commutata Bebb

Salix drummondiana Barratt ex Hook.

Salix nivalis Hook. Syn.: S. reticulata ssp. nivalis Löve et al.

Salix vestita Pursh

Saxifraga adscendens L.

Saxifraga arguta D. Don

Saxifraga bronchialis L. 
Saxifraga caespitosa L.

Saxifraga cernua L.

Saxifraga cespitosa L.

Saxifraga debilis Engelm. ex A. Gray

Saxifraga ferruginea Graham

Saxifraga lyallii Engl.

Saxifraga mertensiana Bong.

Saxifraga occidentalis S. Watson

Saxifraga oppositifolia L.

Scirpus hudsonianus (Michx.) Fernald $=$ Trichophorum alpinum

Scirpus microcarpus J. Presl \& C. Presl

Sedum lanceolatum Torr.

Sedum roseum (L.) Scop. Syn.: Rhodiola rosea L.

Sedum stenopetalum Pursh

Selaginella densa Rydb. var. densa

Selaginella scopulorum Maxon Syn.: S. densa var. scopulorum (Maxon) R.M. Tryon

Selaginella standleyi Maxon Syn.: S. densa var. standleyi (Maxon) R.M. Tryon

Selaginella wallacei Hieron.

Senecio canus Hook.

Senecio conterminus Greenm. (new to Montana, Specimen: Damm \#314/1996 Poia Lake 08-1196)

Senecio cymbalarioides $\quad H$. Buek

Senecio fremontii Torr. \& A. Gray

Senecio megacephalus Nutt.

Senecio triangularis Hook.

Shepherdia canadensis (L.) Nutt.

Sibbaldia procumbens $\mathrm{L}$.

Silene acaulis (L.) Jacq.

Silene parryi (S. Watson) C.L. Hitchc. \& Maguire

Smelowskia calycina A.Gray

Smilacina racemosa (L.) Desv.

Smilacina stellata (L.) Desv.

Solidago multiradiata Aiton

Sorbus scopulina Greene

Sorbus sitchensis $\quad M$. Roem.

Spiraea betulifolia Pall.

Spiraea densiflora Nutt. ex Torr. \& A. Gray

Stellaria americana (T. Porter ex B. Rob.) Standl.

Stellaria calycantha (Ledeb.) Bong.

Stellaria longipes Goldie 
Stenanthium occidentale A. Gray

Streptopus amplexifolius (L.) DC.

Suksdorfia ranunculifolia (Hook.) Engl.

Symphoricarpos albus $\quad$ (L.) S.F. Blake

Taraxacum ceratophorum (Ledeb.) DC.

Taraxacum officinale Weber

Thalictrum occidentale A. Gray

Tofieldia glutinosa (Michx.) Pers.

*Tofieldia pusilla (Michx.) Pers.

Townsendia parryi D.C. Eaton

Trifolium repens $\mathrm{L}$.

$\begin{array}{lll}\text { Trisetum spicatum } & \text { (L.) K. Richt. }\end{array}$

Trisetum wolfii Vasey

Trollius laxus Salisb. ssp. albiflorus (Gray) A.Löve, D.Löve \& Kapoor

Vaccinium caespitosum Michx.

Vaccinium membranaceum Douglas ex Hook.

Vaccinium myrtillus L.

Vaccinium scoparium Leiberg ex Coville

Vahlodea atropurpurea (Wahlenb.) Fr. ex Hartm.

Valeriana occidentalis A. Heller

Valeriana sitchensis Bong.

Veronica wormskjoldii Roem. \& Schult.

Viola adunca Sm.

Viola canadensis $\quad$ L.

Viola glabella Nutt.

Viola pallens (Banks ex DC.) Brainerd

Viola nuttallii Pursh

Viola orbiculata Geyer ex Holz.

Viola palustris $\mathrm{L}$.

Woodsia oregana D.C. Eaton

Woodsia scopulina D.C. Eaton

Xerophyllum tenax (Pursh) Nutt.

Zigadenus elegans Pursh Syn.: Anticlea elegans (Pursh) Rydb.

\section{Mosses}

Aulacomnium androgynum (Hedwig)

Aulacomnium palustre (Hedwig) Schwaegrichen

Aulacomnium turgidum (Wahlenberg) Schwaegrichen

Barbula convoluta Hedw. 
Barbula sp.

Brachythecium albicans (Hedwig) B.S.G. s.l.

Brachythecium collinum (Schleicher ex C.Müller) Schimper in B.S.G

Brachythecium frigidum (C. Mueller) Bescherelle

Brachythecium cf. leibergii Grout

Brachythecium rivulare Schimper in B.S.G.

Brachythecium salebrosum (G. F. Hoffmann ex Weber \& D. Mohr) B.S.G.

*Brachythecium turgidum (C. J. Hartman) Kindberg (Specimen Damm 491/97 !Hedenäs)

Brachythecium spp.

Bryoerythrophyllum recurvirostre (Hedwig) Chen Pan-chieh

Bryum argenteum Hedwig

Bryum caespiticium Hedwig

Bryum capillare Hedwig

Bryum pallens Swartz

Bryum pseudotriquetrum (Hedwig) P. G. Gaertner

Bryum weigelii Sprengel

Bryum spp.

*Calliergonella cuspidata (Hedwig) Loeske

Calliergon giganteum (W. P. Schimper) Kindberg

*Calliergon sarmentosum (Wahlenberg) Kindberg

Calliergon stramineum (Dickson ex Bridel) Kindberg

Campylium chrysophyllum (Bridel) J. M. Lange

Campylium stellatum (Hedwig) C. E. O. Jensen

Campylopus fragilis (Bridel) Bruch \& W. P. Schimper in B.S.G.

Ceratodon purpureus (Hedwig) Bridel

Claopodium bolanderi Best

Climacium dendroides (Hedwig) Weber \& D. Mohr

Cratoneuron filicinum (Hedwig) Spruce

Desmatodon latifolius (Hedwig) Bridel

Dichodontium pellucidum (Hedwig) W. P. Schimper

*Dicranum acutifolium (Lindberg \& H. Arnell) C. E. O. Jensen in Weimarck

Dicranum elongatum Schleicher ex Schwaegrichen

Dicranum scoparium Hedwig

*Dicranum spadiceum J. E. Zetterstedt

Dicranoweisia crispula (Hedwig) Milde

*Dicranella heteromalla (Hedwig) W. P. Schimper

Distichium capillaceum (Hedwig) Bruch \& W. P. Schimper in B.S.G.

*Distichium inclinatum (Hedwig) B.S.G.

Ditrichum flexicaule (Schwaegrichen) Hampe

Drepanocladus aduncus (Hedwig) Warnstorf 
Dryptodon patens (Hedwig) Bridel

Encalypta rhabdocarpa Schwaegrichen

Encalypta vulgaris Hedwig

Eurhynchium pulchellum (Hedwig) Jennings

Funaria hygrometrica Limpricht

Grimmia sp.

Heterocladium dimorphum (Brid.) Schimper in B.S.G.

Homalothecium aeneum (Mitt.) Lawton

Homalothecium cf. nevadense (Lesq.) Ren. \& Card.

Homalothecium sp.

Hygrohypnum luridum (Hedwig) Jennings

Hylocomium splendens (Hedwig) W. P. Schimper in B.S.G.

Hypnum revolutum (Mitten) Lindberg

Hypnum pallescens (Hedwig) P.Beauv. (Specimen Damm 166/95 !Hedenäs)

Hypnum vaucheri Lesquereux

Hypnum sp.

*Kiaeria blyttii (B.S.G.) Brotherus

*Kiaeria starkei (Weber \& D. Mohr) I. Hagen

Lescuraea patens Lindberg $=$ Pseudoleskea patens (Lindb.) Kindb.

Lescuraea radicosa (Mitten) Moenkemeyer $=$ Pseudoleskea radicosa (Mitten) Macoun \& Kindberg

Leskeella nervosa (Bridel) Loeske Syn.: Psedoleskeella nervosa (Bridel) Nyholm

Mnium arizonicum Amann (new to Montana)!Koponen

Mnium blyttii Bruch \& W. P. Schimper in B.S.G.

Mnium lycopodioides Schwaegrichen

Mnium marginatum (Aongstroem) Jaeger

Mnium orthorrhynchum Bridel

Mnium spinulosum B.S.G.

Mnium thomsonii W. P. Schimper

Myurella julacea (Schwaegrichen in Schultes) W. P. Schimper in B.S

*Myurella tenerrima (Bridel) Lindberg

Oncophorus virens (Hedwig) Bridel

Oncophorus wahlenbergii Bridel

Orthotrichum sp.

Palustriella commutata (Hedwig) Ochyra Syn.: Cratoneuron commutatum (Hedwig) G. Roth

Palustriella decipiens (DeNot.) Ochyra Syn: Cratoneuron williamsii Grout

*Paraleucobryum enerve (Thedenius in C. J. Hartman) Loeske

Philonotis fontana (Hedwig) Bridel

Plagiomnium cuspidatum (Hedwig) T. Koponen

Plagiomnium ellipticum (Bridel) T. Koponen 
Plagiomnium insigne (Mitten) T. Koponen

Plagiothecium laetum B.S.G.

Pleurozium schreberi (Willdenow ex Bridel) Mitten

Pogonatum urnigerum (Hedwig) Palisot de Beauvois

Pohlia cruda (Hedwig) Lindberg

Pohlia nutans (Hedwig) Lindberg

Pohlia wahlenbergii (Weber \& D. Mohr) Andrews in Grout

Pohlia sp.

Polytrichastrum alpinum (Hedwig) G. L. Smith Syn.: Polytrichum alpinum Hedwig

Polytrichum formosum Hedwig

Polytrichum juniperinum Hedwig

Polytrichum piliferum Hedwig

*Polytrichum sexangulare Floerke ex Bridel Syn.: Polytrichum norvegicum sensu Frye, non Hedwig

Pottiaceae spp.

Pterygynandrum filiforme Hedwig

Ptilium crista-castrensis (Hedwig) De Notaris

Racomitrium ericoides (Hedwig) Bridel Syn.: Racomitrium canescens fo. ericoides

(Weber ex. Bridel) Bridel

Racomitrium heterostichum (Hedwig) Bridel

Racomitrium lanuginosum (Hedwig) Bridel

Racomitrium sudeticum (Funck) Bruch \& W. P. Schimper in B.S.G.

Rhytidiadelphus loreus (Hedwig) Warnstorf

Rhytidiadelphus squarrosus (Hedwig) Warnstorf

Rhytidiadelphus triquetrus (Hedwig) Warnstorf

Rhytidiopsis robusta (W. J. Hooker) Brotherus

Rhytidium rugosum (Ehrhart ex Hedwig) Kindberg

Sanionia uncinata (Hedwig) Loeske Syn.: Drepanocladus uncinatus (Hedwig) Warnstorf

Schistidium sp.

Scorpidium cossoni (Schimp.) Hedenäs = Limprichtia cossonii (W.P.Schimper) Anderson et al.

Tetraphis pellucida Hedwig

Thuidium abietinum (Hedwig) B.S.G. = Abietinella abietina (Hedwig) Fleischer

Tomentypnum nitens (Hedwig) Loeske Syn.: Homalothecium nitens (Hedwig) Robins.

Tortella fragilis (W. J. Hooker \& Wilson in Drummond) Limpricht

Tortella tortuosa (Hedwig) Limpricht

*Tortula norvegica (Weber) Lindberg

Tortula ruralis (Hedwig) P. G. Gaertner, B. Meyer \& Scherbius

Weissia controversa Hedwig 


\section{Hepatics}

Anthelia juratzkana (Limpricht) Trevisan

Barbilophozia barbata (Schreber) Loeske

Barbilophozia floerkei (Weber \& D. Mohr) Loeske

Barbilophozia hatcheri (Evans) Loeske

Barbilophozia lycopodioides (Wallroth) Loeske

Blepharostoma trichophyllum (Linnaeus) Dumortier

Jungermannia sp.

Leiocolea cf. gillmani

Lepidozia reptans (Linnaeus) Dumortier

Lophocolea heterophylla (Schrader) Dumortier

Lophozia sp.

Lophozia ventricosa (Dickson) Dumortier

Lophozia wenzelii (Nees) Stephani

Marchantia polymorpha Linnaeus

Plagiochila asplenioidis (L.) Dumortier

Preissia quadrata (Scop.) Nees

Ptilidium ciliare (Linnaeus) Hampe

Ptilidium pulcherrimum (G. H. Weber) Hampe

Riccia sp.

Scapania paludosa (K.Mueller) K.Mueller

Tripterocladium leucocladulum (C. Mueller) Jaeger

Tritomaria sp.

Cephaloziella alpina

Cephaloziella sp. 


\section{Lichens}

Acarospora fuscata (Schrader) Arnold

Acarospora schleicheri (Ach.) A. Massal.

Alectoria ochroleuca (Hoffm.) A. Massal.

Arthroraphis citrinella (Ach.) Poelt Syn.: Bacidia citrinella, B. flavovirescens

Arthonia glebosa Tuck.

Aspicilia contorta s.l. (Hoffm.) Kremp. Syn.: Lecanora contorta

Brodoa oroarctica (Krog) Goward Syn.: Hypogymnia oroarctica.

Bryonora castanea (Hepp) Poelt Syn.: Lecanora castanea

Bryoria chalybeiformis (L.) Brodo \& D. Hawksw. Syn.: Alectoria chalybeiformis

Buellia epigaea (Pers.) Tuck.

Buellia geophila (Flörke ex Sommerf.) Lynge

Buellia papillata (Sommerf.) Tuck. Syn.: Buelliopsis papillata

Caloplaca ammiospila (Wahlenb.) H. Olivier Syn.: Caloplaca cinnamomea (Th. Fr.) H. Olivier

Caloplaca cerina (Ehrh. ex Hedwig) Th. Fr.= C. stillicidiorum (Vahl) Lynge

Caloplaca cladodes (Tuck.) Zahlbr.

Caloplaca fraudans (Th. Fr.) H. Olivier

Caloplaca jungermanniae (Vahl) Th. Fr.

Caloplaca sinapisperma (Lam. \& DC.) Maheu \& A. Gillet

Caloplaca tetraspora (Nyl.) H. Olivier (Specimen: Damm \#147/1995 !McCune)

Caloplaca tiroliensis Zahlbr.

Candelariella aurella (Hoffm.) Zahlbr.

Candelariella terrigena Räsänen

Candelariella vitellina (Hoffm.) Müll. Arg.

Candelariella xanthostigma (Ach.)

Catapyrenium squamulosum (Ach.) Breuß = Placidium squamulosum (Ach.) Breuss

Syn.: Dermatocarpon hepaticum auct.

Cetraria commixta (Nyl.) Th. Fr . = Melanelia commixta (Nyl.) Thell

Cetraria cucullata (Bellardi) Ach. = Flavocetraria cucullata (Bellardi) Kärnefelt \& Thell

Cetraria ericetorum Opiz ssp. ericetorum + ssp. reticulata (Räsänen) Kärnefelt

Cetraria hepatizon (Ach.) Vainio = Melanelia hepatizon (Ach.) Thell

Cetraria islandica (L.) Ach. subsp. islandica

Cetraria nivalis (L.) Ach. = Flavocetraria nivalis (L.) Kärnefelt \& Thell

Cetraria tilesii $\quad$ Ach. = Vulpicida tilesii (Ach.) J.-E. Mattsson \& M. J. Lai

Cladina mitis (Sandst.) Hustich Syns.: Cladonia mitis, Cladonia arbuscula subsp. mitis

Cladonia borealis S. Stenroos

Cladonia carneola (Fr.) Fr.

Cladonia cariosa (Ach.) Sprengel 
Cladonia cenotea (Ach.) Schaerer

Cladonia cervicornis (Ach.) Flotow subsp. cervicornis

Cladonia chlorophaea (Flörke ex Sommerf.) Sprengel

Cladonia coniocraea (Flörke) Sprengel

Cladonia cornuta (L.) Hoffm. subsp. cornuta

Cladonia ecmocyna Leighton subsp. ecmocyna

Cladonia fimbriata (L.) Fr.

Cladonia gracilis (L.) Willd. subsp. gracilis

Cladonia macrophyllodes Nyl.

Cladonia phyllophora Hoffm.

Cladonia pleurota (Flörke) Schaerer

Cladonia pocillum (Ach.) Grognot

Cladonia pyxidata (L.) Hoffm.

Cladonia squamosa Hoffm.

Cladonia sp.

Coelocaulon muricatum (Ach.) J. R. Laundon = Cetraria muricata (Ach.) Eckfeldt

Syn.: Cornicularia muricata (Ach.) Ach.

Collema tenax (Sw.) Ach.

Collema sp.

Dactylina ramulosa (Hook.) Tuck.

Dermatocarpon reticulatum $H$. Magn.

Dimelaena oreina (Ach.) Norman Syns.: Rinodina oreina, R. hueana, R. novomexicana, R. suboreina

Diploschistes muscorum (Scop.) R. Sant. subsp. muscorum

Diploschistes scruposus (Schreber) Norman Syn.: Urceolaria scruposa

Endocarpon pusillum Hedwig

Endocarpon tortuosum Herre

Hypogymnia austerodes (Nyl.) Räsänen Syn.: Parmelia austerodes

Icmadophila ericetorum (L.) Zahlbr.

Protoparmelia badia (Hoffm.) Hafellner Syn.: Lecanora badia (Hoffm.) Ach.

Lecanora epibryon (Ach.) Ach.

Lecanora intricata (Ach.) Ach.

Lecanora muralis (Schreber) Rabenh.

Lecanora polytropa (Hoffm.) Rabenh.

Lecanora rupicola (L.) Zahlbr.

Lecanora thomsonii H. Magn.

Lecanora sp.

Lecidea armeniaca (DC.) Fr. $=$ Tephromela armeniaca (DC.) Hertel \& Rambold

Lecidea atrobrunnea (Ramond ex Lam. \& DC.) Schaerer

Lecidea auriculata Th. Fr. 
Lecidoma demissum (Rutstr.) Gotth. Schneider \& Hertel

Lecidea fuscoatra (L.) Ach.Lecidea lapicida (Ach.) Ach.

Lecanora marginata (Schaerer) Hertel \& Rambold Syn.: Lecidea marginata Schaerer

Lecidea tesselata Flörke

Lecidea umbonata (Hepp) Mudd

Lecidia sp.

Lecidella stigmatea (Ach.) Hertel \& Leuckert !Knoph

Lecidella wulfenii (Hepp) Körber Syns.: Lecidea heppii, L. wulfenii

*Lepraria caesioalba (de Lesd.) J. R. Laundon (new to Montana, TLC-checked on various samples)

Lepraria neglecta (Nyl.) Erichsen (TLC-checked on various samples)

Leptogium lichenoides (L.) Zahlbr.

Leptogium saturninum (Dickson) Nyl.

Leptogium tenuissimum (Dickson) Körber

Leptogium sp.

Letharia columbiana (Nutt.) J. W. Thomson

Massalongia carnosa (Dickson) Körber

Melanelia exasperatula (Nyl.) Essl. Syn.; Parmelia exasperatula Nyl.

Melanelia stygia (L.) Essl. Syn.: Parmelia stygia

Mycobilimbia berengeriana (A. Massal.) Hafellner \& V. Wirth Syn.: Lecidea berengeriana

Neofuscelia cf. verruculifera (Nyl.) Essl. Syn.: Parmelia verruculifera

Ochrolechia upsaliensis (L.) A. Massal.

Ochrolechia spp.

Pannaria microphylla "(Sw.)" Müll. Arg. = Fuscopannaria leucophaea (Nyl.) P.M. Jørg.

Pannaria pezizoides $($ Weber) Trevisan = Protopannaria pezizoides $\quad$ P.M. Jørg. \& S. Ekman

Parmelia saxatilis (L.) Ach.

Parmelia sulcata Gyelnik

Peltigera canina (L.) Willd.

Peltigera collina (Ach.) Schrader

Peltigera didactyla (With.) J. R. Laundon = Peltigera spuria

Peltigera elisabethae Gyelnik

Peltigera kristinssonii Vitik.

Peltigera lepidophora (Vainio) Bitter

Peltigera leucophlebia (Nyl.) Gyelnik

Peltigera malacea (Ach.) Funck

Peltigera membranacea (Ach.) Nyl.

Peltigera praetextata (Flörke ex Sommerf.) Zopf

Peltigera rufescens (Weiss) Humb.

Peltigera scabrosa Th. Fr.

Peltigera venosa (L.) Hoffm. 
Pertusaria sp.

Phaeorrhiza nimbosa (Fr.) H. Mayrh. \& Poelt Syns.: Rinodina nimbosa, R. phaeocarpa

Phaeophyscia sciastra (Ach.) Moberg Syns.: Physcia sciastra, P. lithotea

Phaeophyscia decolor (Kashiw.) Essl. cf.

Phaeophyscia sp.

Physcia adscendens (Fr.) H. Olivier

Physcia aipolia (Ehrh. ex Humb.) Fürnr. var. aipolia

Physcia biziana (A. Massal.) Zahlbr.

Physcia caesia (Hoffm.) Fürnr.

Physcia orbicularis $\quad$ (Necker) Poetsch $=$ Phaeophyscia orbicularis

Physcia phaea (Tuck.) J. W. Thomson

Physcia stellaris (L.) Nyl.

Physcia tenella (Scop.) DC.

Physcia sp.

Physconia muscigena (Ach.) Poelt Syn.: Physcia muscigena

Placynthiella oligotropha (J. R. Laundon) Coppins \& P. James Syns.: Saccomorpha oligotropha

Placynthiella sp.

Platismatia glauca (L.) Culb. \& C. Culb. Syn.: Cetraria glauca (L.) Ach.

Pleopsidium chlorophanum (Wahlenb.) Zopf Syn.: Acarospora chlorophana (Wahlenb.) A. Massal.

Polyblastia sendtneri Kremp. !Breuss

Polychidium muscicola (Sw.) Gray

Protoparmelia badia (Hoffm.) Hafellner Syn.: Lecanora badia (Hoffmann) Ach.

Pseudephebe minuscula (Nyl. ex Arnold) Brodo \& D. Hawksw. Syn.: Alectoria minuscula

Pseudephebe pubescens $\quad$ (L.) M. Choisy Syns.: Alectoria pubescens, Parmelia lanata

Psora decipiens (Hedwig) Hoffm. Syn.: Lecidea decipiens

Psora sp. cf.

Psoroma hypnorum (Vahl) Gray Syn.: Pannaria hypnorum

Rhizoplaca chrysoleuca (Sm.) Zopf Syns.: Lecanora chrysoleuca, L. rubina

Rhizoplaca melanophthalma (DC.) Leuckert \& Poelt Syn.: Lecanora melanophthalma

Rhizocarpon disporum (Nägeli ex Hepp) Müll. Arg.

Rhizocarpon geminatum Körber

Rhizocarpon geographicum agg. (L.) DC.

Rhizocarpon grande (Flörke ex Flotow) Arnold

Rhizocarpon sp.

Rinodina archaea (Ach.) Arnold

Rinodina mniaraea (Ach.) Körber

Rinodina roscida (Sommerf.) Arnold

Rinodina turfacea (Wahlenb.) Körber

Rinodina sp. 
Sarcogyne sp.

Solorina bispora Nyl.

Solorina crocea (L.) Ach.

Solorina saccata (L.) Ach.

Sporastatia testudinea (Ach.) A. Massal. Syn.: Biatorella testudinea

Stereocaulon alpinum Laurer ex Funck

Stereocaulon paschale (L.) Hoffm.

Stereocaulon tomentosum Fr.

Stereocaulon sp.

Thamnolia subuliformis (Ehrh.) Culb. (incl. T. vermicularis (Sw.) Ach. ex Schaerer)

Toninia sp. cf.

Trapeliopsis granulosa (Hoffm.) Lumbsch Syns.: Lecidea granulosa, L. quadricolor

Tremolecia atrata (Ach.) Hertel Syns.: Lecidea atrata, L. dicksonii auct.

Umbilicaria cf. arctica (Ach.) Nyl. Syn.: Gyrophora arctica

Umbilicaria deusta (L.) Baumg. Syn.: Gyrophora deusta

Umbilicaria hyperborea (Ach.) Hoffm. var. hyperborea Syn.: Gyrophora hyperborea

Umbilicaria krascheninnikovii (Savicz) Zahlbr. Syn.: Omphalodiscus krascheninnikovii

Umbilicaria polyphylla (L.) Baumg. Syn.: Gyrophora polyphylla

Umbilicaria vellea (L.) Hoffm. Syn.: Gyrophora vellea

Umbilicaria virginis Schaerer Syns.: Omphalodiscus virginis

Verrucaria sp.

Xanthoparmelia coloradoensis (Gyelnik) Hale

Xanthoparmelia wyomingica Hale

Xanthoparmelia sp.

Xanthoria elegans (Link) Th. Fr. Syn.: Caloplaca elegans

Xanthoria sorediata (Vainio) Poelt Syn.: Caloplaca sorediata 


\begin{tabular}{|c|c|c|c|c|c|}
\hline & & & & \multicolumn{2}{|c|}{$\begin{array}{c}\text { Aufnahmebogen Version } 1.5 \mathrm{~d} \\
\text { Time: }\end{array}$} \\
\hline \multirow[t]{2}{*}{ Community: } & & & & Date: & \multirow[t]{2}{*}{ No. } \\
\hline & & \multicolumn{3}{|r|}{ Name: } & \\
\hline \multirow[t]{2}{*}{ Location: } & & & & GPS-File: & Counts: \\
\hline & & UTM: & $E$ & PDOP: & Sats: \\
\hline Elevation: & $m(A)$ & Aspect: & Inclinatio & n: & Size: \\
\hline
\end{tabular}

Vegetation: plot-number:

\# vasc. pl.:__ \# cryptogams:

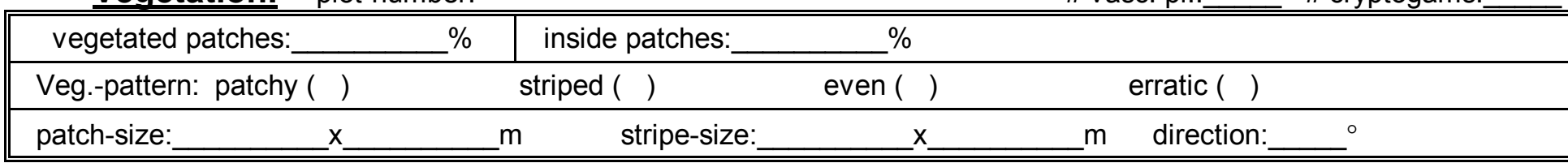

\section{Local distribution of same unit:}

Adjacent vegetation:

Adjacent vegetation:
Disturbance: Erosion ( ) Solifluction ( ) Animals ( ) other:

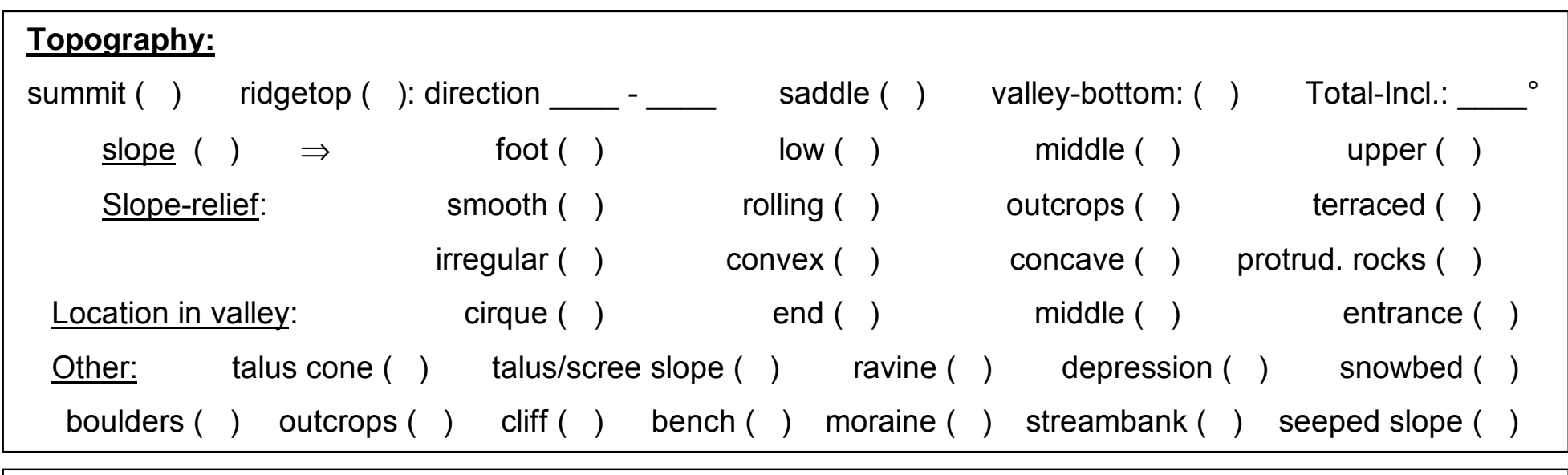

\section{Geology:}

Parent material:

color:

rock cover (incl. lichenized):

$\%$

layer-inclination:

loose ( ) compacted ( )

open soil $(<0,1 \mathrm{~cm})$ :

\begin{tabular}{|c|r|r|r|r|r|r|r|}
\hline size class & $<0,5 \mathrm{~cm}$ & $0,5-2 \mathrm{~cm}$ & $2-5 \mathrm{~cm}$ & $5-10 \mathrm{~cm}$ & $10-25 \mathrm{~cm}$ & $25-50 \mathrm{~cm}$ & $>50 \mathrm{~cm}$ \\
\hline coverage & $\%$ & $\%$ & $\%$ & $\%$ & $\%$ & $\%$ & $\%$ \\
\hline
\end{tabular}

Rock-texture: platy/shaly ( ) isodiam. ( ) sharp-edged ( ) abrased-edged ( ) weathered ( )

Origin: frost rubble ( ) talus/colluvial ( ) glacial, alluvial debris ( ) $\quad$ sorted ( )

Soil:

Profile-depth: __

Organic matter:

Moisture: dry ( )

estimated watercapacity/supply:

Solifluction:

Remarks:

Climate:

Wind-exposure: extreme ( ) high ( ) middle ( ) slight ( ) protected ( ) estimated snow duration: long ( ) reasonable ( ) moderate ( ) exposed ( )

\begin{tabular}{|c|c|c|c|c|}
\hline A & Species & Pheno & & Species \\
\hline 1 & & & 36 & \\
\hline 2 & & & 37 & \\
\hline 3 & & & 38 & \\
\hline 4 & & & 39 & \\
\hline 5 & & & 40 & \\
\hline 6 & & & 41 & \\
\hline 7 & & & 42 & \\
\hline 8 & & & 43 & \\
\hline 9 & & & 44 & \\
\hline 10 & & & 45 & \\
\hline 11 & & & 46 & \\
\hline 12 & & & 47 & \\
\hline 13 & & & 48 & \\
\hline 14 & & & 49 & \\
\hline 15 & & & 50 & \\
\hline 16 & & & 51 & \\
\hline 17 & & & 52 & \\
\hline 18 & & & 53 & \\
\hline 19 & & & 54 & \\
\hline 20 & & & 55 & \\
\hline 21 & & & & \\
\hline 22 & & & & \\
\hline
\end{tabular}

Scheme of plot:

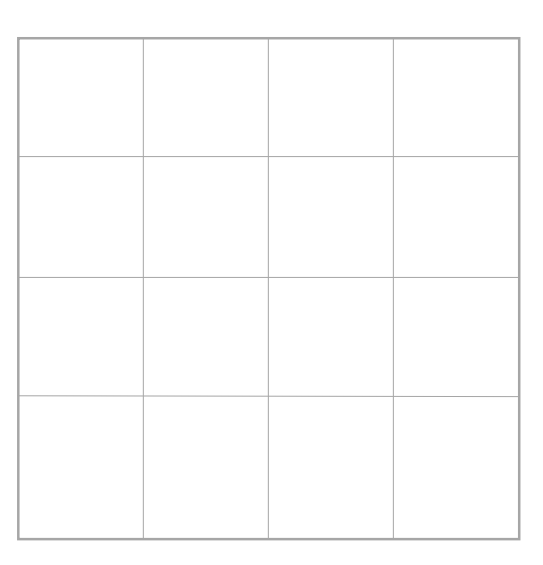

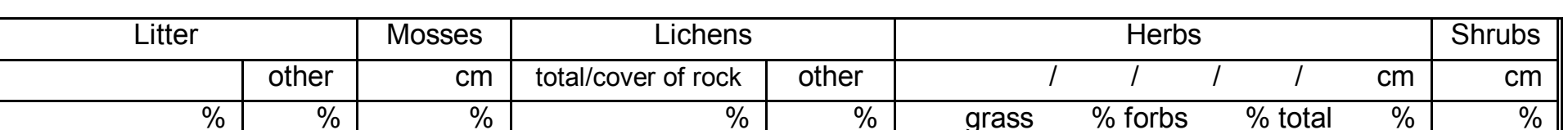
Phenology ( ) Corners marked ( ) $\quad$ Soil collected ( ) $\quad$ Soil datasheet ( ) $\quad \begin{aligned} & \text { Spec. covers ( ) Photo ( ) } \\ & \text { GPSed ( ) Time: }\end{aligned}$ $r=$ single indiv. $\quad r-+=<5$ indiv. $\quad+-r=<20$ indiv. or $<1 \% \quad+=<5 \% \quad 1=>5 \% \quad 2=>10 \% \quad 3=>25 \% \quad 4=>50 \% \quad 5=>75 \%$ 


\section{Appendix E. Table Legends for Association Tables}

\section{Abbreviations used in the Tables}

The following abbreviations have been used in the association tables.

\section{Parent Materials:}

$\begin{array}{ll}\text { GA } & \text { Green Argillite } \\ \text { RA } & \text { Red Argillite } \\ \text { Lim } & \text { Limestone } \\ \text { Dol } & \text { Dolomite } \\ \text { Qzt } & \text { Quarzite } \\ \text { Dio } & \text { Diorite/Igneous rock } \\ \text { GAM } & \text { Green Argillite dominated mix } \\ \text { RAM } & \text { Red Argillite dominated mix } \\ \text { LmM } & \text { Limestone dominated mix } \\ \text { QzM } & \text { Quartzite dominated mix } \\ \text { DiM } & \text { Diorite dominated mix } \\ \text { ArM } & \text { Arenite dominated mix } \\ \text { GLM } & \text { Green Argillite and Limestone } \\ & \text { dominated mix }\end{array}$

RG Red and Green Argillite

GAL Green Argillite with Limestone

RAL Red Argillite with Limestone

GAS Green Argillite with Sandstone

GAQ Green Argillite with Quartzite

RAQ Red Argillite with Quartzite

RGQ Red and Green Argillite with Quartzite

DLi Dolomite and Limestone

ArS Arenite/Sandstone

ArQ Arenite with Quartzite

RGL Red and Green Argillite and Limestone

RGD Red and Green Argillite and Dolomite

Mix Even Mix of different materials

\section{Vegetation Pattern:}

\section{Diagnostic species, data records}

$\begin{array}{ll}\text { spo } & \text { patchy } \\ \text { p/s } & \text { patchy to striped } \\ \text { vst } & \text { vertical stripes } \\ \text { hst } & \text { horizontal stripes } \\ \text { ost } & \text { oblique stripes } \\ \text { eve } & \text { evenly spread } \\ \text { err } & \text { erratic } \\ \text { e/r } & \text { even to erratic } \\ \text { s/e } & \text { striped to even } \\ \text { e/s } & \text { even to striped }\end{array}$

CC Class character species

OC Order character species

VC Alliance character species

AC Association character species

SAC Subassociation character species

Ad Association differential species

() tentative diagnostic species

$\mathrm{x} \quad$ species present

$\mathrm{X} \quad$ species present and dominant

p cryptogam species present

P cryptogam species present and dominant no record 


\section{Location Abbreviations}

The abbreviations give only general areas. Detailed UTM plot location data are available.

\begin{tabular}{|c|c|c|c|}
\hline Ahe & Ahern Pass Westside & $\mathrm{HGr}$ & Highline Trail/Grinnell \\
\hline AIS & Altyn Peak South & $\mathrm{HiA}$ & Highline Trail/Alder Creek \\
\hline $\mathrm{AkS}$ & Apikuni South East & $\mathrm{HiS}$ & Highline Trail south of Granite Park \\
\hline $\mathrm{AkV}$ & Apikuni Valley & $\mathrm{HiT}$ & Highline \\
\hline AlN & Altyn Peak Northeast & $\mathrm{HoE}$ & Hole-in-the-Wall East \\
\hline ApC & Appistoki Valley Cirque & Hol & Hole-in-the Wall \\
\hline ApP & Appistoki Peak (East-slope) & HoW & Hole-in-the Wall West \\
\hline $\mathrm{ApV}$ & Appistoki Valley & $\mathrm{HrE}$ & Mt. Henry East \\
\hline AVN & Apikuni Valley North & Ice & Iceberg Trail \\
\hline Bar & Baring Creek Valley & LDo & Little Dog Mtn. \\
\hline Bis & Bison Mtn.South E & Lee & Lee Ridge \\
\hline $\mathrm{BiW}$ & Bison Mtn. West & $\mathrm{LiP}$ & Lincoln Pass \\
\hline $\mathrm{BoE}$ & Boulder Pass East & LiT & Lincoln Pass Terraces \\
\hline $\mathrm{BoN}$ & Boulder Pass Northeast & LoE & Logan Pass East \\
\hline Bou & Boulder Pass & $\log$ & Logan Pass \\
\hline Bro & Brown Pass & LoR & Logan Pass Reynolds Creek \\
\hline $\mathrm{BrW}$ & Brown Pass West & LoS & Logan Pass South \\
\hline $\mathrm{CaR}$ & Calf Robe Mtn. & LoW & Logan Pass West \\
\hline Cha & Chaney Glacier Ridge & Lun & Lunch Creek \\
\hline Cra & Cracker Lake Ridge & $\mathrm{MeN}$ & Medicine Mtn. North \\
\hline Daw & Dawson Pass & $\mathrm{MeS}$ & Medicine Mtn. South \\
\hline DuL & Dutch Lakes & MOB & Medicine Owl Basin \\
\hline Eas & East Flat & Nat & Natsukin Mtn. \\
\hline EaW & East Flattop West & Old & Oldman Lake \\
\hline Fal & Falling Leaf Lake & OtE & Otokomi Mtn. East \\
\hline Fif & Fifty Mtn. & OtN & Otokomi Mtn. North \\
\hline Fir & Firebrand Pass Basin & OtS & Otokomi Mtn. South \\
\hline FLN & Falling Leaf Lake North & OtW & Otokomi Mtn. West \\
\hline FWL & Feather Woman Lake & Pie & Piegan Pass \\
\hline GOT & Grinnell Overlook Trail & Pit & Pitamakan Pass \\
\hline Gri & Grinnell Glacier Trail & PPE & Preston Park Cirque \\
\hline Gun & Gunsight Pass & Pta & Ptarmigan Area \\
\hline Gyr & Gyrfalcon Lake & PtL & Ptarmigan Lake \\
\hline Hay & Haystack Butte & $\mathrm{PtN}$ & Ptarmigan Tunnel North \\
\hline Hea & Heavens's Peak & $\mathrm{PtS}$ & Ptarmigan TunnelSouth \\
\hline
\end{tabular}




\begin{tabular}{|c|c|}
\hline Red & Redgap Pass \\
\hline $\mathrm{ReN}$ & Mt. Reynolds North \\
\hline ReW & Mt. Reynolds West \\
\hline ScT & Scenic Point Trail \\
\hline $\mathrm{ScW}$ & Scenic Point Plateau West \\
\hline Siy & Siyeh Pass \\
\hline SML & Snow Moon Lake Basin \\
\hline Spe & Sperry Glacier Trail \\
\hline $\mathrm{SpE}$ & Spot Mtn. East \\
\hline $\mathrm{SpF}$ & Sperry Glacier towards Flora Park \\
\hline Spo & Spot Mtn. \\
\hline SPP & Scenic Point Plateau \\
\hline $\mathrm{SpS}$ & Spot Mtn.South \\
\hline SpT & Sperry trail \\
\hline $\mathrm{SpV}$ & Spot Mtn. Valley \\
\hline $\mathrm{SpW}$ & Spot Mtn. West \\
\hline Sue & Sue Lake Plateau \\
\hline SwM & Swiftcurrent Mountain \\
\hline SwP & Swiftcurrent Pass \\
\hline SwW & Swiftcurrent Pass West \\
\hline TDP & Triple Divide Pass \\
\hline TML & Two Medicine Lake \\
\hline $\operatorname{TrP}$ & Trapper Peak \\
\hline Twi & Twin Lakes/Mt.Reynolds South \\
\hline Wyn & Mt.Wynn \\
\hline Yel & Yellow Mtn. \\
\hline
\end{tabular}




\section{Appendix F. Table Legends for Synoptic Tables}

\section{LEGEND TABLE 1: Synopsis of Western North American Fellfield units}

\begin{tabular}{|c|c|c|c|c|c|c|}
\hline No. & Code & Author & Year & Table & Original Community Title & Location \\
\hline 1 & Ach & Achuff et al. & 1997 & $\mathrm{~T} 40$ & Saxicolous lichen tundra & Waterton NP, AB \\
\hline 2 & K75 & Kuchar & 1975 & $\mathrm{~T} 16$ & Cushion rosette tundra & Bald Hills; AB \\
\hline 3 & Bed & Beder & 1967 & $\mathrm{~T} 34$ & Ridge summit ass. & Snow Creek Valley, \\
\hline 4 & Pol & Polster & 1972 & CD6* & Silene acaulis basal community & $\begin{array}{l}\text { Akamina Pass; Clarks } \\
\text { Range, BC }\end{array}$ \\
\hline 5 & Pol & Polster & 1972 & $\mathrm{Ct} 5^{*}$ & $\begin{array}{l}\text { Agropyron latiglume-Draba } \\
\text { paysonis community }\end{array}$ & $\begin{array}{l}\text { Akamina Pass; } \\
\text { Clarks Range, BC }\end{array}$ \\
\hline 6 & Pol & Polster & 1972 & $\mathrm{CD}^{*} *$ & Selected non-Dryas plots & $\begin{array}{l}\text { Akamina Pass; } \\
\text { Clarks Range, BC }\end{array}$ \\
\hline 7 & Dam & Damm & 2001 & T6 & $\begin{array}{l}\text { Myosotido alpestris-Caricetum } \\
\text { albonigrae polemonietosum }\end{array}$ & $\begin{array}{l}\text { Glacier National Park, } \\
\text { MT }\end{array}$ \\
\hline 8 & Dam & Damm & 2001 & T6 & $\begin{array}{l}\text { Arenaria obtusiloba basal } \\
\text { community }\end{array}$ & $\begin{array}{l}\text { Glacier National Park, } \\
\text { MT }\end{array}$ \\
\hline 9 & Dam & Damm & 2001 & T6 & $\begin{array}{l}\text { Myosotido alpestris-Caricetum } \\
\text { albonigrae typicum }\end{array}$ & $\begin{array}{l}\text { Glacier National Park, } \\
\text { MT }\end{array}$ \\
\hline 10 & Dam & Damm & 2001 & T6 & $\begin{array}{l}\text { Myosotido alpestris-Caricetum } \\
\text { albonigrae var. of Campanula } \\
\text { rotundifolia }\end{array}$ & $\begin{array}{l}\text { Glacier National Park, } \\
\text { MT }\end{array}$ \\
\hline 11 & Dam & Damm & 2001 & $\mathrm{~T} 7$ & Oxytropido-Bupleuretum typicum & $\begin{array}{l}\text { Glacier National Park, } \\
\text { MT }\end{array}$ \\
\hline 12 & Dam & Damm & 2001 & $\mathrm{~T} 7$ & $\begin{array}{l}\text { Oxytropido-Bupleuretum variant of } \\
\text { Festuca idahoensis }\end{array}$ & $\begin{array}{l}\text { Glacier National Park, } \\
\text { MT }\end{array}$ \\
\hline 13 & Dam & Damm & 2001 & $\mathrm{~T} 7$ & $\begin{array}{l}\text { Oxytropido-Bupleuretum var. of } \\
\text { Selaginella wallacei }\end{array}$ & $\begin{array}{l}\text { Glacier National Park, } \\
\text { MT }\end{array}$ \\
\hline 14 & $\mathrm{CoL}$ & Cooper et al. & 1997 & CTi & Carex rupestris-Potentilla ovina c.t. & Beaverhead NF, MT \\
\hline 15 & $\mathrm{CoL}$ & Cooper et al. & 1997 & $\mathrm{CTa}$ & $\begin{array}{l}\text { Festuca idahoensis-Potentilla } \\
\text { diversifolia c.t. }\end{array}$ & Beaverhead NF, MT \\
\hline 16 & $\mathrm{CoL}$ & Cooper et al. & 1997 & CTd & Carex elynoides c.t. & Beaverhead NF, MT \\
\hline 17 & $\mathrm{CoL}$ & Cooper et al. & 1997 & $\mathrm{CTm}$ & Dry slope c. t. & Beaverhead NF, MT \\
\hline 18 & $\mathrm{CoL}$ & Cooper et al. & 1997 & $\mathrm{CTe}$ & $\begin{array}{l}\text { Carex scirpoidea-Potentilla } \\
\text { diversifolia c.t. }\end{array}$ & Beaverhead NF, MT \\
\hline 19 & $\mathrm{CoL}$ & Cooper et al. & 1997 & CTf & Carex scirpoidea-Geum rossii c.t. & Beaverhead NF, MT \\
\hline 20 & $\mathrm{CoL}$ & Cooper et al. & 1997 & $\mathrm{CTh}$ & $\begin{array}{l}\text { Salix arctica-Polygonum } \\
\text { bistortioides c.t. }\end{array}$ & Beaverhead NF, MT \\
\hline 21 & $\mathrm{CoL}$ & Cooper et al. & 1997 & $\mathrm{CTj}$ & Geum rossii-Arenaria obtusiloba c.t. & Beaverhead NF, MT \\
\hline 22 & B68 & $\begin{array}{l}\text { Bamberg \& } \\
\text { Major }\end{array}$ & 1968 & $\mathrm{~T} 8 \mathrm{~b}$ & Sedge community & Flint Creek Mtns., M \\
\hline
\end{tabular}


T2 Fellfield stand type

24 B61 Bamberg

1961

T3

Polygon stone stripe

J\&B Johnson \&

1962 Billings

29 Thi Thilenius

Thilenius

1985

1985

31 Thi Thilenius

32 Thi Thilenius

1985

Bli Bliss

1956

$\mathrm{T} 3$

Dry Meadow, turf

TC1 Geum-Trifolium parryi c.t.

TC2 Geum-Trifolium nanum c.t.

TC3 Trifolium dasyphyllum-Geum

TC5 Phlox pulvinata-Trifolium dasyphyllum c.t.

34 Bli Bliss

Bli Bliss

1956

T6

36 Kom Komarkova

195

T6 ridgetop Fellfield

T6 northexposed Fellfield

1979

$\mathrm{T} 8$

37 Kom Komarkova

1979

1979

38

Kom Komarkova

1979

39 Kom Komarkova

1979

1979

40 Kom Komarkova

41 Kom Komarkova

42 Can Cain

1979

1943

$\mathrm{T} 8$

$\mathrm{T} 2$

1979

$7 b$

$1979 \quad 7 d$

\section{Caricetum elynoides}

$\begin{array}{lll}43 & \text { Kom } & \text { Komarkova } \\ 44 & \text { Kom } & \text { Komarkova }\end{array}$

1979

$7 \mathrm{~d}$

45 Kom Komarkova

1979

46 Kom Komarkova
1979
Dry Carex meadow

Fellfield stand type

southexposed Fellfield

Potentillo-Caricetum rupestris

Flint Creek Mtns., Big

Belt

Mtns., MT

Flint Creek Mtns., Big

Belt

Mtns., MT

Crazy Mtns./Beartooth

Plateau/ Absaroka

Range,

Flint Creek Mtns., MT

Beartooth Plateau /

Absaroka Range, MT

Flint Creek Mtns., Big

Belt

Mtns., MT

Beartooth Plateau, MT

Absaroka Mtns; WY

Absaroka Mtns; WY

Absaroka Mtns; WY

Absaroka Mtns; WY

Medicine Bow Mtns.,

WY

Medicine Bow Mtns., WY

Medicine Bow Mtns.,

WY

Indian Peaks Area; CO cespitosae

Indian Peaks Area; CO

Indian Peaks Area; CO

Indian Peaks Area; $\mathrm{CO}$

Indian Peaks Area; CO

Indian Peaks Area; CO

Medicine Bow Mtns.,

WY

Indian Peaks Area; CO

Indian Peaks Area; CO

Indian Peaks Area; $\mathrm{CO}$

Indian Peaks Area; CO 


\begin{tabular}{|c|c|c|c|c|c|c|}
\hline 47 & Wil & Willard & 1979 & $\mathrm{~T} 2$ & Silene acaulis Paronychietum & Trail Ridge; $\mathrm{CO}$ \\
\hline 48 & Wil & Willard & 1979 & $\mathrm{~T} 4$ & Trifolietum dasyphylli & Trail Ridge; $\mathrm{CO}$ \\
\hline 49 & Wil & Willard & 1979 & T5 & facies hymenoxyetosum & Trail Ridge; $\mathrm{CO}$ \\
\hline 50 & Wil & Willard & 1979 & $\mathrm{~T} 17$ & Caricetum elynoides & Trail Ridge; $\mathrm{CO}$ \\
\hline 51 & Wil & Willard & 1979 & $\mathrm{~T} 18$ & Potentillo-Caricetum rupestris & Trail Ridge; $\mathrm{CO}$ \\
\hline 52 & Wil & Willard & 1979 & $\mathrm{~T} 21$ & $\begin{array}{l}\text { Potentillo-Caricetum rupestris } \\
\text { facies eritrichietosum }\end{array}$ & Trail Ridge; CO \\
\hline 53 & Wil & Willard & 1979 & $\mathrm{~T} 21$ & Campanulo uniflorae-Kobresietum & Trail Ridge; CO \\
\hline 54 & Wil & Willard & 1979 & $\mathrm{~T} 27$ & Acomastylidetum rossii & Trail Ridge; $\mathrm{CO}$ \\
\hline 55 & Cox & Cox & 1933 & $\mathrm{~T} 11$ & Elynetum & Longs Peak, CO \\
\hline 56 & Cox & Cox & 1933 & $\mathrm{~T} 10$ & Dry meadow Ass. & Longs Peak, CO \\
\hline 57 & Cox & Cox & 1933 & $\mathrm{~T} 7$ & Fellfield Ass. & Longs Peak, CO \\
\hline 58 & Kie & Kiener & 1940 & T5 & Elynetum & Longs Peak, CO \\
\hline 59 & Edd & $\begin{array}{l}\text { Eddleman \& } \\
\text { Ward }\end{array}$ & 1984 & T3a & $\begin{array}{l}\text { Kobresia myosuroides } \\
\text { (=K.bellardii) turf }\end{array}$ & $\begin{array}{l}\text { Rocky Mountain NP, } \\
\text { CO }\end{array}$ \\
\hline 60 & Edd & $\begin{array}{l}\text { Eddleman \& } \\
\text { Ward }\end{array}$ & 1984 & $\mathrm{~T} 3 \mathrm{~b}$ & Paronychia pulvinata fellfield & $\begin{array}{l}\text { Rocky Mountain NP, } \\
\text { CO }\end{array}$ \\
\hline 61 & Edd & $\begin{array}{l}\text { Eddleman \& } \\
\text { Ward }\end{array}$ & 1984 & $\mathrm{~T} 3 \mathrm{c}$ & $\begin{array}{l}\text { Carex elynoides-Trifolium } \\
\text { dasyphyllum turf }\end{array}$ & $\begin{array}{l}\text { Rocky Mountain NP, } \\
\text { CO }\end{array}$ \\
\hline 62 & Bak & Baker & 1983 & $\mathrm{~T} 2.1$ & Cushion Community & Wheeler Peak, NM \\
\hline 63 & Bak & Baker & 1983 & $\mathrm{~T} 2.2$ & $\begin{array}{l}\text { Carex rupestris/Cushion } \\
\text { Community }\end{array}$ & Wheeler Peak, NM \\
\hline 64 & Bak & Baker & 1983 & $\mathrm{~T} 2.3$ & Carex elynoides Turf & Wheeler Peak, NM \\
\hline 65 & Bak & Baker & 1983 & $\mathrm{~T} 2.4$ & Trifolium dasyphyllum Meadow & Wheeler Peak, NM \\
\hline 66 & Bak & Baker & 1983 & $\mathrm{~T} 2.5$ & Kobresia-Geum Turf & Wheeler Peak, NM \\
\hline 67 & Bak & Baker & 1983 & $\mathrm{~T} 2.6$ & Dwarf Salix Community & Wheeler Peak, NM \\
\hline 68 & Lit & Little & 1941 & text & Alpine Rock Field & San Francisco Mtn., AZ \\
\hline 69 & Lit & Little & 1941 & text & $\begin{array}{l}\text { Alpine species from Little's San } \\
\text { Francisco Mtn. area list }\end{array}$ & San Francisco Mtn., AZ \\
\hline 70 & Moo & Moore & 1965 & text & Alpine Meadow Association & San Francisco Mtn., AZ \\
\hline 71 & Coo & Cooper & 1908 & text & Dry meadow Ass. & Longs Peak, CO \\
\hline 72 & And & Andrews & 1983 & $\mathrm{P} 11$ & Alpine tundra & Upper Pecos River; CO \\
\hline 73 & Rot & $\begin{array}{l}\text { Rottman et } \\
\text { al. }\end{array}$ & 1985 & text & $\begin{array}{l}\text { Geum-Selaginella dry ledge } \\
\text { community }\end{array}$ & San Juan Mtns, AZ \\
\hline 74 & Rot & $\begin{array}{l}\text { Rottman et } \\
\text { al. }\end{array}$ & 1985 & text & 1st Fellfield Habitat Type & San Juan Mtns, AZ \\
\hline 75 & Rot & $\begin{array}{l}\text { Rottman et } \\
\text { al. }\end{array}$ & 1985 & text & 2nd Fellfield Habitat Type & San Juan Mtns, AZ \\
\hline 76 & Ram & Ramaley & 1919 & text & Alpine meadow & Northern Colorado \\
\hline 77 & Ram & Ramaley & 1919 & text & Carex elynoides Grassland Ass. & Northern Colorado \\
\hline 78 & $\mathrm{~B} \& \mathrm{~B}$ & $\begin{array}{l}\text { Billings \& } \\
\text { Bliss }\end{array}$ & 1959 & T-sect & Ridgetop comm. & $\begin{array}{l}\text { Medicine Bow Mtns., } \\
\text { WY }\end{array}$ \\
\hline
\end{tabular}


San Juan Mtns, AZ al.

81 Cai Caicco

1983

\begin{abstract}
82 Cai Caicco
\end{abstract}
83 Cai Caicco

84 Cai Caicco

85 Cai Caicco

86 Cai Caicco

87 Cai Caicco

88 Urb Urbancyzk

89 Urb Urbancyzk

$90 \quad$ Urb Urbancyzk

91 Urb Urbancyzk

1983

1983
CD9* Leucopoa kingii-Phlox pulvinata unit

1983 unit
CD7* Carex elynoides-Phlox pulvinata

\section{3}

1983

$$
* \text { unit }
$$
CD11 Oxytropis sericea-Agropyron scribneri unit

1994

1994

2

\section{3}

1994

1994

92 Urb Urbancyzk

1994

93 Urb Urbancyz

94 CoL Cooper et al.

1994

1997

95
D\&B Douglas \& Bliss p.72 Ivesia gordonii cushion plant community

Ivesia gordonii-Phlox pulvinataAgropyron scribneri unit

Ivesia gordonii-Selaginella densa unit (1)

Carex
unit

Southwest Montana

Copper Basin Area

;Pioneer

Mtns.; White Knob

Mtns., ID

Copper Basin Area

;Pioneer

Mtns.; White Knob

Mtns., ID

Copper Basin Area

;Pioneer

Mtns.; White Knob

Mtns., ID

Copper Basin Area

;Pioneer

Mtns.; White Knob

Mtns., ID

Copper Basin Area

;Pioneer

Mtns.; White Knob

Mtns., ID

Copper Basin Area

;Pioneer

Mtns.; White Knob

Mtns., ID

Copper Basin Area

;Pioneer

Mtns.; White Knob

Mtns., ID

Sheep Mountain; ID

Sheep Mountain; ID haydeniana c.t.

Sheep Mountain; ID

Sheep Mountain; ID elynoides c.t.

Sheep Mountain; ID

Sheep Mountain; ID

Beaverhead NF; MT campestris c.t.

North Cascades, WA 
96 Ham Hamann

97 Ham Hamann

197

98 Del DelMoral
197

192

$\mathrm{T} 2$

972

1979
T21 A lepidus ass.

T22 Erigeron aureus-Lupinus lepidus ass.

Phlox pulvinata-Lupinus lepidus community
Mt. Rainier NP, WA

Mt. Rainier NP, WA

Enchantment Basin, WA

* = original units of Polster and Caicco have been rearranged using the plot data provided by those authors 


\section{LEGEND TABLE 2: Synopsis of Western North American Salix nivalis, Dryas octopetala and Kobresia myosuroides units}

\begin{tabular}{|c|c|c|c|c|c|c|}
\hline No. & Code & Author & $\begin{array}{c}\text { Yea } \\
\mathbf{r}\end{array}$ & Table & Original Community Title & Location \\
\hline 1 & Ach & Achuff et al. & 1982 & $\mathrm{~T} 80$ & Dryas-Kobresia-Arctostaphylos & Banff NP, Jasper NP \\
\hline 2 & Ach & Achuff et al. & 1982 & $\mathrm{~T} 77 \mathrm{a}$ & $\begin{array}{l}\text { Dryas octopetala-Salix nivalis-Silene } \\
\text { acaulis }\end{array}$ & Banff NP, Jasper NP \\
\hline 3 & Ach & Achuff et al. & 1982 & $\mathrm{~T} 77 \mathrm{~b}$ & $\begin{array}{l}\text { Dryas octopetala-Salix nivalis-Silene } \\
\text { acaulis }\end{array}$ & Banff NP, Jasper NP \\
\hline 4 & Ach & Achuff et al. & 1984 & T62 & $\begin{array}{l}\text { Dryas octopetala-Salix nivalis-Silene } \\
\text { acaulis }\end{array}$ & ai NP \\
\hline 5 & Ach & Achuff et al. & 1984 & $\mathrm{~T} 40$ & $\begin{array}{l}\text { Dryas octopetala-Salix nivalis-Silene } \\
\text { acaulis }\end{array}$ & Mt.Revelstoke NP \\
\hline 6 & Ach & Achuff et al. & 1993 & $\mathrm{~T} 70$ & $\begin{array}{l}\text { Dryas octopetala-Salix nivalis-Silene } \\
\text { acaulis }\end{array}$ & Yoho NP \\
\hline 7 & Ach & Achuff et al. & 1997 & T36 & Dryas octopetala & Waterton NP \\
\hline 8 & Ach & Achuff et al. & 1997 & T36 & Dryas octopetala & Waterton NP \\
\hline 9 & Ach & Achuff et al. & 1997 & $\mathrm{~T} 36$ & Saxicolous lichen tundra & Waterton NP \\
\hline 10 & B61 & Bamberg & 1961 & $\mathrm{~T} 14$ & Dryas stand type & Siyeh Pass; Glacier NP \\
\hline 11 & B61 & Bamberg & 1961 & $\mathrm{~T} 14$ & Dryas stand type & Siyeh Pass; Glacier NP \\
\hline 12 & B68 & $\begin{array}{l}\text { Bamberg \& } \\
\text { Major }\end{array}$ & 1968 & $\mathrm{~T} 7$ & Dryas stand type & Siyeh Pass; Glacier NP \\
\hline 13 & B68 & $\begin{array}{l}\text { Bamberg \& } \\
\text { Major }\end{array}$ & 1968 & $\mathrm{~T} 7$ & Dryas stand type & Siyeh Pass; Glacier NP \\
\hline 14 & B68 & $\begin{array}{l}\text { Bamberg \& } \\
\text { Major }\end{array}$ & 968 & $\mathrm{~T} 7$ & Dryas star & Siyeh Pass; Glacier NP \\
\hline 15 & B68 & $\begin{array}{l}\text { Bamberg \& } \\
\text { Major }\end{array}$ & 1968 & T8a & Dryas stand type & Flint Creek Mtns. \\
\hline 16 & Bed & Beder & 1967 & $\mathrm{~T} 36$ & Dryas-Salix arctica & Snow Creek Valley \\
\hline 17 & Bed & Beder & 1967 & $\mathrm{~T} 35$ & Dryas-Kobresia & Snow Creek Valley \\
\hline 18 & Bed & Beder & 1967 & $\mathrm{~T} 32$ & Kobresia myosuroides & Snow Creek Valley \\
\hline 19 & Bro & Broad & 1973 & $\mathrm{~T} 26$ & Dryas-Empetrum nigrum & Snow Creek Valley \\
\hline 20 & $\mathrm{Coo}$ & Cooper et al. & 1997 & $\mathrm{ACk}$ & Dryas octopetala-Carex rupestris c.t. & Beaverhead NF, MT \\
\hline 21 & $\mathrm{Coo}$ & Cooper et al. & 1997 & $\mathrm{ACg}$ & $\begin{array}{l}\text { Dryas octopetala- } \\
\text { Polygonum.viviparum c.t. }\end{array}$ & Beaverhead NF, MT \\
\hline 22 & Cra & Crack & 1977 & $\mathrm{~T} 3$ & Dryas Association & Wilcox Pass; JNP; AB \\
\hline 23 & Cra & Crack & 1977 & T5 & Salix nivalis Association & Wilcox Pass; JNP; AB \\
\hline 24 & Cra & Crack & 1977 & T6 & Cassiope Association & Wilcox Pass; JNP; AB \\
\hline 25 & Cra & Crack & 1977 & $\mathrm{~T} 2$ & Kobresia Association & Wilcox Pass; JNP; AB \\
\hline 26 & $\mathrm{D} \& \mathrm{~B}$ & Douglas \& Bliss & 1977 & $\mathrm{~T} 2 \mathrm{p}$ & Dryas octopetala community & North Cascades, WA \\
\hline 27 & $\mathrm{D} \& \mathrm{~B}$ & Douglas \& Bliss & 1977 & $\mathrm{~T} 2 \mathrm{n}$ & Salix nivalis community & North Cascades, WA \\
\hline
\end{tabular}




\begin{tabular}{|c|c|c|c|c|c|c|}
\hline 28 & $D \& B$ & Douglas \& Bliss & 1977 & $\mathrm{~T} 2 \mathrm{w}$ & Kobresia myosuroides-community & North Cascades, WA \\
\hline 29 & Dam & Damm & 2001 & Kob & Gentiano-Kobresietum myosuroides & Glacier NP, MT \\
\hline 30 & Dam & Damm & 2001 & Kos & $\begin{array}{l}\text { Tofieldio-Kobresietum } \\
\text { simpliciusculae }\end{array}$ & Glacier NP, MT \\
\hline 31 & Dam & Damm & 2001 & DSp & Salici-Dryadetum (poor variant) & Glacier NP, MT \\
\hline & Dam & Damm & 2001 & $\mathrm{DSm}$ & Dryas-Smelowskia community & Glacier NP, MT \\
\hline 3 & Dam & Damm & 2001 & $\mathrm{DFa}$ & Dryas-Cetraria cucullata-local variant & Glacier NP, MT \\
\hline 3 & Dam & Damm & 2001 & $\mathrm{DSt}$ & Salici-Dryadetum typicum & Glacier NP, MT \\
\hline 35 & Dam & Damm & 2001 & MDr & Myosotido-Caricetum Dryas-variant & Glacier NP, MT \\
\hline 3 & Dam & Damm & 2001 & MDS & $\begin{array}{l}\text { Myosotido-Caricetum Dryas-Salix } \\
\text { nivalis-variant }\end{array}$ & Glacier NP, MT \\
\hline 37 & Dam & Damm & 2001 & Dry & Dryas unranked unit & Glacier NP, MT \\
\hline 38 & Edd & $\begin{array}{l}\text { Eddleman \& } \\
\text { Ward }\end{array}$ & 1984 & $\mathrm{~T} 3$ & Dryas octopetala mat shrub & $\begin{array}{l}\text { Rocky Mtn. NP; False } \\
\text { Mummy Pass }\end{array}$ \\
\hline 30 & Hra & Hrapko \& LaRoi & 1978 & T5a & $\begin{array}{l}\text { Dryas octopetala-Oxytropis } \\
\text { podocarpa c.t. }\end{array}$ & Signal Mtn., AB \\
\hline 40 & Hra & Hrapko \& LaRoi & 1978 & $\mathrm{~T} 5 \mathrm{~b}$ & $\begin{array}{l}\text { Dryas octopetala-Festuca } \\
\text { brachyphylla c.t. }\end{array}$ & Signal Mtn., AB \\
\hline 41 & Hra & Hrapko \& LaRoi & 1978 & T5f & $\begin{array}{l}\text { Cassiope tetragona-Dryas octopetala } \\
\text { c.t. }\end{array}$ & Signal Mtn., AB \\
\hline 42 & Hra & Hrapko \& LaRoi & 1978 & T5g & $\begin{array}{l}\text { Dryas octopetala-Empetrum nigrum } \\
\text { c.t. }\end{array}$ & Signal Mtn., AB \\
\hline 43 & Hra & Hrapko \& LaRoi & 1978 & $\mathrm{~T} 5 \mathrm{~h}$ & Dryas octopetala-Salix arctica c.t. & Signal Mtn., AB \\
\hline 44 & Hra & Hrapko \& LaRoi & 1978 & $\mathrm{~T} 5 \mathrm{c}$ & $\begin{array}{l}\text { Dryas octopetala-Kobresia } \\
\text { myosuroides c.t. }\end{array}$ & Signal Mtn., AB \\
\hline 45 & Hra & Hrapko \& LaRoi & 1978 & T5d & Dryas octopetala-Salix nivalis c.t. & Signal Mtn., AB \\
\hline 46 & Hra & Hrapko \& LaRoi & 1978 & $\mathrm{~T} 5 \mathrm{e}$ & $\begin{array}{l}\text { Dryas octopetala-Pedicularis capitata } \\
\text { c.t. }\end{array}$ & Signal Mtn., AB \\
\hline 47 & K73 & Kuchar & 1973 & T10 & Dryas octopetala community & Waterton Lakes NP, AB \\
\hline 48 & K75 & Kuchar & 1975 & T15 & Dryas tundra & Bald Hills; AB \\
\hline 49 & Kie & Kiener & 1939 & T6 & Dryadetum & Longs Peak; CO \\
\hline 50 & Kom & Komárková & 1979 & $11 b$ & Bistorto-Salicetum reticulatae & Indian Peaks Area; CO \\
\hline 51 & Kom & Komárková & 1980 & $\mathrm{~T} 7 \mathrm{fa}$ & Eritricho-Dryadetum & Indian Peaks Area; CO \\
\hline 52 & Kom & Komárková & 1981 & $\mathrm{~T} 7 \mathrm{fb}$ & Eritricho-Dryadetum & Indian Peaks Area; CO \\
\hline 53 & L92 & $\begin{array}{l}\text { Lesica \& } \\
\text { McCune }\end{array}$ & 1992 & B1f & Dryas transsect & $\begin{array}{l}\text { Lunch Creek Basin, } \\
\text { Glacier NP, MT }\end{array}$ \\
\hline 54 & L92 & $\begin{array}{l}\text { Lesica \& } \\
\text { McCune }\end{array}$ & 1992 & B9 & Dryas-Kobresia transsect & $\begin{array}{l}\text { Mt. Reynolds, } \\
\text { Glacier NP, MT }\end{array}$ \\
\hline 55 & Mor & Mortimer & 1978 & $\mathrm{~T} 10$ & Salix arctica-Salix nivalis snowbed & Prospect Mtn.; AB \\
\hline 56 & Mor & Mortimer & 1978 & T-9 & $\begin{array}{l}\text { Phyllodoce glanduliflora-Cassiope } \\
\text { mertensiana }\end{array}$ & Prospect Mtn.; AB \\
\hline
\end{tabular}




\begin{tabular}{|c|c|c|c|c|c|c|}
\hline 57 & Pol & Polster & 1977 & CDs & Dryas-unit, rearranged by author & Akamina Area, BC \\
\hline 58 & Pol & Polster & 1977 & CDs & Dryas-unit, rearranged by author & Akamina Area, BC \\
\hline 59 & Tro & Trottier & 1972 & T34 & Dryas community & Highwood Pass \\
\hline 60 & Tro & Trottier & 1972 & T33 & Carex phaeocephala-Salix nivalis & Highwood Pass \\
\hline 61 & Tro & Trottier & 1972 & $\mathrm{~T} 4$ & $\begin{array}{l}\text { Cassiope tetrgona (Dryas octopetala- } \\
\text { Salix nivalis) }\end{array}$ & Highwood Pass \\
\hline 62 & Tro & Trottier & 1972 & T34 & Salix nivalis & Highwood Pass \\
\hline 63 & Tro & Trottier & 1972 & $\mathrm{~T} 18$ & Dryas octopetala-Salix nivalis & Highwood Pass \\
\hline 64 & Tro & Trottier & 1973 & $\mathrm{~T} 32$ & Kobresia myosuroides & Highwood Pass \\
\hline 65 & Wil & Willard & 1979 & $\mathrm{~T} 6 \mathrm{~b}$ & $\begin{array}{l}\text { Eritricho aretioidis-Dryadetum } \\
\text { octopetalae }\end{array}$ & Trail Ridge; $\mathrm{CO}$ \\
\hline 66 & Wil & Willard & 1979 & T6a & $\begin{array}{l}\text { Eritricho aretioidis-Dryadetum } \\
\text { octopetalae }\end{array}$ & Trail Ridge; CO \\
\hline
\end{tabular}




\section{LEGEND TABLE 3: Synopsis of Western North American Carex nigricans units}

\begin{tabular}{|c|c|c|c|c|c|}
\hline No. & Code & Author & Yea & Table & Original Community Title \\
\hline 1 & Tim & Timoney & 1999 & $\mathrm{~T} 20$ & Carex nigricans group \\
\hline 2 & K75 & Kuchar & 1973 & $\mathrm{~T} 18$ & Carex nigricans type \\
\hline 3 & Bro & Broad & 1973 & $\mathrm{~T} 20$ & Trollius -Caltha herb meadow \\
\hline 4 & Bro & Broad & 1973 & $\mathrm{~T} 21$ & Carex nigricans association \\
\hline 5 & Bed & Beder & 1972 & $\mathrm{~T} 30$ & Carex nigricans association \\
\hline 6 & Cra & Crack & 1977 & $\mathrm{~T} 8$ & Antennaria lanata association \\
\hline 8 & Cra & Crack & 1977 & $\mathrm{~T} 10$ & Salix arctica association \\
\hline 9 & Tro & Trottier & 1972 & $\mathrm{~T} 42$ & Carex nigricans association \\
\hline 10 & Tro & Trottier & 1972 & T41a & Unclassified stand T41a \\
\hline 11 & Hra & Hrapko\&LaRoi & 1978 & $\mathrm{~T} 5 \mathrm{~m}$ & $\begin{array}{l}\text { Carex nigricans-Luzula wahlenbergii } \\
\text { c.t. }\end{array}$ \\
\hline 12 & Ach & Achuff et al. & 1984 & $\mathrm{~T} 63$ & $\begin{array}{l}\text { Carex nigricans-Antennaria lanata } \\
\text { v.t. }\end{array}$ \\
\hline 13 & Ach & Achuff et al. & 1984 & $\mathrm{~T} 71$ & Fireweed-meadow rue v.t. \\
\hline 13 & Ach & Achuff et al. & 1993 & $\mathrm{~T} 71$ & Carex nigricans v.t. \\
\hline 14 & Ach & Achuff et al. & 1982 & $\mathrm{~T} 78$ & $\begin{array}{l}\text { Carex nigricans-Antennaria lanata } \\
\text { v.t. }\end{array}$ \\
\hline 15 & Ach & Achuff et al. & 1984 & $\mathrm{~T} 41$ & $\begin{array}{l}\text { Carex nigricans-Antennaria lanata } \\
\text { v.t. }\end{array}$ \\
\hline 16 & Ach & Achuff et al. & 1997 & T37 & Carex nigricans v.t. \\
\hline 17 & Dam & Damm & 2001 & T19 & $\begin{array}{l}\text { Phleo-Caricetum nigricantis var. of } \\
\text { Juncus mertensianus }\end{array}$ \\
\hline 18 & Dam & Damm & 2001 & T19 & Phleo-Caricetum nigricantis \\
\hline 19 & Pol & Polster & 1977 & $\mathrm{Ct} 7$ & $\begin{array}{l}\text { Juncus drummondii cirque } \\
\text { community, subunit } 1\end{array}$ \\
\hline 20 & Pol & Polster & 1977 & $\mathrm{Ct} 7$ & $\begin{array}{l}\text { Juncus drummondii cirque } \\
\text { community, subunit } 2\end{array}$ \\
\hline 21 & Ead & Eady & 1972 & T60 & $\begin{array}{l}\text { Carex nigricans ass. } \\
\text { Polytrichadelphus lyallii var. }\end{array}$ \\
\hline 22 & Ead & Eady & 1972 & $\mathrm{~T} 27$ & $\begin{array}{l}\text { Phylllodoce empetriformis- } \\
\text { Antennaria lanata ass. }\end{array}$ \\
\hline 23 & Häm & Hämet-Ahti & 1978 & II & Dry Meadow Type \\
\hline 24 & Häm & Hämet-Ahti & 1978 & V & Moist Oligotrophic Meadow Type \\
\hline 25 & $\mathrm{Coo}$ & Cooper et al. & 1997 & $\mathrm{CTl}$ & Carex nigricans c.t. \\
\hline 26 & Kom & Komarkova & 1979 & T9i & Phleo-Caricetum nigricantis \\
\hline 27 & Sch & Schlatterer & 1972 & p79 & $\begin{array}{l}\text { Carex nigricans-Agrostis humilis } \\
\text { type }\end{array}$ \\
\hline
\end{tabular}

28 Ram Ramaley
Yea Table Original Community Title

1999 T20 Carex nigricans group

Location

Alberta

Bald Hills; AB

Snow Creek Valley

Snow Creek Valley

Snow Creek Valley

Wilcox Pass; JNP; AB

Wilcox Pass; JNP; AB

Highwood Pass

Highwood Pass

Signal Mtn., AB

Kootenai NP

Kootenai NP

Yoho NP

Banff+JasperNP

Mt.Revelstoke NP

Waterton NP

Glacier NP

Glacier NP

Akamina Pass;

Clark Range

Akamina Pass;

Clark Range

Big White Mtn.; BC

Big White Mtn.; BC

Wells Gray Park; BC

Wells Gray Park; BC

Beaverhead NF., MT

Indian Peaks Area; CO

Sawtooth, White Cloud,

Boulder, Pioneer Mtns.

ID

Northern Colorado 


\begin{tabular}{|c|c|c|c|c|c|}
\hline Cox & $\operatorname{Cox}$ & 1933 & text & Snow flush community & Longs Peak CO \\
\hline Rot & Rottman et al. & 1985 & text & "central fines of polygons" & San Juan Mtns \\
\hline $\mathrm{D} \& \mathrm{~B}$ & Douglas \& Bliss & 1977 & $\mathrm{~T} 2 \mathrm{c}$ & Carex nigricans community type & North Cascades \\
\hline$K \& B$ & $\begin{array}{l}\text { Kuramoto } \\
\text { Bliss }\end{array}$ & 1970 & $\mathrm{~T} 1 \mathrm{~h}$ & Carex nigricans-dwarf sedge type & Olympic NP \\
\hline Del & DelMoral & 1979 & $\mathrm{~T} 2 \mathrm{c}$ & $\begin{array}{l}\text { Carex nigricans-Lupinus latifolius- } \\
\text { Vaccinium cespitosum community }\end{array}$ & $\begin{array}{l}\text { Enchantment Basin; } \\
\text { Wenatchee Mtns.; WA }\end{array}$ \\
\hline Ham & Hamann & 1972 & $\mathrm{~T} 15$ & Carex nigricans association & Mt. Rainier NP \\
\hline Ham & Hamann & 1972 & $\mathrm{~T} 18$ & Antennaria lanata association & Mt. Rainier NP \\
\hline Hen & Henderson & 1974 & $\mathrm{~T} 2 \mathrm{a}$ & Carex nigricans c.t. & Mt. Rainier NP \\
\hline Hen & Henderson & 1974 & $\mathrm{~T} 17$ & Carex nigricans c.t. & Mt. Rainier NP \\
\hline Brk & Brooke et al. & 1970 & $\mathrm{~T} 28$ & Caricetum nigricantis & British Columbia \\
\hline Bre & Brett et al. & 1998 & 4.1 & Carex nigricans typic subass. & British Columbia \\
\hline Bre & Brett et al. & 1998 & 4.2 & $\begin{array}{l}\text { Carex nigricans Polytrichum } \\
\text { alpinum subass. }\end{array}$ & British Columbia \\
\hline Arc & Archer & 1963 & T58 & Caricetum nigricantis & Garibaldi Park \\
\hline Boc & Bockheim & 1972 & $\mathrm{n} / \mathrm{a}$ & $\begin{array}{l}\text { Subalpine Carex nigricans } \\
\text { community }\end{array}$ & Mt. Baker; WA \\
\hline
\end{tabular}




\section{LEGEND TABLE 4: Synopsis of Western North American Phyllodoce-Cassiope units}

\begin{tabular}{|c|c|c|c|c|c|c|}
\hline No. & Codet & Author & Year & Table & Original Community Title & Location \\
\hline 1 & Hra & Hrapko \& LaRoi & 1978 & T5f & $\begin{array}{l}\text { Cassiope tetragona-Dryas } \\
\text { octopetala c.t. }\end{array}$ & Signal Mtn. \\
\hline 2 & Hra & Hrapko \& LaRoi & 1978 & $\mathrm{~T} 5 \mathrm{~g}$ & $\begin{array}{l}\text { Dryas octopetala-Empetrum } \\
\text { nigrum c.t. }\end{array}$ & Signal Mtn. \\
\hline 3 & A82 & Achuff et al. & 1982 & L4 & $\begin{array}{l}\text { Cassiope tetragona-Dryas } \\
\text { octopetala c.t. }\end{array}$ & Banff+JasperNP \\
\hline 4 & K75 & Kuchar & 1975 & $\mathrm{~T} 17$ & Phyllodoce glanduliflora- type & Bald Hills; AB \\
\hline 5 & Mor & Mortimer & 1978 & T9 & $\begin{array}{l}\text { Cassiope tetragona-Dryas } \\
\text { octopetala c.t. }\end{array}$ & Prospect Mtn.; AB \\
\hline 6 & Cra & Crack & 1977 & $\mathrm{~T} 7$ & Phyllodoce glanduliflora-ass. & Wilcox Pass; JNP; AB \\
\hline 7 & Tro & Trottier & 1972 & T39 & Cassiope tetragona ass. & Highwood Pass \\
\hline 8 & Bed & Beder & 1967 & $\mathrm{~T} 27$ & Cassiope tetragona ass. & Snow Creek Valley \\
\hline 9 & Cra & Crack & 1977 & T6 & Cassiope tetragona ass. & Wilcox Pass; JNP; AB \\
\hline 10 & Bed & Beder & 1967 & $\mathrm{~T} 28$ & $\begin{array}{l}\text { Phyllodoce glanduliflora- } \\
\text { Vaccinium scoparium ass. }\end{array}$ & Snow Creek Valley \\
\hline 11 & Bed & Beder & 1967 & $\mathrm{~T} 29$ & Salix arctica Carex pyrenaica type & Snow Creek Valley \\
\hline 12 & Tro & Trottier & 1972 & $\mathrm{~T} 39$ & Cassiope tetragona ass. & Highwood Pass \\
\hline 13 & Bro & Broad & 1973 & $\mathrm{~T} 22$ & Cassiope tetragona ass. & Snow Creek Valley \\
\hline 14 & Bro & Broad & 1973 & $\mathrm{~T} 23$ & Phyllodoce glanduliflora ass. & Snow Creek Valley \\
\hline 15 & Dam & Damm & 2001 & TCD & Sibbaldio Phyllodocetum & Glacier NP, MT. \\
\hline 15 & Dam & Damm & 2001 & TCD & $\begin{array}{l}\text { Sibbaldio Phyllodocetum } \\
\text { kalmietosum }\end{array}$ & Glacier NP, MT. \\
\hline 17 & Hra & Hrapko \& LaRoi & 1978 & T5i & $\begin{array}{l}\text { Cassiope mertensiana-Phyllodoce } \\
\text { glanduliflora c.t. }\end{array}$ & Signal Mtn. \\
\hline 18 & A93 & Achuff et al. & 1993 & L5 & Heather-Everlasting v.t. & Yoho NP \\
\hline 19 & $\mathrm{CoO}$ & $\begin{array}{l}\text { Cooper \& Lesica } \\
\& \text { Page-Dumroese }\end{array}$ & 1992 & $\mathrm{ACp}$ & $\begin{array}{l}\text { Phyllodoce empetriformis- } \\
\text { Antennaria lanata c.t. }\end{array}$ & Beaverhead NF \\
\hline 20 & A82 & Achuff et al. & 1982 & L5 & Heather-Everlasting v.t. & Banff+JasperNP \\
\hline 21 & K75 & Kuchar & 1975 & T17 & Phyllodoce glanduliflora- type & Bald Hills; AB \\
\hline 22 & $\mathrm{D}+\mathrm{B}$ & Douglas \& Bliss & 1977 & $\mathrm{~T} 2 \mathrm{k}$ & Phyllodoce glanduliflora c.t. & North Cascades, WA \\
\hline 23 & A 84 & Achuff et al. & 1984 & T39 & $\begin{array}{l}\text { Phyllodoce empetriformis- } \\
\text { Antennaria lanata c.t. }\end{array}$ & Mt.Revelstoke NP \\
\hline 24 & A 84 & Achuff et al. & 1984 & $\mathrm{~T} 46$ & $\begin{array}{l}\text { Antennaria lanata-Phyllodoce } \\
\text { empetriformis }\end{array}$ & Mt.Revelstoke NP \\
\hline 25 & Ead & Eady & 1971 & $\mathrm{~T} 27$ & $\begin{array}{l}\text { Phyllodoce empetriformis- } \\
\text { Antennaria lanata ass. }\end{array}$ & Big White Mtn.; B.C. \\
\hline 26 & Dam & Damm & 2001 & TCD & Phyllodoce glanduliflora-stand & Glacier NP, MT. \\
\hline 27 & L88 & Lesica & 1988 & Tc1 & Heather transsects & $\begin{array}{l}\text { GNP, Akaiyan Lake } \\
\text { South }\end{array}$ \\
\hline
\end{tabular}




\begin{tabular}{|c|c|c|c|c|c|c|}
\hline 28 & L88 & Lesica & 1988 & $\mathrm{Tc} 2$ & Heather transsects & $\begin{array}{l}\text { GNP, Akaiyan Lake } \\
\text { North }\end{array}$ \\
\hline 29 & $\mathrm{Coo}$ & $\begin{array}{l}\text { Cooper \& Lesica } \\
\& \text { Page-Dumroese }\end{array}$ & 1992 & $\mathrm{ACq}$ & $\begin{array}{l}\text { Cassiope mertensiana-Carex } \\
\text { paysonis c.t. }\end{array}$ & $\begin{array}{l}\text { Beaverhead NF; } \\
\text { Gravelly Range; Snow } \\
\text { Crest; Tendoy Mtns. }\end{array}$ \\
\hline 30 & Boc & Bockheim & 1972 & 9-M & Vaccinium-Phyllodoce comm. & Mt. Baker; WA \\
\hline 31 & $\mathrm{KuB}$ & Kuramoto \& Bliss & 1970 & $\mathrm{~T} 1 \mathrm{~g}$ & $\begin{array}{l}\text { Phyllodoce empetriformis- } \\
\text { Vaccinium deliciosum-heath type }\end{array}$ & Olympic NP \\
\hline 32 & $\mathrm{DBa}$ & $\begin{array}{l}\text { Douglas \& } \\
\text { Ballard }\end{array}$ & 1971 & $\mathrm{~T} 2$ & $\begin{array}{l}\text { Phyllodoce-Vaccinium deliciosum } \\
\text { community }\end{array}$ & North Cascades, WA \\
\hline 33 & Arc & Archer & 1963 & $\mathrm{~T} 76$ & $\begin{array}{l}\text { Phyllodoceto-Cassiopetum } \\
\text { mertensianae }\end{array}$ & $\begin{array}{l}\text { Garibaldia Provincial } \\
\text { Park Park, BC }\end{array}$ \\
\hline 34 & Häm & Hämet-Ahti & 1978 & $\mathrm{~T} 1$ & $\begin{array}{l}\text { Phyllodoce empetriformis heath } \\
\text { community }\end{array}$ & $\begin{array}{l}\text { Wells Gray Park; } \\
\text { Caribou Mtns.; BC }\end{array}$ \\
\hline 35 & Poj & Pojar & 1991 & T3d & $\begin{array}{l}\text { Cassiope mertensiana- } \\
\text { Barbilophozia hatcheri }\end{array}$ & Gladys Lake, BC \\
\hline 36 & $\mathrm{D}+\mathrm{B}$ & Douglas \& Bliss & 1977 & $\mathrm{~T} 2 \mathrm{j}$ & Phyllodoce empetriformis c.t. & North Cascades, WA \\
\hline 31 & $\mathrm{D}+\mathrm{B}$ & Douglas \& Bliss & 1977 & $\mathrm{~T} 2 \mathrm{i}$ & Cassiope mertensiana c.t. & North Cascades, WA \\
\hline 38 & Ham & Hamann & 1972 & $\mathrm{~T} 7$ & Phyllodoce empetriformis- ass. & Mt. Rainier NP \\
\hline 39 & Ham & Hamann & 1972 & T9 & $\begin{array}{l}\text { Cassiope mertensiana-Phyllodoce } \\
\text { empetriformis ass. }\end{array}$ & Mt. Rainier NP \\
\hline 40 & Ham & Hamann & 1972 & $\mathrm{~T} 23$ & $\begin{array}{l}\text { Phyllodoce glanduliflora-Aster } \\
\text { alpigenus ass. }\end{array}$ & Mt. Rainier NP \\
\hline 41 & Hen & Henderson & 1974 & $\mathrm{~T} 2+6$ & $\begin{array}{l}\text { Phyllodoce empetriformis-- } \\
\text { Vaccinium deliciosum c.t. }\end{array}$ & Mt. Rainier NP \\
\hline 42 & Del & DelMoral & 1979 & $\mathrm{~T} 2 \mathrm{i}$ & $\begin{array}{l}\text { Phyllodoce empetriformis-Juncus } \\
\text { parryi }\end{array}$ & Enchantment Basin, WA \\
\hline 43 & Hen & Henderson & 1974 & $\mathrm{~T} 2+8$ & $\begin{array}{l}\text { Phyllodoce empetriformis- } \\
\text { Lupinus latifolius c.t. }\end{array}$ & Mt. Rainier NP \\
\hline 44 & Hen & Henderson & 1974 & T9 & Phyllodoce glanduliflora c.t. & Mt. Rainier NP \\
\hline 45 & Brk & Brooke et al. & 1970 & $\mathrm{~T} 32$ & $\begin{array}{l}\text { Phyllodoco-Cassiopetum } \\
\text { mertensianae }\end{array}$ & British Columbia \\
\hline 46 & Brk & Brooke et al. & 1970 & $\mathrm{~T} 34$ & $\begin{array}{l}\text { Vacciniuo-Tsugetum } \\
\text { mertensianae }\end{array}$ & British Columbia \\
\hline 47 & Bre & Brett et al. & 1998 & AP3 & $\begin{array}{l}\text { Cassiope mertensiana-Phyllodoce } \\
\text { empetriformis ass. SA Vaccinium } \\
\text { deliciosum }\end{array}$ & British Columbia \\
\hline 48 & Bre & Brett et al. & 1998 & AP3 & $\begin{array}{l}\text { Cassiope mertensiana-Phyllodoce } \\
\text { empetriformis ass. typicum }\end{array}$ & British Columbia \\
\hline 49 & Bre & Brett et al. & 1998 & AP3 & $\begin{array}{l}\text { Cassiope mertensiana-Tsuga } \\
\text { mertensiana subass. Hippuris }\end{array}$ & British Columbia \\
\hline 50 & Bre & Brett et al. & 998 & AP3 & $\begin{array}{l}\text { Cassiope mertensiana-Tsuga } \\
\text { mertensiana ass. typicum }\end{array}$ & British Columbia \\
\hline
\end{tabular}




\begin{tabular}{|c|c|c|c|c|c|c|}
\hline 51 & Bre & Brett et al. & 1998 & AP3 & Luetkea pectinata ass. & British Columbia \\
\hline 52 & Del & DelMoral & 1979 & $\mathrm{~T} 2 \mathrm{~g}$ & $\begin{array}{l}\text { Cassiope mertensiana-Phyllodoce } \\
\text { glanduliflora c.t. }\end{array}$ & Enchantment Basin, WA \\
\hline 53 & Bre & Brett et al. & 1998 & Ap2 & Carex nigricans-typic subass. & British Columbia \\
\hline 54 & Bre & Brett et al. & 1998 & Ap2 & $\begin{array}{l}\text { Carex nigricans-Polytrichum } \\
\text { alpinum subass. }\end{array}$ & British Columbia \\
\hline 55 & Sch & Schlatterer & 1972 & list & $\begin{array}{l}\text { Phyllodoce empetriformis-Ledum } \\
\text { glandulosum type }\end{array}$ & $\begin{array}{l}\text { Sawtooth, White Cloud } \\
\text { Boulder and Pioneer } \\
\text { Mtns }\end{array}$ \\
\hline 56 & Sch & Schlatterer & 1972 & list & Sibbaldia procumbens-type & $\begin{array}{l}\text { Sawtooth, White Cloud } \\
\text { Boulder and Pioneer } \\
\text { Mtns }\end{array}$ \\
\hline
\end{tabular}




\section{LEGEND TABLE 5: Synopsis of Western North American Valeriana sitchensis units}

\begin{tabular}{|c|c|c|c|c|c|c|}
\hline No. & Code & Author & Year & Table & Original Community Title & Location \\
\hline 1 & Kom & $\begin{array}{l}\text { Komárkov } \\
\text { á }\end{array}$ & 1979 & $12 \mathrm{f}$ & Ligustico-Trollietum laxi & Indian Peaks Area; CO \\
\hline 2 & Dam & Damm & 2001 & $\mathrm{~T} 24$ & Luzulo-Erythronietum & Glacier NP \\
\hline 3 & Dam & Damm & 2001 & $\mathrm{~T} 24$ & Luzulo-Erythronietum typicum & Glacier NP \\
\hline 4 & Pol & Polster & 1977 & $\mathrm{C} 10$ & Arnica-Valeriana Cirque Community & Akamina Area, BC \\
\hline 5 & Pol & Polster & 1977 & $\mathrm{C} 11$ & Hackelia Slope Community & Akamina Area, BC \\
\hline 6 & Pol & Polster & 1977 & $\mathrm{C} 12$ & Valeriana Colluvial Slope Community & Akamina Area, BC \\
\hline 7 & Ach & $\begin{array}{l}\text { Achuff et } \\
\text { al. }\end{array}$ & 1982 & T92 & $\begin{array}{l}\text { Erigeron peregrinus-Valeriana } \\
\text { sitchensis }\end{array}$ & Banff+JasperNP \\
\hline 8 & Ach & $\begin{array}{l}\text { Achuff et } \\
\text { al. }\end{array}$ & 1984 & $\mathrm{~T} 45$ & $\begin{array}{l}\text { Erigeron peregrinus-Valeriana } \\
\text { sitchensis }\end{array}$ & Mt.Revelstoke NP \\
\hline 9 & Ach & $\begin{array}{l}\text { Achuff et } \\
\text { al. }\end{array}$ & 1984 & T68 & $\begin{array}{l}\text { Erigeron peregrinus-Valeriana } \\
\text { sitchensis }\end{array}$ & Kootenai NP \\
\hline 10 & Ach & $\begin{array}{l}\text { Achuff et } \\
\text { al. }\end{array}$ & 1993 & $\mathrm{~T} 75$ & $\begin{array}{l}\text { Erigeron peregrinus-Valeriana } \\
\text { sitchensis }\end{array}$ & Yoho NP \\
\hline 11 & Bro & Broad & 1973 & $\mathrm{~T} 25$ & $\begin{array}{l}\text { Pulsatilla occidentalis-Thalictrum } \\
\text { occidentalis-Valeriana sitchensis }\end{array}$ & Snow Creek Valley \\
\hline 12 & Tro & Trottier & 1972 & $\mathrm{~T} 32$ & Thalictrum occidentalis ass. & Highwood Pass \\
\hline 13 & Bed & Beder & 1967 & $\mathrm{~T} 37$ & Rich meadow ass. & Snow Creek Valley \\
\hline 14 & Tim & Timoney & 1999 & A3q & Trollius association & Alberta \\
\hline 15 & Sha & Shaw & 1916 & text & Alpine Meadow & Selkirk Mtns., BC \\
\hline 16 & Sha & Shaw & 1916 & text & Mesophytic Grasslands & Selkirk Mtns., BC \\
\hline 17 & Häm & $\begin{array}{l}\text { Hämet- } \\
\text { Ahti }\end{array}$ & 1978 & III & Mesic Meadow & Wells Gray Park; B.C.; \\
\hline 18 & Ead & Eady & 1971 & T55 & $\begin{array}{l}\text { Valeriana sitchensis-Castilleja elmeri } \\
\text { ass. }\end{array}$ & Big White Mtn.; B.C. \\
\hline 19 & Ead & Eady & 1971 & $\mathrm{~T} 45$ & $\begin{array}{l}\text { Abies lasiocarpa-Valeriana sitchensis } \\
\text { ass. }\end{array}$ & Big White Mtn.; B.C. \\
\hline 20 & Hen & Henderson & 1974 & $\mathrm{~T} 13$ & Valeriana sitchensis c.t. & Mt. Rainier NP \\
\hline 21 & Hen & Henderson & 1974 & $\mathrm{~T} 14$ & $\begin{array}{l}\text { Valeriana sitchensis-Veratrum viride } \\
\text { c.t. }\end{array}$ & Mt. Rainier NP \\
\hline 22 & Hen & Henderson & 1974 & $\mathrm{~T} 15$ & $\begin{array}{l}\text { Lupinus latifolius-Polygonum } \\
\text { bistortoides c.t. }\end{array}$ & Mt. Rainier NP \\
\hline 23 & Hen & Henderson & 1974 & T16 & $\begin{array}{l}\text { Valeriana sitchensis-Lupinus latifolius } \\
\text { c.t. }\end{array}$ & Mt. Rainier NP \\
\hline 24 & Ham & Hamann & 1972 & $\mathrm{~T}-5$ & $\begin{array}{l}\text { Veratrum viride-Valeriana sitchensis } \\
\text { ass. }\end{array}$ & Mt. Rainier NP \\
\hline 25 & Ham & Hamann & 1972 & $\mathrm{~T} 11$ & $\begin{array}{l}\text { Valeriana sitchensis-Ligusticum grayi } \\
\text { ass. }\end{array}$ & Mt. Rainier NP \\
\hline
\end{tabular}


D\&B Douglas \& $1977 \quad$ T2g Lupinus latifolius c.t.

North Cascades, WA

Bliss

27 Arc Archer

1963 T70 Valerianetum sitchensis

Garibaldi Park

28 Boc Bockheim

1972 tab

Lupinus arcticus-Valeriana sitchensis-

Mt. Baker; WA

Polgonum bistortoides

29 E\&F Evans \& $1990 \quad$ T-1 Veratrum viride c.t.

Excelsior Ridge, WA

Fonda

D\&B Douglas \&

1977 T5

Carex spectabilis community

North Cascades

Bliss

31 K\&B Kuramoto

1970 T1f \& Bliss

Vale

32 Bre Brett et al. 1998

ass.

33 Bre Brett et al. $1998 \quad 8.2$ Heracleum maximum-Valeriana sitchensis British Columbia

34 Bre $\quad$ Brett et al. $1998 \quad 8.3 \quad$ Sphagnum-Valeriana sitchensis ass.

British Columbia

35 Poj Pojar

1991 T1 Festuca altaica-Luzula parviflora c.t.

Gladys Lake, BC

36 Poj Pojar

1991 T1 Heracleum sphondylium c.t.

Gladys Lake, BC 
Appendix G. Vegetation Tables: see separate folder 